\title{
ARQUEOLOGÍA DE LA FAJA CENTRAL DE TIERRA DEL FUEGO:
} UNA APROXIMACIÓN FUNCIONAL-ESPACIAL

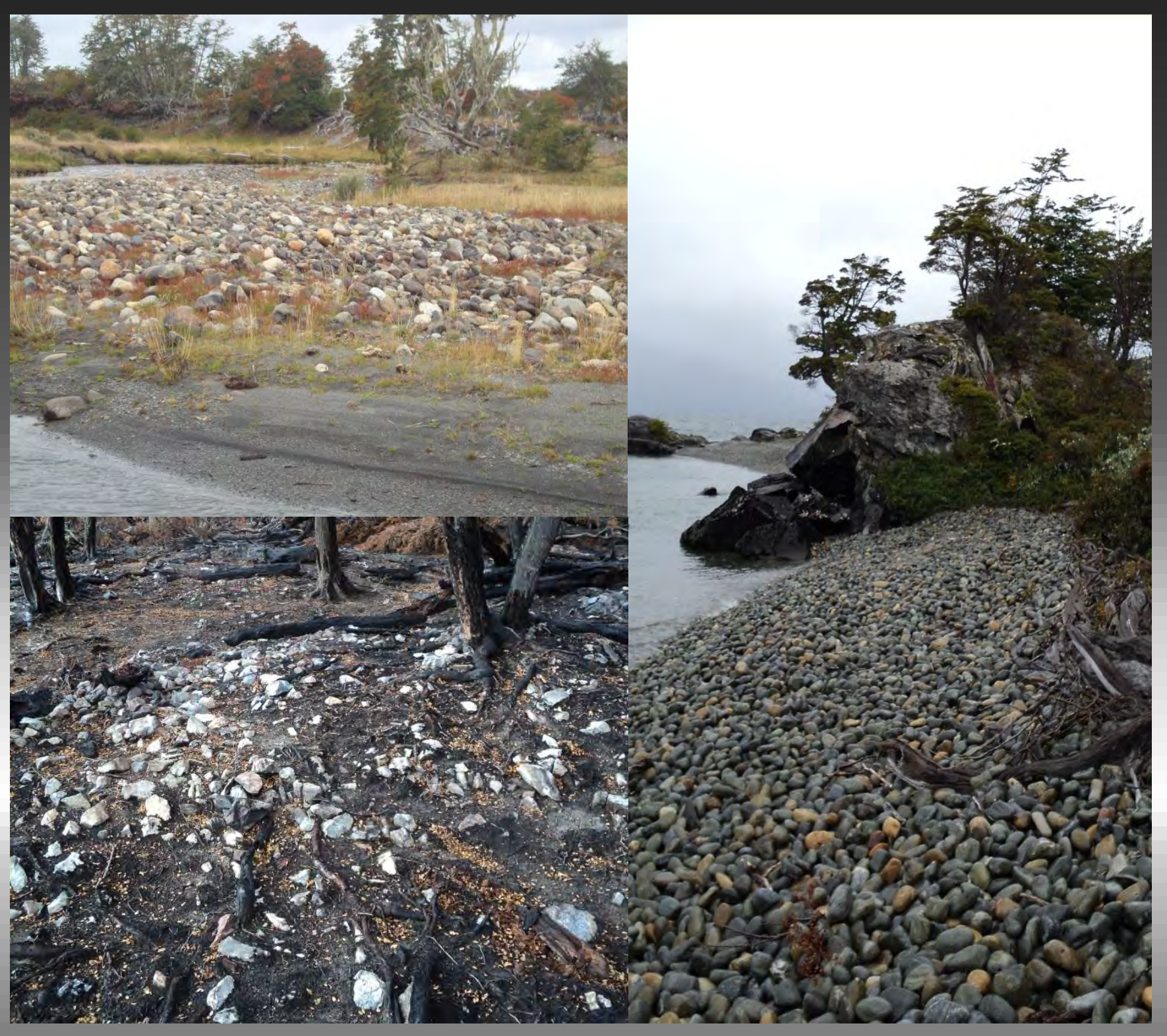

Tesis para optar al Titulo de Doctor en Ciencias Naturales

Hernán De Angelis 2012

Directora: Dra. María Estela Mansur Co-Directora: Dra. Marcela Sandra Leipus 


\section{AGRADECIMIENTOS}

A lo largo de casi 5 años de trabajo, tuve la suerte de cruzarme con muchas personas que me ofrecieron su ayuda sin pedir nada a cambio, a todos ellos mi eterno agradecimiento. También a las instituciones que me dieron la posibilidad de llevar adelante semejante emprendimiento, ANPCYT, CONICET, CADIC y FCNyM UNLP.

En primer lugar quisiera agradecer a mi Directora Estela Mansur, con quien pude compartir mucho más que conocimientos arqueológicos y microscópicos, compartí su amistad y afecto pero por sobre todas las cosas su paciencia única. A mi Co-Directora Marcela Leipus "La Rusa", quien aparte de su amistad me enseño los primeros pasos de la tecnología lítica y funcional. Para las dos no tengo más que palabras de agradecimiento y cariño.

A todos los que de alguna manera han colaborado para que esta tesis llegue a su fin:

A María Celina Álvarez Soncini, una gran amiga con un nombre largo, por la ayuda prestada, trabajando desinteresadamente hasta sábados y domingos y siempre con tan buen humor.

A los muchachos de Geología a quienes molesté y molesté durante todo este tiempo, con mis minúsculas muestras, y aunque me costó mucho trabajo hacerme entender me dieron una mano bárbara: Federico Ponce, Mauricio González Guillot, Pablo Torres Carbonell y Daniel Martinioni.

A Fernando Santiago, a quien también molesté preguntando sobre diversos software y siempre ofreció su ayuda. Adriana Lasa, quien me dio una mano importante en mis comienzos con el funcional. Ernesto Piana, siempre dispuesto a ayudar, corregir o simplemente a charlar; Luis Orquera con su apoyo en cada congreso o en el CADIC y sus consejos siempre positivos. Pancho y Angie por su amistad y sus palabras de aliento.

A todos los que participaron en las campañas 2009, 2010, 2011 y 2012 , que aunque tuvieron que sufrir el frio y el viento, siempre había ganas de seguir trabajando, especialmente a: Vanesa, Marcela, Adriana, Celina, Diana, Mailen, Iván, Andrés, Paloma y Daniel.

A Mariano y Paula por la cena de fin de año en el campo.

A Defensa Civil, Club de caza y pesca, a la Empresa Canal, Ushuaia Nativa y la Familia Echeverría de Bahía El Torito por el apoyo y el interés. 
A los que caminaron tantos kilómetros junto a mí e hicieron que el frio, el viento, la lluvia y, en algunos lugares, la densidad artefactual 0 , no importaran: Vanesa Parmigiani, María Celina Álvarez Soncini, Vanina Reche, Ute Rammerstorfer, Montse Cucurela, Nicolás Prompt, Rodolfo Vallejos y Pablo Vallejos.

También quiero agradecer a los amigos que gracias a este doctorado puede conocer, Ramiro Barberena y Luis Borrero, con quienes compartí varias caminatas y muchas anécdotas increíbles, Karen Borrazzo por todas sus respuestas a mis consultas constantes sobre Miraflores!!!! y por toda la onda y las palabras de aliento. Juan Belardi, dejando el futbol de lado, por haberme recibido en la pasantía y unas cuantas veces más, por las correcciones siempre positivas, y por supuesto a su familia, quienes me han hecho sentir muy cómodo.

A los Jurados de esta Tesis: Alicia Castro, Karen Borrazzo y Darío Hermo por sus aportes y sugerencias las cuales contribuyeron a mejorar este trabajo en diversos aspectos.

A la Familia Eiriz (Mario, Estela y Nicolás) por su amistad a lo largo de este tiempo, por su apoyo moral y logístico!!!! en Tolhuin donde nos sentimos tan cómodos cada vez que vamos, y por supuesto a Don Rubén por esos guisos increíbles.

A mis amigos y amigas, que me acompañaron en distintas etapas de mi vida: Mariano (32 años de aguante), Gastón, Gustavo y David con quienes compartí muchas horas de música. Trini, Sole, Romi y Tahia con quienes compartí muchas horas de estudio. Marta, Miguel, Nene y Eleo con quienes compartí muchas horas de laboratorio. Gabriel, Diego, Viking, Fernando, Nanchi y Guido con quienes compartí muchas horas de Silence. Igor, Raquel, Edgard, Marian, Ester, Xavier, David y Tony amigos transatlánticos con quienes pase muchas horas de aprendizaje y buenos momentos. Fede, Pancho, Mariano, Fabi, Fernando y Santi por las polémicas, el futbol y los asados.

A mi familia TODA, que siempre me apoyo en todo lo que me propuse hacer, incluido esta carrera, la música, todo... Sobre todo por hacerme de Independiente!!!!

A mis viejos Marisa y Daniel, de los que recibo apoyo y amor incondicional siempre y quienes me enseñaron con el ejemplo a seguir mis 
ideales. Mis hermanos Pablo y Andrea que siempre estuvieron a mi lado, aunque todavía piensen que me dedico a juntar piedritas.

Pero especialmente quiero agradecer a mi nonna, Victoria Crippa...por todo lo que me dio.

A mis suegros Gustavo y Lucy, mis cuñados Julio y Pamela que me llenaron de sobrinos y sobrinas. Especialmente a mí ahijada Luciana. Gracias a todos por el apoyo y el cariño que me brindaron todos estos años.

A Vanesa Parmigiani (Vane), nunca voy a saber qué hubiera sido de mi vida sino nos hubiéramos conocido, pero seguro que no hubiera sido tan feliz como lo soy ahora, porque fuiste vos quien hizo que todo esto sea posible, con tu amor, tu ayuda y tu paciencia en cada día de nuestras vidas.

Hernán H. De Angelis Ushuaia 2012 


\section{DEDICATORIA}

A vane,

A mis viejos,

A mis hermanos,

A mi nonna, In bocca al Lupo... 
Ellos vinieron, nos encubrieron; Aquí encontraron, dioses que danzan, y nos dijeron, "cerra los ojos, dame la tierra, tomá la biblia”.

Patriotas importados, nativos sin oreja. La muerte grita, Tierra! y el canto chacarera. Y nos dijeron "tiempo es dinero y en estas tierras sos extranjero". Huelga de amores, huelga de amores, Huelga de amores en el paseo las flores. La historia escrita por vencedores, no pudo hacer callar a los tambores. (Canción: Huelga de amores de R. Mollo / F. Gil Solá / D. Arnedo) 


\section{ÍNDICE GENERAL}

AGRADECIMIENTOS

DEDICATORIA

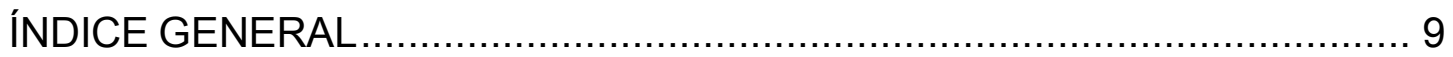

RESUMEN

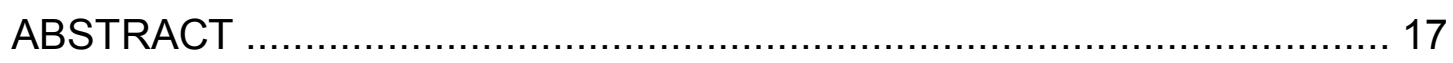

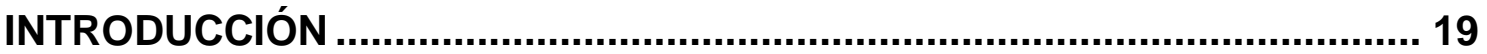

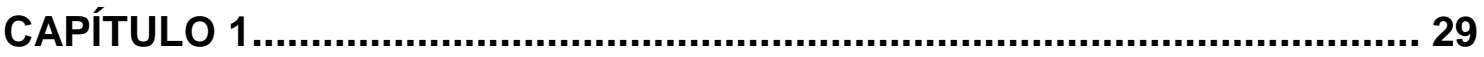

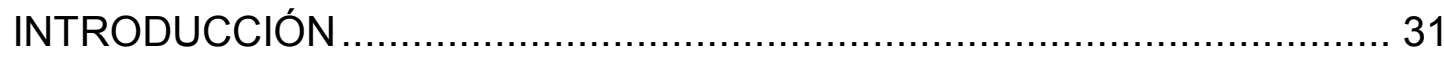

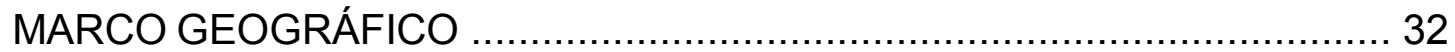

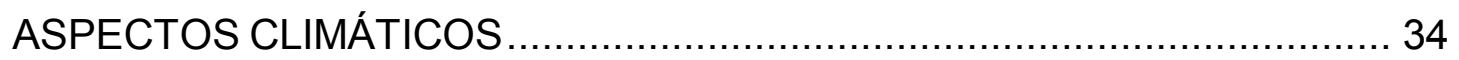

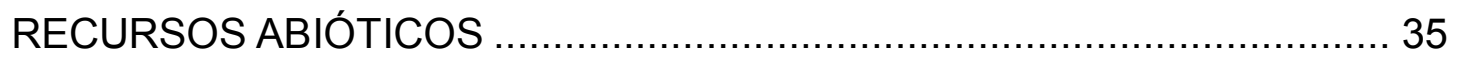

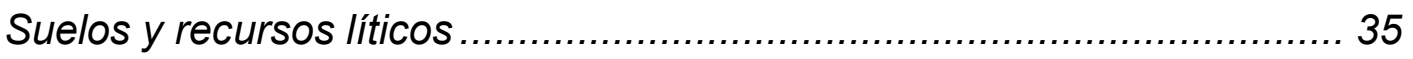

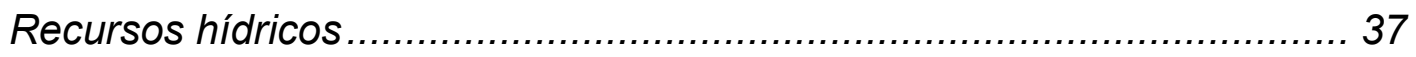

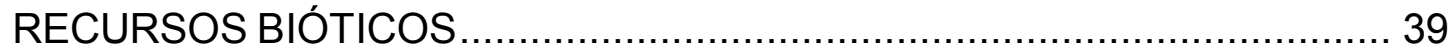

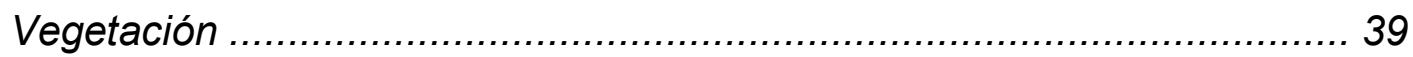

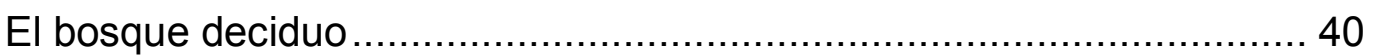

El bosque mixto .................................................................... 40

El bosque explotable o woodland ...................................................... 41

El bosque lluvioso o evergreen forest................................................ 41

Estepa

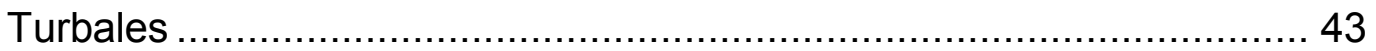

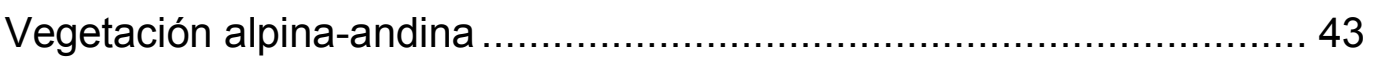

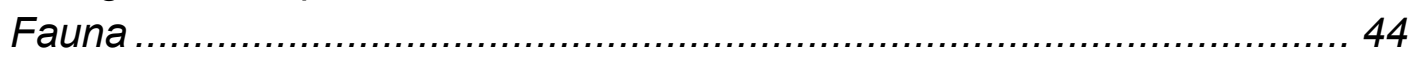

DISCUSIÓN: AMBIENTE Y RECURSOS PARA SOCIEDADES CAZADORAS-

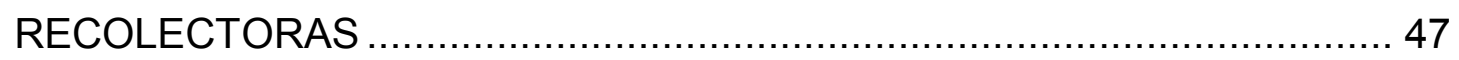

CAPÍTULO 2

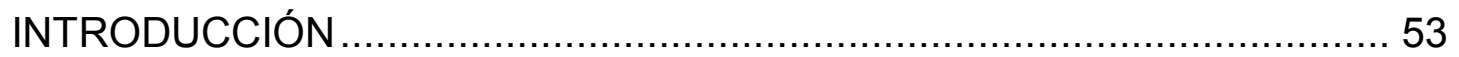

INVESTIGACIONES ARQUEOLÓGICAS EN LA ISLA GRANDE ................ 54

ANTECEDENTES DE INVESTIGACIÓN EN EL ÁREA DE ESTUDIO .......... 60

LOS HABITANTES DE LA REGIÓN EN TIEMPOS HISTÓRICOS Y LAS

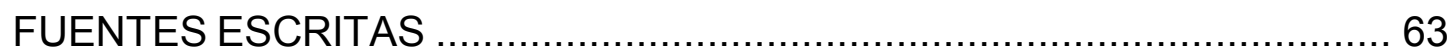

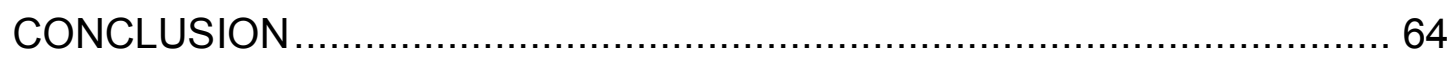

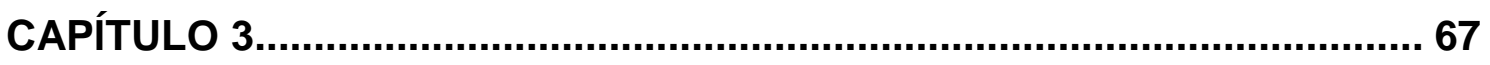

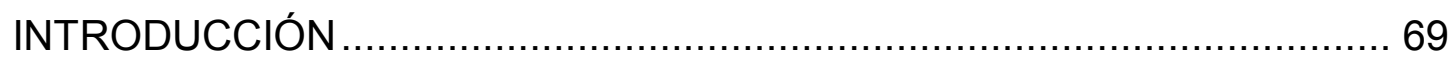

GESTIÓN DE RECURSOS BIÓTICOS Y ABIÓTICOS .................................. 70

Fuentes de materias primas líticas en Tierra del Fuego.......................... 71

EL ESTUDIO DE LA GESTIÓN DE LAS MATERIAS PRIMAS Y EL

CONCEPTO DE CADENA OPERATIVA …............................................. 74

EL ESTUDIO DE LA GESTIÓN DE LOS INSTRUMENTOS Y LOS

PROCESOS DE USO 


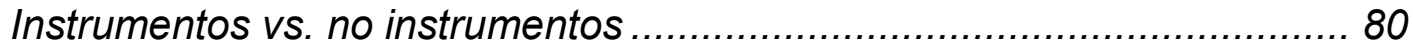

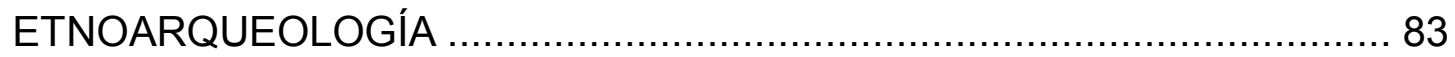

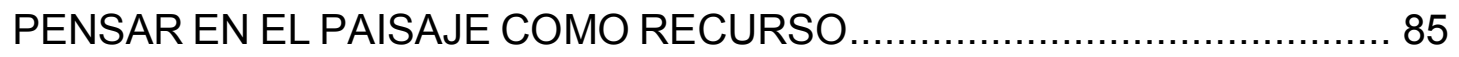

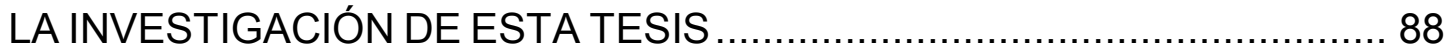

Metodología y estrategias en el trabajo de campo .................................. 91

Prospecciones y estudios distribucionales .......................................... 91

Excavaciones y recolecciones superficiales ....................................... 92

Estudios experimentales................................................................ 93

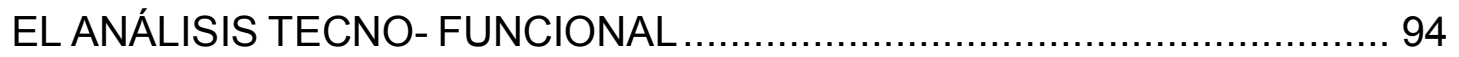

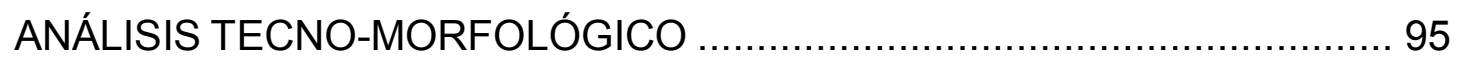

Criterios de análisis de las materias primas........................................... 96

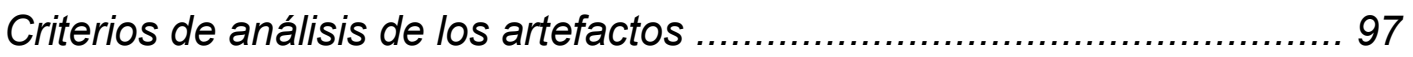

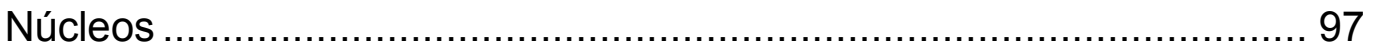

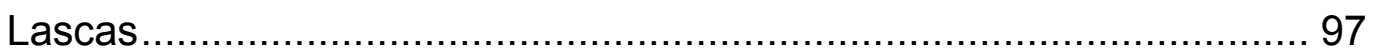

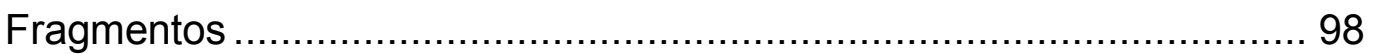

Clasificación según tamaño de los productos de talla .......................... 98

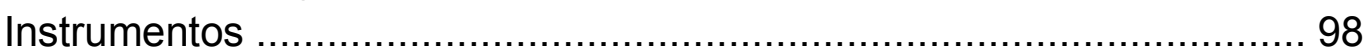

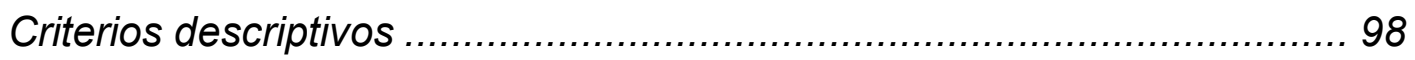

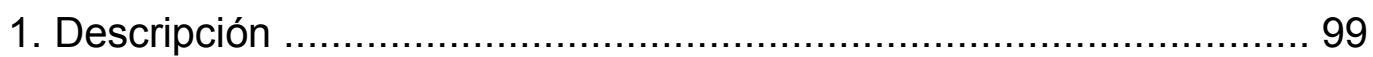

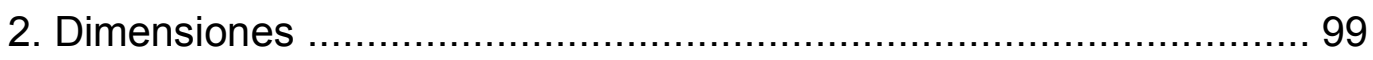

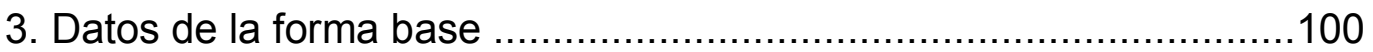

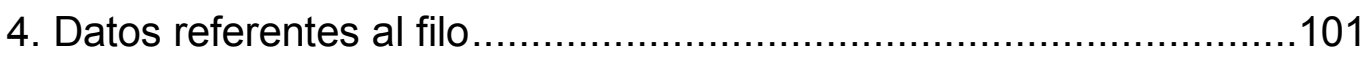

ANÁLISIS FUNCIONAL DE BASE MICROSCÓPICA ..............................102

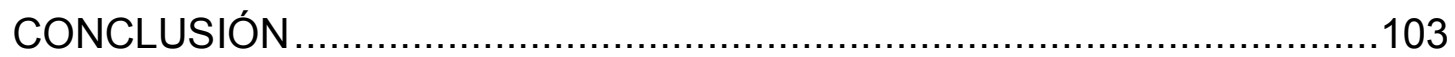

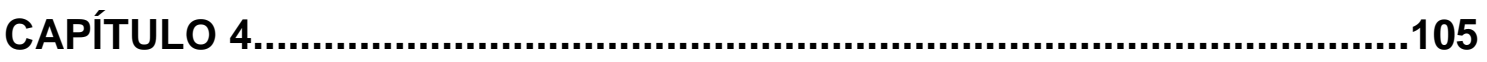

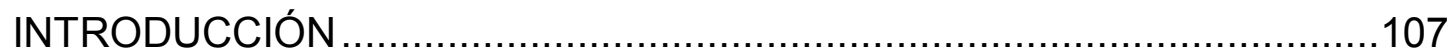

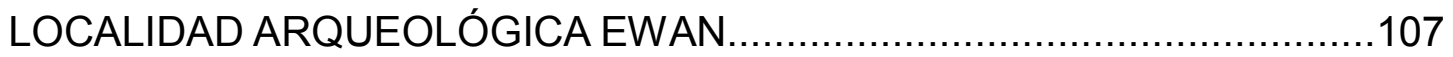

Los sitios arqueológicos Ewan I y Ewan II .........................................111

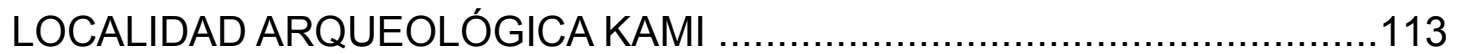

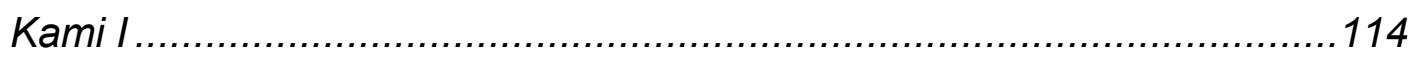

Áreas de combustión, fechados y materiales arqueológicos ................116

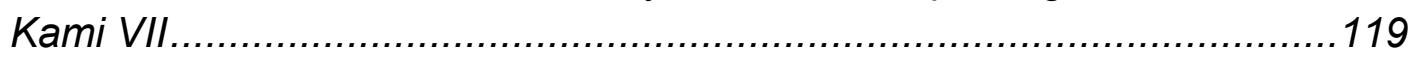

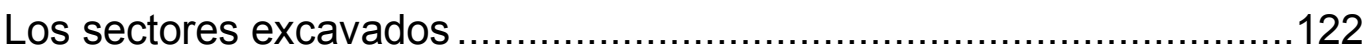

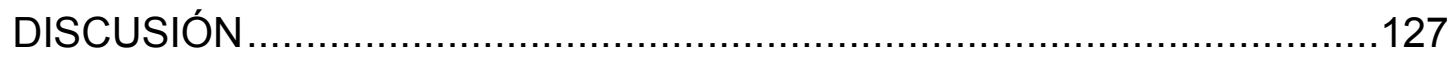

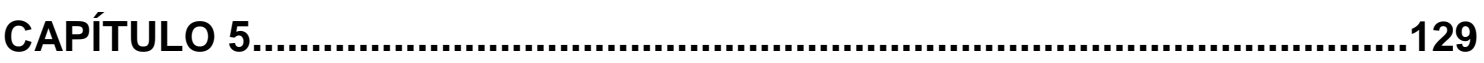

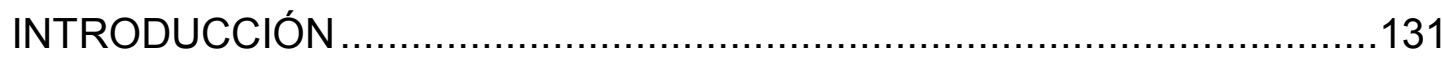

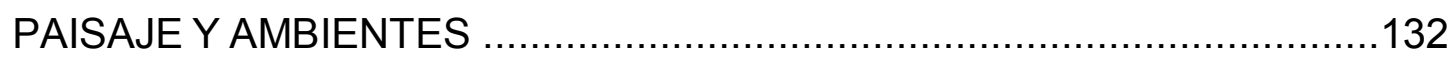

Procesos de formación del registro arqueológico .................................134

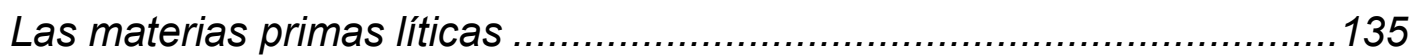

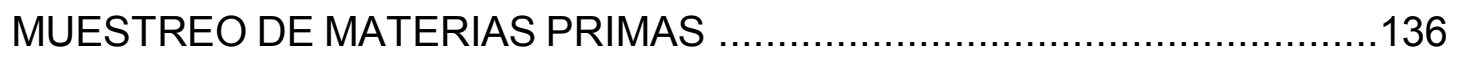

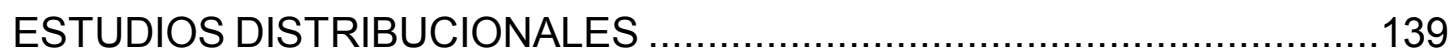

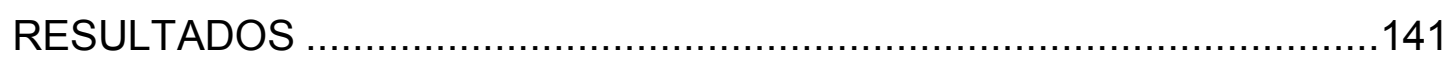




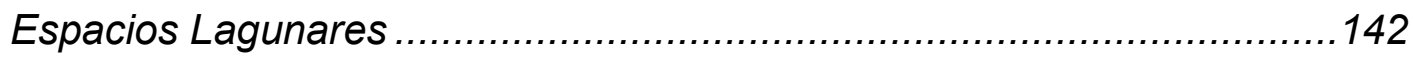

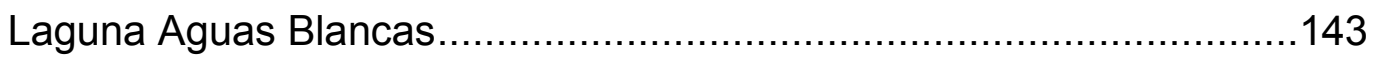

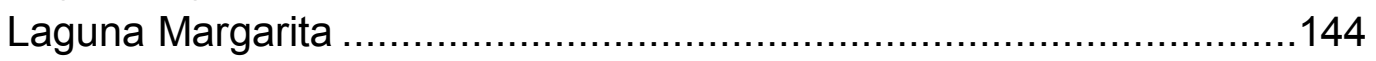

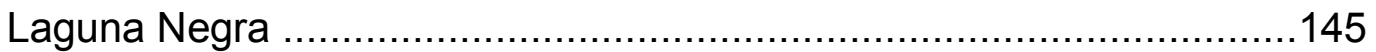

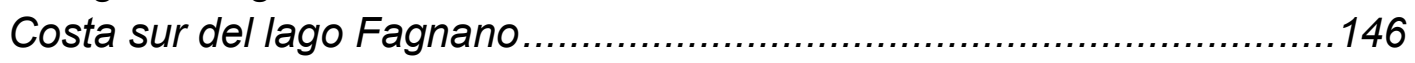

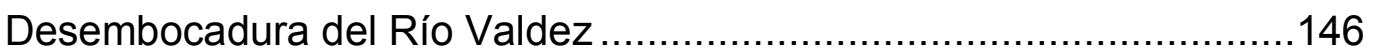

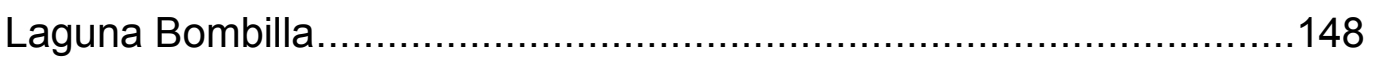

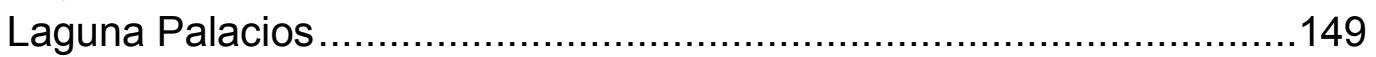

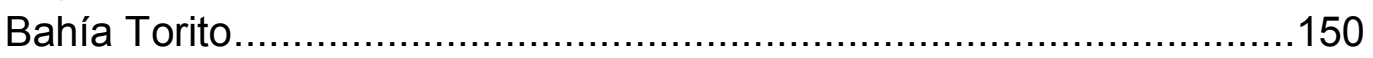

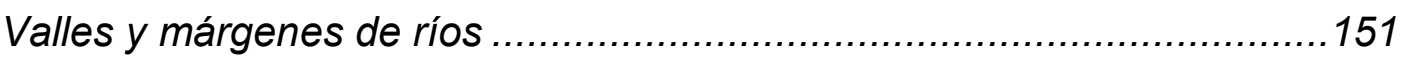

Curso superior y medio del río Irigoyen ............................................152

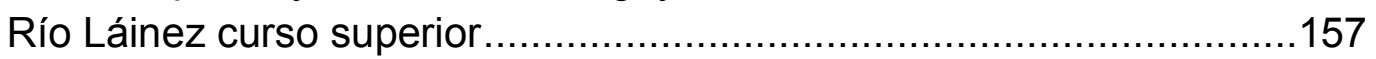

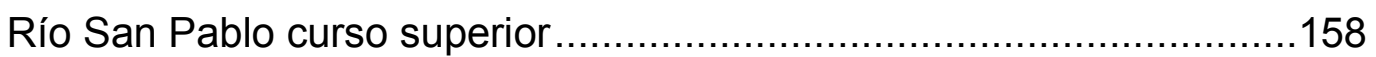

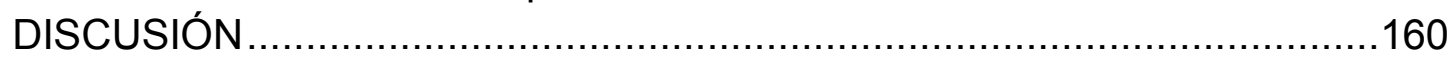

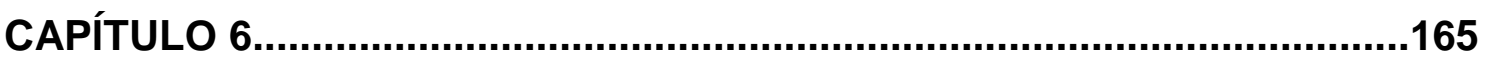

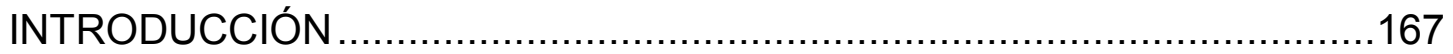

EXPERIMENTACIÓN TECNOLÓGICA Y FUNCIONAL SOBRE

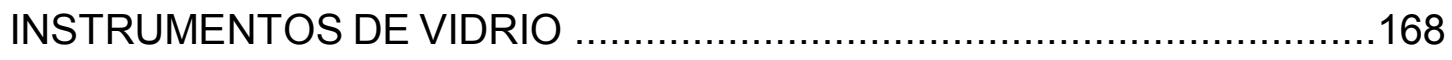

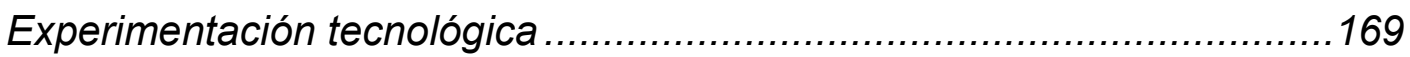

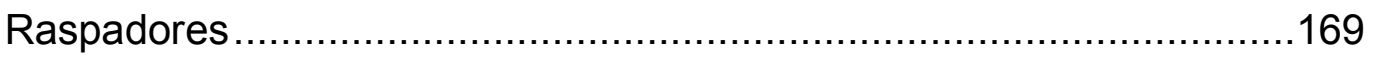

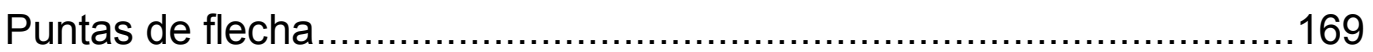

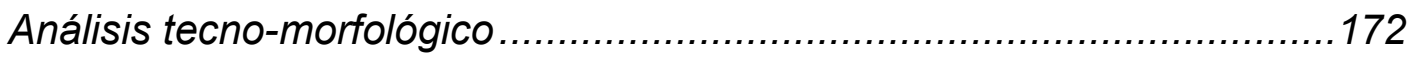

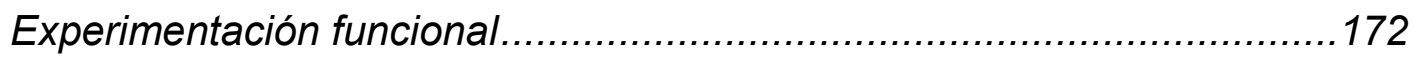

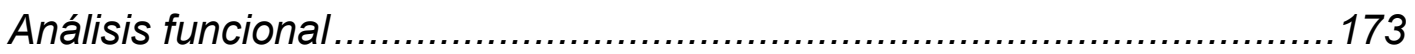

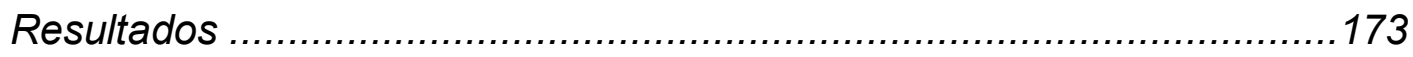

Análisis tecno-morfológico de restos de talla ....................................173

Análisis funcional de los instrumentos ..............................................176

EXPERIMENTACION TECNOLÓGICA Y FUNCIONAL SOBRE TOBA

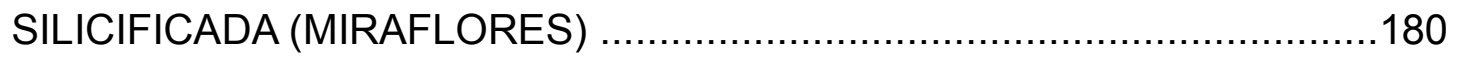

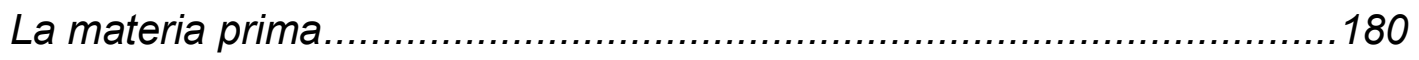

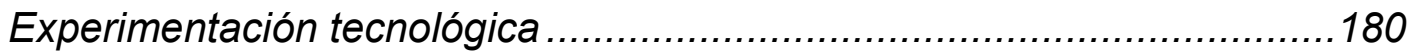

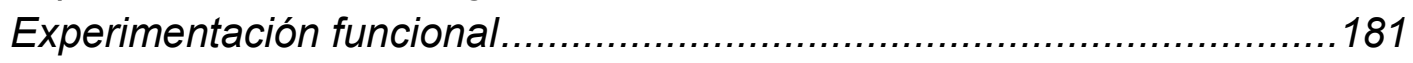

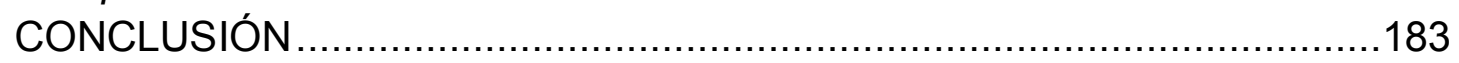

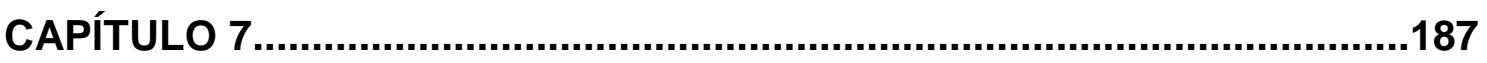

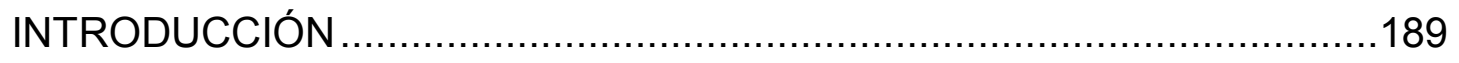

ESTUDIOS TECNO-MORFOLÓGICOS Y FUNCIONALES DE LA

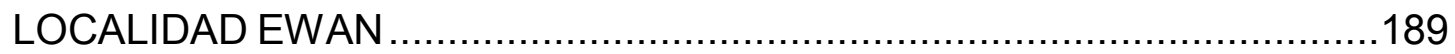

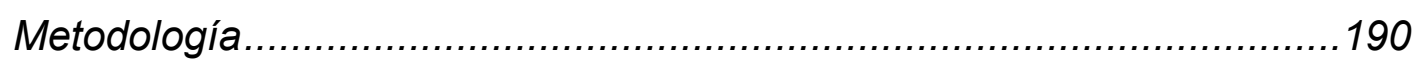

MATERIALES LÍTICOS DEL SITIO EWAN 1 ...........................................191

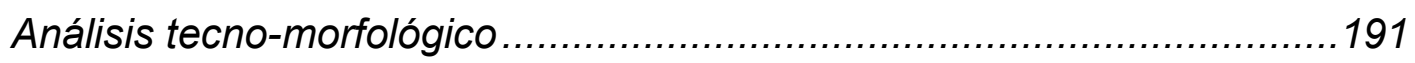

MATERIALES LÍTICOS DEL SITIO EWAN II-UNIDAD $1 \ldots \ldots \ldots \ldots \ldots \ldots \ldots \ldots . . . . . . . . . . . . . . . .193$

Análisis tecno-morfológico ..............................................................193 


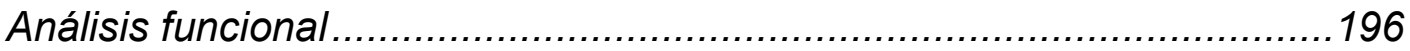

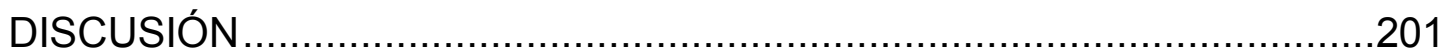

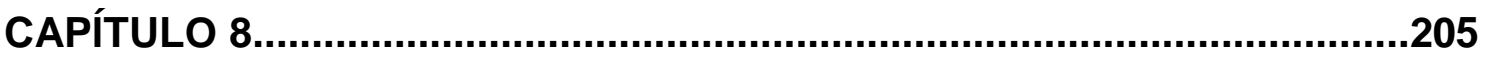

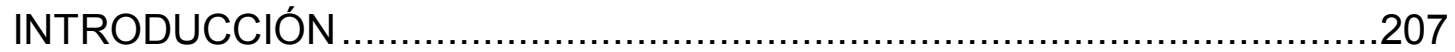

LOS MATERIALES DE LAS CUADRÍCULAS NE …..............................207

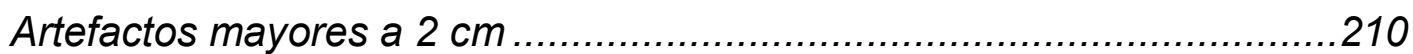

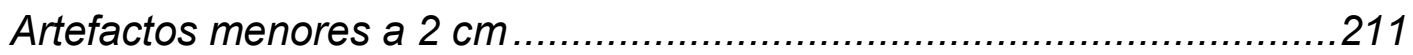

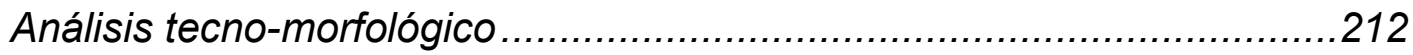

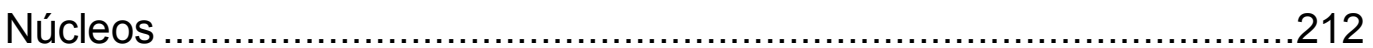

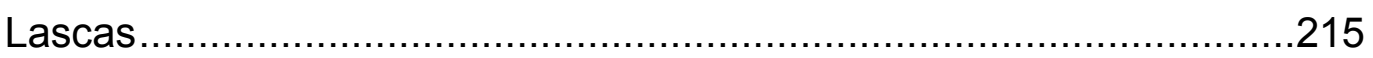

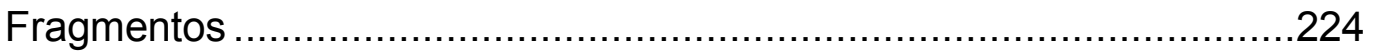

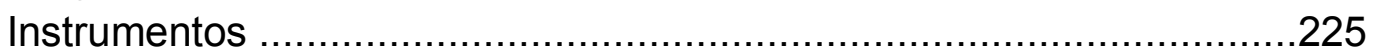

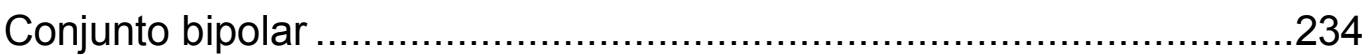

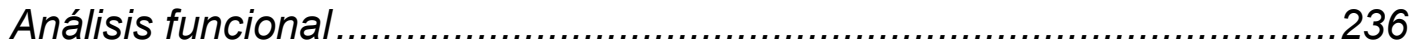

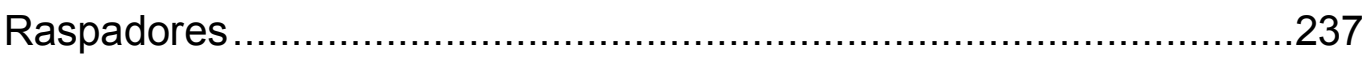

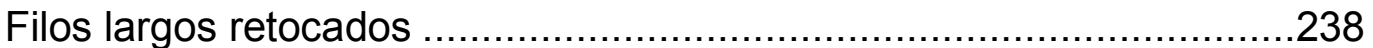

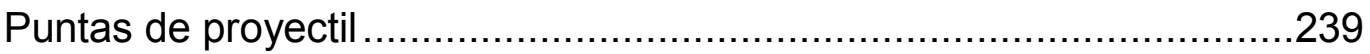

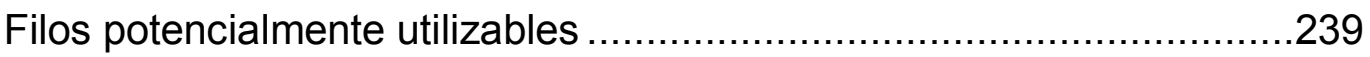

LOS MATERIALES DE RECOLECCIÓN SUPERFICIAL ...........................240

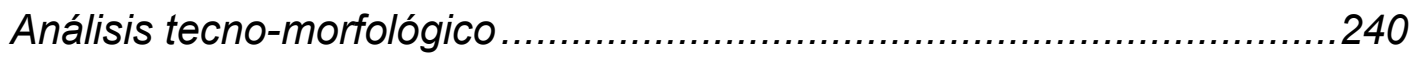

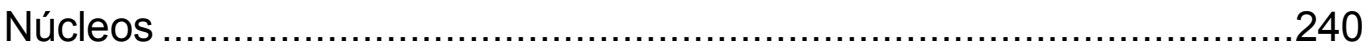

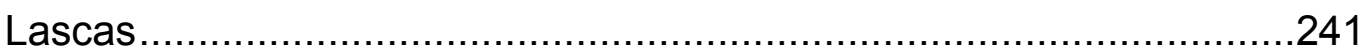

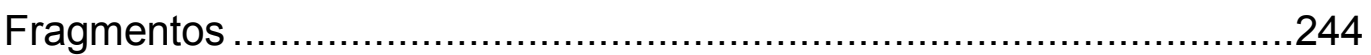

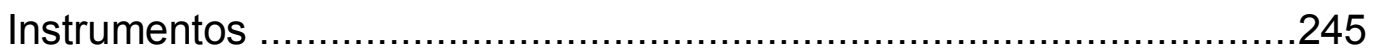

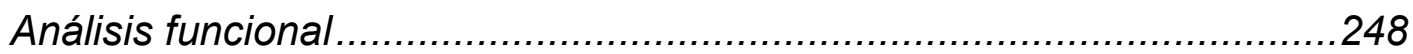

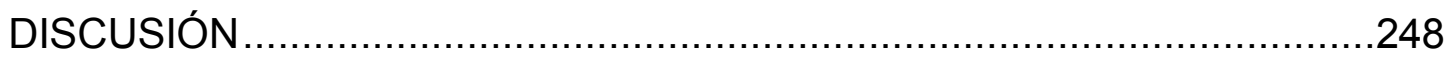

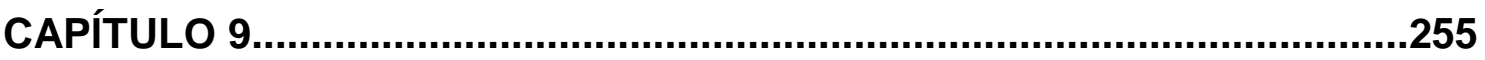

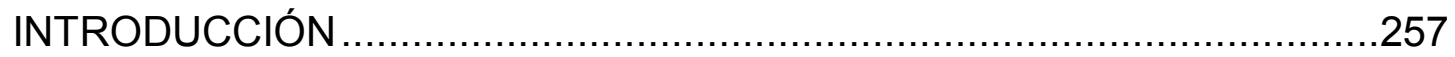

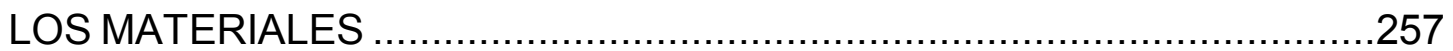

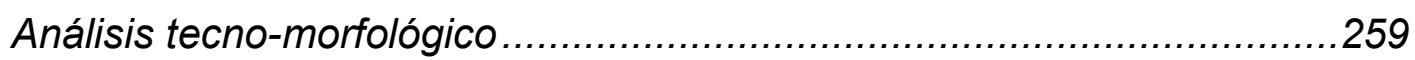

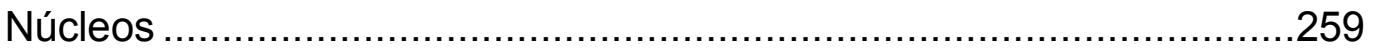

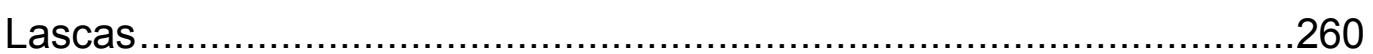

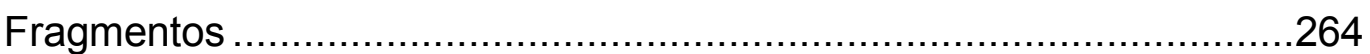

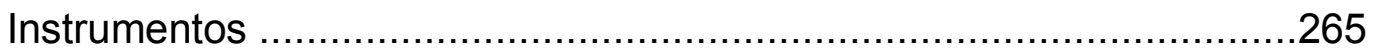

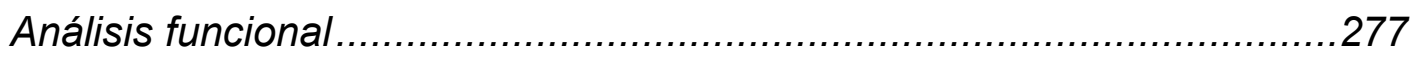

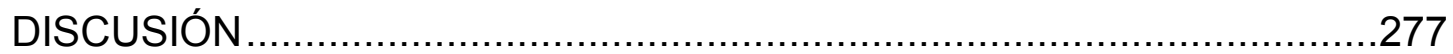

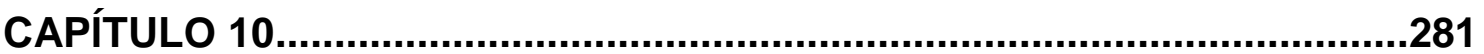

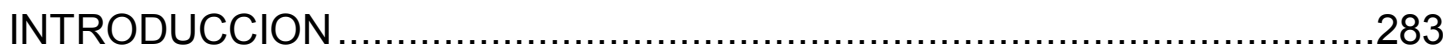

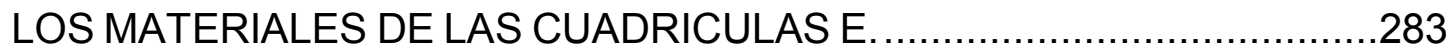

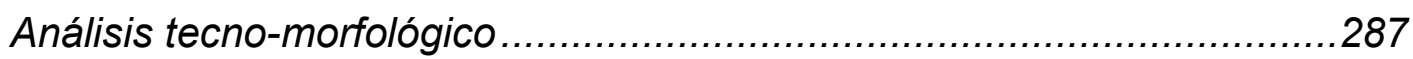

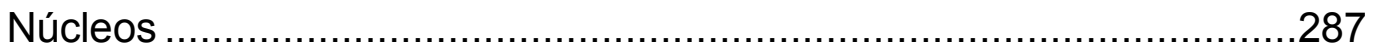




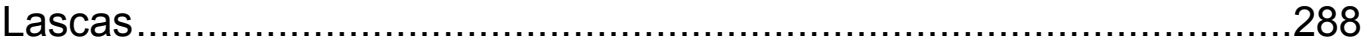

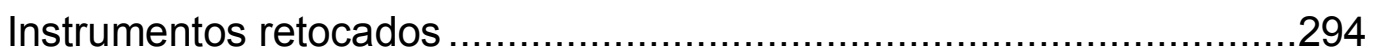

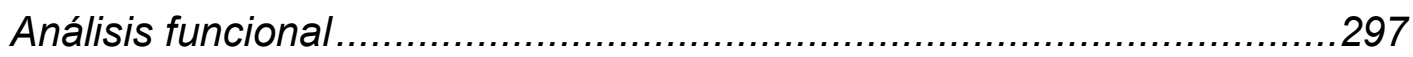

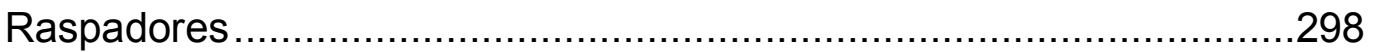

Filos largos retocados ........................................................... 300

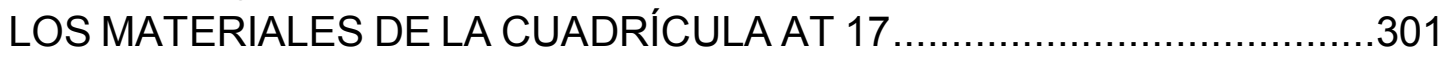

Análisis tecno-morfológico ........................................................ 301

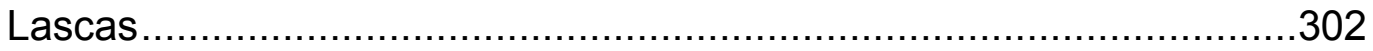

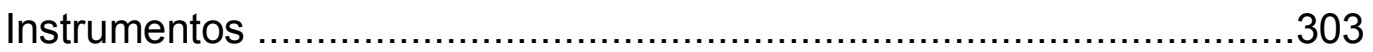

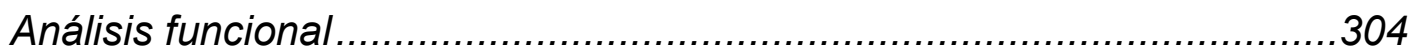

DISCUSIÓN: LOS MATERIALES EXCAVADOS DE KAMI $7 \ldots \ldots \ldots \ldots \ldots \ldots . . . \ldots . . . . . . . . .304$

LOS MATERIALES DE RECOLECCIÓN SUPERFICIAL ...........................306

Análisis tecno-morfológico ............................................................309

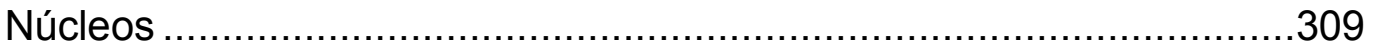

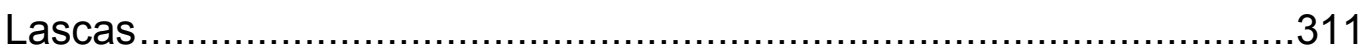

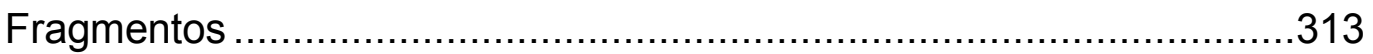

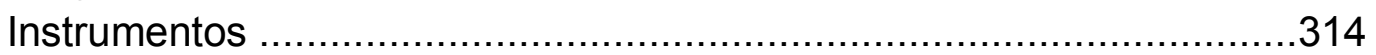

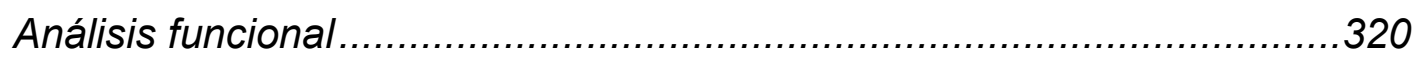

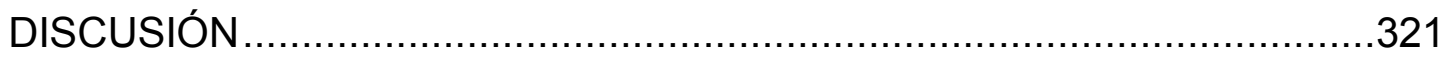

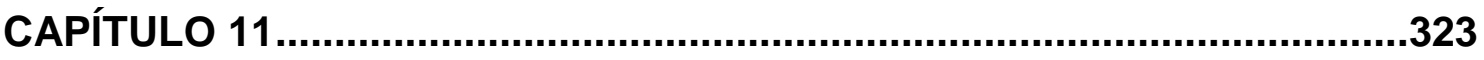

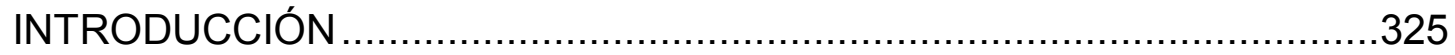

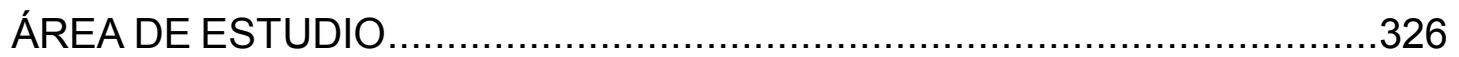

PRIMER EJE: ORGANIZACIÓN TECNOLÓGICA ......................................327

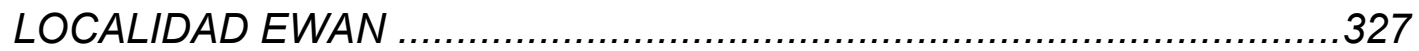

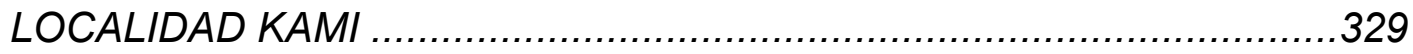

SÍNTESIS TECNO-MORFO-FUNCIONAL Y CADENA OPERATIVA.......333

Discusión sobre la manufactura, contexto de confección y de uso, gestión de los instrumentos y gestión de las materias primas ..........................333

SEGUNDO EJE: OCUPACIÓN DE LOS DIVERSOS AMBIENTES ..............335

ESTUDIO DEL PAISAJE Y LAS POSIBILIDADES DE MOVILIDAD Y

EXPLOTACIÓN DE LAS FUENTES POTENCIALES DE

APROVICIONAMIENTO ............................................................. 335

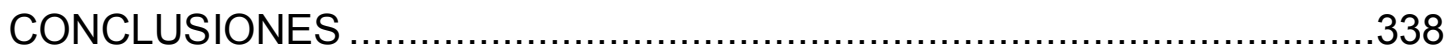

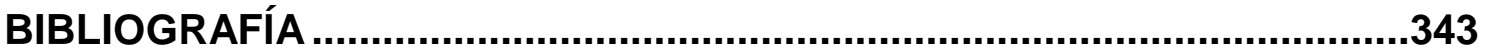

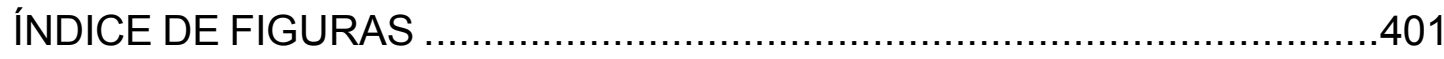

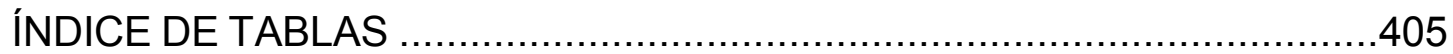

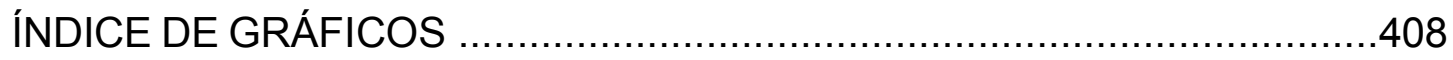




\section{RESUMEN}

Este trabajo de tesis para optar al título de Doctor en Ciencias Naturales con orientación en Antropología constituye un aporte al conocimiento sobre la ocupación humana en la Isla Grande de Tierra del Fuego en relación a la gestión de los recursos bióticos y abióticos por parte de las sociedades cazadoras-recolectoras que habitaron el área hasta comienzos del siglo XX.

El tema en el que se centra este trabajo es el estudio de la organización tecnológica de las sociedades cazadoras-recolectoras de la faja central de Tierra del Fuego, así como la evaluación de la ocupación del espacio, considerando los distintos ambientes representados en el área y la oferta diferencial de recursos.

La principal hipótesis de partida fue considerar que la organización tecnológica, en tanto que estrategia organizativa, depende del marco social en el que está inserta pero además refleja conocimientos y decisiones técnicas que tienen que ver con los modos de gestión de los recursos. Por ello, en un ámbito geográfico como el de la Cordillera fueguina, la evaluación de las características y diversidad de recursos disponibles podía constituir una clave para explicar la variabilidad arqueológica. Propusimos como elementos esenciales para este estudio el de las materias primas líticas y el uso de los instrumentos.

Para abordar esta investigación nos concentramos en los ambientes y sitios arqueológicos conocidos hasta el momento para la región, pero también se evaluó la ocupación humana en uno de los ambientes que aún no había sido explorado, el de la zona que se extiende desde las cabeceras del lago Fagnano hacia la costa atlántica. Nos propusimos diversos objetivos específicos que están interconectados. El primero fue caracterizar el comportamiento de las materias primas presentes en los sitios, tanto al ser talladas con diversas técnicas como al ser utilizadas sobre diversos materiales (madera, piel, hueso, etc.); para ello se abordó un trabajo experimental acotado, dado que ya se cuenta con una importante base de colecciones experimentales, de datos y fotográfica de materias primas de la zona. El segundo fue efectuar el análisis tecno-morfológico integral de los materiales líticos de los sitios seleccionados, a fin de determinar las procedencias de las materias primas utilizadas, evaluar 
las diversas actividades de talla llevadas a cabo e identificar los pasos representados de la cadena operativa. El tercero fue realizar un análisis funcional de base microscópica sobre los conjuntos arqueológicos, con el fin de determinar las actividades desarrolladas en los sitios, en función de los recursos explotados y del contexto total de las relaciones sociales que implican estas actividades. El cuarto fue prospectar el sector oriental del Fagnano a fin de evaluar recursos y ocupación humana en la zona de bosque. Finalmente, buscamos establecer relaciones entre la variabilidad en la densidad del material arqueológico y las características de las series líticas consideradas con la implantación de los sitios, la movilidad de los grupos cazadores recolectores y la ocupación de la zona de bosque.

Para llevarlo a cabo se utilizaron herramientas teórico-metodológicas aplicadas a los estudios sobre organización tecnológica y tecnología lítica, como los análisis tecno-morfológicos y funcionales de base microscópica, así como estudios distribucionales a través del análisis de densidad del registro mediante el uso de transectas.

Los resultados de los estudios y análisis efectuados han permitido confirmar la hipótesis central de esta tesis en cuanto al uso de los recursos líticos por parte de las sociedades cazadoras recolectoras del área. La variabilidad arqueológica detectada en las series de los diferentes sitios puede ser explicada en función de las diversas actividades realizadas en ellos y estas se vinculan con las características y diversidad de recursos disponibles. Esta variabilidad también se relaciona con la explotación de recursos no locales para fines específicos, tal el caso del vidrio europeo para momentos históricos o rocas del norte de la Isla para momentos más tempranos. Estos resultados permiten confirmar la movilidad de estas sociedades asociada a la búsqueda de recursos líticos determinados, ya sea por intercambio o por circuitos que incluyan afloramientos puntuales.

Finalmente, mas allá de los resultados específicos para el ámbito geográfico de la Cordillera fueguina, se discuten las implicancias de estos resultados para el estudio de la organización tecnológica de sociedades cazadoras recolectoras en general, y se señalan las nuevas líneas de investigación que estos generan. 


\section{ABSTRACT}

This research Thesis to qualify for the title of "Doctor en Ciencias Naturales con orientación en Antropología" constitutes a contribution to the knowledge of human occupation in the Isla Grande de Tierra del Fuego, in relation to management of biotic and abiotic resources by hunter-gatherer societies that inhabited the area until the beginnings of the 20th century.

The theme focused in this work is the study of the technological organization of hunter-gatherers societies from the central strip of Tierra del Fuego and the evaluation of human occupation of the area, considering the different environments represented and the differential resources offer.

The main hypothesis was to consider that technological organization, as an organizational strategy, depends on the social context in which it is inserted, but also reflects knowledge and technical decisions related to modes of resource management. Therefore, in a geographic area as the fuegian Cordillera, the evaluation of the characteristics and diversity of available resources could constitute a key to explain archaeological variability. We proposed as fundamental elements for this study both lithic raw materials and tool use.

In order to undertake this research, we focused on the environments and archaeological sites already known for the central strip of the Island, but also assessed the human occupation in an environment that had not been explored so far, the area stretching from the headwaters of Fagnano Lake towards the Atlantic coast. The specific objectives of this research were diverse and interconnected. The first was to characterize the behavior of the raw materials present in the sites, both when being knapped by means of different techniques as when being used to work different materials (wood, leather, bone, etc.); this was dealt with by means of a specific experimental program, as we already have an important basis both of experimental collections, databases and photographic record of raw materials from the area. The second was the integral techno-morphological analysis of the lithic materials of the sites selected for this study, in order to determine provenience of the raw materials used, evaluate the different knapping activities carried out and identify the represented steps of the operative chain. The third one was to conduct a functional analysis of microscopic basis on the archaeological assemblages, in 
order to determine the activities developed at the sites, in relation to resources exploited and the total context of social relations involved in these activities. The fourth was systematically prospecting the eastern sector of the Fagnano Lake, in order to evaluate resources and human occupation in the forest area. Finally, we seek to establish relationships between the variability density of the archaeological material and the characteristics of the lithic series with the implantation of the sites, the mobility of hunter-gatherer groups and the occupation of the forest area.

In order to do so, we used theoretical and methodological tools applied to studies of technological organization and lithic technology, such as technomorphological and microscopic functional analyses, as well as distributional studies of landscape, through the analysis of archaeological record density by means of transects.

The results of studies and analyses developed have allowed confirming the central hypothesis of this thesis regarding the use of the lithic resources by hunter-gatherers societies in the area. The archaeological variability detected in the lithic series of different sites can be explained according to the different activities carried out in them, and these are related with the characteristics and diversity of available resources. This variability can also be explained considering the fact of exploitation of non-local resources that were sought for specific purposes, such as the case of the glass of European origin, used in historical times, or of rocks from the northern part of the Island for early moments of the occupation. These results allow us to confirm the mobility of these societies, associated with the search for specific lithic resources, either by exchange or by circuits that include outcrops.

Finally, beyond the specific results for the geographical region of the fuegian Cordillera, we discuss the implications of these results for the study of the technological organization of hunter-gatherers societies in general, and identify new lines of research which these generate. 
IIntraducción 
Este trabajo de tesis para optar al título de Doctor en Ciencias Naturales con orientación en Antropología fue concebido como un aporte al conocimiento sobre la ocupación humana en la Isla Grande de Tierra del Fuego por parte de las sociedades cazadoras-recolectoras que habitaron el área hasta comienzos del siglo XX.

El tema en el que se centra es el estudio de la organización tecnológica, como aproximación a las estrategias de gestión de los recursos bióticos y abióticos, así como la evaluación de la ocupación del espacio, considerando los distintos ambientes representados en el área y la oferta diferencial de recursos.

La principal hipótesis de partida fue considerar que la organización tecnológica, en tanto que estrategia organizativa, depende del marco social en el que está inserta pero además refleja conocimientos y decisiones técnicas que tienen que ver con los modos de gestión de los recursos. Por ello, en un determinado ámbito geográfico, la evaluación de las características y diversidad de recursos disponibles puede constituir una clave para explicar la variabilidad arqueológica. Para llevar a cabo esta investigación, entonces, se seleccionó el ámbito geográfico de la Cordillera fueguina, que corresponde a la dispersión en la Isla Grande del bosque subantártico.

La investigación se inserta en un proyecto marco titulado "Proyecto Arqueológico Corazón de la Isla" (PACl), dirigido por la Dra. M. E. Mansur, que se desarrolla en el CADIC desde la década del 90. El proyecto tiene por objeto evaluar la implantación humana aborigen y las características de la dinámica de ocupación del bosque subantártico en la faja central de la Isla Grande de Tierra del Fuego. Este se desarrolló en diversas etapas. En la etapa inicial se prospectaron diversas zonas del área norte del lago Fagnano, de las cuencas del río de la Turba y de los lagos Yehuin-Chepelmut y a continuación se excavó el sitio Marina I, permitiendo caracterizar campamentos transitorios de cazadores-recolectores en el rango temporal del Holoceno tardío (Mansur 2002; Mansur et al. 2000; Mansur y De Angelis 2012; De Angelis et al. 2012). La segunda etapa incluyó trabajos en colaboración con la Universidad Autónoma de Barcelona, que fueron codirigidos por la Dra. Raquel Piqué, en cuyo transcurso se prospectaron y excavaron sitios de la zona centro-norte de 
la región Corazón de la Isla, en particular la localidad Ewan (cf. ref. Mansur y Piqué 2009), a la que se hará referencia en este trabajo.

Esta investigación de Tesis se inserta en la tercera etapa del PACl, en particular en los proyectos titulados "Sociedad y ritual: Investigaciones arqueológicas en el Corazón de la Isla" (PICT ANPCYT № 1236) y "Ambiente, recursos y dinámica poblacional en sociedades cazadoras-recolectoras de la faja central de Tierra del Fuego, Argentina" (PICT ANPCYT N²648). Como marco general, ambos proyectos buscan profundizar el estudio de las causas de la variabilidad del registro arqueológico, a fin de proponer metodologías instrumentales que permitan aproximarse a la caracterización de la organización social y económica de las sociedades cazadoras-recolectoras, desde la óptica del análisis de la gestión de los recursos naturales, los recursos introducidos por los europeos como el vidrio y la organización espacial de las actividades técnicas.

\section{Tema y ejes de investigación}

Para abordar la investigación de esta Tesis, nos concentramos en los distintos ambientes y sitios arqueológicos conocidos hasta el momento para la faja central de la Isla. Si proponemos que la organización tecnológica, en tanto que estrategia organizativa social, refleja conocimientos y decisiones técnicas que tienen que ver con los modos de gestión de los recursos, entonces en el caso de estudio, tales conocimientos y decisiones estarán en relación con las actividades vinculadas a la gestión de recursos bióticos y abióticos de los diferentes ambientes de la faja central de la Isla. Por ello, nos propusimos evaluar la diversidad de recursos que ofrecen ambientes que a priori parecen diversos, como la cordillera fueguina, el ecotono y los valles de ríos, ya que pueden constituir un punto clave para explicar la variabilidad arqueológica presente en el área de estudio. Sin embargo, uno de los ambientes no había sido explorado hasta ahora, el de la zona que se extiende desde las cabeceras del lago Fagnano hacia la costa atlántica. Por ello este trabajo también incluyó la evaluación de la ocupación humana en esa zona.

Desde nuestro punto de vista, uno de los elementos clave en la organización tecnológica es la gestión del recurso lítico, ya que el mismo constituye la base para la confección de instrumentos que intervienen en el 
procesamiento de otros recursos. Esto implica que el conocimiento de la localización, la posibilidad de acceso y las ventajas comparativas que pueda ofrecer una fuente de aprovisionamiento lítico (como rocas que respondan efectivamente tanto al proceso de manufactura como al proceso de uso), será un factor a tener en cuenta en la movilidad de las sociedades cazadorasrecolectoras.

En consecuencia, el presente trabajo de investigación fue estructurado según dos formas de acercamiento al estudio de la arqueología de los grupos cazadores-recolectores en la faja central de Tierra del Fuego. Por un lado, y como eje principal, para el abordaje de los materiales, se utilizaron las herramientas teórico-metodológicas aplicadas a los estudios sobre organización tecnológica en general y tecnología lítica en particular, desde la óptica del análisis tecno-funcional. Este enfoque combina análisis de materias primas y fuentes potenciales de aprovisionamiento, cadenas operativas y estudios tecno-morfológicos con análisis funcional de base microscópica. Por otro, a fin de reconocer áreas extensas que nunca habían sido prospectadas, la investigación comprendió estudios mediante enfoque distribucional, para poder lograr un registro general de la densidad de material arqueológico y del paisaje.

\section{Los sitios arqueológicos de la zona central de Tierra del Fuego}

La zona central de Tierra del Fuego se caracteriza por su baja visibilidad arqueológica, debida en parte a las características particulares de formación y conservación de sitios en zonas boscosas y en parte a la particular dinámica social de los grupos cazadores-recolectores del área, al menos según la información de las fuentes etnográficas para la última época de ocupación. En efecto, la mayoría de los sitios arqueológicos conocidos se caracterizaban por ser pequeños y presentar materiales relativamente escasos, por lo cual fueron atribuidos a grupos pequeños de cazadores, altamente móviles y con equipo material ligero, los cuales tienen bajo impacto en el paisaje y pueden dejar muy escaso material no perecedero y no forzosamente en concentraciones (Borrero 1991, Mansur 2002, Mansur et al. 2000).

Dos localidades arqueológicas descubiertas en el transcurso de la segunda y tercera etapa del $\mathrm{PACl}$, las localidades Ewan y Kami, difieren sensiblemente de este modelo general. En ambos casos se trata de sitios 
extensos. El primero de ellos se singulariza porque posee aún una estructura de madera de una choza que está parcialmente conservada. Las investigaciones en esta localidad arqueológica permitieron demostrar que se trata de un evento de agregación, que se refleja en la existencia de un sitio de función ceremonial y otro, con varias estructuras de combustión, de función doméstica. El segundo caso es el de la localidad Kami, que se encuentra ubicada en la costa sur del lago Fagnano. En esta localidad se detectaron numerosos sitios extensos con grandes cantidades de materiales líticos que parecían representar todas las etapas de la cadena operativa. Se propuso como hipótesis que, por sus características y extensión, podrían corresponder ya a algún evento de agregación, ya a un modelo de ocupación recurrente del espacio a lo largo de un cierto tiempo. Por estos motivos, ambas localidades fueron consideradas como casos ideales de estudio para la investigación propuesta (Mansur y Pique 2009, 2012; Mansur y De Angelis 2012).

Una particularidad de los sitios arqueológicos de la zona central de la Isla es que en general se encuentran en zonas donde hay fuentes secundarias de materia prima lítica, correspondiente a formaciones redepositadas de diversa litología y cronología. Sin embargo, aún cuando estas fuentes están extendidas en casi toda la isla, son muy escasos los lugares en donde están formadas por guijarros de grandes dimensiones, abundantes, de materias primas de buena calidad para la talla. Hasta el momento, fuentes de tales características sólo conocemos en sectores de la costa del lago Fagnano, comparables a los depósitos de guijarros de algunos sectores de la costa Atlántica. En los otros casos, las fuentes de materias primas son de baja visibilidad, reducidas y menos diversas. Por tal motivo, creemos que el proceso de gestión de los recursos líticos debió revestir un importante rol en la planificación de desplazamientos y selección de implantaciones para las poblaciones cazadoras-recolectoras que ocuparon el área.

\section{1er eje: el abordaje tecno-funcional}

El estudio de la organización tecnológica (Nelson 1991) es uno de los temas relevantes de las investigaciones referidas a sociedades de cazadoresrecolectores. Entendemos a la tecnología como un sistema complejo que incluye conocimientos y actividades puestos en práctica por las sociedades, 
que permite explotar recursos (identificarlos, adquirirlos y transformarlos) para convertirlos en bienes de uso y/o de consumo. La tecnología implica al mismo tiempo explotación de recursos -naturales y/o artificiales- y establecimiento de relaciones sociales para la producción y el uso de los bienes que genera; en consecuencia, puede ser considerada como mediatizadora de la interrelación entre las sociedades y el medio ambiente (Mansur y Lasa 2005).

El acercamiento a la organización tecnológica requiere de enfoques particulares que permitan caracterizar los comportamientos con respecto a la materia prima y el uso (Binford 1979, Semenov 1964, Keeley 1980), extendiendo el concepto de cadena operativa (Leroi-Gourhan 1964) a la totalidad del proceso tecnológico. Busca evaluar las causas de la selección de determinadas materias primas, a partir de una oferta ambiental variada, el modo en que son transformadas en bienes de consumo y su integración en otras actividades productivas, y considerando los diseños y la localización espacio-temporal de las actividades de producción y uso (Bamforth 1986, Bleed 1986, Nelson 1991).

Para llevarlo adelante, adoptamos el enfoque del análisis tecnofuncional de los conjuntos líticos, que articula selección de materias primas en relación con técnicas de confección, morfologías buscadas (pueden ser formas totales o simplemente formas de filos) y uso al que están destinados los artefactos (Mansur-Franchomme 1983a, 1984). En lo que se refiere a este último punto, la metodología del análisis funcional de base microscópica permite un acercamiento concreto a las actividades en las que estuvieron involucrados los instrumentos. Esta metodología se basa en la identificación de rastros de uso que se generan en los filos de los instrumentos por el contacto con los materiales trabajados (micropulidos, esquirlamientos de los filos, estrías, residuos microscópicos, etc.) (Semenov 1964, Keeley 1981, cf. ref. in Mansur 1999).

\section{2do eje: ambientes y paisajes arqueológicos}

Como se mencionó al comienzo, a fin de reconocer áreas extensas que nunca habían sido prospectadas, la investigación comprendió estudios mediante enfoque distribucional, para poder lograr un registro general de la densidad de material arqueológico en el paisaje. Desde el punto de vista de la 
disponibilidad de recursos bióticos y abióticos así como del de la densidad de ocupación humana, nos interesaba evaluar un ambiente en particular, el que se extiende desde la cabecera del lago Fagnano hacia la costa atlántica.

Para evaluar registros dispersos, consideramos que una herramienta útil es la de los estudios distribucionales (Thomas 1975, Foley 1981a, Dunnell y Dancey 1983, Ebert 1992), ya que permiten determinar, a través de la diferencia en la densidad de materiales arqueológicos (Binford 1992, Thomas 1975), el uso diferencial del paisaje, fundamental para entender el uso de los diferentes ambientes y la movilidad de los grupos cazadores recolectores.

El enfoque distribucional (Thomas 1975, Foley 1981a, Dunnell y Dancey 1983, Ebert 1992) ve al registro arqueológico como una distribución continua pero con picos en su densidad, con lo cual se considera que la variabilidad en la densidad de los artefactos refleja el carácter y la frecuencia de utilización del espacio (Belardi y Garcia 1994, Belardi 2005).

\section{Objetivos específicos de investigación}

En el marco de la investigación propuesta, los principales objetivos específicos fueron los que se enuncian a continuación.

caracterizar el comportamiento de las materias primas presentes en los sitios, tanto al ser talladas con diversas técnicas como al ser utilizadas sobre diversos materiales (madera, piel, hueso, etc.); para ello se abordó un trabajo experimental acotado, dado que ya se cuenta con una base importante tanto de colecciones experimentales, de datos y fotografías de materias primas de la zona.

efectuar el análisis tecno-morfológico integral de los materiales líticos de los sitios mencionados, a fin de determinar las procedencias de las materias primas utilizadas, evaluar las diversas actividades de talla llevadas a cabo e identificar los pasos representados de la cadena operativa.

realizar un análisis funcional de base microscópica sobre los conjuntos arqueológicos, con el fin de determinar las actividades desarrolladas en los sitios, en función de los recursos explotados y del contexto total de las relaciones sociales que implican estas actividades.

prospectar sistemáticamente el sector oriental del Fagnano a fin de evaluar recursos y ocupación humana en la zona de bosque. 
Finalmente, se buscó establecer relaciones entre la variabilidad de la densidad del material arqueológico y las características de las series líticas consideradas con la implantación de los sitios, la movilidad de los grupos cazadores recolectores y la ocupación de la zona de bosque.

\section{Organización de este trabajo de Tesis}

A lo largo de los capítulos de esta tesis se han ido plasmando los distintos aspectos abordados a lo largo de la investigación. En el capítulo 1 se presenta el marco general, ambiental y geológico, del área de estudio, con especial énfasis en el registro de los recursos bióticos y abióticos que pueden llegar a estar disponibles en los distintos ambientes. En el capítulo 2 se hace una breve reseña de los antecedentes de investigaciones arqueológicas en la Isla Grande de Tierra del Fuego en general y en particular en la faja central de la Isla, a fin de contextualizar la problemática de investigación de esta Tesis. En el capítulo 3 se desarrolla el marco teórico-metodológico adoptado para este estudio, la metodología específica utilizada para el análisis tecnofuncional de los materiales líticos en general, así como las estrategias de investigación que permitieron llegar a los resultados buscados. En el capítulo $\mathbf{4}$ se presentan los sitios arqueológicos en los que se efectuaron trabajos de campo (excavaciones y recolecciones superficiales). Primero se describen los sitios de la localidad arqueológica Ewan (Ewan I y Ewan II), considerando las características generales de la localidad así como las similitudes y diferencias de estos sitios entre sí, en cuanto a materiales presentes y la función que cumplió cada uno. A continuación se describen los sitios de la localidad arqueológica Kami (Kami 1, Kami 6 y Kami 7), considerando sus características generales, las metodologías empleadas para los trabajos de campo, los fechados realizados, etc. En el capítulo 5 se exponen los resultados obtenidos en el estudio distribucional planteado para poder abarcar los diferentes ambientes del área de estudio, donde se detallan las diferencias y similitudes que pudieron observarse en cuanto a posibilidad de acceso a ciertos recursos bióticos y abióticos. También se exponen los resultados de los muestreos para evaluación de fuentes de materia prima lítica en el área. En el capítulo 6 se

presentan la metodología y los resultados del programa experimental, planteado a fin de generar un marco interpretativo para ciertas materias primas 
para las que no se contaba con desarrollos metodológico previos, tal el caso del vidrio, o porque son materias primas alóctonas, como en el caso de una toba silicificada proveniente del norte de la Isla. En el capítulo 7 se exponen los resultados de los análisis tecno-morfológicos y funcionales llevados a cabo en los conjuntos líticos provenientes de los sitios Ewan I y Ewan II. En los capítulos 8, 9 y 10 se exponen los resultados de los análisis de los materiales de los sitios de la localidad Kami (Kami 1, Kami 6 y Kami 7), donde se observan las similitudes y diferencias en los procesos de manufactura y uso de los instrumentos líticos.

Finalmente, en el capítulo 11, se discuten los resultados obtenidos a través de los estudios integrados realizados sobre los conjuntos líticos de las localidades arqueológicas, así como sobre la diversidad en la oferta de recursos en los ambientes mencionados y la densidad en la distribución del material arqueológico a lo largo de la faja central de la Isla. Los resultados alcanzados apoyan la hipótesis central planteada al comienzo de esta investigación, en cuanto al uso de los recursos líticos por parte de las sociedades cazadoras-recolectoras del área. Existen indicadores en el registro arqueológico para entender que la variabilidad arqueológica detectada en las series de los diferentes sitios puede ser explicada en función de las diversas actividades realizadas en ellos, y esta se vincula con las características y diversidad de recursos. En este aspecto, son importantes tanto los recursos disponibles como los recursos no locales buscados para fines específicos, tal es el caso de dos tipos de materiales que detectamos, el vidrio de origen europeo para momentos históricos y rocas provenientes del norte de la Isla para momentos más tempranos. Para terminar, más allá de los resultados específicos para el ámbito geográfico de la Cordillera fueguina, se discuten las implicancias de estos resultados para el estudio de la organización tecnológica de sociedades cazadoras recolectoras en general, y se señalan las nuevas líneas de investigación que estos generan. 
Capítulo 1

RECURSOS ABIÓTICOS Y BIÓTICOS 


\section{INTRODUCCIÓN}

Los grupos cazadores-recolectores y pescadores que habitaron la Isla Grande de Tierra del Fuego explotaron una gama amplia de recursos naturales. Incluso podría decirse que explotaron todos los recursos que tenían a mano, tanto bióticos (vegetales, hongos y fauna) como abióticos (por ejemplo líticos), para una gran cantidad de actividades de subsistencia, tecnológicas y simbólicas.

El conocimiento que tenían estos grupos de las condiciones climáticas, el relieve y sus posibilidades de uso y explotación, de los recursos disponibles distribuidos por todo el archipiélago fueguino, les permitió una ocupación desde hace al menos 10.000 años.

Por ello es de fundamental importancia que las investigaciones arqueológicas integren un detallado y abarcativo estudio de los aspectos geológicos, climáticos, así como sobre el ambiente en que se desarrollan las sociedades en estudio. Empero, es conveniente que las presentaciones sobre la parte natural del ambiente se focalicen en aquellas características que o bien son recursos (vg. líticos, de alimentación) o bien pueden actuar sobre las actividades humanas como la movilidad (vg. carga nívea, zonas inundables). Este acercamiento a los recursos, tanto bióticos como abióticos, elegidos y explotados nos permite comprender las relaciones entre unos y otros, la forma de conseguirlos, de usarlos y con qué fines.

Dentro del presente trabajo el estudio de la gestión de los recursos toma un papel central. Ello se debe a la relación que existió entre unos y otros, pero además y fundamentalmente, al hecho que la gestión de recursos es un proceso que implica selecciones y decisiones que están profundamente imbricadas en la dinámica social. 


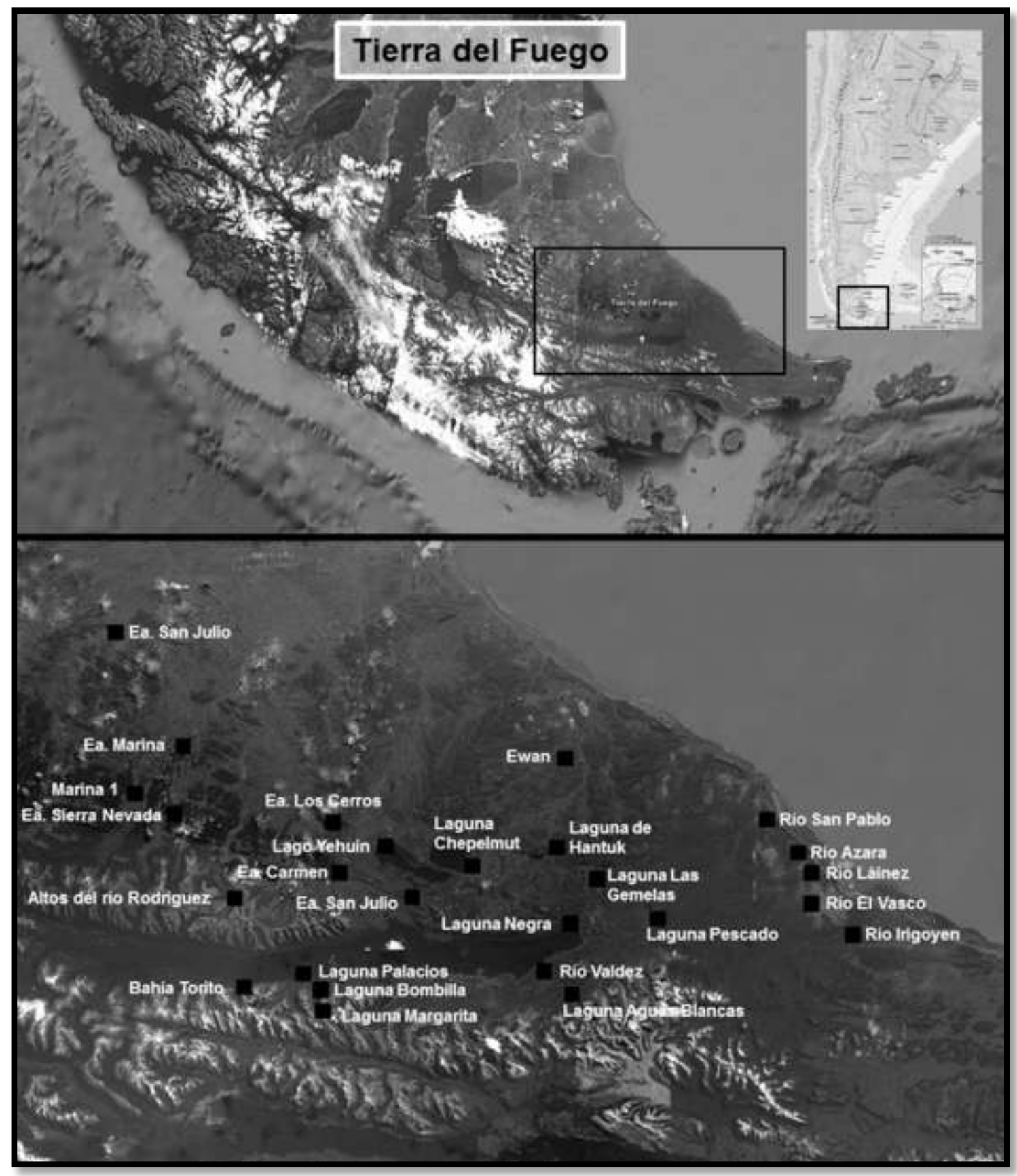

Figura 1. 1. Ubicación del área de estudio con los sitios y lugares incluidos en el trabajo

\section{MARCO GEOGRÁFICO}

El archipiélago Magallánico-Fueguino, ubicado en el extremo austral del continente americano, entre los $52^{\circ}$ y $56^{\circ}$ latitud sur, está compuesto por un gran número de islas pequeñas y una isla principal conocida con el nombre de Isla Grande de Tierra del Fuego. La superficie total del archipiélago se estima alrededor de los $75.000 \mathrm{~km}^{2}$. El mismo se encuentra rodeado por dos océanos, 
al Este por el Atlántico y al oeste por el Pacífico y su límite norte está dado por el estrecho de Magallanes (Figura 1.1).

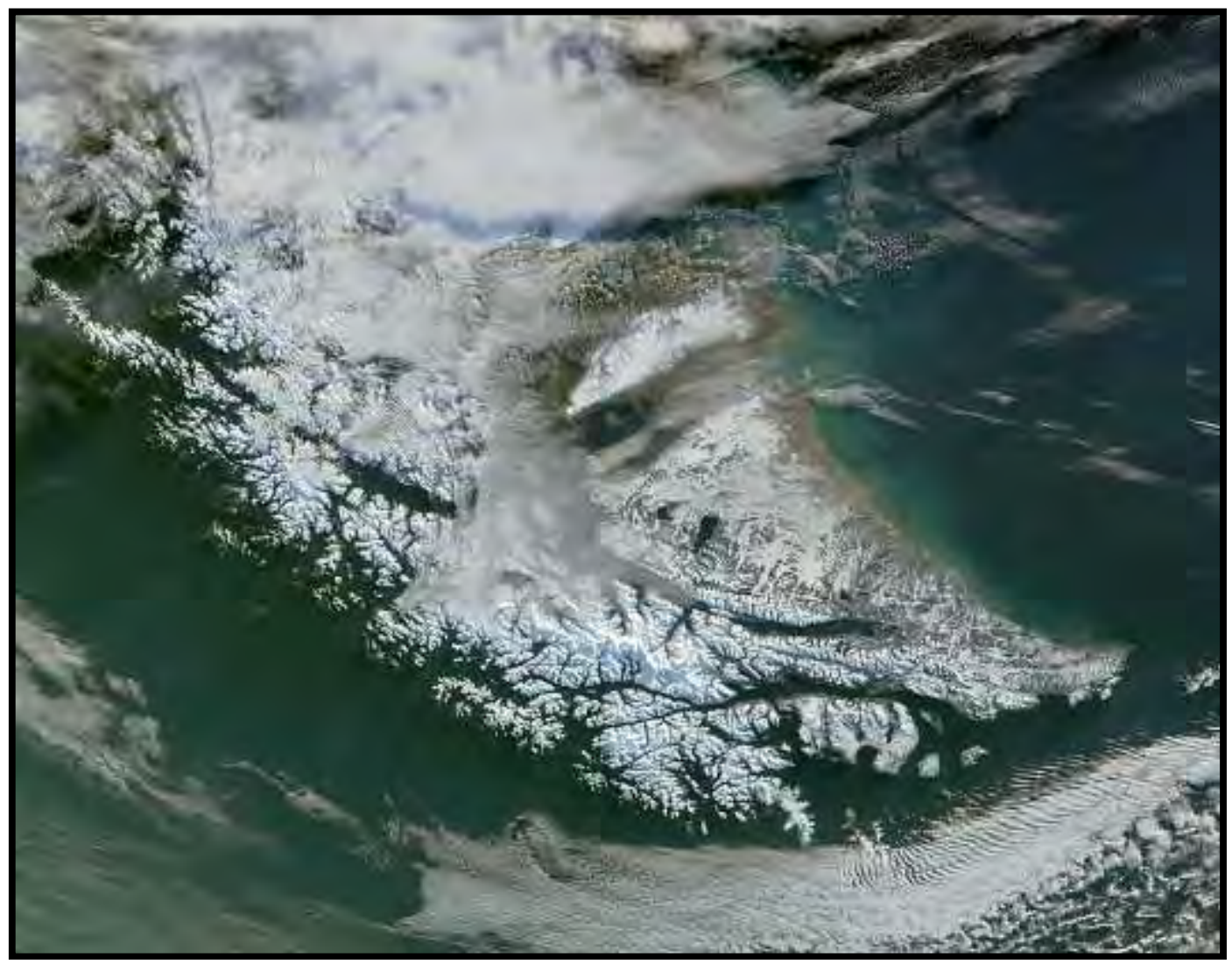

Figura 1. 2. Imagen del archipiélago Fueguino

El relieve de la Isla Grande se encuentra cortado por una gran falla, que es en realidad zona de contacto entre la placa de Nueva Scotia y la de Sudamérica, que es muy notoria en la depresión formada por el seno Almirantazgo y el lago Fagnano. Incluso tiene un desplazamiento opuesto, ya que la placa Sudamericana deriva al oeste y la de Nueva Scotia al este,

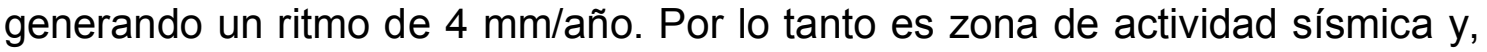
aunque no podamos postular su implicancia en el estilo de vida aborigen, sí la tiene respecto de la conservación de yacimientos arqueológicos.

Dadas las características del relieve, podemos reconocer dos unidades geológicas mayores: la cordillera andina, que forma el lado pacífico y antártico de Tierra del Fuego y funciona como eje vertebrador físico y geológico, cuya orientación va variando primero de N-S, NO-SE y finalmente O-E; y la cuenca sedimentaria de Magallanes o pampa, tierra plana y ondulada del lado Atlántico (Olivero et al. 2007). 
Todo el relieve del archipiélago fueguino-magallánico se encuentra modificado por la acción erosiva y por los depósitos de las diversas glaciaciones que sufrió la zona desde hace millones de años hasta unos 20.000 años aproximadamente (Rabassa et al. 1990).

\section{ASPECTOS CLIMÁTICOS}

La orografía particular de Tierra del Fuego genera condiciones climáticas contrastantes, ya que por un lado tenemos un ambiente de cordillera con precipitaciones muy frecuentes y una baja presencia de luz solar; por el otro lado tenemos un ambiente de estepa, al norte de la Isla Grande, con una disminución de las precipitaciones, condiciones más estables del tiempo y una mayor intensidad y frecuencia de los vientos, dando como resultado un clima transicional templado-frío sin estación seca (Iturraspe y Urciuolo 2007).

Las condiciones térmicas de la Isla Grande están influenciadas en invierno por el océano Pacífico, mostrando una marcada diferencia en el gradiente de las costas de E a $\mathrm{O}$. Si bien toda la zona de la costa y sus alrededores no llegan a medidas por debajo del punto de congelamiento, en las zonas más altas sí muestran períodos de congelamiento. Por otro lado en el interior de la Isla Grande la temperatura media muestra números por debajo del punto de congelamiento, tanto en las zonas altas como en las tierras bajas.

En verano puede verse una influencia de condiciones climáticas más continentales hacia el noreste. El suroeste presenta veranos frescos reflejando la temperatura del océano (alrededor de unos $7^{\circ} \mathrm{C}$ ). Los días cálidos son escasos en general en la Isla Grande, lo cual representa el rasgo más notable del régimen de temperaturas de la región, esto se relaciona con las características del viento del ciclón del este del hemisferio sur. La zona más fría se encuentra en el interior de la Isla Grande (Sierra Carlos). En la región este del lago Fagnano, la temperatura en verano es, probablemente, más alta que en el norte de la Sierra Carlos o que en la costa (Tuhkanen 1992).

El clima de Tierra del Fuego está marcado por las precipitaciones que se dan a lo largo de todo el año, dependiendo de la estación pueden darse en forma de lluvias o lloviznas verano-otoño o en forma de nevadas principalmente 
en invierno-primavera, aunque son esperables nevadas en cualquier momento del año.

En la superficie total de Tierra del Fuego el gradiente de precipitaciones decrece hacia el norte y el este (Iturraspe y Urciuolo 2007). La precipitaciones también muestran un gradiente con dirección O-E. Así en el archipiélago del oeste llueve 3 de cada 4 días, mientras que en Río Grande llueve 60 días al año. Por encima de los 1000 metros de altitud la principal forma de precipitación se da en forma de nieve. Las tormentas eléctricas, con granizo y otras expresiones de fuerte actividad conectiva son prácticamente desconocidas en Tierra del Fuego (Tuhkanen 1992).

Con respecto a las precipitaciones en forma de nevadas la distribución en cuanto a su media anual se da de la siguiente forma: 10 días al año al norte de la Isla, mientras que para Ushuaia se da alrededor de 50 días. Sin embargo la nieve permanece más tiempo en el interior de la Isla Grande: desde mayo hasta septiembre, aproximadamente. También para esta zona el congelamiento de suelo es permanente en este período, alcanzando máximos del orden del metro de profundidad.

Los vientos, son uno de los agentes de mayor influencia tanto en la distribución de la vegetación, como en la degradación de los suelos. Las épocas de mayor persistencia del viento se dan entre primavera y verano. Con una velocidad promedio anual de $3.9 \mathrm{~ms}^{-1}$ en Ushuaia, y unos $8 \mathrm{~ms}^{-1}$ en la costa Atlántica fueguina, como en Río Grande. Durante el invierno la media mensual de velocidad del viento es menor en el interior de la isla que sobre la costa, aunque durante el día puede ser superior hacia el interior (Tuhkanen 1992).

\section{RECURSOS ABIÓTICOS}

\section{Suelos y recursos líticos}

Los suelos se forman a partir de la exposición de la roca a los agentes atmosféricos y bióticos, procesos que suelen ser de larga duración, orientándose en el espacio y el tiempo, progresando, cambiando e inclusive interrumpiéndose (Godagnone y de la Fuente 2011). 
Para la región patagónica se pueden diferenciar 5 tipos de suelos, dos de los cuales representan los suelos de Tierra del Fuego: los denominados Patagonia Andina y Patagonia Extra Andina Austral (Godagnone y de la Fuente 2011). Los suelos patagónicos se caracterizan por haber evolucionado a partir de sedimentos superficiales derivados de aportes eólicos, fluviales y/o de características lacustrinas (Godagnone y de la Fuente 2011). El área de estudio corresponde principalmente a la Patagonia Andina y se caracteriza por el desarrollo del bosque subantártico; sin embargo en él, en función de gradientes climáticos y de sus formaciones fisionómicas vegetales, se desarrollan suelos con características particulares, que se presentan más adelante. Los suelos de la zona central de la Isla se caracterizan por su escasa potencia, por presentar un $\mathrm{pH}$ bajo motivo por el cual son calificados como "Acid Brown ground of the Forest", y por estar sometidos a procesos de congelamiento y descongelamiento (Tuhkanen 1992).

Si bien la estratigrafía de Tierra del Fuego es diversa y compleja, sólo haremos mención aquí de las dos formaciones que, desde el punto de vista arqueológico, se consideran como las dos fuentes principales de materias primas: la Formación Lemaire (del Jurásico) y la Formación Yaghán (Cretácico) (Figura 1.2).

La Formación Lemaire o Tobífera conforma un complejo submarino volcánico-sedimentario que incluye rocas epiclásticas (originalmente, turbiditas, conglomerados, sílex y radiolarias negras y mudstone carbonáceos: (roca compuesta de arcilla o barro); rocas acidas volcánicas y volcaniclásticas (lava riolítica, corrientes piroclásticas, brechas, tobas, y lapillita acrecionaria; porfíricos subvolcánicos de cuarzo); y spillitas basálticas. Las rocas de esta Fm. están fuertemente deformadas. El contacto con la Formación Yahgán es dominantemente tectónico pero en las áreas menos deformadas, en la subsuperficie de la cuenca Austral, el contacto con las rocas del Cretácico inferior es incompatible (Olivero y Malumián 2008).

La Fm Yahgán consiste en grandes brechas y conglomerados, sandstones, turbiditas arenosas y limosas, mudstones negros tobáceos y tobas volcánicas, penetradas por rocas basálticas de afinidades tholeiiticas-calcoalcalina y espilitica. Ajustados pliegues isoclinales, con plano axial de clivaje penetrante, caracterizan a las rocas de grano fino. El grado metamórfico 
alcanza las facies más bajas de greenschist (clorita-ceresita-cuarzo-albitaepidote) y una prehnitización generalizada afectó las rocas originales (Olivero y Malumián 2008).

La Fm Yahgán es interpretada como el relleno vulcaniclástico de la cuenca marginal Rocas Verdes ubicada entre un arco andesítico del Pacífico y el continente Sudamericano. Los clastos en forma de cuña de la geometría de las rocas Yahgán sugieren un frente vulcaniclástico adyacente al arco magmático del Pacífico (Olivero y Malumián 2008).

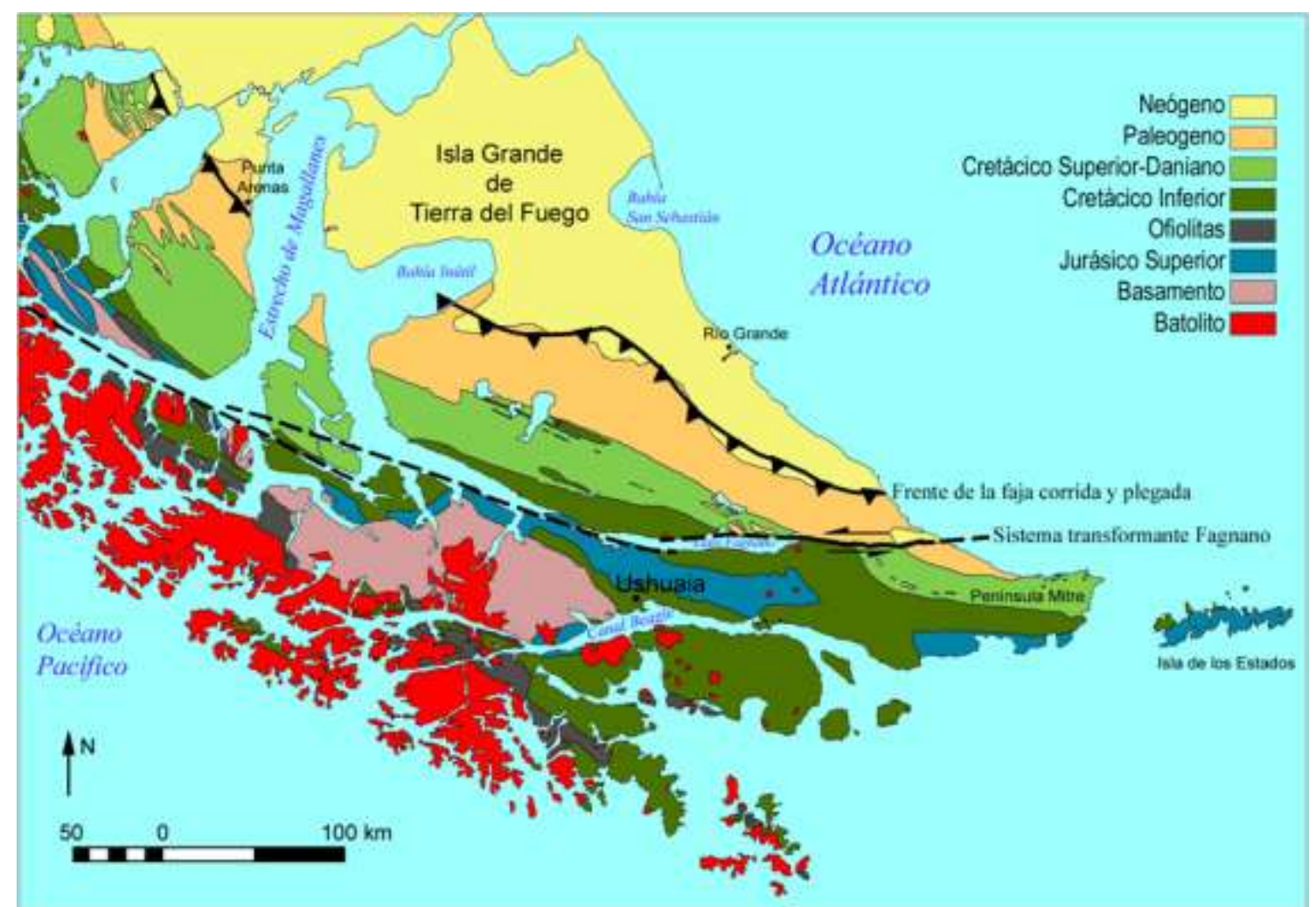

Figura 1. 3. Mapa del extremo austral de América que ilustra simplificadamente la distribución de las unidades geológicas principales hasta el Neógeno (basado principalmente en Olivero et al., 2007 - Argentina-; SERNAGEOMIN, 2003 -Chile-; compilación hecha por P. Torres Carbonell, 2009) Presentado en Martinioni 2010, Fig. 4

\section{Recursos hídricos (Figura 1.3):}

Tierra del Fuego se caracteriza por un paisaje modelado por sucesivas glaciaciones pleistocénicas y cuya última expresión se dio hace unos 20.000 años, con la retracción final que se produjo hace alrededor de 10.000 años. Este paisaje, por lo tanto, muestra cuerpos de agua dulce en gran número y muy dispersos por casi toda su superficie, principalmente la zona central de la 
Isla (Ponce et al. 2007; Coronato et al. 2006; Coronato et al. 2007; Coronato et al. 2008; Coronato et al. 2009).

Tal cantidad de cuerpos de agua de origen glaciario, lagos y lagunas, además de numerosos ríos que cruzan una buena parte de la Isla Grande hace que el recurso agua potable no sea crítico, ya que se lo encuentra casi en cualquier lugar.

Los cuerpos de agua cumplen una función secundaria, aunque no menos importante, como concentradores de fauna y contribuyen a la presencia de vegetación más diversas.

Una característica que acompaña generalmente a este recurso, principalmente a lagos y lagunas es que, debido al trabajo de los glaciares que les dieron origen, sus orillas presentan sectores con una gran cantidad y diversidad de guijarros. Los ríos también ofrecen materiales rocosos en superficie, pero de modo muy puntual y, salvo casos específicos, acceder a ellos no es tan fácil como en los lagos y lagunas.

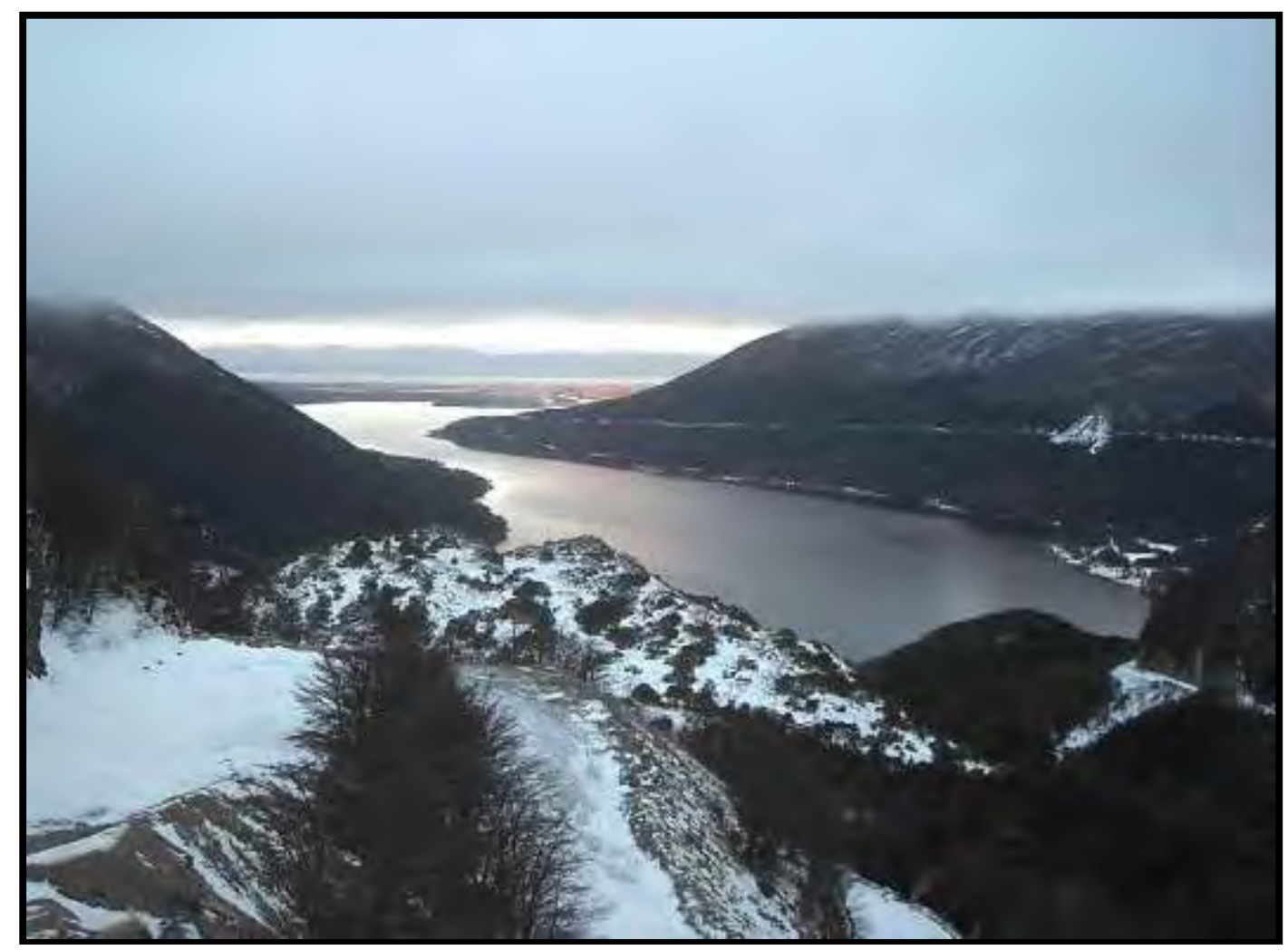

Figura 1. 4. Vista de lago de origen glaciario, lago Escondido 


\section{RECURSOS BIÓTICOS}

\section{Vegetación}

(Figuras 1.4-1.6):

Los bosques constituyen una importante cobertura vegetal dentro del archipiélago fueguino, por ejemplo en la Isla Grande ocupan un $35 \%$ de la superficie total. Las principales especies que forman parte de los diversos tipos de bosque son: Nothofagus pumilio (lenga), N. antárctica (ñire), N. betuloides (guindo) y Drimys winterii (canelo) (Collado 2001). La distribución de los bosques puede estar regulada por la acidez del suelo, así el Guindo se asocia con un $\mathrm{pH}=4.2$; la Lenga con un $\mathrm{pH}=5.5$ y el Ñre con un $\mathrm{pH}=5.2$ (Collantes et al. 1990). Esta característica impacta negativamente en la preservación de los restos orgánicos en los yacimientos arqueológicos. Siguiendo la división propuesta por Sakari Tuhkanen, podemos diferenciar algunos tipos de formaciones fisionómicas vegetales diferenciadas en base a tres gradientes climáticos: cantidad de calor, clima oceánico/continental y humedad/aridez. Estos son el bosque mixto, el bosque o Woodland, el bosque lluvioso o evergreen forest, la estepa, la vegetación alpina-andina y los turbales (Figura 1.4).

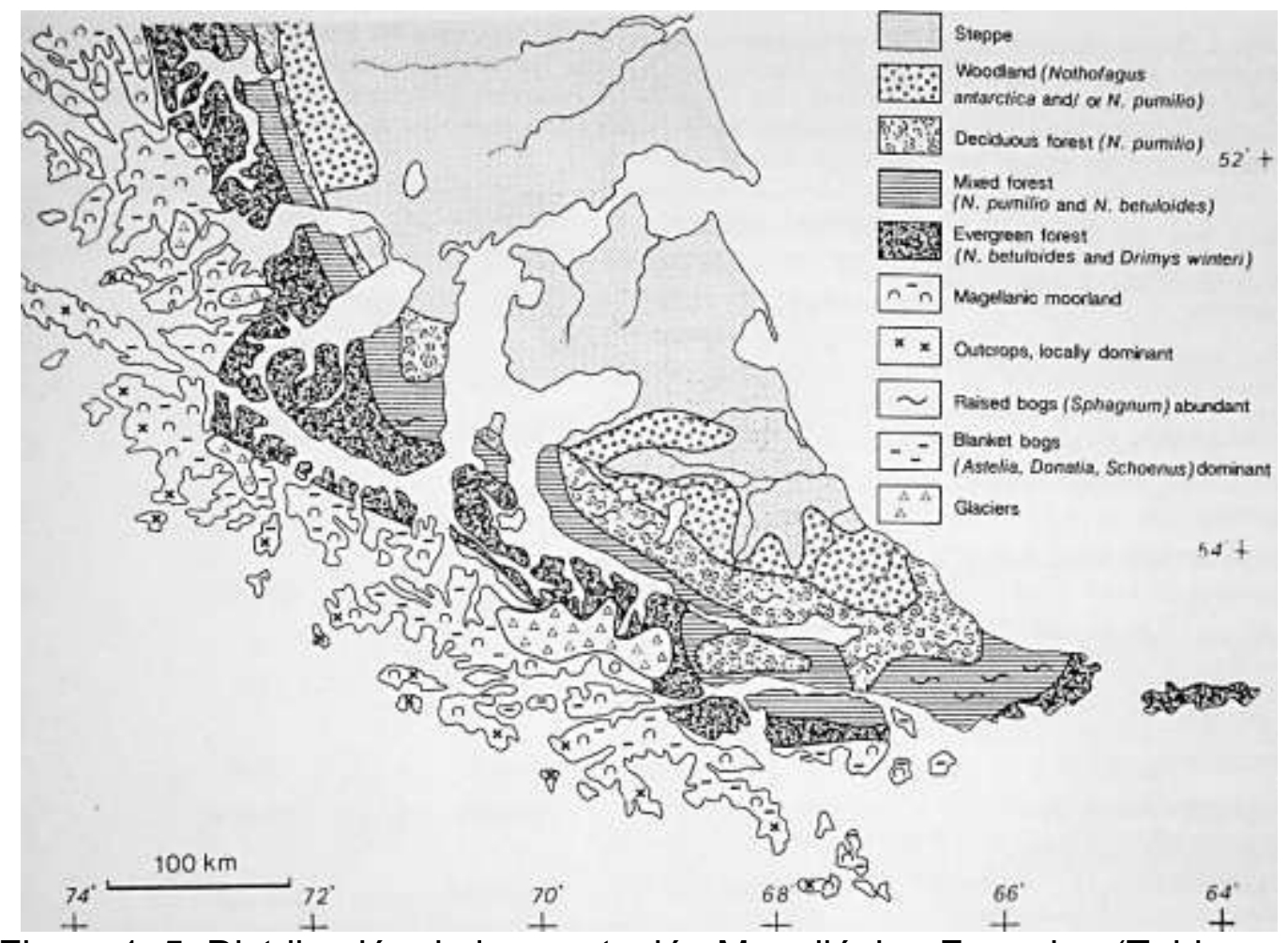

Figura 1. 5. Distribución de la vegetación Magallánica-Fueguina (Tuhkanen 1992) 


\section{El bosque deciduo}

Estos bosques están formados principalmente por Nothofagus pumilio, y en menor medida por Osmorhiza depauperata y O. Chilensis, Adenocaulon chilense, Viola magellanica, Dysopsis glechomoides, Rubus geoides, Acaena ovalifolia y Gaultheria (Pernettya) mucronata. Los turbales presentes en este tipo de bosque están representadas tanto por Sphagnum como por Carex, y se encuentran muy asociadas a Empetrum $s p$.

El bosque deciduo se extiende a través de las subzonas antiboreal (sierra Carlos y Beauvoir) y parte de la subzona hemiantiboreal (costa de la Península Brunswick) (Tuhkanen 1992). La continentalidad de estos bosques es mayor a la de los bosques perennes.

Las temperaturas invernales suelen estar por debajo de los $0^{\circ} \mathrm{C}$, incluso pueden llegar a $-15^{\circ} \mathrm{C}$. Esta característica es fundamental para la delimitación de la frontera entre el bosque deciduo y el bosque perenne. La media de las precipitaciones esta entre los 450 a $650 \mathrm{~mm}$ anuales.

Los suelos son ácidos con una cobertura orgánica generalmente moderna, debido a la hojarasca.

\section{El bosque mixto}

Compuesto por dos especies de Nothofagus, N. pumilio y betuloides, se extiende en el norte de la subzona antiboreal, provincia húmeda. Se encuentran dentro de los bosques más productivos y de mayor altura pudiendo alcanzar hasta 40 metros. Entre las especies más comunes asociadas a dicho bosque se pueden mencionar Hymenophyllum falklandicum, Luzuriaga marginata, Berberis ilicifolia y Codonorchis lessonii.

En este ambiente la paludificación (proceso de expansión de turbera causado por la elevación gradual del nivel freático por medio de la acumulación de turba) de suelo es muy intensiva, donde son muy característicos los turbales con parches de Sphagnum (Archibold 1995).

Las temperaturas en verano pueden llegar hasta los $11^{\circ} \mathrm{C}$ mientras que en invierno, si bien más frío que el bosque lluvioso, no suele llegar por debajo de los $0^{\circ} \mathrm{C}$, entre 0.5 a $2.5^{\circ} \mathrm{C}$. Las precipitaciones son menores que en el bosque lluvioso y en los turbales, promediando entre los 500-600 y hasta los 
$900 \mathrm{~mm}$ anuales. El suelo ácido y marrón, es parecido al del bosque de $N$. pumilio.

\section{El bosque explotable o woodland}

Conformado principalmente por Nothofagus antárctica y N. pumilio, estos bosques se encuentran en el borde noreste del área boscosa fueguina. Forman comunidades intermedias entre bosques y praderas.

No son de gran porte ya que no suelen sobrepasar los 8 metros. Entre otras especies presentes en este bosque se pueden mencionar Berberis buxifolia, chiliotrichum diffusum, Galium aparine, Luzula alopecurus, Ranunculus peduncularis, también Anemone multifida, Vicia magellanica, Taraxacum officinale y Trifolium repens.

Este tipo de bosque se extiende en las subzonas antiboreal medio y parte sur del antiboreal, en el norte del estrecho de Magallanes se ubica en la subzona norte antiboreal y hemiantiboreal.

La temperatura media se encuentra por debajo de los $0^{\circ} \mathrm{C}$ y las precipitaciones anuales van desde 350 a $500 \mathrm{~mm}$.

\section{El bosque lluvioso o evergreen forest}

El bosque lluvioso o perenne, está formado por Nothofagus betuloides y Drimis winteri, también Maytenus magellanica y Embothrium coccineum, por otro lado, entre los arbustos podemos mencionar a Escallonia serrata, Berberis ilicifolia y Geultheria (Pernettya) mucronata. Las especies características del manto son los helechos, Gleichenia quadripartita, y los arbustos enanos Lebetanthus myrsinites y Philesia magellanica. Los turbales, tipo manto están representados por las especies Astelia pumila, Oreobolus obtusangulus y Donatia fascicularis.

Este tipo de bosque puede encontrarse en las subzona antiboreal, en el sector súper oceánico y en la provincia perhúmeda. La media de la temperatura para los momentos más cálidos es de $10^{\circ} \mathrm{C}$ y las precipitaciones pueden ser menores a 600-700 mm por año. 
El bosque crece sin problemas sobre rocas permeables en el este lluvioso fueguino, aunque la turbera no crece sobre la superficie encharcada. Los suelos son ácidos con una alta acumulación de turba.

\section{Estepa}

Es de gran extensión ya que cubre alrededor del $40 \%$ de la Isla Grande de Tierra del Fuego, abarcando una superficie de 405.000 ha, lo que representa aproximadamente un $20 \%$ de la superficie del sector Argentino (Collado 2007). La topografía se caracteriza por la presencia de planicies elevadas y cañadones con una dirección predominante de oeste-este donde las condiciones climáticas son menos severas; también son comunes tanto lagunas temporales como permanentes y algunas de carácter salino (Collado 2007).

En los cañadones se encuentran sectores de "vegas", principalmente a lo largo de los cursos de agua. Dichas vegas están compuestas por gramíneas del género Hordeum, Alopecurus, Deschampsia y ciperáceas del genero Carex la cual forma turbales o "mallines" (Collado 2007).

En la estepa pueden distinguirse matorrales, brezales y pastizales. Las especies más importantes son: Festuca gracilima, generalmente con Agropyron fuegianum, Agrostis flavidula, Festuca magellanica, Poa alopecurus y Trisetum spicatum están comúnmente asociadas. Las hierbas incluyen Acaena pinnaifida, Calceolaria uniflora, Cerastium arvense, Senecio magellanicus, Taraxacum gilliesii, Vicia bijuga y Viola maculata. En la zona de bosque marginal podemos ver las siguientes especies representadas Acaena ovalifolia, Adenocaulon chilense, Baccharis patagonica, Cotula scariosa y Viola magellanica (Tuhkanen 1992, Collado 2007).

En cuanto a las precipitaciones, estas son menores que en el resto de los ambientes, con un promedio anual de $200-400 \mathrm{~mm}$. Las temperaturas en los períodos más cálidos superan generalmente los $10^{\circ} \mathrm{C}$.

La estepa está ubicada en toda la subzona antiboreal y en la provincia semiárida. Uno de sus rasgos climáticos característicos son los vientos predominantes del sector oeste, los cuales se intensifican en los meses de primavera y verano (Tuhkanen 1992, Collado 2007). 


\section{Turbales}

Puede considerarse como una vegetación plurizonal. Se la encuentra en las subzonas al norte a través del hemiantiboreal y del antiboreal del norte hasta el antiboreal medio y ocupando casi toda la zona superoceánica y perhúmeda $($.

Las especies más representadas pueden ser: Astenia pumila, Donatiaf ascicularis, Bolax caespitosa, Oreobolus obtusangulus, Drosera uniflora, Schoenus antarticus, Caltha dioneifolia, Drapetes muscosus y Carpha alpina.

Las precipitaciones anuales llegan hasta los 1500-4800 mm, con una temperatura relativamente baja, dando un promedio para los momentos más cálidos de 7.5 a $9^{\circ} \mathrm{C}$. Existe una importante paludificación del suelo gracias a las rocas impermeables que causan un pobre drenaje.

\section{Vegetación alpina-andina}

La vegetación alpina-andina presenta una importante diversidad. Por un lado en las montañas, donde se encuentra la frontera entre el bosque y la zona de vegetación alpina, existe un cinturón de Krummholz, formado por Nothofagus pumilio y/o N. antarctica bastante denso. Dicha frontera se encuentra en general entre los 600 y 700 metros.

Por otro lado están los brezales constituidos principalmente por Bolax gummífera muy asociada con otras especies formando "colchones" como Abrotanella emarginata, Azorella lycopodioides y Drapetes muscosus. Los colchones de Empetrum rubrum son comunes, junto con Acaena magellanica, Leucheria hahnii, Gamochaeta spiciformis y Gaultheria (Pernettya) pumila.

El feldmark se caracteriza por una densa comunidad de líquenes, e.g. Usnea, hacia la transición de colchón de brezales, Nassauvia latissima, Saxifraga magellanica y Senecio humifusus, junto con algunas gramíneas bajas e.g. Deschampsia párvula, Poa alopecurus y Stipa rariflora.

A lo largo de las márgenes de los arroyos, esteras de Abrotanella linearifolia, Caltha appendiculata y Plantago barbata se dan junto con algunas especies como Acaena antártica, Caltha sagittata, Lagenifera nudicaulis y Oxalis magellanica. Es común un grueso sustrato de Cardamine glacialis, Hamadryas magellanica y Nassauvia magellanica. 
Si el terreno es pantanoso pueden encontrarse, hierbas de hojas e.g. Agrostis magellanica, Corex magellanica, Carpha alpina, Deschampsia atropurpurea, Rostakovia magellanica, Schoneus antarticus, Uncinia kingii y U. lechler.

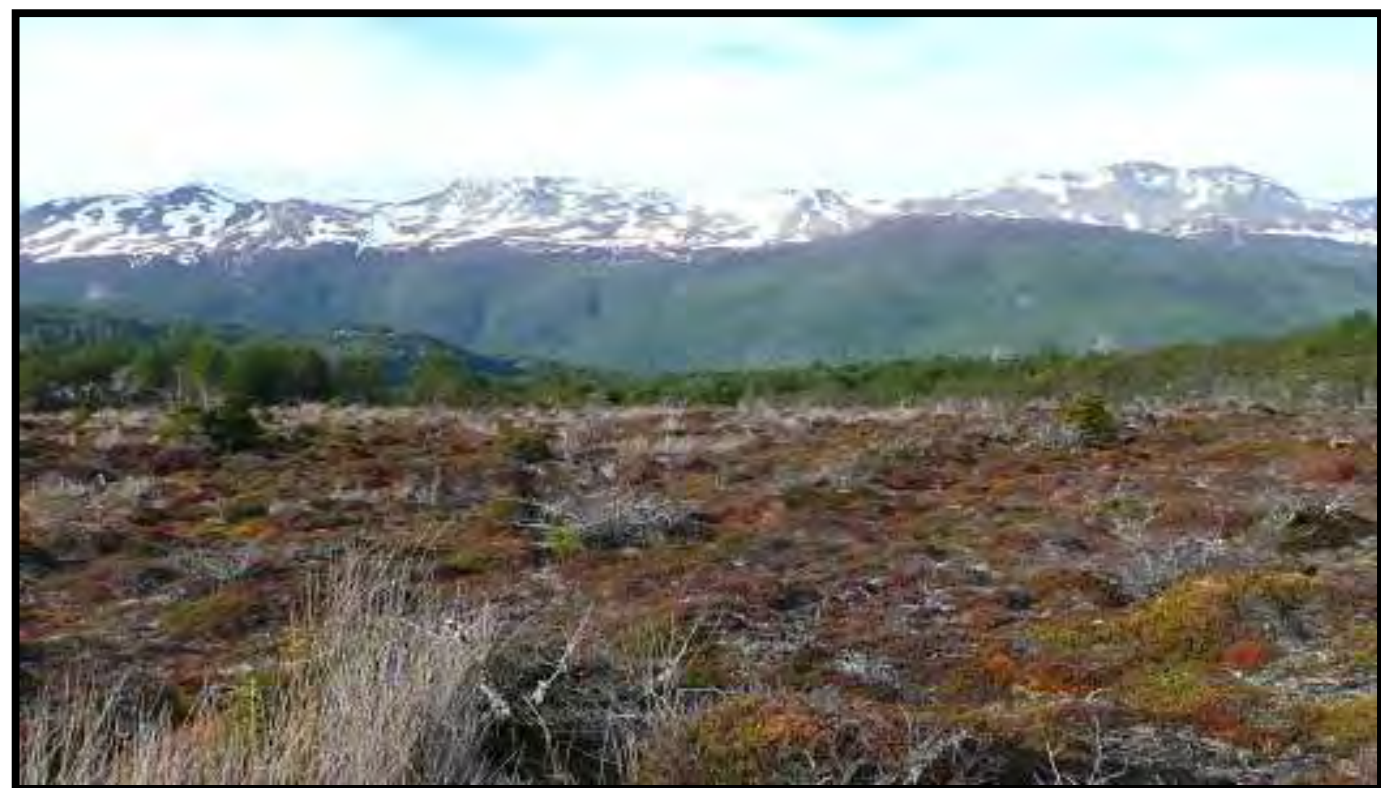

Figura 1.6. Turbal

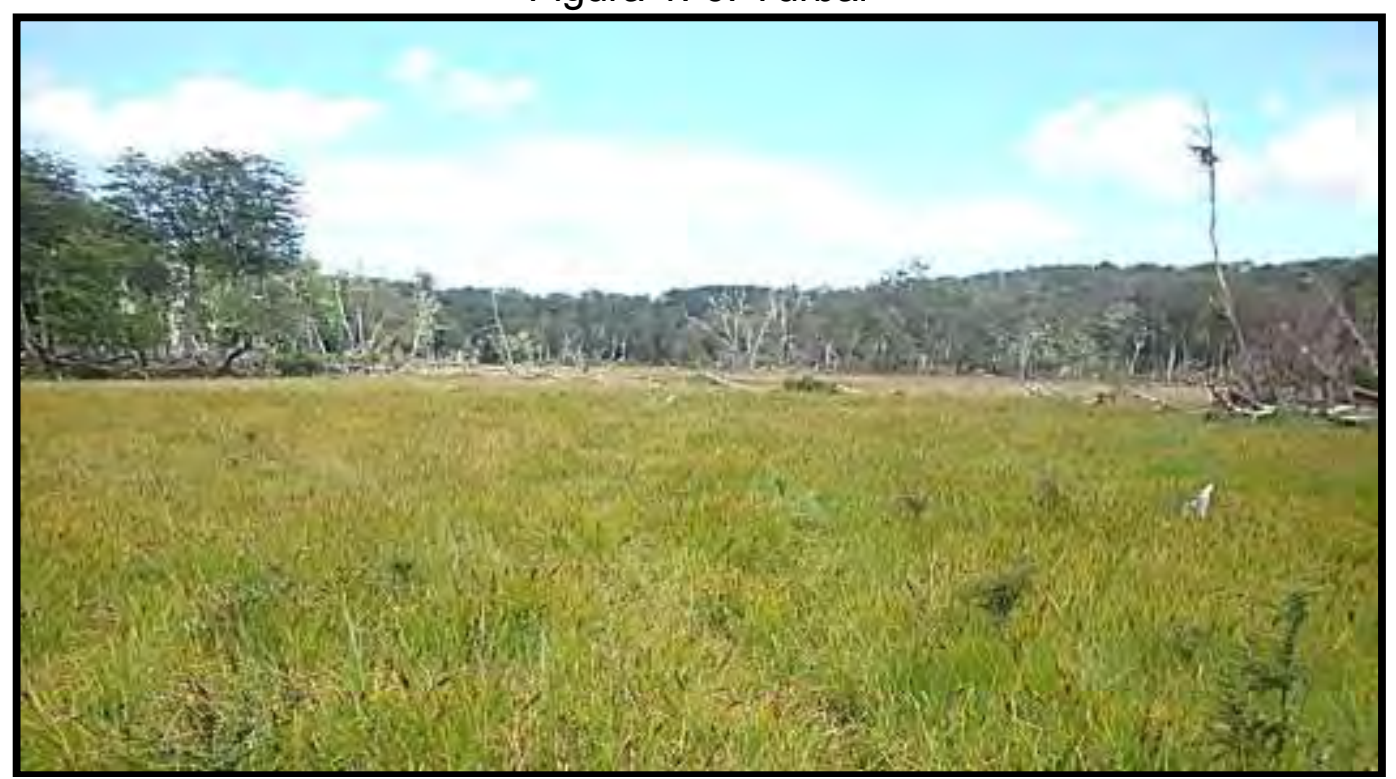

Figura 1. 7. Zona de bosque con pastizal

\section{Fauna}

(Figuras 1.7-1.9):

La fauna terrestre de Tierra del Fuego no se caracteriza por una diversidad de especies, y es más reducida aún cuando nos circunscribimos a una faja espacial especifica. 
Esta faja a la que nos referimos es la faja central de la Isla Grande de Tierra del Fuego. Allí, en los bordes del bosque, los pastos atraen a manadas de guanacos (Lama guanicoe). Los otros mamíferos autóctonos de la zona son el zorro fueguino (Dusicyon culpaeus) y un roedor ("tuco-tuco", Ctenomys magellanicus). Los ambientes de lagos y lagunas convocan a una gran variedad de aves, desde principios de primavera hasta finales de otoño, como la avutarda o cauquén común (Chloephaga picta), el carpintero patagónico (Campephilus magellanicus), loros (Enicgnathus ferrugineus), entre otras (Barquez et al. 2006; Massoia y Chebez 1993).

De todos, el guanaco es sin duda el más importante como recurso. Estos animales son camélidos pastadores y ramoneadores, de hábitos diurnos (Raedeke 1978). Son de tamaño medio, aunque estadísticamente son de mayor tamaño que los guanacos de Patagonia continental, pudiendo pesar en promedio 120 kg (Massoia y Chebez 1993; Barquez et al. 2006; L"Heureux 2007, 2008).

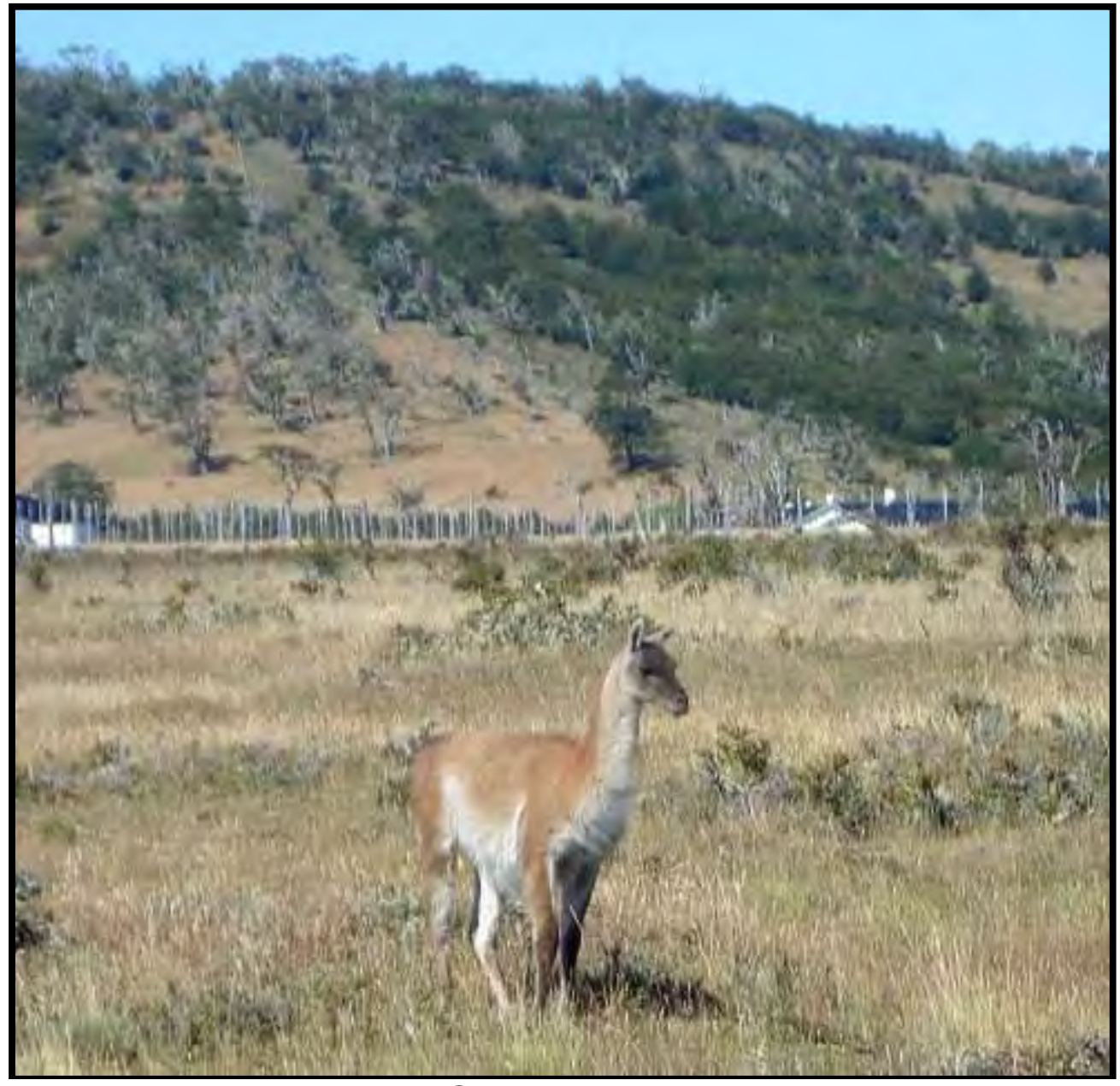

Figura 1. 8. Guanaco (Lama guanicoe) 
En cuanto al zorro, es un animal pequeño que puede alcanzar unos 11 kg y que se alimenta de otros animales más pequeños, aunque también del carroñeo (Atalah et al. 1980).

Dentro de los roedores autóctonos, el de mayor tamaño es el tuco-tuco (Ctenomys magellanicus); otros son el colilargo fueguino (Oligoryzomys magellanicus), la rata conejo (Reithrodon auritus), el ratón lanoso (Abrothrix longipilis). Existen dos especies de murciélagos, el oreja de ratón (Myotis chiloensis) y el orejudo de Magallanes (Histiotus montanus) (Lizarralde et al. 1986a y b; Massoia y Chebez 1993; Lizarralde et al. 1994; Schiavini 2007).

Finalmente los peces autóctonos de agua dulce son extremadamente pocos, siendo el más frecuente el puyen (Galaxis maculatus) que habita en arroyos y lagunas de agua dulce (Lloris y Rucabado 1991; Boy et al. 2005).

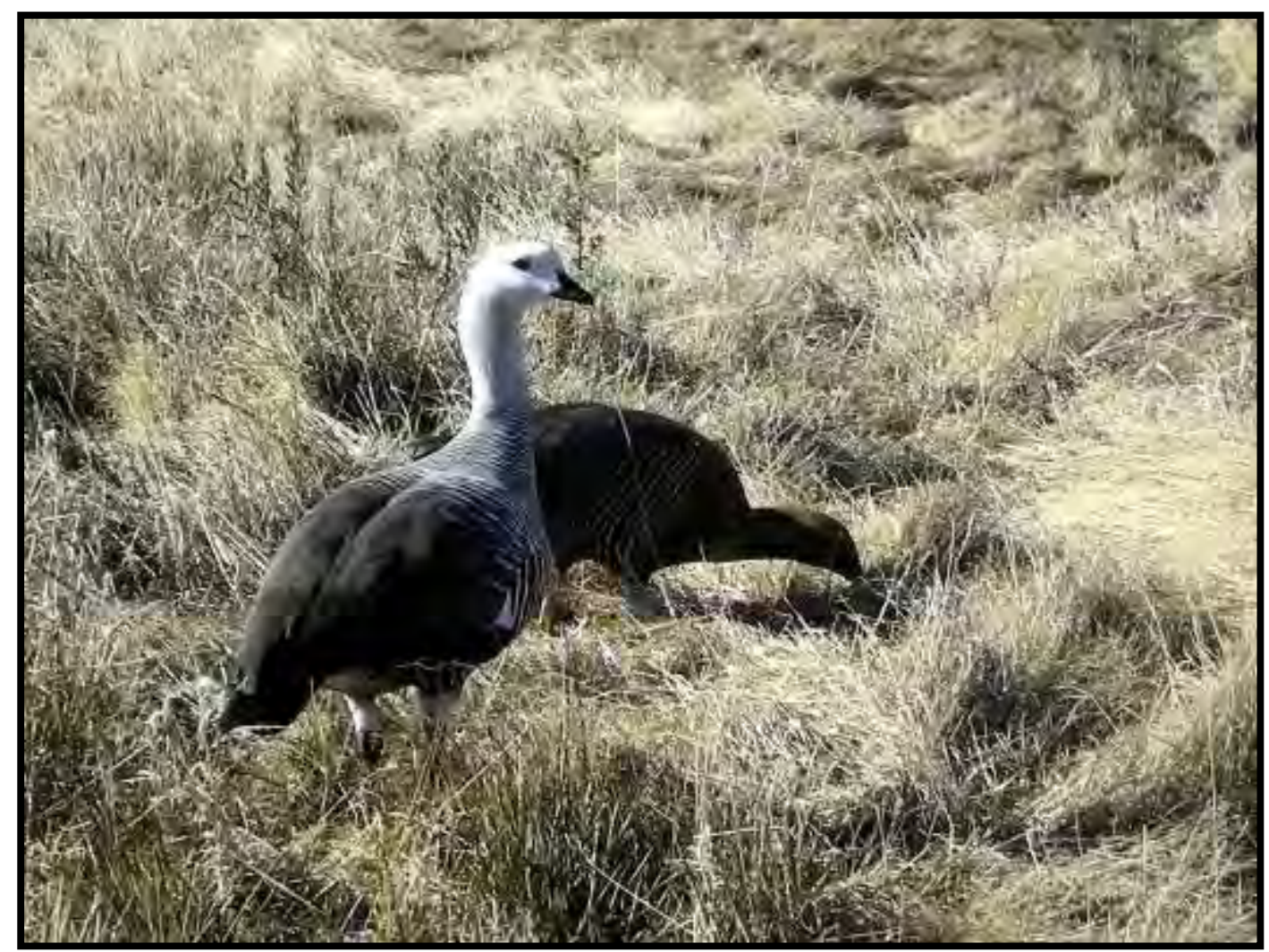

Figura 1. 9. Cauquenes (Chloephaga picta) 


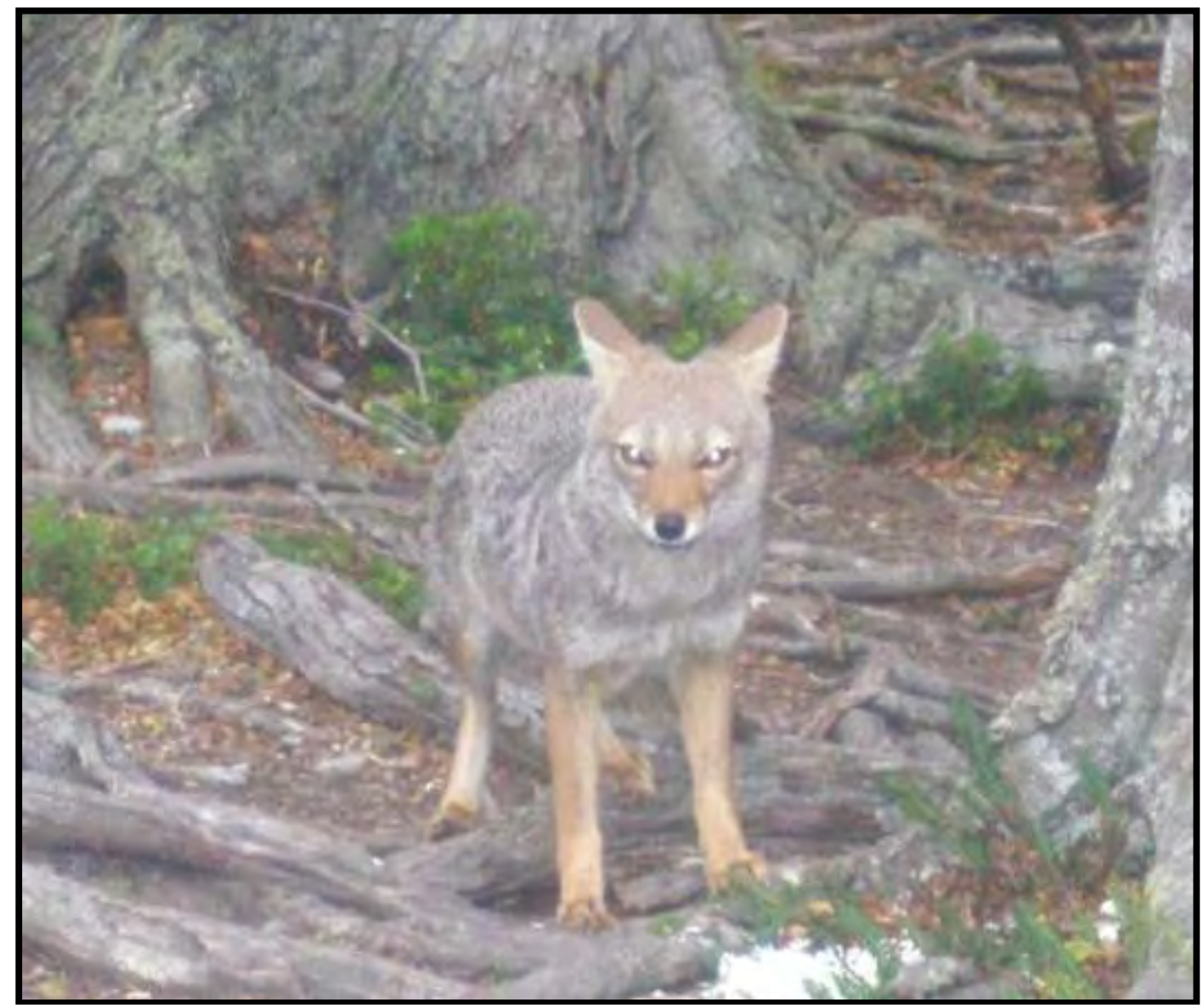

Figura 1. 10. Zorro (Dusicyon culpaeus)

DISCUSIÓN: AMBIENTE Y RECURSOS PARA SOCIEDADES CAZADORASRECOLECTORAS

En comparación con las estepas del norte de la Isla, la región montañosa central se caracteriza por mayor diversidad y abundancia de recursos (Mansur 2002). El bosque ofrece protección, refugio y abundancia de madera, como materia prima y leña, un recurso esencial que está ausente en las estepas del norte.

Las tipos de ambientes de bosque presentados más arriba permiten distinguir en líneas generales tres zonas principales en la zona de estudio: Bosque Perenne mixto, bosque de hojas caducas y bosque caducifolio Woodland (Tukhanen 1992) (ver fig. 1.4.).

Los bosques perennes mixtos se extienden desde la costa sur de la Isla Grande hasta la costa del lago Fagnano; en esta zona existe una amplia diversidad y abundancia de recursos vegetales, en particular de diferentes tipos de plantas. La vegetación de bosque mixto de guindo (Nothofagus betuloides) y lenga ( $N$. pumilio) brinda además reparo y abrigo, así como abundante madera 
para su uso en tecnología, como combustible, etc. Además tiene un importante estrato arbustivo formado principalmente por calafate (Berberis buxifolia), chaura (Pernettya mucronata), michay (Berberis ilicifolia) y parrilla (Ribes magellanicum); todos ellos tienen pequeñas bayas comestibles que maduran durante el verano. Durante esta estación también maduran las pequeñas frutillas de Magallanes (Rubus geoides).

En los bordes de los numerosos lagos y lagunas cercanos hay juncos, que los Selknam utilizaban en cestería. Entre las herbáceas hay una variedad de plantas comestibles tales como el apio silvestre (Apium australe), el diente de león (Taraxacum sp.), el amor del hortelano (Gallium sp.), etc. (Berihuete 2006; Moore 1983)

Otra zona es la de los bosques de hoja caduca ( $N$. pumilio) de las pendientes de la cordillera al sur y este del lago Fagnano, hasta la costa atlántica, donde se desarrollan amplias zonas de turbales interiores alternando con colinas boscosas y valles amplios, pero con menor variedad en el estrato arbustivo.

Finalmente, la zona de bosque caducifolio de $N$. antárctica en las colinas de ecotono bosque-estepa que se extiende hacia el río Grande al norte. En algunas áreas el bosque de "ñire" está bien desarrollado, con árboles de más de $15 \mathrm{~m}$ de altura. Entre los arbustos, uno de las más comunes es Berberis buxifolia ("calafate"), que crece en las montañas más bajas, en los claros y en los bordes del bosque y en las zonas húmedas de la estepa bordeando ríos y manantiales.

En los sitios expuestos al viento, se forma un estrato arbustivo con Chiliotrichium difusum ("mata negra"). Otro arbusto importante es Empetrum rubrum ("murtilla"), que crece en las tierras bajas húmedas y en los bordes de los bosques. Aquí también tanto "calafate" como "murtilla" producen bayas comestibles disponibles durante el verano. Todos los ambientes de bosque son ricos también en una amplia variedad de hongos comestibles, que están disponibles en particular en primavera y otoño (Moore 1983).

Como se desprende de esta presentación, esta región ofrece cantidad y diversidad de recursos explotables, desde rocas para la confección de instrumentos, madera como combustible, para la construcción de estructuras habitacionales, instrumental e incluso ornamental; agua dulce que cumplía la 
doble función de ser un recurso en sí mismo y a la vez concentrar fauna como el guanaco y una gran variedad de aves.

En cuanto a estos recursos, sabemos por los relatos escritos que no sólo se los explotaba por el consumo de carne, sino también que se aprovechaban los cueros para abrigos, viviendas, y confección de otros productos, así como los huesos y los tendones (Gusinde 1937; Chapman 1986; De Agostini 1956; Beavoir 1998 [1915]). Algunos de estos datos han sido confirmados por las evidencias arqueológicas. En los capítulos que siguen, a partir de la presentación de resultados de la evidencia arqueológica analizada, discutiremos el papel que jugó la oferta de recursos del centro de la isla en la configuración de la forma de vida aborigen. 


\section{Capítulo 2}

ANTECEDENTES DE INVESTIGACIÓN 


\section{INTRODUCCIÓN}

El conocimiento de la existencia de grupos humanos en el extremo sur del continente Americano se retrotrae hasta principios del siglo XVI con la entrada de Don Hernando de Magallanes en el estrecho que luego llevaría su nombre.

A partir de este momento fueron llegando expediciones con diversos propósitos, las cuales dejaron diversos registros, cartografía, grabados, fotografías y un gran número de escritos sobre las sociedades que habitaban el archipiélago Fueguino. Estos escritos reflejan en mayor o menor medida el pensamiento, la ideología y las teorías preponderantes del momento (Orquera y Piana 1999).

Sabemos que utilizando estos documentos cuidadosamente se puede recabar información de gran valor. Pero sabemos también que es indispensable confrontarlos con los resultados de las investigaciones arqueológicas, que dan cuenta de una gran cantidad de actividades a través del trabajo directo con el material arqueológico como se han demostrados con diversos trabajos em la región (Legopuil 1989, 1992; Estévez y Vila 1996; Orquera y Piana 1999; Mansur y Pique 2012).

La arqueología del sur de Patagonia continental debe mucho al establecimiento de sus secuencias cronológicas a la existencia de formaciones con cuevas o aleros. Estas formaciones son atractores para la implantación humana y además tienen gran visibilidad arqueológica; en ellas se estudiaron secuencias estratigráficas que se remontan al comienzo del poblamiento. A partir de allí, se ha podido conocer numerosos aspectos de la organización de las sociedades de cazadores recolectores, tales como subsistencia, tecnología, movilidad, y en particular las relaciones que establecieron en la ocupación de los diversos ambientes de la región, desde el período transicional PleistocenoHoloceno (Miotti y Salemme 2004, Borrero 1985, 1991).

En el caso de Tierra del Fuego, los registros en aleros son escasos y se encuentran limitados a los lados de bloques erráticos en la zona de estepas que se desarrolla sobre el modelado glaciario, tal es el caso de los sitios 
Cabeza de León (Borrero 1979) y Marazzi (Laming-Emperaire 1968b, LamingEmperaire Emperaire et al. 1972, Morello et al. 1999) y a los de la Sierra Carmen Sylva (Massone 1987, 2004), todos en la zona norte de la Isla Grande. En la zona sur de la Isla, la costa del canal Beagle se caracteriza por la existencia de formaciones de concheros con topografía anular o en domo, que los hace también sitios de alta visibilidad arqueológica. Tal vez por estas razones, desde sus inicios y hasta hace algunos años, las investigaciones arqueológicas en Tierra del Fuego se concentraron principalmente en el norte de la Isla (Estrecho de Magallanes y costa atlántica) y en las zonas costeras del Canal Beagle. Al contrario, son escasos los estudios realizados en la faja central, en particular en territorios interiores, correspondientes a la zona del bosque subantártico (cf. ref. Mansur y Piqué 2009).

\section{INVESTIGACIONES ARQUEOLÓGICAS EN LA ISLA GRANDE}

El poblamiento de la Isla Grande de Tierra del Fuego, se produjo hace alrededor de 11.000 años. Hacia ese momento la Isla se encontraba conectada al continente por el estrecho de Magallanes, debido a que el bajo nivel del mar dejó al descubierto un puente terrestre por el cual accedieron los primeros pobladores. (Massone 1999, Coronato et al.1999, Mc Culoch y Morello 2009, Morello et al. 2012).

Estos habrían ocupado el sector noroeste de la Isla, perteneciente a la actual república de Chile, en lo que se conoce hoy como el sitio más antiguo, denominado Tres Arroyos 1, nivel "Va" (Massone 1991, 1999, 2004, Massone et al. 1998), y luego el sitio Marazzi con una antigüedad de 14C $9590 \pm 200$ años AP (Laming-Emperaire et al. 1972, Morello et al. 2009, Morello et al. 2012).

Hacia el extremo sur, los primeros habitantes habrían llegado unos miles de años más tarde a ocupar parte de la costa del canal de Beagle, como lo demuestra la capa $S$ del sitio Imiwaia 1 (7840 \pm 50 BP AA 78551) (Piana y Orquera 2009) y en el primer componente de Túnel $1(6680 \pm 210$ BP) (Orquera y Piana 1999).

Numerosas investigaciones arqueológicas dan cuenta de aspectos de la vida de estos grupos cazadores-recolectores. En realidad, la arqueología de Tierra del Fuego tiene una historia que comienza hace al menos 80 años, con 
los trabajos pioneros de Vignati en la década del 20, cuando realizó excavaciones en un conchero ubicado sobre la margen derecha del Río Chico, mencionando la existencia de al menos dos centenares más de concheros. Varios años después, en la década del 50, comenzaron las expediciones arqueológicas de la Misión Científica Francesa dirigidas por Joseph Emperaire y Annette Laming-Emperaire, que se centraron principalmente en las costas del estrecho de Magallanes en el sector chileno de la isla Grande de Tierra del Fuego. Como resultado de esos trabajos, se identificaron las localidades arqueológicas Punta Catalina y Cabo San Vicente (Laming-Emperaire 1972a). En 1965 las expediciones fueron dirigidas por Annette Laming-Emperaire y en este marco se llevaron a cabo prospecciones y excavaciones que dieron como resultado la identificación de una gran cantidad de sitios arqueológicos: Dernier Campement Ona (DCO) en Punta Catalina (Laming-Emperaire 1965); Marazzi 1 (MA1) y Marazzi 3 (MA3) en Bahía Inútil. El sitio MA1 tiene un fechado radiocarbónico con una datación de $9.590 \pm 200$ años $A P$, que fue realizado sobre carbones de los niveles inferiores; para los niveles medios se obtuvo un fechado de $5.570 \pm 400$ años AP (Laming-Emperaire et al. 1972). Finalmente en los 60, el sitio tres Arroyos fue identificado por la Misión Francesa y sondeado por Saxon en 1975 (Laming-Empareaire 1972a y b, 1968a y b; Saxon 1979).

En 1981 Mauricio Massone desembarca en el sector chileno de la Isla Grande, recorriéndola de extremo a extremo en dirección N-S. Allí decide realizar su primer sondeo en el extremo $\mathrm{N}$ en una cueva localizada en la estancia Tres Arroyos, detectando materiales arqueológicos en depósitos profundos. En 1983 regresa al sitio Tres Arroyos y fecha radiocarbónicamente dos fragmentos óseos de los niveles profundos, obteniendo una antigüedad de 10.280 y 10.420 años AP. En 1986 Massone y colaboradores reconocen la asociación de fauna extinta (Hippidion sp., Mylodon sp., Dusicyon avus y Lama sp.) (Caviglia 1985-1986; Mengoni Goñalons 1987) con artefactos culturales, e identifican el primer fogón en cubeta para la región. Así es posible realizar un nuevo fechado, esta vez sobre carbones, que arroja un resultado de 11.880 AP de antigüedad. De esta manera Tres Arroyos 1 se establece como el sitio más antiguo conocido hasta el momento para la Isla (Massone 1982, 1987, 1988, 2004). Dada la relevancia del sitio, este investigador conformó un equipo para 
abordar los primeros estudios de los materiales arqueológicos y su interpretación, incluyendo análisis de los materiales líticos (Jackson 1987, 2002), determinación la fauna extinta (Caviglia 1985-86; Mengoni Goñalons 1987; Prieto y Canto 1997; Latorre 1998), análisis de la tefra de la capa inferior a la ocupación humana (Stern 1990, 1992), determinación de materias primas (Lopez 1999), análisis de fauna: camélidos (Prieto 1999), cánidos (Arroyo 1999) roedores (Martín 1997; Martín y Borrero 1999) (Bibliografía citada en Massone 2004) entre otros.

Desde entonces $M$. Massone y su equipo han realizado trabajos sistemáticos para la región chilena de la isla Grande de Tierra del Fuego. En 1998 Morello y colaboradores, retoman las investigaciones en la localidad Marazzi, realizando nuevas prospecciones, identificando los sitios ya reconocidos por la Misión Francesa e identificando una docena de nuevos sitios. Es en este marco que Morello realiza sondeos en MA1 y fecha los materiales de los niveles medios, proveyendo una nueva fecha para el sitio ca. 5.440 años AP (Morello 1999). Desde entonces este equipo ha identificado más de un centenar de sitios para el área de estudio, Marazzi 2, Marazzi 32, Marazzi 38, sitio Bahía Inútil 3, Punta Baxa 7, Punta Catalina 3, Punta Catalina 4, Punta Catalina 20, Cabo San Vicente. (Morello 2000; Morello et al. 1998; Morello et al. 2004a; Massone 2004; Massone y Torres 2004, Bahamondes 2004, Massone y Morello 2007).

En 1977, Luis Borrero inicia sus primeros trabajos arqueológicos en la zona noreste de la Isla Grande de Tierra del Fuego, en el sector argentino, excavando en la bahía San Sebastián el sitio Cabeza de León 1, fechado en $1.100 \pm 95$ años AP. sobre carbón vegetal (Borrero 1979). En las inmediaciones del sitio Cabeza de León 1, este investigador y colaboradores identifican los sitios Cabeza de León 2, 3 y 4 (Borrero et al. 1981; Horwitz et al. 1992; Favier Dubois 1998; Martin y Borella 1999). En 1979 realiza prospecciones y excavaciones en la costa norte del lago Fagnano (a las que nos referimos más adelante). En 1980 continua con la excavación de Bloque Errático 1, sitio que fue datado sobre un hueso de Lama guanicoe en $785 \pm 120$ años AP. (Borrero y Casiraghi 1980; Yacobaccio 1980; Borrero et al. 1981, 1985; Borrero 1985), e identifica el sitio Bloque Errático 3 (Borrero et al. 1981). En 1983 se realizan exploraciones en el lago Yehuin. En el año 1984 
comienzan los trabajos de excavación en el sitio San Julio 2 (Horwitz et al. 1993-94). En 1992, Horwitz identifica el sitio Espíritu Santo 1 (Horwitz 1996-98, García, 1993-94; Belardi y García 1994, Ratto y García 1996). Posteriormente, en 1995 se identificó la localidad Las Mandíbulas (Guichón 2000; Guichón et al. 2000; Martin 2004; Borrazzo et al. 2007; Borrazzo 2010) y otros sitios de la costa Atlántica como Mudcracks (Horwitz 2004), Los Chorrillos y San Genaro; (Horwitz 1995; García 1993-94; Favier Dubois 1999, 2001; Campan y Manzi 2000; Borella 2004; Campan y Piacentino 2004; Borrazzo et al. 2007, 2008; Borrero et al. 2008).

La mayor parte de las investigaciones realizadas en el área hasta los primeros años de la década del 80 fueron presentadas por Borrero en su tesis doctoral (Borrero 1985). Luego, en 1988, comienza un proyecto de tafonomía regional en el norte de la Isla. Como resultado de sus investigaciones y la de sus colaboradores, se cuenta con gran cantidad de tesis doctorales y artículos producto de las diferentes líneas de investigación en la región: geoarqueología (Favier Dubois 2001); tafonomía de cetáceos (Borella 2004) tafonomía forense (Martin 2006) y tafonomía lítica (Borrazo 2010).

Al norte, en la zona de estepa que se encuentra ubicada entre los cabos San Sebastián y Peñas, en la década del 90 se iniciaron las investigaciones arqueológicas en el marco de un proyecto dirigido por la Dra. M. Salemme. Ella y su equipo identificaron una serie de sitios; entre los más antiguos en estratigrafía está la Arcillosa 1, datada en $5.410 \pm 70$ años AP sobre valvas de Mytilus sp. (Salemme y Bujalesky 2000). El sitio la Arcillosa 2 presenta cuatro fechados, el primero de $4.440 \pm 60$ años AP realizado sobre valvas de Mytilus sp.; el segundo de $3.690 \pm 70$ años AP también sobre valvas de Mytilus sp., el tercer fechado realizado sobre restos óseos humanos, con una antigüedad de $5.205 \pm 58$ años AP, y por último un fechado sobre valvas de Mytilus sp. de $5508 \pm 48$ años AP (Salemme y Bujalesky 2000; Salemme et al. 2007a; Santiago et al. 2007b). También podemos mencionar el sitio Cabo Peñas con una antigüedad de $620 \pm 45$ años AP datado sobre valvas de Mytilus sp. Para el sitio Cabo Domingo, las dataciones radiocarbónicas realizadas sobre valvas de Patinigera dieron como resultado edades modernas (320 \pm 60 años AP) (Salemme y Bujalesky 2000). 
Desde el 2005 hasta el presente, Salemme y su equipo han intensificado los trabajos, explorando la región comprendida entre los ríos Chico y Grande, con la identificación de sitios en estratigrafía, en superficie, concentraciones, y hallazgos aislados (Santiago y Oría 2007; Santiago 2009; Oria 2009); Río Chico 1 (5.856 \pm 44 años AP); Chacra Pafoy 3 (804 \pm 33 años AP); Las Vueltas 1 (949 \pm 41 años AP); las Vueltas 2; Perro 1 (2.984 \pm 37 años AP); Avilés 1 (1.609 \pm 38 ); Avilés 3; Avilés 2, Herradura 1; Pozo Tierra del Fuego 1; Pozo Tierra del Fuego 2; Pozo Tierra del Fuego 3; Amalia 1; Amalia 2; Laguna Grande 1; Laguna Grande 2; Laguna Grande 3; Margen Sur (897 \pm 38 años AP); Los Chorrillos 2 (265 \pm 44 años AP); Los Chorrillos 1; Puesto Pescador 1 (335 \pm 35 años AP); Cantera Rasha (1.314 \pm 36 años AP) Herradura 1; Santa Ana 1 (269 446 años AP), Santa Ana 2 (Salemme et al. 2007b; Santiago et al. 2007a; Santiago 2009; Santiago y Oria 2007) y por ultimo las áreas prospectadas por Oria en 2009, donde la autora identifica sitios y concentraciones de material arqueológico en San Julio 1, San Julio 2, Laguna Arturo, Laguna Amalia, Laguna del carbón, Laguna Hortensia, Lagunas Tres Marías y Rio Chico (Oria 2009).

En cuanto a la costa atlántica central y meridional (Península Mitre), los estudios arqueológicos fueron iniciados a comienzos de la década del 80, en el marco del proyecto PEOAF impulsado por el Museo del Fin del Mundo (Tierra del Fuego, Ushuaia), en el que participaron los investigadores L. Borrero y J.L. Lanata. En 1981 se realizan excavaciones en la localidad arqueológica Punta María y en el sitio San Martín 1 (Borrero 1985; Borella et al. 1996). En 1983 comienzan las excavaciones en San Pablo 1, sitio datado en $290 \pm 70$ años AP. y en 1985 en San Pablo 7, donde además se realizaron diversos sondeos. También se realizaron trabajos en las zonas de Estancia María Luisa, donde se cuenta con un fechado sobre carbones de $1.020 \pm 80$ años AP, Rancho Donata ubicada en la Bahía Policarpo, Bahía Thetis y Cerro Mesa 1 (Borrero y Lanata, 1988; Lanata 1985, 1996; Muñoz 1996). Actualmente se están llevando a cabo nuevamente prospecciones en las costa atlántica impulsadas por el Museo del Fin del Mundo; sus objetivos están enfocados hacia el relevamiento del patrimonio arqueológico e histórico de la región (Borrero et al. 2011).

También en el marco de las investigaciones del PEOAF impulsadas por el Museo del Fin del Mundo en la década del 80, Hernán Vidal realizó una serie 
de trabajos en la zona de península Mitre. En Bahía Valentín, sobre la costa meridional de península Mitre, realiza el hallazgo del sitio Bahía Valentín 11, el cual cuenta con un fechado de ca. 5.900 años AP (Vidal 1985, 1987, 1988). Los trabajos de Lanata, en el área, aportan un fechado de $1.389 \pm 70$ años AP (Lanata 1993). En la actualidad, Vázquez, Zangrando y colaboradores realizan investigaciones en Península Mitre retomando los trabajos en Bahía Valentín (Tessone et al. 2007; Vázquez et al. 2007; Zangrando et al. 2009; Vázquez et al. 2010), para este área se propone una cronología cultural que va desde el 6000 hasta el 3000 años AP. (Zangrando et al. 2009).

En el extremo sur de la isla, sobre la costa norte del canal Beagle, investigaciones sistemáticas comenzaron en el año 1975, enmarcados en el "Proyecto Arqueológico Canal Beagle" dirigido por Luis Orquera y Ernesto Piana (Orquera y Piana 1986-87, 1987). Desde entonces se excavaron y analizaron los sitios Lancha Packewaia, con una datación de edad máxima de $4215 \pm 305$ (sobre carbón) y $4980 \pm 70$ AP (sobre hueso) y los componentes recientes del mismo yacimiento con una edad que llega a $280 \pm 85 \mathrm{AP}$. También los sitios Túnel I, capa $\mathrm{F}$ inferior del primer componente, datado en $6.980 \pm 110$ AP (sin calibrar) sobre carbón, Túnel Il fechado en $1140 \pm 90$ AP sobre carbón, Shamakush I con un fechado sobre carbón de 1927 AP \pm 120 y Shamakush X $500 \pm 100$ AP sobre carbón. Finalmente, Imiwaia I datado sobre carbón (5.872 \pm 147 A.P), y los sitios de excavación de rescate arqueológico Ajej I (1400 \pm 90 AP fechado sobre carbón) y Mischiuen I (4430 \pm 130 AP). Los sitios Túnel VII datado sobre carbón en $100 \pm 45$ AP y Lanashuaia, fueron excavados en el marco de diferentes proyectos arqueológicos de colaboración Hispano-Argentino, siendo los directores de la contraparte hispana, la Dra. Asunción Vila Mitja y el Dr.Jordí Estévez-Escalera (Orquera y Piana 1986-1987, 1999a; Estévez y Vila 1995; Estévez et al. 2001; Piana et al. 1992; Piana et al. 2007; Orquera y Piana 1999; Orquera 2005; Orquera y Piana 2009).

Como resultado de las investigaciones llevadas a cabo en estos sitios se han realizado y publicado varias tesis y numerosos artículos sobre una serie de temáticas específicas como el análisis de la arqueofauna, ictiofauna, aves, tecnología lítica y rastros de uso, análisis espacial, etc. Entre las tesis, se cuentan las de Schiavini 1990; Juan-Muns i Plans 1992; Clemente Conte 1997; Piqué 1999; Fiore 2002; Álvarez 2003; Briz 2004; Zangrando 2008; Tívoli 2010; 
Verdum 2011; entre los artículos, se pueden mencionar Álvarez 1998; Álvarez et al. 2000; Clemente Conte et al. 1990, 1996; Clemente Conte y Terradas 1993, Esteves Escalera et al. 2000; Esteves Escalera y Vila Mitja 1995; Fiore 1999; Mansur 1997; Mansur-Franchome et al. 1987-88; Mansur y Srehnisky 1996, Martinioni 1998; Orquera 1995, 1999, 2002, 2005; Orquera y Piana 198687, 1987, 1992, 1993-94, 1996, 1999a, 1999b, 2000, 2001, 2005a, 2005b, 2006, 2009; Piana 1984, 2005; Piana y Orquera 1995, 2007; Piana y Vázquez 2005; Piana et al. 2000; Piana et al. 2006; Piana et al. 2007; Piana et al. 2008; Tívoli y Zangrando 2011; Zangrando 2002, 2008, 2009, Zangrando et al. 2004; Zangrando et al. 2009, Zangrando et al. 2010), entre otros.

\section{ANTECEDENTES DE INVESTIGACIÓN EN EL ÁREA DE ESTUDIO}

Como se mencionó al comienzo, diversas razones que tienen que ver con la historia de las investigaciones en Tierra del Fuego pero también con las características propias de los sitios arqueológicos, en particular su visibilidad, hicieron que las investigaciones arqueológicas en la zona central de la Isla quedaran postergadas en relación con las desarrolladas en el resto del territorio. Los primeros trabajos fueron los realizados por Borrero en la cabecera del lago Fagnano en 1979 y en 1980; se trató de exploraciones sobre la costa norte, detectando el sitio Cabecera Fagnano 1 (CF1) interpretado como sitio de habitación, luego Cabecera Fagnano 2 (CF2) y a 100 metros de este, el sitio Laguna, interpretados como sitios de habitación y de tareas específicas (Borrero et al. 1981). A pocos metros del sitio CF 2, Borrero y Caviglia, localizaron en 1978 el sitio G, mencionado en su Tesis (Borrero 1985). En la misma refiere también exploraciones en la zona del Yehuin en 1983. También cabe mencionar una publicación de Ramos y Merenzon (2002-2004), sobre análisis de materiales líticos de la zona del lago Fagnano, recolectados durante una expedición de los años 90.

Después de los trabajos mencionados, no se realizaron más investigaciones sistemáticas en la zona hasta el inicio del "Proyecto Arqueológico Corazón de la Isla" (PACl) dirigido por la Dra. M. E. Mansur en el CADIC, a comienzos de la década del 90. Fue planteado con el objetivo de estudiar la ocupación humana en la zona central de la Isla Grande de Tierra del 
Fuego, y en particular de la faja de bosque subantártico que se extiende sobre los flancos de la cordillera fueguina, al norte, este y sur del lago Fagnano. Este proyecto busca caracterizar la dinámica poblacional en cuanto a tipos y localización de asentamientos, explotación de recursos bióticos y abióticos, y organización social.

Los primeros trabajos arqueológicos enmarcados dentro del proyecto $\mathrm{PACl}$ comenzaron con una serie de prospecciones en la zonas al norte del Fagnano, especialmente en las cuencas de los ríos de la Turba y Claro, y en las cuencas de las lagunas Yehuin, Chepelmut y Esperanza, y continuaron con la excavación del sitio Marina 1, ubicado cerca de las nacientes del valle del Río de la Turba, uno de los principales afluentes de la margen derecha del río Grande que corre en dirección sur-norte. Esta primera etapa de investigaciones permitió determinar una ocupación segura de esta zona, con la localización de sitios ubicados en diversos ambientes, algunos en zonas pedemontanas boscosas (sitios CA1, CA2 y MA3), otros en las proximidades de lagos y lagunas (YE1, YE2, YE3, SD1), así como en las márgenes de valles amplios (LC1, MA1 y MA2) o en valles altos (SN1), cercanos al límite del bosque, etc. También se registró un hallazgo aislado de una bola en un pastizal de altura, en el interior cordillerano (AR1) (Mansur et al. 2000), lo que podría estar indicando explotaciones de los recursos disponibles estacionalmente (Mansur et al. 2000).

En cuanto al sitio Marina 1, en él se descubrieron instrumentos de piedra, desechos de talla y restos óseos, asociados a dos fogones con abundantes restos de carbón vegetal, que fueron fechados por radiocarbono, dando una antigüedad de 1.800 años \pm 250 A.P. (muestra AC $n^{\circ} 1471$ ). El análisis funcional de los materiales líticos determino el procesamiento de recursos vegetales y animales; aunque no se han registrado acciones sobre hueso. A partir de los diferentes estudios realizados, el sitio fue interpretado como un campamento de corta duración de un grupo pequeño, que se desplazaba transportando su equipamiento básico. La presencia de dos fogones, junto con los demás materiales evidencia que se realizaron actividades variadas, tales como caza, procesamiento y consumo de animales, preparación de pieles, reparación o reactivación de instrumentos dañados, reemplazo de las puntas de proyectil en los astiles, terminación de 
instrumentos que se encontraban en curso de manufactura, etc. (Mansur et al. 2000).

Desde el año 2001 en adelante, se desarrollaron investigaciones en la zona boscosa que se extiende al $\mathrm{N}$ de la sierra de las Pinturas, especialmente en el curso superior y medio del Ewan, donde desde 2003 y hasta el 2007, se desarrolló un proyecto en colaboración entre el Centro Austral de Investigaciones Científicas (CONICET-CADIC) en Ushuaia, la Universidad Autónoma de Barcelona y el Laboratorio de Arqueología del Consejo Superior de Investigaciones Científicas de España. Los trabajos de campo comprendieron prospecciones y excavaciones que permitieron identificar, estudiar y caracterizar un ámbito ritual de la sociedad selknam, correspondiente a la ceremonia de iniciación de los varones adolescentes selknam, la ceremonia del Hain.

La localidad arqueológica Ewan está constituida hasta el momento por dos espacios diferenciados funcionalmente. Por un lado la choza donde se llevó a cabo la ceremonia del Hain y por el otro al menos 4 estructuras habitacionales, de las cuales hasta el momento se ha excavado una. El fechado por dendrocronología la ubicó temporalmente en la primavera-verano de 1905-1906.

Debido, probablemente, a las diferencias en las actividades llevadas a cabo en uno y otro espacio, los diversos estudios demostraron diferencias en los materiales arqueológicos. Estas diferencias se refieren al tratamiento de los mismos, al consumo de recursos faunísticos y vegetales, así como a la presencia de artefactos líticos (Mansur 2002; Mansur et al. 2004; Berihuete 2006, 2010; Berihuete et al. 2007; Camaros y Parmigiani 2007; De Angelis 2007, 2009; Mansur et al. 2007a y b; Bogdanovic et al. 2009; Camaros et al. 2010; De Angelis y Mansur 2010; De Angelis et al. 2012a; Mansur y Piqué 2012).

Finalmente, en una nueva etapa del PACl se están estudiando sitios de la costa sur del lago Fagnano y prospectando las cuencas de los ríos que se extienden desde allí hacia el este, para desembocar en el océano Atlántico, con ambientes diferentes, en los que se ha puesto énfasis en esta Tesis.

En cuanto a la costa sur del lago Fagnano, las prospecciones realizadas desde 2006 permitieron delimitar varias localidades arqueológicas. 
Inicialmente, las investigaciones se centraron en la localidad arqueológica Kami, con más de 10 sitios ubicados sobre la costa (De Angelis et al. 2012b, Parmigiani et al. 2012). De todos ellos se excavaron hasta el momento dos sitios denominados Kami1 y Kami 7 que se presentarán en detalle más adelante.

Finalmente hacia el sector oriental, se desarrolló un plan de relevamiento del paisaje a partir de transectas que siguieron los cursos de los ríos que nacen cerca de la cabecera del Fagnano y desembocan en el Atlántico, o la circunferencia de las lagunas cercanas a la cabecera del Fagnano. En estas también fueron detectados sitios arqueológicos (De Angelis et al. 2012b).

\section{LOS HABITANTES DE LA REGIÓN EN TIEMPOS HISTÓRICOS Y LAS FUENTES ESCRITAS}

En tiempos históricos, toda la zona centro y norte de la Isla Grande era el ámbito de la sociedad Selknam. El conocimiento que hoy tenemos de ella procede de las numerosas fuentes escritas producidas por viajeros, misioneros, etnógrafos, así como del registro arqueológico del área.

Las primeras son en realidad un número muy elevado de escritos, dejados por los viajeros y navegantes que llegaron a la Isla desde fines del siglo $\mathrm{XVI}$, los exploradores y naturalistas que lo hicieron a lo largo de los siglos XVIII y XIX, los misioneros y colonos que se instalaron desde fines del XIX en adelante. Cada uno de ellos refleja la cosmovisión e ideas de la época; pero aún si no son fuentes absolutas, constituyen un valioso aporte para el estudio de los pueblos originarios de la región (cf. ref. in Orquera y Piana 1999 a, Mansur 2006). Pero indudablemente, las mejores fuentes son las de los misioneros, naturalistas y arqueólogos que estuvieron en Tierra del Fuego en la primera mitad del siglo XX (Vignati 1927, Outes 1906, Gallardo 1910, Bridges 1947, Lothrop 1928, De Agostini 1956; Orquera y Piana 1999a, ver bibliografía allí citada), y en particular los trabajos de los etnógrafos Martín Gusinde (1937) y Anne Chapman (1986). A diferencia de los anteriores, estos etnógrafos tenían un objetivo claro de investigación, con lo cual estaban interesados en registrar todos los aspectos de la vida de estas sociedades: aspectos simbólicos y religiosos, pero también económicos y tecnológicos. 
En cuanto a la información arqueológica, se dispone hoy de la procedente de los sitios de la región ya mencionados, pero también de la información sobre sitios arqueológicos de esta época, conocidos en las otras regiones del área selknam, como la costa atlántica en el sector norte de la isla. La subsistencia de esta sociedad se basaba en la explotación tanto de recursos animales como vegetales: guanacos, roedores, aves, moluscos, bayas, hongos y distintas variedades de plantas. Los grupos locales vivían en territorios, denominados haruwen, en los que se desplazaban con mucha frecuencia. Las fuentes escritas también mencionan desplazamientos hacia otros territorios, ya que existían permisos de paso, momentos de reunión, etc. De hecho, diferentes fuentes referidas a la población Selknam a fines del s. XIX y comienzos del XX, mencionan desplazamientos de grupos hacia el sur (hasta la costa del canal Beagle) y el este (costa atlántica) (Bridges 1978 [1951], Chapman 1986).

Gracias a esta cantidad de datos etnográficos e históricos, así como a las amplias colecciones de materiales etnográficos depositados en diferentes museos argentinos, americanos y europeos, los arqueólogos que trabajamos en Tierra del Fuego podemos confrontar estas diferentes fuentes de información, a fin de proponer y verificar hipótesis con respecto al registro arqueológico, en particular en lo que se refiere a los ámbitos de la gestión de recursos y la tecnología. Esta aproximación es considerada por algunos autores como un enfoque de la etnoarqueología (véase capítulo 3 ) que permite verificar modelos explicativos utilizando las técnicas de la arqueología en el estudio de objetos etnográficos, datos etnográficos para verificar hipótesis metodológicas arqueológicas y datos arqueológicos para refutar o validar afirmaciones etnohistóricas (Estévez y Vila 1995).

\section{CONCLUSION}

Como puede verse a partir de esta breve síntesis, los trabajos arqueológicos en Tierra del Fuego comienzan y se desarrollan a partir de los años 70. En los inicios de las investigaciones, estos se centraron principalmente en el sector norte y el extremo sur de la isla. La zona central quedó relegada de estudios sistemáticos hasta comienzos de la década del 90. 
En cuanto a los temas abarcados, estos fueron muy diversos, e incluyeron la evaluación de la información escrita generada por las diversas fuentes, en relación con los pobladores de la región en tiempos históricos.

A pesar de ello, no es hasta hace algunos años que los estudios sobre organización tecnológica desde una perspectiva tecnofuncional comienzan a tomar relevancia en la Isla en general y en la faja central de Tierra del Fuego en particular. Es en este sentido que se desarrolló este trabajo de Tesis, con el objetivo de aportar al conocimiento sobre la relación que existe entre la disponibilidad de recursos, el conocimiento que las sociedades cazadorasrecolectoras tenían de ellos, que se evidencia en las elecciones técnicas en el proceso de producción lítica y en el proceso de uso de los instrumentos. 


\section{Capítulo 3}

MARCO TEÓRICO Y METODOLÓGICO 


\section{INTRODUCCIÓN}

Como se mencionó en la Introducción, el presente trabajo de investigación fue estructurado según dos formas de acercamiento al estudio de la arqueología de los grupos cazadores-recolectores en la faja central de Tierra del Fuego. Por un lado, y como eje principal, el estudio fue encarado con base en la organización tecnológica en general y en la tecnología lítica en particular, a partir del análisis de materias primas y fuentes potenciales de aprovisionamiento, cadenas operativas y estudios tecno-morfológicos y funcionales del material lítico. Por otro, a fin de reconocer áreas extensas que nunca habían sido prospectadas, la investigación comprendió estudios mediante enfoque distribucional, para poder lograr un registro general de la densidad de material arqueológico en el paisaje.

El estudio de la organización tecnológica es un tema relevante de las investigaciones referidas a sociedades de cazadores-recolectores, que ha puesto a la "tecnología" en el centro de atención, por sus dimensiones social y material. Entendemos a la tecnología como un sistema complejo que incluye conocimientos y actividades puestos en práctica por las sociedades, que permite explotar recursos (identificarlos, adquirirlos y transformarlos) para convertirlos en bienes de uso y/o de consumo. La tecnología implica al mismo tiempo explotación de recursos naturales y establecimiento de relaciones sociales para la producción y el uso de los bienes que genera; en consecuencia, puede ser considerada como mediatizadora de la interrelación entre las sociedades y el medio ambiente (Mansur et al. 2009). Sin embargo, para abordar el estudio de la dimensión tecnológica, es indispensable contar con registros arqueológicos de sitios en estratigrafía o superficie, que ya estén trabajados de modo integral y sistemático, y que tengan materiales abundantes para encarar un estudio de este tipo.

Por otra parte, el estudio distribucional facilita el abordaje de la evidencia arqueológica a escala regional, y permite registrar datos sobre la visibilidad, la preservación diferencial y la densidad de los materiales de superficie. Para ello, se trabajó con el planteo de transectas abarcando la mayor diversidad de 
ambientes posible. El problema principal que presenta la zona de estudio es su poca visibilidad arqueológica, dado que gran parte corresponde a zona de bosque y que la superficie del terreno se encuentra casi totalmente cubierta por hojarasca, pastizales, grandes turberas o zonas con muchos derrumbes de árboles (Lencinas et al. 2001).

Sin embargo, el aprovechamiento de ventanas de visibilidad que ofrecen las caídas de árboles, los perfiles de los lechos de ríos, sectores afectados por incendios, aperturas de caminos por los aserraderos, orillas de lagunas y lagos, etc. permiten observar la presencia o no de material arqueológico.

\section{GESTIÓN DE RECURSOS BIÓTICOS Y ABIÓTICOS}

Los estudios sobre la gestión de los recursos por parte de los grupos cazadores recolectores generalmente se han concentrado en la gestión de las materias primas líticas, que han ocupado un importante espacio dentro de las investigaciones arqueológicas desde los primeros estudios sistemáticos aplicados al Paleolítico europeo en la década de 1980. Desde entonces, estos estudios han sido encarados desde diversos aspectos como la circulación (incluyendo determinación litológica), la movilidad, la economía, lo simbólico, la tecnología, el uso, etc. (Charlin 2002; Demars 1982, 1991; Franco y Aragón 2002, 2004; Flegenheimer y Bayón 2002; Franco y Cirigliano 2009; Meltzer 1989; Renfrew 1977).

Las rocas constituyeron sin duda uno de los recursos más explotados por las sociedades pasadas, por su importancia como materias primas fundamentales, ya que nos permiten acercarnos a las tareas de subsistencia, o a las actividades cotidianas, las que generalmente se desarrollaban con instrumentos líticos. Además la confección de artefactos líticos es una actividad extractiva, por lo cual genera una gran cantidad de desechos de talla que se conservan en el registro. En consecuencia, a partir del análisis del material lítico es posible inferir técnicas de manufactura y uso, que implican decisiones tanto a nivel cultural como individual (Mansur Franchomme 1984, 1986-1990). Por todo ello como por su perdurabilidad, es que el material lítico constituye uno de los recursos más importantes para la arqueología para dar cuenta de 
las actividades desarrolladas y de las estrategias de gestión de recursos puestas en práctica por las sociedades pasadas.

En cuanto a los recursos bióticos, muchas veces su uso puede ser evaluado directamente a partir del registro arqueológico, como en el caso de restos faunísticos conservados. Sin embargo, muchas veces, inferencias sobre la explotación de determinado tipo de recursos sólo pueden hacerse a partir de los rastros de uso que conservan los instrumentos líticos utilizados para procesarlos, como en el caso del trabajo de materiales vegetales (AndersonGerfaud 1981; Mansur-Franchomme 1986; Clemente Comnte 1997; Álvarez 2004c; Leipus 2004). En la problemática planteada en este trabajo, se vinculan entonces los análisis funcionales de los instrumentos con los resultados del registro de recursos bióticos de los estudios distribucionales y los datos derivados del registro etnográfico.

Uno de los ejes centrales de esta investigación es la problemática de las materias primas líticas en Tierra del Fuego, específicamente en la faja central de la Isla Grande. Esta comprende no sólo las materias primas locales, sino también materiales de origen no local, tanto naturales como artificiales, es decir diversos tipos de rocas procedentes de zonas distantes, y también materiales de origen artificial que jugaron un papel muy importante en los momentos históricos, tal el caso del vidrio.

\section{Fuentes de materias primas líticas en Tierra del Fuego}

Los estudios sobre tecnología lítica suelen presentar un problema en común y es el de la materia prima, el porqué de su selección, de dónde proviene, las estrategias para su obtención, la tecnología de abastecimiento, etc. Por ello, su estudio implica un conocimiento detallado sobre aspectos tales como tipos de fuentes y sus características, su origen, su distribución, como aparecen estas en el terreno, tipos de roca y características, etc.

Desde el punto de vista arqueológico, las fuentes potenciales de aprovisionamiento lítico pueden ser clasificadas en primarias, secundarias, y terciarias (AGI 1976; Nami 1992; Church 1994).

Las fuentes primarias serían aquellas en las cuales las rocas se presentan en su lugar de origen. Las fuentes secundarias, al contrario, son 
aquellas en las que las rocas fueron transportadas por diversos agentes erosivos como por ejemplo ríos, glaciares, etc., desde su lugar de origen, y redepositadas (Luedtke 1979; Olausson 1982-1983; Nami 1992). Finalmente, llamamos fuentes de aprovisionamiento terciarias a espacios formados por el movimiento de rocas por parte de las sociedades humanas, que luego de ser abandonadas son explotadas por otros grupos (AGI 1976; Church 1994)

Para Tierra del Fuego, las dos fuentes primarias de materias primas son las rocas provenientes de las formaciones Lemaire y Yaghán, que mencionamos en el capítulo 1.

La Formación Lemaire o Tobífera (Caminos 1980; Caminos et al. 1981) se extiende a través de los Andes desde la Isla de Los Estados hasta el estrecho de Magallanes. Los afloramientos de mayor tamaño se encuentran en las elevaciones al sur de lago Fagnano, principalmente en la Sierra Alvear. Sin embargo, se pueden encontrar en forma de clastos en afloramientos cuaternarios, generalmente de origen glaciario, en posición secundaria (Olivero y Malumián 2008).

En cuanto a la formación Yaghan, la misma se extiende por la costa del canal Beagle donde se encuentran los mayores afloramientos. También en este caso, rocas de la formación Yaghan pueden ser encontradas en las formaciones redepositadas cuaternarias, es decir en posición secundaria.

Por la dificultad que a veces revisten para su determinación precisa a ojo desnudo, a los fines de los estudios arqueológicos, estas rocas han sido clasificadas según su génesis en dos grandes grupos: metamorfitas y vulcanitas (Orquera y Piana 1986-1987; Mansur-Franchomme et al. 1987-1988; Terradas 1996). Entre las primeras, las más utilizadas en los contextos arqueológicos son riolitas y cineritas. Si bien no siempre es fácil distinguirlas a simple vista, estas presentan diferencias en varios aspectos, pero el principal es su granulometría. Las riolitas presentan vitroclastos entre 2 y 0,065 mm., mientras que los asociados a las cineritas son inferiores a 0,065 mm. Las primeras son más sódicas y las segundas más potásicas. También hay diferencias en cuanto a su formación, siendo las riolitas formadas mediante dispersión subaérea a partir del emplazamiento de los piroclastos bajo una forma intrusiva y/o efusiva, mientras que las cineritas se formaron a partir de la lluvia de cenizas (Terradas 1996; Álvarez 2003). 
Las vulcanitas de la Fm Yaghan son rocas metamórficas, principalmente pizarras radiolaríticas de color negro y grisáceo con una estructura bandeada y una laminación transversal muy marcada (Caminos 1980; Caminos et al. 1981; Terradas 1995, 1996), su calidad para la talla es baja, por lo que su uso para producción de artefactos es escaso (Terradas 1995, 1996). Si bien fueron utilizadas en algunos momentos y sectores de la costa del Canal Beagle, están poco representadas en los conjuntos de la zona central de la isla.

Además de los afloramientos de estas formaciones, que deben ser considerados como fuentes primarias, existen importantes acumulaciones de rocas en formaciones redepositadas, que corresponderían a lo que llamamos afloramientos o canteras secundarias. Ello se debe a que las rocas de ambas formaciones de la Cordillera fueron fuertemente afectadas por los diferentes procesos erosivos posteriores al levantamiento, y en particular por la acción de los glaciares. Así, fragmentos de las dos formaciones fueron extraídos y transportados a grandes distancias, hacia la costa sur, hasta el Canal Beagle, y hacia el norte, por acción de los glaciares que las depositaron en las morenas, pero también tuvieron una amplia dispersión por acción glacifluvial y fluvial posterior (Olivero y Malumian 2008; Olivero et al. 2007). En consecuencia, guijarros de metamorfitas de dimensiones variables se encuentran fácilmente disponibles en las formaciones redepositadas de guijarros, que funcionan como fuentes secundarias (Borrero 1998; Mansur et. al. 2000; Mansur et. al. 2010; Mansur y De Angelis 2012)

También el cuarzo es una materia prima bastante representada en diversos contextos arqueológicos del área. En cuanto a su disponibilidad, se trata de una materia prima relativamente ubicua ya que si bien aparece en filones, también está presente en formaciones redepositadas como pequeños rodados (Mansur et. al. 2000; Olivero y Malumian 2008; Olivero et al. 2007)).

En relación con las fuentes de aprovisionamiento secundarias, se puede incluir dentro de ellas a los vidrios, provenientes por ejemplo de naufragios, aportados por el mar a las playas, ampliamente utilizados en momentos inmediatamente previos al contacto con los europeos (Mansur y De Angelis 2012).

En cuanto a las fuentes terciarias, considero plausible incluir los materiales de las construcciones europeas que se fueron asentando en los 
distintos lugares de la Isla. Estos materiales funcionaron muchas veces como posibles fuentes de materias primas como el vidrio o el metal (De Angelis 2012).

\section{EL ESTUDIO DE LA GESTIÓN DE LAS MATERIAS PRIMAS Y EL CONCEPTO DE CADENA OPERATIVA}

Para abordar el estudio de la organización tecnológica, es importante considerar una serie de estrategias tecnológicas propuestas por diversos autores: conservación, expeditividad y comportamiento oportunístico (Binford 1979; Bamforth 1986; Nelson 1984, 1991; Andrefsky 1994; Hayden et al. 1996). Estas estrategias se incluyen dentro del estudio de los que Torrence (2001) llamó macro-escala, la cual se enfoca en cómo es estructurada la variabilidad tecnológica.

La estrategia conservada, desarrollada principalmente por Binford (1979), se refiere a conjuntos o instrumentos que son efectivos para una variedad de tareas, cuya manufactura es anticipada a su uso. A lo largo de su vida útil reciben mantenimiento y son transportados y reciclados, en muchos casos también pueden ser almacenados en forma de escondrijos: "caches". Se caracteriza por un uso intensivo de la materia prima (Binford 1979; Nelson 1991).

La estrategia expeditiva, muchas veces fue utilizada como algo opuesto a la estrategia conservada, sin embargo ambas pueden darse de manera conjunta, pudiendo considerarse opciones diferentes bajo condiciones diferentes (Binford 1979; Magne 1989; Nelson 1991). Por ejemplo al acumular una cantidad de materia prima en escondrijos "caches", estrategia conservada, podría permitir hacer uso de esa materia prima a partir de la expeditividad, utilizándola y descartándola luego de su uso. La estrategia expeditiva permite un menor esfuerzo tecnológico cuando la materia prima, el tiempo y el lugar son predecibles. Se supone un descarte mayor de instrumentos dado que la materia prima se encuentra disponible en cantidad.

En cuanto al comportamiento oportunístico, éste comprende aquellas estrategias que no son planificadas, se dan en un momento dado bajo condiciones inmediatas y no anticipadas. 
Estas diversas formas o estrategias tecnológicas generan diversidad en el registro arqueológico no sólo en cuanto a su distribución, sino también en el diseño de los artefactos (Leipus 2006).

En cuanto al diseño, es importante destacar cinco variables que ayudan a caracterizar el comportamiento de los materiales: confiabilidad, mantenimiento, transportabilidad, flexibilidad y versatilidad (Bleed 1986; Nelson 1991). Estas variables están relacionadas con la función, las necesidades y con la vida útil del instrumento a confeccionar. Así, la confiabilidad puede asociarse con funciones redundantes, y esto llevaría a una estandarización de los instrumentos. A su vez la flexibilidad y la versatilidad se asocian a aquellos instrumentos que cambian de forma según diferentes necesidades y a aquellos que no cambian de forma según las necesidades, respectivamente (Nelson 1991).

Dentro del enfoque a micro-escala, el concepto de cadena operativa nos permite analizar las características y el orden de sucesión de los diversos gestos técnicos involucrados en la manufactura, uso y descarte de los instrumentos líticos.

El concepto de cadena operativa fue propuesto por Leroi-Gourhan, como el conjunto de operaciones llevadas a cabo con el fin de transformar la materia prima en productos; con el tiempo se fue ampliando (Leroi-Gourhan 1964; Pélegrin 1984, 1990; Karlin 1984, 1991a, 1991b), introduciendo dos tipos de aproximaciones teórico-metodológicas: la aproximación tecno-psicológica cuyo interés se basa en los gestos mentales que guían las operaciones técnicas (Balfet 1991) y la aproximación tecno-económica con un énfasis puesto en la transformación de la materia prima en producto (Creswell 1983).

Esta última aproximación ofrece un marco cronológico y espacial a las operaciones técnicas (Geneste 1985; Perles 1987); de esta forma podemos determinar en qué estado de la cadena operativa se encuentra un conjunto determinado y si esto es debido a cuando y donde se llevaron a cabo los distintos procesos de confección de los artefactos que forman parte del conjunto lítico (Geneste1983; Karlin et al. 1991).

Así, podemos dividir la cadena operativa en fases, que reorganizan el tiempo técnico de la elaboración de los productos; un ejemplo es el que ofrece Geneste (1985, esquema obtenido de Terradas 2001): 
- $\quad$ adquisición de materiales

- producción: débitage de los materiales adquiridos con el objetivo de obtener los productos que servirán de soporte a los útiles

- $\quad$ consumo: transformación de los materiales en útiles y utilización de los mismos

- abandono de los productos empleados, eventualmente después de su reciclaje y reutilización

Estas aproximaciones, presentan cierta similitud con las aproximaciones tecnológica y económica utilizadas por otros autores (Pigeot 1987; Olive 1988). La primera de estas aproximaciones, tecnológica, intenta evidenciar los procedimientos técnicos realizados por el tallador para poder reconstruir el conjunto de gestos técnicos empleados por el tallador. La segunda, económica, busca las leyes socioculturales que gobiernan los rasgos tecno-económicos de la producción lítica (Terradas 2001).

Sin embargo autores como Martínez Fernández y Afonso Marrero (1998), consideran que estos enfoques no profundizan en aspectos tales como las condiciones sociales necesarias para que la producción lítica exista, dado que se estudia la capacidad de cada uno para conocer la realidad y no la capacidad como ser social para producir y reproducirse. Es un estudio individual del comportamiento humano. Para salvar esta situación, proponen un concepto nuevo o diferente del de cadena operativa, es el de cadena de producción lítica, donde se articulan varias técnicas para producir valores de uso (Martínez Fernández y Afonso Marrero 1998).

Asimismo, Terradas (2001) analiza estas aproximaciones y concluye que sólo a través de su contrastación mediante el análisis funcional se puede corroborar la validez de los resultados en relación a la reconstrucción de los procesos técnicos y las estrategias relacionadas con la gestión de las materias primas y la producción lítica (Pie y Vila 1992; Terradas 2001).

El trabajo que se presenta en esta tesis intenta acercarse a este enfoque. Sin embargo, nuestro objetivo no es aplicarlo de modo estricto; pero lo consideramos porque está en estrecha relación con lo que llamamos enfoque tecnofuncional en el análisis lítico. 


\section{EL ESTUDIO DE LA GESTIÓN DE LOS INSTRUMENTOS Y LOS PROCESOS DE USO}

El enfoque tecnofuncional de los conjuntos líticos no se queda en el estudio específico de la manufactura de cada tipo de artefacto, sino que articula selección de materias primas en relación con técnicas de confección, morfologías buscadas (pueden ser formas totales o simplemente formas de filos) y uso al que están destinados los artefactos (Mansur-Franchomme 1983a, 1984). Para llevarlo adelante, esta autora realiza una selección de variables en función de criterios que tienen relevancia desde el punto de vista tecnológico, tal como fueron presentados por Tixier et al. (1980). Así, de la serie de variables posibles del análisis tipológico clásico, se priorizan las que tienen relevancia desde el punto de vista tecnológico y/o funcional.

En la esfera de la organización tecnológica, los instrumentos líticos juegan un rol esencial. Al tratarse de instrumentos que son confeccionados para ser utilizados en diferentes secuencias de producción, puede decirse que el estudio de las formas de producción y uso de los instrumentos, incluido en el campo de la tecnología, permite acercarse a una mejor comprensión del funcionamiento global de un sistema social, a partir de aspectos tales como cuál es el modo particular de gestión de los recursos puesto en práctica y en qué marco de relaciones sociales.

El acercamiento a la organización tecnológica (Nelson 1991) requiere de enfoques particulares que permitan caracterizar los comportamientos con respecto a la materia prima y el uso (Semenov 1964; Binford 1979; Keeley 1980), extendiendo el concepto de cadena operativa (Leroi-Gourhan 1964) a la totalidad del proceso tecnológico, para evaluar las causas de la selección de determinadas materias primas, a partir de una oferta ambiental variada, el modo en que son transformadas en bienes de consumo de naturaleza mineral y su integración en otras actividades productivas, y considerando los diseños y la localización espacio-temporal de las actividades de producción y uso (Bamforth 1986; Bleed 1986; Nelson 1991).

En lo que se refiere al uso de los instrumentos, la metodología de análisis funcional de base microscópica permite un acercamiento concreto a las actividades en las que estuvieron involucrados. Esta metodología se basa en la identificación de rastros de uso que se generan en los filos de los instrumentos 
por el contacto con los materiales trabajados (micropulidos, esquirlamientos de los filos, estrías, residuos microscópicos, etc.). Para ello es necesario analizar sus características mediante el uso de lupas binoculares y microscopios de reflexión, ya que los rastros de uso presentan diferencias diagnósticas según los materiales sobre los que fueron utilizados los filos (i.e. madera, piel, hueso) (Semenov 1964; Keeley 1980; Vaughan 1981; Anderson-Gerfaud 1981; Mansur-Franchomme 1983 a, b, 1986; Plisson 1985; Beyries 1988; Castro 1994, 1996).

El comienzo de la metodología de análisis funcional puede ubicarse a mediados del siglo $\mathrm{XX}$, con el trabajo de $\mathrm{S}$. Semenov en la Academia de Ciencias de Leningrado y la traducción al inglés en 1964 de su obra "Prehistoric Technology" (Semenov 1964). En los años subsiguientes se produjo un incremento en Occidente de trabajos sobre el análisis funcional de microrrastros, que permitieron consolidar la metodología de análisis. Las primeras publicaciones fueron las de R. Tringham y colaboradores (1974) y L. Keeley (1974), a partir de las cuales se planteó una polémica que llevó a la falsa impresión de que existían diferentes enfoques posibles para realizar análisis funcional. Fue lo que llamaron método "de los bajos aumentos" y de "los altos aumentos", según se trabajara con microscopios de reflexión o con lupas binoculares (véase más adelante). Sin embargo trabajos importantes de índole metodológica desarrollados en el transcurso de los años subsiguientes fueron más allá de esta dicotomía, estableciendo una metodología de análisis única para el estudio funcional, como por ejemplo los de L. Keeley (1980); P. Vaughan (1981); P. Anderson-Gerfaud (1981); M. E. Mansur-Franchomme (1983 a, b, 1986); H. Plisson (1985); S. Beyries (1988). Desde entonces se han desarrollado numerosos trabajos sobre análisis funcional en Argentina, citamos sólo algunos como ejemplo: A. Castro (1994, 1996); Mansur y Srehnisky (1996); M. E. Mansur (1999, 2002); M. Leipus (2001, 2004, 2006); M. Álvarez (2003, 2004a, b, c); Mansur y Lasa (2005); Leipus y Mansur (2007).

M. Nelson (1991), en su estudio sobre la organización tecnológica y los diversos niveles de comportamiento incluidos en ella, la define como "el estudio de la selección e integración de estrategias para confeccionar, usar, transportar y descartar los utensilios y los materiales necesarios para su manufactura y mantenimiento". También afirma que "La organización tecnológica es una 
respuesta a las condiciones ambientales, incluyendo la previsibilidad, la distribución, periodicidad, productividad y movilidad de los recursos (Binford 1978a, 1979 y 1980; Torrence 1983; Nelson 1984; Bamforth 1986; Bleed 1986; Gamble 1986; Shott 1986; Kelly 1988), el tamaño y la parcelación del área de recursos (Binford 1977; 1980) y posibles azares (Binford 1977; Nelson 1991). Finalmente considera que los estudios sobre la organización tecnológica permiten un mejor entendimiento de la función de los utensilios al incluir variables de estrategias económicas, ya que este tipo de estudios abarcan el comportamiento económico, social e ideológico.

Como se mencionó anteriormente, para poder abarcar el estudio de la organización tecnológica, plantea una serie de niveles organizados a partir de la distancia desde las consecuencias materiales de cada uno. En cada uno de estos niveles se analizan las condiciones ambientales, estrategias sociales y económicas; en segundo término lo que define como estrategias tecnológicas; y finalmente tratará los diseños y las distribuciones de las actividades asociadas con las estrategias tecnológicas (Nelson 1991) (Figura 3.1).

R. Torrence (2001), en un estudio sobre la tecnología en los cazadores recolectores, discute propuestas metodológicas para el estudio de dicha tecnología y propone un enfoque que comprende dos escalas. En la más amplia, denominada macro-escala, el énfasis está puesto en el ambiente, las materias primas y los instrumentos; en la segunda, llamada micro-escala, se enfatizan los casos particulares, los actores y el conocimiento (Torrence 2001).

En este marco, entendemos que el acercamiento a la organización tecnológica requiere de enfoques particulares que permitan caracterizar dos series de comportamientos: los que se refieren a la gestión de las materias primas (producción de instrumentos) y los que se refieren a la gestión de los instrumentos (uso). 


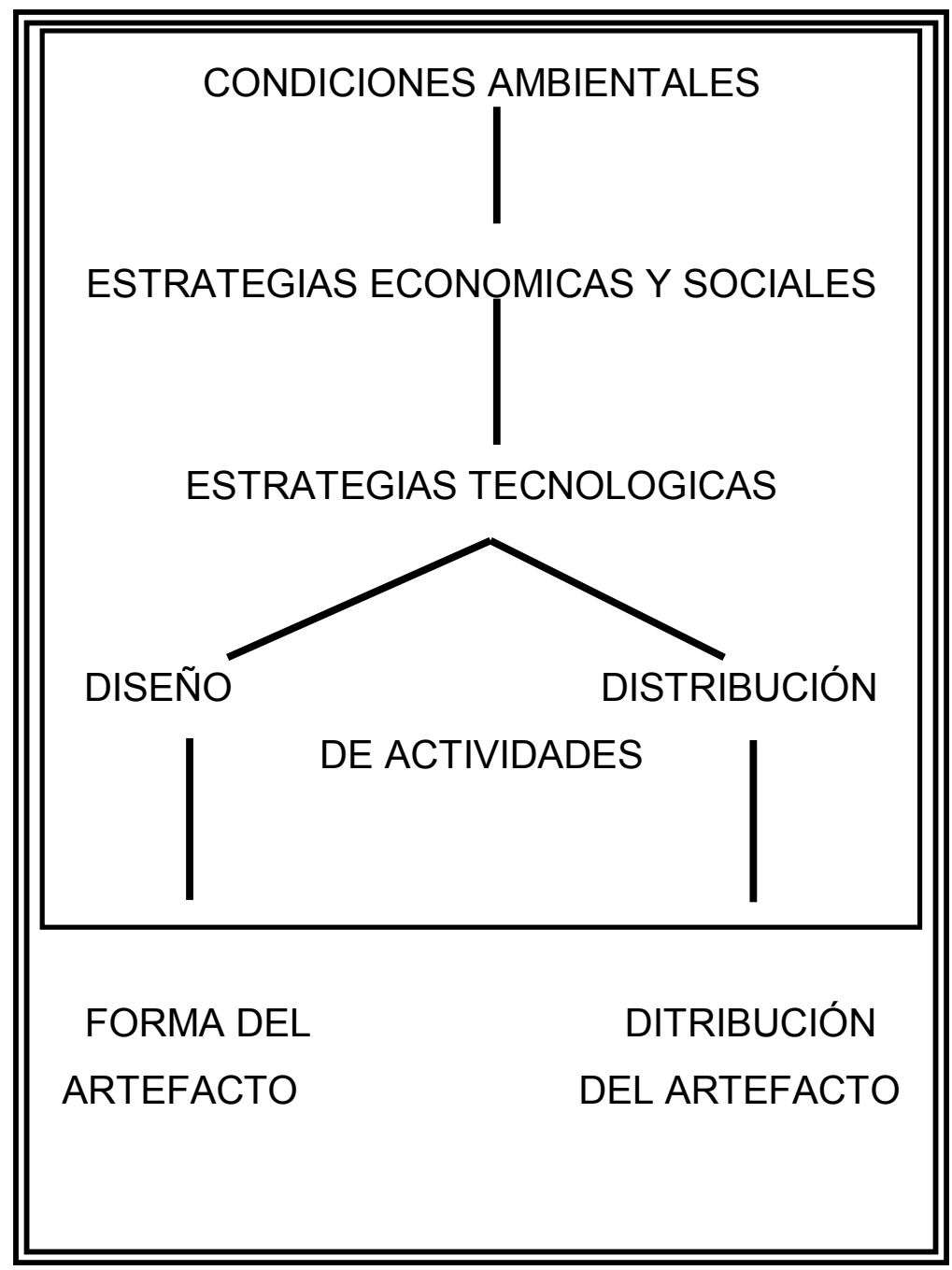

Figura 3. 1. Niveles de análisis de la investigación (tomada de Nelson, 1991)

\section{Instrumentos vs. no instrumentos}

El concepto de instrumento lítico se encuentra desde hace tiempo en una discusión sobre cuándo, porqué y qué cosa debe considerarse como un artefacto lítico, instrumento, o artefacto retocado, desecho, lasca, filos potencialmente utilizables, etc.

Prácticamente desde el comienzo de las investigaciones en Prehistoria fueron considerados como instrumentos sólo aquellos artefactos que presentaban evidencias, generalmente macroscópicas, de haber sido confeccionados mediante la formatización por talla (eg. retoque), piqueteamiento o pulimentación, buscando determinadas características de formas o filos, que aparecían de modo recurrente en los conjuntos líticos. Al contrario, los artefactos que no presentaban tales características, como las 
lascas, los núcleos, etc., no fueron considerados instrumentos sino restos de talla. A los instrumentos se les dieron diferentes denominaciones, muchas de ellas en relación con sus usos posibles, inferidos a partir de la comparación con instrumentos contemporáneos o etnográficos, experiencias de simulación, observación de rastros macroscópicos, etc. (Mansur-Franchomme 1983a, 1987a y b). Muchas de estas denominaciones aún hoy se siguen utilizando, como raederas, cuchillos, raspadores, etc. Sin embargo, desde la generalización de las tipologías tecnomorfológicas, ha quedado en claro que tales denominaciones se usan sólo por hábito, pero que han perdido su connotación funcional (Bordes 1961).

A mediados del siglo $X X$, en Rusia, el Dr. S. Semenov amplió las posibilidades de analizar un conjunto lítico a partir del desarrollo del análisis funcional de base microscópica (Semenov 1964). Si bien con algunas dificultades, como por ejemplo la discusión sobre los bajos y altos aumentos, el análisis propuesto por este investigador se expandió y utilizó en diversas partes del mundo.

Así, a partir de la traducción del trabajo de Semenov, esta práctica tomo preponderancia entre los arqueólogos occidentales de la década del 70. Los primeros intentos de análisis funcional fueron hechos por investigadores norteamericanos. Un grupo trabajó principalmente en Estados Unidos, con lupas binoculares, a partir del estudio de los microesquirlamientos, ya que es el único tipo de rastro observable con este tipo de instrumental óptico. Es por ello que este enfoque se denominó "Low Power Approach" o método de los bajos aumentos (Tringham et al. 1974; Hayden 1979).

En contraposición L. Keeley (1974) efectuó sus trabajos orientándolos hacia el enfoque propuesto por Semenov, utilizando tanto lupas binoculares como microscopios de reflexión de tipo metalográficos. Es por ello que este enfoque tomo el nombre de "High Power Approach" o método de altos aumentos y su principal lugar de desarrollo se centra en Europa hacia finales de la década del 70 y comienzos de los 80 .

Como se mencionó en el acápite anterior, las publicaciones de Tringham y colaboradores por un lado, y las de L. Keeley por otro, plantearon una polémica que llevó a la falsa impresión de que existían diferentes enfoques posibles para realizar análisis funcional, según un método "de los bajos 
aumentos" y otro de "los altos aumentos", según se trabajara con microscopios de reflexión o con lupas binoculares. Sin embargo, ya desde mediados de la década del 80 ha quedado en claro que existe un sólo método de análisis de los rastros de uso, y es el que considera la totalidad de tipos de rastros, inicialmente descritos por Semenov, utilizando de modo complementario los equipos necesarios para su análisis (Vaughan 1981; Plisson 1985; MansurFranchomme 1986; Mansur 1999; entre otros). Este es el enfoque de todos los trabajos sobre análisis funcional que se desarrollan en la actualidad en Europa occidental, Estados Unidos y Latinoamérica.

En cuanto al concepto de instrumento, a partir de los análisis funcionales, así como de los estudios experimentales sobre utilización de instrumentos realizados por diferentes investigadores, resultó evidente que un instrumento no es simplemente un artefacto formatizado, ya que muchos instrumentos son usados sin ninguna formatización de filos o puntas. De esta forma se hace necesario el uso de un concepto de instrumento que incluya la utilización efectiva de un artefacto tenga éste o no evidencias de formatización; el análisis de los procesos tecnológicos, nada pueden decirnos de su utilización final o efectiva (Ingold 1997).

Pero tanto los procesos tecnológicos como los procesos de uso de los instrumentos tienen fuertes improntas culturales que dependen de sus contextos sociales. Entonces, podemos definir a un instrumento como cualquier artefacto lítico que haya sido utilizado, mediante una técnica desarrollada en un contexto social específico (Álvarez 2003). Para algunos autores, son aquellos artefactos líticos que presentan en su superficie rastros de haber sido utilizados para uno o varios trabajos, a diferencia de aquellos artefactos formatizados que presentan evidencias de retoque, etc. pero que no han sido utilizados (Clemente 1995). Para otros, el artefacto lítico, formatizado o no, adquiere su dimensión real de "instrumento" por su destino de uso. De tal modo, corresponden a la categoría de instrumentos todos aquellos que presentan características morfotécnicas de formatización de formas o filos recurrentes, aún cuando no presenten rastros de uso, pero también los filos no modificados que fueron efectivamente utilizados (Mansur-Franchomme 1987a). 


\section{ETNOARQUEOLOGÍA}

El enfoque tecno-funcional del análisis lítico requiere el desarrollo de dos líneas esenciales para su concreción: el trabajo experimental, por un lado, para comprender el modo de producción y uso de los instrumentos, y la etnoarqueología, como generadora de hipótesis con respecto a la producción y uso de instrumentos.

A lo largo de su desarrollo histórico, en Antropología han existido diversidad de corrientes y formas de ver la actividad cultural y la forma en que esta se relaciona con su entorno. En este marco, la etnoarqueología no puede ser considerada y vista de la misma forma por los diversos actores que hacen uso de ella (Binford 1978b; Gould 1978; Hodder 1982a; David y Kramer 2001; González Ruibal 2003; Politis 2004; Mansur 2006; entre otros). Para algunos es una sub-disciplina, una herramienta de la arqueología (Politis 2004; González Ruibal 2003, 2009) o una clave para entender la diferencia de aquel mundo pasado con el mundo globalizado o pos-industrial (Hernando 2006); mientras que para otros funciona como una interfase entre arqueología y etnografía (Estévez y Vila 1995; Vila 2006).

Resulta imposible presentar in extenso aquí las principales posturas que se vienen desarrollando, enmarcadas en la etnoarqueología, por eso se presentará una síntesis de sus aspectos esenciales.

Desde un punto de vista general, existen dos posturas dentro de lo que habitualmente se llama etnoarqueología. La diferencia básica entre ambas se relaciona con la inclusión en el trabajo de campo, de la interacción con sociedades actuales pre-industriales, por parte del arqueólogo.

Una de las posturas considera como un aspecto fundamental el trabajo con sociedades preindustriales actuales, a partir de las cuales poder, a través de analogías, comprender procesos que dieron origen a los restos materiales recuperados arqueológicamente.

Dicha postura tiene relación con el origen de la etnoarqueología, que puede ubicarse hacia mediados del siglo XX con los trabajos de Binford (1977, 1978b y 1979), enmarcados en la Nueva Arqueología o Arqueología Procesual y luego con los trabajos de Hodder (1982a, 1982b) con la Arqueología Pos- 
procesual. Ambos autores llevaron a cabo trabajos de campo con sociedades actuales preindustriales.

La aproximación de la Arqueología Procesual se vinculó más con las actividades tecno-económicas desarrolladas por las sociedades; a partir de la teoría de alcance medio, establecía analogías directas entre algunas actividades del "presente antropológico y del pasado arqueológico" (Binford1967 y 1978; Gould 1980). Al contrario, la Arqueología Pos-procesual “...apunta al entendimiento de niveles mayores de complejidad, intentando discernir los correlatos materiales de los aspectos cognitivos, sociales e ideológicos. Se comienza entonces a proponer un abordaje etnoarqueológico de los aspectos superestructurales, los que habian sido ignorados en las investigaciones anteriores" (Politis 2004).

Esta idea, de búsqueda de factores causales sociales e ideacionales de la conducta de las sociedades cazadoras recolectoras, para poder generar modelos que permitan reconocerlos en el registro arqueológico, también puede encontrarse en trabajos actuales, aunque sin perder de vista los aspectos materiales de las sociedades estudiadas (Politis 1998; Politis y Jaimes 2005).

Por otra parte, desde el viejo mundo, surge un concepto diferente de la etnoarqueología no sólo como una forma de comparar y realizar analogías aplicables a los restos materiales arqueológicos (González Ruibal 2009) sino como una forma de devolverle a las sociedades preindustriales que fueron colonizadas, esclavizadas y transformadas a la fuerza, algo de aquello que se les había quitado. Una mirada más crítica y menos sesgada de la arqueología, haciendo partícipes a las sociedades estudiadas, teniendo en cuenta sus tradiciones, ideas y puntos de vista (González Ruibal 2009). Plantea así utilizar otro concepto, como el de Arqueología del presente:

“...La arqueología del presente, como su nombre indica, estudia a sociedades actuales mediante la metodología y teoría arqueológicas. En esto, en principio, no es muy diferente de la etnoarqueología. Sin embargo, existen tres diferencias notables: como ya he señalado, su objetivo último no es analógico, aunque sus resultados puedan ser utilizados de forma comparativa para otros períodos. En segundo lugar, la arqueología del presente estudia potencialmente todo el mundo actual: tanto sociedades no modernas como capitalistas. No establece una distinción tajante entre nosotros y los otros. En 
tercer lugar, este tipo de arqueología no contempla una distinción drástica entre pasado y presente: en vez de considerar el uno al servicio del otro, como hace la etnoarqueología, cree que ambos, pasado y presente, están inextricablemente unidos..." (González Ruibal 2009).

La etnoarqueología estructural también hace su aporte a la discusión, explicando que es posible usar las analogías para comprender el comportamiento de las sociedades prehistóricas, siempre y cuando consigamos entender la estructura de correlaciones básicas que rige el orden de racionalidad de un grupo cazador-recolector, o cualquier otro. Esta corriente postula que existe una relación estructural y por tanto necesaria, entre el grado de complejidad socio-económica de un grupo y la estructura básica de la percepción que este grupo tiene del mundo (Hernando 2006).

La segunda postura, en cuanto al trabajo de campo con sociedades actuales pre-industriales, parte de la base de considerar a la etnoarqueología como una interfase entre la etnografía y la arqueología. La etnoarqueología se define entonces desde esta perspectiva, considerando una relación dialéctica entre estas dos disciplinas y sin postular como indispensable el uso de la observación participante con sociedades subactuales. Su objetivo es depurar la metodología arqueológica, así como verificar modelos explicativos o leyes generales del modo de producción, utilizando las técnicas de la arqueología en el estudio de objetos etnográficos, datos etnográficos para verificar hipótesis metodológicas, arqueológicas y datos arqueológicos para refutar o validar afirmaciones etnohistóricas (Estévez y Vila 1995).

\section{PENSAR EN EL PAISAJE COMO RECURSO}

Tal como mencionamos al comienzo, nuestro enfoque en el estudio de la organización tecnológica no se restringe a las características particulares de los materiales arqueológicos y de los sitios conocidos, sino que contempla como elemento fundamental la ocupación del espacio y los desplazamientos de poblaciones en la zona boscosa. Ello requiere la realización de prospecciones sistemáticas y trabajos distribucionales a partir de la implementación de transectas, ya que en esta zona la intensidad de sitios y por ende, de materiales arqueológicos, es menor que en otro tipo de ambientes, como por 
ejemplo la costa (Borrero y Casiraghi 1980; Borrero et al. 1981; Borrero 1985; Borrero et al. 1985).

Desde la etnología y etnoarqueología se han propuesto modelos que vinculan la frecuencia de desplazamiento de una población con la densidad de alimentos (Kelly 1995) y que establecen que la movilidad aumenta a medida que la temperatura decrece y la aridez se incrementa (Low 1990; Mandryk 1993; Belardi y Garcia 1994; Belardi 2005). En este caso, creemos que la disponibilidad de materias primas líticas puede constituir un factor condicionante en relación con los sitios de implantación y movilidad de las poblaciones.

Una de las premisas del proyecto en el que se inserta esta investigación, es que las zonas de bosques constituyen ambientes ricos en recursos, que provee de abrigo, reparo, combustible vegetal, plantas, madera como materia prima, etc. y por lo tanto pueden constituir un ambiente favorables para cazadores-recolectores, tal como se ha visto en numerosos estudios arqueológicos en el viejo mundo y en América (Piqué 1999; Berihuete 2006; Berihuete et al. 2007).

En el caso del bosque en la zona central de Tierra del fuego tiene además zonas lagunares que funcionan como espacios concentradores de avifauna en primavera y verano. Con respecto a los claros, éstos conservan guanacos durante el invierno, etc., (Mansur 2002; Mansur y Piqué 2009).

Sin embargo, las ocupaciones arqueológicas son siempre difíciles de detectar, y ello probablemente no tenga que ver con que la intensidad de ocupación del bosque sea menor que la de la estepa o con que el bosque no haya sido usado, sino con el problema de formación y conservación de sitios y de visibilidad arqueológica (ver capítulo 5).

Para abordar el estudio de esta zona son de gran importancia en lo metodológico los estudios distribucionales (Thomas 1975; Foley 1981a; Dunnell y Dancey 1983; Ebert 1992; Belardi y Garcia 1994; Belardi 2005; Barberena 2008), ya que permiten determinar, a través de la diferencia en la densidad de materiales arqueológicos, los sitios de lo no sitios (Thomas 1975; Binford 1992), ambos importantes para entender el uso de los diferentes ambientes y la movilidad de los grupos cazadores recolectores. El enfoque distribucional (Thomas 1975; Foley 1981a; Dunnell y Dancey 1983; Ebert 1992) ve el registro 
como algo continuo pero con picos en su densidad, con lo cual la variabilidad en la densidad de los artefactos será el reflejo del carácter y la frecuencia de utilización del espacio.

El estudio distribucional permite un análisis en dos escalas diferentes: un estudio regional (i.e. densidades artefactuales) y uno suprarregional (i.e. proveniencia de materia prima) (Belardi y Garcia 1994; Belardi 2005). Para ello son fundamentales la utilización de diversos tipos de transectas: lineales, en cruz, etc. (Belardi y Garcia 1994; Belardi 2005), o dirigidas en lugares específicos donde se encuentren perturbaciones producidas por diferentes factores como por ejemplo revolcaderos, conejeras, caída de árboles, etc.

A partir de lo mencionado anteriormente, y considerando que el registro arqueológico es constante, y se encuentra diferencialmente distribuido en el paisaje, proponemos que debería existir una relación estrecha entre los lugares con mayor concentración de recursos y densidad de material arqueológico, disminuyendo la densidad en aquellos lugares donde los recursos se encuentran muy separados unos de otros o son muy escasos.

Para poder abarcar un estudio de este tipo puede plantearse, como punto de partida, la determinación de diversos rasgos del paisaje, entendido no como medio ambiente sino como éste en relación con las sociedades humanas (Wandsnider 1998; Anschuetz et al. 2001), y jerarquizarlos según la cantidad de recursos que comprenda cada uno.

Es fundamental agregar a este tipo de esquema la variable visibilidad arqueológica en relación a la cobertura vegetal de los diversos ambientes, lo que para la Isla Grande de Tierra del Fuego no es algo sin importancia, dado que gran parte de la misma se encuentra cubierta por diversas especies vegetales (Foley 1981a, b; Bintliff y Snodgrass 1988; Borrero et al. 1992; entre otros).

El paso siguiente es ver cuál de los ambientes disponibles en la región funcionaría como el mayor atractor para los grupos humanos que la habitaron, partiendo del supuesto que cuantos más recursos ofrezca un ambiente, mayor pudo haber sido su explotación (Bettinger 2001). Por lo tanto, también es esperable la reocupación de aquellos ambientes que brinden seguridad en cuanto a la explotación de algún recurso. Esta redundancia ocupacional sería 
uno de los posibles factores que intervengan en la variabilidad en la densidad de artefactos arqueológicos (Dyson-Hudson y Smith 1978).

De esta forma se puede desarrollar una jerarquización hipotética del uso del espacio por parte de los grupos cazadores recolectores del interior de la Isla, que luego habrá que contrastar en el terreno, (a partir del diseño del estudio distribucional que puede incluir) en base a diversas metodologías como por ejemplo las transectas, prospecciones, sondeos, etc. (Belardi y García 1994; Belardi 2005).

Para ello es importante trabajar con escalas amplias que puedan abarcar un porcentaje del paisaje de tal modo que las características o los recursos de dicho paisaje no aparezcan como casos únicos o exóticos. Además, este tipo de análisis, nos permite comparar espacios mucho más amplios que si nos centramos únicamente en análisis de sitio (Binford 1992; Belardi 2005).

Por otro lado, los datos etnográficos nos ofrecen información acerca de la movilidad de las poblaciones cazadoras-recolectoras, en relación con la accesibilidad a los recursos, y que es esta movilidad la que les permite tener un control constante sobre el paisaje (Binford 1980; Belardi 2005). Para el área de estudio contamos con el aporte fundamental de las numerosas fuentes escritas de diversos autores mencionados en el capítulo 2, de las cuales las más completas son sin duda los estudios etnográficos de Gusinde (1982 [1937]) y Chapman (1986), los cuales brindan información que abarca el período final de las poblaciones cazadoras-recolectoras del centro de la Isla. La información de estos escritos, junto con la que aporta la arqueología, nos ayuda a comprender cual pudo ser la importancia que tuvieron los bosques para las sociedades fueguinas, no sólo para utilizar la madera como combustible, herramientas, sino también para la construcción de las chozas de actividades tanto cotidianas como ceremoniales (Mansur et al. 2007a, 2007b; Mansur y Piqué 2009).

\section{LA INVESTIGACIÓN DE ESTA TESIS}

En función a la problemática planteada y a fin de comprender el rol de las materias primas en la organización tecnológica, resultaba indispensable llevar a cabo estudios experimentales y aplicados, orientados específicamente hacia el objetivo propuesto, así como estudios distribucionales a fin de 
acercarse a la caracterización de la ocupación del espacio en la zona de bosque subantártico.

Para ello, el trabajo fue planteado siguiendo diferentes líneas:

La primera se focalizó en el caso de los sitios de la localidad Ewan, a fin de determinar diferencias y similitudes en función ceremonial y doméstica.

Una segunda línea incluyó el análisis de los materiales de la localidad Kami, considerando su distribución espacial.

Otra línea estuvo específicamente orientada hacia la caracterización de las materias primas utilizadas y la búsqueda de fuentes potenciales de provisión, a fin de generar un marco que pueda ser utilizado en relación con el análisis de implantaciones y desplazamientos.

Una cuarta línea corresponde a la prospección en la zona boscosa comprendida entre la zona del Fagnano y la costa atlántica, a fin de evaluar el grado de ocupación del espacio y permanencia en este ámbito.

La metodología implementada comprende:

* Prospección y estudios distribucionales, a partir de transectas, utilizando la metodología estándar aplicada en zonas del norte de Tierra del Fuego y sur de Patagonia continental (cf. ref. in Barberena 2008).

* Localización de fuentes de materias primas mediante prospecciones, cartografía e imágenes satelitales, evaluación de fuentes geológicas. Testeo de abundancia, características y calidad para la talla de materias primas en los diversos ambientes.

Para ello se procede de la siguiente manera: en un sector al azar de una fuente de aprovisionamiento potencial, por ejemplo en una playa de guijarros, se delimita un área de 1 metro cuadrado, de la cual se registran las dimensiones de los guijarros y la morfología (aplanados, redondeados, etc.). A continuación, se seleccionan 10 guijarros al azar, se los testea, se registra la calidad para la talla de cada uno, la dificultad de esta actividad, así como la dureza de las rocas y se toman las muestras para conformar una colección comparativa.

Las fuentes de aprovisionamiento corresponden todas a fuentes secundarias, generadas por la redepositación glaci-fluvial. Es por ello que en general se tratan de guijarros redondeados, de diversas materias primas, ya que provienen de diferentes formaciones geológicas. Estas fuentes se 
encuentran emplazadas en las orillas de los ríos, que en esta zona son de carácter meandroso, lo cual permite que existan sectores de acumulación de guijarros de tamaños aptos para la talla por percusión directa; en las orillas de lagos y lagunas también pueden encontrarse sectores con presencia de guijarros con características similares.

* Excavaciones: se realizan utilizando la metodología estándar, siguiendo capas naturales y subdividiéndolas en niveles artificiales si es necesario, con registro tridimensional de materiales y sedimentos en planta, flotación de sedimentos para recuperación de microrrestos y análisis arqueobotánico, etc. (cf. Mansur et al. 2007 b).

* Experimentación tecnológica, mediante talla experimental sobre materias primas locales, para replicar instrumentos y analizar integralmente los desechos de talla generados: La experimentación abarco una diversidad de materias primas líticas locales como riolitas, cineritas y basalto; y materias primas no locales como cuarcitas, calcedonias, madera petrificada y toba silicificada, que permitió tener un espectro amplio de los comportamientos de estas rocas al ser utilizadas sobre diversos materiales como por ejemplo madera, cuero y hueso.

* Análisis tecno-morfológico de instrumentos y restos de talla, siguiendo los criterios planteados por Mansur (1983) a partir de definiciones de Bordes (1961); Aschero (1975-83); Tixier et al. (1980); Orquera y Piana (1986); estudio tecnológico y análisis de distribución y remontajes de materiales arqueológicos, para caracterizar las técnicas de confección y cadenas operativas (sensu Geneste 1991, 1992; Geneste y Rigaud 1989)

* Análisis funcional de base microscópica, según los criterios de análisis y modos de registro y tratamiento de datos desarrollados para materias primas de Patagonia y Tierra del Fuego (Mansur 1983a, 1999), teniendo en cuenta el modelo de formación de rastros de uso en materiales homogéneos y considerando diferentes variables referidas al esquirlamiento y/o redondeamiento de los filos, estrías y micropulidos (cf. Mansur 1999), como se presenta al final de este capítulo.

* Correlación entre diversos aspectos de la tecnología lítica como por ejemplo: morfología, colores, materias primas, función, técnicas de talla, etc. 


\section{Metodología y estrategias en el trabajo de campo}

\section{Prospecciones y estudios distribucionales}

Como se decía al comienzo, la Isla Grande de Tierra del Fuego presenta paisajes bien definidos, con características diferentes: paisaje de montaña, de bosque y de estepa. Ellos tienen diferencias en cuanto a la vegetación y distribución de otros recursos, como por ejemplo materias primas, e incluso la fauna. Nuestro caso de estudio se ubica dentro de la zona de bosques, que se desarrolla en los cordones cordilleranos y valles intermedios, con turbales y depresiones ocupadas por lagos de origen glaciario, con gramíneas y juncos en los fondos de valles y ondulaciones y colinas que decrecen gradualmente en altitud hacia el norte. Los rasgos del paisaje que podemos tomar entonces pueden ser: sectores inter-lagunas, arroyos o ríos, orillas de lagos o lagunas, barrancas, los diversos sectores de bosque como zonas abiertas, borde de bosque, interior; laderas de montaña o sectores puntuales de afloramientos de determinada materia prima, y finalmente los turbales; mientras que entre los recursos podemos mencionar: agua, madera, fauna, afloramientos líticos, recursos vegetales que no sean madera (juncos, semillas, frutos, etc.).

A partir de la definición tanto de los ambientes como de los recursos críticos, se pueden organizar o combinar determinando una jerarquización de los mismos, por ejemplo volcándolos en una planilla como se muestra en la tabla 3.1:

\begin{tabular}{|l|c|r|r|r|r|}
\hline Recursos & Todos & Al menos 4 & Sólo 3 & Sólo 2 & Al menos 1 \\
\hline Materia Prima & $\mathrm{X}$ & $\mathrm{X}$ & $\mathrm{X}$ & $\mathrm{X}$ & $\mathrm{X}$ \\
\hline Fauna & $\mathrm{X}$ & $\mathrm{X}$ & $\mathrm{X}$ & $\mathrm{X}$ & \\
\hline Madera & $\mathrm{X}$ & $\mathrm{X}$ & $\mathrm{X}$ & & \\
\hline Agua & $\mathrm{X}$ & $\mathrm{X}$ & & & \\
\hline $\begin{array}{c}\text { Otros recursos } \\
\text { vegetales }\end{array}$ & $\mathrm{X}$ & & & & \\
\hline Jerarquización & $\mathbf{1 0}$ & $\mathbf{2}$ & $3^{\circ}$ & $\mathbf{4}^{\circ}$ & 50 \\
\hline
\end{tabular}

Tabla 3. 1. Planilla modelo de jerarquización hipotética de ambientes 
En cuanto al trabajo en el campo se plantearon transectas de $5 \mathrm{~km}$ de longitud, con una separación entre las personas de 5 metros. En las mismas se registraron recursos bióticos y abióticos principales así como la existencia de materiales arqueológicos y evaluación de la visibilidad arqueológica. No se realizaron sondeos, pero en los casos de hallazgo de materiales arqueológicos sí se llevaron a cabo recolecciones de los materiales presentes en la superficie. Con respecto a este punto es importante mencionar que la recolección sólo se llevó a cabo de forma completa cuando los materiales corrían algún riesgo de pérdida, como la caída desde barrancos o hallarse sobre caminos transitados, etc.

A partir de lo anteriormente expuesto, consideramos que el uso de diversas escalas, espaciales y temporales, permite una visión más amplia de la distribución, y por lo tanto del uso del espacio, del registro material que formó parte de las sociedades cazadoras recolectoras (Binford 1992; Belardi y García 1994; Belardi 2005).

En los lugares asociados a los espacios donde se desarrollan las transectas, en los cuales afloran guijarros, se procedió a realizar testeos de materia prima para determinar las calidades que presentaban estas para la talla.

\section{Excavaciones y recolecciones superficiales}

A partir de un punto 0 , se extendieron líneas con orientación $\mathrm{E} O$, las cuales se nombraron con números, para luego reticular toda la zona con el tendido de otras orientadas norte sur, las cuales se nombraron con letras. El punto 0 queda ubicado en una de las cuadrículas, a partir de la cual aumentaban las letras hacia el $\mathrm{N}$ y los números hacia el $\mathrm{O}$. La orientación de las líneas de cuadrículas se hizo con brújula de mano y cinta métrica de metal, dado que el error dentro del bosque del material electrónico es superior a los 4 metros.

Las dimensiones de las cuadriculas son de $2 \times 2$, las cuales fueron dividas en sectores de $1 \times 1$ por su posición geográfica dentro de la misma (NO, SO, NE, SE), estos sectores a su vez se dividieron en micro sectores de $50 \times 50 \mathrm{~cm}$. denominados con letras (a, b, c, d). 
En el transcurso de la excavación, se procedió a limpiar el sedimento para exponer los materiales arqueológicos en superficies continuas con técnica de decapado, para luego tridimiensionar y recolectar según coordenadas. En cuanto al sedimento en sí, se tomaron muestras de modo sistemático en todas las cuadrículas excavadas para destinarlas a la técnica de análisis por flotación con máquina, para la recuperación de los fragmentos más pequeños como por ejemplo semillas, carbones y microlascas. Esta técnica permite separar el sedimento extraído en la excavación en tres niveles diferenciados por tamaño (fracciones gruesa, media y fina), según el grosor de las mayas utilizadas en la máquina. Finalmente, una vez secos los materiales de cada fracción, se procede al triado de los mismos. Ello consiste en la separación de cada tipo de material (óseo, lítico y vegetal). La fracción final es analizada por arqueobotánicos para la identificación por ejemplo de semillas.

En cuanto a las recolecciones superficiales, cabe mencionar que se utilizaron las mismas técnicas y estrategias de campo que en las excavaciones, es decir reticulado total de los sectores identificados y recolección integral no selectiva de materiales, con embolsado individual y catalogación.

\section{Estudios experimentales}

Los estudios experimentales se aplicaron específicamente sobre materiales líticos (rocas locales y no locales) y vidrios, y se fundamentan en aspectos relacionados con problemáticas específicas que presentaron los materiales líticos provenientes de los sitios arqueológicos que se presentan en esta Tesis.

Por un lado, dado la escasez de trabajos teórico-metodológicos específicos sobre análisis tecno-funcional de instrumentos de vidrio, en el marco del proyecto en el que se desarrolló parte de este trabajo, se decidió diseñar y ejecutar un programa experimental, que se detalla más adelante. Su objetivo principal fue generar bases para comprender la dinámica de reducción del vidrio para formatizar artefactos comparables a los del registro arqueológico, así como las propiedades y modificaciones de los filos de instrumentos de vidrio cuando son empleados en diferentes procesos de uso. Los resultados obtenidos en los estudios experimentales (De Angelis et al. 
2009) permitieron abordar el análisis tecnofuncional de los materiales de los sitios Ewan I y Ewan II-unidad 1.

Por otro lado, la presencia de materias primas alóctonas en los sitios excavados, generó la necesidad de búsqueda del afloramiento, adquisición de muestras y experimentación tecno-funcional. Tal es el caso de la toba silicificada proveniente del afloramiento conocido como Miraflores al norte de la isla de Tierra del Fuego, en el sector chileno.

El programa experimental siguió los lineamientos generales aplicados en otros estudios de este tipo e incluyó los siguientes pasos:

- Experimentación tecnológica:

- adquisición de materia prima, en este caso en particular vidrio y toba silicificada proveniente del afloramiento mencionado.

- confección de una serie de raspadores y otra de puntas de flecha de vidrio, y raspadores de toba silicificada, buscando replicar las formas base y características de filos y retoques de los documentados en el registro arqueológico;

- recolección y análisis de las esquirlas de retoque, a fin de sistematizar sus características morfotécnicas;

- Experimentación funcional

La experimentación funcional se basó en la utilización de los raspadores, de las diversas materias primas sobre materiales básicos (madera de los géneros Nothofagus y Berberis, con y sin corteza; hueso fresco y pieles, con aditivos y sin ellos), considerando diferentes cinemáticas y ángulos de trabajo. La utilización se llevó a cabo en intervalos cronometrados (5, 15 y 30 minutos), al finalizar cada uno de ellos se procedió a registrar y ubicar las modificaciones de los filos por uso y a fotografiarlas a través del sistema integrado digital. Además se fueron llenando las planillas específicas de la experimentación funcional para la descripción del desarrollo de los micropulidos que se produjeron a lo largo del proceso de uso.

\section{EL ANÁLISIS TECNO- FUNCIONAL}

Como se mencionó mas arriba, el enfoque empleado en este trabajo para el estudio de los conjuntos líticos, se caracteriza por ser amplio, 
abarcativo; el mismo articula la selección de materias primas relacionadas con diversas actividades que incluyen: técnicas de confección, morfologías buscadas y uso al que están destinados los artefactos.

De esta forma el análisis tecno-funcional tiene por finalidad vincular las variables tecno-morfológicas y funcionales de los artefactos, a fin de utilizarlas en la discusión sobre las elecciones y decisiones en cuanto a materias primas utilizadas para cada tipo de instrumento, técnicas seleccionadas para cada materia prima, usos dados a cada uno, etc. (Mansur Franchomme 1983a, 1984, Mansur 1999). Así, a partir de datos concretos analizables en los conjuntos, es posible discutir las estrategias de gestión de las materias primas y los instrumentos, las técnicas empleadas para su confección, los procesos de uso. Todos ellos se integran en la secuencia de la cadena operativa, que permite vincular estos procesos de uso con los de procesamiento de otros recursos (Leroi-Gourhan 1964; Pélegrin 1984, 1990; Karlin 1984, 1991a, 1991b; Balfet 1991; Creswell 1983; Geneste 1985; Perles 1987).

\section{ANÁLISIS TECNO-MORFOLÓGICO}

Este tipo de análisis ofrece la ventaja de trabajar desde dos perspectivas diferentes. Por un lado, desde la tecnológica, existen toda una serie de marcas que se producen en una pieza al ser tallada que permiten identificar la técnica utilizada, reconocer las estrategias de explotación de los núcleos o formas base, reconstruir la forma en que las piezas fueron confeccionadas, determinar el grado de explotación de las diversas materias primas en relación con sus cualidades y con las posibilidades de acceso a las mismas, etc. Por el otro, la perspectiva morfológica puede informarnos sobre la selección y/o elección de ciertas formas base para la confección de las piezas líticas en relación a materias primas disponibles, usos determinados o técnicas y estrategias de talla específicas empleadas para cada materia prima y forma, entre otras. A esta diferencia y complementariedad de perspectivas nos referimos en el capítulo de metodología.

Las variables usadas para el análisis de los materiales son esencialmente las mismas que fueron descritas originalmente por Bordes (1961), Aschero (1975-83), Tixier y colaboradores (1980) y que utilizan Orquera y Piana (1986-87) para los conjuntos de Tierra del Fuego. Sin embargo, 
siguiendo a Mansur (1983a y 1984), se seleccionaron sólo parte de las variables posibles, las que consideramos como importantes indicadores tecnomorfológicos y funcionales. Esta selección de variables se relaciona directamente con el objetivo de abordar este tipo de análisis, considerando los interrogantes planteados anteriormente.

\section{Criterios de análisis de las materias primas}

La determinación de las materias primas de los artefactos fue inicialmente realizada siguiendo criterios descriptivos macroscópicos, equivalentes a las determinaciones efectuadas en las fuentes primarias y secundarias en muestra de mano, y luego mediante la observación de las superficies de fractura o de cortezas en microscopio de reflexión a 200X. Como una de las finalidades esenciales de este enfoque tecno-funcional es vincular la selección de la materia prima con el uso de los artefactos, a los fines de la discusión de resultados, estas fueron reunidas en grupos siguiendo criterios que revisten importancia desde el punto de vista del análisis funcional. Estos son, por ejemplo, las cualidades para la talla de cada una (como granulometría, tipo de fractura, clivaje), composición mineralógica y textura.

Con respecto a este último punto, se adoptó el criterio de denominar "heterogéneas" a las rocas formadas por cristales incluidos en una pasta o matriz, y "homogéneas" a las rocas que no tienen textura porfírica, tanto cristalinas (cuarzo) como amorfas (obsidiana) (Alonso y Mansur 1986-90; Mansur 1991, 1997; Terradas 1996; Álvarez 2003; Leipus 2006; Leipus y Mansur 2007).

Así, dentro del grupo de materias primas heterogéneas, incluimos tanto a un grupo formado por rocas volcánicas tales como riolitas y cineritas, como a otro que incluye sedimentitas químicas como ftanita (sílex), calcedonias, etc. Dentro del segundo grupo, las homogéneas, se encuentran esencialmente el cuarzo hialino y las obsidianas. Como la finalidad del análisis es tecnofuncional, esta forma de agruparlas se relaciona con las características que presentan las diversas materias primas al ser utilizadas. Por un lado aquellas, con buena cohesión de los granos, que ofrecen mayor resistencia al desgranamiento de los filos conservándolos agudos a lo largo del trabajo, pero 
que presentan mayor tendencia la esquirlamiento (sílex, calcedonias, cuarzo y obsidianas). Por el otro están las que se desgranan más fácilmente y tienden al redondeamiento de los filos (riolitas y cineritas) (Mansur 1991, 1999)

\section{Criterios de análisis de los artefactos}

\section{Núcleos}

Los núcleos son aquellos soportes a partir de los cuales se extraen lascas. Estos pueden presentar diversos grados de explotación, que van desde un núcleo apenas iniciado a un núcleo agotado, en el cual se han acabado las plataformas y ángulos de percusión posibles para continuar su aprovechamiento. En los núcleos, es importante distinguir los planos de lascado (negativos de extracciones) de las fracturas. Es a partir de ellas que consideramos a un núcleo entero o fragmentado. En el primer caso podemos definir el tamaño aproximado original del núcleo, mientras que en el segundo, si bien puede seguir siendo utilizado, el tamaño original es imposible de determinar.

Además en este caso particular de estudio, en cuanto a la roca o lito original, que denominamos soporte del núcleo, registramos criterios morfológicos y planos de corteza, que nos permitan identificar si se trata de guijarros costeros o provienen de afloramientos rocosos primarios, etc.

\section{Lascas}

Las lascas son productos extraídos a partir de un núcleo, que pueden o no haber sido utilizados como soporte para instrumentos retocados. Sin embargo, el concepto de lasca ha sido, en muchos casos, utilizado casi como sinónimo de desechos de talla. Si bien es cierto que las lascas son el resultado del trabajo de talla, esto no significa que todas las lascas no modificadas por retoque que se encuentran en un sitio sean desechos o restos de talla, ya que en muchos casos estas pueden ser los soportes buscados, no sólo como formas base sino para su utilización directa, para la explotación de filos naturales, que en muchas materias primas pueden ser más efectivos que los retocados. 
Es por ello que diferenciamos e incluimos dentro del análisis funcional de base microscópica a las lascas que presentan filos que consideramos potencialmente utilizables. Para estos conjuntos, decidimos adoptar el criterio utilizado en otros trabajos de la región que incluyen filos naturales que sean mayores a $2 \mathrm{~cm}$ y medianamente regulares (Álvarez y Mansur 2004).

\section{Fragmentos}

Los fragmentos son aquellos productos de talla en los cuales por el grado de fragmentación y la falta de rasgos tecnológicos no se puede determinar de dónde provienen, si son resultado del estallido de un núcleo o de fragmentación de otros restos de talla por factores tafonómicos. Por tal motivo, preferimos separarlos de las lascas y tratarlos por separado.

\section{Clasificación según tamaño de los productos de talla}

Según su tamaño, los productos de talla se agrupan en tres categorías: 1) mayores de $2 \mathrm{~cm}$ : lascas y fragmentos; 2) entre 0,5 y $2 \mathrm{~cm}$, lasquitas y debris; y finalmente 3) menores de $0,5 \mathrm{~cm}$ : microlascas y microfragmentos.

\section{Instrumentos}

Habitualmente denominamos instrumentos a todos aquellos artefactos en los cuales las formas base (lascas, fragmentos, clastos, etc.), fueron modificadas intencionalmente por talla, retoque, pulimentación o cualquier otra técnica, para ser utilizado en alguna actividad. Esto no significa que forzosamente que todos los instrumentos con una misma morfología, o confeccionados mediante la misma técnica, hayan sido utilizados para los mismos fines (Mansur 1983a, 1986), pero indica un cierto grado de estandarización de los modelos de instrumentos buscados (Tixier et al. 1980).

\section{Criterios descriptivos}

Las variables descriptivas tecno-morfológicas fueron organizadas en 4 partes y volcadas en una planilla, que comprende los siguientes campos: 1 . Descripción; 2. Dimensiones; 3 . Datos de la forma base y 4. Datos referentes a 
los filos (sean naturales o retocados). A continuación se exponen algunos criterios.

\section{Descripción}

Incluye todos los datos descriptivos generales de cada pieza, como por ejemplo el estado de conservación, alteraciones que pudieron sufrir las piezas a lo largo del tiempo, materia prima, color, el grado de fragmentación (pieza entera, fragmentada, o fragmento cuando no podemos prácticamente reconocer ningún rasgo tecnológico), rastros macroscópicos como por ejemplo adherencias, esquirlamiento, redondeamiento.

Se ubica en esta sección el tipo al que se puede asignar el artefacto, si corresponde el subtipo, o si es una lasca, una raedera o un núcleo, etc. Finalmente se tiene en consideración aquí la cantidad de filos que pueda presentar la pieza.

Tal como dijimos anteriormente, los tipos son tecno-morfológicos, en el sentido de una morfología buscada que se obtiene mediante la aplicación de determinadas técnicas. Pero aun cuando sus denominaciones puedan serlo, no tienen connotación funcional.

\section{Dimensiones}

En esta parte se toman las medidas de las piezas, largo, ancho y espesor que permiten clasificarlas en:

Muy grande: superior a $12 \mathrm{~cm}$

Grande: de 8 a $12 \mathrm{~cm}$

Mediano: 4 a $8 \mathrm{~cm}$

Chico: 2 a $4 \mathrm{~cm}$

Muy chico: menor a $2 \mathrm{~cm}$

El uso de los módulos de longitud/ancho (L/A) (relación entre longitud, máxima sobre ancho máximo) y ancho/espesor ( $A / E$ ) (relación entre ancho máximo y espesor máximo), permiten comprender que características dimensionales y morfológicas presentan los conjuntos líticos en general.

Esto permite agrupar las piezas en: 
Según modulo L/A:

Cortos: $\leq$ que 1

Medios: 1,1 a 1,9

Largos: $\geq 2$

Según modulo $A / E$ :

Delgado: $\geq$ que 5

Medio: 4,9 a 2,8

Grueso: < a 2,7

\section{Datos de la forma base}

Podríamos decir que aquí los aspectos morfológicos de las piezas tienen un papel central, ya que las variables apuntan principalmente hacia la forma del artefacto.

Se incluyen en esta sección los soportes, que después de su obtención permitirán formatizar un determinado instrumento, o que pueden quedar en el estadio de lasca y no ser retocados, por diversos motivos (o bien porque corresponden a una lasca de desbaste sin otro objetivo que ese, o bien porque el objetivo del tallador fue buscar esa lasca con filos naturales para utilizarla directamente, entre otras posibilidades).

Es por ello que se toma en cuenta la forma de la pieza vista desde la cara dorsal. Esta nos permite definir si las formas buscadas responden a un patrón que este asociado a la producción final de los instrumentos.

En relación directa con la técnica de talla, está la sección longitudinal de la pieza, la cual puede ser cóncava, convexa, plana, helicoidal (curvatura presente generalmente en lascas de adelgazamiento bifacial), y una combinación de estas como por ejemplo plana-cóncava, cóncavo-convexa, etc.

Los accidentes son tenidos en cuenta ya que también nos pueden estar indicando aspectos de la tecnología. La presencia de estos accidentes puede indicar el uso de percutores muy duros, o la búsqueda de estos accidentes en relación a la necesidad de una forma particular de lasca, como podría ser una 
lasca ancha y espesa. También nos da información sobre la dureza de la materia prima sobre la cual estuvieron tallando.

Las características de los talones se encuentran muy asociado a los tipos de percutores y a las técnicas de talla utilizadas. Los tipos de talones (lisos, lineales, naturales, en ala de pájaro etc.) nos están mostrando una diversidad de gestos tecnológicos sobre el conjunto lítico, que junto con la dirección de los talones (ya sean rectos, oblicuos o muy oblicuos), y la evidencia de preparación o no de los mismos, permite inferir una parte importante de la cadena operativa.

Como rasgos complementarios tomamos la presencia y tipos de bulbo y labio que están muy asociados con la forma en que esas lascas fueron extraídas y con las materias primas que se seleccionaron para la confección de filos buscados.

Un último aspecto en relación a la forma base de las piezas en la presencia de corteza, es decir en qué porcentaje aparece representada en cada elemento del conjunto lítico. Este aspecto es fundamental y está profundamente relacionado con las actividades y etapas en la cadena operativa, ya que nos permite ver por ejemplo si el desbaste de un núcleo, junto con otras variables, se pudo haber llevado a cabo en el sitio o fuera de este, también la presencia de corteza puede estar indicando la posibilidad de acceso a un determinado recurso lítico.

\section{Datos referentes al filo}

El estudio de los filos sean estos naturales o retocados completa el análisis de los artefactos con filos potencialmente utilizables. Por lo tanto comenzamos con variables que incluyan a los dos tipos de filos (naturales y retocados) como por ejemplo la situación del filo, que se refiere a donde están ubicados orientando la pieza, siempre que sea posible, tecnológicamente. Luego su delineación (filos rectos, cóncavos, convexos, semicirculares, etc.).

A partir de aquí comienzan a diferenciarse para unos y otros, ya que al analizar la morfología tenemos para los filos naturales solamente si es un filo regular o irregular, mientras que para los filos retocados tenemos en cuenta si el tipo de retoque es regular o no, si es denticulado regular o no, en muesca, etc. 
En cuanto a la sección longitudinal, está relacionada a la forma del filo en relación a las características del retoque, pudiendo ser un filo sinuoso, muy sinuoso, recto, etc.

La longitud del filo se toma, para ambos igual, en forma recta siguiendo la cuerda del arco. El ángulo se toma, en los filos naturales, directamente el ángulo de filo; pero en los filos retocados se toma el ángulo del retoque.

De aquí en adelante las variables están relacionadas con las características del retoque sobre las piezas. Por ejemplo la posición del retoque, que se refiere a la cara sobre la que se encuentran los negativos del retoque. Para los instrumentos unifaciales, si la talla es desde la cara ventral hacia la dorsal, es un retoque directo, e inverso si fue al revés. También pueden ser filos bifaciales o alternantes.

La extensión del retoque está en relación a si los filos son largos, cortos, restringidos ya sea por muecas o por algún accidente presente en la pieza, extendido o perimetral. En cuanto a la repartición, si los filos no presentan interrupciones en el retoque son continuos, sino pueden ser discontinuos 0 parciales. Finalmente la profundidad del retoque, que se define por cuanto entra el retoque hacia el interior de la pieza. Esta puede dividirse en muy marginales, marginales (menos de $5 \mathrm{~mm}$ ), profundo (más de $5 \mathrm{~mm}$ ) y muy profundo.

\section{ANÁLISIS FUNCIONAL DE BASE MICROSCÓPICA}

El análisis funcional de base microscópica constituye el mejor método para conocer el uso al que fueron sometidos los artefactos, pero también como modo de identificación de alteraciones superficiales producidas por procesos tafonómicos, accidentales, etc. (Mansur-Franchomme 1983, 1986; Mansur 1999).

La metodología aplicada se fundamenta en el modelo de formación de rastros de uso en materiales homogéneos y heterogéneos (Mansur 1999). Para llevarlo a cabo se requiere el empleo de un equipo óptico integrado fundamentalmente por una lupa binocular y un microscopio metalográfico también denominado microscopio de luz reflejada o de luz incidente con sistema directo para captura y digitalización de imágenes. Los aumentos 
utilizados por uno y otro instrumental utilizado en este caso, varían entre los $5 \mathrm{x}$ a los 50x en el caso de la lupa y desde los 50x hasta 500x para el microscopio. Los materiales a analizar fueron tratados para su limpieza con agua, detergente y alcohol al 100\%. Ello permite la eliminación de los residuos grasos generados por la manipulación en el laboratorio. Los pasos metodológicos seguidos fueron:

- análisis en lupa binocular y microscopía óptica de reflexión

- localización de rastros de uso, accidentes y alteraciones

- captura y tratamiento de imágenes (según la metodología de Vila y Gallart 1993)

- determinación funcional (Mansur-Franchomme 1986, 198690)

El análisis comprende el barrido completo de todas las superficies y filos, y el registro de variables referidas a 4 clases de rastros: esquirlamiento $y / 0$ redondeamiento de los filos, estrías, micropulidos y residuos microscópicos (cf. Mansur 1999).

\section{CONCLUSIÓN}

Las estrategias teórico metodológicas presentadas en este capítulo fueron aplicadas al estudio de la problemática de la ocupación del área central de Tierra del Fuego. En función de los objetivos de investigación y de las hipótesis iniciales, se seleccionaron los modos de abordaje que se consideraron los más adecuados. En los próximos capítulos se presentan los modos específicos de análisis y los resultados obtenidos. 


\section{Capítulo 4}

SITIOS ARQUEOLÓGICOS DE LA FAJA CENTRAL DE TIERRA DEL FUEGO 


\section{INTRODUCCIÓN}

En este capítulo se presentan los resultados de un trabajo de campo que comprendió prospecciones amplias y un diseño específico de transectas (ver capítulo 3), que implicaron recolecciones superficiales en un principio para luego evaluar y definir los sectores a excavar.

Como se mencionó al comienzo, uno de los aspectos principales que orientaron este estudio es comprender la relación entre las sociedades cazadoras-recolectoras y los recursos que ofrece el medioambiente donde habitan.

Es por ello que la selección de los sitios arqueológicos a estudiar se efectuó en función de las diferencias en cuanto a los ambientes donde se emplazan. Uno de ellos, la localidad arqueológica Ewan, está ubicado al norte de la cordillera, en una zona de colinas bajas donde la vegetación se caracteriza por parches de bosque mixto y pastizales, con algún curso de agua cercano. Otros sitios, los de la localidad arqueológica Kami, se encuentran emplazados en la zona de valles cordilleranos, al pie de la cordillera, sobre la costa sur del lago más importante de la Isla Grande de Tierra del Fuego, el lago Fagnano. Estos también están rodeados por bosque mixto, aunque con diferencias marcadas principalmente en relación con el sotobosque. Finalmente, una serie de prospecciones sistemáticas fue realizada en la zona que se extiende desde las cabeceras del Fagnano hasta la costa atlántica, caracterizada por terrenos que descienden en altura hasta la costa, en formaciones mesetiformes cortadas por las cuencas de ríos de esta vertiente. De ellas se tratará en el próximo capítulo.

\section{LOCALIDAD ARQUEOLÓGICA EWAN}

La localidad arqueológica Ewan se ubica en la cercanía de la Estancia La Catalana, próxima al curso medio del sector norte del río Ewan, dentro de la el municipio de Tolhuin. La distancia a la costa Atlántica, en línea recta es de 
unos $12 \mathrm{~km}$. Se encuentra dentro del ambiente de bosque caducifolio/Woodland (cf. capítulo 1).

Esta localidad se encuentra constituida por dos espacios diferentes, tanto en cuanto a su ubicación, a su función y a sus dimensiones, como a las actividades que se llevaron a cabo en cada uno y, sobre todo, a quienes podían y no podían ocuparlos. Sin embargo, estos dos espacios funcionan al unísono, ya que dependen uno del otro. Como se explicará a continuación, las investigaciones en el sitio demostraron que sus características corresponden a las de un emplazamiento ceremonial como los utilizados para el ritual del Hain (Mansur y Piqué 2012).

Uno de los espacios, llamado Ewan I, tiene una choza cuyos postes principales aún se encuentran en pie, alejada del espacio que conforma el otro sector del sitio. Las dimensiones, si bien con el correr del tiempo se fueron achicando, rondan entre los tres metros de alto por unos seis metros de diámetro. Los tres palos principales presentan terminación en horqueta donde se unen unos a otros, característicos de las chozas descritas por Gusinde (1982 [1937]) para las chozas confeccionadas exclusivamente para la ceremonia del Hain, donde los varones realizaban el pasaje de niños a adultos (Figura 4.1). 


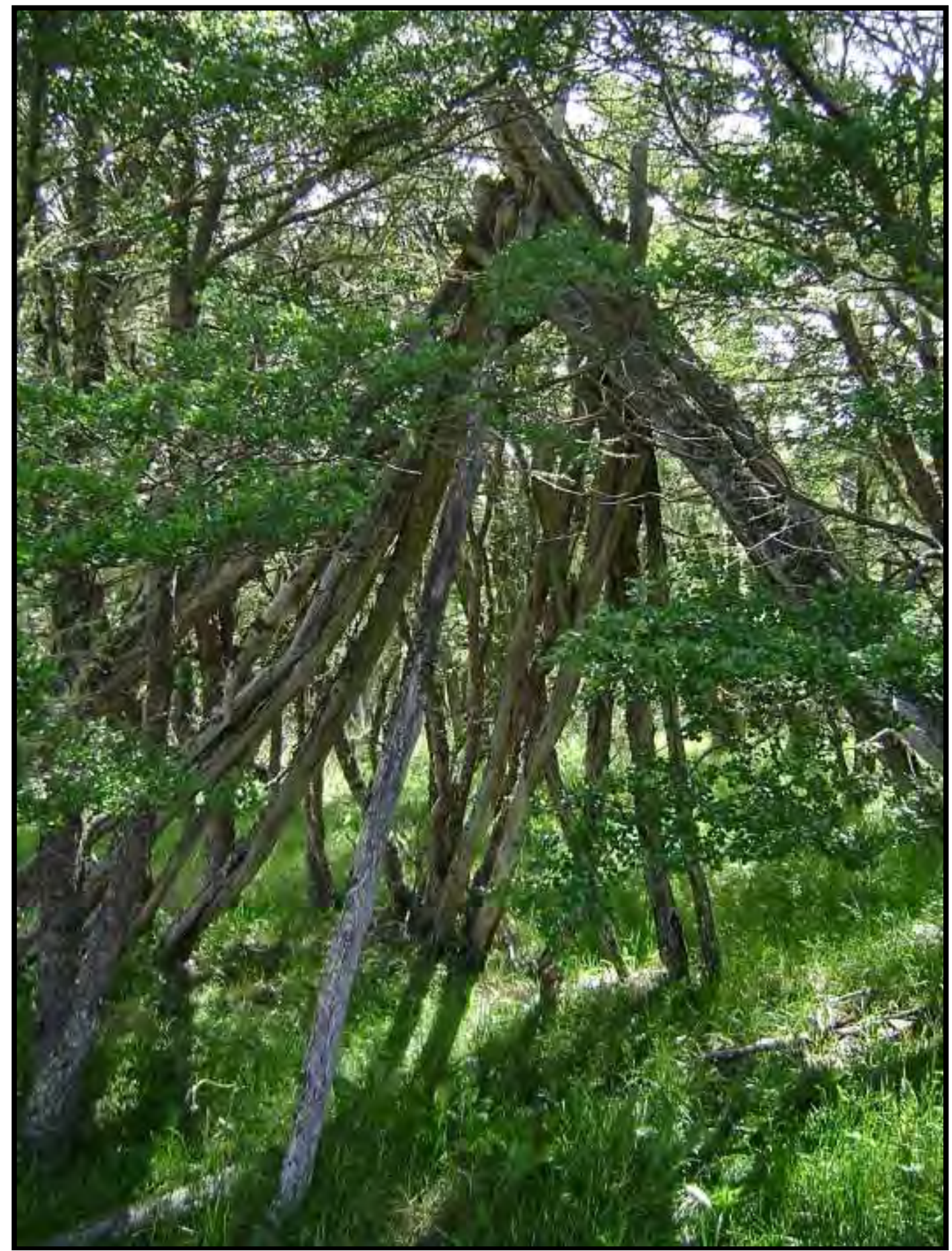

Figura 4. 1. Ewan 1, choza ceremonial del Hain.

En esta estructura y su periferia se llevaron a cabo excavaciones sistemáticas, donde se cubrió una superficie de $37 \mathrm{~m}^{2}$. La metodología de excavación se basó en la técnica de decapado por niveles artificiales y registro tridimensional completo de restos, tratamiento de los sedimentos con la técnica de flotación para la recuperación de los materiales de menor tamaño como por ejemplo semillas, microlascas, fragmentos óseos, etc., así como registro y 
análisis de los restos constructivos. La cronología de la choza fue establecida a través del estudio por dendrocronología de los troncos, técnica que reveló que fueron cortados en la primavera del año 1905.

El otro espacio, llamado Ewan II, está ubicado a unos 200 metros hacia el oeste de Ewan I. Se caracteriza por la presencia de cuatro áreas de combustión que pertenecerían a estructuras de madera de tipo choza, aunque de menor tamaño, que a diferencia de Ewan I no se encontraban en pie. La metodología de trabajo fue la misma que para Ewan I, pero en ésta por sus características fue posible llevar a cabo un estudio geoestadístico completo. Cabe mencionar que sólo se ha excavado una de las cuatro áreas de combustión, alcanzando los $28 \mathrm{~m}^{2}$.

Los materiales arqueológicos de ambos sitios presentan grandes similitudes pero también diferencias entre sí, que se presentan más adelante. Entre tanto, nos interesa mencionar que tanto el patrón de asentamiento, como los materiales hallados en los sitios, son coherentes con la información oral con respecto a Ewan, que decía que podía tratarse de un lugar donde se celebró una ceremonia de Hain. Ello requiere que se haga una breve reseña acerca del contexto histórico y cultural en el que se encontraban los habitantes de la localidad arqueológica Ewan.

Para la época en que se llevó a cabo esta ceremonia, las sociedad Selknam, así como las otras sociedades originarias fueguinas, estaban en absoluto proceso de aculturación y en total disminución de la población debido principalmente a las enfermedades y el trato al que fueron sometidos por la gran mayoría de blancos que se encontraban por diversos motivos en Tierra del Fuego (Chapman 2008).

En cuanto al contexto específico de la ceremonia, ésta se trataba de un momento de gran importancia para esta sociedad, principalmente para los hombres, aunque todas las personas participaban de una u otra forma en todo el proceso de la ceremonia. El Hain, tenía como objetivo específico iniciar a los jóvenes varones en las actividades de los adultos y así pasar de la niñez, en la cual pasaban más tiempo con las mujeres, a ser hombres y poder llevar a delante una familia. Pero más allá de ello, los hacía ingresar a una cofradía masculina encargada de mantener el secreto de la dominación sobre las mujeres. Así, el Hain constituía una ceremonia esencial para toda la sociedad, 
ya que en ella se reafirmaba el patriarcado, columna vertebral de todo el sistema social selknam (Chapman 1986).

Para ello los iniciados eran puestos en constante evaluación a partir de diversas pruebas como cacerías individuales, luchas con espíritus, pasar horas en posiciones sumamente incomodas sin moverse, etc. (Gusinde 1982 [1937]).

Según los distintos autores que tratan sobre el tema (Gusinde 1982 [1937], Chapman 1986) esta ceremonia podía durar mucho tiempo, esto dependía de diversos factores, como la posibilidad de conseguir alimento, la cantidad de iniciados, etc. Sin embargo, generalmente duraban varias semanas. La diferencia más marcada entre los dos autores mencionados es en cuanto a la participación de las mujeres en dicha ceremonia. Para Gusinde las mujeres no tenían ningún tipo de participación en la ceremonia, más que la de proveer de comida y otras tareas domésticas como el cuidado de las niñas y niños. Por el contrario, Chapman considera que el papel de las mujeres es central y sus actividades formaban parte de una actuación en acuerdo con los hombres para hacer más real todas las actividades que rodeaban la ceremonia.

\section{Los sitios arqueológicos Ewan I y Ewan II}

No me extenderé aquí en detalles sobre la ceremonia del Hain, debido a la gran cantidad de información y publicaciones que existen sobre este tema en general (Gallardo 1998 [1910]; Lothrop 2002 [1928]; Bridges 1978 [1951]; Gusinde 1982 [1937]; De Agostini 1956; Chapman 1986). Tampoco en cuanto a investigaciones y resultados sobre la localidad Ewan en particular, porque también existe bibliografía publicada (Bogdanovic et al. 2009 y bibliografía allí citada) y (Mansur y Pique 2012).

Como mencionamos anteriormente el contexto de esta localidad es muy particular, y los estudios llevados a cabo en ella se orientaban, en parte, a comprender arqueológicamente qué parámetros podrían estar indicando, a partir de los restos materiales, actividades ceremoniales.

Los resultados de este trabajo muestran que ambos sitios presentan una gran similitud y a la vez importantes diferencias.

En cuanto al primer punto, podemos resumirlo diciendo que se explotaron básicamente los mismos recursos en uno y otro sitio. Los restos 
faunísticos tienen un alto grado de alteración causado principalmente por termoalteración, que provocó fracturas numerosas; sin embargo los estudios arqueofaunísticos mostraron consumo de Lama guanicoe (guanaco) y Ovis aries (oveja) e incluso se pudieron recuperar restos de aves, moluscos, lapas (Nacella sp.) y peces, aunque estos últimos están representados en frecuencias muy bajas, provenientes de la costa atlántica, cuya distancia al sitio es de unos 12 km (Parmigiani y Camarós 2012). Desde la arquebotánica se pudo determinar la presencia de Nothofagus antárctica, restos carbonizados de bayas comestibles como Gallum aparine (amor del hortelano) y Empetrum rubrum (murtilla), además de especies aportadas desde cierta distancia como por ejemplo Cyperaceae (junco) y Plantaginaceae que crecen en medios acuáticos (Mansur y Piqué 2009). Pero lo más importante para este estudio es que en Ewan el material lítico estaba representado por una única materia prima: el vidrio (De Angelis 2012).

Esta similitud cambia cuando se hacen comparaciones intersitio. Así podemos ver que las diferencias se dan no sólo en el consumo diferencial de los recursos, sino también en el tratamiento que se le dan a los restos materiales, resultado de las diferentes actividades llevadas a cabo en uno y otro sitio, en relación a la función que cumplió cada uno.

En relación a los restos faunísticos, en Ewan II pudo determinarse la presencia tanto de Lama guanicoe como de Ovis aries casi en la misma proporción, mientras que en Ewan I sólo pudo determinarse la presencia de guanaco (Camarós y Parmigiani 2007; Parmigiani y Camarós 2012). En cuanto a los restos vegetales, se pudo ver una elevada frecuencia de Gallium en Ewan II y Empetrum en Ewan I.

Los conjuntos líticos estaban representados en ambos sitios por una única materia prima, el vidrio. Sin embargo, las diferencias se pueden apreciar desde otro aspecto. Los materiales líticos de Ewan I sólo estaban representados por microlascas y microfragmentos de vidrio, con un total de 97 piezas, mientras que el conjunto lítico de Ewan II estaba representado tanto por microlascas y microfragmentos como por fragmentos e instrumentos retocados como raspadores, puntas de proyectil enteras y fragmentadas y un filo largo retocado unifacialmente dando un total de $n=4458$ piezas. Otra diferencia llamativa es la presencia de una gran diversidad de colores entre los restos de 
vidrio de Ewan I (rojo, transparente, azul, verde, turquesa, violeta y celeste) mientras que para el otro sitio sólo se contaron materiales transparentes y verdes. Por estos motivos, el sitio fue considerado como un caso ideal para encarar el estudio tecnofuncional propuesto en esta Tesis (el análisis tecnomorfológico y funcional de los materiales se presenta en el capítulo 7) (De Angelis 2012).

Así a partir de los diversos estudios realizados en Ewan, se pudo determinar que se trató de un lugar de reunión donde se llevó a cabo una ceremonia del Hain, cuyo escenario constaba de dos sectores uno ocupado por la choza ceremonial y el otro ocupado por las estructuras domésticas; las diferencias que se presentan en cada uno de los sitios están relacionadas a las actividades diferenciales que se llevaron a cabo en ellos (Mansur y Piqué 2012).

\section{LOCALIDAD ARQUEOLÓGICA KAMI}

Kami es el nombre selknam del lago Fagnano, el cuerpo de agua dulce más importante de la zona central de la Isla Grande de Tierra del Fuego, ya que presenta una longitud de $110 \mathrm{~km}$ de largo y unos $20 \mathrm{~km}$ de ancho. Sus costas se encuentran rodeadas por bosque mixto, que siguen las ondulaciones del relieve de las playas que van desde elevados acantilados hasta playas suaves de pequeños guijarros.

Si bien es cierto que para la faja central de la Isla el agua no es un recurso crítico, las costas del lago Fagnano presentan una diversidad de recursos que pudieron haber funcionado como atractores para que los grupos a lo largo del tiempo ocuparan y reocuparan dichas costas. Nos referimos a la abundante madera, que fue utilizada como combustible, materia prima, etc., así como también a la fauna que se encuentra asociada a estos cuerpos de agua. Pero fundamentalmente, las costas de lago Fagnano contienen un recurso muy importante y cuya distribución no es tan generalizada como los recursos antes mencionados, nos referimos a las materias primas líticas redepositadas por el arrastre glaciario que conforma gran parte de la costa del lago.

De esta manera, las particularidades que presenta la costa del lago, con recursos como agua, madera, fauna y flora, materia prima lítica en abundancia 
y de calidad para la talla, brindaron un espacio con cierta estabilidad para su explotación, lo que queda evidenciado en la gran cantidad de material arqueológico distribuido sobre la margen sur. Esto contrasta con las características de los sitios detectados en general en la zona de bosques del centro de la Isla, que se presentaron en la Introducción. En la zona boscosa se habían detectado sitios pequeños, con estructuras de combustión difusas, poca conservación de restos óseos y registro lítico escaso, atribuidos a grupos familiares reducidos y móviles.

A diferencia de las otras áreas lagunares de la zona central de la Isla, la costa sur del lago Fagnano está formada por acantilados, interrumpidos por pequeñas bahías con playas de guijarros de grandes dimensiones. En proximidad a estas playas, los trabajos de campo permitieron localizar sitios arqueológicos extensos. Estos se encontraban visibles en parte debido a las perturbaciones antrópicas, causadas por sendas turísticas, y en parte por procesos naturales: pequeñas elevaciones causadas por congelamientodescongelamiento del suelo, caída de árboles exponiendo el sedimento, elevación del material por acción de las raíces, etc. Dada la abundancia y las grandes dimensiones del material lítico observado en superficie, se propuso como hipótesis que las concentraciones de guijarros funcionaron como elemento atractor para la implantación humana, y que entonces la materia prima podía haber circulado a partir de allí hacia otras localidades (Mansur y De Angelis 2012). Por estos motivos, los sitios de la localidad Kami constituían también registros ideales para abordar el estudio propuesto en esta Tesis.

\section{Kami I}

El sitio Kami 1 es un sitio extenso (aproximadamente $180 \mathrm{~m}$ de largo), ubicado sobre la margen sur del lago Fagnano, a poca distancia hacia el este de la laguna Bombilla. Por su accesibilidad y características de la costa, la zona es frecuentada por turistas y pescadores, que estaban provocando la destrucción del sitio. Por ello desde su descubrimiento, se planificaron campañas para recuperar toda la información y materiales posibles.

Para su registro, el sitio fue íntegramente sectorizado en cuadriculas de $2 \mathrm{~m}$ de lado, subdivididas a su vez en cuadrantes o sectores de $1 \mathrm{~m}$ de lado y subcuadrantes o microsectores de $0.5 \mathrm{~m}$ (Figuras 4.2 y 4.3). A partir de este 
reticulado fue posible efectuar la recolección de todo el material superficial, principalmente en los sectores que quedaban expuestos al pisoteo de caminantes y en aquellos que se encontraban en el borde del acantilado.

La excavación se planteó en un sector en el que aparecía material lítico superficial sobre una de las sendas turísticas. En la primera campaña se excavaron las cuadrículas K21 completa y los cuadrantes contiguos de K20, K22, J21 y J22. En la segunda etapa de trabajo, llevada a cabo durante el año 2010, se completaron estas cuadrículas y se excavaron L21 completa y sectores de 121 y L20, totalizando $22,75 \mathrm{~m}^{2}$.

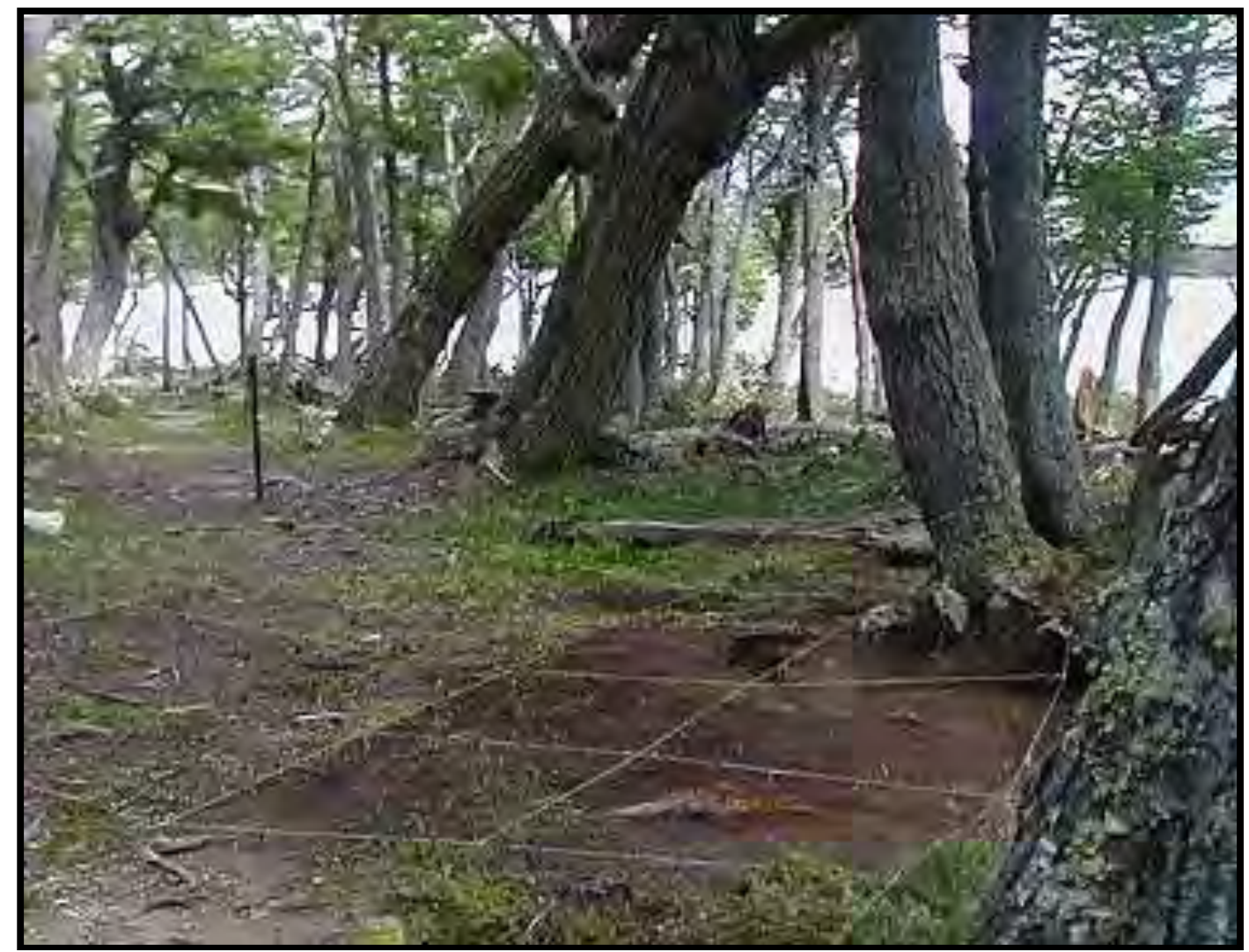

Figura 4. 2. Reticulado en el sector SE de Kami 1

Todos los materiales arqueológicos determinables así como los no determinables superiores a $2 \mathrm{~cm}$ fueron coordenados tridimensionalmente; los inferiores a $2 \mathrm{~cm}$ fueron recogidos por subcuadrante $(0,50 \times 0,50)$.

En cuanto al tratamiento del sedimento, todo el procedente de áreas de combustión fue tratado por flotación en máquina, a fin de recuperar macro y microrrestos carbonizados, así como todos los restos de pequeño tamaño. Se utilizaron tamices de $1 \mathrm{~mm}$ y $0,4 \mathrm{~mm}$. También se flotó de modo sistemático una muestra de sedimento de cada uno de los cuadrantes excavados 
(subcuadrante d). El resto del sedimento fue cribado en seco o en agua, según el estado del mismo, en zarandas de $2 \mathrm{~mm}$.

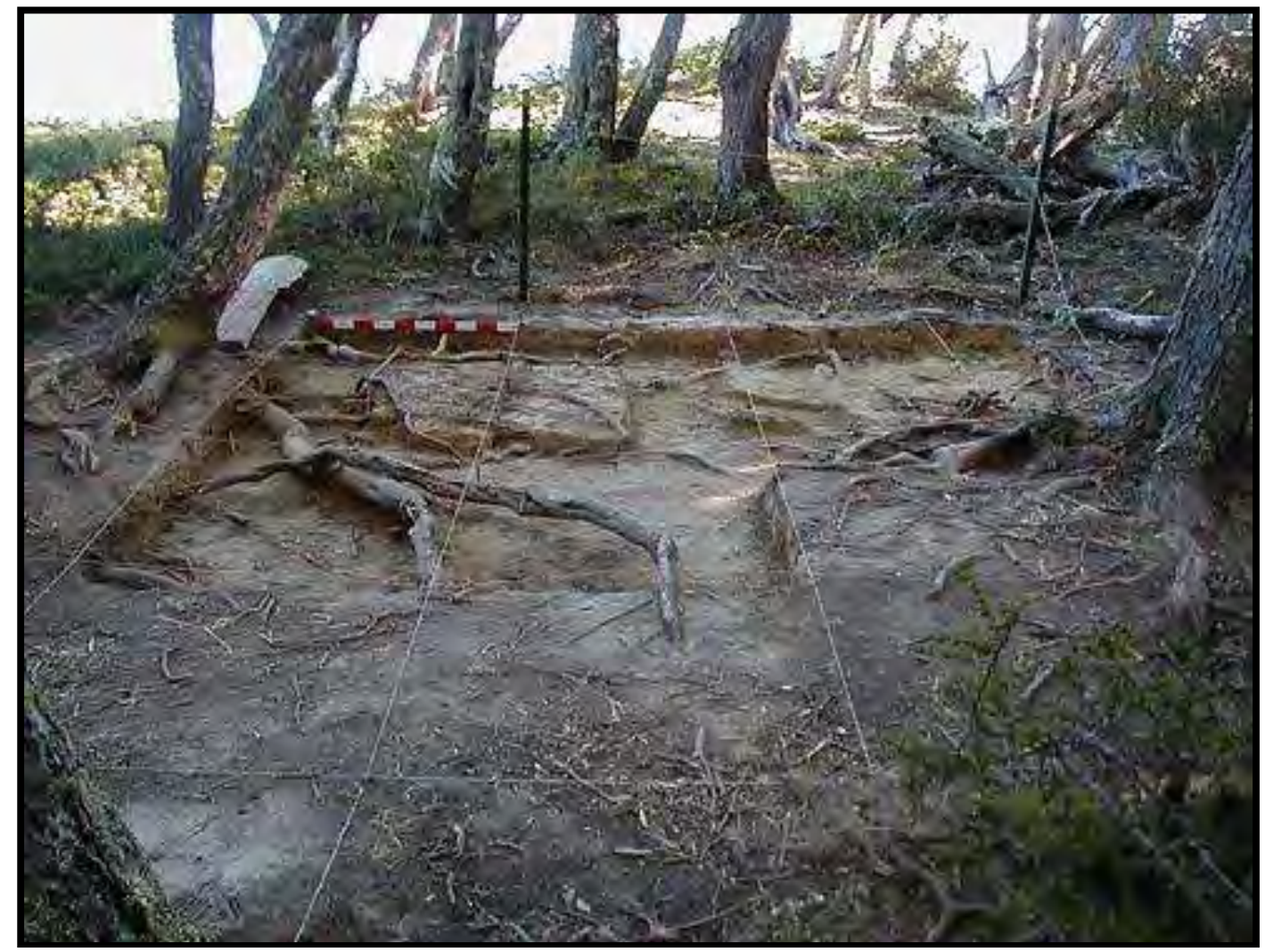

Figura 4. 3. Detalle de cuadrículas campaña 2009.

La estratigrafía está formada por cuatro capas, que se corresponden con el desarrollo del suelo de fondo de bosque. La más superficial (que llamamos capa A) es el mantillo orgánico; la capa B es un sedimento suelto terroso de color marrón oscuro, de alrededor de $3 \mathrm{~cm}$ de espesor; la capa $C$ es un sedimento arcilloso de color marrón anaranjado y en ella se encuentra la casi totalidad del material arqueológico. Finalmente el sedimento $D$ es el till morénico, que se caracteriza por ser de color grisáceo, fino y más compacto. En algunos sectores presenta pequeños rodados producto del arrastre glaciario.

\section{Áreas de combustión, fechados y materiales arqueológicos}

En el transcurso de la excavación, se detectó un fogón ubicado entre las cuadrículas $\mathrm{K} 21$ y K22, con un diámetro de alrededor de $1 \mathrm{~m}$ y una potencia de más de $15 \mathrm{~cm}$, rodeado por sedimento ceniciento más compactado (Figura 4.4a). En él se localizaron gran cantidad de carbones de diversos tamaños, así como lascas y microlascas, algunos instrumentos y guijarros termoalterados, 
hueso quemado, etc. (Figura 4.4b). En la periferia del fogón se registró abundante material arqueológico, en particular instrumentos y restos de talla.

Además de este fogón, se identificaron tres áreas de combustión de menor tamaño y potencia, ubicadas en las cuadrículas L21, K20 y J21/l21 (Figura 4.4c).
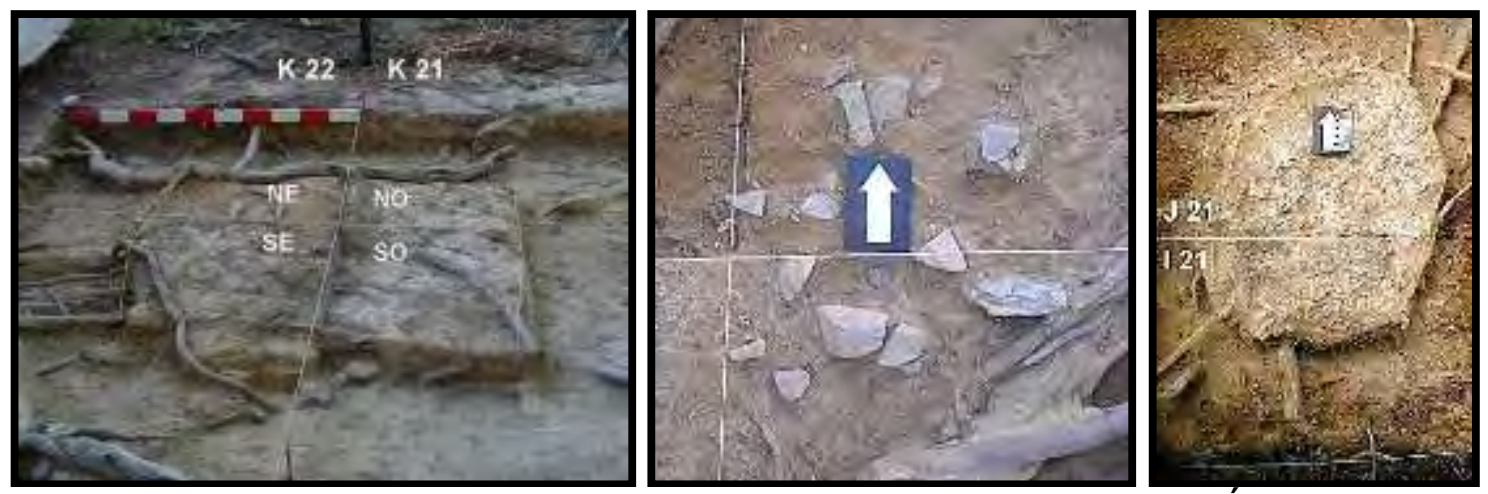

Figura 4. 4. a. Fogón; b. Material arqueológico asociado; c. Área de combustión.

Se efectuaron dos fechados radiocarbónicos a partir de muestras de carbón vegetal, una del interior del fogón de las cuadrículas K21 y K22 (LP 2164) y otra con carbones de la periferia (cuadrícula K21, LP 2163), que dieron los siguientes resultados: $3210 \pm 80$ AP (LP 2164) y $1130 \pm 60$ AP (LP 2163). Para ver si se trataba realmente de dos episodios diferentes, se decidió realizar un nuevo fechado a partir de carbones del interior del fogón, el cual arrojo una fecha de $\div 1170 \pm 60$ AP (LP 2201) (Tabla 4.1). Estos resultados podrían estar sugiriendo eventos independientes de ocupación, que se solapan parcialmente en extensión horizontal, y cuyos patrones de implantación y características del material lítico tienen similitudes, que hacen virtualmente imposible discriminarlos entre sí.

En cuanto a los materiales recuperados en los sectores excavados, el registro faunístico es relativamente escaso. Se contabilizaron 143 fragmentos óseos de los cuales sólo uno es mayor a $2 \mathrm{~cm}$. Todos muestran indicios de diversos grados de termoalteración.

A diferencia del material óseo, el lítico de los sectores excavados es muy abundante superando las 7500 piezas. Aún cuando en el capítulo 7 nos dedicaremos en detalle a discutir las características de este material, por el momento es necesario aclarar que del total mencionado, 1171 artefactos corresponden a elementos mayores de $2 \mathrm{~cm}$, representado por lascas $(n=751)$, 
fragmentos $(n=370)$, raederas $(n=33)$ (Figura 4.5), raspadores $(n=34)$, fragmentos de instrumentos $(n=36)$, fragmentos de punta de proyectil $(n=7)$, que suman un total de 3 puntas, y sólo un instrumento compuesto. Los núcleos enteros $(n=4)$ y núcleos fragmentados $(n=24)$ representan casi el $2 \%$. Por su parte, los elementos menores a $2 \mathrm{~cm}$ alcanzan un $n=6234$ representados por lasquitas $(n=2589)$, debris $(n=2126)$, microlascas $(n=760)$ y microfragmentos $(n=738)$.

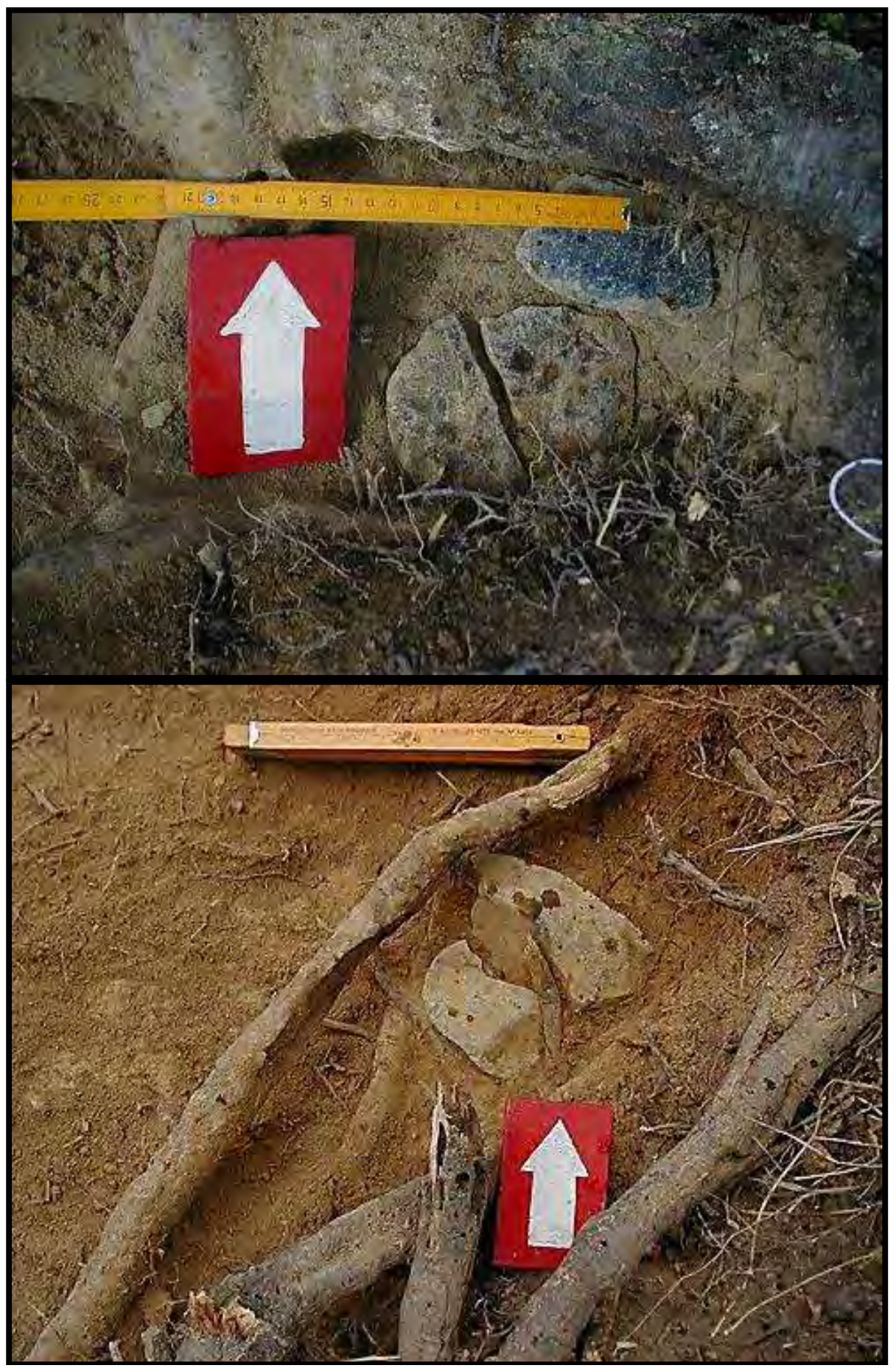

Figura 4. 5. Detalle de los filos largos retocados fracturados in situ. 
Las materias primas representadas son variadas, incluyendo riolitas, cineritas, cuarzos, cuarcitas y rocas silíceas. En cuanto a las técnicas de talla, los artefactos más abundantes provienen de la talla por percusión directa, sin embargo interesa mencionar la existencia de abundantes productos de talla bipolar.

Además de los sectores excavados, la recolección superficial intensiva realizada en todos los sectores del sitio brindó abundantes materiales líticos con las mismas características. El análisis tecnofuncional de los conjuntos se presenta en el capítulo 8.

\section{Kami VII}

La elección del sitio Kami 7 para este estudio se debió a determinadas características, entre ellas la gran similitud que guarda con el sitio Kami 1: tales son su emplazamiento en una elevación, la cercanía a la playa con rodados, la abundancia de materiales líticos observados en superficie, que permitirían obtener información valiosa para aportar a la problemática de la ocupación humana en el lago Fagnano y la gestión de los recursos tanto bióticos como abióticos (Mansur y De Angelis 2012).

El sitio Kami 7 se encuentra emplazado sobre una elevación de till de base, cubierta por un suelo delgado que en muchos sectores está erosionado, en el que se desarrolla el bosque mixto perennifolio de Nothofagus pumilio y Nothofagus betuloides. Está junto a la costa del lago, que en este sector presenta promontorios formados por grandes bloques rocosos, expuestos por la acción glaciaria, alternando con playas de guijarros de diversos tamaños. La elevación que contiene al sitio se encuentra delimitada hacia el este y el sur por un turbal que la rodea y hacia el oeste y el norte por la costa del lago Fagnano.

Antrópicamente el sitio está delimitado por una ruta que pasa por el sur y lo bordea por el extremo oeste, desde donde se abre un camino que lo atraviesa en dirección O-E. Este camino es frecuentado por los pescadores para acceder a la playa, situada al este, lugar que utilizan para embarcar y desembarcar vehículos de navegación a motor (botes y lanchas), por ser un área naturalmente protegida de los vientos característicos de esta zona. El camino también es usado por turistas en actividades de senderismo. 
El sitio fue descubierto por la existencia de material arqueológico en superficie en las áreas del bosque que se encontraban perturbadas ya sea antrópicamente, por caminos y senderos, como naturalmente por derrumbes del borde del acantilado y caídas de árboles. La elevación donde se encontraban los materiales tiene una forma irregular. La extensión del sitio fue calculada por la presencia de material lítico en superficie, registrándose $120 \mathrm{~m}$ de largo en dirección E-O y 50 m en dirección N-S en su eje más largo.

Los trabajos de campo en Kami 7 se iniciaron en febrero de 2010 y se extendieron a lo largo de la temporada de campo de 2011. Comenzaron con la sectorización total del sitio en cuadrículas de $2 \times 2 \mathrm{~m}$, que se agrupan en cuatro sectores (NO, NE, SO y SE) (Figura 4.6a). Interiormente, las cuadrículas se subdividen en cuadrantes o sectores de $1 \mathrm{~m}$ de lado y microsectores de $0.5 \mathrm{~m}$ (Figura 4.6a y $4.7 \mathrm{~b}$ ).

A partir de este reticulado, se efectuó la recolección superficial sistemática de materiales en toda la extensión visible del sitio, a lo largo de dos campañas (febrero de 2010 y diciembre 2010/enero 2011). Al igual que en Kami 1, la recolección del material superficial se realizó de manera intensiva no selectiva dentro de cada cuadricula, sin considerar sus subdivisiones menores.

En este caso, dentro de cada cuadrícula se registró y mapeó la ubicación de lo que denominamos unidades de recolección. Estas pueden ser de sólo una pieza, en el caso de materiales semi aislados, o de un conjunto, en el caso de materiales agrupados. La estrategia es equivalente a la que se utiliza en excavación para el registro tridimensional de hallazgos.

También se registraron aquellos cuadrantes en los que además del material en superficie se podía visualizar su continuidad en estratigrafía, para ser excavados en las próximas temporadas de campo.

La distribución del material en superficie no era continua; una vez mapeados los hallazgos, se pudo observar que había una clara concentración en los sectores NE y NO, que son los más cercanos a la costa (Figura 4.6a). 


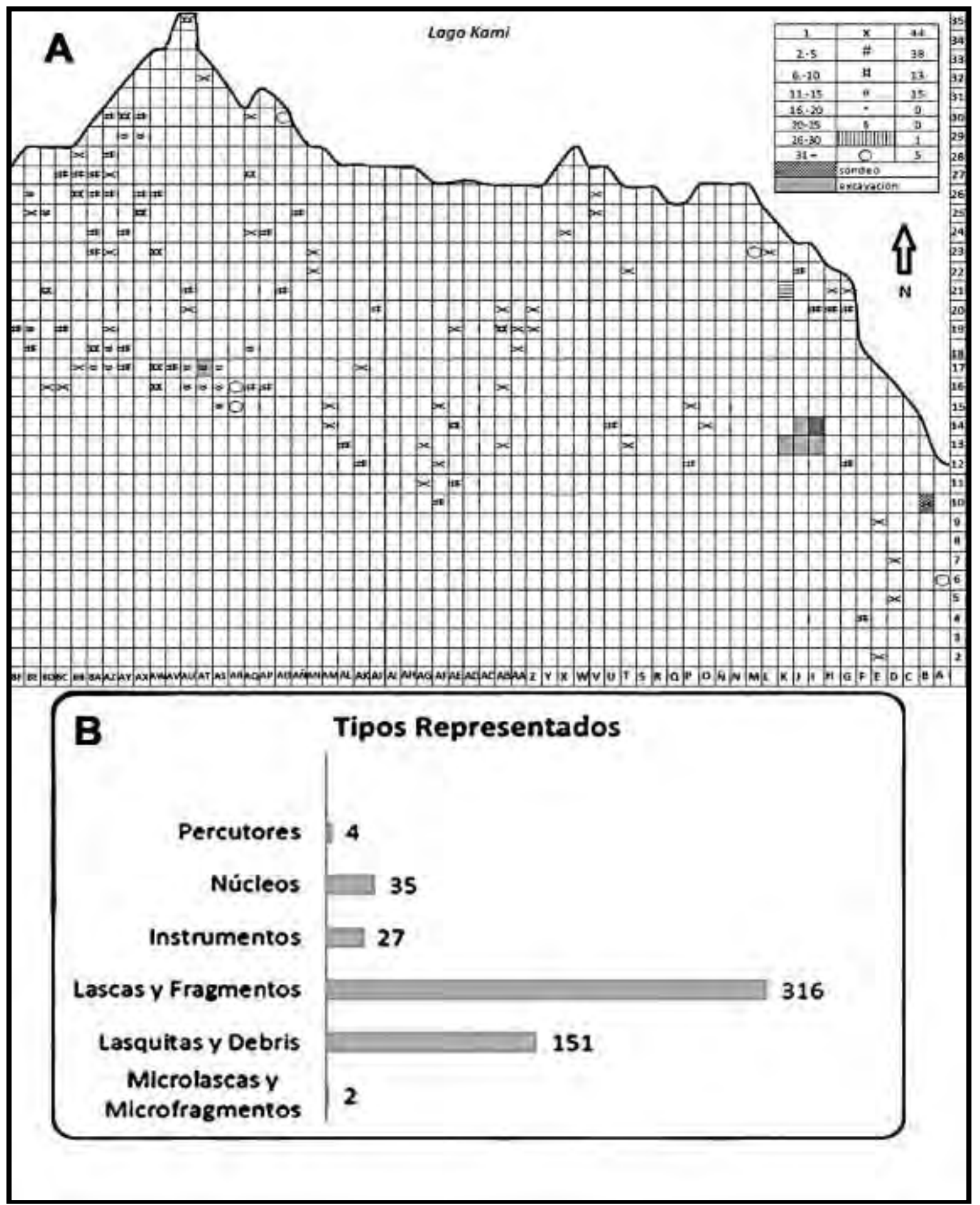

Figura 4. 6. a. Distribución del material superficial y emplazamiento de los sondeos y las cuadrículas excavadas; b. Tipos representados en la recolección superficial.

Se registraron 235 unidades de recolección distribuidas en 116 cuadriculas. De ellas, 44 contenían un sólo objeto; 38 de dos a cinco; 15 de seis a diez, 13 de 11 a 15; 3 entre 25 a 30 y 3 contenían más de 30 objetos (Figura 4.6a). Cabe mencionar que los hallazgos de superficie fueron sólo 
artefactos líticos, incluyendo microlascas, lascas, instrumentos y núcleos, entre otros (Figura 4.6b).

\section{Los sectores excavados}

Cuadrículas del sector Oriental

Antes de comenzar la excavación, se efectuaron dos sondeos en sectores con alta densidad de materiales en superficie y en donde se veía la continuidad de materiales arqueológicos en estratigrafía, a fin de establecer las características del sedimento y la profundidad en la que aparecían los materiales (Parmigiani et al. 2012).

Para ello, fueron seleccionados dos sectores de $1 \times 1 \mathrm{~m}$, dentro de dos cuadrículas del reticulado: $\mathrm{B}-10$ e $\mathrm{l}-14$.

Los sondeos se realizaron por decapado, siguiendo las capas naturales, y su excavación sirvió para definir la estratigrafía asociada con el sitio arqueológico, que se corresponde con la descripta para los suelos de bosque típicos del área (Frangi et al. 2004). En general los suelos forestales de Tierra del Fuego son poco profundos y están compuestos por A) un horizonte orgánico, seguido de B) un horizonte de till edafizado y C) un horizonte formado por till sin alteraciones (Coronato et al. 2009). En los sondeos en Kami 7, se observó que la capa superficial que corresponde al mantillo orgánico (1) tiene un espesor de aproximadamente $1 \mathrm{~cm}$. El horizonte $B$ tiene una fina capa de tierra marrón oscuro (2) cuya presencia no es continua en toda la superficie, y generalmente no supera $1 \mathrm{~cm}$ de espesor y otra de tierra limosa de color marrón claro amarillento donde se encuentra casi todo el potencial arqueológico con un espesor de $2 \mathrm{~cm}$ aproximadamente (3). Por debajo comienzan a aparecer pequeños guijarros pertenecientes al horizonte $C$ constituido por el till morénico (4) (Figura 4.7a).

En el sondeo $\mathrm{N}^{\circ} 1$, ubicado en el sector NE de la cuadrícula B-10 (Figura 4.6) se descubrieron siete artefactos líticos: dos raederas, un fragmento, dos lasquitas, un debris y un microfragmento. 


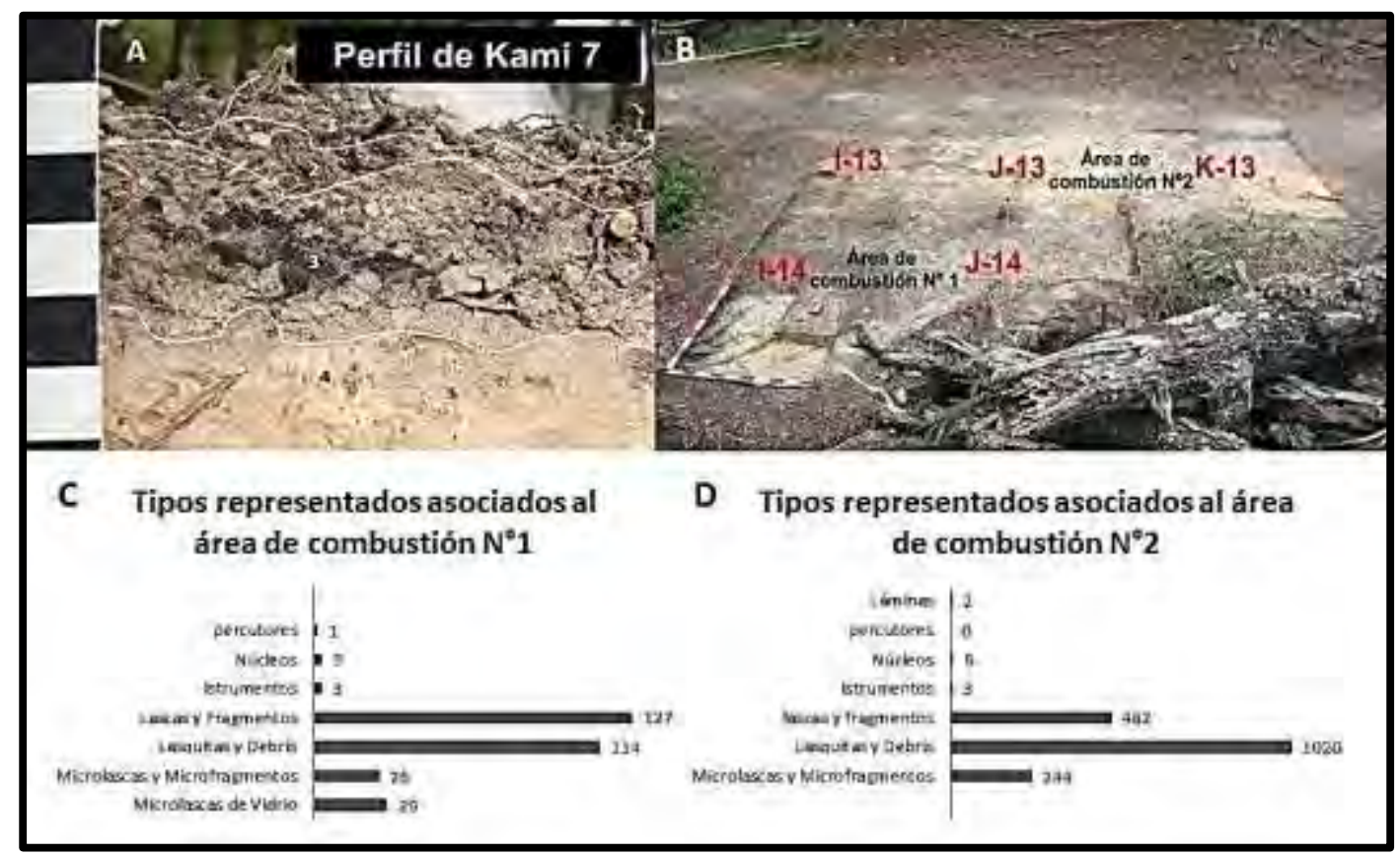

Figura 4. 7. a. Estratigrafía asociada al sitio Kami 7; b. Cuadrículas excavadas y delimitación de las áreas de combustión; c. Material lítico asociado al área de combustión $\mathrm{N}^{\circ} 1$; d. Material lítico asociado al área de combustión $\mathrm{N}^{\circ} 2$.

El sondeo $\mathrm{N}^{\circ}$ 2, ubicado en el sector NO de la cuadrícula I-14, contenía abundante material arqueológico en superficie y en estratigrafía: lascas, fragmentos óseos y carbones. Por ello se decidió continuar con la excavación hacia otros sectores de l-14 y cuadrículas contiguas.

Hasta el momento se ha excavado una superficie total de $12,75 \mathrm{~m}^{2}$, que incluye las cuadrículas K-13 (todos los sectores), J-13 (sólo sectores NO, NE Y SE), I-13 (sector NO y el microsector b del sector SO), J-14 (sectores NE, SE y SO) e I-14 (sectores NO y SO).

En la excavación se pudieron determinar dos áreas de combustión, ubicadas a $1 \mathrm{~m}$ de distancia una de la otra. Estas áreas presentan importantes diferencias entre sí, en cuanto a los materiales arqueológicos de los que se puede decir con seguridad que están asociados a una o a la otra, tal como se presenta a continuación. Pero también hay materiales que aún no han podido ser asignados a un área de combustión específica, En particular llama la atención la presencia en estratigrafía de varios cristales de cuarzo $(\mathrm{N}=7)$ con marcas de talla bipolar, cuyas medidas van de 1 a $4 \mathrm{~cm}$; hasta la fecha no se han detectado fuentes de aprovisionamiento de esta materia prima en las cercanías del sitio. 
Todos los materiales arqueológicos determinables así como los no determinables superiores a $2 \mathrm{~cm}$ fueron coordenados tridimensionalmente; los inferiores a $2 \mathrm{~cm}$ fueron recogidos por microsector $(0,50 \times 0,50)$.

Se tomaron muestras de sedimentos de las dos áreas de combustión y de todos los sectores de las 5 cuadrículas, que fueron tratados mediante la técnica de flotación por máquina para recuperar microrestos vegetales, líticos y óseos. Se utilizaron tamices de $1 \mathrm{~mm}$ y $0,4 \mathrm{~mm}$. El resto del sedimento fue cribado en seco en zarandas de $2 \mathrm{~mm}$.

Área de combustión $\mathrm{N}^{\circ} 1$

El área de combustión $\mathrm{N}^{\circ} 1$ está ubicada en las cuadrículas, l-14 (sector NO microsector C; sector SO, microsector A) y J-14 (sector NE, microsector B y $\mathrm{D}$; sector SE, microsector B). Fue identificada en función de la coloración grisácea y compactación de los sedimentos, que se encontraban termoalterados y conteniendo cenizas y carbones. Su diámetro aproximado era de $60 \mathrm{~cm}$ y su espesor no superaba los $3 \mathrm{~cm}$. El material arqueológico asociado incluye carbones, restos óseos, restos de tecnología lítica y de vidrio (lasquitas y microlascas).

En cuanto al material arqueofaunístico excavado en el sitio sólo podemos decir que los restos óseos asociados a esta área de combustión son fragmentos y astillas óseas, la mayor parte modificados por alteraciones térmicas. Los fragmentos que no han sido modificados por termoalteración, presentan una estructura muy frágil; es por ello que el microsector que los contenía (I-14-NO-C) fue levantado en bloque y excavado en el laboratorio, donde fue posible remontar los fragmentos óseos que se encontraban muy deteriorados, recuperando así formas anatómicas identificables. Algunas de ellas podrían corresponder a Lama guanicoe.

El conjunto lítico está representado por un total de 303 artefactos. La mayor parte de ellos corresponden a elementos menores de $2 \mathrm{~cm}$, seguidos por lascas y fragmentos de diversos tamaños; también se hallaron instrumentos, núcleos y percutores en menor proporción (detalle en Figura 4.7c). En esta área de combustión en particular, las materias primas representadas son diversos tipos de riolitas y vidrio industrial de color verde. 
Finalmente se puede mencionar la presencia de carbones, bien conservados y de diversos tamaños.

La presencia de microlascas de vidrio en esta área de combustión implica su formación en momentos posteriores al contacto con los europeos y la dispersión de las mismas supone una ocupación del sitio en dicho período.

Área de combustión $\mathrm{N}^{\circ} 2$

El área de combustión №2 está ubicada en las cuadriculas J-13 (sector NO, microsector $C$ y Sector SO microsector $A$ ) y K-13 (sector NE, microsector D y sector SE microsector B). También fue identificada en función de la coloración grisácea y compactación de los sedimentos termoalterados. Su diámetro aproximado era de $50 \mathrm{~cm}$ y su espesor no superaba los $2 \mathrm{~cm}$. En ella se recuperaron restos líticos y carbones.

Este conjunto lítico está representado por 1.757 elementos. La mayoría corresponden a restos de talla menores a $2 \mathrm{~cm}$, les siguen en número las lascas y fragmentos de diversos tamaños, en tanto que los instrumentos terminados son muy escasos, así como los núcleos (detalle en Figura 4.7d). Las materias primas representadas son principalmente las riolitas de grano fino y medio, y luego las cineritas.

Los carbones de este sector son abundantes, de diversos tamaños y con una dispersión más amplia que el área de combustión $\mathrm{N}^{\circ} 1$.

Para esta área de combustión se obtuvo por análisis de AMS sobre una muestra de carbón vegetal un fechado de $1.217 \pm 38$ años $C^{14}$ AP no cal (AA94284; carbón vegetal; d13C $=-26.0 \%$ ) lo que implica que el sitio fue ocupado -por lo menos- también en esta antigüedad (Tabla 4.1).

El análisis tecno-morfológico de los materiales se presenta en conjunto en el capítulo 8.

Excavación en la cuadricula AT-17: el área de combustión $N^{\circ} 3$

En el sector NO del sitio Kami 7, durante los trabajos de recolección superficial, se identificó una concentración de materiales arqueológicos, contenidos en sedimentos termoalterados con alto contenido de carbones que quedaron expuestos tras el derrumbe de un árbol. Todo el material estaba retenido por las raíces y cubierto por una densa capa de musgos (Figura 4.8a). 


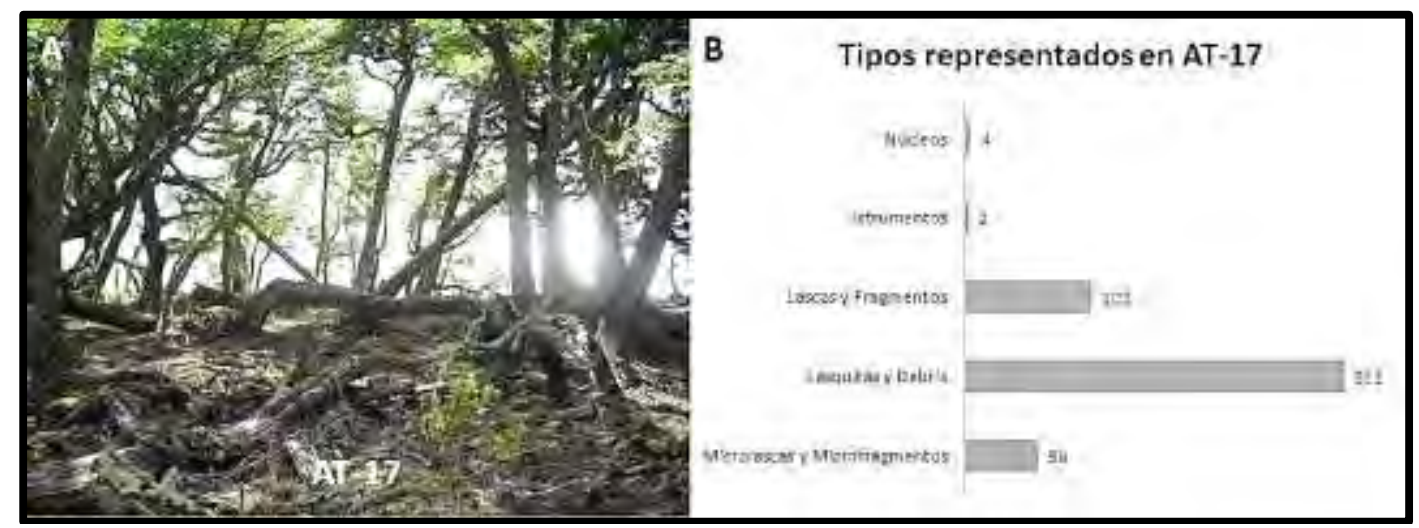

Figura 4. 8. a. Ubicación del cuadrante AT-17; b. Material lítico recuperado en la excavación.

Esos materiales, por encontrarse al costado del camino, corrían el riesgo de ser destruidos por el frecuente paso de vehículos, por lo que se efectuó una excavación puntual en el sector afectado.

Esta concentración estaba ubicada en el sector NE de la cuadrícula AT17 (Figura 4.6a y 4.8a). El sedimento más superficial, que se encontraba protegido por la densa capa de musgos, fue guardado para ser tratado por flotación (20 litros). Todo el sedimento que se encontraba por debajo de esta capa fue tamizado con zaranda fina $(2 \mathrm{~mm})$ y el material triado en el campo, recuperándose abundantes carbones de diversos tamaños, material lítico y restos óseos que se encontraban termoalterados en su totalidad.

El conjunto arqueofaunístico, analizado por la Lic. Parmigiani, está compuesto por 3.561 especímenes óseos, de los cuales 3.177 son fragmentos menores a $2 \mathrm{~cm}, 370$ son mayores a $2 \mathrm{~cm}$ y sólo 14 son anatómica y taxonómicamente reconocibles, encontrándose un hueso de ave con marcas, y los restantes de pertenecientes a Lama guanicoe (Parmigiani com. pers).

El conjunto lítico $(\mathrm{N}=479)$ está constituido por fragmentos de núcleos, lascas y desechos de talla (detalle en Figura 4.8b). El análisis de los materiales se presenta en el capítulo 8.

Una muestra de carbón vegetal de este sector fue utilizada para fechar esta agregación de materiales a través del método AMS, obteniendo una fecha de $178 \pm 34$ años $C^{14}$ AP no cal (AA-94285; carbón vegetal; d13C = -25.1\%o) (Tabla 4.1). 


\section{DISCUSIÓN}

En este capítulo se presentaron dos localidades arqueológicas Ewan y Kami. Si bien ambas presentan diferencias muy marcadas entre sí, tienen sin embargo aspectos compartidos.

Por un lado Ewan, ubicada en la zona de ecotono al norte del lago Fagnano, en el interior del bosque, tiene como característica particular la presencia de una choza aún en pie (Ewan I), de principios del siglo XX, donde se llevó a cabo una de las ceremonias más importantes de los Selknam, el Hain. Esta ceremonia tenía como finalidad el pase de los niños a la adultez a través de diversas pruebas físicas, espirituales, etc.

Para poder determinar la funcionalidad del sitio Ewan I, como parte de una ceremonia del Hain, había que ubicar el sector de actividades cotidianas, para ello se tomaron en cuenta los escritos etnográficos disponibles (Gusinde 1982 [1931]) De esta forma se localizaron diversas áreas de combustión, Ewan II, a unos 200 metros de la choza ceremonial (Bogdanovic et al. 2009; Mansur y Piqué 2012).

Los resultados obtenidos a partir de los materiales provenientes de las excavaciones en uno y otro sitio, demostraron que ambos son contemporáneos y con características muy similares, como por ejemplo el tipo de materia prima utilizada para la confección de instrumentos, el vidrio y los restos faunísticos (Bogdanovic et al. 2009; Mansur y Piqué 2012).

La otra localidad arqueológica, Kami, está emplazada sobre la costa sur del lago, zona de pie de monte cordillerano, rodeado por bosque cerrado, lagunas y ríos que desembocan en el Fagnano o tienen sus cabeceras en la zona de montaña y desembocan en el Atlántico.

La localidad se caracteriza por la presencia de diversos sectores con concentración de material arqueológico, principalmente lítico. A partir de los trabajos de campo, se decidió llevar a cabo excavaciones en los sitios Kami 1 y Kami 7, junto con la cuadriculación de otros sectores para poder realizar recolección de la totalidad de los materiales de superficie.

Los fechados, realizados sobre carbón y la presencia de restos de talla en vidrio provenientes del sitio Kami 7, permiten verificar la reutilización de la costa sur del lago Fagnano desde hace al menos 1000 años hasta el momento de contacto con los europeos. 
Finalmente se puede decir que si bien ambos sitios muestran diferencias, guardan similitudes que los hacen relevantes para este estudio. Por un lado, cuentan con una diversidad de materias primas utilizadas; por otro, pueden ser clasificados como sitios extensos ya que ambos presentan concentraciones de materiales que se superponen y cubren una gran superficie. Además aparecen fogones diferentes, separados entre sí. Por su extensión estos sitios pueden representar tanto eventos de reocupación de un mismo ambiente durante un cierto lapso (como en el caso de las reocupaciones estacionales, como creemos que ocurre en la localidad arqueológica Kami) o eventos de agregación por una actividad particular como lo demuestra la localidad arqueológica Ewan.

\begin{tabular}{|l|l|l|l|l|l|l|l|}
\hline Sitio & Cuadrícula & Sector & Muestra & \multicolumn{1}{|c|}{ Método } & Laboratorio & $\mathbf{N}^{\circ}$ & \multicolumn{1}{c|}{ Resultado } \\
\hline Ewan & & & Madera & Dendrocronología & CADIC & & Primavera 1905 \\
\hline Kami 1 & K 21 & NO & Carbón & Radiocarbono & LP & 2164 & $3210 \pm 80$ \\
\hline Kami 1 & K 21 & SO & Carbón & Radiocarbono & LP & 2163 & $1130 \pm 60$ \\
\hline Kami 1 & K 21 & NO & Carbón & Radiocarbono & LP & 2201 & $1170 \pm 60$ \\
\hline Kami 7 & J 17 & NO & Carbón & AMS & AA & 94284 & $1217 \pm 38$ \\
\hline Kami 7 & AT 17 & NO & Carbón & AMS & AA & 94285 & $178 \pm 34$ \\
\hline
\end{tabular}

Tabla 4. 1. Dataciones de los sitios Ewan I y II; Kami 1 y Kami 7. 


\section{Capítulo 5}

PROSPECCIONES Y ESTUDIO DISTRIBUCIONAL 


\section{INTRODUCCIÓN}

Uno de los objetivos de esta tesis es evaluar la gestión de los recursos que se encuentran presentes en el paisaje por parte de las sociedades cazadoras recolectoras que habitaron la faja central de la Isla. Por ello se consideró que un análisis de tipo distribucional (Thomas 1975; Foley 1981a; Dunnell y Dancey 1983; Ebert 1992) sería apropiado para tal fin, por los motivos que se detallan más adelante.

El uso de diversas escalas, espaciales y temporales, permite una visión más amplia de la distribución, y por lo tanto del uso del espacio, y del registro material que formó parte de las sociedades cazadoras recolectoras (Binford 1992; Belardi y García 1994; Belardi 2005).

Como se dijo en el capítulo 1, los rasgos esenciales que caracterizan a la zona del corazón de la Isla son el desarrollo de los cordones cordilleranos y del bosque subantártico, así como una muy baja visibilidad arqueológica que retrasó el inicio de los estudios arqueológicos. El objetivo de este capítulo es sintetizar los resultados del estudio distribucional del paisaje y las prospecciones de materias primas, así como actualizar la situación del registro arqueológico para esta zona. Para ello se toman los trabajos efectuados en el marco de esta tesis Doctoral durante los últimos cuatro años en la costa sur del lago Fagnano (laguna Bombilla, Palacios, laguna del Indio, desembocadura del río Valdez y bahía Torito) y en las lagunas Margarita, Aguas Blancas y laguna Negra, ubicadas hacia el sur y el este del lago Fagnano. Además los cursos inferior y superior de los ríos San Pablo, Azara, Láinez y EI Vasco.

A lo largo de este capítulo veremos que, a pesar de la diversidad de recursos que puedan presentar los ambientes, el acceso a las fuentes secundarias de aprovisionamiento lítico juega un papel central en relación a la distribución del registro arqueológico. 


\section{PAISAJE Y AMBIENTES}

La zona del centro de la Isla no es un área homogénea, sino que en ella se encuentran representados tres paisajes principales (cf. Mansur y De Angelis 2012). El primero es el de los cordones cordilleranos y valles intermedios, con turbales y depresiones ocupadas por lagos de origen glaciario, que se extiende hacia el sur del lago Fagnano. En cuanto a la vegetación, esta zona corresponde al bosque mixto (ver capítulo 1) con una especie perenne, el guindo o coihue ( $N$. betuloides), con estrato arbustivo, así como gramíneas y juncos en los fondos de valles. El segundo paisaje, de montañas y valles fluviales, se encuentra hacia el este; conserva estas mismas características principales, pero la vegetación cambia progresivamente a bosque caducifolio con abundantes valles de ríos que desembocan en la costa Atlántica. Finalmente, el paisaje de ecotono, presenta ondulaciones y colinas; se extiende desde la vertiente norte de la cordillera hacia el río Grande y corresponde a la zona de bosque caducifolio discontinuo de lenga o de ñire (N. antarctica), tipo Woodland (ver capítulo 1), con claros, vegas y valles amplios (Figura 5.1).

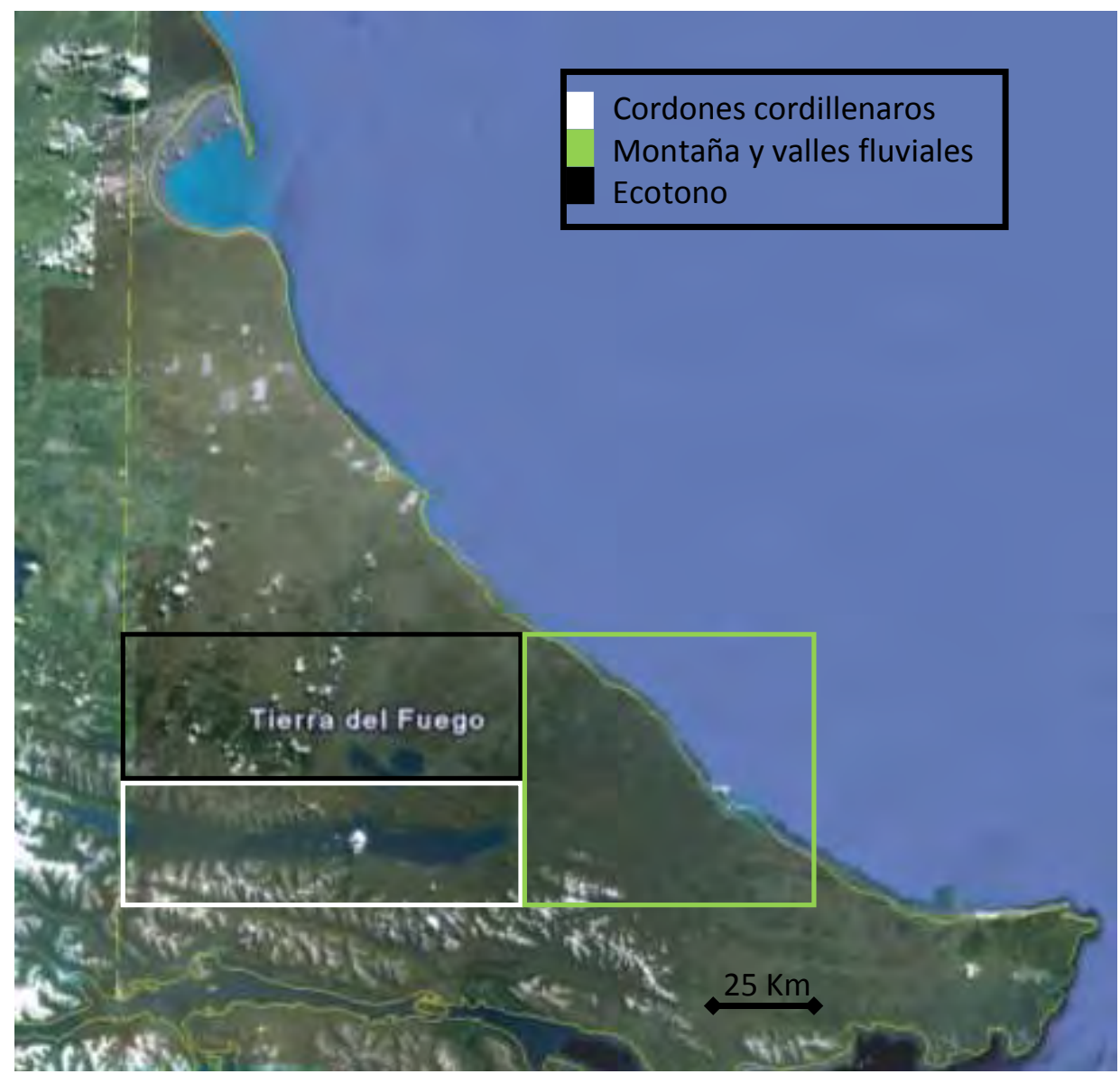

Figura 5. 1. Paisajes de la faja central de Tierra del Fuego. 


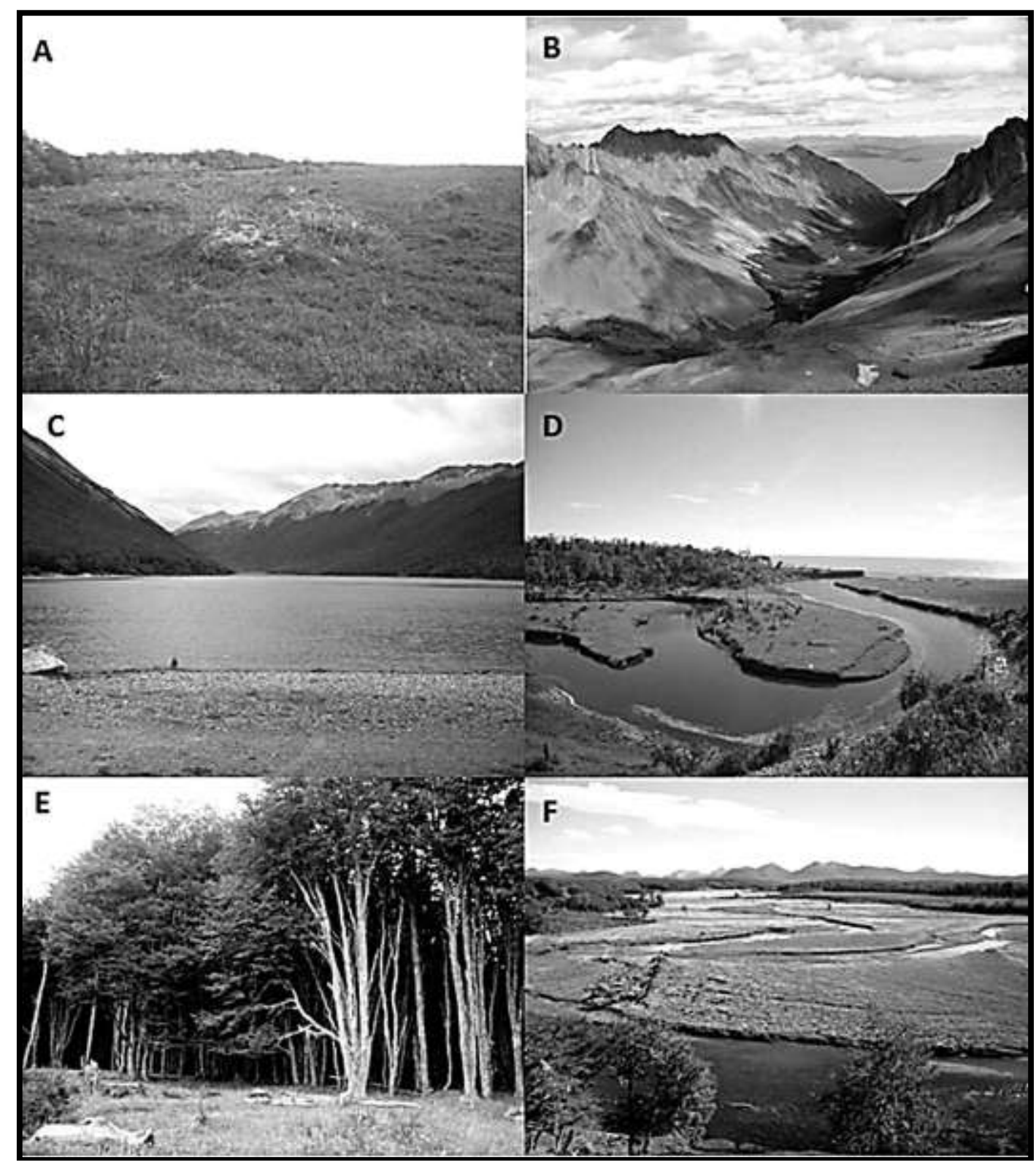

Figura 5. 2. Ambientes de la zona central de Tierra del Fuego. a- Turbal; bMontaña; c- Laguna Margarita; d- Desembocadura del río Azara hacia la costa Atlántica; e- Bosque de Nothofagus; f- Valle del río Láinez. (a y e zona de ecotono), (b y c zona cordillerana), (d y f zona de valles)

Como se mencionó en el capítulo 2, los suelos de la zona central de la Isla y por lo tanto de los tres paisajes mencionados, se caracterizan por su escasa potencia (10 a $40 \mathrm{~cm}$.) y están formados por una capa superficial de mantillo orgánico sobre otra basal compacta, que se desarrolla sobre sedimentos glaciarios. Son suelos ácidos calificados como "Acid Brown ground of the Forest", que están sometidos a procesos de congelamiento y descongelamiento (Tuhkanen 1992). 


\section{Procesos de formación del registro arqueológico}

Por las características climáticas y la vegetación de bosque, la superficie del suelo se recubre permanentemente de hojas que inician un proceso de descomposición. Además los suelos están surcados por raíces y otros factores de perturbación biogénica. Las posibilidades de conservación de materiales arqueológicos se ven limitadas por estos factores, principalmente por la acidez de los sedimentos de fondo de bosque que presenta un $\mathrm{pH} \geq 5$ (Bava 1998; Frangi et al. 2004; Moretto et al. 2005).

Otro factor perturbador es la acción de los animales como el conejo (Oryctolagus cuniculus) y el castor (Castor canadensis), introducidos a la Isla para su explotación. En la zona de estudio es el castor el que produce mayores cambios en la fisionomía del paisaje. A través de los trabajos de campo pudimos constatar la presencia de innumerables castoreras resultando en grandes espacios anegados con sectores de bosque muy deteriorados. La caída de árboles no sólo se produce por el trabajo de los castores sino que las zonas inundadas afectan de tal forma a los árboles que estos se terminan secando y cayendo.

Por todo ello, la visibilidad arqueológica es baja a muy baja, y en consecuencia la localización de sitios arqueológicos es tarea difícil que requiere de un programa con un enfoque distribucional el cual permite ampliar la escala espacial y redirigir la búsqueda hacia espacios con mejor visibilidad (Figura 5.3).

Para evaluar la intensidad y la distribución de ocupación de la zona boscosa del centro de la Isla Grande, se decidió iniciar un programa de registro sistemático del material arqueológico. Si bien es cierto que esta área presenta una escasa visibilidad arqueológica, también es cierto que al comprender amplios sectores lagunares, existen zonas donde la visibilidad aumenta considerablemente. Además, los sectores de lagunas asociadas a bosques presentan importantes recursos tanto en abundancia como en diversidad: agua, madera, fauna, afloramientos líticos, recursos vegetales; que consideramos fundamentales para llevar a cabo las actividades sociales, de subsistencia, producción, etc. de los grupos cazadores-recolectores que habitaron el centro de la Isla. 


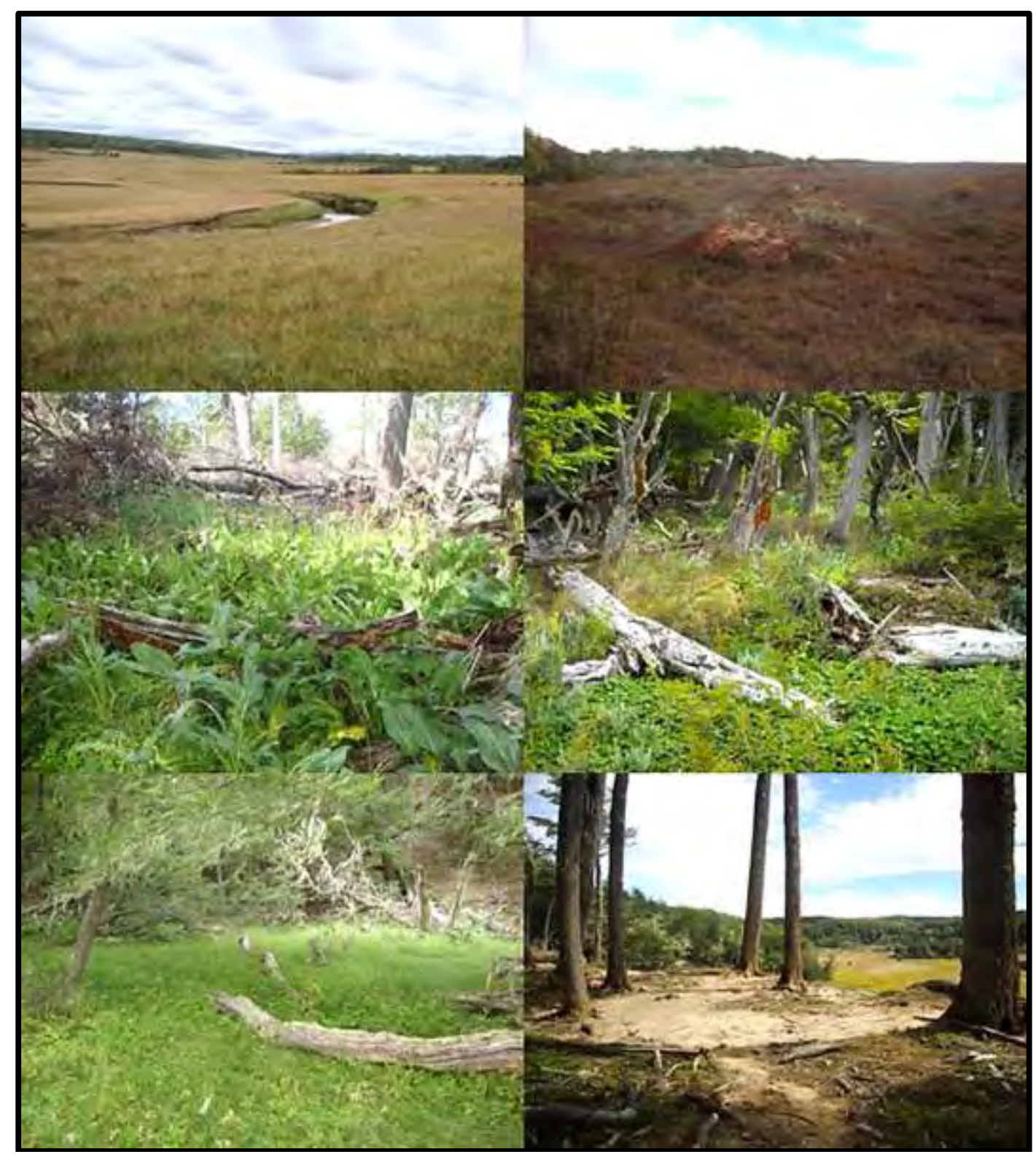

Figura 5. 3. Cobertura vegetal del centro de la Isla. Arriba pastizales de ambiente fluvial (visibilidad baja). Centro vegetación de zonas anegadas (visibilidad muy baja). Abajo bosque en zona aledaña al valle (visibilidad intermedia).

\section{Las materias primas líticas}

Uno de los aspectos determinantes para la configuración de los conjuntos arqueológicos es la materia prima lítica. Es cierto que las materias primas de buena calidad para la talla, tales como riolitas de grano medio y fino, cineritas, limolitas silicificadas, son medianamente abundantes en la región, pero sin embargo su distribución no es ubicua sino localizada, lo que dificulta su ubicación y extracción. En forma de guijarros, se encuentran en los depósitos de drift glaciario, que tienen variados niveles de redistribución en 
relación con los sistemas hidrológicos (Borrero 1998). Por ello, en la práctica, como se mencionó, las principales fuentes de materias primas las constituyen los guijarros modelados por acción glacifluvial, que se encuentran en pequeños sectores de playas del lago Fagnano y de la costa atlántica. Es probable que la obtención y transformación de esta materia prima haya revestido un importante rol en la planificación de los desplazamientos y selección para el establecimiento de los cazadores recolectores que ocuparon toda la zona de la faja central de Tierra del Fuego (Mansur et al. 2010).

\section{MUESTREO DE MATERIAS PRIMAS}

El objetivo de llevar a cabo un muestreo de materias primas en los diversos ambientes se entiende por la importancia que toma este recurso para la presente tesis. El muestreo sistemático de materias primas se orientó principalmente a conocer la posibilidad de acceso a las fuentes de aprovisionamiento y a testear la calidad de las rocas para la talla en dichos afloramientos (Aragón y Franco 1997).

Para llevarlo a cabo se efectuaron muestreos cada vez que las transectas interceptaban lugares con guijarros cuyos tamaños permitiesen la talla por percusión directa (mínimo $10 \mathrm{~cm}$ de largo) (Figura 5.7). Estos consistieron en el planteo de un sector de un metro cuadrado. En cada uno de ellos se tomaron 10 nódulos al azar, se procedió a la talla in situ de los nódulos y el registro de sus características, junto con la toma de las muestras de materia prima para generar una base de materias primas líticas de la zona en estudio. La talla se efectuó en todos los casos con percusión directa.

Las fuentes de aprovisionamiento corresponden todas a fuentes secundarias, generadas por la redepositación glaci-fluvial. Es por ello que en general se trata de guijarros redondeados, de diversas materias primas, ya que provienen de diferentes formaciones geológicas. Estas fuentes se encuentran emplazadas en las orillas de los ríos, que en esta zona son de carácter meandroso (Figura 5.4 y 5.5), lo cual permite que existan sectores de acumulación de guijarros de tamaños aptos para la talla por percusión directa; en las orillas de lagos y lagunas también pueden encontrarse sectores con presencia de guijarros con características similares (Figura 5.6). 
Los resultados obtenidos permitieron comenzar a generar datos en cuanto a disponibilidad y características de la materia prima disponible. En primer lugar, con respecto a las materias primas, la riolita es predominante en todos los casos. En cantidades mucho menores aparecen las pizarras. En cuanto a ambos tipos de emplazamientos, orilla de ríos o lagunas, si bien ambos presentan sectores con guijarros potencialmente utilizables para la talla, es en las orillas de lagos o lagunas donde se pudieron identificar las fuentes con mayor facilidad. Además, en ellos los guijarros presentaron mejor calidad para la talla en una relación de 7 a 3 , mientras que en las fuentes asociadas a los ríos la relación es un poco menor tal vez de 5 a 5 , entre guijarros de buena y mala calidad para la talla. En cuanto a los ríos, las fuentes potenciales de materias primas se encontraron más fácilmente, con materiales de mayores dimensiones y calidad para la talla en el curso superior, mientras que en los últimos $5 \mathrm{~km}$ (exceptuando la desembocadura) los depósitos rocosos presentan guijarros muy pequeños impidiendo la talla por percusión directa, incluso en algunos sectores los tamaños tampoco permitirían talla bipolar. Estas características se relacionan directamente con la baja visibilidad de estas fuentes (Tabla 5.1).

\begin{tabular}{|l|l|l|r|r|r|}
\hline \multicolumn{3}{|c|}{ Emplazamiento } & \multicolumn{3}{c|}{ Calidad } \\
\hline Tipo & \multicolumn{1}{|c|}{ Ubicación } & Fuente & Buena & Regular & Mala \\
\hline Lago & Kami 1 & Secundaria & 6 & 4 & 0 \\
\hline Lago & Kami 7 & Secundaria & 4 & 4 & 2 \\
\hline Lago & Sur 54 & Secundaria & 4 & 4 & 2 \\
\hline Lago & Bahia Torito & Secundaria & 2 & 4 & 4 \\
\hline Laguna & Laguna Negra & Secundaria & 7 & 3 & 0 \\
\hline Laguna & Laguna Margarita & Secundaria & 5 & 3 & 2 \\
\hline Lago & Río Valdéz & Secundaria & 7 & 2 & 1 \\
\hline Rio & San Pablo sup. & Secundaria & 3 & 4 & 3 \\
\hline Rio & Lainez sup. & Secundaria & 2 & 3 & 5 \\
\hline Rio & Irigoyen Sup. & Secundaria & 2 & 4 & 4 \\
\hline Total & & & 42 & 35 & 23 \\
\hline
\end{tabular}

Tabla 5. 1. Muestreo de Materias primas según los ambientes 


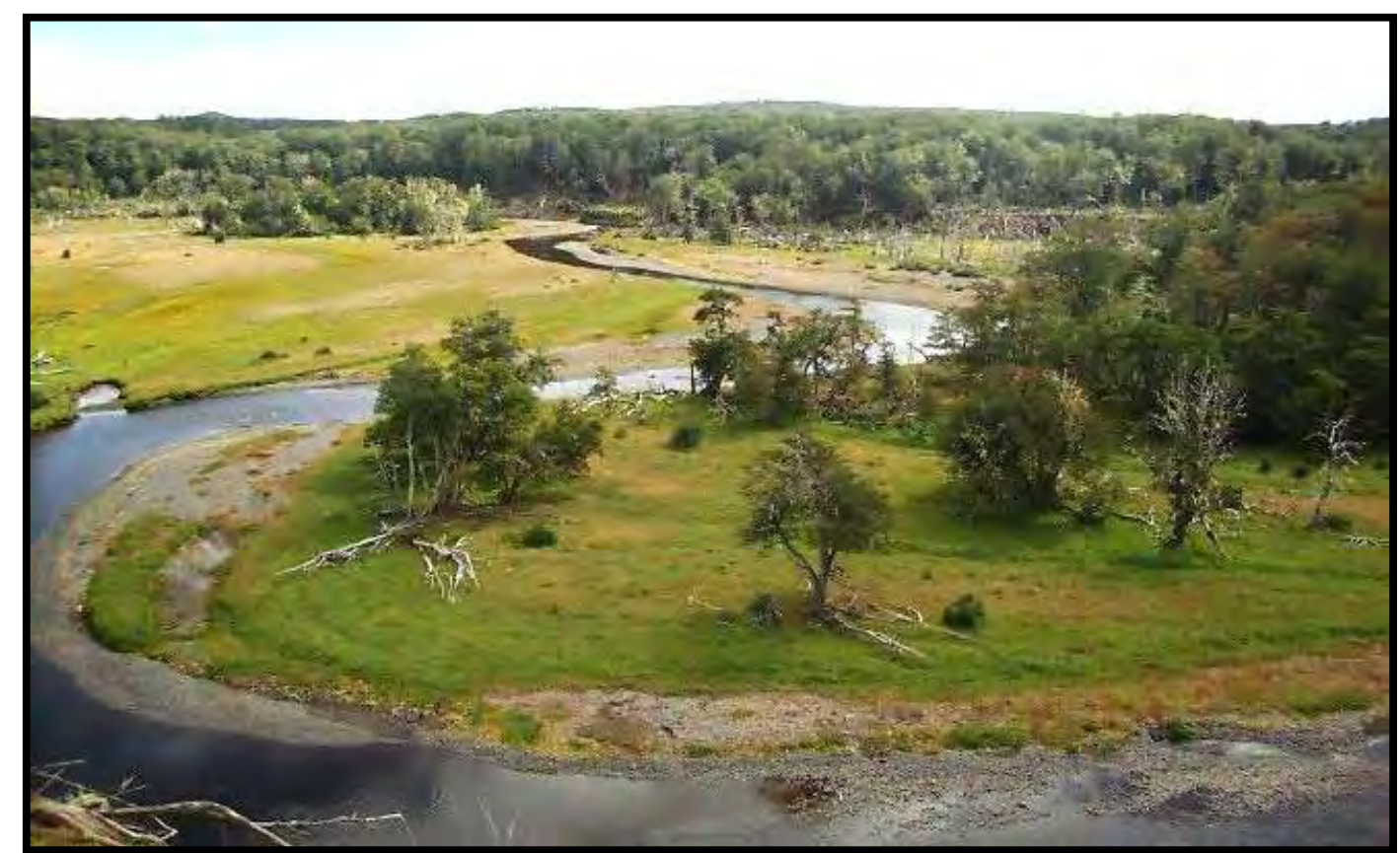

Figura 5. 4. Visual del valle del rio Irigoyen con sector de acumulación de guijarros

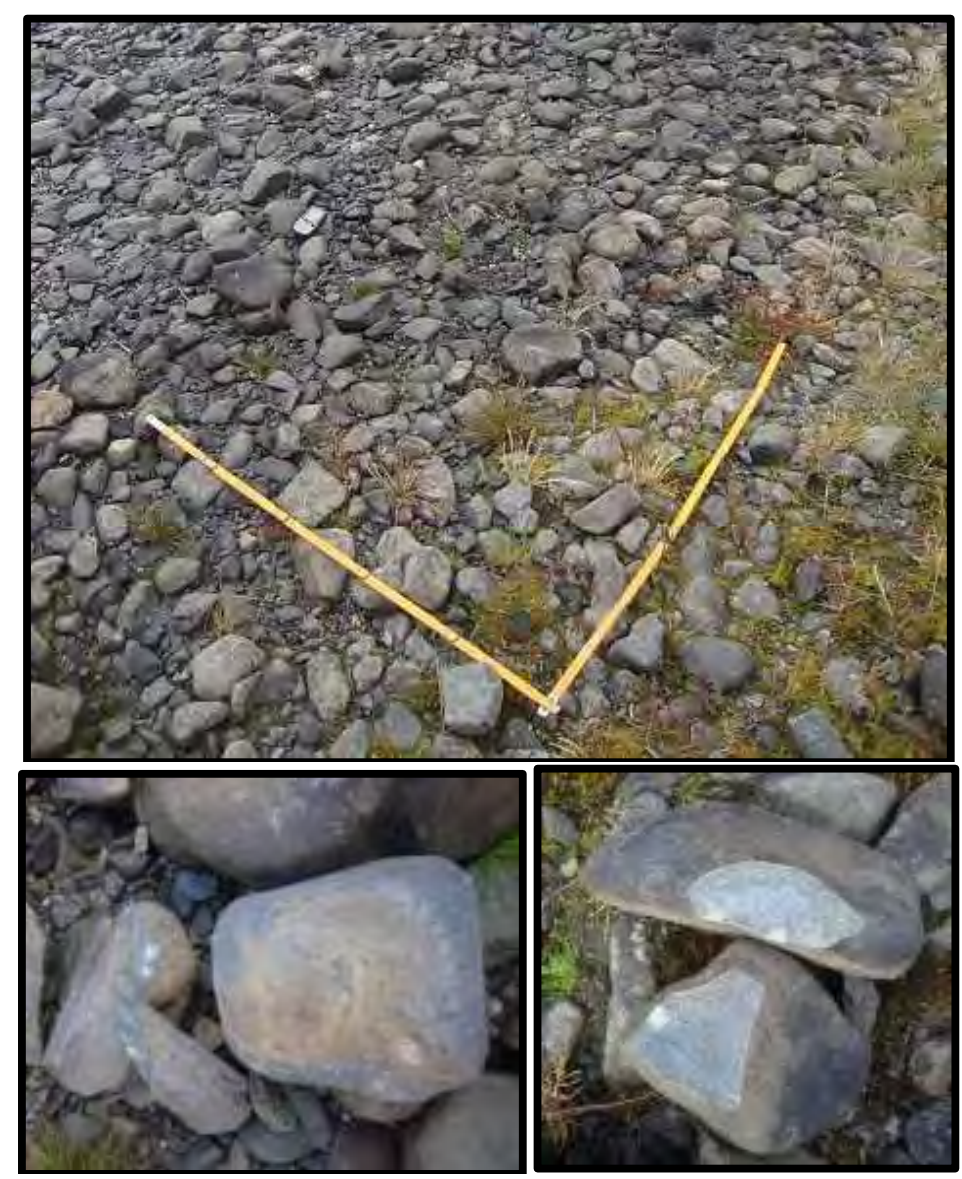

Figura 5. 5. Detalle de testeo de materias primas; Arriba: sector de 1x1 m; Abajo izquierda: pizarras; derecha: riolita 


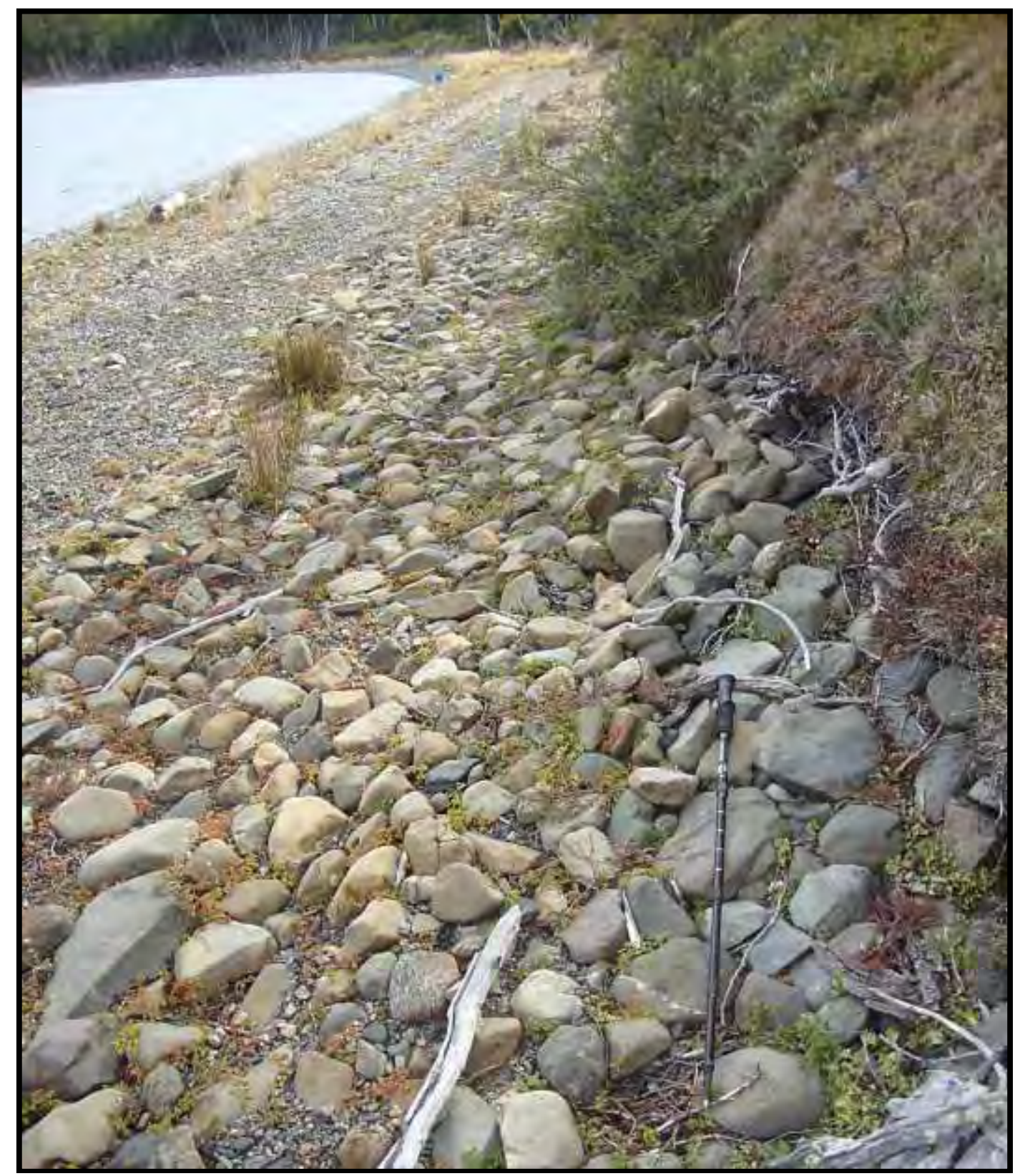

Figura 5. 6. Laguna Negra, costa norte con acumulación de guijarros

\section{ESTUDIOS DISTRIBUCIONALES}

La zona de estudio se caracteriza por la presencia de escasos espacios con media o buena visibilidad arqueológica, ello es así por el tipo de vegetación, las características de los suelos de bosque, la perturbación de las especies introducidas que generan constantes cambios en la fisionomía del paisaje generando amplios espacios de bosques muertos con abundante caída de árboles y zonas anegadas. Por todo ello, se decidió relevar el área de 
estudio partiendo de los postulados del enfoque distribucional (Thomas 1975; Foley 1981a; Dunnell y Dancey 1983; Ebert 1992).

El enfoque distribucional ve el registro como una distribución continua pero con picos en su densidad, con lo cual la variabilidad en la densidad de artefactos será el reflejo del carácter y la frecuencia de utilización del espacio (Belardi y García 1994; Belardi 2005). Así, es posible que exista una correlación entre espacios con alta densidad de material arqueológico y lugares con mayor concentración de recursos, disminuyendo la densidad donde los recursos no son críticos, o se encuentran muy separados unos de otros, o bien son muy escasos.

Para poder abarcar un estudio de este tipo puede plantearse como punto de partida la determinación de diversos rasgos del paisaje, en relación con las sociedades humanas, (Wandsnider 1998; Anschuetz et al. 2001) y jerarquizarlos según la diversidad y frecuencia de recursos que comprenda cada uno. Por ello, para desarrollar el estudio distribucional en la zona, se propuso abarcar la mayor diversidad de ambientes dentro de los paisajes mencionados anteriormente: en sectores cordilleranos, en sectores de bosque, y aquellos ambientes de valle asociados directamente con cuerpos de agua (ríos, lagos y lagunas).

En cuanto a la metodología de campo, se plantearon transectas de $5 \mathrm{~km}$ de longitud, con una separación de 5 metros entre las personas. En las mismas se registraron recursos bióticos y abióticos principales, así como la existencia de materiales arqueológicos y evaluación de la visibilidad arqueológica. Esta fue considerada una primera instancia, por lo tanto no se realizaron sondeos; sin embargo en los casos de hallazgo de materiales arqueológicos sí se llevaron a cabo recolecciones sistemáticas de los materiales presentes en la superficie. Como se mencionó en el capítulo 3 la recolección sólo se llevó a cabo de forma completa cuando los materiales corrían algún riesgo de pérdida, ya sea por hallarse en los bordes de los barrancos o por hallarse sobre caminos transitados. En caso contrario, sólo se procedió a realizar un muestreo del material de superficie, que permitiera tener un panorama general de materias primas, tipos de artefactos, etc.

En los lugares asociados a los espacios donde se desarrollan las transectas, en los cuales afloran guijarros, se procedió a realizar los testeos de 
materia prima antes mencionados, para determinar las calidades que presentaban estas para la talla. De la misma manera se relevó la presencia de guanacos en cada salida de campo, los cuales se pudieron ver en general en todas las salidas, principalmente en las zonas de valle y ecotono; en menor medida en la zona cordillerana. En relación a los recursos vegetales, dada la altura del año, verano, pudo constatarse la presencia de bayas comestibles como calafate (Berberis buxifolia), en las tres zona por igual; también murtilla (Empetrum sp.), principalmente en las zonas de turbales; chaura (Pernettya $s p$ ) en las zonas de borde de bosque mixto, además del apio silvestre (Apium australe) ampliamente distribuído en los ambientes húmedos y frutilla silvestre. Los hongos comestibles también estaban presentes en abundancia, principalmente los champiñones y el pan de indio (Cyttaria harioti). Sin embargo uno de los recursos que más abunda en la zona de estudio es el agua dulce, la cual se presenta a través de lagos, lagunas, ríos, arroyos y chorrillos.

\section{RESULTADOS}

Como mencionamos anteriormente, podemos dividir al área de estudio en tres ambientes con diferencias bien marcadas. Por un lado, el ambiente de ecotono, ubicado a grandes rasgos al norte del lago Fagnano; en segundo término el ambiente de cordillera ubicado sobre la costa sur del mismo lago, y finalmente el ambiente de valles y bosque ubicado al este del lago y que llega casi hasta la costa Atlántica (Mansur et al. 2010).

La investigación comprendió sectores lagunares, sectores de bosque, sectores próximos a la costa marina y márgenes de ríos (Figura 5.7). 


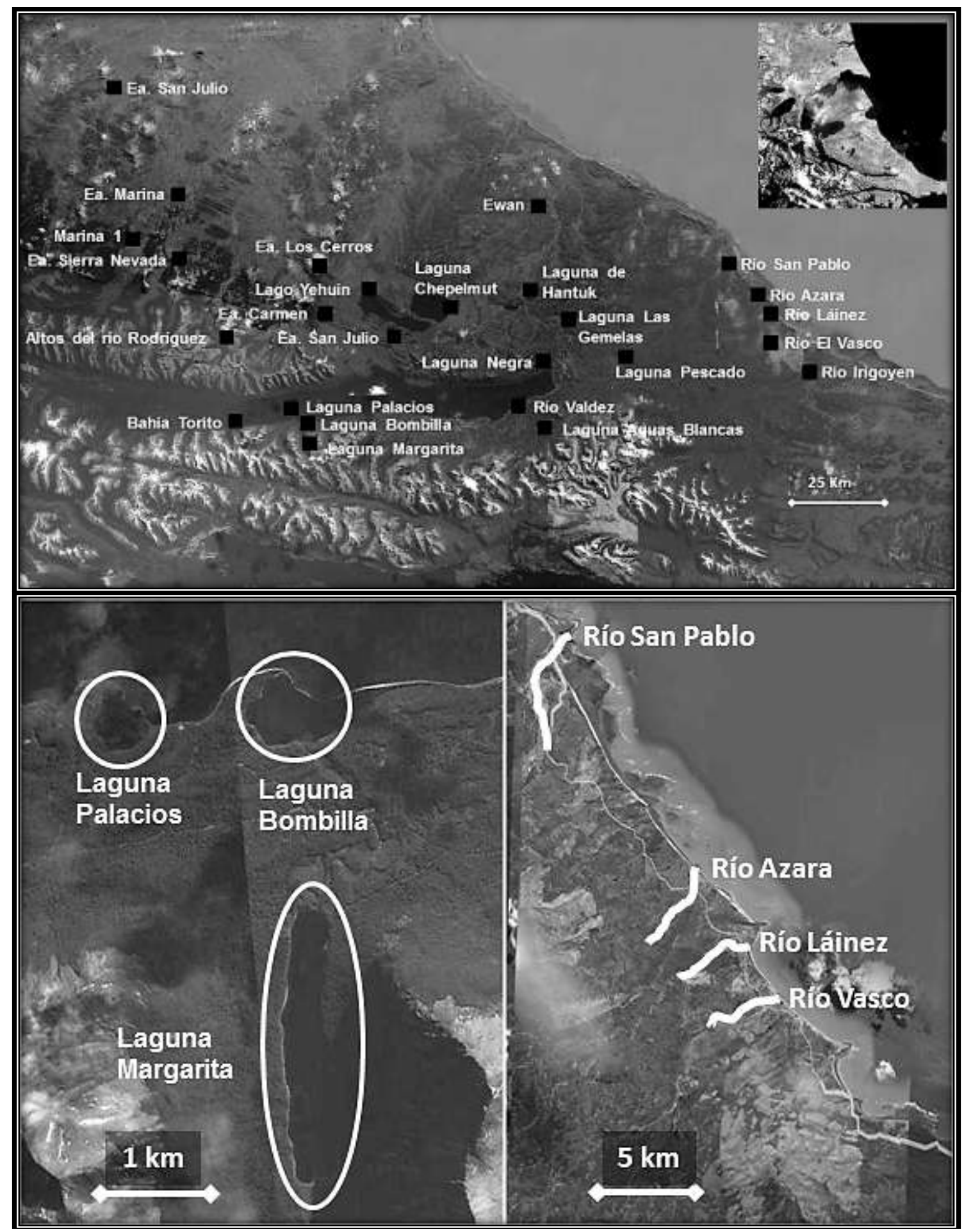

Figura 5. 7. Arriba, distribución del material arqueológico. Abajo izq. transectas en lagunas; der. Transectas en curso inferior de ríos que desembocan en el Atlántico.

\section{Espacios Lagunares}

El retroceso de los glaciares, hace aproximadamente 10.000 años, fue dejando a su paso un gran número de lagos y lagunas de agua dulce, como por ejemplo el lago Fagnano; pero también originó una gran cantidad de rocas 
resultado del desprendimiento de las diversas Formaciones geológicas, en forma de guijarros.

\section{Laguna Aguas Blancas}

(Figura 5.7)

La laguna Aguas Blancas se encuentra a unos $7 \mathrm{~km}$ de la costa sur del lago Fagnano y a no más de cuatro km del cerro JeuJepen. La laguna es alimentada por el arroyo López; la misma presenta una forma arriñonada con un largo máximo de un $\mathrm{km}$ y un ancho de $40 \mathrm{~m}$ aproximadamente.

A lo largo de la costa hay un pequeño turbal que luego se continúa con bosque cerrado, interrumpido por una castorera y también por sectores abiertos con pastizales (Figura 5.8).

En cuanto a la presencia de recursos líticos, las costas presentan diversos espacios donde se pueden ver guijarros de diversos tamaños, incluso muy grandes, llegando a superar los $50 \mathrm{~cm}$, cuyas características para la talla son muy diversas. Podemos encontrar guijarros desde muy mala a buena calidad para la talla (Nami 1992; Aragón y Franco 1997; Andrefsky 1998; Ratto y Nestiero 1998).

Sobre la costa sur, lugar donde se encontró la mayor concentración de guijarros de gran tamaño y donde se efectuaron dos hallazgos aislados, se decidió, dadas estas características, desarrollar una serie de transectas de 50 $\mathrm{m}$ de largo y separadas unas de otras por $5 \mathrm{~m}$, con orientación N-S. El largo de la costa permitió el planteo de 40 transectas que dieron como resultados dos hallazgos aislados. En ambos casos se trata de núcleos de riolita prácticamente agotados (Tabla 5.2 y 5.3). 


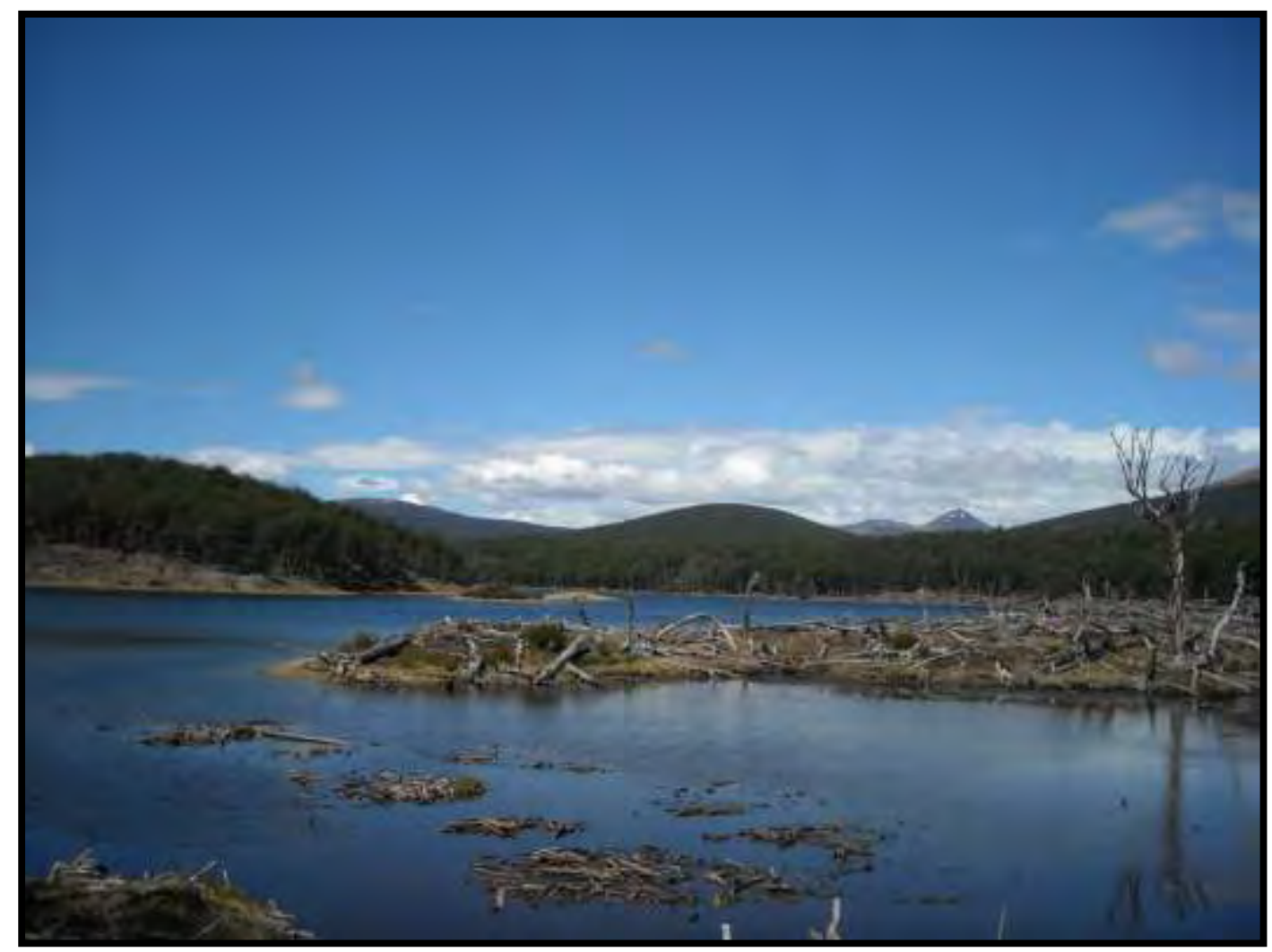

Figura 5. 8. Vista general de la laguna Aguas Blancas

\section{Laguna Margarita}

(Figura 5.7)

La laguna Margarita se encuentra ubicada muy cerca del lago Fagnano, hacia el $\mathrm{S}$ a una distancia de $1,5 \mathrm{~km}$, en la base del valle con orientación N-S formado por dos elevaciones pertenecientes a las sierras de Alvear. La misma presenta una longitud máxima de $2,5 \mathrm{~km}$ y su ancho alcanza los 0,4 km aproximadamente.

La laguna se encuentra rodeada de bosque con sectores de playas suaves, donde se pudieron documentar guijarros o rodados glaciarios de gran tamaño de diversas calidades para la talla (Figura 5.9) (Nami 1992; Aragón y Franco 1997; Andrefsky 1998; Ratto y Nestiero 1998).

Se realizaron tres hallazgos aislados en los sectores elevados ubicados al $\mathrm{N}$ y NE de la laguna, separados unos de otros por varios metros. Los mismos estaban representados por una raedera fracturada en dos partes que se encontraban juntas y dos raspadores de gran tamaño (Tabla 5.2 y 5.3). 


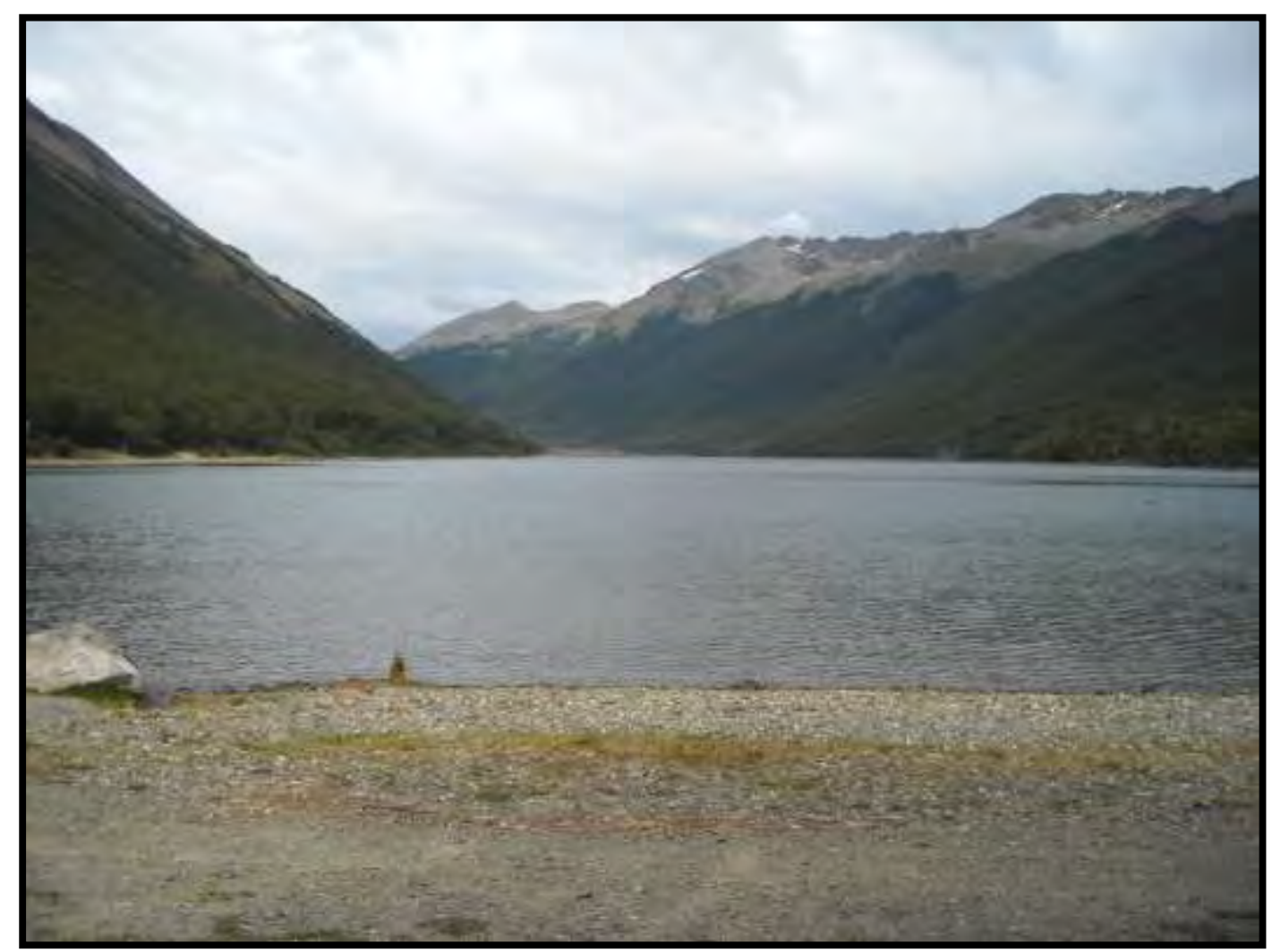

Figura 5. 9. Vista general de la laguna Margarita

\section{Laguna Negra}

(Figura 5.7)

Es una laguna que se encuentra ubicada entre los ríos Láinez e Irigoyen, aunque más cercana a este último. La misma tiene un largo máximo de 1,7 km, un ancho de $1,2 \mathrm{~km}$ y una circunferencia de $5 \mathrm{~km}$. Una de sus márgenes se encuentra completamente ocupado por el camino que permite el acceso al río Irigoyen, ubicado hacia el sureste (Figura 5.10).

Ésta laguna al igual que las demás recorridas, presenta diversidad en sus costas, algunas con rodados de gran tamaño y de diversas calidades para la talla, otras con sedimentos más finos, tipo arena gruesa, otros con barrancas cubiertas por bosque alternadas con turbales y finalmente sectores alterados por la presencia de castores.

Sobre la costa que presentaba barrancas cubiertas por bosque se halló material arqueológico en superficie, se trata de una raedera y a unos metros de ella una lasca (Tabla 5.3). 


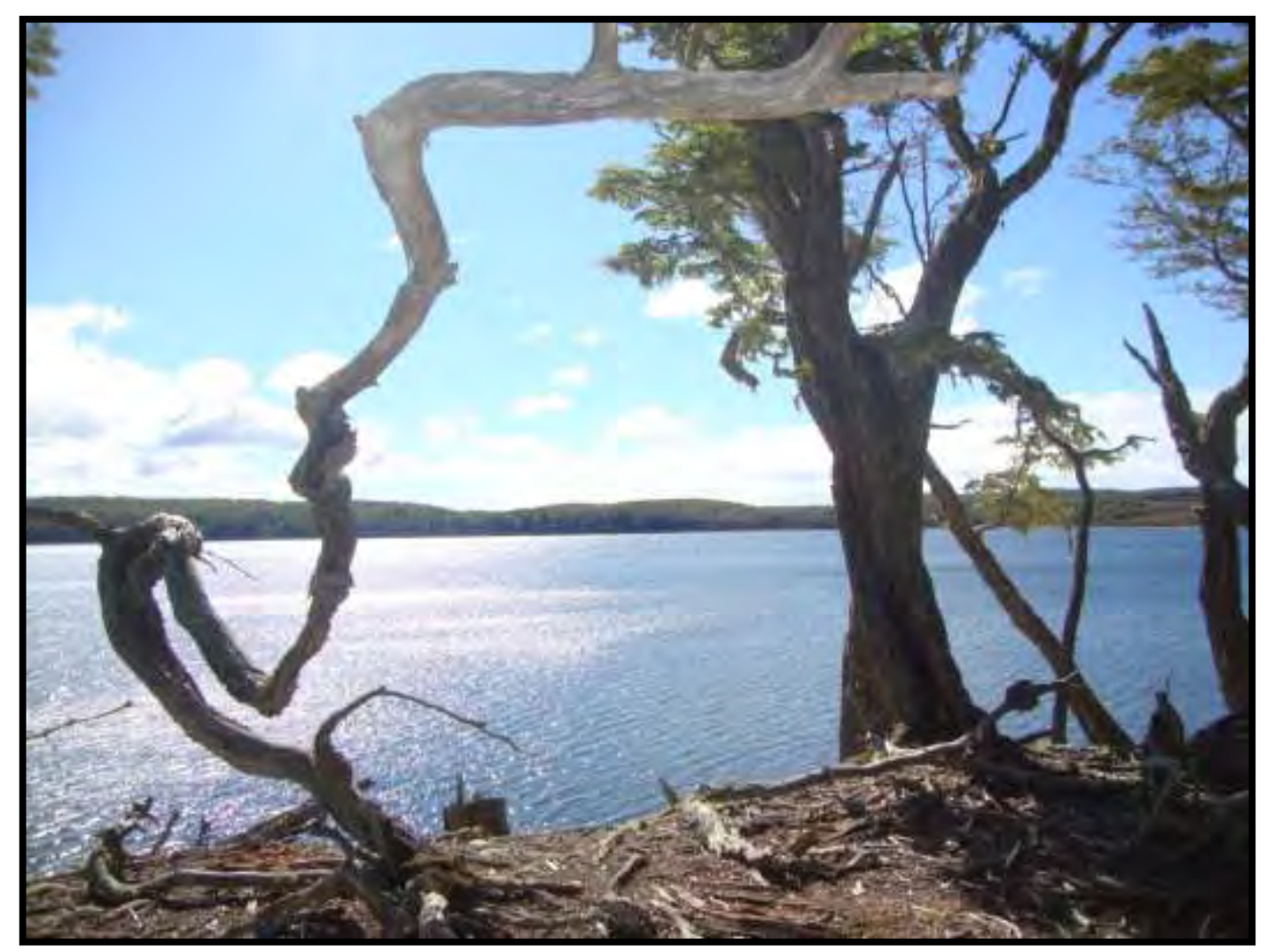

Figura 5. 10. Vista general de la laguna Negra

\section{Costa sur del lago Fagnano}

(Figura 5.7)

A lo largo de la costa sur del lago Fagnano pudimos reconocer una importante serie de concentraciones de material arqueológico en cada transecta. Cada una de ellas reveló tanto sitios como hallazgos aislados.

Por ello es que a continuación se presenta el trabajo realizado en este sector con diferentes nombres y se los muestra individualmente (Tabla 5.2 y $5.3)$.

\section{Desembocadura del Río Valdez}

(Figura 5.7)

Se trata de un sector sobre una barranca del lago Fagnano, hacia el oeste de la desembocadura del rio Valdez, a unos $15 \mathrm{~km}$ de la ciudad de Tolhuin, que funciona como mirador, y donde el In.Fue.Tur tiene previsto el emplazamiento de una pasarela, a fin de minimizar el impacto antrópico sobre el lugar. En él se realizó una evaluación de impacto arqueológico, en la cual se 
detectaron materiales sobre la superficie del terreno: dos instrumentos líticos (una raedera y un raspador, ambos confeccionados en riolita), un núcleo (confeccionado en limolita litificada) y un fragmento óseo, epífisis distal de metapodio de guanaco (Lama guanicoe), que no corresponde a un elemento óseo moderno, sin embargo, dado el contexto del hallazgo no se puede confirmar que formara parte de un contexto arqueológico. El estado de conservación de los materiales no sugiere que los mismos hayan sufrido transporte por acciones naturales (tal como rodamiento en sedimentos) ni alteraciones por procesos intensos (Tabla 5.2).

El área total que abarca la transecta planteada para el relevamiento va desde la laguna del Indio (Figura 5.11) hasta el arroyo Guanaco. Junto con los materiales que se encontraban en la parte del mirador, a lo largo de toda la transecta fueron apareciendo concentraciones de material arqueológico, únicamente lítico, representado por lascas $n=17$, núcleos $n=2$; raedera, fragmento de instrumento, y raspador $n=1$; como así también elementos menores a $2 \mathrm{~cm}$, lasquitas $\mathrm{n}=7$ y debris $\mathrm{n}=2$ (Tabla 5.3 ).

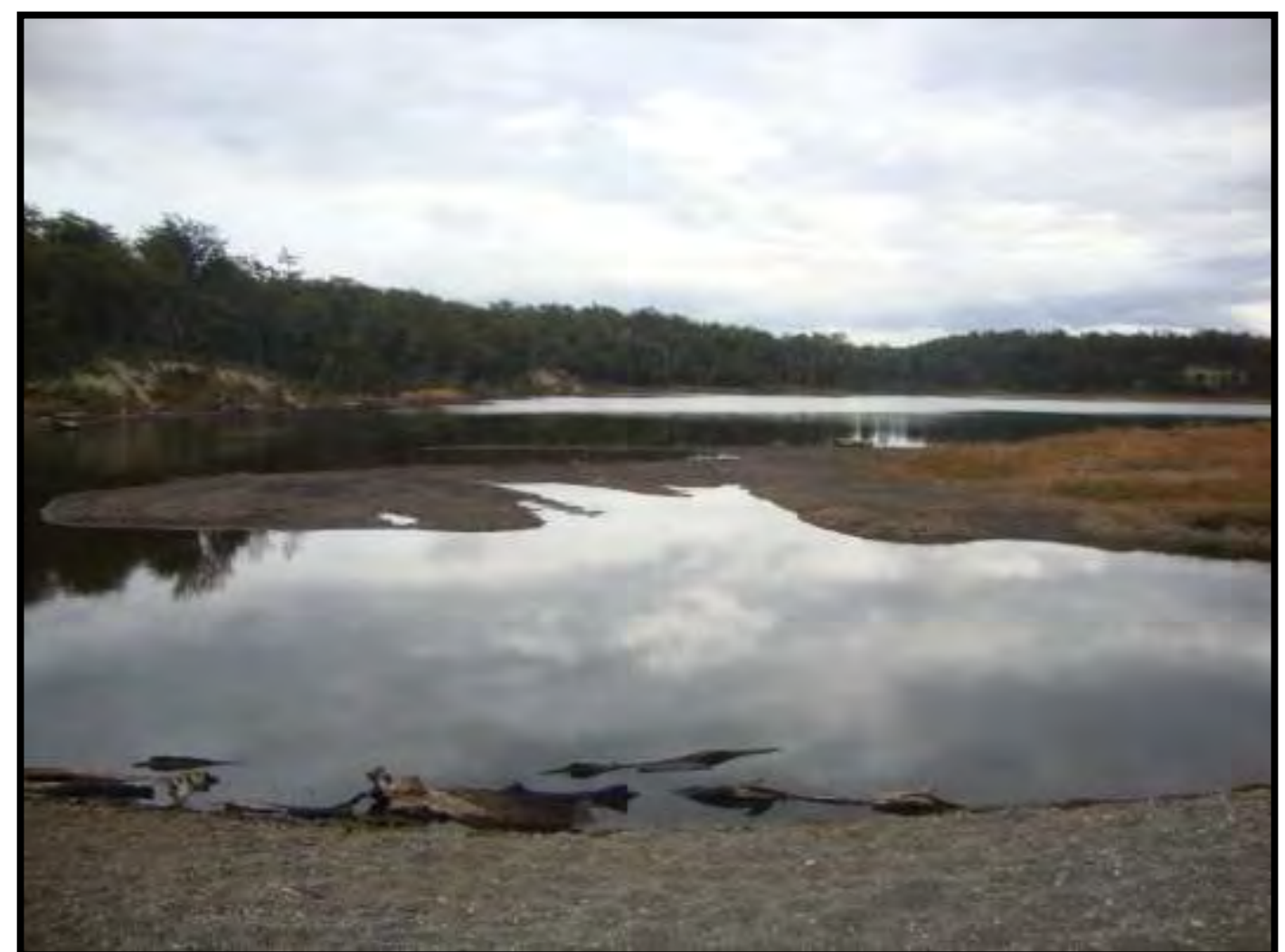

Figura 5. 11. Vista de la laguna del Indio cercana a la desembocadura del río Valdés 


\section{Laguna Bombilla}

(Figura 5.7)

La laguna Bombilla se encuentra ubicada sobre la margen sur del lago Fagnano. En la zona se vienen desarrollando trabajos de prospección y excavación desde el año 2007 (Figura 5.12) (Mansur et al. 2010).

Presenta una longitud máxima N-S de 0,6 km y E-O de $1 \mathrm{~km}$ aproximadamente. Se caracteriza por el desarrollo de una espiga donde comienza a crecer vegetación, que la separa del lago Fagnano, aunque existe un espacio abierto debido a un menor espesor de la espiga mencionada, como si se sumergiera en el lago.

El bosque se encuentra rodeando la laguna, aunque el paisaje está bastante alterado por el paso constante de vehículos y porque es utilizado como lugar de campamento por eventuales visitantes.

El sector interno de la playa de la laguna tiene costas con guijarros de diversos tamaños, desde muy chicos $(-2 \mathrm{~cm}$ ) hasta grandes bloques (+ de 50 $\mathrm{cm}$ ), aunque existen sectores de playa sin guijarros, conformada sólo con arena y piedras muy pequeñas.

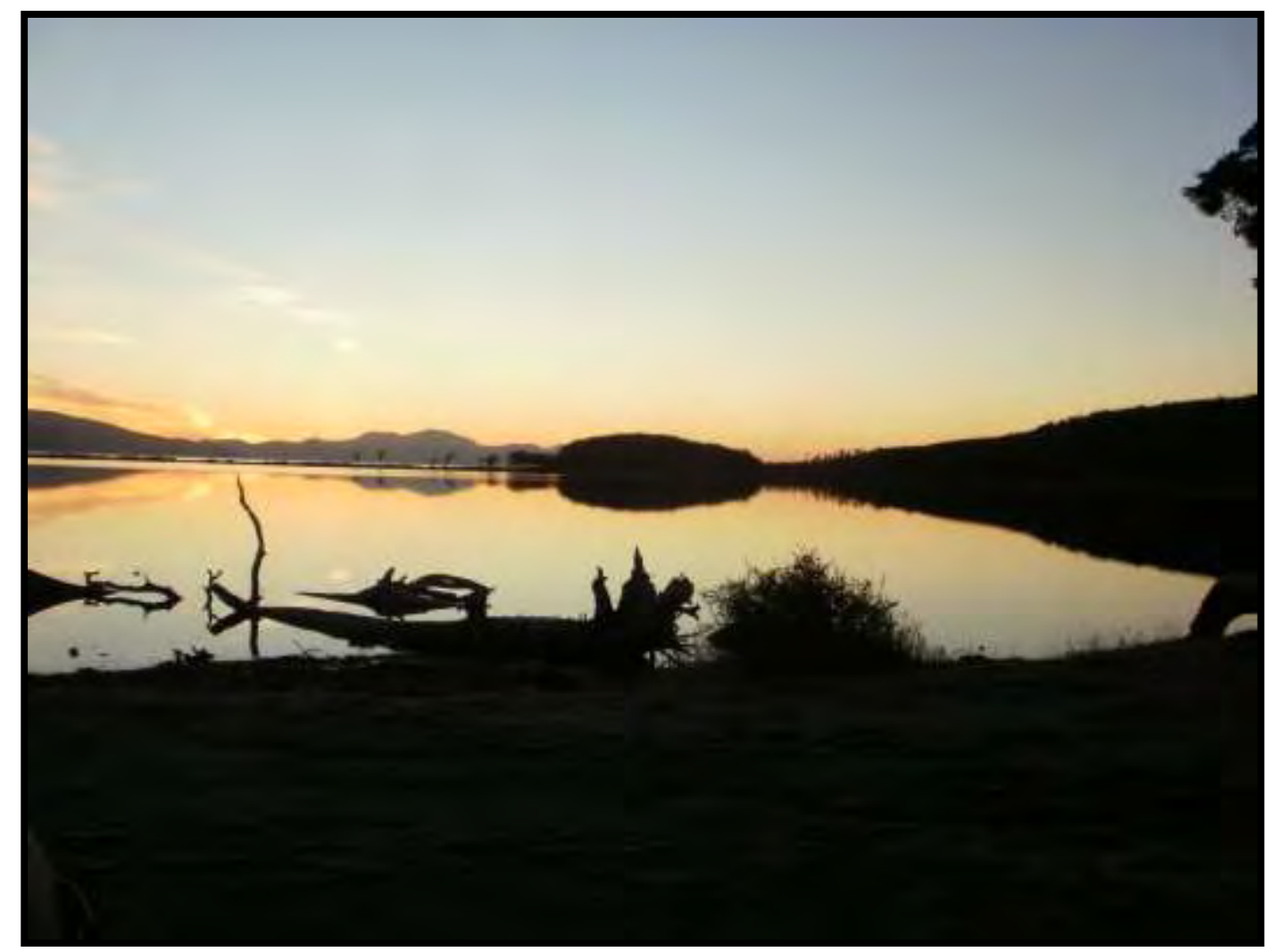

Figura 5. 12. Vista general de la laguna Bombilla 
El trabajo permitió detectar diferentes sectores con presencia de material arqueológico. Dos de las concentraciones menores se encuentran sobre la costa Este de la laguna (Kami 2 y Kami 3). Estas no presentaban una alta frecuencia de material arqueológico en superficie. Sin embargo, el sector de costa que se encuentra sobre la barranca, que forma parte de la espiga (Kami $6)$, presenta una dispersión y frecuencia muy alta de material, principalmente lítico. En cuanto al material óseo, se recuperaron dos posibles retocadores de hueso, uno confeccionado sobre una epífisis distal de metapodio de guanaco y otro sobre un hueso largo de guanaco (Figura 5.13). El primero corresponde al sector de costa final (costa Fagnano) y el otro al sector costa Este.
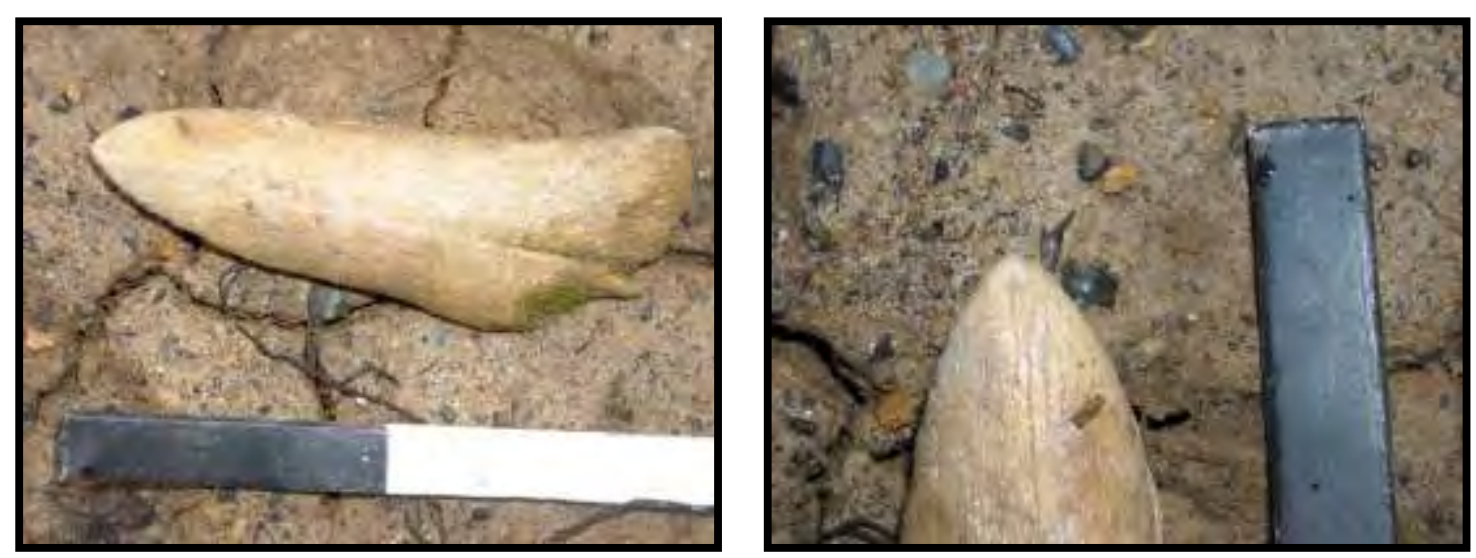

Figura 5. 13. Posibles retocadores de hueso, confeccionados sobre epífisis distal de metapodio de Lama guanicoe.

Hacia el oeste de esta laguna, sobre la costa del lago Fagnano, se encuentra el sitio Kami 1, excavado durante las campañas del 2009 y 2010 (Mansur et al. 2010), y las concentraciones superficiales Kami 4 y Kami 5 (Tabla 5.2 y 5.3 ).

\section{Laguna Palacios}

(Figura 5.7)

La laguna Palacios está ubicada sobre la costa sur del lago Fagnano, rodeada por bosque y por turbales. Al igual que el caso anterior, esta laguna se caracteriza por la presencia de una espiga en el sector NE que la separa, aunque no completamente, del lago Fagnano (Figura 5.14). Sus dimensiones son menores, con un largo de 0,5 km y un ancho similar de 0,48 km. 
Hasta el momento no se ha descubierto material arqueológico en la parte interna de la laguna. Sin embargo sobre la parte elevada de la espiga (sector oeste de la laguna), sobre el lago Fagnano, comienzan una serie de concentraciones de material que se extienden por unos 15 metros aproximadamente.

Hacia el oeste la barranca se corta por una pequeña playa de guijarros, con un pequeño turbal hacia atrás, para continuar con una costa más elevada, boscosa, donde se pudieron identificar diversas concentraciones de material lítico denominadas Kami 7 (Parmigiani et al. 2012) (Tabla 5.2 y 5.3).

A menos de un kilómetro hacia el oeste de Kami 7, sobre la costa del lago Fagnano, otra concentración de artefactos líticos da nombre a Kami 8. Por varios metros aparecen restos líticos asociados, otra vez, a una playa de guijarros. El testeo de los guijarros mostró varios de buena calidad para la talla. El sector de bosque asociado con estos materiales había sufrido un incendio lo que produjo una ventana arqueológica amplia con muy buena visibilidad. Los materiales son principalmente restos de talla (Tabla 5.2 y 5.3).

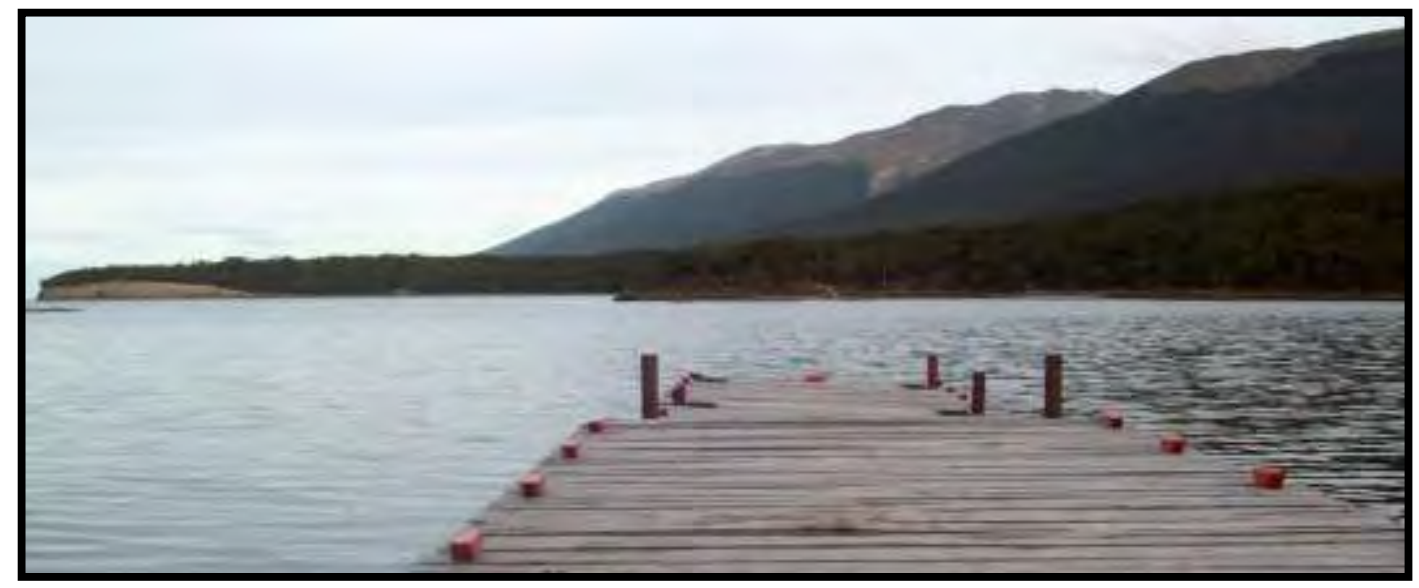

Figura 5. 14. Vista general de la laguna Palacios

\section{Bahía Torito}

(Figura 5.7)

De las áreas relevadas hasta el momento es la que se encuentra más hacia el oeste. Se trata de un sector de la costa sur del Fagnano con muy difícil acceso, ya que sólo se puede llegar o bien navegando a lo largo de la costa, o por un sendero que la conecta con la costa sur de la isla, por el que se demoran dos días para llegar (Figura 5.15). A partir de información oral sobre 
existencia de material arqueológico en superficie en algunos sectores cercanos a la bahía, se decidió realizar una primera prospección al lugar. En su transcurso se recorrieron tanto la franja a lo largo de la costa del lago como un sendero hacia el interior del bosque. En ambos pudo constatarse la existencia de material arqueológico, hasta el momento sólo lítico (Tabla 5.2 y 5.3).

En una segunda visita al lugar se amplió la transecta hasta completar los $5 \mathrm{~km}$. El objetivo de esta visita fue evaluar el impacto de un gran incendio forestal que afecto al menos 2000 has. Si bien el material reconocido dentro de la transecta es muy numeroso, sólo se tomaron algunas muestras para complementar las obtenidas la vez anterior. El material arqueológico supera ampliamente el recolectado.

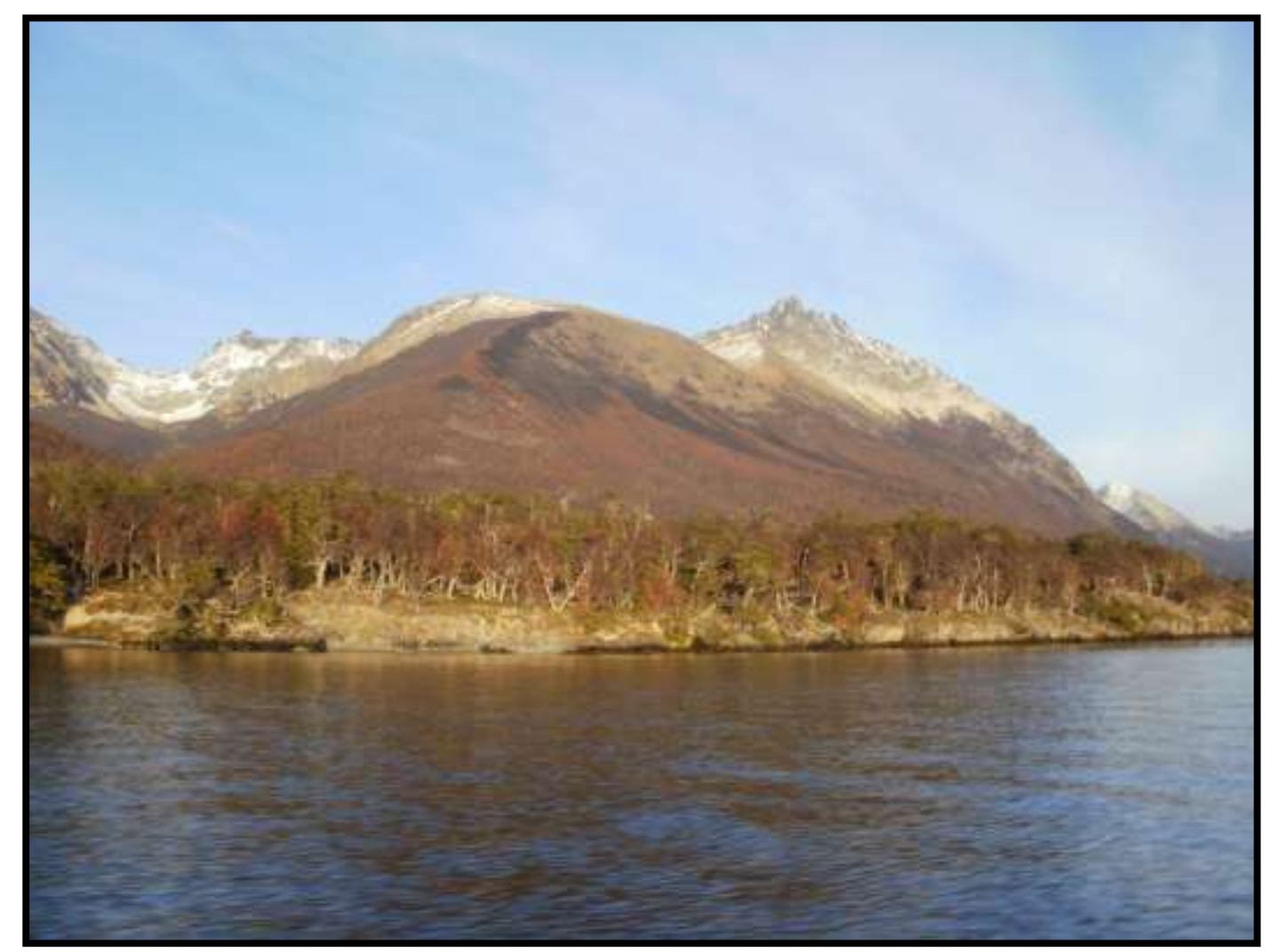

Figura 5. 15. Vista de la costa sur del lago Fagnano en la zona de Bahía Torito

\section{Valles y márgenes de ríos}

(Figura 5.7)

En cuanto a la zona de valles y márgenes de ríos (Vasco, Láinez, Azara y San Pablo), se comenzó con el curso inferior de los ríos mencionados. La exploración comprendió los últimos $5 \mathrm{~km}$ de cada uno, hasta su desembocadura en el océano Atlántico (Figura 5.16). 
En líneas generales todos presentan una vegetación muy similar, con pastizales de gramíneas hacia los bordes de los ríos y bases del valle, interrumpidos por turbales extensos. Hacia las laderas de las montañas comienzan los bosques abiertos.

En cuanto a los recursos líticos, en todos los casos se pudo identificar pequeños sectores con guijarros de diversos tamaños. Estos se corresponden con los meandros donde el río acumula el material que arrastra. La densidad de materia prima es baja, igual que sucede con la densidad el registro arqueológico.

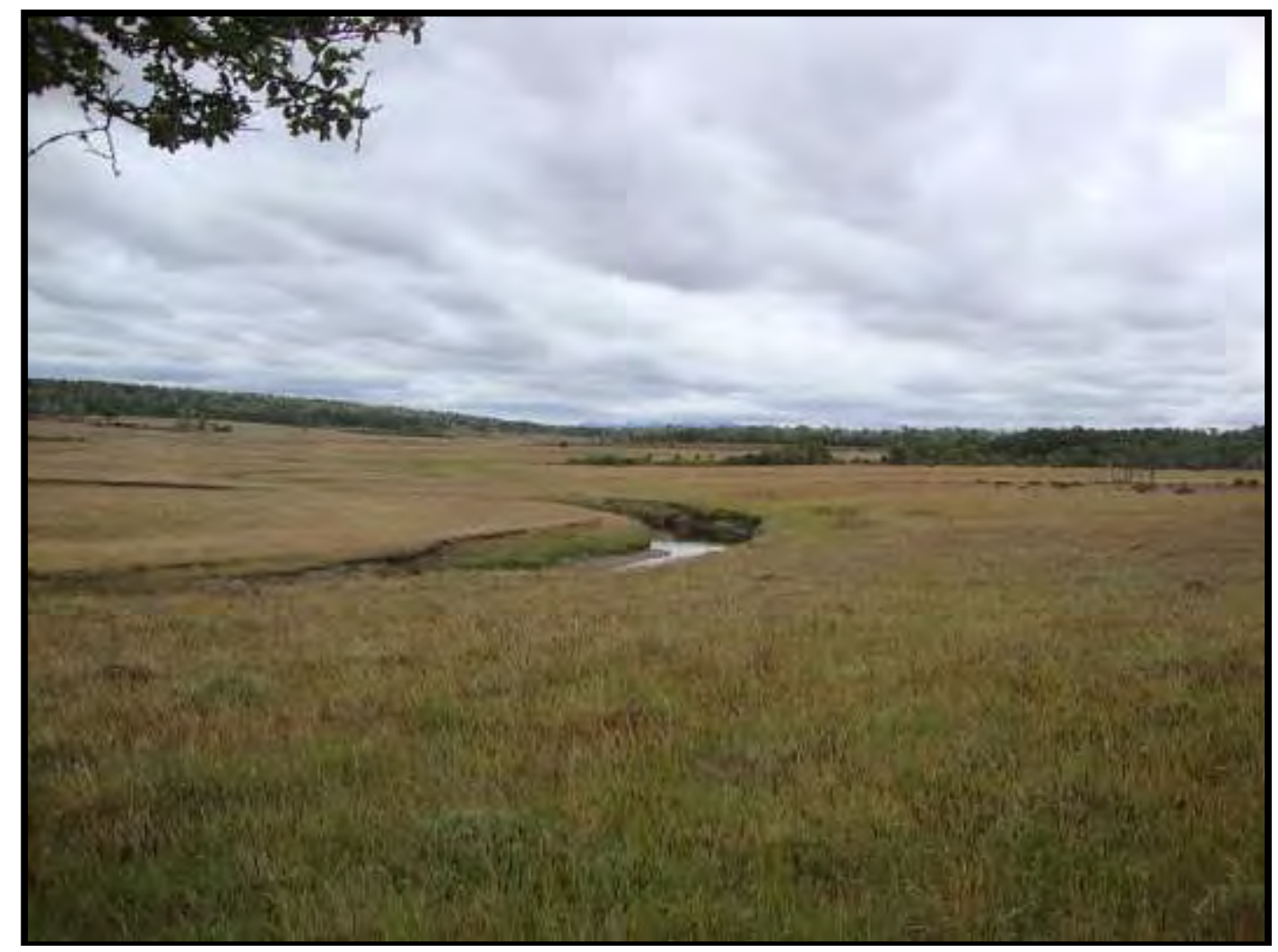

Figura 5. 16. Curso inferior del río El Vasco

\section{Curso superior y medio del río Irigoyen}

\section{Curso superior}

El punto de partida que se tomo fue el puente que cruza el rio por la ruta 23. Se tomó hacia la izquierda siguiendo el rio y a unos pocos metros la orilla de éste comienza a elevarse quedando un gran paredón hacia el rio (Figura 5.17). Sobre esta elevación se extiende el bosque sobre una superficie medianamente plana, con gran caída de árboles y mucha vegetación, debido a la época del año. Sin embargo hacia la línea de barranca se encuentra un 
sector sin vegetación con un sedimento marrón claro amarillento, allí se observaron materiales líticos en superficie (Figura 5.18). Se mapeó el lugar y luego se lo reticuló en cuadriculas de $1 \times 1 \mathrm{~m}$ que definieron las unidades de recolección (Figura 5.19) (Tabla 5.2 y 5.3).

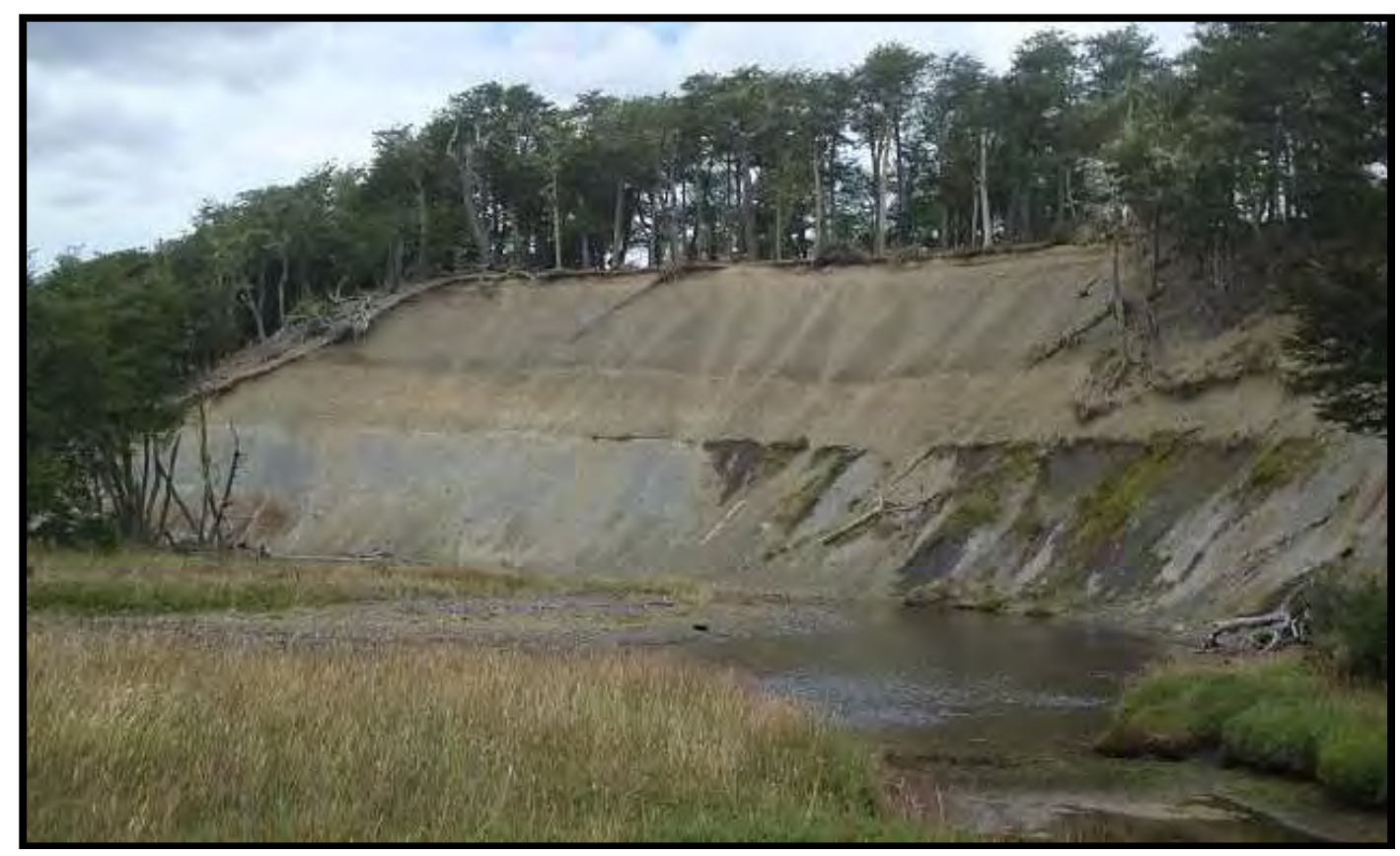

Figura 5. 17. Barranca de la margen derecha del río Irigoyen

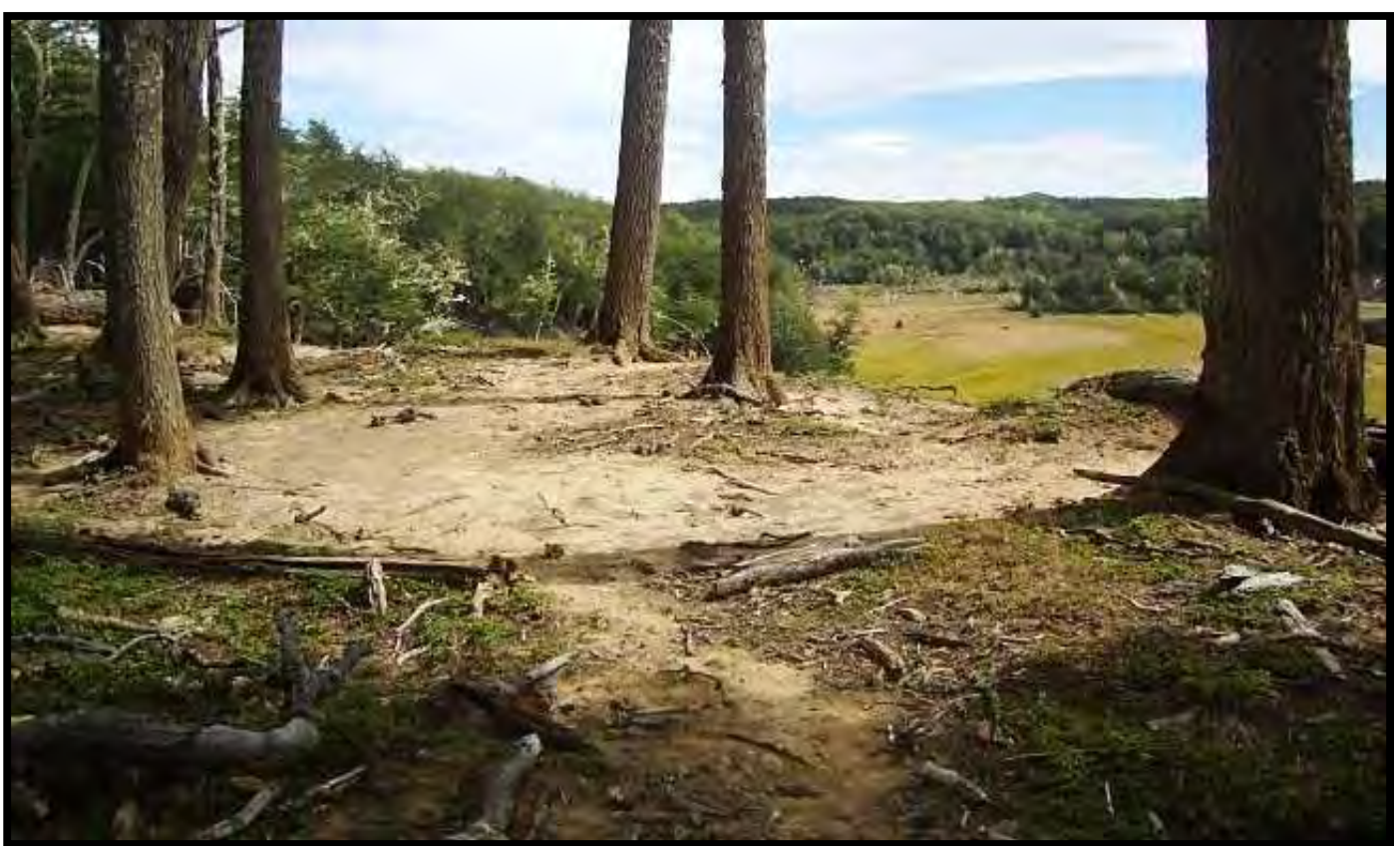

Figura 5. 18. Sector con material lítico

El espacio donde se encuentran estos materiales tiene una superficie de unos 8 x $16 \mathrm{~ms}$. aproximadamente. Se levantó el material superficial en su totalidad, debido a su proximidad a la línea de caída por el barranco. El mismo 
consta de lascas, núcleos e instrumentos retocados como raspadores y raederas (Figura 5.20). Debido que la barranca cae directamente sobre el rio fue imposible constatar la existencia de materiales caídos, sin embargo alguno de los artefactos recolectados se encontraban sobre el borde de la barranca.

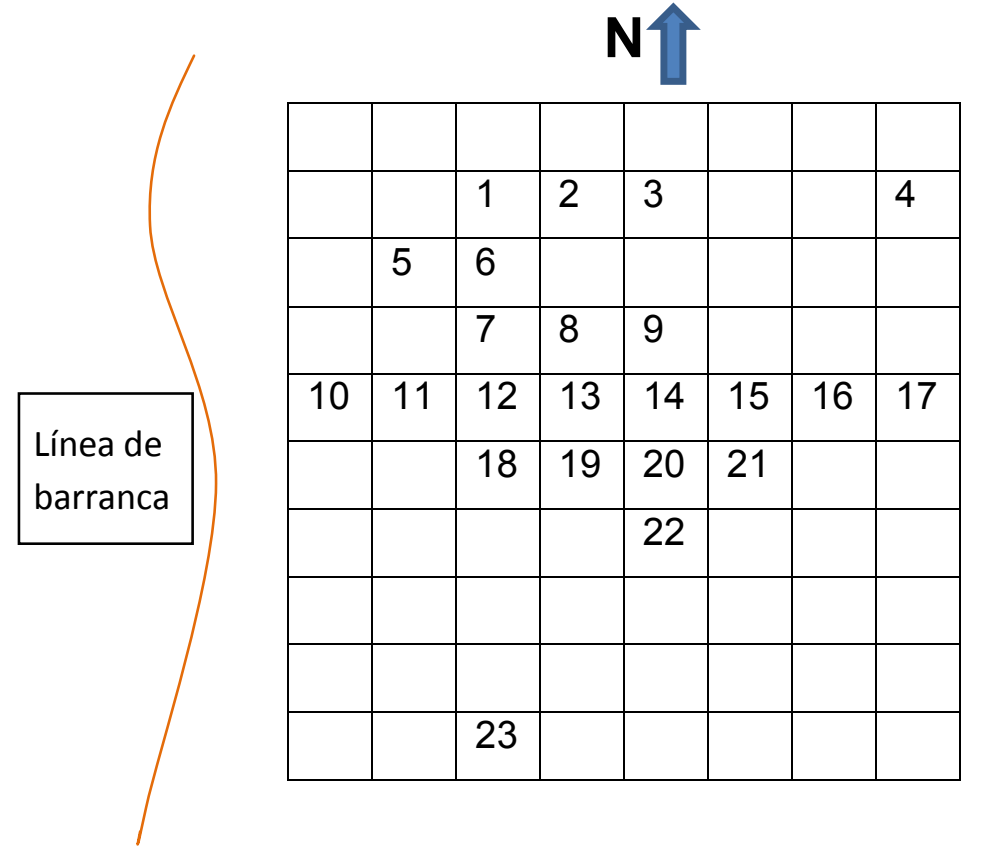

Figura 5. 19. Reticulado y unidades de recolección (cuad. 1 x $1 \mathrm{~m}$ )
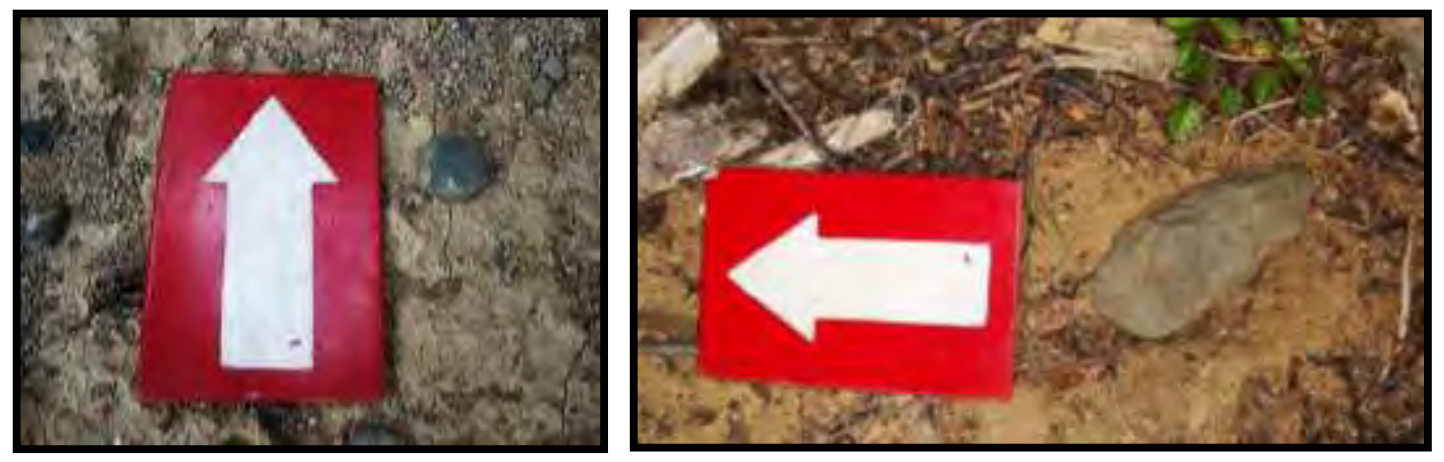

Figura 5. 20. Izquierda: raspador; derecha: raedera (flecha=10 cm)

Hacia el sur el bosque estaba cortado por un camino pegado al borde del barranco, que iba desde la ruta 23 hasta un puesto, posiblemente de algún aserradero. Dado que el camino permitía una buena visibilidad arqueológica, a diferencia del resto del lugar, se decidió seguir la transecta sobre el camino (Figura 5.21). 


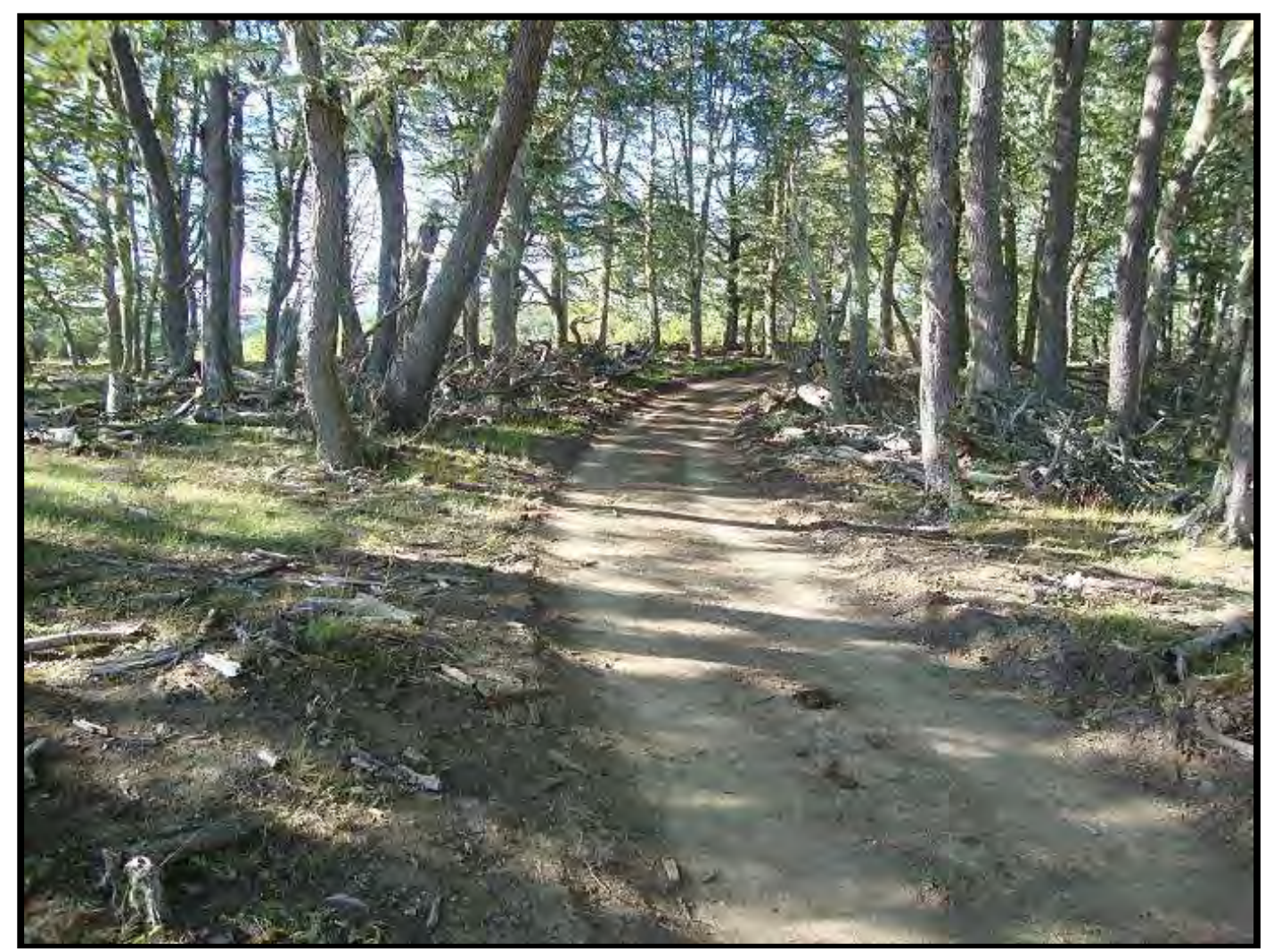

Figura 5. 21. Camino dentro del bosque.

Sobre el camino pudieron recuperarse algunos artefactos líticos. El primero de ellos fue una raedera, a los 200 metros aproximadamente un guijarro que en una de sus caras tenia rastros de haber sido utilizado como yunque y en la otra cara un plano muy pulido sugiriendo que pudo haber sido utilizado como sobador. Luego a unos 60 metros, y por unos 150 metros más, aparecieron sobre el camino algunos artefactos líticos $n=8$ (fragmentos $n=4$, lascas $n=3$, raedera $n=1$ ). Cabe mencionar, que en uno de los bordes del camino se pudo determinar la presencia de fragmentos óseos quemados y algunos carbones de los cuales se tomaron muestras (Tabla 5.2 y 5.3 ).

En el centro de la transecta se encontraba un puente que permite pasar sobre el río. El primer día se tomó el rumbo oeste, hacia la cabecera del río, al día siguiente se tomó el rumbo contrario, hacia la desembocadura, a unos 300 metros aproximadamente desde el punto de partida se recuperaron dos hallazgos aislados, dos lascas.

Es interesante mencionar que el bosque, en este sector del río, es más húmedo que hacia el otro lado, probablemente debido a la presencia de varios chorrillos, que permiten que se desarrolle una vegetación características de 
zonas anegadas o pantanosas (Figura 5.22). Incluso algunos parches del bosque presentaban sectores con turbales. En todo el recorrido se pudo observar una gran cantidad de árboles caídos impidiendo el paso por amplios espacios (Figura 5.23).

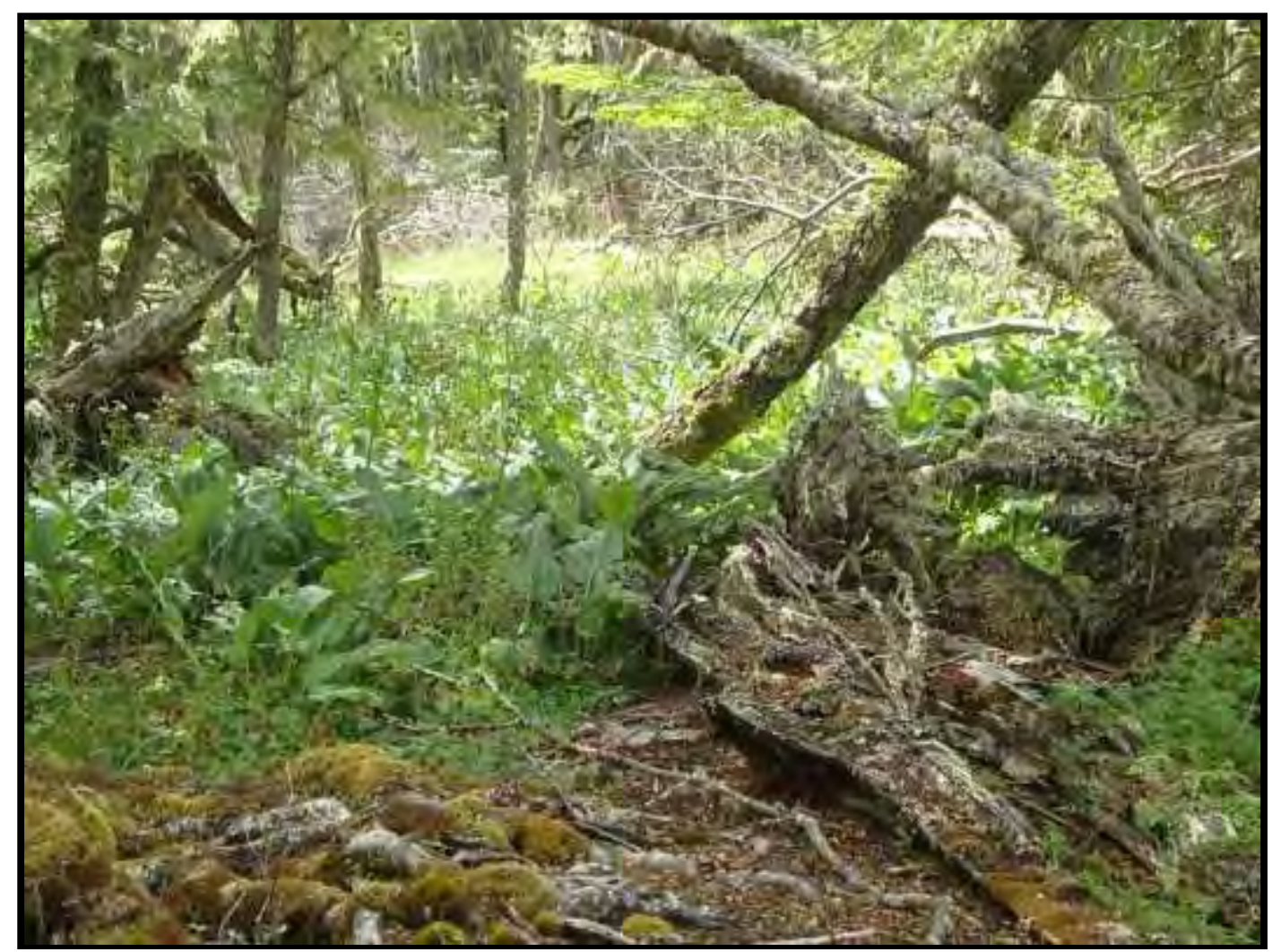

Figura 5. 22. Vegetación de zona anegada 


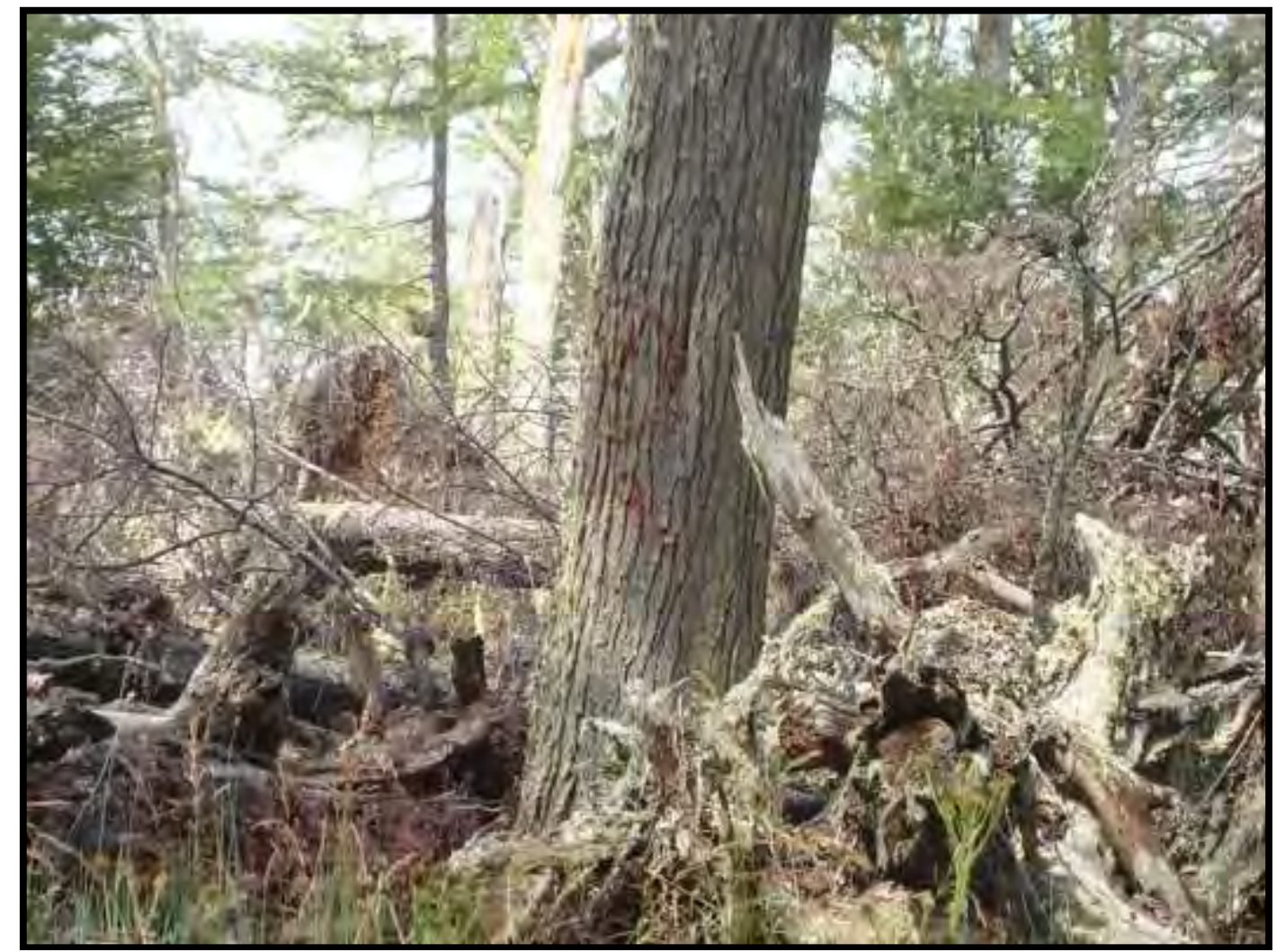

Figura 5. 23. Sector de caída de árboles

Curso medio

La transecta se realizó sobre la margen derecha. Sólo se recuperó una raedera sobre la barranca y a pocos metros huesos quemados aunque sin ninguna asociación con material arqueológico (Tabla 5.2 y 5.3).

\section{Río Láinez curso superior}

(Figura 5.24)

En el primer sector cercano al camino abierto por los aserraderos se pudo identificar material lítico en superficie con restos de carbón asociados, se realizó una pequeña muestra de cucharín donde se registró material lítico, unas microlascas y un raspador. Donde se encontraban los carbones el sedimento por debajo de la tierra marrón, era de color rojizo (Tabla 5.2 y 5.3).

A unos metros a este sitio, sobre una lomada cubierta por bosque antiguo de Nothofagus, pudo identificarse también material lítico, que quedó expuesto por el levantamiento de sedimento, resultado del movimiento de las raíces. Estos se fueron dando por varios metros siguiendo el río hacia la cabecera, pero sobre esta parte elevada. En uno de los sectores con 
concentración de material se pudo tomar una muestra de carbón que estaba asociada a material lítico.

Luego, al pasar la parte elevada se encuentra un amplio valle ocupado por turbal. A partir de aquí no se pudo encontrar material.

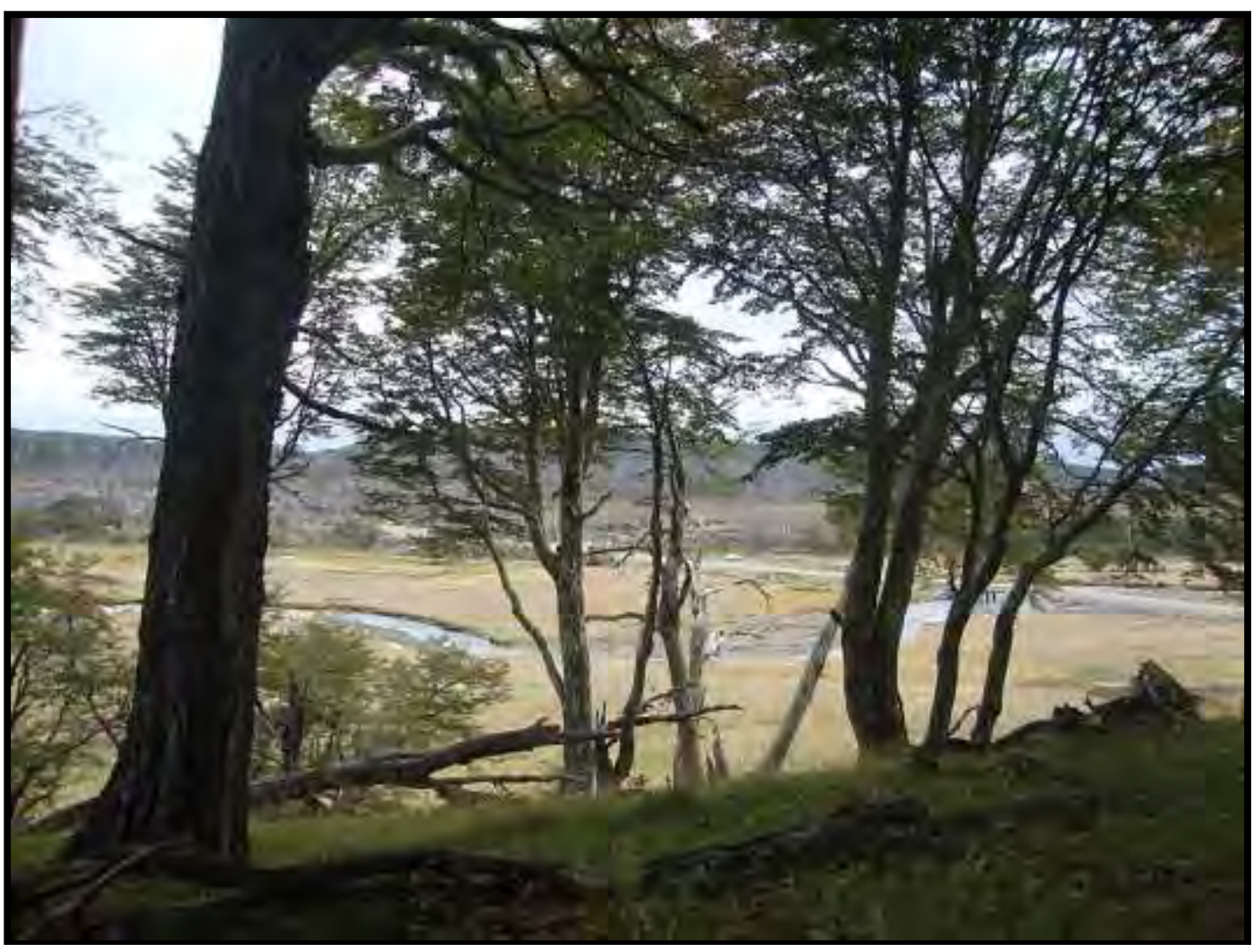

Figura 5. 24. Vista del curso superior del río Láinez

\section{$\underline{\text { Río San Pablo curso superior }}$}

Este sector corresponde a uno de los brazos que forman la cabecera del río San Pablo (Figura 5.25). También es una zona con muchos turbales y muy alterada por la presencia de castores. Tanto en la margen derecha como de la izquierda no se realizaron hallazgos de materiales arqueológicos (Tabla 5.2 y 5.3). 


\begin{tabular}{|l|l|r|l|r|r|}
\hline Nombre & ms l. & Sup. m2 & Ambiente & Hallazgos & Densidad \\
\hline Laguna Aguas Blancas & 3317 & 33.170 & Borde laguna & 2 & 0,00006 \\
\hline Laguna Margarita & 5465 & 54.650 & Borde laguna & 3 & 0,00005 \\
\hline Laguna Bombilla (Kami 2 a 6) & 5000 & 75.000 & Borde laguna & 625 & 0,008 \\
\hline Laguna Palacios (Kami 8) & 5000 & 75.000 & Borde laguna & 33 & 0,0004 \\
\hline Laguna Negra & 5000 & 100.000 & Borde laguna & 2 & 0,00002 \\
\hline Bahía Torito & 5000 & 75.000 & Costa lago & 28 & 0,0003 \\
\hline Río Valdez desembocadura & 5000 & 75.000 & Costa lago & 38 & 0,0005 \\
\hline Río San Pablo desembocadura & $5000 \times$ margen & 100.000 & Valle & 0 & 0 \\
\hline Río Láinez desembocadura & $5000 \times$ margen & 175.000 & Valle & 1 & 0,000005 \\
\hline Río Azara desembocadura & $5000 \times$ margen & 150.000 & Valle & 12 & 0,00008 \\
\hline Río Vasco desembocadura & $5000 \times$ margen & 150.000 & Valle & 0 & 0 \\
\hline Río San Pablo cabecera. & $5000 \times$ margen & 175.000 & Valle & 0 & 0 \\
\hline Río Láinez cabecera & $5000 \times$ margen & 150.000 & Valle & 63 & 0,0004 \\
\hline Río Irigoyen cabecera & $5000 \times$ margen & 150.000 & Valle & 84 & 0,0005 \\
\hline Río Irigoyen curso medio & 5000 & 150.000 & valle & 1 & 0,000006 \\
\hline
\end{tabular}

Tabla 5. 2. Sectores donde se llevaron a cabo las transectas entre 2009 y 2012.

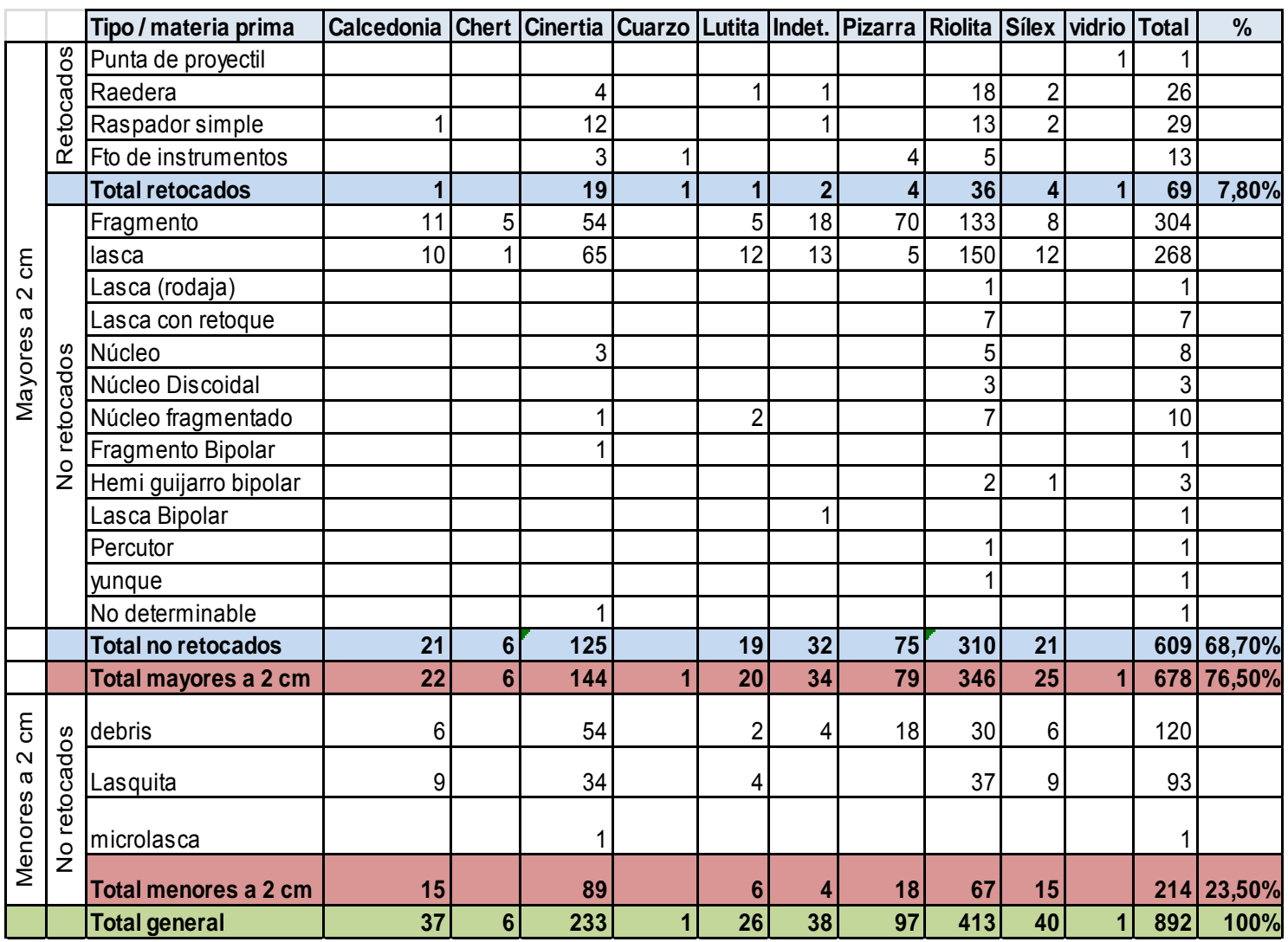

Tabla 5. 3. Cantidades y relación entre de tipos y materias primas. 


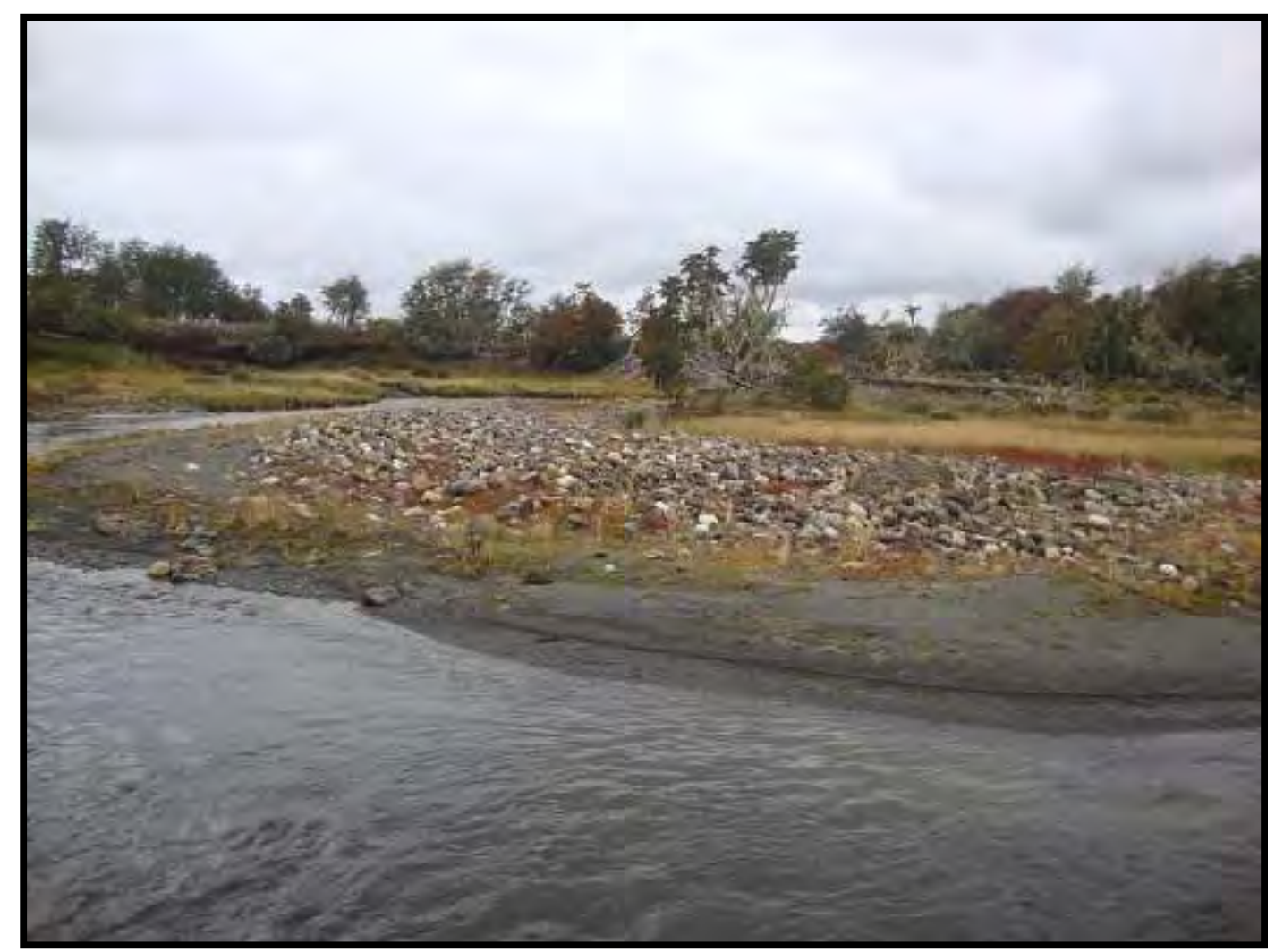

Figura 5. 25. Vista del curso superior del río San Pablo

\section{DISCUSIÓN}

La Isla Grande de Tierra del Fuego tiene una serie de ambientes bien definidos, con características particulares que les confieren diversas posibilidades en relación con la ocupación humana: paisaje de montaña, de bosque, de estepa, costas marítimas. Ellos varían en cuanto a la distribución de la vegetación, la fauna y las materias primas.

Como se indicó al comienzo, nuestro caso de estudio se ubica dentro de la zona de bosque Magallánico, que comprende cordones cordilleranos con bosque, valles intermedios y depresiones ocupadas por lagos de origen glaciario, con turbales, gramíneas o juncos en los fondos de valles, así como ondulaciones y colinas que alternan con planicies y fondos de valles hacia el norte.

Los rasgos del paisaje que podemos tomar en consideración son principalmente: sectores inter-lagunas, arroyos o ríos, orillas de lagos o lagunas, barrancas, los diversos sectores de bosque como zonas abiertas, 
borde de bosque, interior; laderas de montaña o sectores puntuales de afloramientos de materia prima lítica y, finalmente, los turbales.

Para este trabajo se decidió considerar aquellos ambientes asociados directamente con cuerpos de agua (ríos, lagos y lagunas) dado que son los que mayor diversidad y concentración de recursos bióticos y abióticos presenta.

Partimos del supuesto que cuantos más recursos ofrezca un ambiente, mayor pudo haber sido su explotación (Bettinger 2001). Por lo tanto, también es esperable la reocupación de aquellos ambientes que brinden seguridad en cuanto a la explotación de algún recurso. Esta redundancia ocupacional sería uno de los posibles factores que intervengan en la variabilidad de la densidad de artefactos arqueológicos (Massone 1997; Morello et al. 1999).

Hasta el momento, la redundancia ocupacional era difícil de demostrar en una zona con las características mencionadas. Sin embargo, gracias a la excavación de algunas de las concentraciones detectadas fue posible identificar sitios extensos cuyo tamaño y distribución espacial de materiales sugieren ocupación reiterada, tal vez estacional, como los de Kami 1 y Kami 7. En uno de los sitios excavados pudo corroborarse la reocupación a partir de fechados radiocarbónicos de tres fogones a los que nos referimos en el capítulo anterior. De todos modos, se esperan los estudios de vegetales carbonizados recuperados en flotación, que se encuentran todavía en curso, los cuales podrían decirnos estacionalidad de la ocupación en relación con las especies representadas.

Dos aspectos a considerar en relación con la variabilidad de la densidad del material arqueológico son la movilidad de los grupos cazadores recolectores y la ocupación de la zona de bosque. Con respecto al primero, creemos que la movilidad es un criterio fundamental para explicar la distribución y densidad del material arqueológico en los distintos ambientes (Tabla 5.2). La misma responde a diversos factores. Por ejemplo, desde la etnología y etnoarqueología se han propuesto modelos que vinculan la frecuencia de desplazamiento de una población con la densidad de alimentos y que establecen que la movilidad aumenta a medida que la temperatura decrece y la aridez se incrementa (Kelly 1995). Otros modelos consideran factores tales como la accesibilidad a las materias primas para la confección de los artefactos 
líticos, los recursos comestibles, una estacionalidad marcada, etc. (Binford 1980, 1982, 1983; Bettinger y Baumhoff 1982).

Las tres zonas que mencionamos, es decir ecotono, cordillera y valles de ríos, presentan en general una diversidad similar de recursos, ya que en todos ellos podemos encontrar madera, agua, fauna, y recursos líticos. Sin embargo lo que diferencia a estas zonas es la accesibilidad a estos recursos, o su localización en el paisaje. En relación a esto se pudo ver que hay ciertos recursos que son más ubicuos que otros, como por ejemplo el agua de fácil acceso en todos los ambientes mencionados, los recursos vegetales y hongos. En contraposición, un recurso fundamental como el lítico se presenta de forma puntual en el paisaje, principalmente aquellos afloramientos con rocas de buena calidad para la talla como son los guijarros costeros. Tal es el caso de los bordes de lagos y lagunas, pero también algunos sectores en las nacientes de los ríos, donde se pudo constatar pequeños espacios donde el río va acumulando guijarros. Sin embargo esto no se da a lo largo de todo el río, ya que existen extensas partes asociadas a los valles, principalmente, donde no pudo registrarse afloramientos líticos.

El segundo aspecto es la ocupación de la zona de bosque en general. Según la evaluación inicial de la zona boscosa presentada por Mansur (2002) para el Corazón de la Isla, la zona de bosque puede constituir un ambiente favorable para cazadores-recolectores, ya que provee de una amplia variedad de recursos que son propios del bosque: reparo natural, abrigo, combustible vegetal para lumbre, madera como materia prima para construcción y para bienes de uso y consumo, etc.

En efecto, en comparación con la estepa fueguina, la disponibilidad de recursos vegetales es mucho más diversa y mayor, en cuanto a biomasa vegetal y sotobosque, en la zona boscosa del centro de la Isla (Collado 2007, Frangi et al. 2004). En ella, aparte de la abundancia de madera, existe una gran diversidad de recursos comestibles como hongos: el pan de Indio (Cyttaria darwinii), hongo del campo (Agaricus), Gran Bejín (Calvatia Coelata), Champiñon (Cortinarius magellanicus Spegazzini) que son ricos en proteínas y carbohidratos; también arbustos con bayas como calafate (Berberis buxifolia), murtilla (Empetrum rubrum), etc.; herbáceas comestibles tales como el apio silvestre (Apium australe), el diente de león (Taraxacum sp.), el amor del 
hortelano (Gallium sp.), etc. En cuanto a tecnología, existe un amplio registro de vegetales utilizados para la confección de bienes, aunque los más conocidos son los juncos que crecen en los turbales (Marsippospermum grandiflorum y Rostkovia magellanica) (Moore 1983). En cuanto a la fauna, las zonas lagunares funcionan como espacios concentradores de avifauna en primavera y verano. Con respecto a los claros, éstos conservan guanacos durante el invierno, etc. (Mansur 2002; Mansur y Piqué 2009).

Los resultados presentados muestran una distribución espacial de los materiales arqueológicos que nos permite ver una ocupación general de todos los ambientes dentro de la zona de bosque subantártico. Sin embargo, esta distribución es heterogénea, con mayores concentraciones en la zona costera sur del lago Fagnano y menores en los otros ambientes registrados (Mansur et al. 2010).

Para este caso, creemos que uno de los factores que debieron influir en la movilidad de los grupos es la accesibilidad a fuentes de materias primas de buena calidad para la talla. Ello explicaría la densidad de material arqueológico encontrada en la costa sur del lago Fagnano, donde hemos registrado las mayores concentraciones de guijarros de buena calidad y grandes dimensiones, a diferencia de lo que ocurre en los sectores próximos a la desembocadura de los ríos donde prácticamente no se detectaron fuentes de aprovisionamiento lítico. Esto queda evidenciado si observamos las diferencias entre las densidades de hallazgos arqueológicos presentados en la tabla 5.2, entre las transectas ubicadas sobre la costa del Fagnano y aquellas ubicadas en los cursos inferiores de los ríos o las transectas que rodean las lagunas que se encuentran en el interior de bosque (ver Tabla 5.2 y 5.3).

En cuanto al tipo de material encontrado vemos que en general son artefactos mayores de $2 \mathrm{~cm}$, aunque no son tan escasos los elementos entre 2 y $0,5 \mathrm{~cm}$ como lasquitas y debris. Los más abundantes son los restos de talla como lascas y fragmentos, principalmente de materias primas que se encuentran con facilidad en todos los depósitos rocosos testeados, como riolita y cinerita. En cuanto a los instrumentos retocados, las raederas y raspadores son prácticamente exclusivos, salvo por varios fragmentos de instrumentos, lascas con retoque y una punta de proyectil. En su mayoría estos instrumentos fueron confeccionados también sobre rocas locales (Tabla 5.3). 
Finalmente, otro factor subsidiario de los anteriores a considerar en la movilidad de las sociedades cazadoras recolectoras del área es la distribución estacional de los recursos vegetales y animales. En relación con esto, resulta fundamental tener en cuenta la marcada estacionalidad invernal en cuanto a la disponibilidad de pasto. En este período del año el suelo se encuentra congelado y cubierto de nieve por lo que los guanacos deben buscar alimento en zonas menos comprometidas. En cuanto al recurso de las aves, estas al ser migratorias sólo están disponibles en los períodos más cálidos (Borrero 2007).

Estudios arqueobotánicos efectuados sobre restos de semillas carbonizadas han demostrado el uso del ambiente de bosque durante la primavera (Berihuete 2010; Mansur et al. 2010), tal es el caso del sitio Ewan. En contraposición a esto, el análisis del sedimento de las áreas de combustión del sitio Kami 1 mostró ausencia casi total de semillas, lo que podría estar indicando ocupación invernal para esta parte del lago Fagnano.

En resumen, el trabajo se centró en el relevamiento de los diversos ambientes (cordillera, bosque, valles, y cuerpos de agua) asociados con tres paisajes que definen la zona de estudio, como son la zona de cordillera, el ecotono y la zona de valles al sur, norte y este del lago Fagnano respectivamente. El objetivo principal es poder aportar a la discusión en relación con la distribución y densidad de ocupación humana dentro de la faja central de Tierra del Fuego. 


\section{Capítulo 6}

\section{PROGRAMA EXPERIMENTAL}




\section{INTRODUCCIÓN}

La arqueología experimental es una forma de generar información útil con respecto al registro arqueológico, a partir de una serie de experimentos como los que replican artefactos arqueológicos, alteraciones, etc. (Martinez y Aschero 2003). A través de ellos, podemos inferir aquellos comportamientos que no pueden ser observados directamente en los restos arqueológicos.

Este tipo de acercamiento resulta de gran ayuda cuando nos enfrentamos a nuevos problemas. Por ejemplo, determinar técnicas de talla, inferir la producción lítica de un conjunto a partir de los restos de talla cuando faltan los instrumentos terminados, etc. Desde el punto de vista del análisis funcional, la experimentación nos permite comprender las propiedades y modificaciones de los filos de instrumentos cuando son empleados en diferentes procesos de uso.

El programa experimental que se expondrá a continuación se desarrolló en primer término para el análisis de un conjunto de artefactos de vidrio. Dicho programa abarca aspectos tecnológicos y funcionales, desde el proceso de manufactura del instrumento y su utilización en diversos materiales. En segundo término se aplicó a otras materias primas como es el caso de la toba silicificada Miraflores, proveniente del norte de la Isla Grande de Tierra del Fuego. El programa también abarcó, de forma complementaria, rocas de origen local, como las riolitas, cineritas y cuarzo, pero también rocas de diversos orígenes como Patagonia continental, lo que permitió tener un amplio espectro sobre el conocimiento de las modificaciones que sufren los diversos tipos de rocas en el proceso de manufactura y utilización. Por ello sólo se presentarán aquí el trabajo sobre vidrio y toba silicificada 


\section{EXPERIMENTACIÓN TECNOLÓGICA Y FUNCIONAL SOBRE INSTRUMENTOS DE VIDRIO}

Comenzaremos con la presentación del programa experimental aplicado a los materiales de vidrio. Dado la escasez de trabajos teórico-metodológicos específicos sobre análisis tecnofuncional de instrumentos de este material, se decidió diseñar y ejecutar un programa experimental, que se detalla más adelante. Su objetivo principal fue generar bases para comprender la dinámica de reducción del vidrio para formatizar artefactos comparables a los del registro arqueológico, así como las propiedades y modificaciones de los filos de los instrumentos cuando son empleados en diferentes procesos de uso (De Angelis et al. 2009).

El programa experimental responde a la problemática planteada por la presencia de un conjunto lítico confeccionado con un sólo tipo de materia prima, el vidrio. Dicho conjunto corresponde a la localidad arqueológica Ewan, que como se verá más adelante presenta características particulares.

Este trabajo experimental se desarrolló siguiendo cuatro objetivos. EI objetivo principal es aportar al marco de referencia general para el análisis de artefactos de vidrio. Un segundo objetivo es profundizar el análisis tecnomorfológico de microlascas de vidrio para determinar, a partir sólo de este tipo de registro, qué instrumentos se pudieron haber confeccionado en un sitio. Un tercer objetivo es comprender las propiedades y modificaciones de los filos de instrumentos de vidrio cuando son empleados en diferentes procesos de uso. Finalmente, el cuarto objetivo, intenta dar cuanta de las diferencias entre los desechos de talla para la confección de raspadores y puntas de proyectil.

En lo metodológico, el programa experimental siguió los lineamientos generales aplicados en otros estudios de este tipo e incluyó los siguientes pasos:

- confección de una serie de raspadores y otra de puntas de flecha de vidrio, buscando replicar las formas base y características de filos y retoques de los documentados en el registro arqueológico;

- recolección y análisis de las esquirlas de retoque, a fin de sistematizar sus características morfotécnicas;

- utilización experimental de los raspadores para trabajar tres tipos básicos de materiales (madera de los géneros Nothofagus y Berberis, con y sin 
corteza; hueso fresco y pieles, con aditivos y sin ellos), considerando diferentes cinemáticas y ángulos de trabajo;

- análisis funcional de base microscópica de los filos previa a la utilización, para caracterizar los rastros tecnológicos producidos durante el proceso de manufactura, seguida por análisis a intervalos constantes, para documentar las modificaciones producidas a lo largo del proceso de uso.

\section{Experimentación tecnológica}

\section{Raspadores}

Se confeccionó una serie de 13 raspadores de vidrio a partir de fragmentos de botella comparables a los documentados en los sitios, buscando replicar las características de forma base, filos y retoques de los raspadores arqueológicos (los responsables de la confección de estos raspadores fueron Lucas Sosa y Gustavo Valdés) (De Angelis et al. 2009). Los filos se caracterizan por ser rectos a ligeramente convexos, con sección longitudinal regular. En vista frontal, la cara ventral es convexa a ligeramente convexa. El retoque de los frentes fue realizado por presión utilizando retocadores de asta y hueso (Figura 6.1).

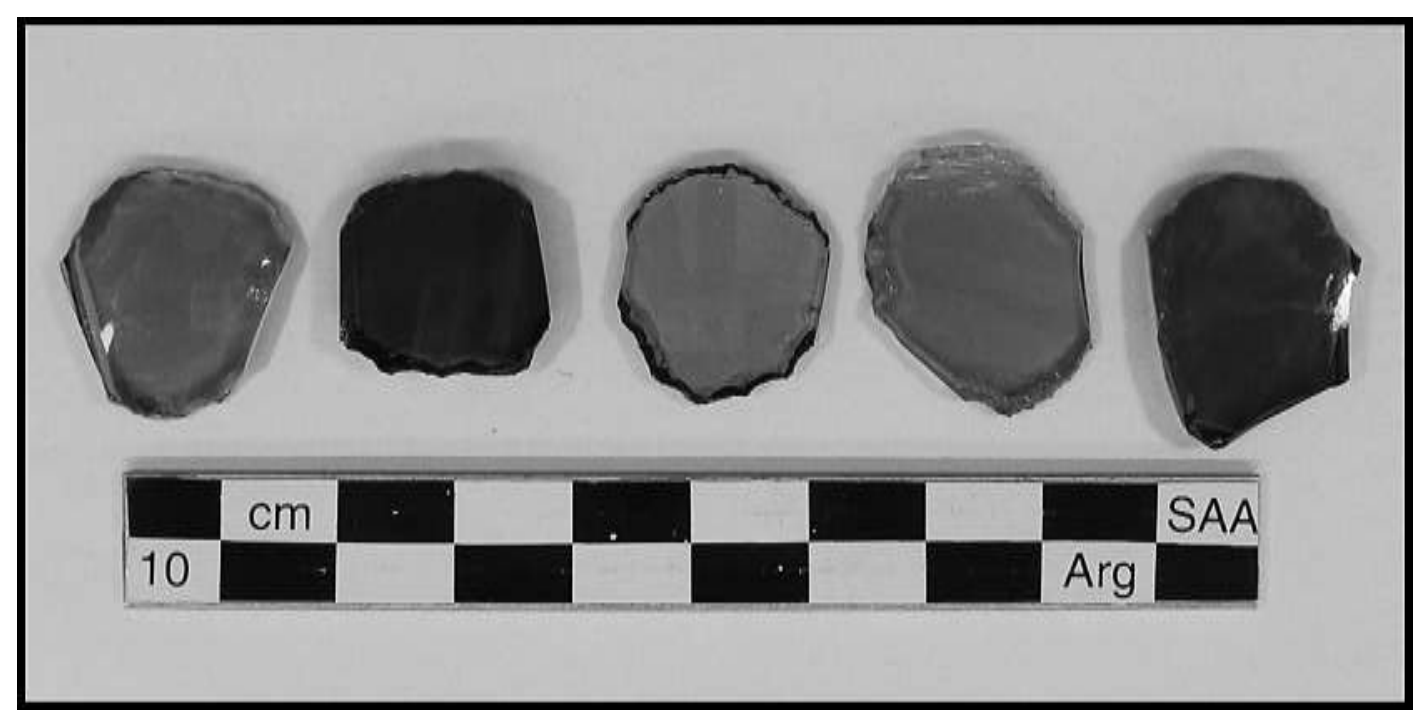

Figura 6. 1. Raspadores experimentales.

\section{Puntas de flecha}

Se confeccionó una serie de igual cantidad de puntas de flecha, siguiendo los mismos lineamientos. La formatización fue realizada considerando tres estadios de reducción: 
Estadio 1: preparación de filos laterales por retoque alterno

Estadio 2: adelgazamiento general de la forma base

Estadio 3: adelgazamiento final para obtener la morfología definitiva (Figura 6.2).

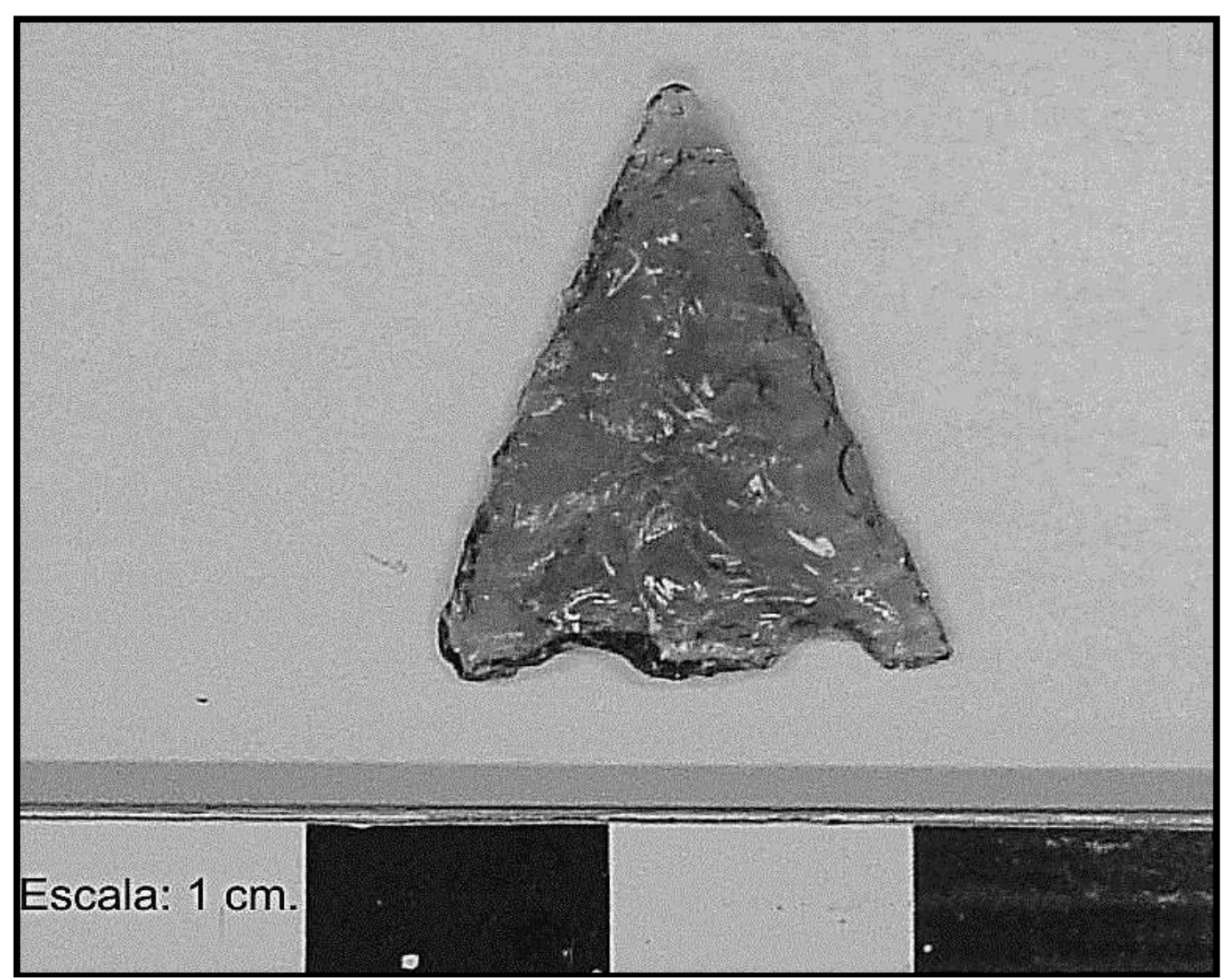

Figura 6. 2. Punta de flecha experimental. 


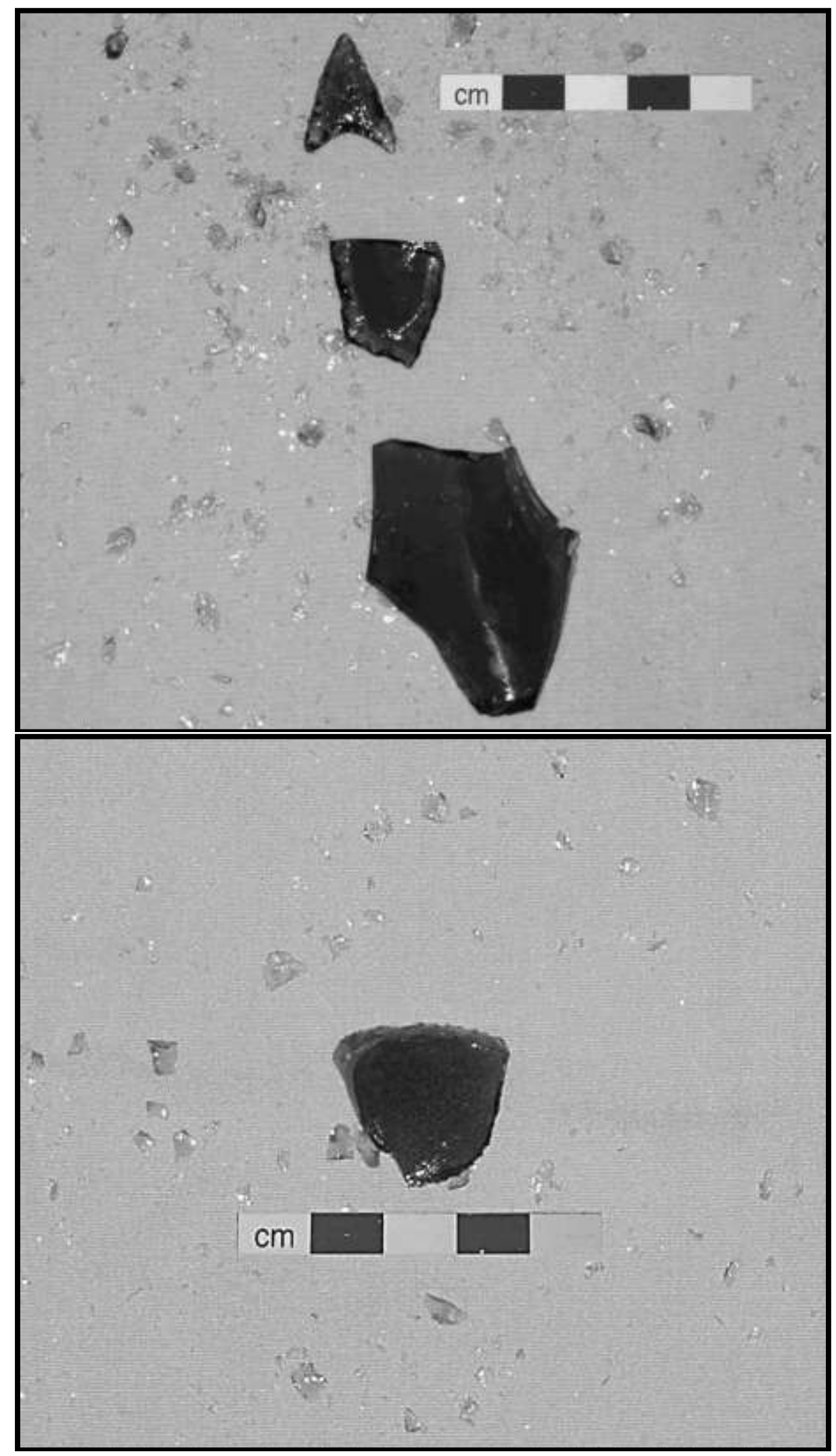

Figura 6. 3. Restos de talla en el proceso de confección de instrumentos de vidrio. Arriba: puntas de flecha. Abajo: raspador. 


\section{Análisis tecno-morfológico}

Durante el proceso de confección de raspadores y puntas, se recolectó la totalidad de los desechos de talla (microlascas) de cada uno de los artefactos, a fin de sistematizar sus características morfotécnicas (Figura 6.3). Para las puntas de flecha, en uno de los casos los desechos de talla fueron recolectados separando los diferentes estadios de reducción (Tabla 6.1).

Los restos de talla fueron en su totalidad microlascas y microfragmentos. En consecuencia, el análisis tecno-morfológico de los restos de talla producidos durante la confección de cada uno de los raspadores y de una de las puntas de flecha fue efectuado mediante observación con lupa binocular, con aumentos entre $10 \mathrm{X}$ y $60 \mathrm{X}$.

Los criterios registrados para cada una de las microlascas fueron los siguientes: dimensiones, talón (aspecto, forma, presencia, inclinación), labio, curvatura, porcentaje de corteza, fracturas. El análisis fue realizado considerando tres categorías de tamaño: inferiores a $2 \mathrm{~mm}$, de 2 a $5 \mathrm{~mm}$ y mayores de $5 \mathrm{~mm}$.

\section{Experimentación funcional}

Los raspadores fueron utilizados para trabajar tres tipos de materiales. Cinco trabajaron sobre madera fresca (gén. Nothofagus y Berberis), con y sin corteza, y cinco sobre hueso fresco (bóvido). Sólo tres fueron usados sobre pieles (oveja y cordero) secas y con aditivo de grasa y pigmento mineral, ya que el análisis microscópico revelaba rastros característicos e idénticos entre sí.

En todos los casos se utilizó cinemática transversal (eje del filo transversal al movimiento realizado), con cara inferior como cara de contacto y con diferentes ángulos de trabajo. Cada pieza fue utilizada por intervalos de 15 minutos al cabo de los cuales fue limpiada y sometida a análisis microscópico, hasta totalizar $30 \mathrm{~min}$.

Durante la experimentación, las piezas fueron dibujadas en fichas individuales y se efectuó un registro detallado de datos de utilización, considerando ángulo de uso, efectividad de la tarea, accidentes producidos durante el uso, fracturas, etc. 


\section{Análisis funcional}

El análisis de los instrumentos fue realizado siguiendo los lineamientos presentados en el cap. 3. Se consideró el modelo de formación de rastros de uso en materiales homogéneos, diferentes variables referidas al esquirlamiento y/o redondeamiento de los filos, estrías y micropulidos (cf. Mansur, 1999). Se utilizaron lupa binocular (10X a 60X) y microscopio de reflexión de tipo metalográfico con sistema directo para captura y digitalización de imágenes y aumentos comprendidos entre 50X y 500X.

Se realizaron análisis sistemáticos de todos los filos en estado fresco (antes de la utilización) para caracterizar los rastros tecnológicos producidos durante el proceso de manufactura y prefijar puntos referentes de observación. Luego se efectuaron análisis después de intervalos de uso de 15 y 30 minutos, con captura y digitalización de imágenes en los puntos referentes, para documentar las modificaciones producidas durante el proceso de uso (Figuras 6.5 y 6.6$)$.

Después de cada utilización, los instrumentos fueron lavados con agua y jabón; antes y durante el análisis se efectuaron limpiezas con alcohol. Se utilizaron dos ángulos de observación, uno con cara ventral perpendicular al haz de luz, otro con ángulo superior a $90^{\circ}$ para exponer el bisel del filo.

\section{Resultados}

Análisis tecno-morfológico de restos de talla

La experimentación tecnológica mostró que la confección de instrumentos por presión a partir de fragmentos de vidrio es tarea simple y relativamente rápida; especialmente en el caso de la confección de pequeñas puntas de proyectil, la reducción a partir de fragmentos de vidrio resulta más económica, eficaz y predecible que a partir de las rocas locales.

El análisis de las microlascas generadas durante el proceso de formatización de una de las puntas fue realizado por separado para cada uno de los estadios de reducción, considerando las variables mencionadas anteriormente. En cuanto a las lascas de preparación de filo, tanto las comprendidas entre 2 y $5 \mathrm{~mm}$ como las de más de $5 \mathrm{~mm}$ presentaron morfologías similares entre sí, con formas redondeadas, bulbos prominentes y 
talones con inclinación. En el primer grupo se registraron abundantes lascas fracturadas, pero también lascas con curvatura, características de la reducción bifacial. Los desechos de menos de $2 \mathrm{~mm}$ son microesquirlas intensamente fracturadas, en las cuales no es posible observar ninguno de los atributos considerados para el análisis, sin embargo un pequeño porcentaje puede ser reconocido como microlascas, algunas incluso con la forma redondeada de las anteriores, en general planas.

Las lascas de adelgazamiento (estadios 2 y 3 ) no superan $1 \mathrm{~mm}$ de espesor y en general están fracturadas en el extremo distal. La mayoría presenta talones pequeños e inclinados, bulbos difusos y muy pocas tienen labio. Morfológicamente difieren de las lascas de preparación, que son más gruesas y más anchas que largas. En el grupo de las lascas de más $5 \mathrm{~mm}$, el porcentaje de lascas con curvatura es mayor entre las de adelgazamiento; además son frecuentes los talones escalonados. En cuanto a las comprendidas entre 2 y $5 \mathrm{~mm}$, la mayor parte son fragmentos no diferenciados con gran cantidad de fracturas. Finalmente, en el grupo de las menores de $2 \mathrm{~mm}$, al igual que entre las lascas de preparación, la casi totalidad son microesquirlas intensamente fracturadas en las cuales no es posible observar ninguno de los atributos considerados para el análisis.

La formatización de los frentes de los raspadores produjo residuos con características particulares que fueron también clasificados por tamaños en tres categorías: mayores de $5 \mathrm{~mm}$, entre 5 y $2 \mathrm{~mm}$ e inferiores a $2 \mathrm{~mm}$. Los inferiores a $2 \mathrm{~mm}$ son también pequeñas microesquirlas intensamente fracturadas; al contrario, en las dos primeras categorías de tamaño, fue posible reconocer un tipo de lasca que merece una mención especial, ya que resulta característico de la formatización del filo del raspador. Se trata de productos con ligera curvatura, con un bulbo pequeño y que generalmente no presentan labio. Estas lascas tienen pequeños talones lisos corticales y presentan en la extremidad distal un plano liso también cortical - lascas sobrepasadas en las que ambos planos corticales corresponden a la "corteza" de ambas caras del fragmento de vidrio original (Figura 6.4). 


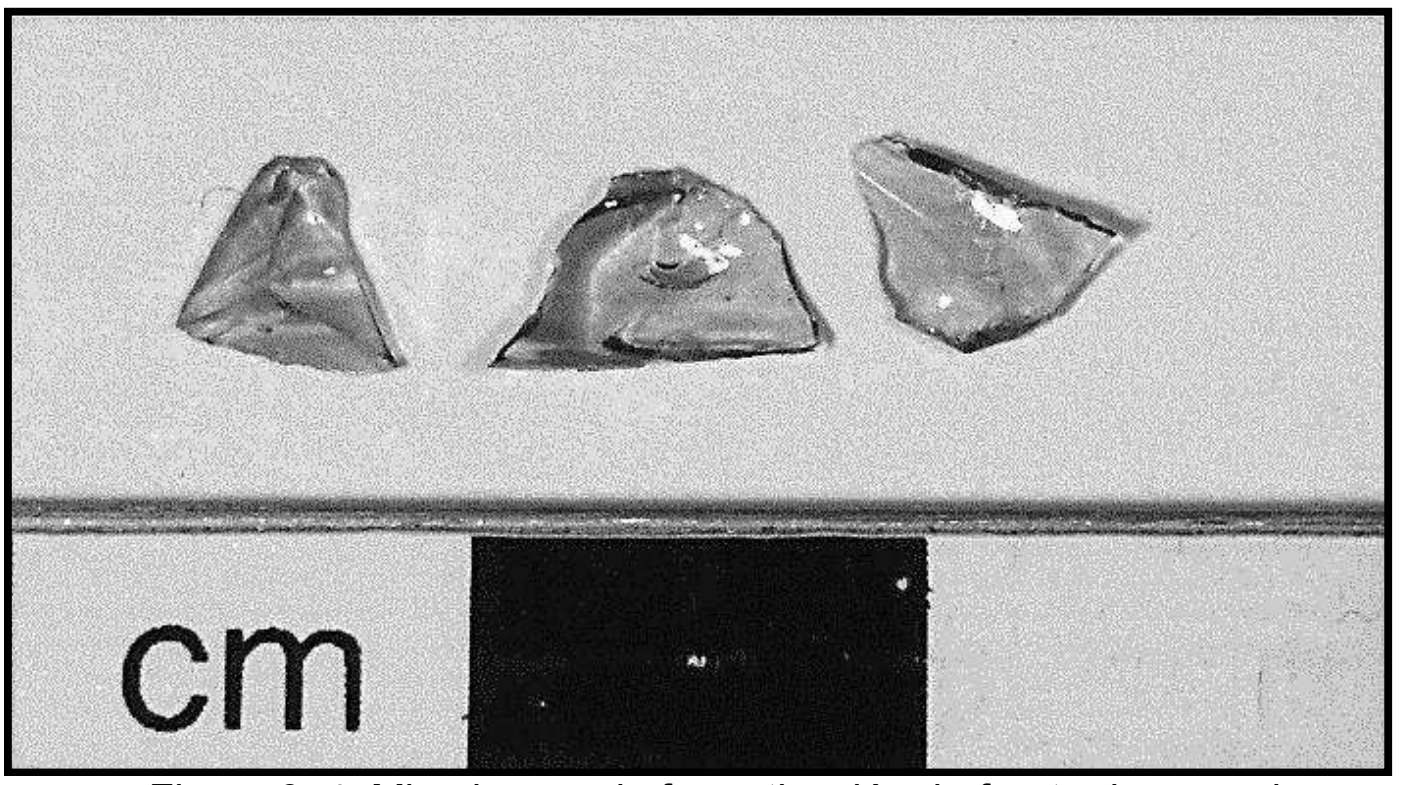

Figura 6. 4. Microlascas de formatización de frente de raspador.

También se debe mencionar que, más allá de las características morfotécnicas de las microlascas y microesquirlas generadas durante ambos procesos, es notable la diferencia en abundancia: la cantidad de desechos es mucho mayor durante la reducción de puntas de proyectil que en la manufactura de raspadores (ver Tablas 6.1 y 6.2).

\begin{tabular}{|c|c|c|c|c|c|c|}
\hline & \multicolumn{6}{|c|}{ Microlascas (en mm) } \\
\hline & \multirow{2}{*}{10} & \multirow[t]{2}{*}{$5-10$} & \multirow{2}{*}{-5} & \multicolumn{3}{|c|}{$<2$} \\
\hline & & & & Escaso & Interm. & Abund. \\
\hline Estadio 1 & & 35 & 8 & & $\mathrm{X}$ & \\
\hline Estadio 2 & & 34 & 11 & & & $\mathrm{X}$ \\
\hline Estadio 3 & & 8 & 0 & & & $\mathrm{X}$ \\
\hline TOTAL & & 77 & 59 & & & \\
\hline
\end{tabular}

Tabla 6. 1. Restos de talla en la producción de una punta de proyectil 


\begin{tabular}{|c|c|c|c|c|c|c|}
\hline \multirow{3}{*}{ Pieza } & \multicolumn{6}{|c|}{ Microlascas (en mm) } \\
\hline & \multirow[t]{2}{*}{10} & \multirow[t]{2}{*}{$5-10$} & \multirow[t]{2}{*}{-5} & \multicolumn{3}{|c|}{$<2$} \\
\hline & & & & Escaso & Interm. & Abund. \\
\hline \multirow[t]{2}{*}{1} & & & & $x$ & & \\
\hline & & 0 & 6 & & & \\
\hline \multirow[t]{2}{*}{2} & & & & $x$ & & \\
\hline & & 2 & 4 & & & \\
\hline \multirow[t]{2}{*}{3} & & & & & & $x$ \\
\hline & & 2 & 3 & & & \\
\hline \multirow[t]{2}{*}{4} & & 7 & & $x$ & & \\
\hline & & & & & & \\
\hline \multirow[t]{2}{*}{5} & & 3 & & $x$ & & \\
\hline & & & 0 & & & \\
\hline \multirow[t]{2}{*}{6} & & 9 & & & $\bar{x}$ & \\
\hline & & & 8 & & & \\
\hline \multirow[t]{2}{*}{7} & & 6 & & & & $x$ \\
\hline & & & 7 & & & \\
\hline \multirow[t]{2}{*}{8} & & 12 & & & & $\bar{x}$ \\
\hline & & & 3 & & & \\
\hline \multirow[t]{2}{*}{9} & & 12 & & & $x$ & \\
\hline & & & 6 & & & \\
\hline \multirow[t]{2}{*}{10} & & 1 & & & & $\bar{x}$ \\
\hline & & & 00 & & & \\
\hline \multirow[t]{2}{*}{11} & & 7 & & & $\bar{x}$ & \\
\hline & & & 7 & & & \\
\hline \multirow[t]{2}{*}{12} & & 5 & & $x$ & & \\
\hline & & & 1 & & & \\
\hline \multirow[t]{2}{*}{13} & & 2 & & & $x$ & \\
\hline & & & 0 & & & \\
\hline MEDIA & $\overline{0,3}$ & 7,5 & 46,7 & & & \\
\hline
\end{tabular}

Tabla 6. 2. Restos de talla en la producción de raspadores

\section{Análisis funcional de los instrumentos}

La utilización de los raspadores de vidrio permitió constatar una serie de procesos particulares en cuanto a la formación de los rastros de uso. El rasgo más notorio es que al ser utilizados, los filos se fracturan desprendiendo 
pequeñas microesquirlas, tanto en sus frentes como en la cara de contacto, hasta que llegan a regularizarse, alcanzando su perfil de estabilidad.

El análisis microscópico de los filos antes de ser utilizados revela caras relativamente lisas. Al cabo de los primeros 15 minutos de uso se observan numerosos negativos de esquirlamiento en los que aparecen los rasgos tecnológicos característicos: ondas, estrías de percusión, cometas, etc. No se observan micropulidos bien desarrollados; al contrario, prácticamente todos los filos muestran micropulidos correspondientes a los primeros estadios de desarrollo, que se manifiestan por el suavizado hasta la casi obliteración de los rasgos tecnológicos.

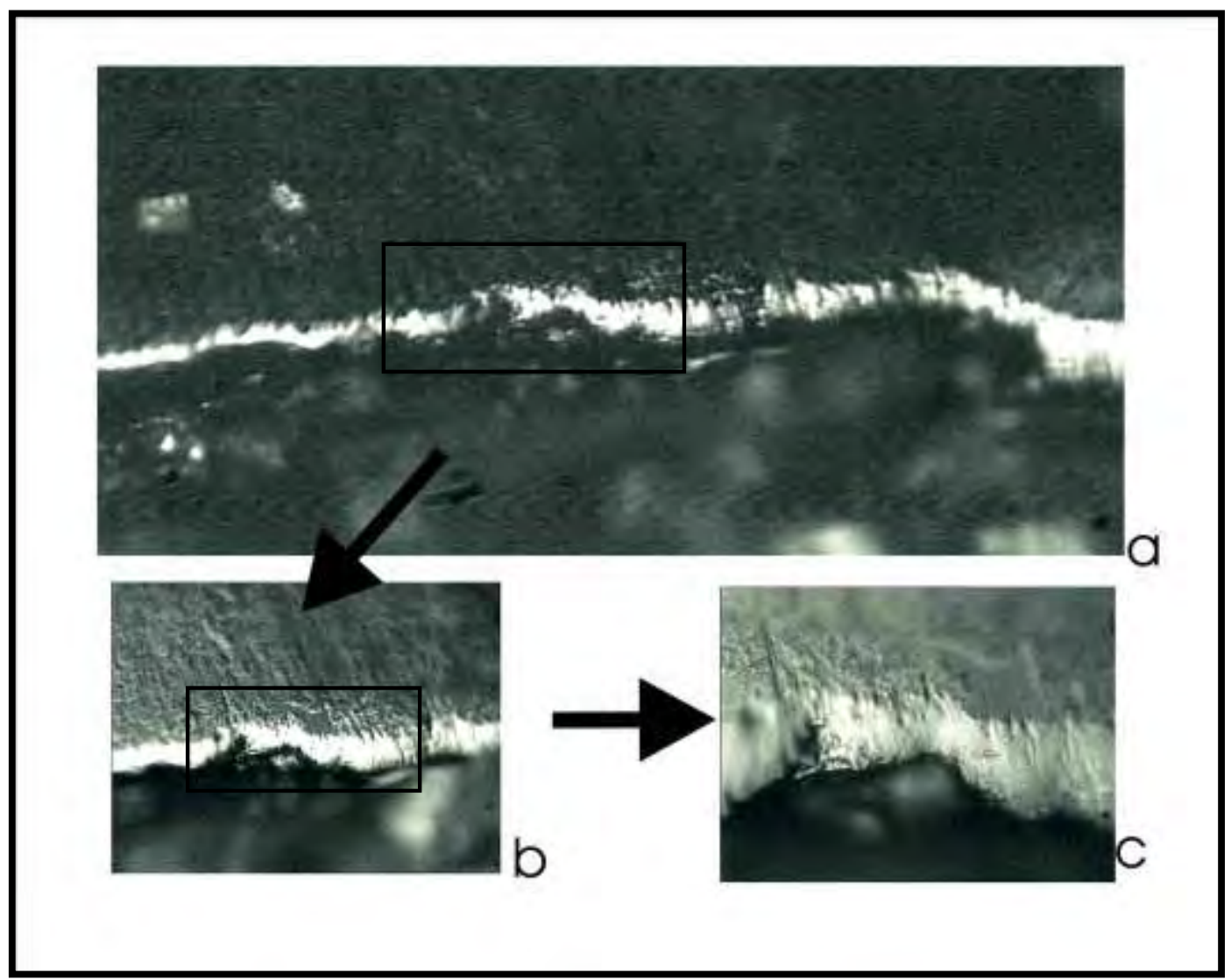

Figura 6. 5. Rastros de uso sobre artefactos experimentales. a: fotomicrografía de filo de un raspador experimental de vidrio después de 30 minutos de uso sobre hueso fresco, tomada a 100X. b: detalle del sector señalado en a, 200X. c: detalle del sector señalado en b, 500X 


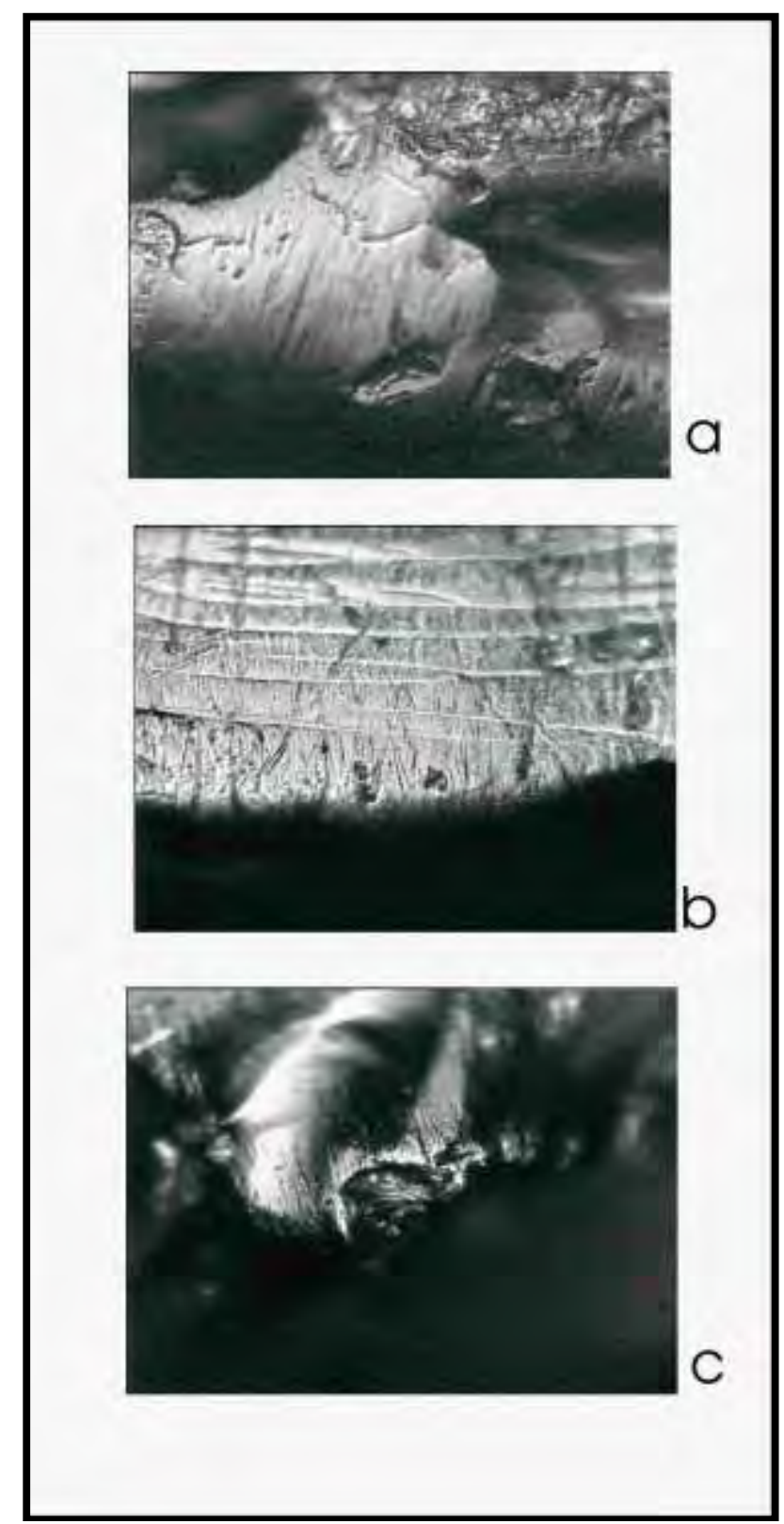

Figura 6. 6. Rastros de uso sobre diferentes materiales. a: trabajo sobre hueso, $30 \mathrm{~min}, 200 \mathrm{X}$. b: trabajo sobre cuero, $30 \mathrm{~min}, 200 \mathrm{X}$. c: trabajo sobre madera, 30 $\min , 200 X$.

En el caso del trabajo de pieles, el filo muestra un marcado redondeamiento acompañado por estrías orientadas según la dirección de utilización. Al contrario en los materiales duros (tanto vegetal como animal), el esquirlamiento del filo es mucho más pronunciado; los micropulidos son brillantes, más desarrollados en las zonas altas de la microtopografía, con superficies lisas y aspecto ligeramente ondulado. El desprendimiento de esquirlas provoca el retroceso de los frentes de los raspadores, que va removiendo las zonas del filo en las que se desarrollan micropulidos e impide 
que se alcance el estadio de micropulido bien desarrollado. Este proceso se hace evidente al comparar el grado de desarrollo de los rastros de uso en los puntos de referencia seleccionados para ello (Figura 6.6).

El análisis de los instrumentos después de la segunda fase de trabajo, al cabo de 30 minutos, permitió detectar micropulidos bien desarrollados y característicos del material trabajado (Figura 6.7). En el caso del trabajo sobre madera y hueso éstos son casi siempre poco extendidos a lo largo del filo, apareciendo sólo en algunas porciones. El micropulido producido por el trabajo del hueso presenta el "craquélé" característico observado sobre otras materias primas; es profundo, pero siempre presenta menos volumen que el producido por el trabajo de la madera. Este último al contrario es ligeramente más espeso y además presenta estrías características. En los instrumentos utilizados sobre pieles se observa un marcado redondeamiento, que se manifiesta a lo largo de prácticamente toda la porción del filo que estuvo implicada en el proceso de uso. El micropulido está bien desarrollado y va acompañado por estrías perpendiculares; tanto redondeamiento como estrías son mucho más abundantes en el caso del trabajo con agregado de pigmento mineral.

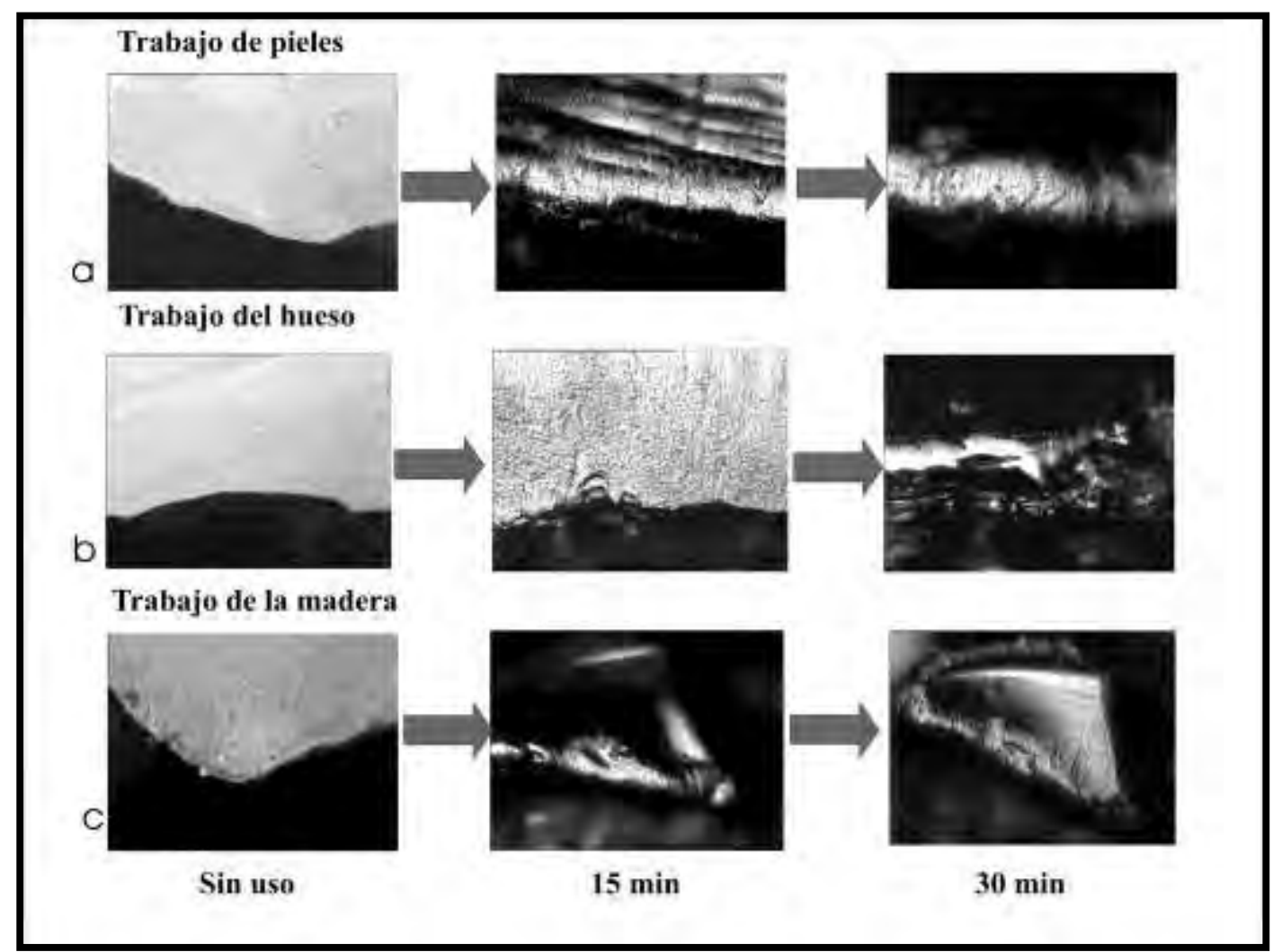

Figura 6. 7. Modificación de la microtopografía durante el proceso de uso. Fotomicrografías de filos de tres raspadores de vidrio tomadas a diferentes intervalos, $200 \mathrm{X}$. 


\section{EXPERIMENTACION TECNOLÓGICA Y FUNCIONAL SOBRE TOBA SILICIFICADA (MIRAFLORES)}

La decisión de experimentar en esta materia prima se debe a la presencia de la misma en uno de los sitios ubicado en el lago Fagnano. En efecto en el sitio Kami 1 aparecieron una cantidad importante de raspadores confeccionados sobre toba silicificada. Una vez que se pudo determinar el posible origen del afloramiento, y obtenidas las muestras necesarias, cedidas gentilmente por la Lic. Flavia Morello y equipo, se llevó a cabo el trabajo experimental.

Dado que el programa experimental sobre esta materia prima, comenzó hace poco tiempo, se presentarán aquí los resultados obtenidos hasta ahora. Los mismos abarcan trabajos sobre dos tipos de materiales, madera y piel.

\section{La materia prima}

La toba silicificada Miraflores procede de un afloramiento primario perteneciente a la Formación Palomares del Terciario Superior (Prieto et al. 2004; Borrazzo 2009; Borrazzo et al. 2010), localizado en el valle del chorrillo Miraflores ubicado en territorio chileno al oeste de las nacientes del río Cullen. El afloramiento está siendo estudiado por investigadores de la Universidad de Magallanes, Chile, quienes facilitaron dos nódulos de tamaño mediano pequeño y forma irregular que permitieron la extracción de lascas para la confección de los instrumentos.

\section{Experimentación tecnológica}

Para este trabajo se confeccionaron dos raspadores simples de filo distal corto a fin de utilizarlos para trabajar cada uno de los materiales mencionados. Para ello se extrajeron lascas por percusión directa. El retoque fue efectuado de forma directa, desde la cara ventral hacia la dorsal con un retocador con punta de cobre.

Durante el proceso de manufactura de los instrumentos pudo notarse que la baja flexibilidad de la materia prima, que se fracturaba fácilmente. Por otra parte, la estructura de la roca mostraba, al mirarla con lupa binocular, sectores de microporosidad que probablemente ayudaran a que se fracturara tan fácilmente mientras se formatizaban los filos. En consecuencia, los filos 
obtenidos tenían bordes filosos, que se regularizan rápidamente pero que no se embotan con facilidad.

\section{Experimentación funcional}

A los fines de la experimentación funcional, los dos raspadores fueron usados para procesar madera fresca de lenga (gen. Nothofagus) y cuero fresco de oveja (Ovis aries). Los tiempos de uso, al igual que con el vidrio, se dividieron en intervalos de 0-5, 5-15 y 15-30 minutos, en los cuales se registró a través de microfotografía digital la evolución del micropulido en el mismo sector del filo.

Antes de comenzar el trabajo, los filos presentan una topografía bastante particular. Son filos muy regulares, con una superficie lisa (Figura 6.8), pero que en ciertos lugares muestran sectores con microporosidad (Figura 6.8).

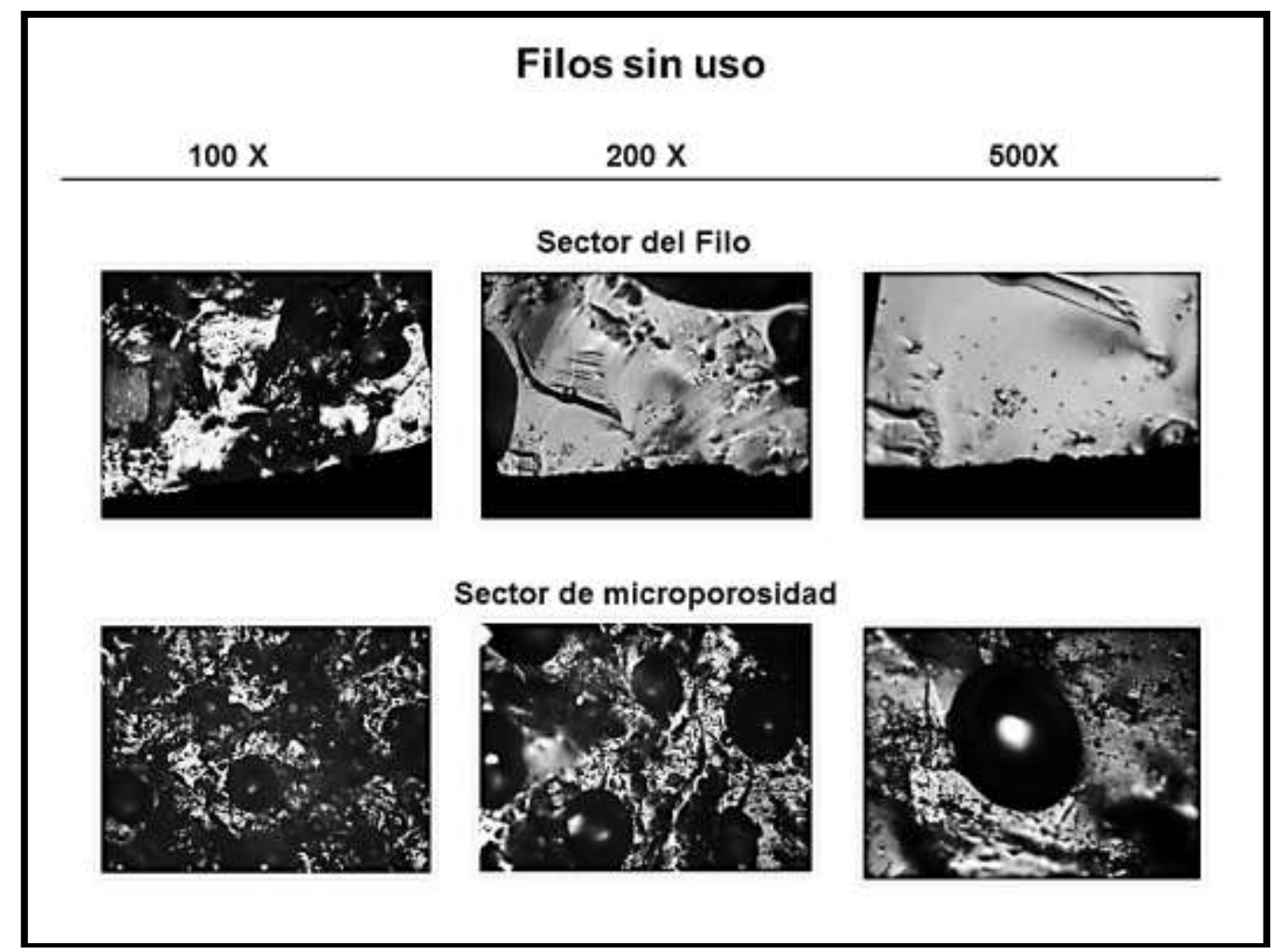

Figura 6. 8. Imagen de los filos frescos y de los sectores que presentan microporosidad. Fotomicrografías tomadas a 100X, 200X y 500X

En la primera etapa, al comenzar el trabajo sobre los dos materiales (madera y piel), sólo se desprendieron aquellas microlascas adventicias y microfragmentos que no se habían desprendido durante el proceso de retoque 
para la formatización de los filos, pero luego, una vez que estos elementos se desprendieron del borde los filos, estos se mantuvieron bastante estables (Figura 6.9). Tal vez en el caso de la madera se produjo un mayor desgranamiento del filo, aunque este no fue muy importante. Durante la segunda etapa, 15 minutos, los filos fueron redondeándose y generando estrías de uso, que permiten determinar la cinemática del trabajo (Figura 6.9). De todas formas no se observaron micropulidos bien desarrollados, sino micropulidos correspondientes a los primeros estadios de desarrollo, que se manifiestan por el suavizado hasta la casi obliteración de los rasgos tecnológicos.

Como sucede en la mayoría de las rocas heterogéneas, en el trabajo de pieles, el filo muestra un marcado redondeamiento acompañado por estrías orientadas según la dirección de utilización. Al contrario en el material duro de origen vegetal, los micropulidos son brillantes, más desarrollados en las zonas altas de la microtopografía, con superficies lisas y aspecto ligeramente ondulado.

El análisis de los instrumentos después de la tercera etapa, 30 minutos, permitió detectar micropulidos bien desarrollados y característicos del material trabajado (Figura 6.9). En el caso del trabajo sobre pieles se observa un marcado redondeamiento, que se manifiesta a lo largo de prácticamente toda la porción del filo que estuvo implicada en el proceso de uso. En el instrumento utilizado sobre madera el micropulido es casi siempre poco extendido a lo largo del filo, apareciendo sólo en algunas porciones; es ligeramente espeso y presenta estrías características. 


\section{Filos utilizados}

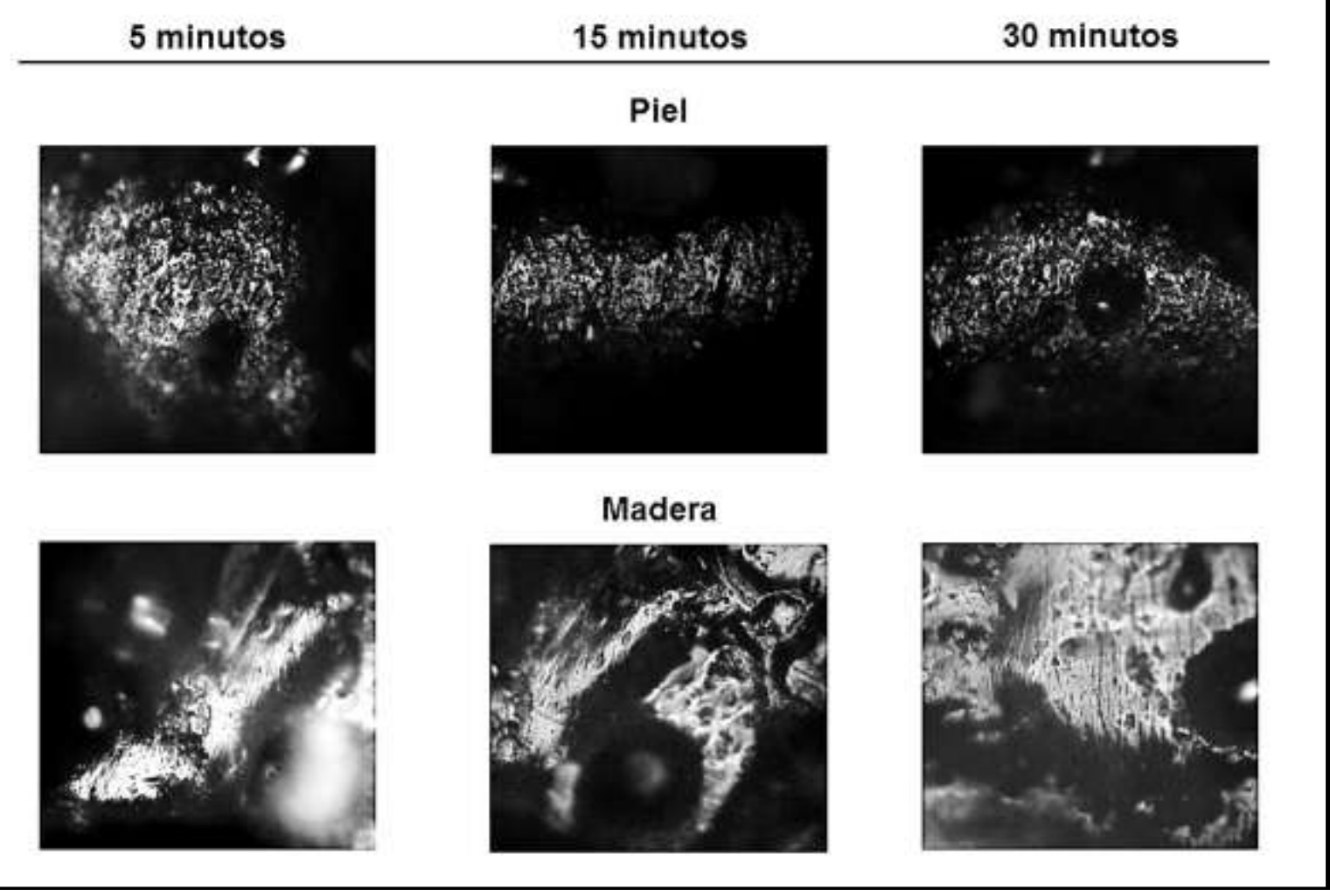

Figura 6. 9. Desarrollo de los micropulidos en las distintas etapas de trabajo. Fotomicrografía tomada a $200 \mathrm{X}$

\section{CONCLUSIÓN}

El estudio experimental nos permitió abordar el material arqueológico desde una problemática nueva planteada a partir de la utilización de materias primas atípicas para el área de estudio.

Para el caso de los instrumentos confeccionados en vidrio, los resultados obtenidos desde el análisis tecno-morfológico en relación con los productos de talla generados por los procesos de manufactura de artefactos, como las microlascas, en especial en el caso de los raspadores, sugieren que pueden ser extendidos a otros conjuntos artefactuales con características de fragmentos soporte (forma base) y tecnomorfológicas comparables a los aquí analizados, es decir confeccionados en vidrio que se caracteriza por la existencia de dos caras planas.

El estudio tecno-morfológico permitió constatar que, más allá de la gran distancia numérica entre la cantidad de desechos que se producen durante la reducción de una punta de proyectil y la confección de un raspador, se 
observan diferencias en cuanto a las características de los desechos producidos. Ello implica que la recolección y el análisis sistemático de todos los microdesechos de talla debería permitir determinar qué tipo de instrumento se confeccionó en un sitio en particular, aún en ausencia de los instrumentos. En consecuencia, estos criterios fueron aplicados al análisis de los materiales del sitio Ewan I que se presentan en el capítulo 7.

En cuanto al análisis funcional de los raspadores utilizados en diferentes procesos de uso, fue posible llegar a una primera caracterización de los procesos de formación de rastros microscópicos en vidrio, considerando sus grados de desarrollo para los distintos tiempos de uso y materiales trabajados. Las características observadas son compatibles con el modelo general de formación de rastros de uso que explica las transformaciones que se producen en la interfase, para rocas homogéneas y heterogéneas. La principal observación a tener en cuenta es que, dada la fragilidad de los filos antes de que logren alcanzar su perfil de estabilidad, se produce un marcado esquirlamiento sobre ambas caras (tanto la cara ventral como el propio frente del raspador) que remueve constantemente las zonas del filo en los que se han ido desarrollando micropulidos. En consecuencia, los tiempos de uso requeridos para que se formen micropulidos extendidos con buen nivel de desarrollo y en los que es posible identificar el material trabajado es mayor que en el caso de otros materiales analizados.

Con respecto a los raspadores confeccionados sobre toba silicificada, a partir de los primeros minutos de uso se pudo constatar que los microesquirlamientos cesaron y comenzaron a regularizarse para completar micropulidos bien desarrollados al cabo de 30 minutos de trabajo. En relación con esto, se podría decir que en el trabajo sobre madera el esquirlamiento fue un poco más importante que en el trabajo sobre piel. En comparación con el vidrio, la toba silicificada Miraflores puede producir micropulidos diagnósticos en menor tiempo, ya que no producen tanto esquirlamiento durante el proceso de uso.

Los raspadores de toba silicificada demostraron ser efectivos al momento de trabajar sobre los materiales mencionados. El trabajo de raspado sobre uno y otro no presentó dificultad, debido principalmente al bajo grado de desgranamiento y de embote de los filos. Esto permitió un trabajo parejo a lo 
largo de los 30 minutos. Las riolitas en cambio sufren un poco más de desgranamiento al comienzo, aunque es una materia prima muy dura en la cual el desarrollo de micropulidos es mucho más lento. Esta dureza también influye al momento de confeccionar un instrumento. Al seleccionar una materia prima para realizar instrumentos específicos como los microrraspadores por ejemplo, puede ser más atractivo trabajar con una roca que no presenta gran dificultad para la talla y además efectiva para el uso para la que fue elegida. 


\section{Capítulo 7}

ANÁLISIS TECNO-MORFOLÓGICO Y FUNCIONAL DE LOS CONJUNTOS LÍTICOS: LA LOCALIDAD EWAN 


\section{INTRODUCCIÓN}

En este capítulo se presentarán los resultados de los análisis realizados sobre los conjuntos líticos de las localidades arqueológicas Ewan y Kami. Estos conjuntos, por sus características, juegan un rol fundamental para comprender los procesos de gestión de las materias primas y de los recursos líticos por parte de la sociedad Selknam y pre-Selknam en la zona central de Tierra del Fuego. Por ello es imprescindible encarar un estudio múltiple, que incluya análisis tecnológicos, morfológicos y funcionales integrados, desde la perspectiva del análisis tecno-funcional (cf. capítulo 3).

\section{ESTUDIOS TECNO-MORFOLÓGICOS Y FUNCIONALES DE LA LOCALIDAD EWAN}

A continuación presentamos los resultados de los análisis de los sitios de la localidad Ewan y, en el capítulo próximo, los de la localidad Kami. La forma en que se organizan los datos sigue el orden, en general, de las variables presentadas más arriba. Luego, al finalizar la presentación de los datos en relación a cada variable, se muestra la relación que tiene cada una de ellas con las materias primas representadas en el sitio.

El caso de Ewan, que presentamos en primer lugar, es totalmente excepcional y se aparta un poco de ese modelo, ya que tiene la particularidad de tratarse de un sitio en el que la materia prima seleccionada para los artefactos es única.

Como decíamos al comienzo, el eje que centra este estudio es el concepto de cadena operativa, que abarca todas las actividades sociales relacionadas con la producción lítica. Las mismas incluyen desde la búsqueda de las materias primas, el transporte, la transformación de las rocas en formas base y los artefactos retocados o no, los restos de la confección de estos artefactos y finalmente el uso y descarte de los instrumentos. También incluye la reparación y el reciclado de los instrumentos líticos.

El conjunto lítico proveniente de los sitios de la localidad arqueológica Ewan, se caracteriza por estar confeccionados únicamente en vidrio. Como se 
mencionó en el capítulo 4 el detalle más llamativo de esta localidad arqueológica es su función ceremonial. Ewan está compuesta por dos sitios separados por 200 metros aproximadamente, pero que son totalmente contemporáneos uno del otro.

El conjunto lítico del primer sitio se caracteriza por la presencia de restos de talla menores a $2 \mathrm{~cm}$, mientras que el conjunto del segundo sitio aparte de estar conformado por restos de talla menores a $2 \mathrm{~cm}$, presenta instrumentos retocados como raspadores, puntas de proyectil y un filo retocado unifacialmente.

\section{Metodología}

Para desarrollar el análisis de los materiales recuperados en los sitios arqueológicos de la localidad Ewan, el problema que se presentaba, como se mencionó con anterioridad, era la escasez de trabajos teóricos-metodológicos sobre el vidrio como materia prima. Por ello se decidió llevar a cabo una etapa preparatoria, tal como se presentó en el capítulo 6. Esta consistió en realizar un programa experimental para evaluar las características de los residuos generados al replicar los instrumentos de vidrio descubiertos en los sitios y, en particular, si las microlascas podrían informarnos de la confección de algún instrumento en particular. A continuación, se efectuó la experimentación funcional, para determinar las características de los rastros de uso sobre esta materia prima (ver capítulo 6) (De Angelis et al. 2009).

El análisis tecno-morfológico de los restos de talla así como de los instrumentos fue efectuado siguiendo los lineamientos propuestos tanto por Aschero (1975/1983), como por Piana y Orquera (1986) y Bellelli et al. (198587), dado que con su complementación permitieron un mejor análisis; pero con la salvedad de que todo fue efectuado utilizando lupa binocular debido a que se trata de microlascas.

El análisis funcional de base microscópica fue realizado teniendo en cuenta el modelo de formación de rastros de uso en materiales homogéneos y considerando diferentes variables referidas al esquirlamiento y/o redondeamiento de los filos, estrías y micropulidos (cf. capítulo 3). Se utilizaron 
tanto lupa binocular como microscopio de reflexión de tipo metalográfico con sistema directo para captura y digitalización de imágenes.

Estos lineamientos se siguieron tanto para la confección en la etapa experimental como para el análisis de los materiales arqueológicos provenientes de la localidad arqueológica Ewan.

\section{MATERIALES LÍTICOS DEL SITIO EWAN 1}

El total de la muestra de microlascas de este sitio está representado por un $n=97$, de las cuales 69 son menores o igual que $5 \mathrm{~mm}, 26$ son mayores que $5 \mathrm{~mm}$ y 2 son indeterminadas debido a su forma redondeada.

Los materiales fueron recuperados según dos unidades de extracción (A1 y A3), ambas correspondientes a una misma ocupación. Los materiales líticos se encuentran distribuidos de forma desigual, así vemos que en el nivel A1 tenemos un total de 15 microlascas y en el nivel $A 3$ el mayor número de microlascas, con un $\mathrm{n}=78$, sólo 4 microlascas no pudieron relacionarse con ninguna de las unidades mencionadas.

\section{Análisis tecno-morfológico}

Del total de microlascas un 33\% $(n=32)$ presentan curvatura. Un número similar muestran aquellas que presentan algún porcentaje de corteza con un $n=$ 38. El bulbo está presente en 78 piezas mientras que sólo 12 del total de microlascas tienen labio. Un número alto de las mismas presentan talón, con un $n=83$.

Con respecto a las fracturas, el número está medianamente distribuido con 52 microlascas que presentan fractura y 45 que no presentan. Dentro de las alteraciones se destacan las piezas con una alteración por alta temperatura que les da un aspecto de rodado, $n=37$. También se encuentran algunas piezas con presencia de pátina con un $n=12$.

Un punto a tener en cuenta es la presencia de una gran variedad de colores en los restos arqueológicos recuperados en el Sitio Ewan I. Si bien como mencionamos anteriormente la única materia prima presente es el vidrio, estos se presentan en una gama variada de colores como por ejemplo: azul, 
celeste, transparente, turquesa, rojo con transparente, verde y violeta (Gráfico 7.1 y Figura 7.1$)$.

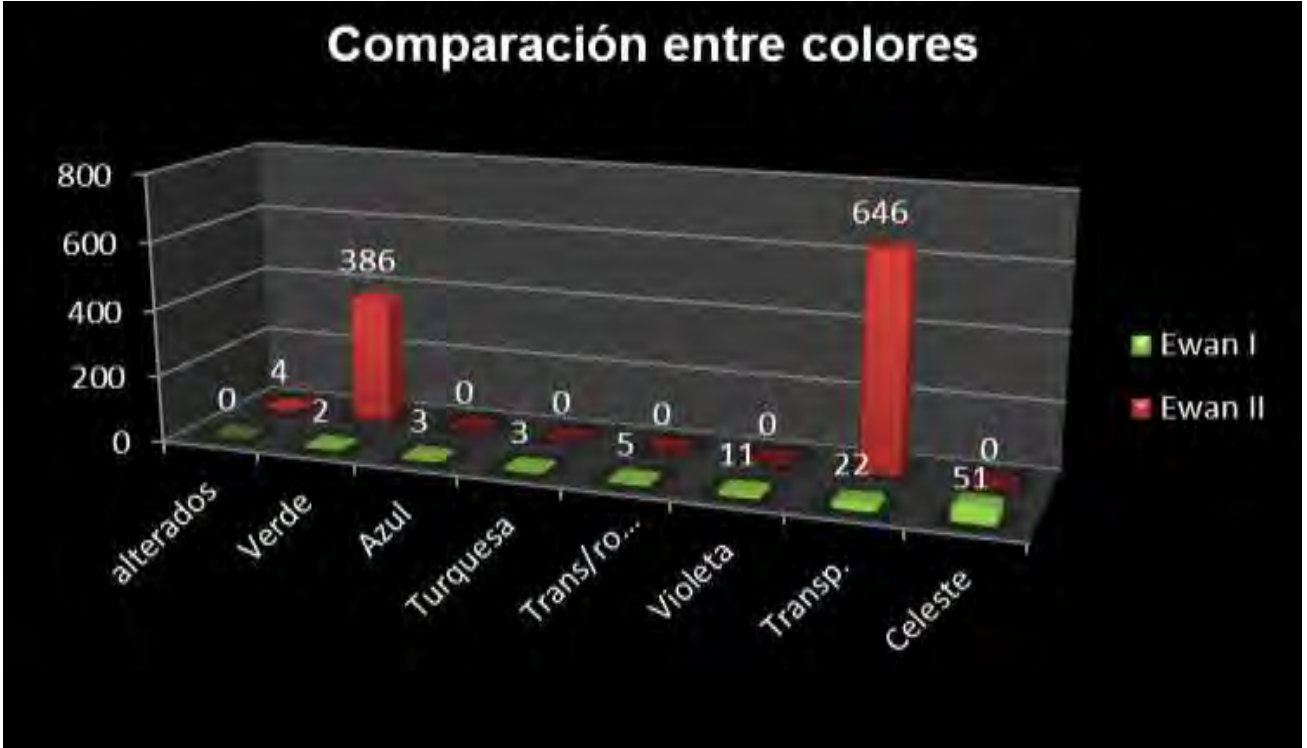

Gráfico 7. 1. Gráfico que muestra la cantidad de microlascas de Ewan I y IIunidad 1 discriminadas por colores.

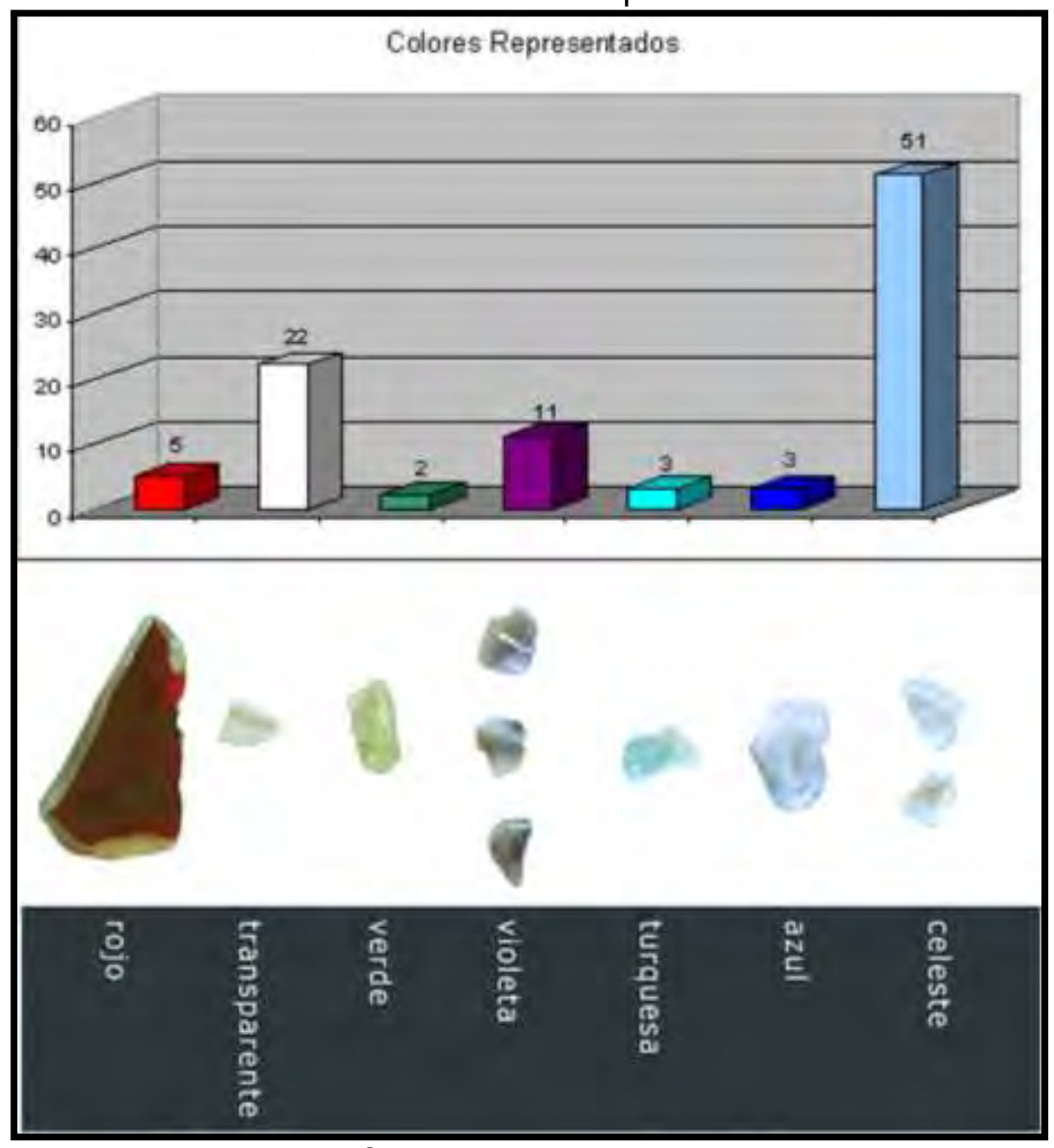

Figura 7. 1. Colores representados en Ewan I 
Finalmente, en cuanto a las morfologías de las microlascas, fue posible identificar microlascas de formatización de filo de raspador, que están representadas por un $n=9$, que correspondería a un $9 \%$ del total de las microlascas recuperadas. Entre las lascas restantes también se pudo reconocer un pequeño grupo que por sus características (curvatura de tipo helicoidal, talones inclinados y longitud) pertenecen a lascas de adelgazamiento bifacial generadas por presión para la confección de puntas de proyectil. Esta correspondencia fue corroborada por los resultados de la experimentación presentada en el capítulo anterior.

\section{MATERIALES LÍTICOS DEL SITIO EWAN II-UNIDAD 1}

A diferencia del sitio anterior, en Ewan II-unidad 1 el número total de microlascas recuperadas es de 4.458, por lo que se decidió hacer un muestreo selectivo basado en la distribución del material en los cuadrantes más cercanos al área de combustión, arrojando un $n=1035$, de las cuales 693 son menores a $5 \mathrm{~mm}$ y 342 son superiores a los $5 \mathrm{~mm}$.

\section{Análisis tecno-morfológico}

Las microlascas que presentan curvatura, corresponden al $45 \%$ de la muestra total. Con respecto a las que conservan corteza tenemos un $56 \%$ del total de la muestra, mientras que un $38 \%$ no presentan corteza en su superficie y hay sólo un $6 \%$ de microlascas que no se pueden determinar por el alto grado de alteración.

El número de microlascas que presentan bulbo es muy alto con un $n=$ 833. Lo inverso sucede con aquellas piezas que presentan labio con un $n=144$. Los talones se encuentran ampliamente representados con un $n=841$. A diferencia que en Ewan I las piezas fracturadas son menos frecuentes que las no fracturadas, 417 y 618 respectivamente.

En cuanto a las alteraciones térmicas, un tercio de la muestra analizada $(n=343)$ presenta dicho tipo de alteración. Algunas sólo presentan pequeñas manchas en su superficie, otras un aspecto como de rodamiento, y otro grupo escasamente representada presenta un aspecto fundido tanto en las superficies planas como en las aristas. Por otro lado existen algunas 
microlascas que presentan pátina con un $n=159$. Estas diferencias podrían estar relacionadas con la cercanía o el contacto directo con el área de combustión.

Con respecto a los colores se encuentran representados, sólo dos colores: transparente con un $\mathrm{n}=637 \mathrm{y}$, verde $\mathrm{n}=385$. También se contabilizaron 9 de un color gris producido por alteración por temperatura. Sólo hay 4 microlascas en las cuales no se pudo definir el color por el alto grado de termoalteración (pepitas) (Gráfico 7.2).

Las microlascas de formatización de filo de raspador si bien en cantidad son muy superiores a las recuperadas en el sitio Ewan I, con un $n=153$, en proporción al número de microlascas analizados de Ewan II-unidad 1 (1036) se comporta de manera similar, a Ewan I, ya que representa un $14 \%$ del total de la muestra (Gráfico 7.2). En cuanto a las microlascas generadas por adelgazamiento bifacial las mismas alcanzan el $10 \%$ de la muestra analizada y coinciden con aquellas reconocidas con los restos de confección de puntas de proyectil.

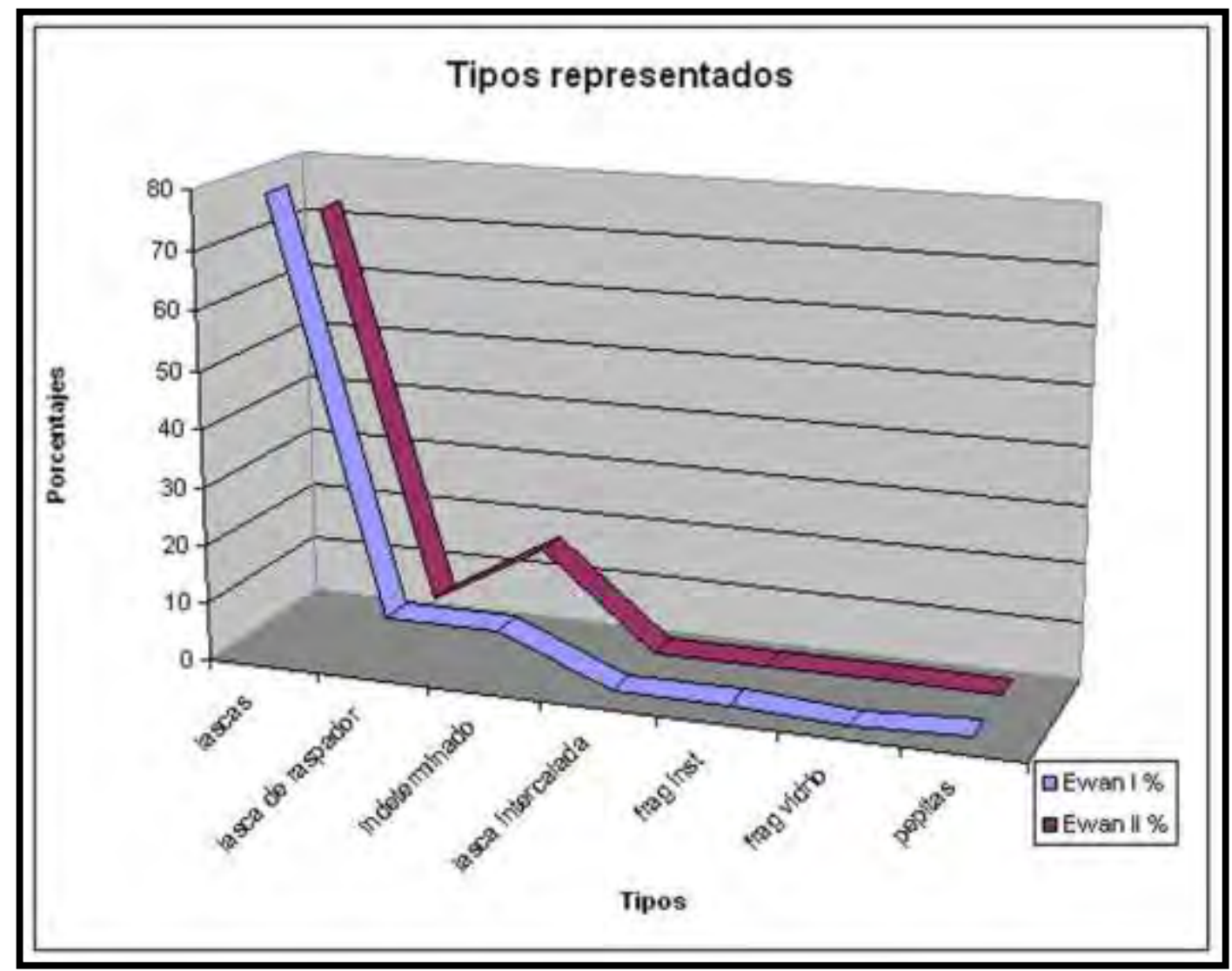

Gráfico 7. 2. Porcentajes de tipos tecno-morfológicos de restos de talla representados, para Ewan I y II 
Los instrumentos retocados recuperados en el sitio son escasos, y se encuentran representados tecnomorfológicamente por 3 tipos diferentes: Puntas de proyectil, raspadores y filo largo retocado unifacialmente.

Las siete puntas de proyectil presentan fracturas, aunque en diferentes lugares y grados. Dos son las menos afectadas, una confeccionada sobre vidrio transparente cuyas medidas son $1,7 \mathrm{~cm}$. de largo por $1 \mathrm{~cm}$. de ancho, la cual muestra una fractura en un extremo del pedúnculo, la otra de mayor tamaño 2,2 cm. de largo por 1,7 cm. de ancho, de color verde, opacado por la alteración térmica, sólo presenta una pequeña fractura en el pedúnculo. Una tercera punta está representada por el limbo casi completo, de vidrio transparente. Dentro de los fragmentos que presentan mayor alteración podemos mencionar cuatro aletas, tres de las cuales son de color verde y una transparente, así como dos fragmentos distales de limbo de color transparente (Figura 7.2).

En cuanto a la morfología particular de ambas puntas podemos mencionar para los dos casos un limbo corto, anchura máxima ubicada en la base del limbo (post-expandido), y la forma del ápice es normal. En cuanto a las aletas, ambas presentan aletas dobles y simétricas, aunque las de la punta de color verde corresponden a las denominadas destacadas y las de la punta transparente a las rectas. En cuanto a la forma de la base también pueden verse diferencias dado que en la primera es escotada y en la otra pedunculada. En ambos casos los pedúnculos están fracturados, aunque en la pieza transparente al haber conservado una parte del mismo se lo podría ubicar dentro de los denominados paralelos cóncavos.

Finalmente, en relación al retoque, ambas piezas, se caracterizan por tener un retoque regular extendido, sin presentar restos de corteza.

En cuanto al filo lateral largo, el mismo presenta dos fracturas una longitudinal, a lo largo de toda la pieza, y otra transversal, por lo que no se descarta la posibilidad de que corresponda a una forma base para la confección de una punta de proyectil. Los retoques son escamoso regular, parcialmente extendido, unifaciales. Este instrumento se confeccionó sobre vidrio de color verde (Figura 7.2). 


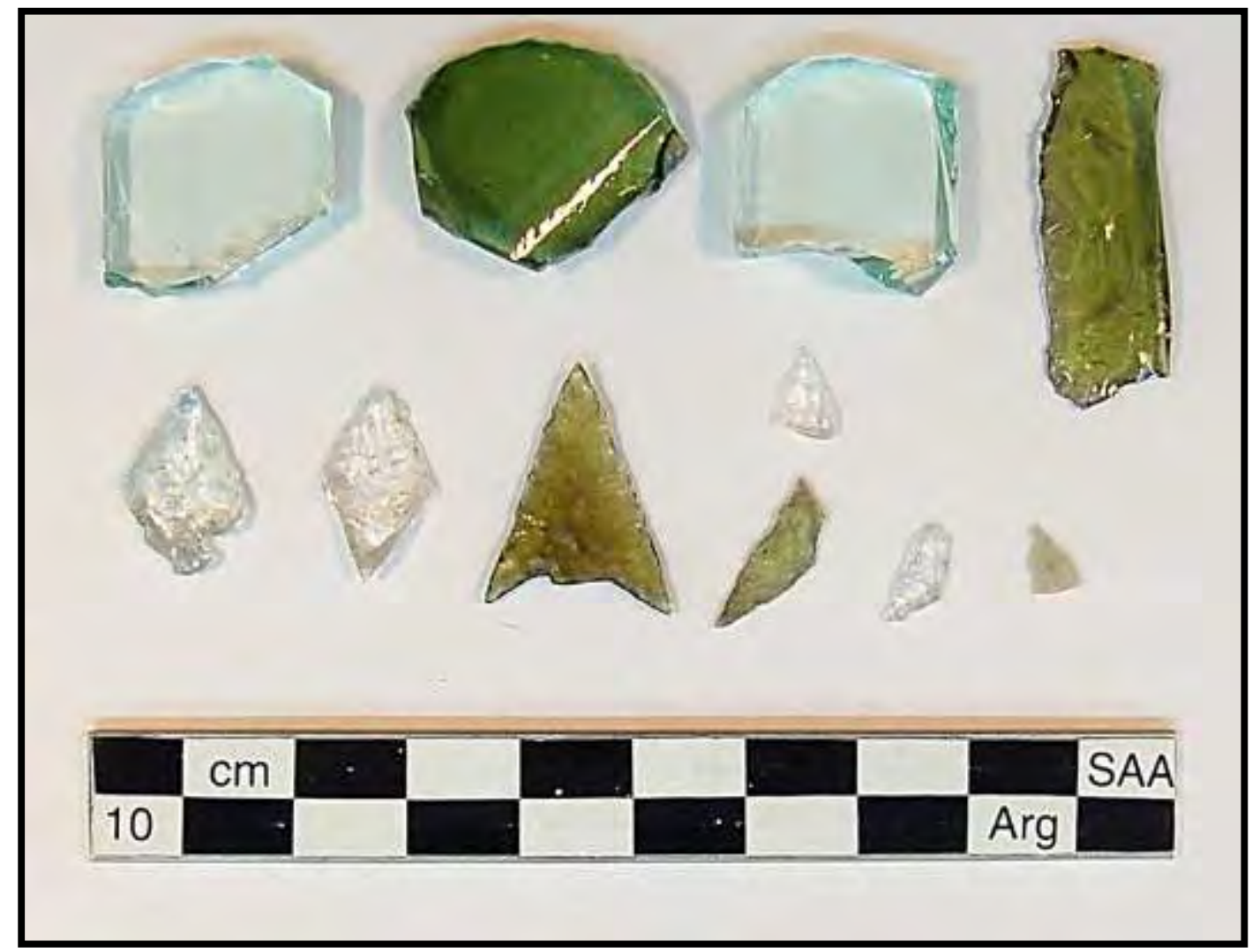

Figura 7. 2. Arriba: De izquierda a derecha: raspadores y filo largo retocado. Abajo: Puntas y fragmentos de puntas de proyectil del sitio Ewan II-unidad 1

Como se mencionó anteriormente, entre los instrumentos se recuperaron tres raspadores que presentan básicamente las mismas características: todos corresponderían a raspadores unguiformes, las dimensiones rondan los $2 \mathrm{~cm}$ por $2 \mathrm{~cm}$. el retoque es paralelo, regular. La diferencia se presenta en los colores ya que dos están confeccionados sobre vidrio transparente y uno sobre vidrio de color verde (Figura 7.2).

\section{Análisis funcional}

El análisis funcional de base microscópica se llevó a cabo sólo sobre los instrumentos retocados recuperados en el sitio Ewan II-estructura 1, dado que en Ewan I no se encontraron artefactos con filos naturales potencialmente utilizables. Con respecto a los retoques intencionales, en materias primas como el vidrio, estos pueden confundirse, algunas veces, con aquellos producidos por factores tafonómicos como por ejemplo el pisoteo o la misma presión del sedimento. Sin embargo, hay ciertas características que permiten diferenciar unos de otros, entre ellas podemos mencionar que los retoques tafonómicos, 
en general, son muy superficiales y por lo tanto no logran un adelgazamiento o aguzamiento del filo tan pronunciado como cuando el retoque es realizado por un retocador (Clemente Conte y Gómez Romero 2006, 2008). Por otro lado, dado que gran parte de los materiales se encontraban cercanos al área de combustión, algunos de ellos se encuentran parcial o totalmente alterados por el fuego. Los instrumentos retocados seleccionados para el análisis funcional se encuentran representados por tres raspadores, un filo largo retocado unifacialmente y dos puntas de proyectil.

El análisis microscópico de los materiales permitió poner en evidencia los principales rasgos microscópicos de la termoalteración, que se manifiestan como una pátina y un aspecto rodado en la superficie, que impidió la identificación de microrrastros de uso. Entre los artefactos retocados alterados por el fogón podemos mencionar el filo largo retocado y las puntas de proyectil, sin embargo los tres raspadores recuperados en la excavación no presentaron ningún indicio de termoalteración.

El análisis funcional sobre los filos retocados de los raspadores permitió determinar que los tres fueron utilizados, que además hubo casos de reactivación de los filos, también se pudo determinar tanto la cinemática como el material sobre el que trabajo el instrumento.

\section{Raspador 156:}

Este raspador fue confeccionado sobre vidrio transparente, cuyos bordes laterales pueden definirse como fracturas perpendiculares al plano ventral, y están frescos en su totalidad (Figura 7.3), el borde proximal es un plano de fractura compuesto, también perpendicular al plano ventral y tiene astilladuras que parecen accidentales.

El filo del frente de raspador tiene rastros de uso, intensos bien desarrollados en la mitad derecha, es un filo redondeado brillante, pero sin las estrías perpendiculares características del trabajo sobre piel (Figura 7.3). En vista ventral sí pudieron verse estrías, pequeñas, entrecruzadas, muy abundantes características del trabajo sobre piel. Todo esto sugiere que el trabajo se realizó con un ángulo relativamente bajo. Este filo presenta en la mitad izquierda rastros menos desarrollados localizados sólo en las porciones 
salientes del filo, mientras que en las concavidades no hay rastro y sí marcas tecnológicas, pudiendo indicar reactivación.

Raspador 110:

Para la confección de este instrumento se utilizó vidrio de color verde. El filo frontal, muy extendido, termina en dos puntas, y los rastros de uso se encuentran muy bien desarrollados a lo largo de todo el filo e incluso en las dos extremidades del mismo, presentando redondeamiento y estrías sobre la cara ventral.

Presenta gran cantidad de marcas de alteración postdepositacionales (estrías y rayas grandes) (Figura 7.4) y el extremo proximal se encuentra astillado. El filo lateral derecho se caracteriza por la presencia de un retoque alternante, sin rastros de uso, mientras que el filo lateral izquierdo es un plano perpendicular a la cara ventral y tiene micropulido con estrías perpendiculares al filo que se extienden desde la unión con el frente hasta la mitad del filo lateral $(1 \mathrm{~cm})$. No pudieron observarse marcas de enmangue. La extensión de los rastros de uso a lo largo del filo y extremidades del filo y lateral izquierdo sugieren que no se utilizó enmangado y que, aparentemente, no fue reactivado (Figura 7.4).

\section{Raspador 024:}

Al igual que el primer raspador, fue realizado sobre vidrio transparente. El filo frontal es ligeramente convexo, mientras los dos bordes laterales son planos perpendiculares a la cara ventral. El filo lateral izquierdo presenta esquirlamientos discontinuos, algunas estrías y marcas tafonómicas, aunque ningún rastro funcional. El frente del raspador, en el ángulo con el filo izquierdo, tiene rastros de uso apenas desarrollados, luego hay puntos de rastros más intensos aproximadamente a un cm. del ángulo, después los rastros aparecen poco desarrollados en la parte media del filo. Hacia la derecha del filo frontal, cerca del ángulo que forma con el filo derecho, hay otro punto con rastros más desarrollados. Los puntos de los micropulidos intensos no están relacionados con salientes del filo, lo que podría estar indicando reactivación (Figura 7.5). En el filo lateral derecho no pudieron observarse rastros de uso, aunque sí un microesquirlamiento intenso bien desarrollado y continuo (Figura 7.5). En el 
extremo proximal hay un filo restringido con retoque, tipo raspador, inverso, en relación con el filo frontal, sin rastros de uso y con algunas estrías postdepositacionales. Dicho filo pudo haber sido preparado para la protección de la mano, o por procesos postdepositacionales. Todo lo que es el extremo proximal se complementa con una fractura.
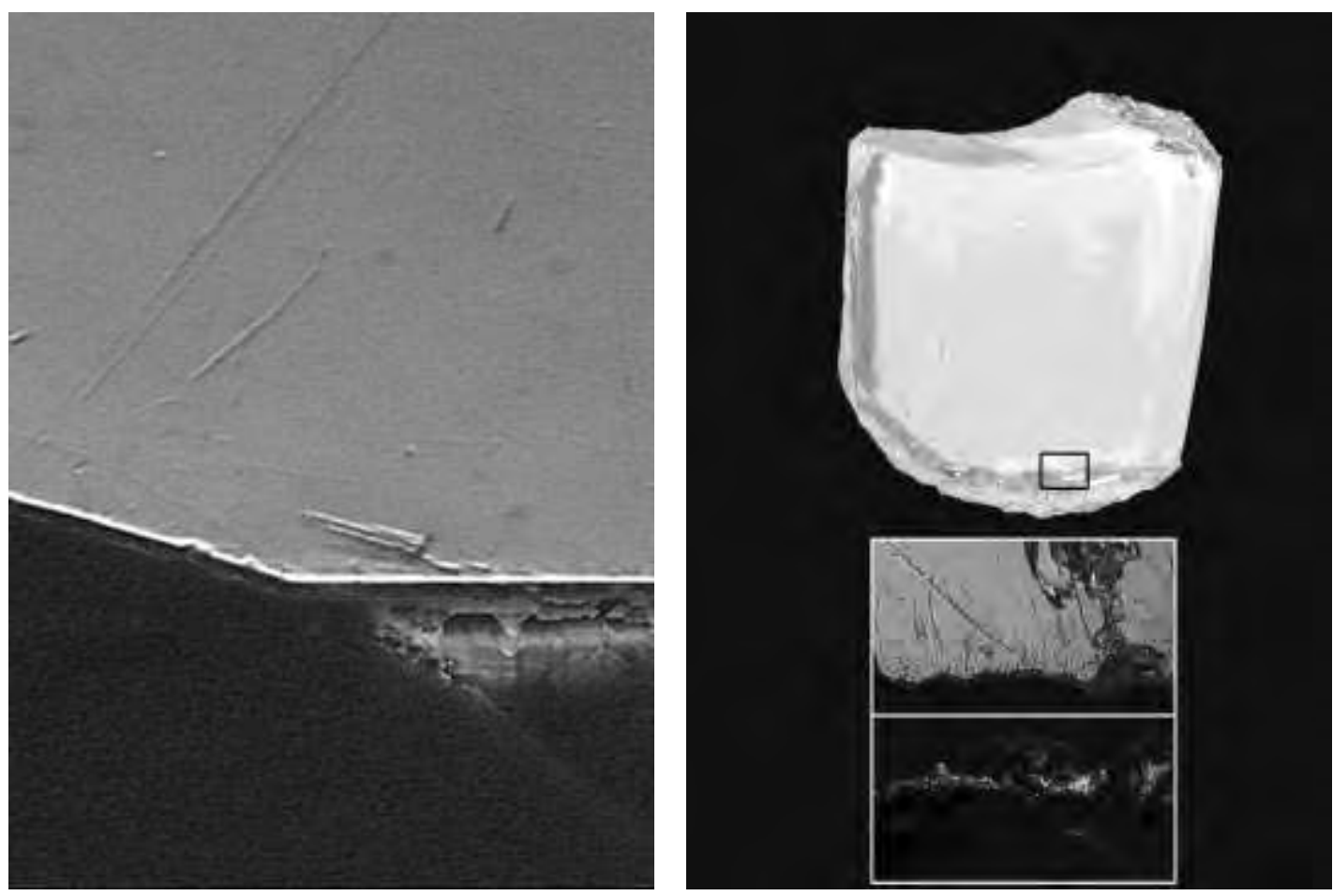

Figura 7. 3. Raspador 156. Izquierda: microfotografía de filo lateral, fresco. Derecha: frente con rastros de uso sobre piel. 200X. 

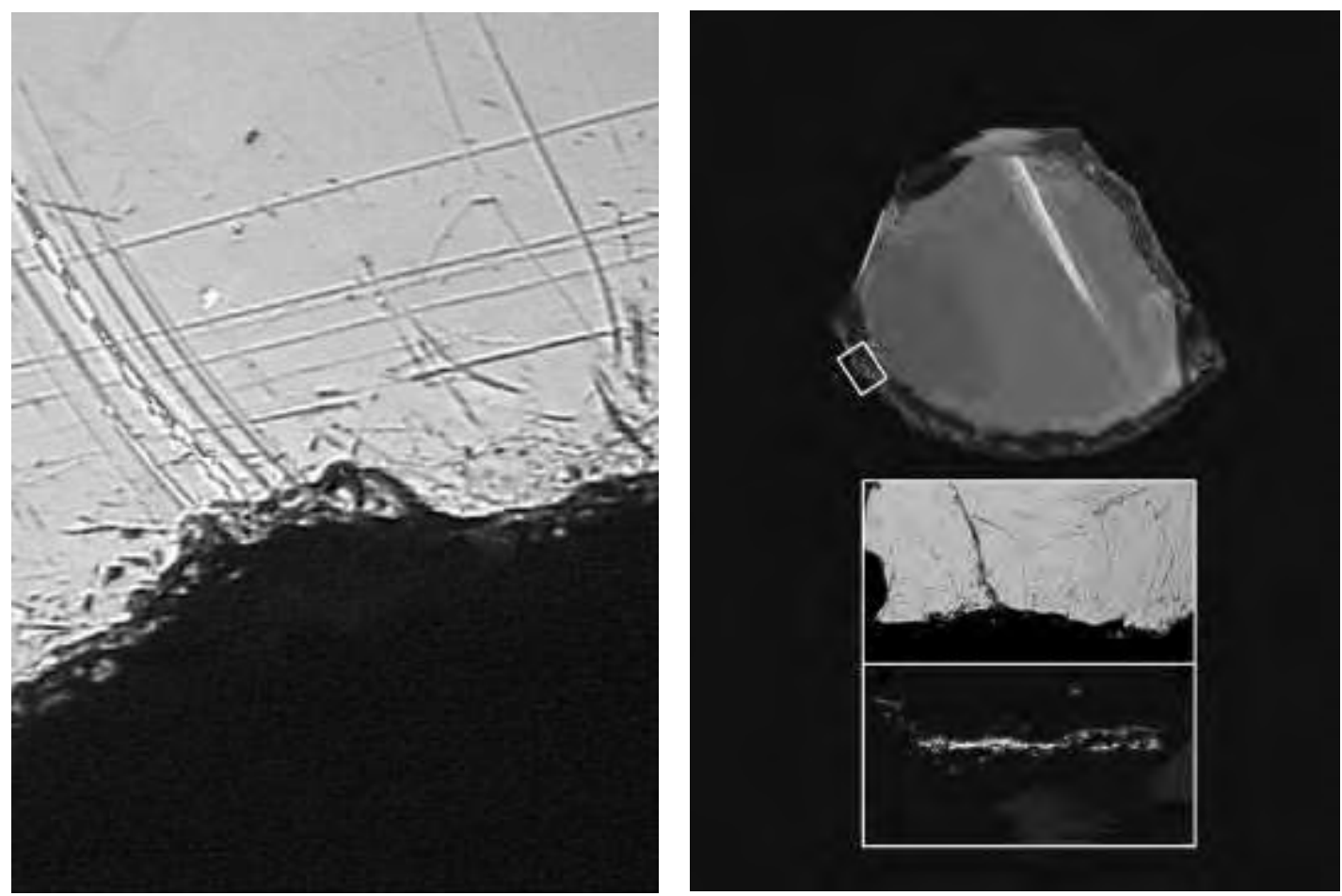

Figura 7. 4. Raspador 110. Izquierda: microfotografía de alteraciones tecnológicas y postdepositacionales. Derecha: filo frontal con estrías y rastros de uso sobre piel. 200X.
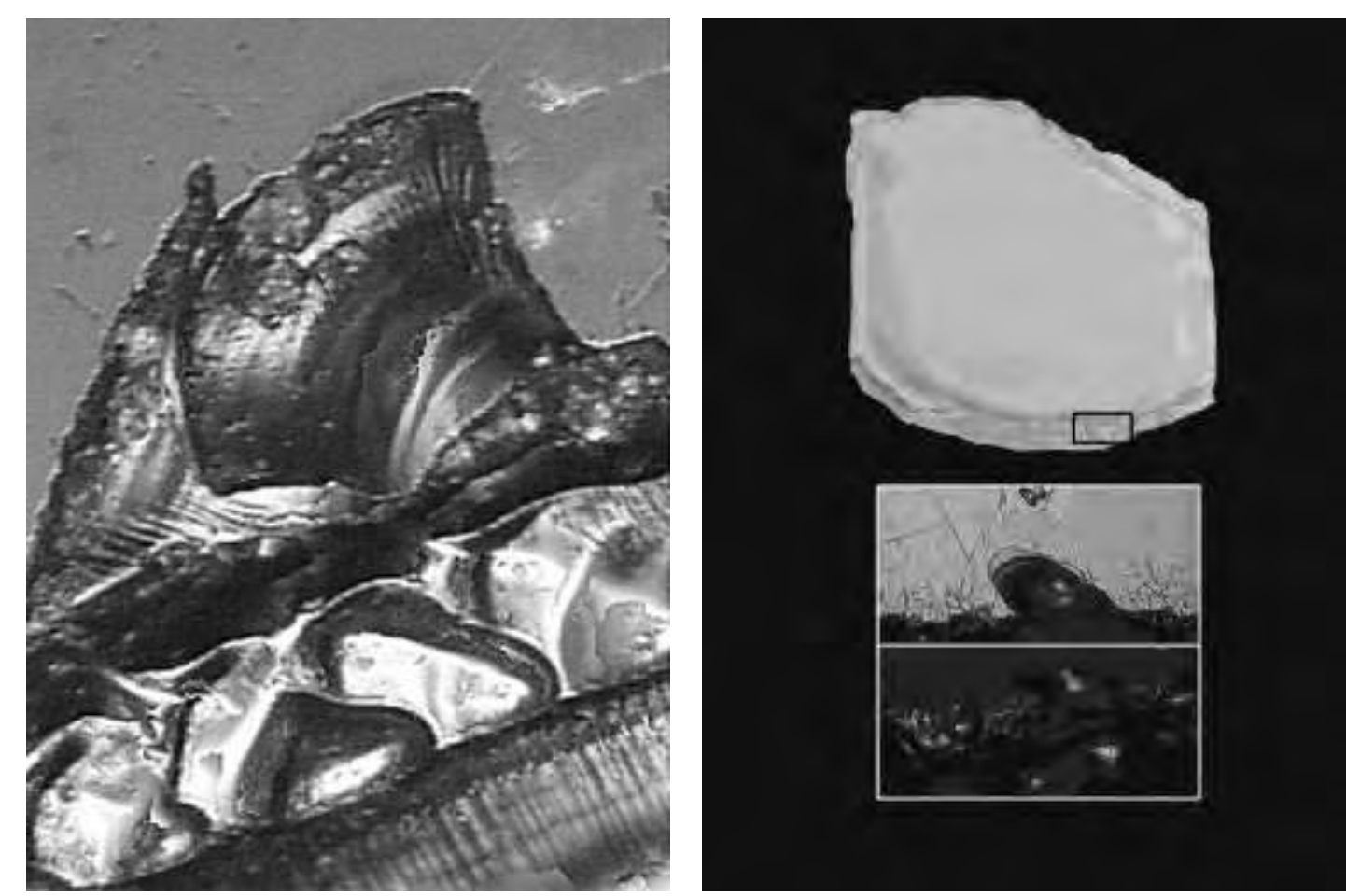

Figura 7. 5. Raspador 024. Izquierda: microfotografía de microesquirlamientos tecnológicos. Derecha filo frontal con estrías y rastros de uso sobre piel. 200X. 


\section{DISCUSIÓN}

El estudio de los materiales excavados en los sitios Ewan I y Ewan II (estructura 1) permitió por primera vez tener acceso a un sitio con un tipo de comportamiento singular con respecto a la materia prima para la confección de artefactos líticos. En efecto, se trata de una única materia prima, el vidrio.

La selección de este material para los instrumentos confeccionados puede tener que ver con sus cualidades para la talla y la facilidad que presenta para la confección de instrumentos como los raspadores o puntas de proyectil, en relación con las materias primas locales. Además el vidrio presenta instrumentos con filos que tienen características comparables a las de los materiales homogéneos y son altamente efectivos.

A modo de resumen, como puede observarse por los datos mencionados precedentemente, entre los dos sitios existen importantes similitudes en el comportamiento del material lítico recuperado en las excavaciones, como por ejemplo el tipo de materia prima y el porcentaje de microlascas que indican formatización de raspadores, que es prácticamente el mismo en ambos sitios. (Gráfico 7.2).

Sin embargo también existen importantes diferencias que estarían relacionadas a las diversas actividades llevadas a cabo en cada uno de los sitios. Dentro de estas cabe mencionar al menos dos:

- Una es la gran variedad de colores representados en los desechos de talla del sitio Ewan I, que no provendrían de ventanas o botellas sino de otro tipo de objeto, dado no sólo por los colores sino por las texturas, formas que podrían estar más relacionadas con elementos mucho más decorados. En relación con esto es importante mencionar que ya desde los primeros viajes por parte de los europeos se intercambiaron cuentas de vidrio, frascos y demás objetos de vidrio con los habitantes de Tierra del Fuego (Gusinde 1982 [1937]).

- Otra diferencia que pudo observarse entre ambos sitios es la presencia de instrumentos retocados en Ewan II-unidad 1, también tallados sobre vidrio, donde se encuentran representados raspadores $(n=3)$, puntas de proyectil $(n=$ 3) y fragmentos de puntas ( $n=6$ : tres aletas verdes y una aleta transparente, y 2 fragmentos distales de limbo), y un filo largo retocado. En contraposición, en 
Ewan I no apareció ningún instrumento retocado y solamente se recuperó un fragmento de instrumento alterado posiblemente por termoalteración.

También se observan algunas diferencias en cuanto a los porcentajes de corteza representados en las microlascas. Tanto en Ewan I como II las mayores concentraciones se encuentran entre 0 y 1 . Sin embargo, la distribución en Ewan I es mucho más abrupta que en el sitio II agrupándose un $63 \%$ del total de la muestra entre los porcentajes 0 y 1 . Mientras que en Ewan II-unidad 1 sólo un $39 \%$ representa dichos porcentajes. Con respecto a las indeterminadas sólo se ven representadas en el sitio Ewan II-unidad 1. También es notoria la diferencia numérica en la cantidad de restos de talla descubiertos en ambos sitios.

Finalmente, en cuanto a la aplicación de los resultados experimentales, el trabajo experimental permitió caracterizar diferentes tipos de microlascas correspondientes a la confección de determinados instrumentos retocados, tal es el caso de las microlascas que se producen en la confección de los filos de raspador y de puntas de flecha a partir de fragmentos de vidrio con dos caras planas identificables. Este, según las fuentes etnográficas, era utilizado por los grupos cazadores recolectores tiempo antes de la instalación de los europeos en la isla, ya que podría provenir de naufragios, y podría ser recogido de las playas al momento de incursiones en búsqueda de recursos costeros. Como se mencionó, microlascas resultantes de la producción de frente de raspadores y bifaciales de la confección de puntas de proyectil fueron identificadas en ambos sitios.

Ciertas actividades pueden estar mostrando un patrón del manejo de los recursos, pero también nos están informando sobre el tratamiento que se les daba a los desechos resultantes. Tal es el caso del uso del fogón para eliminar todos los desechos de talla, o los restos de fauna utilizados en la choza del Hain. Ese patrón también puede verse en los desechos recuperados en el área de combustión de la choza doméstica, pero en ella existe también una gran cantidad de restos en la periferia del fogón, especialmente en el fondo de la choza. Así, el caso de Ewan I podría evidenciar una intencionalidad en la eliminación u ocultamiento de todos aquellos restos que revelen las actividades llevadas a cabo durante la ceremonia, dado que todos los restos de talla se recuperaron en la periferia inmediata al centro del fogón. 
En relación a esto, pueden plantearse al menos dos actividades. En primer lugar la ubicación de los desechos de talla de vidrio cerca del área de combustión puede deberse simplemente a la acción, por parte de tallador, de quitar las microlascas muy filosas, ya sea del cuero o cualquier otro elemento que utilice para sujetar el instrumento mientras trabaja por presión. Otra actividad puede asociarse con la limpieza del interior de la choza, ya sea para ocultar las actividades desarrolladas o simplemente limpieza del suelo del interior de la choza.

En cuanto al análisis funcional realizado sobre los raspadores, que fueron los únicos instrumentos que no presentaron alteración por contacto o cercanía con el fuego, se pudo determinar tanto el material sobre el cual trabajaron los tres raspadores (piel), el movimiento (transversal al filo) y además se pudo comprobar la reactivación de los filos, al menos en dos de los raspadores, ya que estos presentaban mucho desarrollo de rastros en algún sector del filo, como en los extremos y muy poco, no relacionado con sectores sobresalientes, en las partes centrales de los filos frontales.

En relación a los rastros de uso, se pudo observar redondeamiento en algunos sectores del filo y una gran cantidad de estrías, pequeñas, sobre la cara ventral del raspador, lo que estaría indicando un ángulo de trabajo preferentemente agudo. Por otro lado en ninguno de los casos se encontraron evidencias de enmangamiento de los raspadores para su utilización.

Finalmente, cabe destacar que en el caso de los sitios estudiados, el análisis de las microlascas de vidrio ha permitido acercarse a la interpretación de la gestión de este recurso y su manejo en el contexto social. 


\section{Capítulo 8}

ANÁLISIS TECNO-MORFOLÓGICO Y FUNCIONAL DE LOS CONJUNTOS LÍTICOS DE KAMI 1 


\section{INTRODUCCIÓN}

En los capítulos que siguen se presentarán los resultados de los análisis realizados sobre los conjuntos líticos de la localidad arqueológica Kami. Por sus características, resultaban ideales para encarar un estudio múltiple, que incluya análisis tecnológicos, morfológicos y funcionales integrados, desde la perspectiva del análisis tecno-funcional. El mismo siguió los lineamientos metodológicos expuestos en capítulo 3.

El análisis de los materiales incluyó tanto a los provenientes de sitios en los que se realizaron excavaciones sistemáticas, como los recolectados en superficie asociados con los sitios excavados, resultado de las prospecciones que se desarrollaron en el marco de esta tesis. El primero que consideraremos en este capítulo es el sitio Kami 1.

\section{LOS MATERIALES DE LAS CUADRÍCULAS NE}

El conjunto que se presenta a continuación proviene de la excavación realizada en el sitio Kami 1, que presentamos en el capítulo 5 (Figura 8.1). El mismo consta de 7509 elementos líticos (Tabla 8.1). 


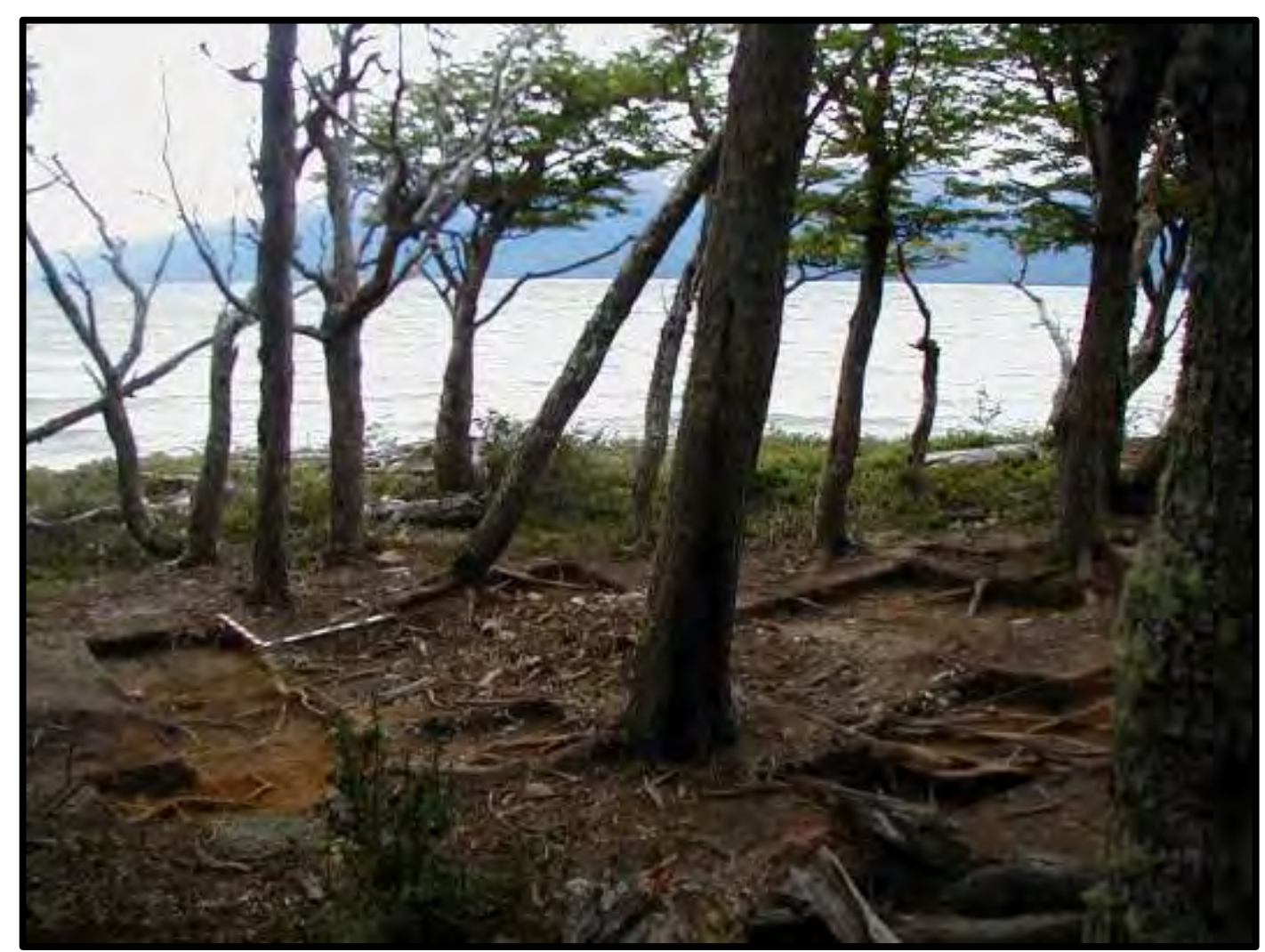

Figura 8. 1. Vista general del sitio Kami 1

Tal como se indicó en el capítulo 3, los productos de talla se agrupan en conjuntos a partir de un límite arbitrario fijado en $2 \mathrm{~cm}$. Esta delimitación permite dividir entre los productos de preparación de plataformas, los restos de la parte final de formatización de instrumentos, de los de talla o de los productos de los primeros estadios de desbaste, etc. La misma división se puede mantener para los instrumentos formatizados.

Así, puede dividirse al conjunto en dos subgrupos: artefactos (retocados y no retocados) mayores y menores a $2 \mathrm{~cm}$, que sin embargo no se deben considerar como grupos sin relación, sino todo lo contrario. 


\begin{tabular}{|c|c|c|c|c|c|c|c|c|c|c|c|c|c|c|c|c|c|c|c|c|c|c|c|c|c|c|c|c|c|c|c|c|c|}
\hline \multirow[b]{3}{*}{ } & & \multicolumn{10}{|c|}{ Artefactos menores a $2 \mathrm{~cm}$} & & \multicolumn{20}{|c|}{ Artefactos mayores a $\mathbf{2} \mathrm{cm}$} & \\
\hline & & \multicolumn{5}{|c|}{ No retocados } & \multicolumn{5}{|c|}{ Retocados } & & \multicolumn{8}{|c|}{ No retocados } & \multicolumn{12}{|c|}{ Retocados } & \\
\hline & 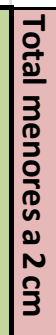 & 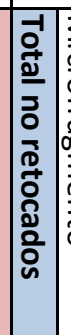 & 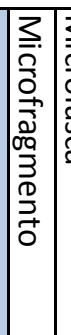 & 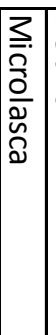 & 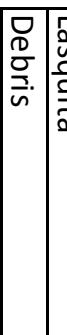 & 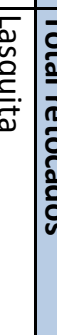 & 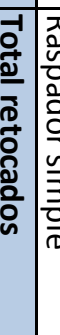 & 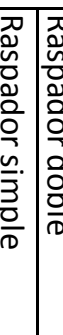 & 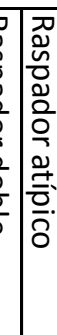 & 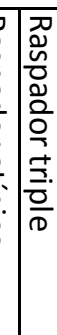 & 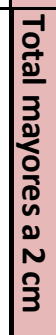 & 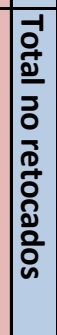 & 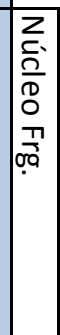 & 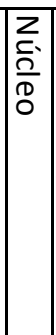 & 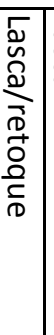 & 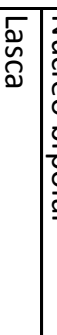 & 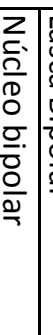 & 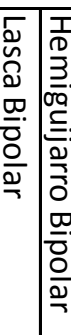 & 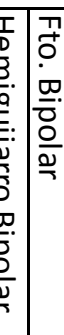 & 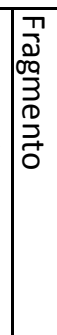 & 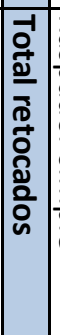 & 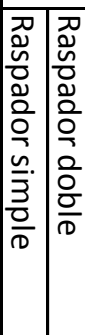 & 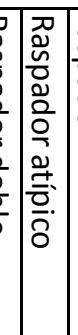 & 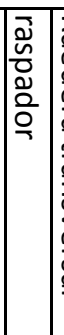 & 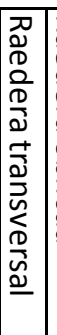 & 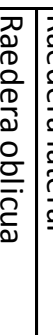 & 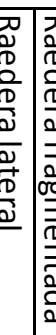 & 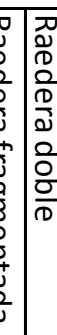 & 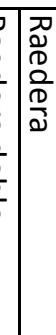 & 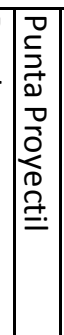 & 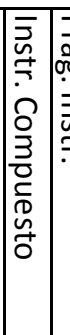 & 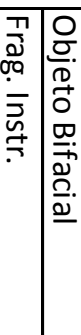 & 큼 \\
\hline$\mapsto$ & $\mapsto$ & $\mapsto$ & & & & $\mapsto$ & & & & & 10 & & & & & & & & & & & & & & & & & & & & & & $\frac{1}{3}$ \\
\hline$\omega$ & 0 & & & & & & & & & & $\omega$ & $N$ & & & & $\sim$ & & & & & $\mapsto$ & & & & & $\bullet$ & & & & & & & बं \\
\hline 6 & 10 & v & & & $\sim c$ & $\omega$ & $\mapsto$ & $\mapsto$ & & & $\omega$ & $\omega$ & $\mapsto$ & & & $N$ & & & & & & & & & & & & & & & & & $\overline{0}$ \\
\hline 药 & \% & $\ddot{\circ}$ & $\vec{v}$ & ज & $\stackrel{P}{i}$ & 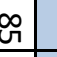 & & & & & $\ddot{\omega}$ & $\stackrel{n}{\sim}$ & $\mapsto$ & & & $\infty$ & & & & $\omega$ & $\mapsto$ & $\mapsto$ & & & & & & & & & & & ข \\
\hline$\tilde{\sigma}$ & w & w & $\mapsto$ & $\mapsto$ & \begin{tabular}{|l|l|l}
$\infty$ & $t$ \\
\end{tabular} & 호 & & & & & a & $v$ & $N$ & & & $\mapsto$ & & & $\mapsto$ & $\mapsto$ & $\mapsto$ & $\mapsto$ & & & & & & & & & & & $\stackrel{0}{7}$ \\
\hline 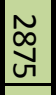 & జ్心 & 岕 & $\begin{array}{l}\omega \\
\delta\end{array}$ & 苟 & $\begin{array}{lll}2 \\
0\end{array}$ & $\stackrel{\vec{\omega}}{\underline{\Xi}}$ & & & & & $\underset{\tilde{\infty}}{\tilde{\infty}}$ & $\underset{\perp}{N}$ & $a$ & & $\mapsto$ & 点 & & & $\mapsto$ & 9 & 5 & $\mapsto \mapsto$ & & $\mapsto$ & $\mapsto$ & & & & $\omega$ & $N$ & & $\triangle 1$ & $\mid \frac{\overrightarrow{0}}{\bar{\Xi}}$ \\
\hline 忎 & 点 & $\overrightarrow{\tilde{n}}$ & $\omega_{\infty}$ & & \begin{tabular}{l|l}
$\infty$ & 1 \\
$\infty$ & 1
\end{tabular} & N & & & & & กั & $\tilde{A}$ & & & & v & & & & 5 & N & & & & & & & & & & & & 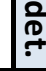 \\
\hline$\tilde{\xi}$ & $\tilde{\mathbf{\omega}}$ & $\tilde{\tilde{\omega}}$ & 15 & $\underline{w}$ & $y=$ & $\frac{+}{\infty}$ & & & & & 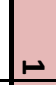 & $\mapsto$ & & & & & & & & & $\mapsto$ & & & & & & & & & $\mapsto$ & & & 突 \\
\hline \begin{tabular}{|l|}
$\vec{w}$ \\
$\infty$ \\
\end{tabular} & $\mathbb{E}$ & $\stackrel{\bullet}{\mapsto}$ & N & & $\infty$ & 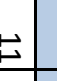 & & & & & N & $\tilde{N}$ & & & & $\infty$ & & & & $\sqrt{ }$ & $N$ & & & & $\mapsto$ & & & & $\mapsto$ & & & & गَّ \\
\hline$\underset{\sim}{N}$ & 忎 & 岕 & wis & $N$ & $\stackrel{\infty}{\ominus}$ & N.1. & $\mapsto$ & $\mapsto$ & & & 8 & 9 & & & & $\omega$ & $\infty$ & $\vec{\omega} \mid \omega$ & 0 & v & $\sim$ & $N$ & & & & & & & & & & & స్ \\
\hline 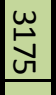 & $\begin{array}{c}\mathfrak{N} \\
\underset{\mathfrak{w}}{\mathbf{v}} \\
\end{array}$ & $\mid \begin{array}{c}\tilde{N} \\
\infty \\
v\end{array}$ & ชิ & '̆ & $\begin{array}{c}\infty \\
w \\
\omega\end{array}$ & 宫 & & & & & $\begin{array}{l}\infty \\
\infty \\
\infty\end{array}$ & $\stackrel{\infty}{v}$ & $\vec{\omega}$ & $\omega$ & 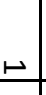 & ज్ & & & $N$ & $\tilde{\tilde{\omega}}$ & 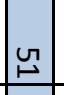 & & $\mapsto$ & & $\mapsto$ & $\perp$ & a 10 & $\pi$ & v & & $\mapsto$ & $\left.\vec{v}\right|_{n}$ & 흘 \\
\hline$\stackrel{\rho}{\ominus}$ & 足 & 兄 & $\sim$ & $\omega$ & 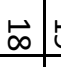 & ம & & & & & $\bullet$ & $\vec{v}$ & $\mapsto$ & & & $\infty$ & & $\mapsto$ & & $u$ & $\triangle$ & & & & & & & & & & & $N$ N & $\overline{\bar{D}}$ \\
\hline$\vec{\omega}$ & 实 & $\mid \begin{array}{c}w \\
\infty \\
N \\
N\end{array}$ & 定 & 8 & $\underset{\sim}{\sim}$ & \begin{tabular}{c|l}
$\infty$ & $\vdots$ \\
\end{tabular} & $\overrightarrow{0}$ & $\vec{\sigma}$ & $\mapsto$ & $\mid$ & $\underset{\omega}{w}$ & $\tilde{\sigma}$ & & $\mapsto$ & & $\begin{array}{lll} & 1\end{array}$ & $\sim$ & $\mapsto$ & $\omega$ & 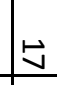 & a & $u$ & & & & & & & & & & $\mapsto$ & $\underline{\square}$ \\
\hline जั & 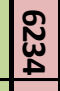 & $\underset{\stackrel{\sim}{\omega}}{\stackrel{\sim}{\omega}}$ & $\underset{\infty}{u}$ & ठั & $\begin{array}{c}\tilde{\tilde{a}} \\
\tilde{\sigma}\end{array}$ & . & $\underset{\sim}{\sim}$ & ${ }_{\infty} \mid$ & 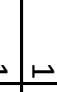 & 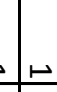 & 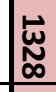 & $\mid$\begin{tabular}{|}
$\tilde{E}$ \\
$\tilde{E}$
\end{tabular} & $\tilde{\Delta}$ & 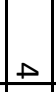 & $\sim$ & $\begin{array}{c}\widetilde{D} \\
\infty\end{array}$ & 이 & $\vec{v}$ & \begin{tabular}{l|l} 
\\
.
\end{tabular} & $\begin{array}{l}w \\
\text { v }\end{array}$ & $\stackrel{\infty}{\infty}$ & $\mid \begin{array}{ll} & 1\end{array}$ & $\Delta$ & $\mapsto$ & $\vec{\omega}$ & G & alu & ת & 6 & $\omega$ & $\mapsto$ & $\tilde{D}$ & 总 \\
\hline ㄴㅇㅇ & 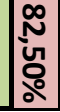 & 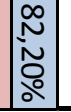 & & & & 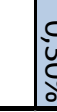 & 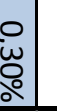 & & & & 占 & 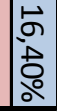 & & & & & & & & & $\mid \begin{array}{l}\bullet \\
\stackrel{5}{\circ} \\
2\end{array}$ & & & & & & & & & & & & $\circ$ \\
\hline
\end{tabular}




\section{Artefactos mayores a $2 \mathrm{~cm}$}

Los artefactos no retocados mayores a $2 \mathrm{~cm}$ totalizan un $\mathrm{n}=1.244$. En general, se encuentran confeccionados principalmente en materias primas locales, entre las cuales riolitas y cineritas representan el $65 \%$ y $17 \%$ respectivamente. Les siguen, en orden decreciente y en números mucho menores, el cuarzo con un $8 \%$ (artefactos que pertenecen todos al subconjunto de los bipolares), luego la toba silicificada representando al $4 \%$ del conjunto. Finalmente se encuentran pizarra $2 \%$, sílice y calcedonia con un $1 \%$ cada una. Las indeterminadas alcanzan un $2 \%$ del conjunto.

Si consideramos los artefactos retocados mayores a $2 \mathrm{~cm}$, la riolita continúa siendo la más representada $(n=52)$, luego la cinerita $(n=13)$, en tercer lugar la toba silicificada $(n=6)$. Luego aparecen los artefactos confeccionados sobre sílice $(n=4)$, sobre cuarzo y pizarra $(n=2)$ para cada uno. Los instrumentos con $n=1$ son los confeccionados sobre lutita, chert, calcedonia y andesita. Finalmente aparecen dos fragmentos de instrumentos sobre materias primas que no pudieron ser determinadas.

Las materias primas que muestran mayor variabilidad en cuanto a tipos representados son las riolitas y las cineritas, mientras que las tobas silicificadas sólo fueron utilizadas para la confección de raspadores al igual que el cuarzo. Las pizarras fueron empleadas para la confección de filos largos retocados y las materias primas silíceas fueron utilizadas para artefactos de talla bifacial.

Dentro de este subgrupo y de acuerdo con la técnica de talla utilizada, se pueden definir dos conjuntos: artefactos por talla directa (no retocados, retocados, núcleos y bifaciales) y artefactos de talla bipolar (no retocados, retocados y núcleos).

El conjunto compuesto por artefactos de talla directa, se encuentra dominado por los no retocados, con un $61 \%$ representado por lascas $(n=751)$ y un $30 \%$ por fragmentos $(n=370)$, luego representando un $7 \%$ los retocados, que podemos dividirlos de la siguiente manera: raederas $(n=33)$, raspadores $(n=14)$, fragmentos de instrumentos $(n=36)$, fragmentos de punta de proyectil $(n=7)$, que suman un total de 3 puntas y sólo un instrumento compuesto. Los núcleos enteros $(n=4)$, núcleos fragmentados $(n=24)$ representan casi el $2 \%$.

El conjunto de los artefactos bipolares está representado en primer lugar por los fragmentos bipolares con $n=36$, en segundo lugar aparecen las lascas 
bipolares con $n=15$, luego los núcleos bipolares $n=10$ y finalmente los hemiguijarros bipolares con $n=9$. Los instrumentos retocados bipolares están representados sólo por raspadores con $n=7$ (entre los cuales 2 corresponden al subgrupo de los menores a $2 \mathrm{~cm}$ )

\section{Artefactos menores a $2 \mathrm{~cm}$}

En el subgrupo que incluye los artefactos no formatizados menores a 2 $\mathrm{cm}$, predominan las materias primas riolita y cinerita como en el caso anterior. Sin embargo, en este caso se invierte el orden, ya que son las cineritas las que presentan mayor predominancia con respecto a las riolitas. Luego en una escala mucho menor sigue la toba silicificada, lutita, calcedonia, cuarzo y pizarra. Finalmente los sílex, chert y basalto con un $\mathrm{n}$ menor a 50 piezas, para terminar en sólo una lasquita de hornblendita (Gráfico 8.1 y 8.2). Al subgrupo de instrumentos retocados menores a $2 \mathrm{~cm}$ sólo lo representan los microrraspadores con un $n=21$ (más detalle en la sección de análisis de raspadores).

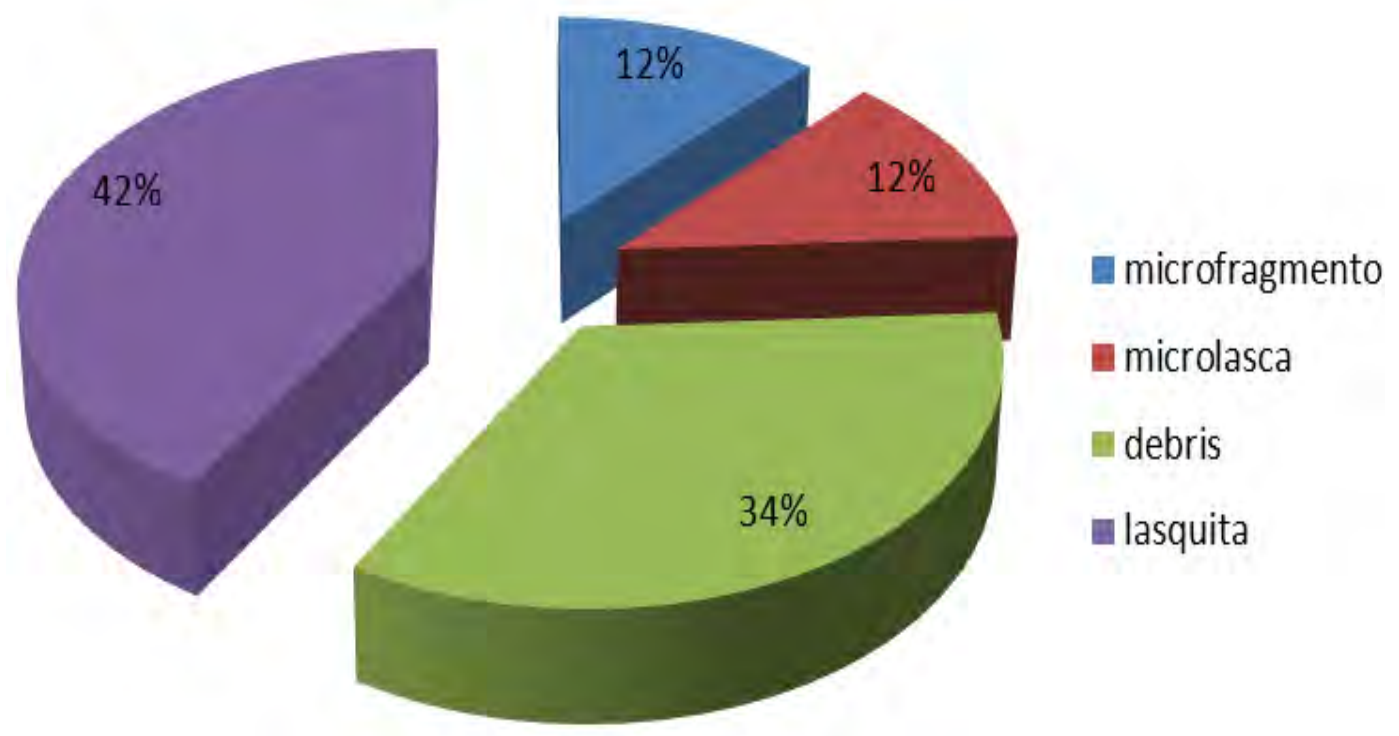

Gráfico 8. 1. Porcentaje de artefactos menores a $2 \mathrm{~cm}$ 


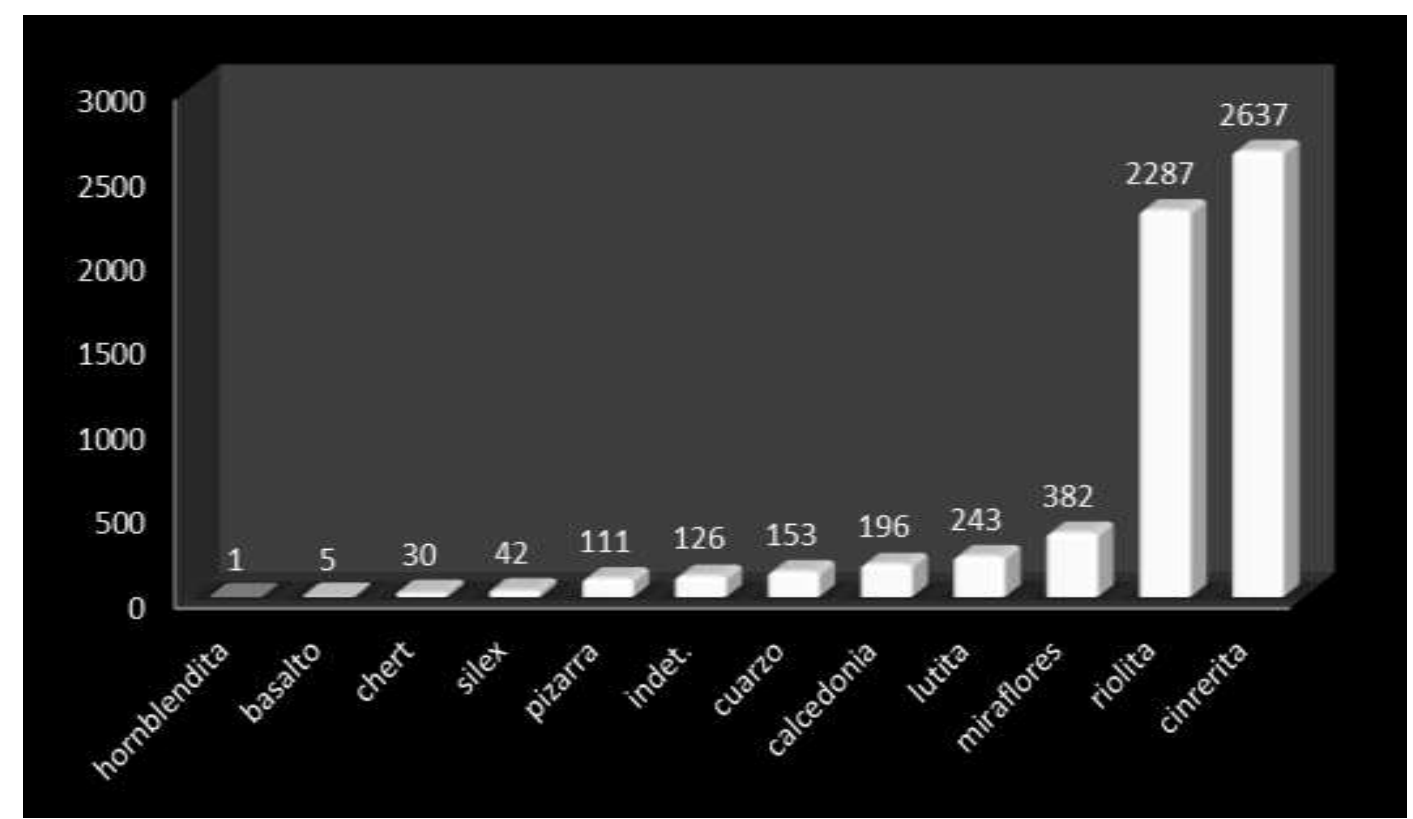

Gráfico 8. 2. Cantidad de materias primas en artefactos menores a $2 \mathrm{~cm}$.

Finalmente, en cuanto al total del subgrupo de artefactos menores a 2 $\mathrm{cm}$, vemos que hay una diferencia numérica entre aquellos restos de talla menores a $0,5 \mathrm{~cm}$ con un $\mathrm{n}=1498$ y aquellos comprendidos entre los 5,0 y los $2 \mathrm{~cm} \mathrm{n}=4715$. Esto podría estar relacionado con las actividades de talla llevadas a cabo en el sitio.

\section{Análisis tecno-morfológico}

Núcleos

Por el grado fragmentación o de explotación que presentan los núcleos, en la mayoría de los casos $(n=24)$ no es posible determinar, a partir de la morfología del núcleo, cuáles fueron los soportes seleccionados para la talla (Figura 8.2.). Sólo unos pocos $(n=4)$ presentan características que permiten reconocer los soportes como guijarros costeros de diversos tamaños. Por ello para hacer la determinación nos basamos también en las características de los restos de corteza que presentan los núcleos. De esta forma, se puede decir que todas se acercan más a las cortezas características de los guijarros costeros que a las cortezas de rocas provenientes de afloramientos primarios. 


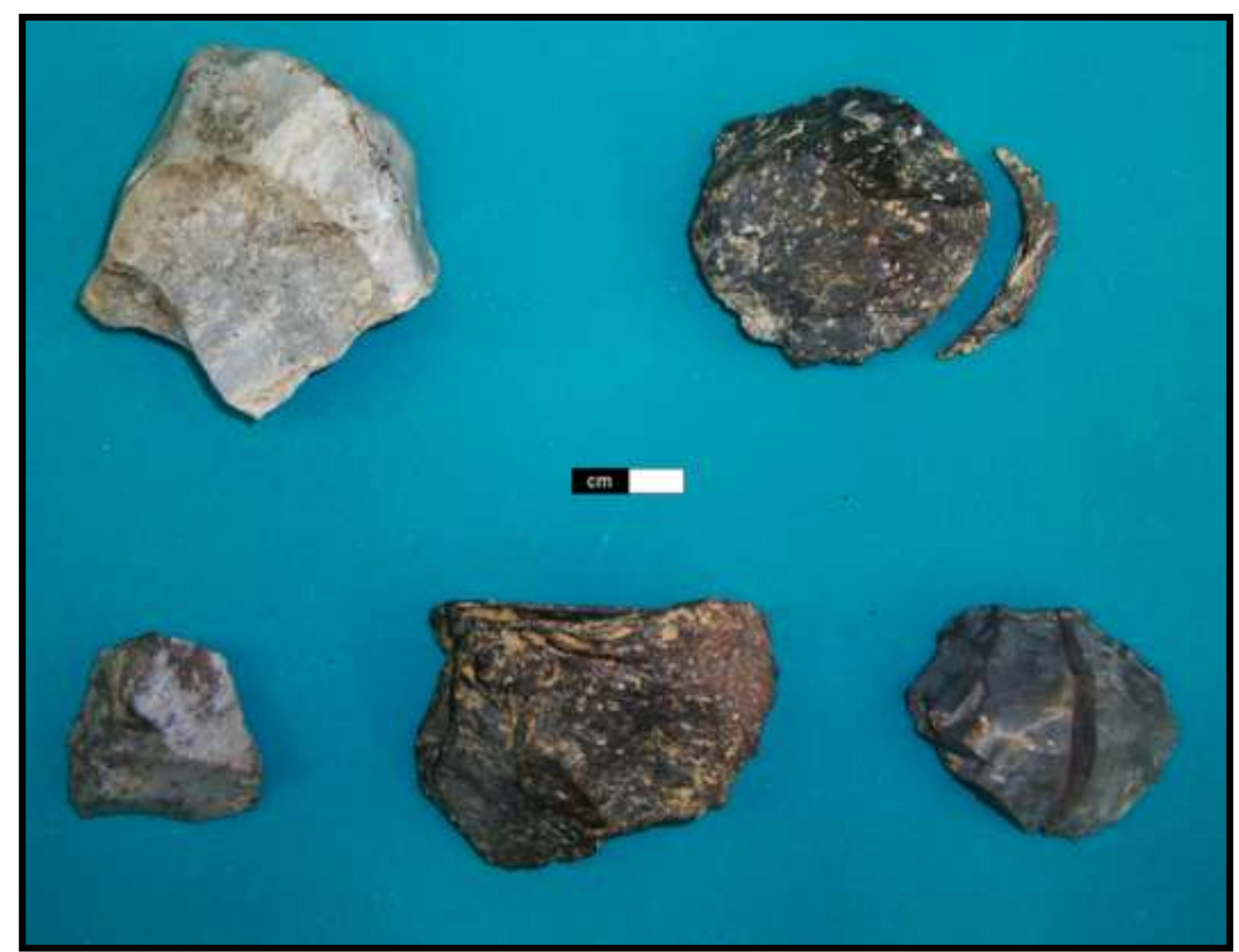

Figura 8. 2. Ejemplo de algunos núcleos de diversas materias primas. Arriba: riolita. Debajo de izquierda a derecha: toba silicificada, riolita, chert

Las materias primas más representadas son las riolitas y las cineritas, con un $n=18$ y un $n=6$, respectivamente. (Tabla 8.2, Gráfico 8.3).

\begin{tabular}{|l|c|c|c|c|c|c|c|c|}
\hline $\begin{array}{l}\text { Tipo de Núcleo / } \\
\text { Materia prima }\end{array}$ & Calcedonia & Sílex & $\begin{array}{c}\text { Toba } \\
\text { silicificada }\end{array}$ & Basalto & Chert & Cinerita & Riolita & Total \\
\hline No Determinable & & 1 & & & & 3 & 8 & 12 \\
\hline Amorfo & 1 & & 1 & 1 & & 3 & 4 & 10 \\
\hline Discoidal & & & & & 2 & & 2 & 4 \\
\hline Apical & & & & & & & 2 & 2 \\
\hline Total general & $\mathbf{1}$ & $\mathbf{1}$ & $\mathbf{1}$ & $\mathbf{1}$ & $\mathbf{2}$ & $\mathbf{6}$ & $\mathbf{1 6}$ & $\mathbf{2 8}$ \\
\hline
\end{tabular}

Tabla 8. 2. Relación entre tipos de núcleo y materia prima

Entre los tipos de núcleos que pudieron ser determinados los principales son los amorfos con un $n=10$, luego los discoidales $n=4$ y dos apicales. Sin embargo los más abundantes son los núcleos no determinables $(n=12)$. En cuanto a las materias primas, sobre riolita se encuentran representados todos los tipos de núcleo, incluso los dos núcleos apicales del conjunto, en tanto que cinerita y toba silicificada sólo presentan tipos no determinados y amorfos. El 
núcleo fragmentado sobre sílex corresponde a los no determinables. En cuanto a las materias primas que sólo están representadas en tipos amorfos, se encuentra un núcleo de calcedonia, uno de toba silicificada y otro de basalto. Finalmente los núcleos discoidales están representados por chert $n=2$, lo mismo ocurre con los de riolita.

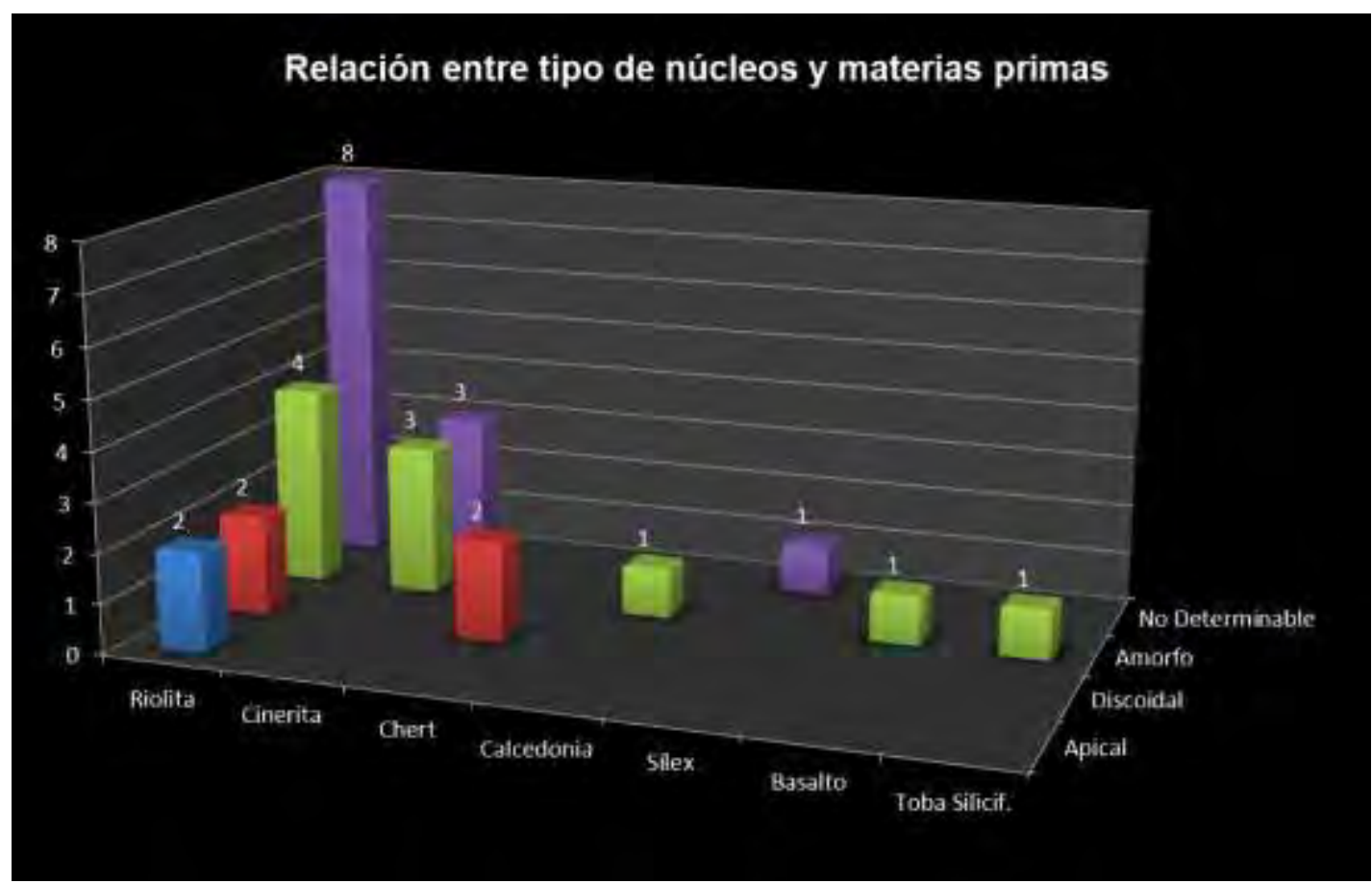

Gráfico 8. 3. Relación entre tipo de núcleos y materia prima

Casi un $80 \%$ de los núcleos presentan algún porcentaje de corteza, mientras que el $20 \%$ restante carece por completo de ella. Dentro de los primeros $n=8$ presentan abundante corteza (50-75\% de la superficie cubierta), con $n=5$ tanto los núcleos con presencia parcial (25-50\%) como escasa (menos del 25\%) y finalmente con $\mathrm{n}=4$ los que presentan corteza muy abundante (más del 75\%) (Tabla 8.3).

\begin{tabular}{|l|c|c|c|c|c|c|c|c|}
\hline $\begin{array}{l}\text { Corteza/ } \\
\text { Mat. Prim. }\end{array}$ & Calcedonia & Sílex & $\begin{array}{c}\text { Toba } \\
\text { Silicificada }\end{array}$ & Basalto & Chert & Cinerita & Riolita & Total \\
\hline Abundante & & & & 1 & & 1 & 6 & 8 \\
\hline No presenta & & & 1 & & 2 & 1 & 2 & 6 \\
\hline Parcial & 1 & & & & & 2 & 2 & 5 \\
\hline Escasa & & & & & & 1 & 4 & 5 \\
\hline Muy abundante & & 1 & & & & 1 & 2 & 4 \\
\hline Total & $\mathbf{1}$ & $\mathbf{1}$ & $\mathbf{1}$ & $\mathbf{1}$ & $\mathbf{2}$ & $\mathbf{6}$ & $\mathbf{1 6}$ & $\mathbf{2 8}$ \\
\hline
\end{tabular}

Tabla 8. 3. Presencia de corteza en núcleos y materias primas 
En cuanto a las dimensiones, los más comunes son los núcleos de longitud media y gruesa $n=19$, luego los de longitud y grosor medio $n=4$; con $\mathrm{n}=2$ los cortos y gruesos y finalmente con $\mathrm{n}=1$ los cortos y de grosor medio, largo y delgado y largo y grueso.

El grado de explotación de los núcleos se divide entre aquellos agotados y aquellos a los que todavía se le pueden extraer lascas. Para este conjunto hay un $90 \%$ con un bajo grado de explotación y un $10 \%$ agotados (Tabla 8.4 ).

\begin{tabular}{|l|c|c|c|c|c|}
\hline $\begin{array}{l}\text { Materias Primas / grado } \\
\text { de explotación }\end{array}$ & Apical & Discoidal & Amorfo & Indet. & Total \\
\hline Explotables & $\mathbf{2}$ & $\mathbf{4}$ & $\mathbf{8}$ & $\mathbf{1 1}$ & $\mathbf{2 5}$ \\
\hline Calcedonia & & & 1 & & 1 \\
\hline Sílex & & & & 1 & 1 \\
\hline Basalto & & & 1 & & 1 \\
\hline Chert & & 2 & & & 2 \\
\hline Cinerita & & & 2 & 3 & 5 \\
\hline Riolita & 2 & 2 & 4 & 7 & 15 \\
\hline Agotados & & & $\mathbf{2}$ & $\mathbf{1}$ & $\mathbf{3}$ \\
\hline Toba Silicificada & & & 1 & & 1 \\
\hline Cinerita & & & & 1 & 1 \\
\hline Riolita & $\mathbf{2}$ & $\mathbf{4}$ & $\mathbf{1 0}$ & $\mathbf{1 2}$ & $\mathbf{2 8}$ \\
\hline Total & & & 1 & \\
\hline
\end{tabular}

Tabla 8. 4. Grado de explotación de los núcleos

\section{Lascas}

El conjunto de lascas consta de un total de 750 artefactos $(n=2$ son lascas con retoque), de los cuales un $73 \%$ está formado por lascas de riolita. La cinerita aparece representada en un $20 \%$ del conjunto. Para el resto de materias primas los porcentajes son mucho menores (Gráfico 8.4). 


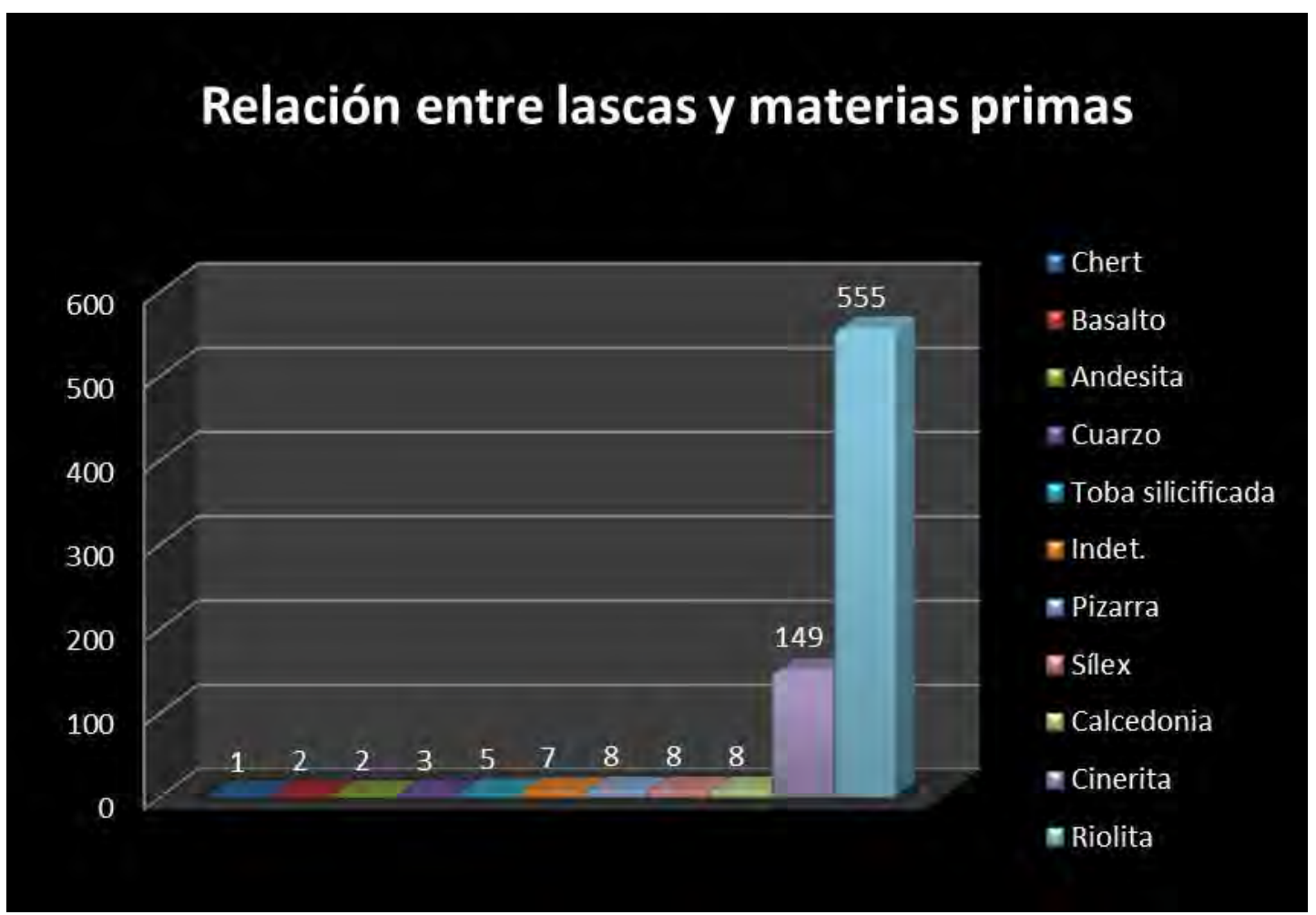

Gráfico 8. 4. Relación entre lascas y materia prima

El conjunto de lascas presenta en un 97\% una conservación buena, mientras que el 3\% restante muestran algún tipo de patina o alteración por alta temperatura. Así 12 lascas presentan rastros de termoalteración y en 8 se ve la presencia de patinas blanca y amarillenta. Las lascas presentan grado de fragmentación tipo $1 \mathrm{n}=398$, tipo $2 \mathrm{n}=4$, y enteras $n=348$. En relación a las materias primas, se presentan casi las mismas cantidades de lascas por materia prima para las fragmentadas (tipo 1) que para las enteras.

\section{Corteza}

En cuanto a la presencia de corteza, como podemos visualizar en el gráfico, un $70 \%$ de la muestra no presenta rastros de corteza. El resto se divide entre aquellas con escasa corteza el $16 \%$, con presencia parcial un $5 \%$, mientras que las lascas con abundante y muy abundante presencia de corteza representan un $4 \%$ cada una. Sólo el $1 \%$ no pudo determinarse debido a las alteraciones presentes en las piezas (Gráfico 8.5). 


\section{Presencia de corteza en lascas}

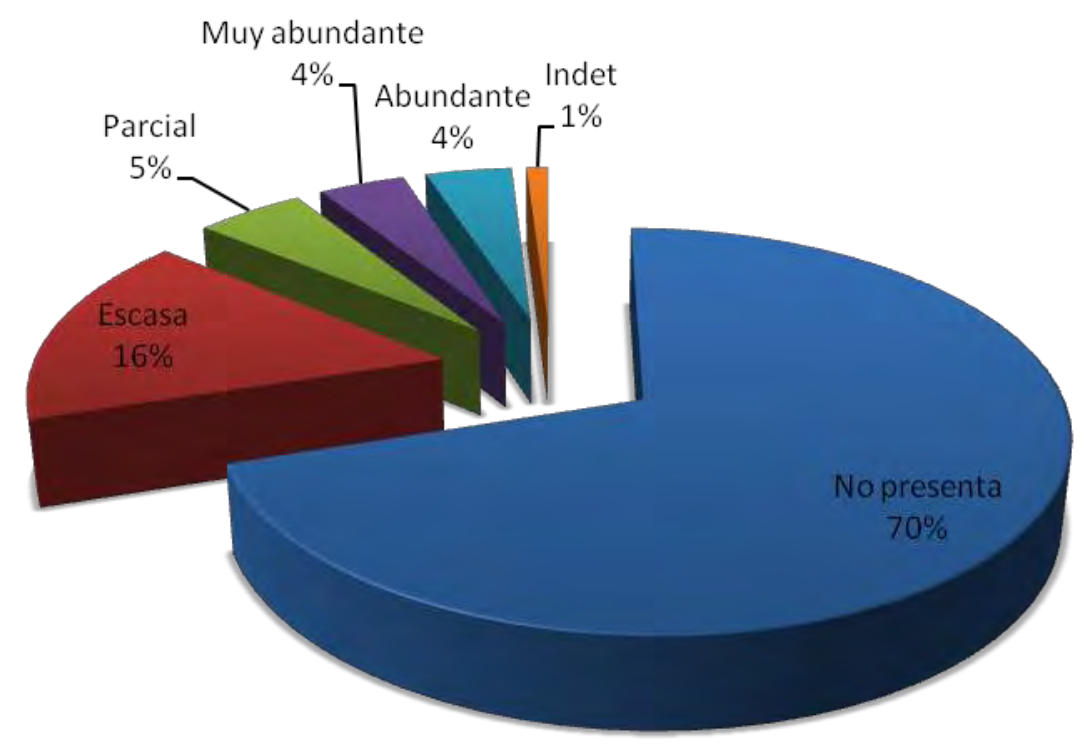

Gráfico 8. 5. Porcentajes de corteza en lascas

Filos potencialmente utilizables

En este conjunto sólo un $9 \%$ presenta filos cuyas características nos permiten considerarlos como potencialmente utilizables, y entonces incluirlos para el análisis funcional. De este 9\%, 59 lascas presentan sólo un filo (44 son de riolita, 11 de cinerita, 2 de pizarra, una de calcedonia y una de toba silicificada). En cuanto a la posición de los filos un $34 \%$ tienen una ubicación distal, el 29\% del lado izquierdo de la pieza, el 19\% del lado derecho, un 15\% indeterminado por fracturas, y un 3\% corresponde a los filos proximales. Las que presentan dos filos potenciales son sólo 5 lascas de riolita, que incluyen 4 piezas con filos laterales mientras que sólo una presenta filos distal y proximal (Tabla 8.5). 


\begin{tabular}{|l|c|c|c|c|}
\hline $\begin{array}{l}\text { Materias } \\
\text { primas/filos }\end{array}$ & Sin filos & Un filo & Dos filos & Total \\
\hline Cuarzo & 1 & & & 1 \\
\hline Chert & 1 & & & 1 \\
\hline Andesita & 2 & & & 2 \\
\hline Basalto & 2 & & & 2 \\
\hline Toba silicificada & 2 & 1 & & 3 \\
\hline Sílex & 6 & & & 6 \\
\hline Indet. & 7 & & & 7 \\
\hline Pizarra & 6 & 2 & & 8 \\
\hline Calcedonia & 7 & 1 & & 8 \\
\hline Cinerita & 88 & 11 & & 99 \\
\hline RIO & 399 & 44 & 5 & 448 \\
\hline Total general & $\mathbf{5 2 1}$ & $\mathbf{5 9}$ & $\mathbf{5}$ & $\mathbf{5 8 5}$ \\
\hline
\end{tabular}

Tabla 8. 5. Lascas con filos potencialmente utilizables

\section{Dimensiones}

Las lascas más representadas son las cortas y delgadas con un $n=299$, continúan las de longitud media y delgadas, y las cortas de espesor medio con $\mathrm{n}=137$ y 136 respectivamente; luego siguen las de longitud y espesor medio con $n=120$. Tanto las largas con los diversos espesores como las gruesas con los diversos largos son las menos representadas. Las lascas largas y cortas con espesores gruesos cuentan con 8 artefactos cada uno, mientras que las de largo medio cuentan con 25 unidades. Finalmente las lascas largas con espesor medio y delgado, las menos representadas, cuentan con 6 y 5 unidades respectivamente (Gráfico 8.6).

\section{Relación Módulos LA/AE}

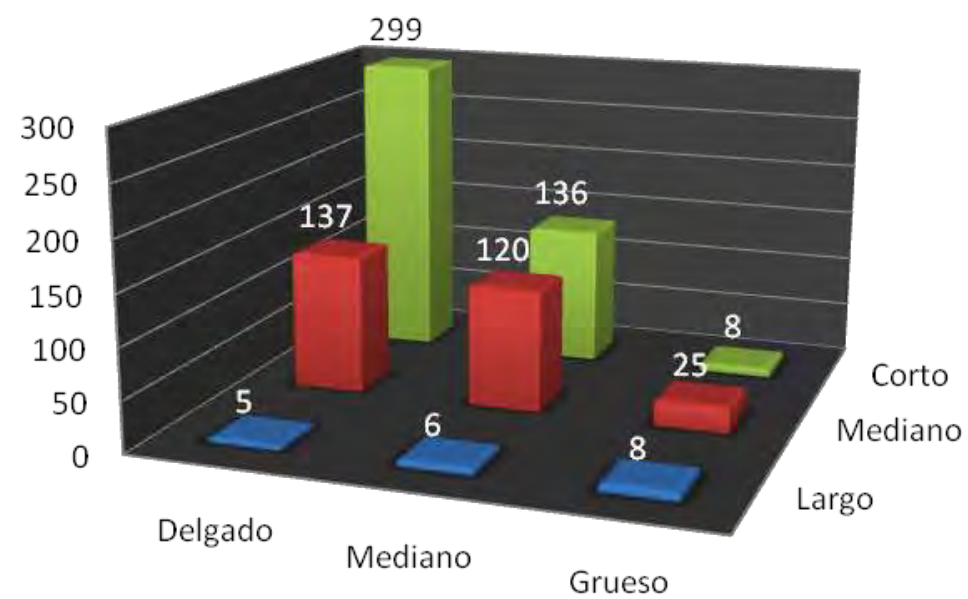

Gráfico 8. 6. Relación entre los módulos Largo-Ancho/Ancho-Espesor 


\section{Materias primas}

Si tenemos en cuenta las materias primas y los módulos de tamaño vemos que las riolitas y cineritas son las más representadas y que se encuentran distribuidas principalmente entre aquellas lascas con longitudes corta/mediana y con espesores medio/delgado.

En cuanto a las materias primas restantes, vemos que donde menos diversidad hay es dentro de aquellas lascas largas con espesores medio/delgado. Con un poco más de diversidad, aparecen las lascas con largos medianos con espesores medio/delgado. Finalmente, donde mayor diversidad se observa es en aquellas lascas cuya longitud es corta, con mayor representación de espesores medios y delgados y mucho menores con espesores gruesos.

La morfología desde la cara dorsal se caracteriza por artefactos anchos $n=248$ (representada en casi todas las materias primas); luego siguen las piezas largas $n=220$ (también están representadas casi todas las materias primas); continúan las oblicuas con un $n=191$; y con menores cantidades las semicirculares $n=40$; trapezoidales $n=23$ y finalmente las indeterminadas $n=$ 18. Sólo riolita, cinerita y calcedonia presenta todas las morfologías mencionadas. En contraposición el chert sólo está presente en la morfología oblicua y la metamórfica sólo en ancha (Tabla 8.6).

\begin{tabular}{|c|c|c|c|c|c|c|c|}
\hline $\begin{array}{l}\text { Materia prima / } \\
\text { forma }\end{array}$ & Indet & Trapezoidal & Semicircular & Oblicua & Alargada & Ancha & Total \\
\hline Chert & & & & 1 & & & 1 \\
\hline Metamórfica & & & & & & 1 & 1 \\
\hline Cuarzo & & & & & 2 & 1 & 3 \\
\hline Basalto & & & 1 & & 1 & & 2 \\
\hline Andesita & & & & & & 2 & 2 \\
\hline Toba silicificada & & & & 1 & 1 & 1 & 3 \\
\hline Indet. & & & 1 & 1 & 2 & 3 & 7 \\
\hline Calcedonia & & 1 & 1 & 1 & 2 & 3 & 8 \\
\hline Sílex & 1 & & & 1 & 4 & 2 & 8 \\
\hline Pizarra & & & & 1 & 3 & 4 & 8 \\
\hline Cinerita & 5 & 3 & 4 & 38 & 49 & 50 & 149 \\
\hline Riolita & 12 & 23 & 33 & 147 & 156 & 181 & 552 \\
\hline Total & 18 & 27 & 40 & 191 & 220 & 248 & 744 \\
\hline
\end{tabular}

Tabla 8. 6. Morfologías y su relación con las materias primas 


\section{Soportes}

Los tipos de lasca (o soportes) que se pueden diferenciar dentro del conjunto son 5. El más abundante es el de las lascas, con un $n=613$; el segundo, lasca de talla bifacial $n=89$; el tercero, lasca con dorso natural $n=32$; el cuarto, lasca inicial de descortezamiento $n=9$ y finalmente lasca de borde $o$ flanco de núcleo $n=7$ (Gráfico 8.7).

\section{Soportes}

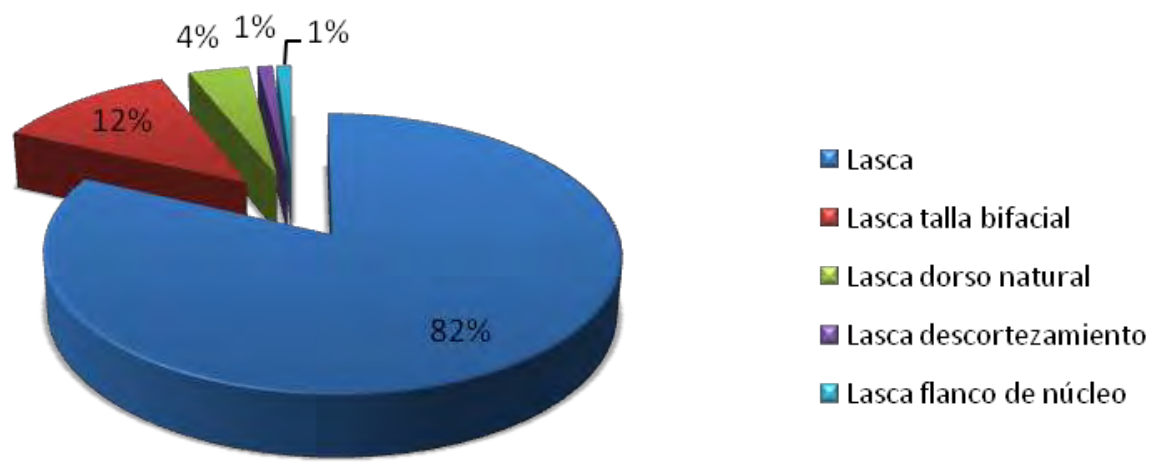

Gráfico 8. 7. Representatividad de soportes

La distribución de las materias primas en relación a los soportes sigue el mismo patrón que se vio anteriormente: las riolitas y cineritas están presentes en todos los tipos de soporte y son las más numerosas. El tipo "lasca" está representado en todas las materias primas, mientras que el de las lascas de talla bifacial incluye sólo riolita, cinerita, calcedonia y andesita. También puede verse una mayor diversidad de materias primas entre las lascas de dorso natural, que incluye basalto, calcedonia, pizarra, cinerita y riolita. Sólo hay 8 lascas iniciales de descortezamiento en riolita y una en cinerita, mientras que las lascas de borde de núcleo están representadas por 3 de riolita y cinerita y una de cuarzo, (Gráfico 8.8). 


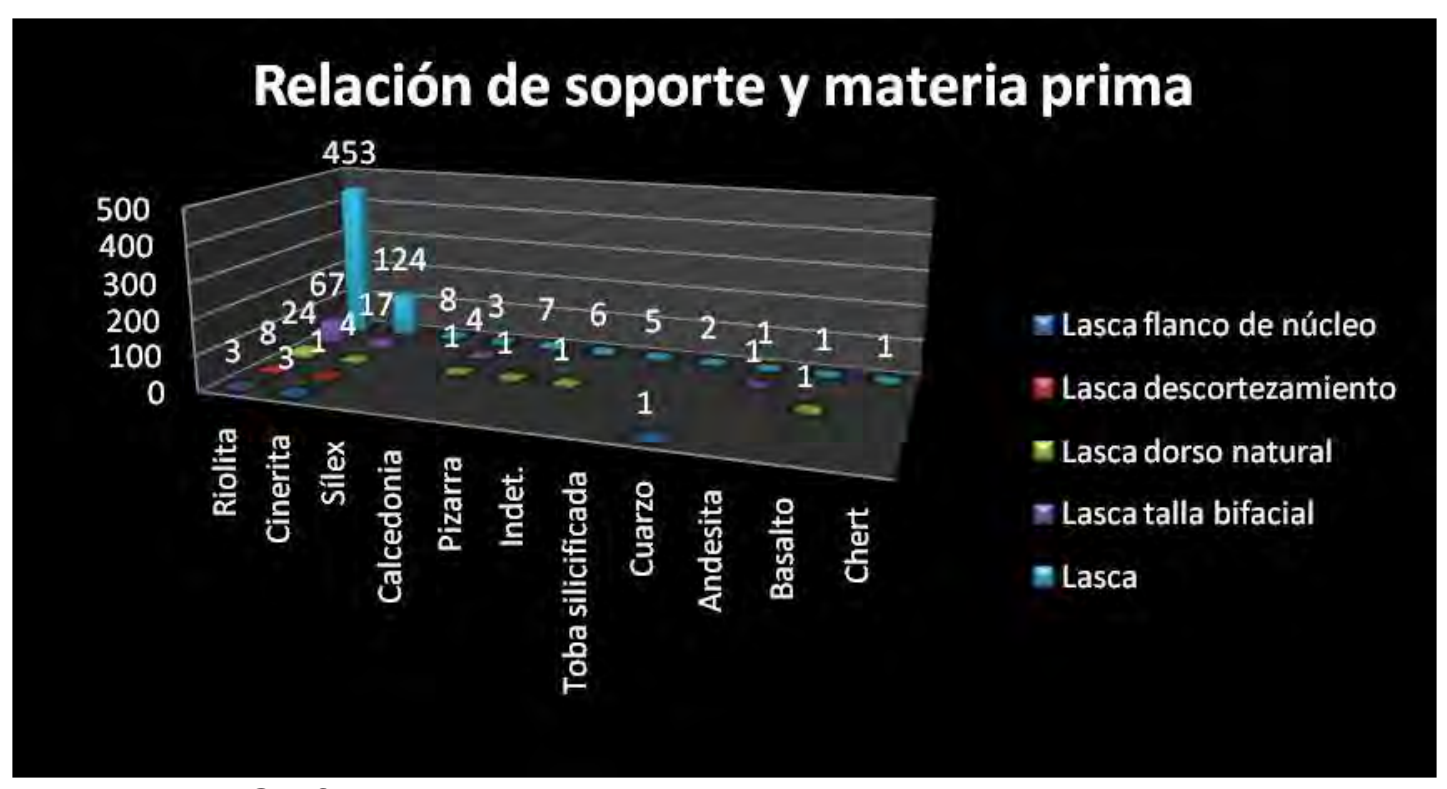

Gráfico 8. 8. Relación entre soporte y materia prima

Talones

Los talones predominantes son los lisos abarcando un $58 \%$ de la muestra, luego los naturales (corticales) con un 13\%, los facetados y los lineales comprenden el $7 \%$ y $6 \%$ respectivamente. En cuanto a los tipos en ala de pájaro (sección cóncavo-convexa) se presentan en dos formas, facetados (sólo uno) y lisos (4\% de la muestra). Con el $3 \%$ aparecen los talones diedros y finalmente con $1 \%$ los puntiformes. Casi un $9 \%$ de lascas no presenta talones, debido a fracturas o a su desaparición por retalla (Tabla 8.7).

En cuanto a la preparación de los talones, el $70 \%$ del conjunto no presenta talones preparados, mientras que los preparados se corresponden con el $21 \%$ de la muestra, el $9 \%$ restante no se pudo determinar.

Los talones son principalmente oblicuos en un $44 \%$, los rectos cuentan un $35 \%$, los muy oblicuos están en tercer lugar con un $13 \%$, y finalmente un $8 \%$ no pudieron determinarse. 


\begin{tabular}{|l|c|c|c|c|c|c|c|c|c|c|}
\hline & Ausente & Diedro & Facet. & $\begin{array}{l}\text { Fac. ala } \\
\text { pájaro }\end{array}$ & Liso & $\begin{array}{l}\text { Liso } \\
\text { Nat. }\end{array}$ & $\begin{array}{l}\text { Liso ala } \\
\text { pájaro }\end{array}$ & Natural & Puntif. & Total \\
\hline Riolita & 40 & 21 & 30 & & 335 & 28 & 20 & 74 & 7 & 555 \\
\hline Cinerita & 18 & 5 & 21 & & 78 & 8 & 8 & 11 & & 149 \\
\hline Sílex & 2 & & & 1 & 1 & & & 3 & 1 & 8 \\
\hline Calcedonia & 1 & & & & 6 & 1 & & & & 8 \\
\hline Pizarra & & & & & 4 & 2 & & 2 & & 8 \\
\hline Indet. & 1 & & & & 4 & 1 & & 1 & & 7 \\
\hline Toba silic. & 2 & & & & 1 & 1 & & 1 & & 5 \\
\hline Cuarzo & & & & & 1 & 1 & & 1 & & 3 \\
\hline Andesita & & & & & 1 & & & 1 & & 2 \\
\hline Basalto & & & & & 1 & 1 & & & & 2 \\
\hline Chert & & & & & & & & 1 & & 1 \\
\hline Total & $\mathbf{5 9}$ & $\mathbf{2 6}$ & $\mathbf{5 1}$ & $\mathbf{1}$ & $\mathbf{4 3 2}$ & $\mathbf{4 3}$ & $\mathbf{2 8}$ & $\mathbf{9 5}$ & $\mathbf{8}$ & $\mathbf{7 4 8}$ \\
\hline
\end{tabular}

Tabla 8. 7. Relación entre tipo de talones y materia prima

Si consideramos la relación entre los talones y las diversas materias primas vemos que en riolitas y cineritas es donde se encuentra la mayor diversidad de tipos de talones. Los más abundantes son los talones lisos en riolitas $n=333$, luego los lisos sobre cinerita $n=78$. En el caso de los talones naturales en las riolitas se encuentran presentes en un $n=72$.

Siguiendo el gráfico, más abajo, podemos ver que los talones que más materias primas abarcan son por un lado los lisos, luego los naturales y finalmente los lineales. Tanto los facetados, los diedros, como los facetados en ala de pájaro están presentes sólo en riolitas y cineritas. Luego los puntiformes en números muy bajos sólo en una lasca de sílex y sobre 7 lascas de riolita. Finalmente el único talón liso en ala de pájaro pertenece a una lasca de sílex.

En cuanto a las lascas con ausencia de talón por fractura o talla, sólo se vio en artefactos de riolita y cinerita, las más abundantes; en dos lascas de sílex y en una materia prima indeterminada.

\section{Materia prima y corteza}

La presencia de corteza en relación con las materias primas se distribuyen de la siguiente manera: riolita, cinerita y pizarra abarcan todas las posibilidades, desde lascas sin corteza (las más abundantes) hasta lascas con presencia muy abundante. El resto de materias primas se concentran principalmente en lascas sin corteza o con escasa presencia de ella, y en 
menor medida entre aquellas con cobertura parcial, abundante y muy abundante de corteza (Tabla 8.8).

\begin{tabular}{|c|c|c|c|c|c|c|c|}
\hline $\begin{array}{l}\text { Materias primas / } \\
\text { Corteza }\end{array}$ & Abundante & Escasa & Indet. & Muy abundante & No presenta & Parcial & Total \\
\hline Chert & & 1 & & & & & 1 \\
\hline Basalto & & & & 1 & 1 & & 2 \\
\hline Andesita & 1 & & & & 1 & & 2 \\
\hline Cuarzo & & & & & 2 & 1 & 3 \\
\hline Toba silicificada & & 1 & & & 4 & & 5 \\
\hline Indet. & & 1 & 2 & 1 & 3 & & 7 \\
\hline Pizarra & 1 & 2 & & 1 & 3 & 1 & 8 \\
\hline Sílex & & 1 & & & 5 & 2 & 8 \\
\hline Calcedonia & & & & 1 & 7 & & 8 \\
\hline Cinerita & 6 & 20 & & 4 & 113 & 6 & 149 \\
\hline Riolita & 16 & 93 & 3 & 23 & 389 & 31 & 555 \\
\hline Total general & 24 & 119 & 5 & 31 & 526 & 41 & 748 \\
\hline
\end{tabular}

Tabla 8. 8. Relación entre presencia de corteza y materia prima

En cuanto a las características tanto del bulbo como del labio podemos mencionar que el primero se presenta en general difuso en todas las materias primas, principalmente debido a la dureza de las mismas, mientras que aquellas lascas con bulbos espesos se encuentran representadas en pocas materias primas y en número mucho menor. Podemos mencionar sólo un caso de bulbo doble sobre una lasca de riolita (Tabla 8.9). La presencia de labio normal se da en casi todas las materias primas y es el más representado, seguido por lascas con ausencia del mismo, y en tercer lugar con labios difusos. En cuanto a la presencia de lascas con labios evertidos sólo pudieron reconocerse 6 en toda la muestra (Tabla 8.10). 


\begin{tabular}{|l|l|l|r|r|l|l|l|l|r|}
\hline $\begin{array}{l}\text { Materia } \\
\text { prima / bulbo }\end{array}$ & $\begin{array}{l}\text { No } \\
\text { Presenta }\end{array}$ & Ausente & Indet. & Difuso & $\begin{array}{l}\text { Difuso } \\
\text { Esquirl. }\end{array}$ & Espesos & $\begin{array}{l}\text { Espeso } \\
\text { Esquirl. }\end{array}$ & Doble & \multicolumn{1}{c|}{ Total } \\
\hline Chert & & & & 1 & & & & & 1 \\
\hline Basalto & & & & 2 & & & & & 2 \\
\hline Andesita & & & & 2 & & & & & 2 \\
\hline Cuarzo & & & & 3 & & & & & 3 \\
\hline $\begin{array}{l}\text { Toba } \\
\text { silicificada }\end{array}$ & & & & 4 & & 1 & & & 5 \\
\hline Indet. & & & & 7 & & & & & 7 \\
\hline Pizarra & & & & 7 & & 1 & & & 8 \\
\hline Sílex & & & & 4 & & 4 & & & 8 \\
\hline Calcedonia & & & & 8 & & & & & 8 \\
\hline Cinerita & 1 & 3 & & 106 & 4 & 34 & & & 1 \\
\hline Riolita & 4 & 3 & 1 & 428 & 1 & 116 & 2 & & 149 \\
\hline Total & $\mathbf{5}$ & $\mathbf{6}$ & $\mathbf{1}$ & $\mathbf{5 7 2}$ & $\mathbf{5}$ & $\mathbf{1 5 6}$ & $\mathbf{2}$ & $\mathbf{1}$ & $\mathbf{7 4 8}$ \\
\hline
\end{tabular}

Tabla 8. 9. Relación entre tipo de bulbo y materia prima

Finalmente los accidentes de talla están prácticamente ausentes en la mayoría de las materias primas, excepto en aquellas más duras como las riolitas y cineritas donde el más común es el reflejado y luego el reflejado con lengüeta (comúnmente llamados charnelas), en cuanto a lascas sobrepasadas sólo contamos con 5 en todo conjunto.

\begin{tabular}{|l|c|c|c|c|c|c|c|}
\hline $\begin{array}{l}\text { Materia prima } \\
\text { / labio }\end{array}$ & Indet. & Ausente & Evertido & Difuso & $\begin{array}{l}\text { No } \\
\text { posee }\end{array}$ & Normal & Total \\
\hline Chert & & & & & & 1 & 1 \\
\hline Basalto & & & & 1 & & 1 & 2 \\
\hline Andesita & & & & & & 2 & 2 \\
\hline Cuarzo & & & & 2 & & 1 & 3 \\
\hline Toba silicificada & & & & 2 & 1 & 2 & 5 \\
\hline Indet. & & 1 & & & & 6 & 7 \\
\hline Pizarra & & & & 1 & & 7 & 8 \\
\hline Sílex & & & & & 3 & 5 & 8 \\
\hline Calcedonia & & 2 & & & & 6 & 8 \\
\hline Cinerita & & & 4 & 8 & 28 & 109 & 149 \\
\hline Riolita & 1 & 1 & 2 & 47 & 64 & 440 & 555 \\
\hline Total & $\mathbf{1}$ & $\mathbf{4}$ & $\mathbf{6}$ & $\mathbf{6 1}$ & $\mathbf{9 6}$ & $\mathbf{5 8 0}$ & $\mathbf{7 4 8}$ \\
\hline
\end{tabular}

Tabla 8. 10. Relación entre tipo de labio y materia prima

\section{Fragmentos}

Los fragmentos constituyen el $30 \%$ del subgrupo de más de $2 \mathrm{~cm}$ ( $\mathrm{n}=$ 395), de los cuales el $67 \%$ son de riolita, el $17 \%$ de cinerita. En tercer lugar aparecen las tobas silicificadas con un $4 \%$ al igual que los fragmentos de 
materias primas no determinables, luego calcedonia, sílex y cuarzo con un 1\% cada uno y un poco menos todavía el chert (Gráfico 8.9). El caso de la pizarra (5\%), es complicado dada su naturaleza frágil y clivaje muy alto, por lo tanto es muy difícil determinar si los fragmentos sobre esta materia prima son naturales o no.

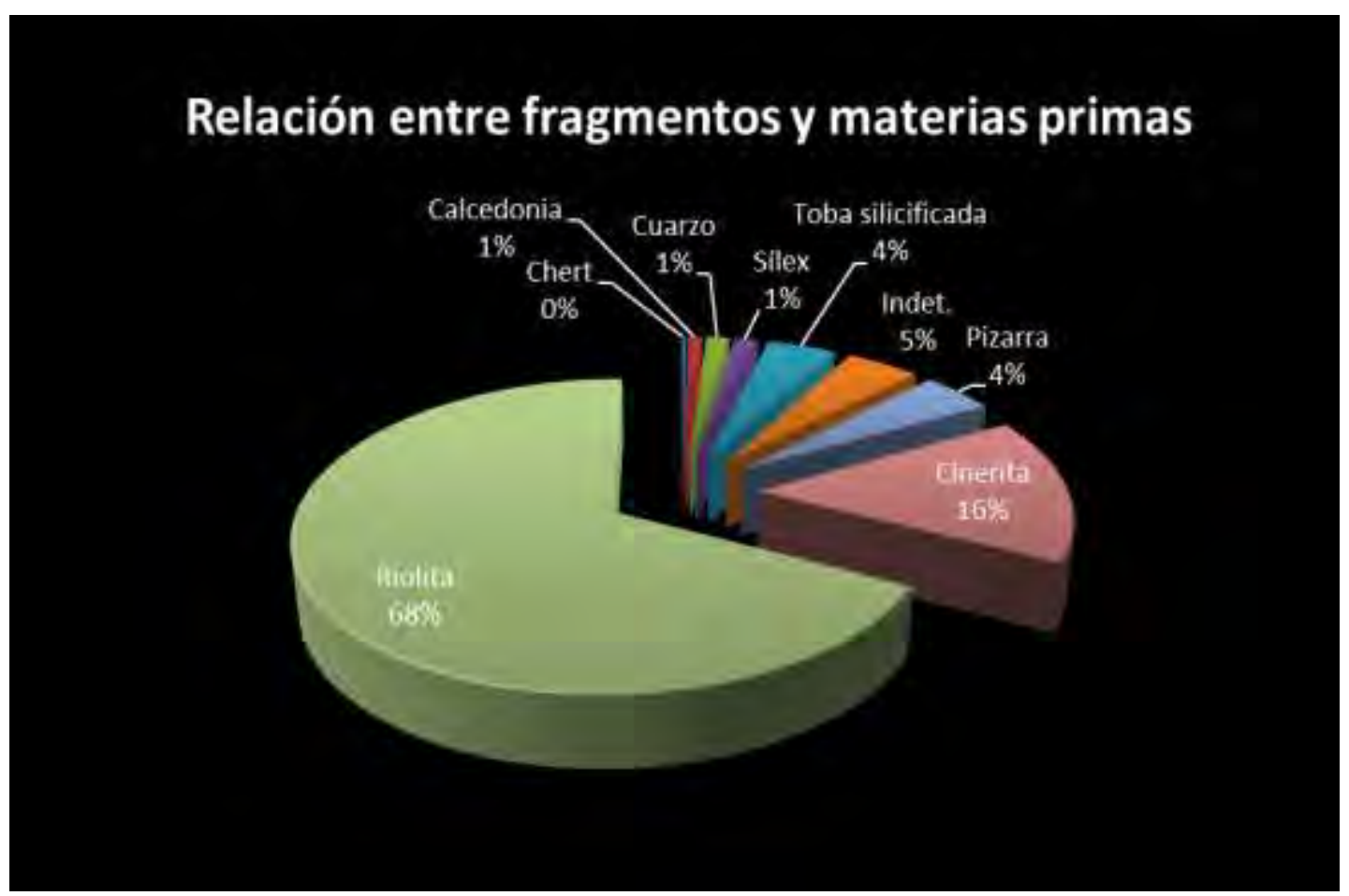

Gráfico 8. 9. Relación entre fragmento y materia prima

\section{Instrumentos}

Básicamente consta de 3 grupos bien definidos: los raspadores, los filos largos retocados (sólo representados por raederas) y los artefactos bifaciales.

\section{Raspadores}

El $\mathrm{N}$ total de raspadores es de 34 piezas, sin embargo el número de filos asciende a 44 (Figura 8.3). En cuanto a las materias primas representadas por los raspadores podemos definir a grandes rasgos 7: toba silicificada, cuarzo, riolita, basalto, calcedonia, chert y cinerita. La más abundante para este conjunto son: toba silicificada con un $n=24$, luego cuarzo y cinerita con un $n=$ 3 , finalmente riolita, chert, calcedonia y basalto con un $n=1$. 


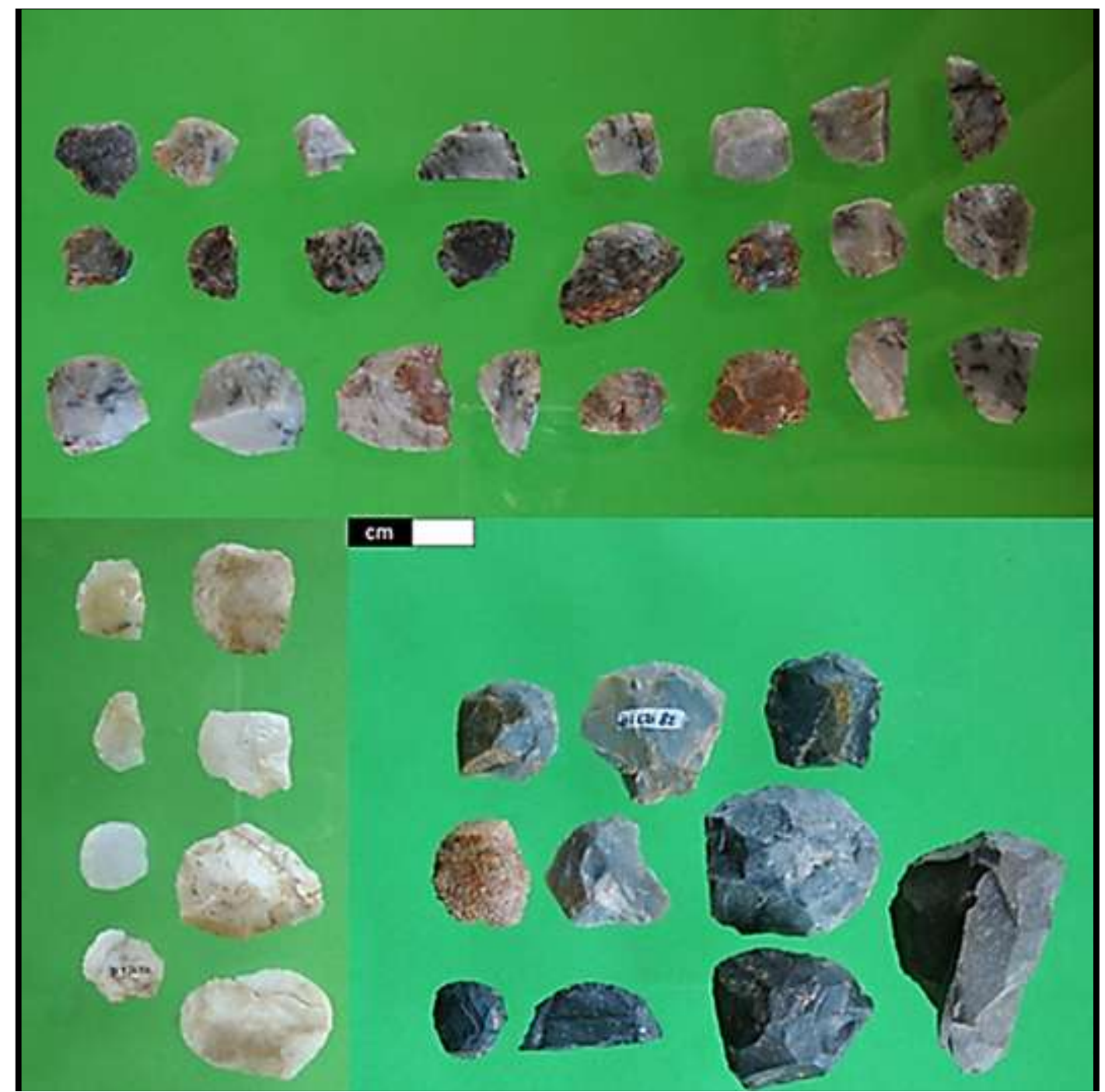

Figura 8. 3. Raspadores. Arriba: raspadores en toba silicificada Miraflores. Abajo izquierda: raspadores en cuarzo, derecha: raspadores en otras materias primas

Los tipos que incluye el conjunto no presentan una gran diversidad, entre ellos podemos mencionar los raspadores simples $(n=28)$, los atípicos o no estandarizados $(n=2)$, los dobles $(n=2)$, finalmente un sólo raspador triple y uno al que sólo puede definirse genéricamente como raspador debido a las fracturas. El grado de conservación, desde un punto de vista macroscópico, es bueno, pudiéndose mencionar un caso de presencia de pátina. El grado de fragmentación es variable presentándose de la siguiente forma: 23 raspadores enteros, 7 con fracturas y 4 corresponden a fragmentos.

Las dimensiones del conjunto permiten que agrupemos a los raspadores entre microrraspadores 21 , raspadores chicos 9 y raspadores largos 4 . Para este análisis se tomaron en cuenta los módulos de longitud-anchura y el de 
ancho-espesor. El primero de ellos arrojo los siguientes resultados: 18 piezas cortas, 14 medianas y 2 largas, mientras que el segundo módulo mostró: gruesas 21 , medianas 12 y delgada 1 . Estos resultados nos están hablando de un conjunto de pequeño porte pero espeso.

Finalmente, en cuanto a la morfología de los raspadores, la forma base presenta las siguientes características: en relación a los soportes sobre los que se confeccionaron los raspadores se pudo determinar que 21 de ellos se realizaron sobre lascas, 7 a partir de lascas bipolares, 4 sobre fragmentos, uno sobre una lasca de dorso natural y en uno no pudo determinarse la forma base. Los talones son principalmente lisos $n=15$, luego se dividen entre diedros $y$ facetados $\operatorname{con} n=2$ cada uno, lineales $n=3$, corticales $n=4$, liso en ala de pájaro $n=1$ y sólo uno no pudo determinarse. Seis raspadores no presentaban talones ya sea que desaparecieron por talla o fracturas, y en tres se pudo determinar preparación de talón. En cuanto a la inclinación de los talones 21 son rectos, mientras que 5 son oblicuos.

De las 19 piezas que presentan bulbo, en 13 casos es difuso (uno con esquirlamiento) y los 6 restantes corresponden a los espesos. El labio se encuentra representado en 14 instrumentos, 5 presentan labio difuso y 9 labio normal.

En general los raspadores no presentan rastros de corteza, sólo 5 presentan corteza en diversos porcentajes. Dentro de ellos en las categorías muy abundante y abundante se encuentran los confeccionados sobre cuarzo, mientras que en la categoría parcial está incluido el de calcedonia y el de basalto presenta escasa corteza. En los raspadores confeccionados sobre toba silicificada no pudo determinarse si presentan o no corteza debido a que se pueden confundir con impurezas propias de la roca.

\section{Soportes y materias primas}

En cuanto a la relación de los soportes reconocidos para la confección de raspadores y las materias primas, la que mayor diversidad presenta es la toba silicificada dentro de la cual se reconocieron raspadores sobre lascas, lascas bipolares, fragmentos y una lasca de dorso natural, los raspadores de cuarzo fueron confeccionados sobre lascas bipolares al igual que el raspador de chert, mientras que hay dos de cinerita sobre lasca y uno no pudo 
determinarse el soporte. Los raspadores de basalto, riolita y calcedonia fueron confeccionados sobre lasca, (Tabla 8.11).

\begin{tabular}{|l|c|c|c|c|c|c|c|c|}
\hline $\begin{array}{l}\text { Soportes / } \\
\text { materia prima }\end{array}$ & Calcedonia & Chert & Riolita & Basalto & Cinerita & Cuarzo & Toba Silicificada & Total \\
\hline Indet. & & & & & 1 & & & 1 \\
\hline L. dorso natural & & & & & & & 1 & 1 \\
\hline Fragmento & & & & & & & 4 & 4 \\
\hline Lasca bipolar & & 1 & & & & 3 & 3 & 7 \\
\hline Lasca & 1 & & 1 & 1 & 2 & & 16 & 21 \\
\hline Total general & $\mathbf{1}$ & $\mathbf{1}$ & $\mathbf{1}$ & $\mathbf{1}$ & $\mathbf{3}$ & $\mathbf{3}$ & $\mathbf{2 4}$ & $\mathbf{3 4}$ \\
\hline
\end{tabular}

Tabla 8. 11. Relación entre soportes utilizados para la confección de raspadores y materia prima

Forma base:

Los rapadores de cuarzo podrían provenir de pequeños guijarros, dada la forma y las características de la corteza (redondeada), además de la evidencia del uso de la técnica bipolar para su producción; los confeccionados sobre toba silicificada podrían tener dos posibles orígenes, por un lado provenir, al igual que los anteriores de pequeños guijarros y por otro lado podrían pertenecer todos a un mismo núcleo a partir del cual fueron extraídos en pequeños fragmentos. Es importante mencionar que los raspadores sobre cuarzo y toba silicificada son los que presentan características morfológicas más uniformes entre sí, en tanto que los que fueron confeccionados sobre otras materias primas como riolita y cinerita presentan un mayor grado de variabilidad. Esto puede estar relacionado con las características de estas materias primas y por cómo se presentan en los afloramientos (rodados de gran tamaño), junto con el empleo de técnicas específicas para la obtención de las formas base como por ejemplo talla por percusión directa o talla bipolar.

Detalle de los filos:

El total de filos supera al número de raspadores dado que, si bien el conjunto se caracteriza por la presencia de piezas con un sólo filo $(n=25)$, hay 8 con dos filos y uno presenta tres filos retocados, lo que eleva el número de filos a un total de $n=44$.

Entre los filos se destacan los distales $(n=20)$, luego los izquierdos $(n=16)$ y finalmente los derechos $(n=8)$. La delineación muestra una gran 
representatividad de filos convexos $(n=32)$, le siguen los rectos $(n=7)$ y finalmente los semicirculares $(n=5)$. Los filos en su sección longitudinal son principalmente rectos. Casi la mitad de los raspadores presentan filos que no superan los 2 centímetros de largo y los $0,3 \mathrm{~cm}$ de alto, luego a partir de filos con alturas de 0,4 en adelante vemos longitudes que van desde 0,9 a $3,4 \mathrm{~cm}$.

\section{Detalle del retoque:}

El retoque presenta una homogeneidad más marcada que en el resto de los atributos antes mencionados, el ángulo es en general intermedio aunque hay algunos rectos, la posición del retoque es directo en 40 de los 44 filos y la extensión es principalmente larga, aunque también hay filos con extensiones restringidas, extendidas y cortas. Casi todos son filos con retoque continuo y principalmente marginal $(n=36)$, aunque 7 de ellos presentan una profundidad muy marginal y uno sólo profunda.

Filos largos retocados (raederas)

El conjunto de los filos largos retocados está constituido por un $n=39$, con una predominancia de instrumentos confeccionados sobre riolita, el 79\% de la muestra, luego en lutitas con un $8 \%$, pizarra y cinerita con $5 \%$ y finalmente un instrumento confeccionado sobre andesita $3 \%$ (Figura 8.4 y 8.5 ).

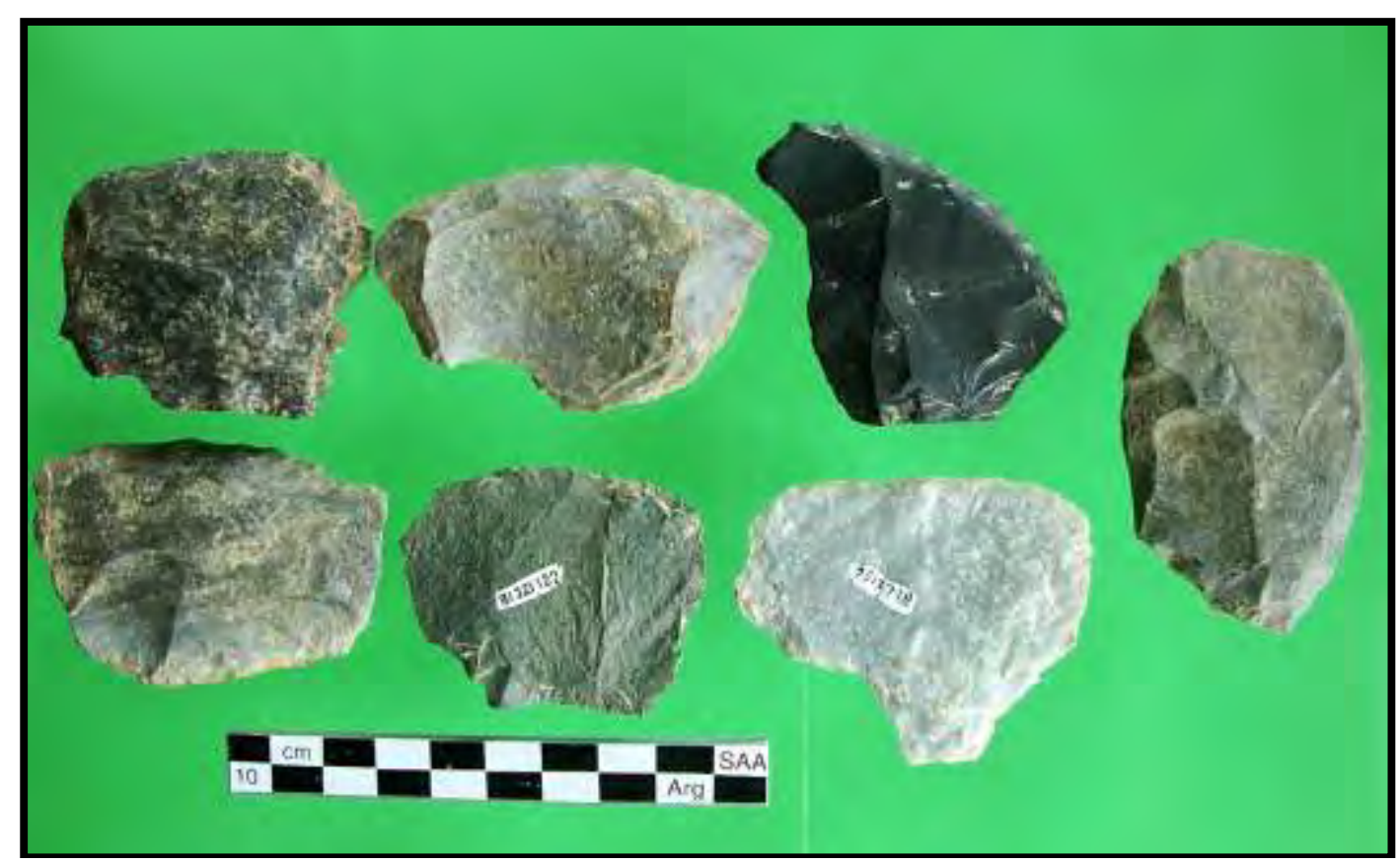

Figura 8. 4. Filos largos retocados de tamaño mediano 


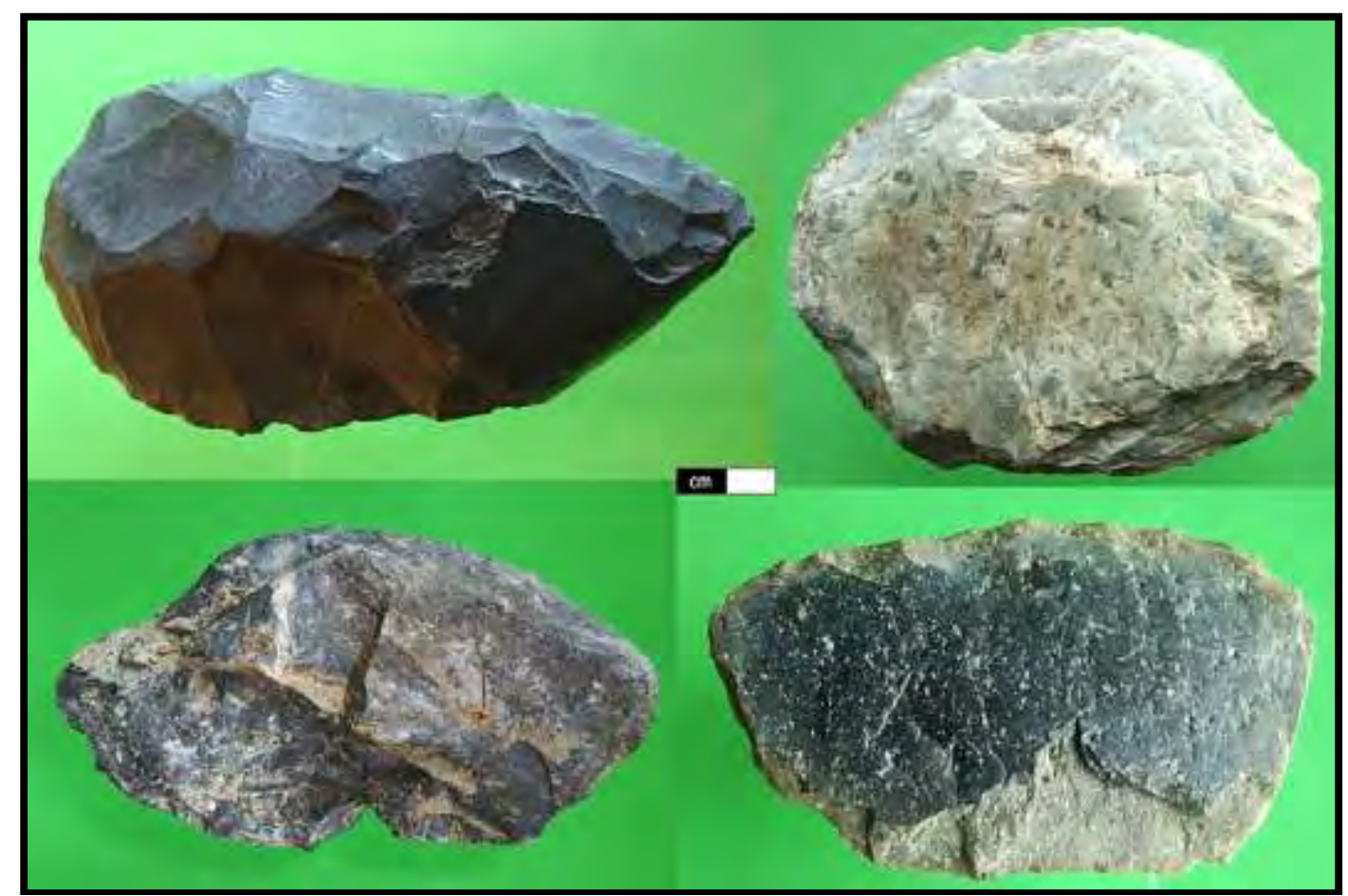

Figura 8. 5. Filos largos retocados de tamaño grande

$\mathrm{Si}$ bien los tipos representados son diversos, las raederas simples transversales (RAT) son las más abundantes con $n=14$, en segundo lugar se presentan las raederas (RA) con $n=9$, en este caso las denominamos raederas sin otra característica ya que las fracturas que presentan no nos permiten más detalle en la clasificación; luego las raederas simples laterales (RAS) $\operatorname{con} n=8$, siguen las raederas simples oblicuas $(R A O)$ con $n=7$ y sólo una raedera doble convergente (RAC).

En cuanto al estado de las piezas, $n=18$ están enteras, $n=3$ presentan fracturas pero que no afectan los filos, $n=7$ presentan fracturas que afectan la zona del filo retocado y $n=11$ artefactos se presentan fracturados en varios fragmentos (de 2 a 4). De todas formas, en algunos casos, pudo reconstruirse el instrumento de forma completa.

En relación a lo anterior, podemos ver que la mayoría de las raederas que presentan fracturas muestran indicios de termoalteración por contacto con fuego o al menos con altas temperaturas y planos de fractura que podría estar relacionado con esto. Sin embargo, también hay otras que presentan fracturas tecnológicas producidas por accidentes durante la talla (Figura 8.6). 


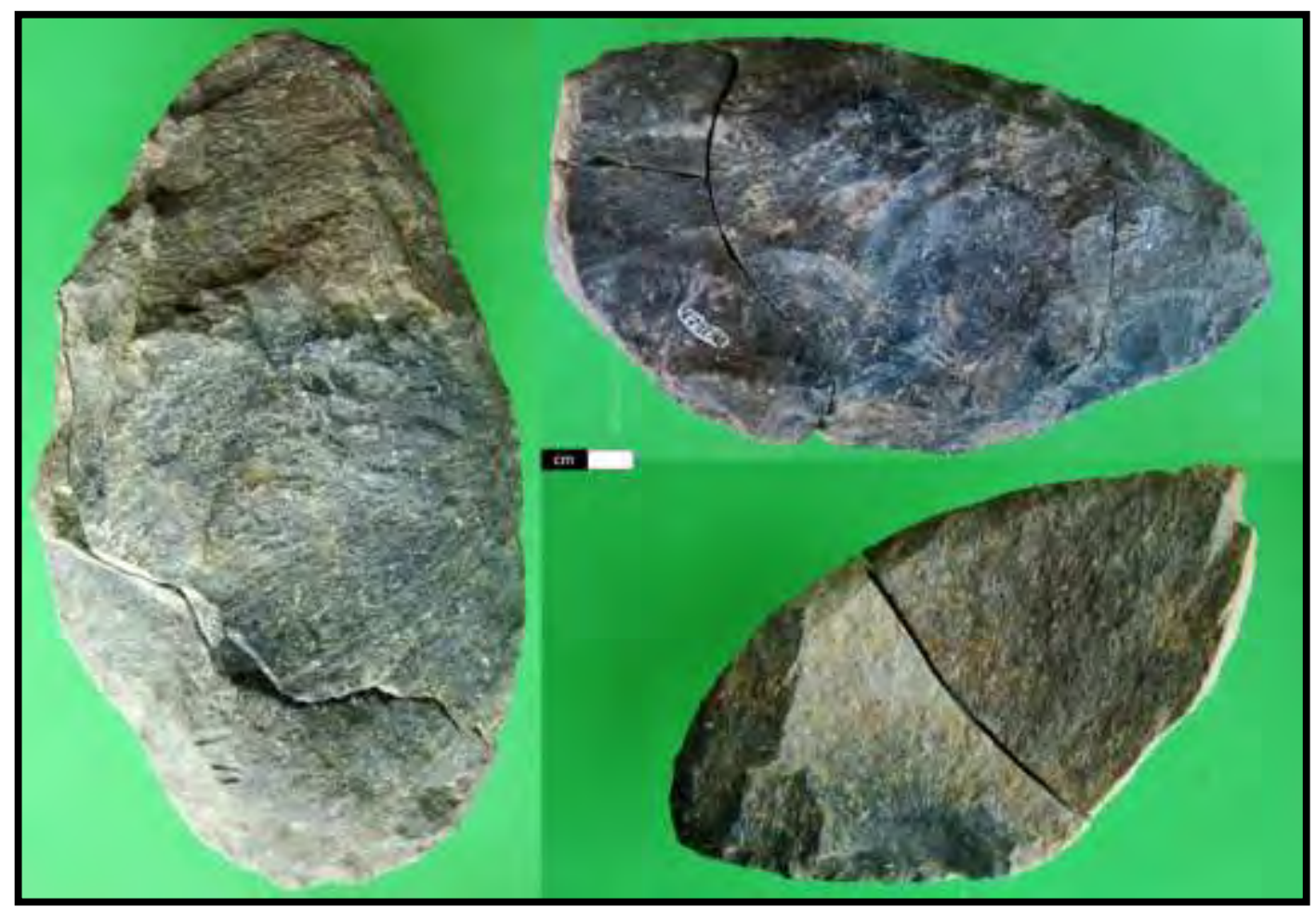

Figura 8. 6. Filos largos retocados fracturados

La distribución de tipos en las diversas materias primas muestra mayor diversidad en las riolitas, donde están representados todos los tipos de raederas, luego sobre lutita se confeccionaron 2 raederas y una raedera simple transversal, mientras que sobre pizarra se produjo una transversal y una raedera. En el caso de cinerita se confeccionaron 2 raederas y finalmente sobre andesita sólo una raedera simple oblicua (Tabla 8.12).

\begin{tabular}{|l|c|c|c|c|c|l|}
\hline $\begin{array}{l}\text { Tipos de raedera y } \\
\text { materias primas }\end{array}$ & Lutita & Andesita & Pizarra & Cinerita & Riolita & $\begin{array}{l}\text { Total } \\
\text { general }\end{array}$ \\
\hline Raedera & 2 & & 1 & 2 & 4 & 9 \\
\hline Raedera doble conv. & & & & & 1 & 1 \\
\hline Raedera Oblicua & & 1 & & & 6 & 7 \\
\hline Raedera lateral & & & & & 8 & 8 \\
\hline Raedera Transversal & 1 & & 1 & & 12 & 14 \\
\hline Total general & $\mathbf{1}$ & $\mathbf{1}$ & $\mathbf{2}$ & $\mathbf{3}$ & $\mathbf{3 2}$ & $\mathbf{3 9}$ \\
\hline
\end{tabular}

Tabla 8. 12. Relación entre tipo de raedera y materia prima

El soporte más utilizado para la producción de los filos largos retocados fueron las lascas, principalmente de riolita pero también se puede ver uno sobre lutita, uno sobre pizarra y otro sobre andesita. En segundo lugar aparecen las lascas de dorso natural, 3 sobre riolita, y uno sobre lutita y pizarra. Por último, hay 4 artefactos dos sobre cinerita, unos sobre riolita y otro 
sobre lutita, que debido al grado de fragmentación no se pudo determinar el tipo de soporte elegido.

La corteza está ausente en un $38 \%$ de la muestra, mientras que el resto podemos agruparlo de la siguiente manera: con un $38 \%$ corteza escasa, el $13 \%$ corteza parcial, el $8 \%$ corteza muy abundante y un $3 \%$ con cobertura abundante. Para ver en detalle la presencia de corteza en relación a las materias primas ver gráficos a continuación (Gráfico 8.10 ).

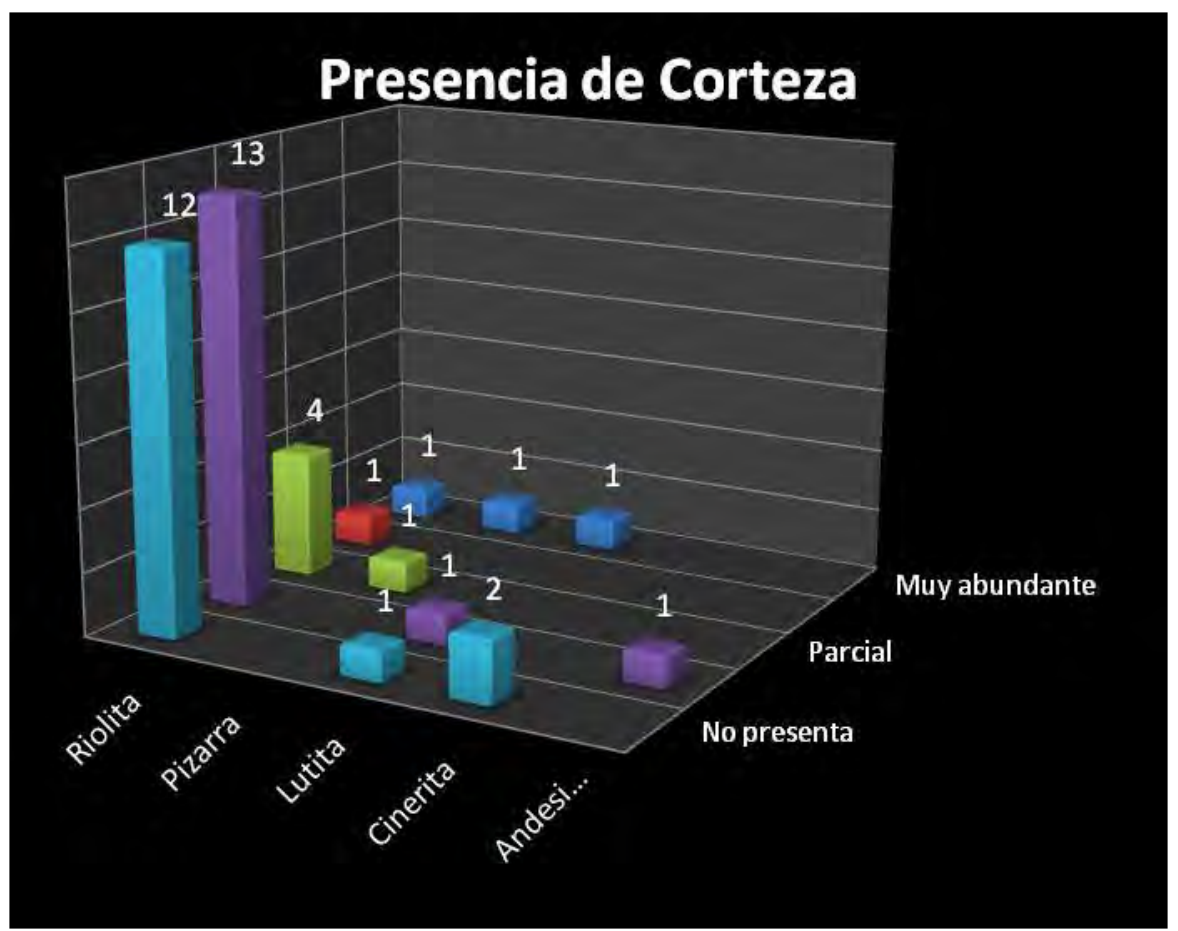

Gráfico 8. 10. Presencia de corteza en los filos largos retocados y su relación con las materias primas

Los filos largos retocados son generalmente piezas cortas, con grosores delgados $n=13$ y medianos $n=8$, en menor medida piezas de longitud media y grosor intermedio $n=11$, delgadas $n=3$ y gruesas $n=2$. Por último sólo dos piezas presentan longitudes que corresponden a artefactos largos y gruesos.

El conjunto se caracteriza por presentar piezas con un sólo filo, sólo una raedera de riolita formatizada sobre una lascas presenta dos filos. La situación de los filos se presenta principalmente en la parte distal de la pieza $n=21$, luego en el sector derecho $n=11$, sobre el sector izquierdo $n=5$ y dos indeterminadas debido a la fragmentación de las piezas. 
En cuanto a la delineación de los filos 24 de ellos son convexos, mientras que los rectos presentan un $n=9$, luego aparecen los curvados con $n=$ 4 y los filos circulares se presentan en dos piezas.

Los filos muestran principalmente retoque irregular, excepto la pieza confeccionada sobre andesita. En 37 de los 39 artefactos formatizados como raederas, los filos son unifaciales y en general la posición del retoque es directa en 32 casos, mientras que los retoques con posición invertida se dieron en 5 casos. El retoque bifacial sólo se dio en dos pieza. En cuanto a la extensión del retoque a lo largo del filo, pudimos determinar que 30 pertenecen a los filos largos mientras que 9 se encuentran restringidos ya sea por fracturas o por algún otro tipo de particularidad del filo. Excepto un caso, todos los filos presentan retoque continuo.

En relación a la profundidad del retoque, éste generalmente es marginal $n=28$, continuado por retoque profundo $n=7 y$ con retoque muy marginal $n=4$.

\section{Puntas de proyectil}

Las puntas de proyectil constituyen el tipo menos representado, dentro de los artefactos retocados. A partir del remontaje de las partes recuperadas en la excavación se pudo determinar la presencia de 3 puntas, dos de estas se remontaron de forma completa, mientras que una sólo presenta la parte media y distal. Las primeras dos fueron confeccionadas sobre riolita de grano fino, mientras que la tercera fue confeccionada sobre un sílex marrón (Figura 8.7).

En cuanto a la forma, sólo podemos hacer referencia a las dos puntas completas. Ambas son apedunculadas, con muesca en la base. Sin embargo una es de forma triangular con limbos rectos cuya parte más ancha se encuentra en la base, mientras que la otra presenta una forma más curvada presentando el máximo de ancho en la mitad de la pieza.

Una de las puntas esta disgregada en tres fragmentos, una fractura en el sector medial; además, en la parte de la base, presenta una fractura longitudinal que atraviesa el centro de la muesca basal. La otra, disgregada en dos fragmentos, presenta una fractura oblicua que comienza en la parte media y sube hasta la parte distal. La tercera, tiene dos fragmentos que corresponden, como mencionamos anteriormente, a la parte distal y medial con fracturas transversales. En cuanto a las fracturas, en general, en todos los 
casos concuerdan con fracturas tecnológicas, además ningún fragmento presenta evidencias de alteración por alta temperatura.

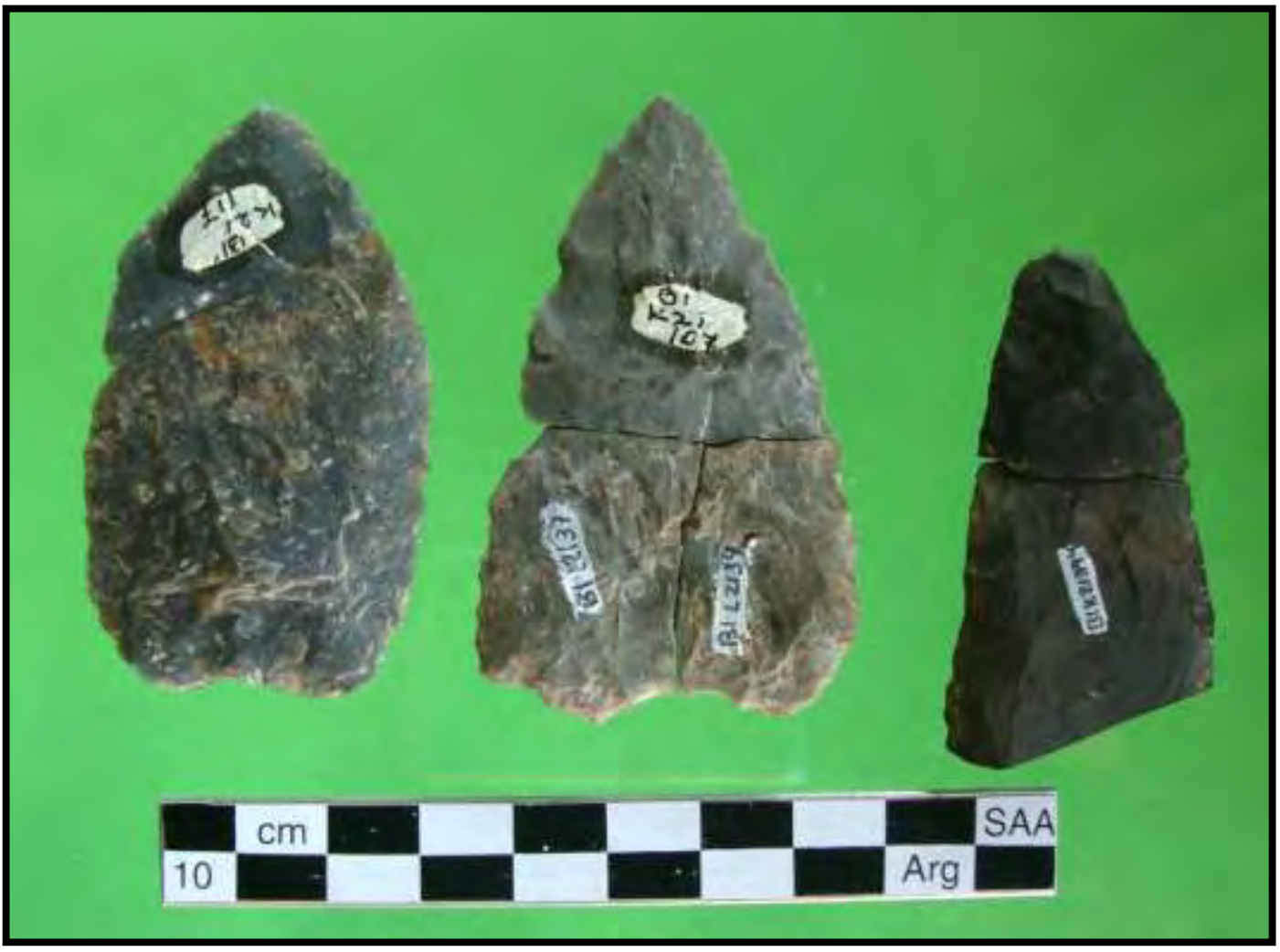

Figura 8. 7. Puntas de proyectil

\section{Conjunto bipolar}

No referiremos aquí a los materiales líticos no retocados (lascas, fragmentos, núcleos, etc.) -dado que los artefactos retocados (raspadores) fueron presentados más arriba- obtenidos por la técnica de talla bipolar, donde se utiliza un yunque fijo y uno móvil. Esta técnica permite obtener lascas a partir de pequeños guijarros o de núcleos prácticamente agotados, en los cuales no es posible la extracción de lascas por percusión directa.

Los materiales provenientes del sitio Kami 1 conforman un conjunto pequeño $(\mathrm{N}=67)$, pero muy consistente en cuanto a las materias primas representadas, que son principalmente cuarzo en un $86 \%$, continuando muy por debajo con las tobas silicificadas en un $8 \%$, en menor cantidad cinerita, chert y sílex alcanzando un $2 \%$ cada una.

Los fragmentos bipolares abarcan la mitad del conjunto, mientras que las lascas bipolares alcanzan el $22 \%$ de la muestra, seguidas por los núcleos 
bipolares con un $15 \%$ y finalizando la lista los hemiguijarros obtenidos por esta técnica con el 14\% (Gráfico 8.11).

En relación con las dimensiones, el conjunto se caracteriza por artefactos comprendidos entre los 2 y los $4 \mathrm{~cm}$ de largo en todas las materias primas representadas.

Cabe destacar que entre las lascas se pudieron reconocer al menos dos pièces esquillées (Figura 8.8), una sobre sílex y otra sobre cuarzo.

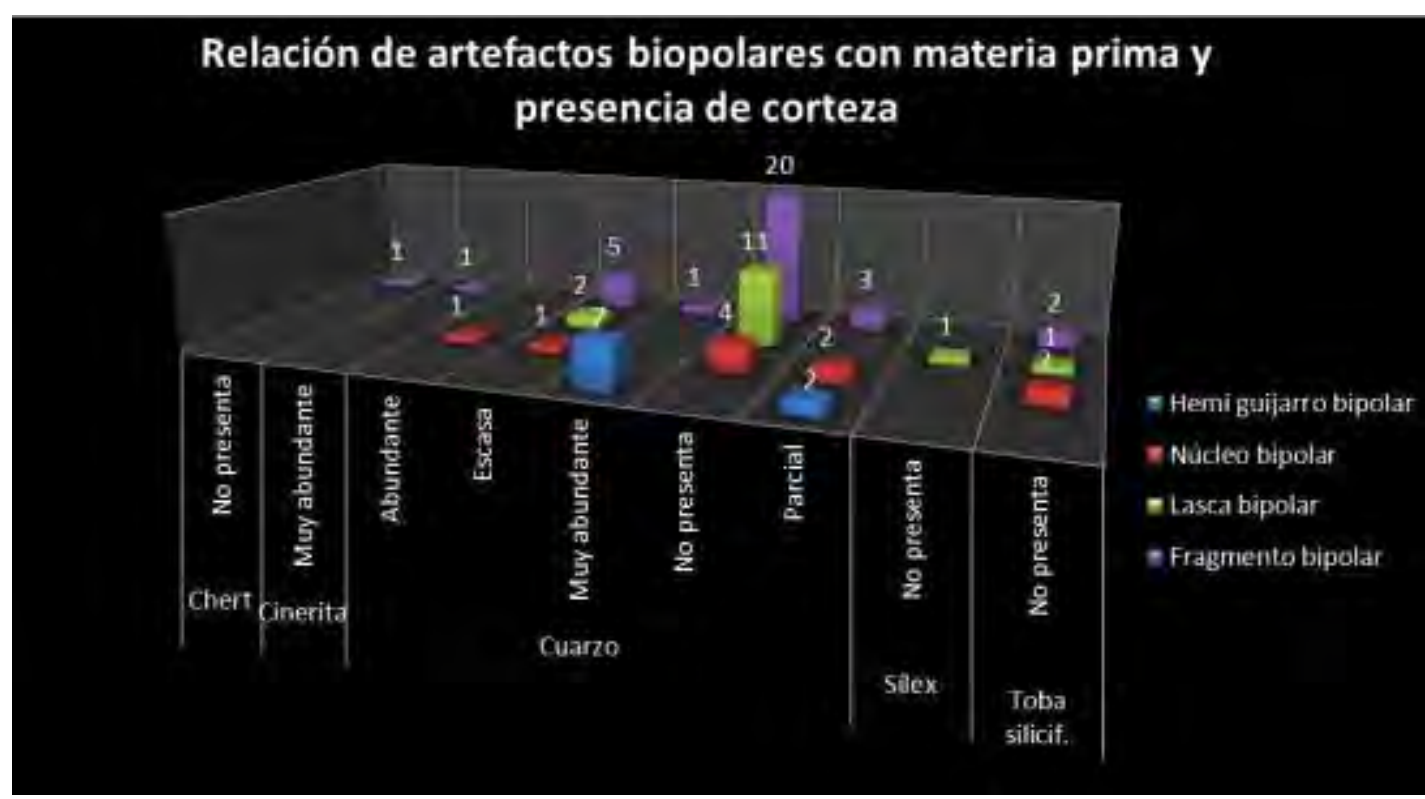

Gráfico 8. 11. Relación entre presencia de corteza en artefactos bipolares y materia prima

La corteza está ausente en un $63 \%$ de la muestra, principalmente en fragmentos y lascas, mientras que un $13 \%$ muestra una presencia muy abundante de corteza representado en los hemiguijarros y en dos fragmentos, un $12 \%$ distribuido entre fragmentos, lascas y un núcleo presentan escasa corteza; en cuanto a aquellas piezas que muestran una presencia parcial, estas ocupan un $10 \%$ y representan fragmentos, núcleos y hemiguijarros, finalmente sólo un núcleo presenta corteza abundante. 


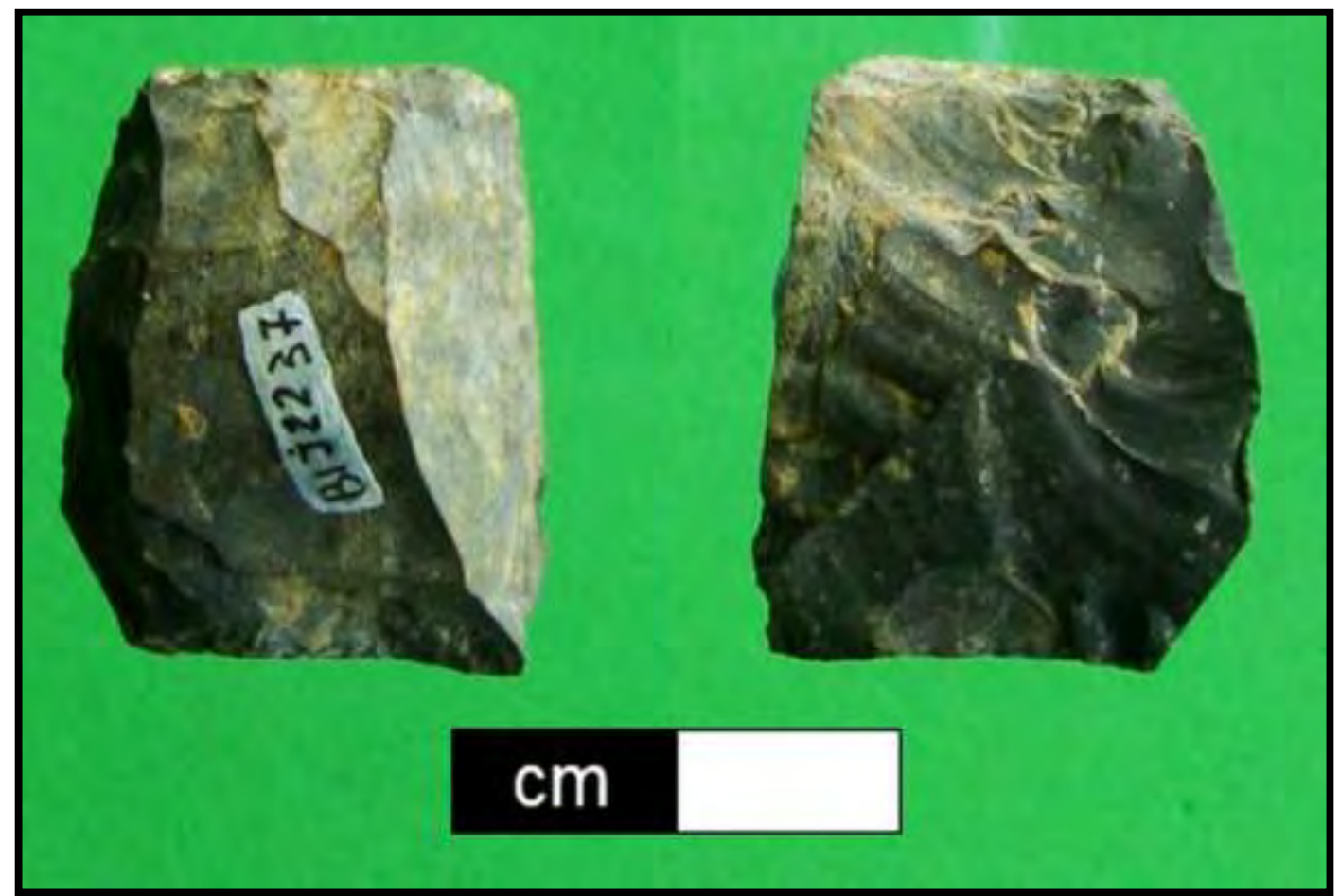

Figura 8. 8. Pieza bipolar, pièces esquillées en sílex

\section{Análisis funcional}

El análisis fue realizado según los lineamientos presentados en el capítulo 3. Se realizaron análisis sistemáticos de todos los filos retocados y los filos potencialmente utilizables. Los instrumentos fueron lavados con agua y jabón; antes y durante el análisis se efectuaron limpiezas con alcohol.

La utilización de la lupa permitió definir aquellas características de los filos, que precisan ser vistos tridimensionalmente, como por ejemplo los microlascados, microesquirlamientos, que pueden estar relacionados con el uso de la pieza. Además este equipo permite un acercamiento previo a la conservación de la superficie de la pieza en relación a la presencia de pátinas o cualquier otro tipo de alteración que escape al análisis a ojo desnudo.

A partir del análisis de base microscópica se puede decir en líneas generales, que el estado de conservación a esta escala es parcial, si bien son varios los artefactos que aportaron información respecto del uso, también son varios los que presentaron grados de alteración a nivel microscópico, tan altos que impidieron llegar a conclusiones en cuanto a la utilización del instrumento. En algunos casos la alteración por alta temperatura fue la causa de ello y en otros el grado de abrasión de la pieza. 


\section{Raspadores}

Los resultados del análisis funcional, permitieron identificar rastros de uso en 17 de los 44 filos, con diversos grados de desarrollo, aunque el más representado fue el grado 3 (rastros de uso bien desarrollados). Las piezas en las cuales no pudo determinarse su uso, en algunos casos se debió principalmente a que no fueron muy utilizadas, mientras que en otros se debe a la presencia de alteraciones postdepositacionales (químicas) o por alteraciones térmicas.

En cuanto a la cinemática y ángulo de trabajo, en todos los casos determinables el movimiento es transversal al filo, raspado, y generalmente el ángulo de trabajo es intermedio a recto.

Material: en 16 casos pudo determinarse uso sobre piel (Figura 8.9), mientras que un caso podría tratarse de material duro vegetal.

No se pudo determinar presencia de abrasivos durante el uso en ninguno de los raspadores analizados; ni tampoco de procesamiento con materiales colorantes (hematita, etc.). Tampoco se detectaron rastros de enmangue, sin embargo este se infiere principalmente del tamaño de las piezas.

En cuanto a la reactivación, pudieron verse algunos casos donde la evidencia tanto macro como microscópica indicarían posible reactivación. En cuanto a las primeras se pudieron observar instrumentos con ángulos muy rectos, en el caso de las evidencias microscópicas se pudo determinar alternancia de zonas con rastros de uso con otras con muy poco o nada de rastros. 


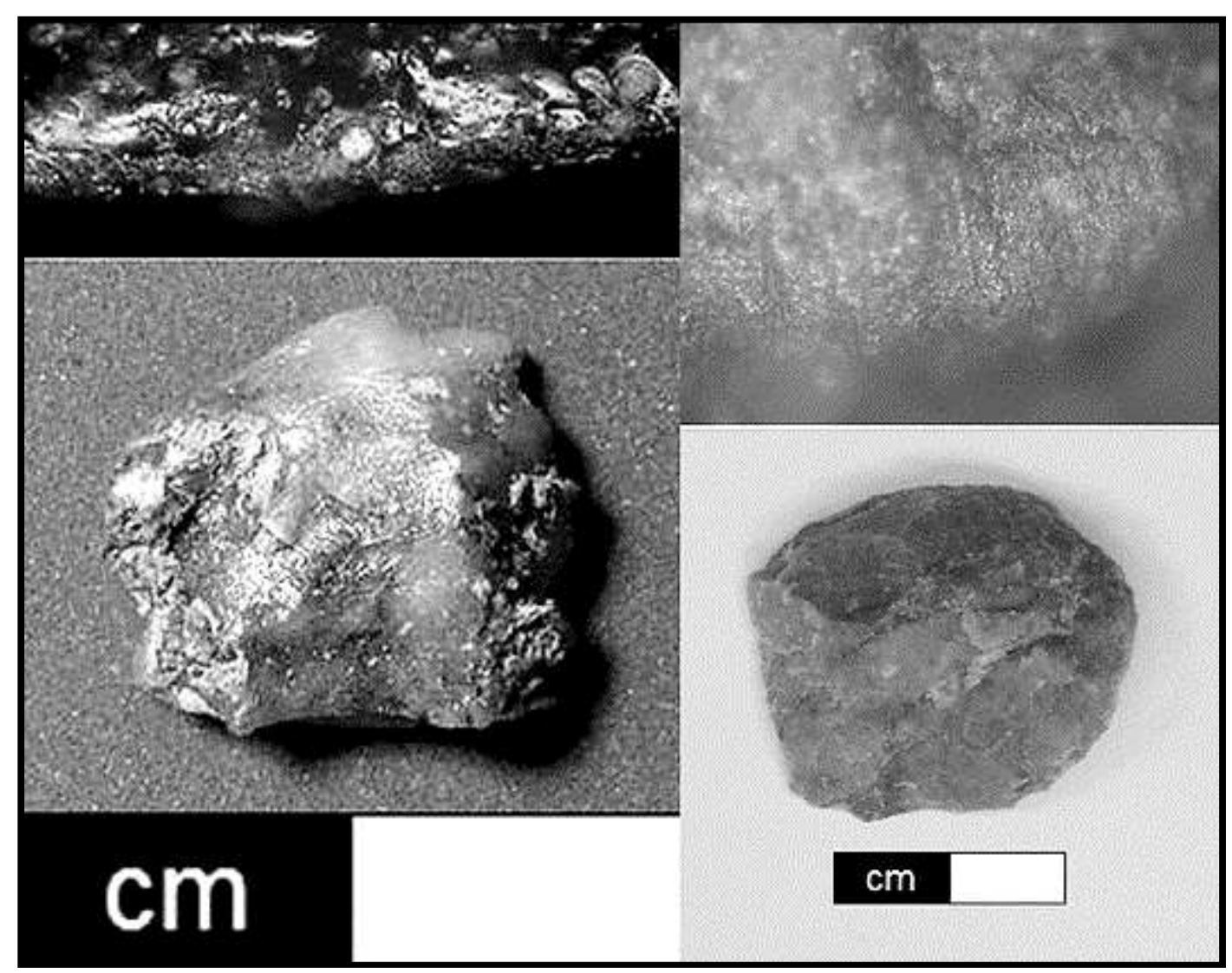

Figura 8. 9. izq. Micro-raspador de toba silicificada con micropulido de piel; der. Micro-raspador de riolita con micropulido de piel. Microfotografía a 200X

\section{Filos largos retocados}

Dentro de los filos largos retocados, incluimos a todos los instrumentos que tienen retoque sobre un filo largo, independientemente de su ángulo.

El total de filos asciende a $n=40$, de los cuales 16 pueden considerarse con uso seguro, 8 con uso probable, 11 son no determinables y 4 no presentan evidencias de uso. Dentro de los filos con uso seguro los micropulidos corresponden 10 a aquellos con grado de desarrollo 3 y los 6 filos restantes a grado de desarrollo 2.

Dado el desarrollo de los micropulidos se pudo identificar el material trabajado, el cual fue madera para 15 de los filos (Figura 8.10) y piel para dos de ellos (Figura 8.10); esto es porque en una de las piezas un filo extendido trabajo madera en un sector y piel en la porción distal.

La cinemática de trabajo es tanto transversal en $n=9$ filos (se incluyen aquí los dos filos que trabajaron piel), como longitudinal/oblicua $n=7$ (dado que no se vio trabajo totalmente longitudinal). 
En ninguno de los casos se identificó evidencia de utilización de abrasivos, ni de reactivación de filos. En cuanto al enmangue, en algunos casos pudieron reconocerse pulidos de tipo $G$ en el lado opuesto del filo utilizado.
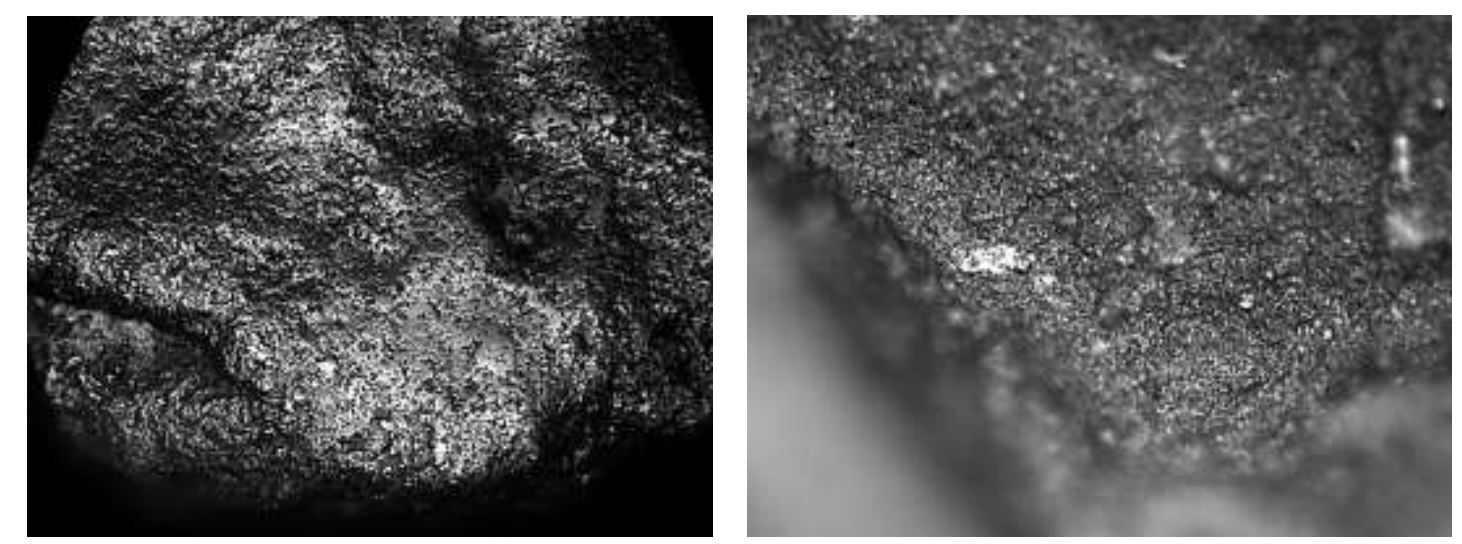

Figura 8. 10. izq. Micropulido de madera; der. Micropulido de piel. microfotografía a $200 \mathrm{x}$

\section{Puntas de proyectil}

Las puntas de proyectil, como se indicó en el análisis, presentan fracturas producidas durante la talla. De todos modos, se realizó el análisis microscópico de los filos, pero estos no presentaron ninguna evidencia de utilización.

\section{Filos potencialmente utilizables}

Como se mencionó el $9 \%$ del conjunto de lascas presenta filos potencialmente utilizables. Todas ellas fueron analizadas microscópicamente y la mayor parte presentaban rasgos tecnológicos que sugieren que no fueron utilizadas. Sólo un $n=10$ presentaron filos con un mínimo redondeamiento y un brillo tenue, que podrían indicar una utilización muy breve, pero se trata de un incipiente desarrollo de micropulido que no permite identificar ni dirección ni material trabajado y no es suficiente para diferenciarlo de un lustre de suelo pronunciado. 


\section{LOS MATERIALES DE RECOLECCIÓN SUPERFICIAL}

Los materiales de superficie provienen de la recolección intensiva realizada en el reticulado total del sitio (ver cap. 4 y 5 ).

El conjunto se conforma de $n=118$ artefactos líticos, los más abundantes son los fragmentos $n=72$, lascas $n=33$, retocados $n=6$ y núcleos (incluyendo núcleos bipolares) $n=4$; los menores a $2 \mathrm{~cm}$ sólo cuentan con 2 lasquitas. En cuanto a las materias primas las riolitas presentan $n=57$, cinerita $n=36$, pizarra $n=11$, no determinada $n=10$ y con $n=1$ chert, cuarzo, calcedonia y lutita (Tabla 8.13).

\begin{tabular}{|c|c|c|c|c|c|c|c|c|c|c|c|}
\hline & Tipos / Materia prima & Cuarzo & Calcedonia & Lutita & Chert & Indet. & Pizarra & Cinerita & Riolita & Total & $\%$ \\
\hline "s & Raspador simple & & & & & & & 1 & 1 & 2 & \\
\hline 要 & Raedera transversal & & & & & & & 1 & 3 & 4 & \\
\hline 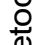 & Fragmento instrumento & & & & & & & 1 & & 1 & \\
\hline$\underline{\square}$ & Total retocados & & & & & & & 3 & 4 & 7 & $6 \%$ \\
\hline & Núcleo discoidal & & & & & & & & 1 & 1 & \\
\hline 8 & Núcleo apical & & & & & & & & 1 & 1 & \\
\hline$\frac{\overline{0}}{0}$ & Núcleo bipolar & & & 1 & 1 & & & & & 2 & \\
\hline 8 & Lasca & & 1 & & & 1 & & 9 & 22 & 33 & \\
\hline$\stackrel{0}{0}$ & Fragmento & 1 & & & & 9 & 11 & 22 & 29 & 72 & \\
\hline $\mathbf{z}$ & Lasquita & & & & & & & 2 & & 2 & \\
\hline & Total no retocados & 1 & 1 & 1 & 1 & 10 & 11 & 33 & 53 & 111 & $94 \%$ \\
\hline & Total general & 1 & 1 & 1 & 1 & 10 & 11 & 36 & 57 & 118 & $100 \%$ \\
\hline
\end{tabular}

Tabla 8. 13. Materiales de Kami 1, recolección superficial

\section{Análisis tecno-morfológico}

Núcleos

Como mencionamos, los núcleos alcanzan un $n=4$, de los cuales dos son bipolares (uno en chert y otro en lutita) y dos son de talla directa (ambos sobre riolita). Los cuatro presentan pátinas y adherencias sobre la superficie.

En cuanto a la corteza hay dos núcleos sin corteza, mientras que uno presenta corteza muy abundante (en riolita) y otro presenta corteza abundante (lutita). En relación a esto, se encuentra el grado de explotación, ya que los dos núcleos que presentan corteza también presentan un grado de explotación tipo 1 , mientras que los otros dos están agotados. 


\section{Lascas}

El conjunto de lascas tiene un $n=33$, de las cuales $n=22$ son en riolita, $\mathrm{n}=9$ son en cinerita, $\mathrm{n}=1$ en calcedonia y no determinada. La conservación es buena en la mitad de las piezas $n=16$, las restantes presentan pátina $n=11 \mathrm{y}$ líquenes $n=6$. Algo similar ocurre con las adherencias ya que se presentan en $n=12$. La fragmentación es baja, sólo hay 3 lascas con grado tipo 1 y una con grado tipo 2 de fragmentación. Ninguna de las lascas presenta filos potencialmente utilizables.

\section{Forma base}

El tipo lasca es el más abundante dentro de los soportes $n=28$ (en riolita $n=18$, cinerita $n=8$, calcedonia y no determinada $n=1$ ), luego lascas de dorso natural $n=3$ (en riolita $n=2$ y en cinerita $n=1$ ) y finalmente lascas primarias de descortezamiento $\mathrm{n}=2$ en riolita (Tabla 8.14).

\begin{tabular}{|l|r|r|r|r|r|}
\hline Soporte / Materia prima & Indet. & Calcedonia & Cinerita & Riolita & Total \\
\hline Lasca & 1 & 1 & 8 & 18 & 28 \\
\hline Lasca dorso natural & & & 1 & 2 & 3 \\
\hline Lasca de descortezamiento & & & & 2 & 2 \\
\hline Total & $\mathbf{1}$ & $\mathbf{1}$ & $\mathbf{9}$ & $\mathbf{2 2}$ & $\mathbf{3 3}$ \\
\hline
\end{tabular}

Tabla 8. 14. Relación entre tipo de lascas y materia prima

En relación a la morfología la mayoría de las lascas son alargadas $n=18$ (en riolita $n=10$, cinerita $n=6$, calcedonia y no determinada $n=1$ ), anchas $n=$ 10 (en riolita $n=7$, cinerita $n=3$ ), oblicuas $n=5$ (sólo en riolita). La forma de las piezas desde la sección longitudinal son muy variadas entre ellas se pudo distinguir cóncavo-convexa $n=11$, cóncavo-plana $n=9$, helicoidal $n=4$, plana $n=2$ y bicóncava y biconvexa $n=1$. Las no determinables presentan un $n=5$ (Tabla 8.15). 


\begin{tabular}{|l|c|c|c|c|c|}
\hline $\begin{array}{l}\text { Morfología y } \\
\text { materias primas }\end{array}$ & Indet. & Calcedonia & Cinerita & Riolita & Total \\
\hline Oblicua & & & & 5 & 5 \\
\hline Ancha & & & 3 & 7 & 10 \\
\hline Alargada & 1 & 1 & 6 & 10 & 18 \\
\hline Total & $\mathbf{1}$ & $\mathbf{1}$ & $\mathbf{9}$ & $\mathbf{2 2}$ & $\mathbf{3 3}$ \\
\hline Sección longitudinal & & & & & \\
\hline Bicóncava & & & & 1 & 1 \\
\hline Biconvexa & & & 1 & & 1 \\
\hline Plana & & 1 & & 1 & 2 \\
\hline Helicoidal & & & 1 & 3 & 4 \\
\hline Indet. & & & 1 & 4 & 5 \\
\hline Cóncavo-plana & 1 & & 1 & 7 & 9 \\
\hline Cóncavo-convexa & & & 5 & 6 & 11 \\
\hline Total & $\mathbf{1}$ & $\mathbf{1}$ & $\mathbf{9}$ & $\mathbf{2 2}$ & $\mathbf{3 3}$ \\
\hline
\end{tabular}

Tabla 8. 15. Morfología y sección longitudinal en relación con materias primas

En cuanto a los accidentes de talla en el conjunto existen $n=3$ lascas reflejadas con lengüeta (en riolita) y $n=2$ lascas reflejadas (en riolita), el resto $\mathrm{n}=28$ no presentan accidentes.

\section{Talones}

Los talones están presentes en la mayoría de las lascas, el más representado es el liso $n=13$ (en riolita $n=9$, cinerita $n=3$ y uno en calcedonia), los naturales $n=9$ (en riolita $n=8$ y uno en cinerita), lineales y facetados $n=2$ cada uno tanto en riolita como en cinerita, finalmente un talón liso en ala de pájaro en una materia prima no determinada. La preparación del talón sólo pudo determinarse para $n=4$ (en riolita $n=2$, cinerita y calcedonia $n=1$ ). En relación con la inclinación los talones rectos son los más abundantes $n=16$ (en todas las materias primas), oblicuos $n=9$ (en riolita y cinerita) y los muy oblicuos $n=2$ (en riolita y cinerita) (Tabla 8.16). 


\begin{tabular}{|l|c|c|c|c|c|}
\hline Talón/ Materia prima & Indet. & Calcedonia & Cinerita & Riolita & Total \\
\hline Preparación No & $\mathbf{1}$ & & $\mathbf{7}$ & $\mathbf{1 8}$ & $\mathbf{2 6}$ \\
\hline Facetado & & & 1 & & 1 \\
\hline Liso en ala de Pájaro & 1 & & & & 1 \\
\hline Lineal & & & 1 & & 1 \\
\hline Ausente & & & 2 & 1 & 3 \\
\hline Natural & & & 1 & 8 & 9 \\
\hline Liso & & & 2 & 9 & 11 \\
\hline Preparación indet. & & & $\mathbf{1}$ & $\mathbf{2}$ & $\mathbf{3}$ \\
\hline Ausente & & & 1 & 2 & 3 \\
\hline Preparación Si & & $\mathbf{1}$ & $\mathbf{1}$ & $\mathbf{2}$ & $\mathbf{4}$ \\
\hline Lineal & & & & 1 & 1 \\
\hline Facetado & & & & 1 & 1 \\
\hline Liso & & 1 & 1 & & 2 \\
\hline Total general & $\mathbf{1}$ & $\mathbf{1}$ & $\mathbf{9}$ & $\mathbf{2 2}$ & $\mathbf{3 3}$ \\
\hline
\end{tabular}

Tabla 8. 16. Presencia de tipo de talones con presencia/ausencia de preparación y materia prima

El bulbo se presenta como difuso en $n=32$, mientras que sólo una lasca (en materia prima no determinada) tiene un bulbo doble. En cuanto al labio son principalmente difusos $n=26$, uno evertido en cinerita, y $n=6$ no está presentes.

\section{Corteza}

Las lascas sin corteza son más abundantes $n=19$, sin embargo entre aquellas con presencia de corteza podemos mencionar lascas con escasa corteza $n=7$ (en riolita $n=6$ y en cinerita $n=1$ ), con corteza muy abundante $n=$ 4 (en riolita $n=3$ y en cinerita $n=1)$, con corteza parcial $n=2$ en riolita y con abundante corteza una en riolita (Tabla 8.17).

\begin{tabular}{|l|r|l|r|r|r|}
\hline Presencia de corteza & Indet. & Calcedonia & Cinerita & Riolita & Total \\
\hline Abundante & & & & 1 & 1 \\
\hline Parcial & & & & 2 & 2 \\
\hline Muy abundante & & & 1 & 3 & 4 \\
\hline Escasa & & & 1 & 6 & 7 \\
\hline No presenta & 1 & 1 & 7 & 10 & 19 \\
\hline Total general & $\mathbf{1}$ & $\mathbf{1}$ & $\mathbf{9}$ & $\mathbf{2 2}$ & $\mathbf{3 3}$ \\
\hline
\end{tabular}

Tabla 8. 17. Relación entre presencia de corteza y materia prima 


\section{Dimensiones}

Dado que el conjunto es poco numeroso, lo dividiremos entre lascas menores y mayores a $4 \mathrm{~cm}$; el primer grupo alcanza un $n=23$, mientras que el segundo un $n=10$.

En relación a los módulos de LA y AE podemos describir al conjunto de la siguiente manera: lascas cortas y delgadas $n=5$ (en riolita $n=4$, en cinerita $n=1$ ); cortas de grosor intermedio $n=8$ (en riolita $n=3$, en cinerita $n=4$ y en no determinada $n=1$ ); cortas y gruesas $n=4$, todas en riolita. Lascas de longitud media y delgadas $n=3$ (en riolita $n=1$, en cinerita $n=2$ ); longitud y grosor intermedio $n=11$ (en riolita $n=8$, en cinerita $n=3$, en calcedonia $n=1$ ); longitud media y gruesas $n=2$, en riolita. Las lascas largas ya sean delgadas, intermedias o gruesas están ausentes.

\section{Fragmentos}

Este conjunto está compuesto por $n=72$ fragmentos. Las materias primas más representadas son la riolita $n=29$ y la cinerita $n=22$, luego pizarra $\mathrm{n}=11$, no determinada $\mathrm{n}=9 \mathrm{y}$ un fragmento de cuarzo. Como puede verse en la tabla aproximadamente un $60 \%$ de la muestra presenta alteraciones como pátinas y líquenes, incluso alteración por fuego o alta temperatura (Tabla 8.18).

\begin{tabular}{|l|c|c|c|c|c|c|}
\hline Conservación & Cuarzo & Indet. & Pizarra & Cinerita & Riolita & Total \\
\hline Pátina/Liquen & & & & 1 & & 1 \\
\hline Oxido & & & 1 & & & 1 \\
\hline Liquen & & 1 & 2 & 2 & & 5 \\
\hline Quemado & & 6 & & & & 6 \\
\hline Pátina amarilla & 1 & & 2 & 1 & 7 & 11 \\
\hline Pátina & & 1 & 1 & 7 & 10 & 19 \\
\hline Buena & & 1 & 5 & 11 & 12 & 29 \\
\hline Total general & $\mathbf{1}$ & $\mathbf{9}$ & $\mathbf{1 1}$ & $\mathbf{2 2}$ & $\mathbf{2 9}$ & $\mathbf{7 2}$ \\
\hline
\end{tabular}

Tabla 8. 18. Conservación de los fragmentos por materia prima

La mayoría de los fragmentos no presentan corteza. Dentro de los que si presentan corteza podemos ver la siguiente distribución en relación con el grado de presencia: corteza parcial $n=9$ (en riolita y cinerita $n=3$, en pizarra $n=$ 1 y en no determinada $n=2$ ), corteza escasa $n=4$ (en riolita $n=2$, cinerita y no determinada $n=1$ ), abundante $n=2$ (en cinerita y en no determinada $n=1)$, muy 
abundante $n=2$ en riolita, por último hay $n=5$ fragmentos que debido al grado de alteración no pudo determinarse si presentan o no corteza (Tabla 8.19).

\begin{tabular}{|l|c|c|c|c|c|c|}
\hline Presencia de corteza & Cuarzo & Indet. & Pizarra & Cinerita & Riolita & Total \\
\hline Muy abundante & & & & & 2 & 2 \\
\hline Abundante & & 1 & & 1 & & 2 \\
\hline Indet. & & 3 & 1 & & 1 & 5 \\
\hline Escasa & & 1 & & 1 & 2 & 4 \\
\hline Parcial & & 2 & 1 & 3 & 3 & 9 \\
\hline No presenta & 1 & 2 & 9 & 17 & 21 & 50 \\
\hline Total general & $\mathbf{1}$ & $\mathbf{9}$ & $\mathbf{1 1}$ & $\mathbf{2 2}$ & $\mathbf{2 9}$ & $\mathbf{7 2}$ \\
\hline
\end{tabular}

Tabla 8. 19. Relación entre presencia de corteza en fragmentos y materia prima

\section{Instrumentos}

El conjunto de artefactos retocados está conformado por dos raspadores simples (uno en riolita y otro en cinerita), tres raederas transversales (dos en riolita y una en cinerita) y un artefacto retocado atípico (en riolita).

\section{Raspadores}

Los raspadores presentan un grado de conservación malo ya que ambos presentan pátina y fragmentación.

\section{Forma base}

Ambos están confeccionados sobre lascas, de morfología es semicircular para aquel confeccionado en riolita (desde la cara dorsal), mientras que no se pudo determinar para el otro caso. La sección longitudinal es cóncavo-plana para el primero y cóncavo-convexo para el segundo. Los accidentes de talla están ausentes en los dos artefactos. Para el raspador en riolita el talón es lineal, oblicuo y no presenta evidencias de preparación. En cambio, el raspador de cinerita presenta un talón lineal, recto con evidencias de preparación.

En cuanto al bulbo y el labio, tanto un artefacto como el otro presentan bulbo y labio difusos. Ninguno de los dos muestra restos de corteza sobre la superficie.

En cuanto a las dimensiones ambos corresponden a piezas chicas. En relación con los módulos $\mathrm{LA} / \mathrm{AE}$ el raspador de cinerita se corresponde con un 
artefacto de longitud y grosor medio, mientras que el de riolita con uno corto y delgado.

Detalle de los filos

Ambas piezas presentan un filo, para el caso del raspador en riolita la situación del filo es semicircular, mientras que el otro presenta el filo sobre el sector derecho de la pieza. Los dos presentan una delineación semicircular y de sección longitudinal recta.

\section{Detalle del retoque}

El retoque es irregular, directo y con una profundidad de tipo marginal. Mientras que para el raspador de cinerita la extensión del retoque produce un filo corto, con una repartición parcial y un ángulo de $55^{\circ}$; el raspador de riolita presenta una extensión restringida con una repartición discontinua y un ángulo de $75^{\circ}$.

Filos largos retocados (raederas)

El conjunto de raederas como mencionamos anteriormente, está compuesto por tres artefactos, dos en riolita y uno en cinerita. Dos de las piezas presentan pátina y líquenes. En cuanto al grado de fragmentación la tres están enteras.

\section{Forma base}

En los tres casos se utilizaron lascas como soporte para la manufactura de los instrumentos, de las cuales dos corresponden a lascas anchas (una en riolita y otra en cinerita), y la restante a una lasca alargada (riolita). En cuanto a la sección longitudinal, esta última pieza presenta una forma cóncavo-convexa, mientras que en las raederas sobre lascas anchas la forma es biconvexa en la de riolita y cóncavo-plana en la de cinerita. Ninguna presenta accidentes de talla.

En relación al talón sólo una presenta talón de tipo liso, muy oblicuo y sin evidencias de preparación. En cuanto al bulbo y al labio, el primero se presenta 
de forma difusa en dos de las piezas (una en riolita y otra en cinerita), mientras que el labio sólo se presenta, en la única raedera con talón, de forma difusa.

La corteza se encuentra presente de forma escasa en dos de los instrumentos, uno en cada materia prima, mientras que el restante no presenta corteza.

\section{Detalle del filo}

Las raederas constan de un filo cada una, de los cuales $n=2$ son distales (uno en riolita y otro cinerita) y el izquierdo en la restante de riolita. La delineación de los filos es diferente para cada uno de ellos, el filo en la pieza de cinerita es recto, mientras que en las de riolita uno es convexo y el otro semicircular. En cuanto a la sección longitudinal, estas últimas la presentan de forma curvada, mientras que en la de cinerita es de forma recta.

\section{Detalle del retoque}

El retoque es irregular y continuo para todos los artefactos. En la raedera bifacial el filo es extendido y el retoque profundo, mientras que las raederas con retoque directo los filos son largos y con retoque marginal.

Los retoques presentan ángulos que van desde los $50^{\circ}$ (pieza bifacial) hasta los $65^{\circ}$ (en los otros dos instrumentos). En cuanto a las longitudes, el más corto presenta un filo de $6,6 \mathrm{~cm}$, sigue un filo de $6,9 \mathrm{~cm}$ (bifacial) y finalmente el más extenso con $9,5 \mathrm{~cm}$.

Instrumento atípico

Se trata de un artefacto confeccionado en riolita, sin fragmentación pero la conservación es mala debido a la presencia de pátinas y adherencias en su superficie.

Este instrumento fue manufacturado sobre una lasca, cuya morfología es semicircular y de sección longitudinal cóncavo-plana y sin accidentes de talla. El talón es facetado y oblicuo, pero sin evidencias de preparación y tanto el bulbo como el labio son difusos, la corteza está ausente.

El filo es distal con una delineación semicircular y la sección longitudinal es curva. El retoque es particular, podríamos decir que es del tipo festoneado 
regular o tal vez formado por varias muescas. Se trata de un retoque directo sobre un filo extendido de tipo profundo. El ángulo del retoque es de $72^{\circ}$, mientras que la longitud alcanza los $5,2 \mathrm{~cm}$.

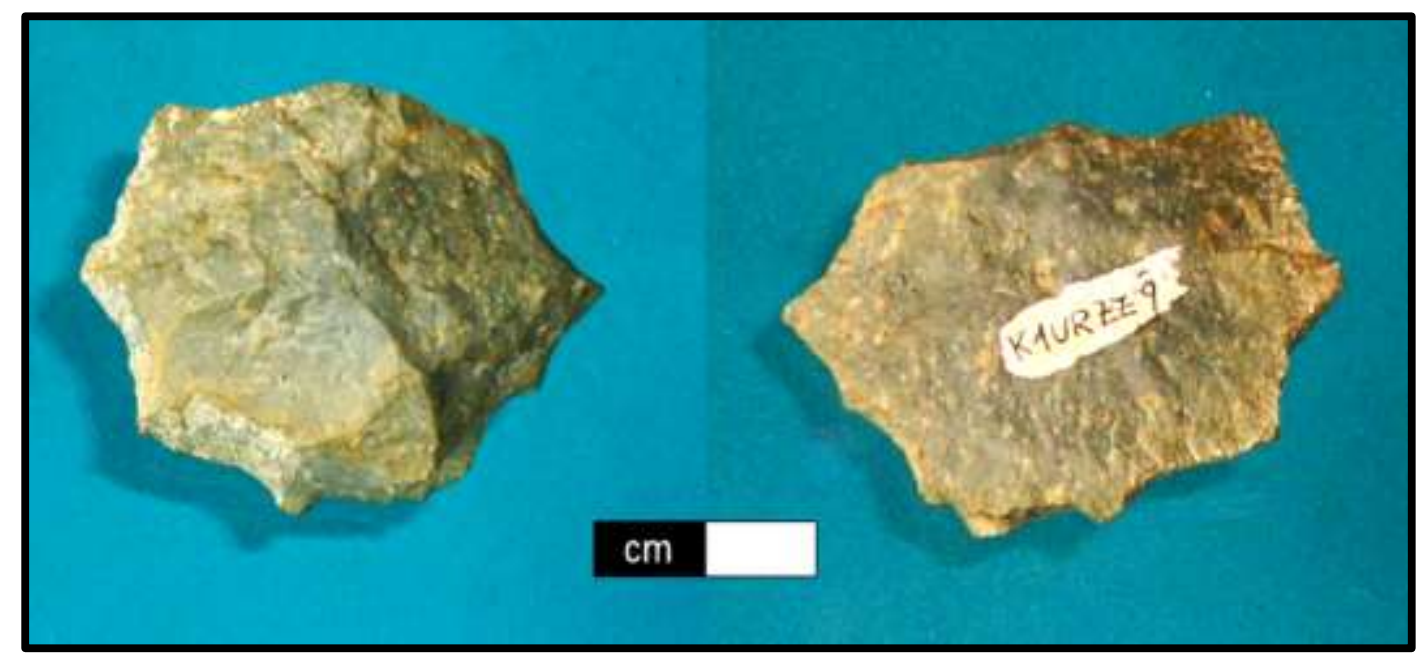

Figura 8. 11. Instrumento atípico

Como síntesis en cuanto a las materias primas, cabe señalar que las raederas fueron confeccionadas en las mismas materias primas y con similares dimensiones que las de Kami 1 excavación, en cuanto a los raspadores: son sólo 2, manufacturados en las mismas materias primas que para los filos largos retocados.

\section{Análisis funcional}

No fue posible identificar rastros de uso en estos materiales, debido al estado de conservación de las superficies y al redondeamiento de los filos. Dado que los rastros de uso normalmente aparecen pegados al filo en una extensión que rara vez supera medio $\mathrm{mm}$, el redondeamiento y abrasión tafonómicos alteraron totalmente 0 eliminaron los posibles rastros microscópicos que evidencien uso.

\section{DISCUSIÓN}

Los resultados del análisis morfotécnico de los materiales líticos del sitio Kami 1 proporcionan datos de interés para discutir la interrelación entre 
aspectos morfológicos, tecnológicos, diversidad de materias primas y funcionales.

En primera instancia, en cuanto a las materias primas, la presencia de riolitas y cineritas en todo el conjunto es predominante sobre cualquier otra, incluso en el subgrupo de artefactos menores a $2 \mathrm{~cm}$, donde si bien se invierten las cantidades ubicando en primer lugar a las cineritas, ambas materias primas siguen siendo las más representadas. Sin embargo, existe una excepción, los raspadores. En este caso la toba silicificada es el principal material explotado.

Otra materia prima con un comportamiento diferente a las riolitas y cineritas es la lutita, que se encuentra totalmente ausente en todos los restos de talla mayores a $2 \mathrm{~cm}$, ya sean núcleos, lascas o fragmentos. Sólo se presenta en un instrumento retocado, una raedera, y luego aparece representada en todos los tipos del subgrupo de no retocados menores a $2 \mathrm{~cm}$. Es probable que esta haya ingresado al sitio o bien como forma base y terminada allí, o bien como instrumento terminado; los restos de talla menores a $2 \mathrm{~cm}$ estarían relacionados por ejemplo con la reactivación del filo.

En cuanto a la relación de las materias primas y los instrumentos retocados, vemos una división notoria entre aquellas utilizadas para la confección de instrumentos con filos largos retocados y las empleadas para la producción de filos cortos utilizados en el raspado de pieles (raspadores). Los primeros fueron confeccionados principalmente con rocas heterogéneas (riolitas y cineritas), mientras que los raspadores se confeccionaron mayoritariamente sobre rocas sedimentarias criptocristalinas (como los sílex o ftanitas y calcedonia), pero principalmente sobre tobas silicificadas. Esto puede estar relacionado, con el comportamiento de los filos de las materias primas en relación al uso. Tanto las riolitas como las cineritas tienden a desgranarse produciendo un redondeamiento rápido del filo. Esta tendencia al desgranamiento es perjudicial en determinados trabajos como el raspado de cueros, ya que puede producir cortes en el mismo; por otro lado estos filos tienden a embotarse muy rápidamente al trabajar sobre este tipo de material. En cambio, las materias primas como los sílex, ftanitas y por lo que pudimos ver, la toba silicificada, presentan filos que no se desgranan y se mantienen más estables. Estas observaciones son totalmente coincidentes con las efectuadas por Mansur en diferentes conjuntos de Pampa y Patagonia (Mansur 
y Leipus 1999; Mansur et al. 2004; Mansur y Lasa 2005; Mansur 2006; Leipus y Mansur 2007) que llevaron a la propuesta de un modelo de comportamiento de filos en los dos grupos de materiales.

La única excepción son los dos raspadores de superficie del sitio Kami 1, confeccionados en riolita y cinerita, en los cuales lamentablemente debido a su procedencia superficial y el estado de conservación, no se pudo efectuar identificación funcional.

Una materia prima que aparece muy esporádicamente es la andesita, sólo en el subgrupo mayor a $2 \mathrm{~cm}$, representada por dos lascas y una raedera. Este caso es similar al de la lutita, pudiendo haber ingresado al sitio ya en una etapa avanzada de formatización. Dentro de los menores a $2 \mathrm{~cm}$ aparece la única pieza de hornblendita de todo el conjunto, material utilizado generalmente para la fabricación de bolas de boleadora. Se trata de un fragmento solamente, y no hay nada en esta pieza que permita inferir la confección de algún artefacto.

Más específico, la relación que existe entre materias primas, núcleos, lascas y fragmentos y la presencia de corteza, muestra que en general los primeros estadios de desbaste no se llevaron a cabo en el sitio. En efecto, las lascas primarias de descortezamiento y las lascas con corteza muy abundante son las menos representadas, en comparación a las piezas con escaso o nulo porcentaje de corteza.

Unas pocas materias primas es probable que llegaran al lugar a través de transporte humano, como por ejemplo la lutita, la hornblendita, la toba silicificada o los sílex.

En cuanto a las materias primas locales (riolita, cinerita), la escasez de núcleos y de lascas grandes de descortezamiento, sugieren que el proceso de desbaste primario podría estar desarrollándose en una primera instancia sobre la costa misma donde se encuentran los guijarros y ser introducidos en el sitio, medianamente descortezados.

En relación a las materias primas que podrían estar proviniendo de mayores distancias, como es el caso de la lutita, toba silicificada o la andesita, es probable que hayan sido introducidas al sitio o bien como pre-formas o como lascas. Dentro de las materias primas no locales, la toba silicificada es la más llamativa de todas. Si bien es cierto que tobas silicificadas se encuentran 
en diversos lugares cercanos a la zona de cordillera (Petersen 1949; Caminos et al. 1981; González Guillot et al. 2010), al analizar las características de la materia prima encontrada en el sitio vimos que no era similar a la tobas de las zonas circundantes, sino que difería tanto por su textura, como por el brillo y la fractura. Los materiales presentes en el sitio se caracterizan por poseer un brillo vítreo, ser de granulometría muy compacta y presentar una buena fractura concoidea.

Además los restos de talla de esta materia prima son pequeños y poco numerosos y los instrumentos confeccionados sobre este material son raspadores, muchos de ellos microrraspadores e incluso algunos confeccionados sobre soportes bipolares. Todo ello muestra un uso muy específico y económico de esta materia prima.

Gracias al trabajo realizado por Karen Borrazzo y colaboradores en el norte de la Isla Grande de Tierra del Fuego, es que pudimos ubicar el origen probable de esta materia prima. En la zona del valle del chorrillo Miraflores existe una serie de afloramientos de toba silicificada en el paraje conocido como Miraflores (Prieto et al. 2004; Massone 2009; Borrazzo et al. 2010; Borrazzo 2012), los materiales confeccionados con ella son de características muy similares a los de Kami 1.

También se llevó a cabo una experimentación tecno-funcional con muestras provenientes de esos afloramientos, recolectadas por la Lic. Flavia Morello. De esta forma pudimos utilizar materia prima para experimentación tecnológica y funcional, en la que se confeccionaron y usaron una serie de pequeños raspadores similares a los encontrados en Kami 1. Los resultados obtenidos en la experimentación y comparación de resultados con los de los raspadores arqueológicos permiten concluir que es altamente probable que la toba silicificada proveniente de las excavaciones de Kami 1 haya sido traída desde el norte de la Isla.

Volviendo al conjunto lítico total, las variables morfológicas dimensionales lo caracterizan en primer término como un conjunto de artefactos cortos de espesores delgados y medios, en menor proporción los de longitud media con espesores delgados e intermedios, siendo los artefactos largos con espesores intermedios y gruesos los menos representados. Dado que esto se da en general en todos los artefactos del conjunto (retocados y no 
retocados), con la excepción de algunas raederas, es altamente probable que estas dimensiones estén relacionadas con una selección asociada con los instrumentos buscados, que llevó a aplicar estrategias de reducción de núcleos para producir tales tipos de soportes.

En relación con lo anterior, en la morfología de las piezas en vista dorsal predominan los elementos anchos, luego alargados, seguidos por artefactos oblicuos y semicirculares. Es curioso que este patrón se repita tanto en lascas, como en raspadores y raederas, donde uno esperaría patrones diversos en relación a los tipos de artefactos. Además muchos de ellos es probable que hayan estado enmangados (raspadores, microrraspadores).

Desde el punto de vista tecnológico vimos que el conjunto no se caracteriza por la preparación de núcleos específicos, como así tampoco las lascas presentan talones preparados en altas proporciones, sino por unas estrategias de abordaje para obtener productos de las características antes mencionadas. En general, creo que el conjunto podría acercarse, en ciertos aspectos, a un conjunto más bien expeditivo, en el sentido de menor esfuerzo tecnológico cuando la materia prima, el tiempo y el lugar son predecibles y esto supone un descarte mayor de instrumentos dado que la materia prima se encuentra disponible en cantidad (Binford 1979; Magne 1989; Nelson 1991). Para este caso vemos una gran explotación de materias primas locales, ubicadas muy cerca del sitio, no más de 10 metros, con gran abundancia de guijarros entre los que se encuentran muchos de buena calidad para la talla. Esto no significa que los artefactos retocados tengan que ser simples o que tengan poca inversión de tiempo. Una excepción a esto podrían ser los núcleos discoidales de chert y de riolita de grano muy fino. En cuanto a los raspadores/microrraspadores, estos pudieron haber sido abandonados al tratarse de instrumento prácticamente agotados impidiendo la posibilidad de ser reactivados, principalmente por sus tamaños.

En cuanto a los filos, pudimos ver que entre los naturales y retocados hay una diferencia. Mientras que entre los primeros predominan los filos rectos y luego los convexos, ocurre lo inverso entre los filos retocados, incluidas las raederas. En cambio la sección longitudinal en casi todos los filos es recta y en menor proporción sinuosa y curva. 
La extensión del filo presenta mayor diversidad entre los raspadores que entre las raederas. En los primeros los predominantes son los largos y restringidos, luego los extendidos y sólo un filo corto, mientras que para las raederas los filos son principalmente largos y luego, muy por debajo, filos restringidos. En cuanto al tipo de retoque casi la totalidad son irregulares, lo cual probablemente esté relacionado a la dureza que presentan las materias primas.

Vimos hasta aquí los materiales producidos por percusión directa. Con respecto a los productos bipolares, podemos decir que no es un conjunto muy numeroso, que está representado principalmente por cuarzo y por tobas silicificadas, y que incluye tanto lascas, núcleos, algunos hemi-guijarros, como instrumentos retocados, puntualmente raspadores.

En este caso, la utilización de la técnica bipolar podría estar en relación al mismo tiempo con la búsqueda de formas bases particulares en relación al instrumento a confeccionar (raspadores) como con una técnica utilizada para economizar materia prima. Esto se debe principalmente a que, por un lado los guijarros pequeños de cuarzo son muy comunes en la costa del lago, y estos requieren forzosamente por su morfología y dimensiones de la técnica de apertura bipolar. En cuanto a la toba silicificada, podría darse un poco de ambas posibilidades, teniendo en cuenta que por la distancia del afloramiento y el poco material de desecho, es probable que los fragmentos introducidos al sitio hayan tenido muy pequeñas dimensiones.

En conclusión, se trata de un conjunto abundante y no muy diverso en cuanto a tipos de artefactos, pero sí en relación a las materias primas, que fueron variadas. En cuanto a su empleo se puede observar una selección de estas para cada tipo de instrumento, junto con una homogeneidad en la búsqueda de determinados tipos de soportes para la producción de los mismos.

Podemos ver como la ausencia de determinados elementos nos indica que al menos las primeras etapas del proceso de producción pudieron haberse llevado a cabo, ya sea en la costa inmediata al sitio, en cuanto a las materias primas locales, o bien en los afloramientos primarios en aquellas materias primas "exóticas", que debieron entrar al campamento ya sea como preformas o núcleos descortezados o directamente como instrumentos y haber sido 
reactivados o terminados de formatizar en el sitio. Esto se apoya en la presencia de los numerosos elementos inferiores a los $2 \mathrm{~cm}$, entre los cuales aparecieron representadas todas las materias primas líticas.

En cuanto al análisis funcional, como se pudo ver hay una diferenciación notable entre la utilización de los filos largos retocados y los raspadores. En los primeros el trabajo fue casi exclusivamente de madera, aunque no solamente longitudinal. Varios filos mostraron trabajo transversal sin tener que significar raspado de madera, sino más bien podría deberse al trabajo de, por ejemplo descortezamiento de ramas. Por otro lado los raspadores fueron utilizados casi exclusivamente para el trabajo de piel, en este caso todos fueron utilizados con cinemática transversal al filo.

En relación con esto, es interesante resaltar la búsqueda de materias primas específicas para unos y otros instrumentos. Por un lado los filos largos retocados fueron confeccionados sobre rocas locales, riolitas y cineritas principalmente, mientras que los raspadores están confeccionados en toba silicificada y cuarzo, y en menor medida por otras materias primas como sílex. 


\section{Capítula 9}

ANÁLISIS TECNO-MORFOLÓGICO Y FUNCIONAL DE LOS MATERIALES DEL SITIO KAMI 6 


\section{INTRODUCCIÓN}

El sitio Kami 6 también se encuentra ubicado sobre la margen sur del lago Fagnano, hacia el este del sitio Kami 1. Las características del sitio y de los trabajos realizados fueron presentadas en el capítulo 5 .

El conjunto lítico del sitio Kami 6 tiene un $n=537$ artefactos, que podemos discriminar en aquellos $\sin$ retoque, como lascas $n=276$, fragmentos $\mathrm{n}=168$, núcleos y núcleos fragmentados $n=19$. Entre los artefactos retocados hay raederas $n=28$, raspadores $n=17$, fragmentos de instrumento $n=8$ y finalmente lascas con retoque $n=1$. Los elementos bipolares se presentan de la siguiente forma: lascas $n=6$, hemiguijarros $n=2$ y un fragmento. Finalmente, el subgrupo de artefactos no formatizados menor a $2 \mathrm{~cm}$, es muy pequeño representado únicamente por $n=8$ lasquitas (Tabla 9.1).

\section{LOS MATERIALES}

Si ordenamos las materias primas en relación a su presencia, vemos que las riolitas son las más abundantes $n=410$, no determinadas $n=45$, cinerita $n=42$, calcedonia $n=9$, cuarzo y basalto $n=7$ cada uno, volcánicas no determinables $n=6$, pizarra $n=3$, andesita $n=2$. 


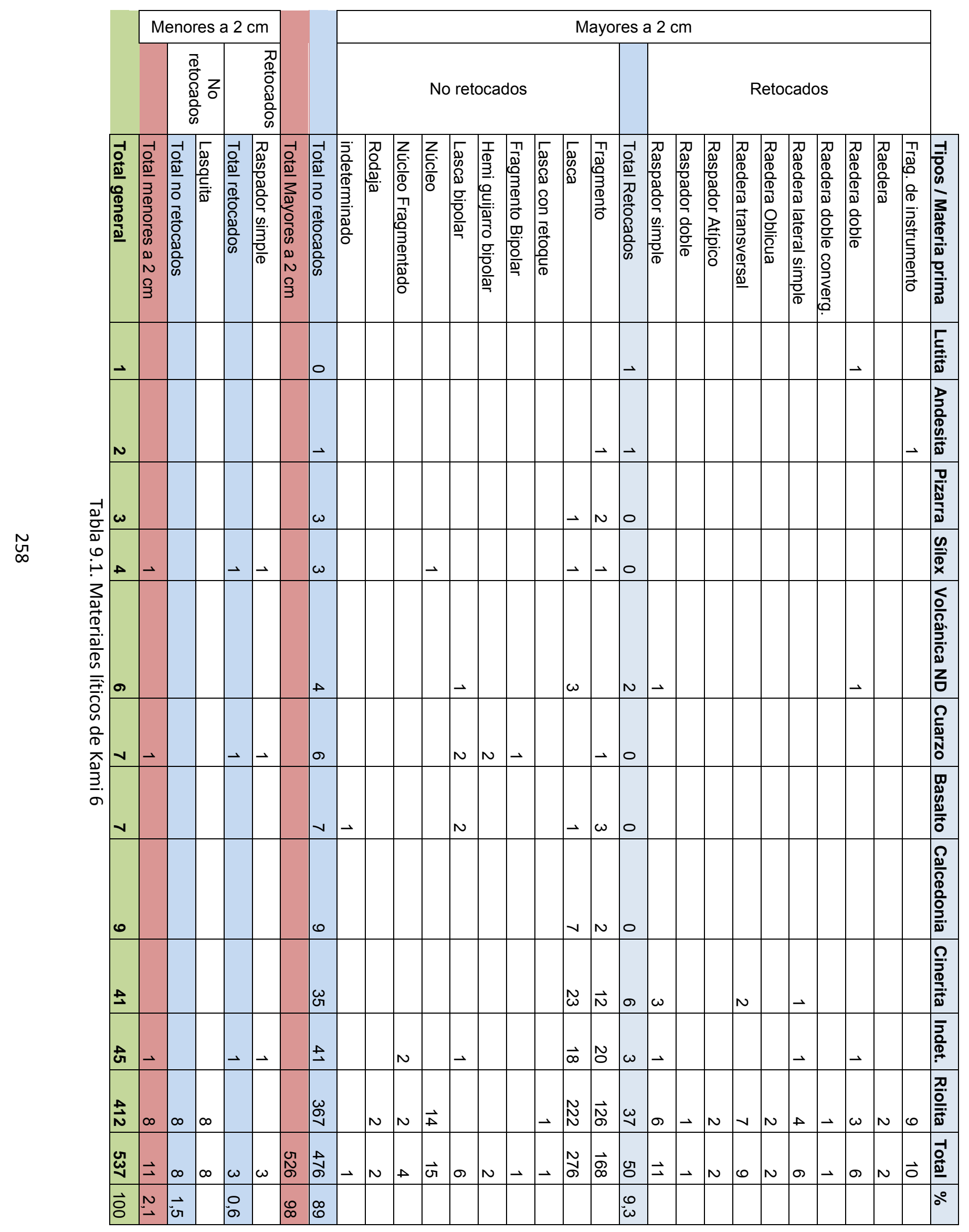




\section{Análisis tecno-morfológico}

\section{Núcleos}

Los núcleos son principalmente de riolita $(n=14)$, con sólo uno de sílex. Para éste último el tipo de núcleo es amorfo, mientras que en riolita pueden distinguirse los siguientes: amorfos $n=8$, discoidales $n=5$ y apicales $n=1$. En cuanto a los núcleos fragmentados, estos se presentan como amorfos, dos son de riolita y uno no pudo determinarse la materia prima (Tabla 9.2).

\begin{tabular}{|l|c|c|c|c|}
\hline Tipo y estado de núcleos & Indet. & Rioita & Sílex & Total \\
\hline Núcleos enteros & & $\mathbf{1 4}$ & $\mathbf{1}$ & $\mathbf{1 5}$ \\
\hline Amorfos & & 8 & 1 & 9 \\
\hline Apicales & & 1 & & 1 \\
\hline Discoidales & & 5 & & 5 \\
\hline Núcleos fragmentados & $\mathbf{1}$ & $\mathbf{2}$ & & $\mathbf{3}$ \\
\hline Amorfo & 1 & 2 & & 3 \\
\hline Total general & $\mathbf{1}$ & $\mathbf{1 6}$ & $\mathbf{1}$ & $\mathbf{1 8}$ \\
\hline
\end{tabular}

Tabla 9. 2. Relación entre tipo de núcleos, estado de fragmentación y materia prima

La conservación es en general mala, en relación con la situación de los materiales que se encontraban en superficie, debido a la presencia de pátinas blancas y amarillas y líquenes en las caras de los núcleos. En contraposición, la fragmentación es baja ya que $n=13$ están enteros, mientras que $n=5$ presentan grado de fragmentación tipo 1.

Los soportes sobre los que fueron tallados los núcleos no pudieron ser determinados principalmente por el bajo porcentaje de corteza que presentan las piezas. En orden decreciente de porcentaje de corteza, los núcleos quedan agrupados de la siguiente manera: muy abundante $n=2$, abundante $n=1$, parcial $n=1$, escasa $n=7$, sin corteza $n=6$ y en una pieza no pudo determinarse la presencia de corteza debido al estado de conservación (Tabla 9.3). 


\begin{tabular}{|l|c|c|c|}
\hline $\begin{array}{l}\text { Presencia de corteza / } \\
\text { soporte }\end{array}$ & Guijarro & Indet. & Total \\
\hline Indet. & & 1 & 1 \\
\hline Parcial & & 1 & 1 \\
\hline Abundante & & 1 & 1 \\
\hline Muy abundante & 1 & 1 & 2 \\
\hline No presenta & & 6 & 6 \\
\hline Escasa & & 7 & 7 \\
\hline Total & $\mathbf{1}$ & $\mathbf{1 7}$ & $\mathbf{1 8}$ \\
\hline
\end{tabular}

Tabla 9. 3. Presencia de corteza en soportes utilizados

En cuanto a las dimensiones en relación a los módulos $L A$ y $A E$, el conjunto se caracteriza por piezas de longitud media cuyos espesores se dividen en gruesos $n=13$, medio $n=2$ y delgado $n=1$. Luego aparece un núcleo largo y de espesor medio y uno corto y grueso. Cabe mencionar que entre los núcleos de longitud mediana y espesor grueso se encuentran tanto el sílex como el de materia prima no determinada.

Los núcleos con grado de explotación de tipo 1 son $n=11$ (todos en riolita), mientras que aquellos con alto grado de explotación presentan un $n=7$. En este último caso se encuentran las dos materias primas diferentes y de muy buena calidad para la talla.

\section{Lascas}

El conjunto de lascas está representado tipológicamente por: lascas en general $n=265$, lascas primarias de descortezamiento $n=8$ y lascas con dorso natural $n=3$. La conservación es mala, ya que el $91 \%$ presenta pátinas blanquecinas y amarillas, líquenes, adherencias, etc. En cambio, el grado de fragmentación es muy bajo, el $95 \%$ de las piezas están enteras, y sólo el $5 \%$ presentan un grado de fragmentación tipo 1 (Tabla 9.4).

Las materias primas son diversas, aunque la más representadas es la riolita $n=222$, luego la cinerita $n=23$, no determinada $n=18$, calcedonia $n=7$, volcánica no determinada $n=3$, finalmente pizarra, sílex y basalto con $n=1$. 


\begin{tabular}{|c|c|c|c|c|c|c|c|c|c|}
\hline Conservación & Basalto & Sílex & Pizarra & Volcánica ND & Calcedonia & Indet. & Cinerita & Riolita & Total \\
\hline Buena & & & & & & 1 & 3 & 21 & 25 \\
\hline Liquen & & & 1 & 1 & 1 & 7 & 4 & 63 & 77 \\
\hline Liquen/pátina & & & & & 2 & & & 12 & 14 \\
\hline Pátina & 1 & 1 & & 2 & 4 & 10 & 16 & 125 & 159 \\
\hline Rodado & & & & & & & & 1 & 1 \\
\hline Total & 1 & 1 & 1 & 3 & 7 & 18 & 23 & 222 & 276 \\
\hline
\end{tabular}

Tabla 9. 4. Conservación en lascas por materia prima

\section{Forma base}

La morfología de las lascas, desde la cara dorsal, incluye lascas oblicuas $n=149$, alargadas $n=65$, anchas $n=43$, semicirculares $n=6$ y trapezoidales $n=$ 4 , las no determinables alcanzan un $n=9$.

En relación con las materias primas vemos que las lascas de riolita, si bien están presentes en todas las morfologías, son más abundantes las oblicuas, lo mismo ocurre con las lasca de cinerita y las de calcedonia. Las rocas volcánicas (nd) presentan una lasca semicircular, una ancha y una alargada, en tanto que el sílex y basalto presentan también lascas oblicuas (Tabla 9.5).

\begin{tabular}{|l|l|l|l|c|c|c|c|c|c|}
\hline Morfología & Basalto & Sílex & Pizarra & Volcánica ND & Calcedonia & Indet. & Cinerita & Riolita & Total \\
\hline Trapezoidal & & & & & 1 & & & 3 & 4 \\
\hline Indet. & & & & & & & & 9 & 9 \\
\hline Semicircular & & & & 1 & & 1 & 3 & 1 & 6 \\
\hline Ancha & & & 1 & 1 & & 2 & 3 & 36 & 43 \\
\hline Alargada & & & & 1 & 2 & 8 & 5 & 49 & 65 \\
\hline Oblicua & 1 & 1 & & & 4 & 7 & 12 & 124 & 149 \\
\hline Total & $\mathbf{1}$ & $\mathbf{1}$ & $\mathbf{1}$ & $\mathbf{3}$ & $\mathbf{7}$ & $\mathbf{1 8}$ & $\mathbf{2 3}$ & $\mathbf{2 2 2}$ & $\mathbf{2 7 6}$ \\
\hline
\end{tabular}

Tabla 9. 5. Relación entre morfología de lascas y materia prima

Los accidentes de talla se presentan de la siguiente manera: lascas sin accidentes $n=196$ (todas las materias primas representadas), lascas reflejadas $n=54$ (en riolita $n=41$, cinerita $n=4$, no determinada $n=6$, calcedonia $n=2 y$ pizarra $n=1$ ), lascas reflejadas con lengüeta $n=21$ (en riolita $n=18$; cinerita calcedonia y no determinada $n=1$ ) y lascas sobrepasadas $n=2$ (una en riolita y otra en cinerita)

Los talones presentan una alta diversidad; están presentes los talones lisos $n=125$ (en riolita $n=102$, en cinerita $n=12$, en no determinada $n=8$; en 
calcedonia, basalto y volcánica $n d n=1$ ); naturales $n=40$ (en riolita $n=34$, en cinerita $n=1$, en no determinada $n=3$; en calcedonia, sílex y basalto $n=1$ ); facetados $n=29$ (en riolita $n=25$, en cinerita $n=3$ y en calcedonia $n=1$ ); liso en ala de pájaro $n=5$ (en riolita $n=3$, en cinerita $n=1$ y en calcedonia $n=1$ ); lineal $n=2$ (en riolita $n=1$, en no determinada $n=1$ ) y facetado en ala de pájaro $n=1$ en riolita. Las lascas que no presentan talones son $n=74$ (en riolita $n=56$, en cinerita $n=6$, en no determinada $n=6$; en calcedonia $n=3$, volcánica $n d n=2 y$ en pizarra $n=1$ ) (Tabla 9.6).

Los talones que presentan evidencias de preparación son $n=72$ (en riolita $n=52$, en cinerita $n=12$, en no determinada $n=6$; en calcedonia $y$ volcánica $n d n=1)$. A su vez, los talones oblicuos son los más abundantes $n=$ 112 (en riolita $n=89$, en cinerita $n=12$, en no determinada $n=9$; en calcedonia y basalto $n=1$ ); los rectos $n=88$ (en riolita $n=75$, en cinerita $n=5$, en no determinada y en calcedonia $n=3$, en volcánica nd y sílex $n=1$ ) y los muy oblicuos $n=1$ en riolita.

\begin{tabular}{|l|l|l|l|l|l|l|l|l|l|}
\hline Tipo de talón & Basalto & $\begin{array}{l}\text { Síle } \\
\mathbf{x}\end{array}$ & $\begin{array}{l}\text { Pizarr } \\
\mathbf{a}\end{array}$ & $\begin{array}{l}\text { Volcánic } \\
\mathbf{a}\end{array}$ & $\begin{array}{l}\text { Calcedoni } \\
\mathbf{a}\end{array}$ & $\begin{array}{l}\text { Indet } \\
\text { - }\end{array}$ & $\begin{array}{l}\text { Cinerit } \\
\mathbf{a}\end{array}$ & $\begin{array}{l}\text { Riolit } \\
\mathbf{a}\end{array}$ & $\begin{array}{l}\text { Tota } \\
\mathbf{I}\end{array}$ \\
\hline $\begin{array}{l}\text { Facet. ala de } \\
\text { pájaro }\end{array}$ & & & & & & & & 1 & 1 \\
\hline Lineal & & & & & & 1 & & 1 & 2 \\
\hline Liso ala de pájaro & & & & & 1 & & 1 & 3 & 5 \\
\hline Facetado & & & & & 1 & & 3 & 25 & 29 \\
\hline Natural & & 1 & & & 1 & 3 & 1 & 34 & 40 \\
\hline Ausentes & & & 1 & 2 & 3 & 6 & 6 & 55 & 73 \\
\hline Lisos & 1 & & & 1 & 1 & 8 & 12 & 102 & 125 \\
\hline Total general & $\mathbf{1}$ & $\mathbf{1}$ & $\mathbf{1}$ & $\mathbf{3}$ & $\mathbf{7}$ & $\mathbf{1 8}$ & $\mathbf{2 3}$ & $\mathbf{2 2 2}$ & $\mathbf{2 7 6}$ \\
\hline
\end{tabular}

Tabla 9. 6. Relación entre tipo de talón y materia prima

\section{Bulbo y labio}

Los bulbos presentan diversidad en sus tipos, el más abundante es el difuso $n=229$ (en riolita $n=186$, en cinerita $n=17$, en no determinada $n=18$; en calcedonia $n=4$; en volcánica $n d$, pizarra, sílex y basalto $n=1$ ); difusos con esquirlamiento $n=20$ (en riolita $n=14$, en cinerita $n=3$, volcánica $n d n=2$ y en calcedonia $n=1$ ); espesos $n=7$ (en riolita $n=6$, en cinerita $n=1$ ); espeso con esquirlamiento $n=2$ (uno en riolita y otro en cinerita) y doble sólo en dos casos, uno en riolita y otro en calcedonia. La ausencia de bulbo se da en $n=16$ piezas. 
Los labios al igual que los bulbos son principalmente difusos y luego los normales, representados en todas las materias primas. Además aparecen lascas con labios evertidos $n=9($ en riolita $n=6$ y en cinerita $n=3$ )

\section{Corteza}

La corteza se encuentra ausente en $n=165$ lascas (en riolita $n=131$, en cinerita $n=17$, en no determinada $n=10$; en calcedonia $n=4$; en volcánica $n d$ $n=2$ y en basalto $n=1$ ); corteza escasa $n=44$ (en riolita $n=40$, en cinerita $n=1$, en no determinada $n=2$ y en sílex $n=1$ ); muy abundante $n=24$ (en riolita $n=19$, en cinerita $n=1$, en no determinada y calcedonia $n=2$ ) corteza parcial $n=21$ (en riolita $n=19$, en cinerita $n=1$; en calcedonia $n=1$ ); corteza abundante $n=14$ (en riolita $n=12$, en cinerita y volcánica $n d n=1$ ). Las piezas en las cuales no se pudo determinar la presencia de corteza son $n=8$ (en riolita $n=1$, en cinerita $n=2$, en no determinada $n=4$ y en pizarra $n=1$ ) (Tabla 9.7).

\begin{tabular}{|l|l|l|l|c|c|c|c|c|c|}
\hline $\begin{array}{l}\text { Presencia de } \\
\text { corteza }\end{array}$ & $\begin{array}{l}\text { Basalt } \\
\mathbf{0}\end{array}$ & $\begin{array}{l}\text { Síle } \\
\mathbf{x}\end{array}$ & $\begin{array}{l}\text { Pizarr } \\
\mathbf{a}\end{array}$ & $\begin{array}{l}\text { Volcánic } \\
\mathbf{a}\end{array}$ & $\begin{array}{l}\text { Calcedoni } \\
\mathbf{a}\end{array}$ & $\begin{array}{l}\text { Indet } \\
\text { - }\end{array}$ & $\begin{array}{l}\text { Cinerit } \\
\mathbf{a}\end{array}$ & $\begin{array}{l}\text { Riolit } \\
\mathbf{a}\end{array}$ & $\begin{array}{l}\text { Tota } \\
\mathbf{l}\end{array}$ \\
\hline Indet. & & & & & & 2 & 1 & 8 \\
\hline Abundante & & & & & 2 & 2 & 1 & 16 & 24 \\
\hline Muy abundante & & & & 1 & & 1 & 19 & 21 \\
\hline Parcial & & & & & & 2 & 1 & 40 & 44 \\
\hline Escasa & & 1 & & & & & 1 & 12 & 14 \\
\hline No presenta & 1 & & & 2 & 4 & 10 & 17 & 131 & 165 \\
\hline Total & $\mathbf{1}$ & $\mathbf{1}$ & $\mathbf{1}$ & $\mathbf{3}$ & $\mathbf{7}$ & $\mathbf{1 8}$ & $\mathbf{2 3}$ & $\mathbf{2 2 2}$ & $\mathbf{2 7 6}$ \\
\hline
\end{tabular}

Tabla 9. 7. Relación de corteza en lascas y materia prima

Dimensiones

En relación con los módulos LA y AE predominan en el conjunto las piezas cortas. Entre ellas, las preponderantes son las que presentan longitudes cortas y delgadas $n=81$ (en riolita $n=63$, en cinerita $n=11$, en no determinada $n=3$; en calcedonia $n=2$; en volcánica y pizarra $n=1$ ). Siguen las cortas y de grosor intermedio $n=78$ (en riolita $n=69$, en cinerita $n=2$, en no determinada $n=3$; en calcedonia $n=3$ y en volcánica $n d n=1$ ), y luego las cortas y gruesas $n=19$ (en riolita $n=16$, en cinerita $n=2$, en no determinada $n=1)$. En cuanto a las de longitud intermedia, hay de longitud intermedia y delgadas $n=17$ (en riolita $n=11$, en cinerita y no determinada $n=3$ ), de longitud y grosor intermedio $=46$ (en riolita $n=31$, en cinerita $n=5$, en no determinada $n=7$; en calcedonia, 
volcánica nd y sílex $n=1$ ), longitud intermedio y gruesas $n=20$ (en riolita $n=19$ $y$ cinerita $n=1$ ). Finalmente, enguanto a las lascas de longitud larga, hay lascas de largas $y$ de grosor intermedio $n=1$ de basalto, $y$ finalmente lascas largas $y$ gruesas $n=10$ (en riolita $n=9$ y en cinerita $n=1$ ), no se encuentran representadas lascas largas y delgadas.

\section{Fragmentos}

Los fragmentos cuentan con un $n=168$, y están presentes en todas las materias primas: en riolita $n=126$, cinerita $n=12$, basalto $n=3$, calcedonia y pizarra $n=2$ para cada una; sílex, andesita y cuarzo $n=1$. Los fragmentos cuyas materias primas no pudieron ser determinadas alcanzan $n=20$.

La conservación es en general mala, ya que sólo el $18 \%$ de los fragmentos presenta buena conservación $(n=30)$. Sobre el resto pueden verse las siguientes alteraciones: pátinas (blancas, amarillentas, etc.) $n=89$, líquenes $n=40$, líquenes y pátinas $n=8$ y finalmente óxido $n=1$.

En cuanto a la corteza, todas las materias primas presentan piezas con ausencia total de corteza $n=116$ distribuidas de la siguiente manera: riolita $n=$ 87; no determinadas $n=12$; cinerita $n=10$; basalto $n=2$, finalmente con $n=1$ pizarra, calcedonia, sílex, andesita y cuarzo (Tabla 9.8).

Con escasa presencia de corteza: riolita $n=11$; $\operatorname{con} n=1$ no determinadas y calcedonia. Con presencia parcial de corteza riolita $n=7$; cinerita $n=2$ y basalto $n=1$. Muy abundante y abundante sólo en riolita $n=8$ y 7 respectivamente, además de una no determinada también con muy abundante presencia de corteza.

Los fragmentos en los cuales no pudo determinarse la presencia de corteza alcanzan un $n=13$; en riolita $n=6$, no determinadas $n=6$ y pizarra $n=1$. 


\begin{tabular}{|l|c|c|c|c|c|c|c|c|c|c|}
\hline Corteza & Cuarzo & Andesita & Sílex & Pizarra & Calced. & Basalto & Cinerita & Indet. & Riolita & Total \\
\hline Abundante & & & & & & & & & 7 & 7 \\
\hline M/ abundante & & & & & & & & 1 & 8 & 9 \\
\hline Parcial & & & & & & 1 & 2 & & 7 & 10 \\
\hline Indet. & & & & 1 & & & & 6 & 6 & 13 \\
\hline Escasa & & & & & 1 & & & 1 & 11 & 13 \\
\hline No presenta & 1 & 1 & 1 & 1 & 1 & 2 & 10 & 12 & 87 & 116 \\
\hline Total & $\mathbf{1}$ & $\mathbf{1}$ & $\mathbf{1}$ & $\mathbf{2}$ & $\mathbf{2}$ & $\mathbf{3}$ & $\mathbf{1 2}$ & $\mathbf{2 0}$ & $\mathbf{1 2 6}$ & $\mathbf{1 6 8}$ \\
\hline
\end{tabular}

Tabla 9. 8. Relación entre corteza en fragmentos y materia prima

$\underline{\text { Instrumentos }}$

Raspadores

El conjunto de raspadores está compuesto por $n=17$, los más abundantes son los confeccionados en riolita $n=9$, en segundo lugar en cinerita $n=3$, luego con $n=2$ sobre materia prima no determinada, y con $n=1$ en sílex, cuarzo y una roca volcánica no determinada (Tabla 9.9). La conservación es buena sólo en uno de los raspadores de cinerita, el resto presenta las siguientes alteraciones: Pátina $n=13$ (en riolita $n=8$, cinerita, volcánica no determinada y sílex $n=1$ y materia prima no determinada $n=2$ ); líquenes $n=4$ (riolita $n=2$, cinerita y cuarzo $n=1$ ). La mayoría presenta adherencias en su superficie $n=17$, lo mismo ocurre en relación al grado de fragmentación ya que $\mathrm{n}=10$ están enteras, $\mathrm{n}=6$ presentan fragmentación de tipo 1 y sólo dos presentan grado de tipo 2 . 


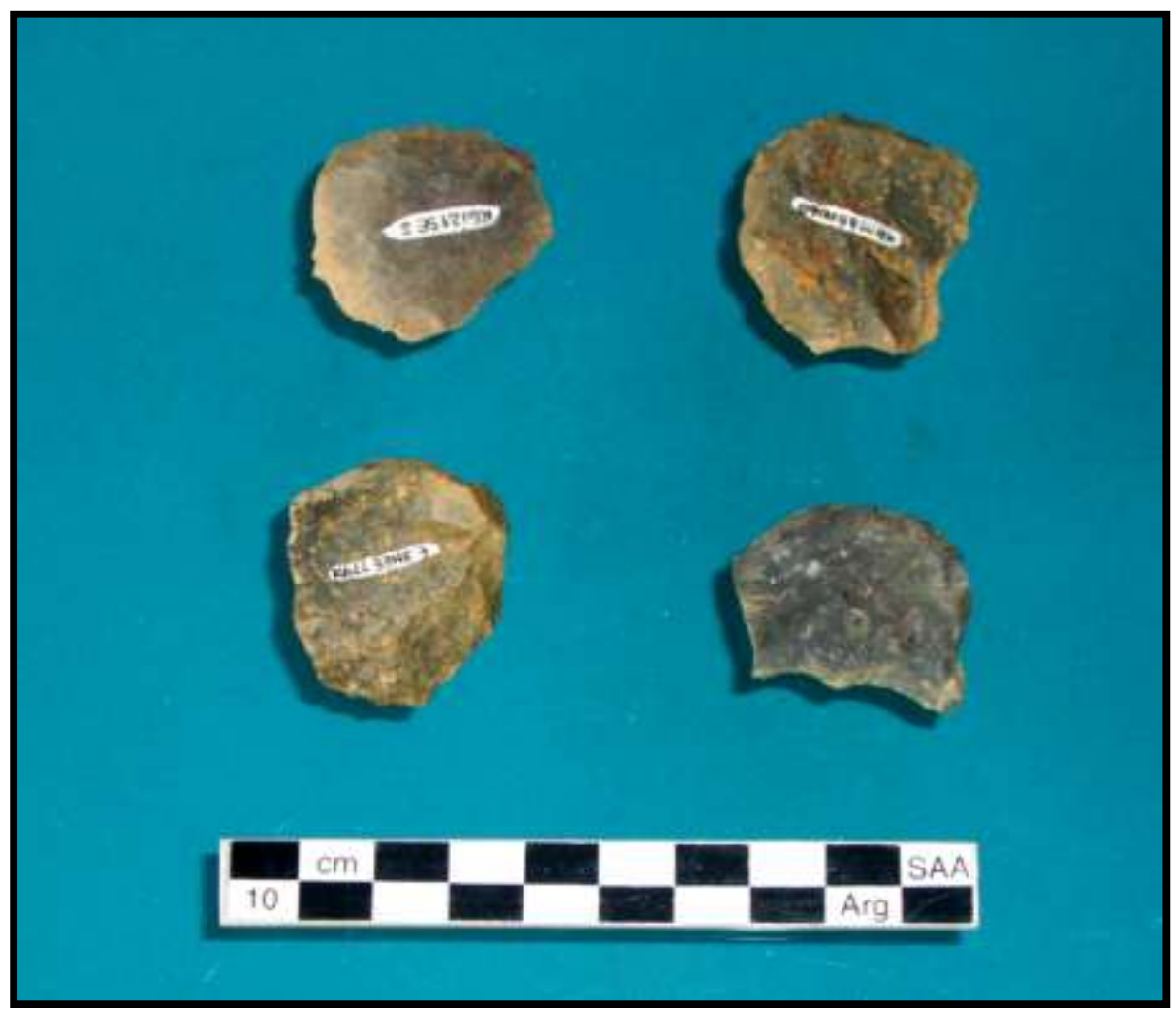

Figura 9. 1. Raspadores

\begin{tabular}{|l|c|c|c|c|c|c|c|}
\hline Tipo/ materia prima & Cuarzo & Volcánica ND & Sílex & Indet. & Cinerita & Riolita & Total \\
\hline Raspador Atípico & & & & & & 2 & 2 \\
\hline Raspador doble & & & & & & 1 & 1 \\
\hline Raspador simple & 1 & 1 & 1 & 2 & 3 & 6 & 14 \\
\hline Total & $\mathbf{1}$ & $\mathbf{1}$ & $\mathbf{1}$ & $\mathbf{2}$ & $\mathbf{3}$ & $\mathbf{9}$ & $\mathbf{1 7}$ \\
\hline
\end{tabular}

Tabla 9. 9. Tipos de raspador y materia prima

Los raspadores corresponden a tres tipo diferentes, raspadores simples $n=14$ (en riolita $n=6$, en cinerita $n=3$, en no determinada $n=2$; con $n=1$ en cuarzo, sílex y volcánica no determinada); raspadores atípicos $n=2$ (ambos en riolita) y raspadores dobles, sólo uno sobre riolita.

\section{Dimensiones}

Tomando el largo máximo de los raspadores podemos agruparlos de la siguiente manera: microrraspadores $n=3$ (en sílex, cuarzo y no determinada $n=$ 1 ); chicos $n=11$ (en riolita $n=6$, cinerita $n=3$, en volcánica nd y no determinada $n=1$ ) y medianos $n=3$, todos en riolita.

En cuanto a las dimensiones en relación con los módulos LA/AE el conjunto se caracteriza por elementos cortos de grosor intermedio $n=11$ (en 
riolita $n=6$, cinerita $n=1$ y no determinada $n=2$ ); cortos y gruesos $n=2$ (uno en riolita y uno en cinerita); corto y delgado sólo uno en sílex. Aquellos con longitudes y grosores intermedios $n=2$ (uno en riolita y uno en cinerita) y finalmente en riolita uno de longitud intermedia y delgado.

\section{Forma base}

Los soportes sobre los cuales fueron confeccionados los raspadores son principalmente lascas $n=14$ (en riolita $n=7$, en cinerita $n=3$, no determinada $n=$ 2 , sílex y la roca volcánica $n=1$ ), luego lascas bipolares $n=2$ (uno sobre riolita y otro sobre cuarzo) y finalmente sobre un fragmento $n=1$ (sobre riolita) (Tabla 9.10).

\begin{tabular}{|l|c|c|c|c|c|c|c|}
\hline Soporte/materia prima & Cuarzo & Volcánica ND & Sílex & Indet. & Cinerita & Riolita & Total \\
\hline Fragmento & & & & & & 1 & 1 \\
\hline Lasca & & 1 & 1 & 2 & 3 & 7 & 14 \\
\hline Lasca Bipolar & 1 & & & & & 1 & 2 \\
\hline Total & $\mathbf{1}$ & $\mathbf{1}$ & $\mathbf{1}$ & $\mathbf{2}$ & $\mathbf{3}$ & $\mathbf{9}$ & $\mathbf{1 7}$ \\
\hline
\end{tabular}

Tabla 9. 10. Relación entre soporte y materia prima en raspadores

Vistos desde la cara dorsal, la morfología de los raspadores es preponderantemente semicircular $n=9$ (en riolita $n=4$; en cinerita $n=2$; en sílex, cuarzo y no determinada $n=1$ ); alargada $n=4$ (riolita $n=2$, cinerita y volcánica $n=1$ ); oblicua $n=3$ (riolita $n=2$, no determinada $n=1$ ); ancha $n=1$ en riolita (Tabla 9.11).

\begin{tabular}{|l|c|c|c|c|c|c|c|}
\hline Morfología/materia prima & Cuarzo & Volcánica ND & Sílex & Indet. & Cinerita & Riolita & Total \\
\hline Ancha & & & & & & 1 & 1 \\
\hline Oblicua & & & & 1 & & 2 & 3 \\
\hline Alargada & & 1 & & & 1 & 2 & 4 \\
\hline Semicircular & 1 & & 1 & 1 & 2 & 4 & 9 \\
\hline Total & $\mathbf{1}$ & $\mathbf{1}$ & $\mathbf{1}$ & $\mathbf{2}$ & $\mathbf{3}$ & $\mathbf{9}$ & $\mathbf{1 7}$ \\
\hline
\end{tabular}

Tabla 9. 11. Morfología de los raspadores y materia prima

La sección longitudinal del soporte más representada es la cóncavoplana $n=6$, y luego cóncavo-convexa $n=4$, no determinables $n=2$, biconvexa $n=2$, finalmente con $n=1$ las irregular, plana y helicoidal. En cuanto a los accidentes de talla, están ausentes en todos los raspadores.

Talones, bulbos y labios 
Los talones están ausentes en $n=4$ artefactos debido principalmente a la actividad de talla. Entre los tipos de talones presentes los más abundantes son los lisos con $n=8$ (en riolita $n=4$, sílex y cuarzo $n=1$, y no determinada $n=2$ ), los restantes son natural $\mathrm{n}=1$ en cinerita; facetado $\mathrm{n}=1$ en riolita, no determinado $n=1$ también en riolita y puntiforme $n=1$ en volcánica $n d$. La preparación de los talones sólo pudo definirse en 5 raspadores: 2 en riolita (facetado y lineal), uno en cinerita (ausente), otro en sílex (liso) y finalmente uno en volcánica nd (puntiforme) (Tabla 9.12).

En cuanto a la inclinación de los talones podemos mencionar rectos $n=9$ (en riolita $n=4$; luego $n=1$ en las materias primas restantes); no determinable $\mathrm{n}=5$ (en riolita $\mathrm{n}=3$, cinerita $\mathrm{n}=2$ ); oblicuos $\mathrm{n}=3$ (en riolita $\mathrm{n}=2$, no determinada $\mathrm{n}=1$ ).

\begin{tabular}{|l|c|c|c|c|c|c|c|}
\hline Tipo de talón/materia prima & Cuarzo & Volcánica ND & Sílex & Indet. & Cinerita & Riolita & Total \\
\hline Lineal & & & & & & 1 & 1 \\
\hline Facetado & & & & & & 1 & 1 \\
\hline Natural & & & & & 1 & & 1 \\
\hline Puntiforme & & 1 & & & & & 1 \\
\hline Indet. & & & & & & 1 & 1 \\
\hline Ausente & & & & & 2 & 2 & 4 \\
\hline Liso & 1 & & 1 & 2 & & 4 & 8 \\
\hline Total & $\mathbf{1}$ & $\mathbf{1}$ & $\mathbf{1}$ & $\mathbf{2}$ & $\mathbf{3}$ & $\mathbf{9}$ & $\mathbf{1 7}$ \\
\hline
\end{tabular}

Tabla 9. 12. Tipos de talones representados en raspadores y materia prima

El bulbo se presenta en $n=14$ raspadores de forma difusa (en riolita $n=$ 7 , cinerita $n=3$-uno con esquirlamiento-, materia prima no determinada $n=2$; en sílex, volcánica ( $\mathrm{nd}$ ) y cuarzo $\mathrm{n}=1$ ). En los casos restantes están ausentes ya sea por talla o por fragmentación de la pieza (Tabla 9.13). En cuanto al labio, está ausente en $n=8$, difuso $n=7$ y normal $n=2$.

\begin{tabular}{|l|c|c|c|c|c|c|c|}
\hline Bulbo/materia prima & Cuarzo & Volcánica ND & Sílex & Indet. & Cinerita & Riolita & Total \\
\hline Ausente & & & & & & 2 & 2 \\
\hline Difuso & 1 & 1 & 1 & 2 & 2 & 7 & 14 \\
\hline Difuso con esquirlamiento & & & & & 1 & & 1 \\
\hline Total & $\mathbf{1}$ & $\mathbf{1}$ & $\mathbf{1}$ & $\mathbf{2}$ & $\mathbf{3}$ & $\mathbf{9}$ & $\mathbf{1 7}$ \\
\hline
\end{tabular}

Tabla 9. 13. Tipo de bulbo en raspadores y materia prima 
El conjunto de los raspadores está compuesto principalmente por piezas sin corteza $n=13$ (en todas las materias primas). Las restantes se presentan de la siguiente manera: corteza muy abundante $n=1$ en riolita, corteza escasa $n=$ 1 en no determinada, corteza parcial $n=1$ en cinerita. Por último una pieza en la que no pudo determinarse la presencia de corteza ni la materia prima (Tabla 9.14).

\begin{tabular}{|l|c|c|c|c|c|c|c|}
\hline Presencia de corteza & Cuarzo & Volcánica ND & Sílex & Indet. & Cinerita & Riolita & Total \\
\hline Muy abundante & & & & & & 1 & 1 \\
\hline Escasa & & & & 1 & & & 1 \\
\hline Parcial & & & & & 1 & & 1 \\
\hline Indet. & & & & 1 & & & 1 \\
\hline No presenta & 1 & 1 & 1 & & 2 & 8 & 13 \\
\hline Total & $\mathbf{1}$ & $\mathbf{1}$ & $\mathbf{1}$ & $\mathbf{2}$ & $\mathbf{3}$ & $\mathbf{9}$ & $\mathbf{1 7}$ \\
\hline
\end{tabular}

Tabla 9. 14. Presencia de corteza en raspadores

Detalle de los filos

Debido a que uno de los raspadores presenta dos filos, estos ascienden a $n=19$. De ellos $n=12$ son distales (en riolita $n=7$, cinerita $n=3$, no determinada y volcánica $n d n=1$ ); izquierdos $n=3$ (en riolita, sílex y no determinada $n=1$ ); no determinables $n=2$, (en riolita y en cuarzo $n=1$ ) y dos derechos en riolita (Tabla 9.15).

En cuanto a la delineación, los convexos están presentes en todas las materias primas $n=15$, (en riolita $n=8$, luego en cinerita $n=3$ y $n=1$ en las restantes). Los semicirculares $n=3$ (en riolita $n=2$ y en cinerita $n=1$ ) y le único filo recto está en el raspador doble confeccionado sobre riolita. La sección longitudinal de los filos es en primer término recta $n=16$, las 3 restantes son curvas.

\begin{tabular}{|l|c|c|c|c|c|c|c|}
\hline Filos/materia prima & Cuarzo & Volcánica ND & Sílex & Indet. & Cinerita & Riolita & Total \\
\hline 1 Filo & $\mathbf{1}$ & $\mathbf{1}$ & $\mathbf{1}$ & $\mathbf{2}$ & $\mathbf{3}$ & $\mathbf{9}$ & $\mathbf{1 7}$ \\
\hline Derecho & & & & & & 1 & 1 \\
\hline Distal & & 1 & & 1 & 3 & 7 & 12 \\
\hline Izquierdo & & & 1 & 1 & & & 2 \\
\hline Indet. & 1 & & & & & 1 & 2 \\
\hline 2 Filos & & & & & & $\mathbf{1}$ & $\mathbf{1}$ \\
\hline Derecho & & & & & & 1 & 1 \\
\hline Total & $\mathbf{1}$ & $\mathbf{1}$ & $\mathbf{1}$ & $\mathbf{2}$ & $\mathbf{3}$ & $\mathbf{9}$ & $\mathbf{1 8}$ \\
\hline
\end{tabular}

Tabla 9. 15. Posición y cantidad de filos en raspadores 


\section{Detalle del retoque}

Todos los raspadores presentan retoque irregular sobre los filos; la posición del retoque es directa en $n=17$ y no determinable $n=2$. En cuanto a la extensión del retoque vemos que hay filos restringidos $n=12$, extendidos $n=5$, cortos $n=1$ y no determinable $n=1$; todos ellos son continuos. En relación a la profundidad $n=13$ son marginales, $n=4$ son profundos $y$ uno es muy marginal.

Los ángulos presentan una distribución diversa desde los $40^{\circ}$ a los $85^{\circ}$. $Y$ se distribuyen de la siguiente manera: entre $40^{\circ}$ y $65^{\circ} n=5$; entre los $65^{\circ}$ y los $75^{\circ} n=12^{\circ}$, entre los $75^{\circ}$ y los $85^{\circ} n=2$.

La longitud de los filos también presenta una amplia diversidad, filos menores de $2 \mathrm{~cm} \mathrm{n}=3$; filos entre 2 y $3 \mathrm{~cm} \mathrm{n}=9$; filos entre 3 y $4 \mathrm{~cm} \mathrm{n}=6$ y filos superiores a los $5 \mathrm{~cm}$ sólo uno. Los filos más cortos se presentan en cinerita, sílex y en la materia prima no determinada, a medida que aumentan los tamaños comienzan a tomar preponderancia los raspadores de riolita.

Filos largos retocados (raederas)

Este conjunto se encuentra constituido por $n=26$ piezas, principalmente confeccionadas sobre riolita $n=19$, en cinerita $n=3$, en lutita $n=1$, en roca volcánica no determinable $\mathrm{n}=1$ y hay dos artefactos cuyas materias primas no pudieron ser determinadas. Al igual que el caso de los raspadores, la conservación es muy mala sobre todo por la presencia de pátinas (amarillas y blancas) $n=15$, mientras que las piezas con líquenes asciende a $n=9$. Sólo uno presenta pátina y líquenes en su superficie. En cuanto a la fragmentación el conjunto presenta piezas enteras en $n=21$, siendo $n=5$ las que presentan un grado de fragmentación de tipo 1 . De las 26 raederas, 25 presentan rastros macroscópicos, que en este caso son adherencias.

Los tipos de raederas son los siguientes: transversales $n=9$ (en riolita $n=$ 7 , en cinerita $n=2$ ); raederas dobles $n=6$ (en riolita $n=3$; lutita, volcánica $n d y$ no determinada $n=1$ ); raederas laterales $n=6$ (en riolita $n=4$; en cinerita y no determinada $n=1$ ) raederas oblicuas $n=2$ en riolita; doble convergente $n=1$ en riolita, y finalmente dos raederas a las que se les pudo adscribir un subtipo debido al grado de fragmentación (Tabla 9.16). 


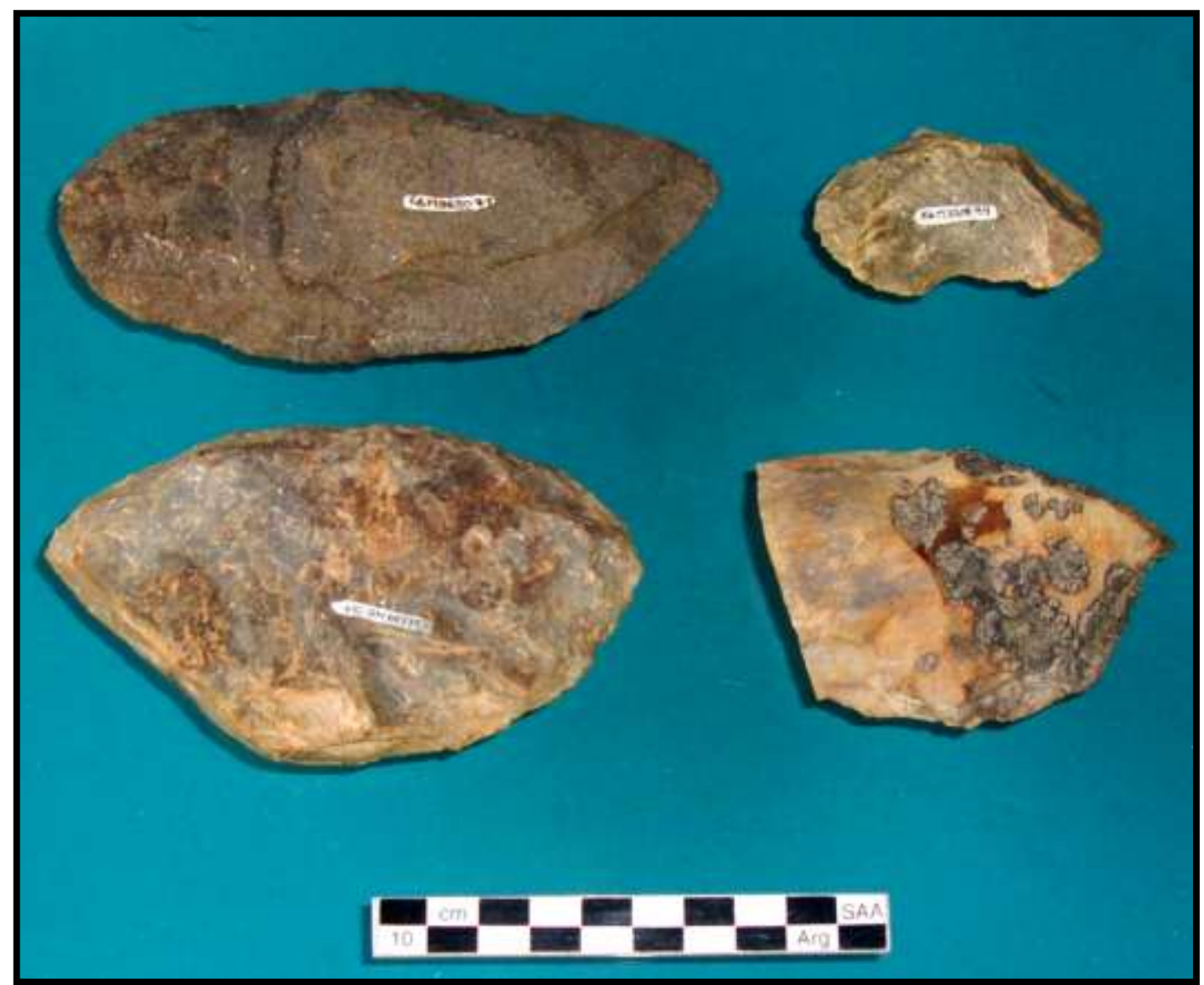

Figura 9. 2.Filos largos retocados

\begin{tabular}{|l|c|c|c|c|c|c|}
\hline Tipos/materia prima & Lutita & Volcánica ND & Indet. & Cinerita & Riolita & Total \\
\hline Raedera & & & & & 2 & 2 \\
\hline Raedera doble & 1 & 1 & 1 & & 3 & 6 \\
\hline Raedera doble convergente & & & & & 1 & 1 \\
\hline Raedera lateral simple & & & 1 & 1 & 4 & 6 \\
\hline Raedera Oblicua & & & & & 2 & 2 \\
\hline Raedera transversal & & & & 2 & 7 & 9 \\
\hline Total & $\mathbf{1}$ & $\mathbf{1}$ & $\mathbf{2}$ & $\mathbf{3}$ & $\mathbf{1 9}$ & $\mathbf{2 6}$ \\
\hline
\end{tabular}

Tabla 9. 16. Tipos de raedera y materia prima

\section{Forma base}

Todos los artefactos se confeccionaron sobre lascas. Presentan morfología oblicua en $n=11$ (en riolita $n=9$, cinerita $n=1$ y no determinada $n=$ 1); anchas $n=7$ (en riolita $n=5$, cinerita $n=1$ y volcánica $n d n=1$ ); alargadas $n=$ 4 (riolita $n=2$, cinerita $n=1$ y no determinada $n=1$ ); subcircular sólo una de cinerita. En cuanto a las morfologías no determinables son $n=3$ en riolita (Tabla 9.17). 


\begin{tabular}{|l|c|c|c|c|c|c|}
\hline Morfología/materia prima & Lutita & Volcánica ND & Indet. & Cinerita & Riolita & Total \\
\hline Subcircular & & & & 1 & & 1 \\
\hline Indet. & & & & & 3 & 3 \\
\hline Alargada & 1 & & 1 & & 2 & 4 \\
\hline Ancha & & 1 & & 1 & 5 & 7 \\
\hline Oblicua & & & 1 & 1 & 9 & 11 \\
\hline Total & $\mathbf{1}$ & $\mathbf{1}$ & $\mathbf{2}$ & $\mathbf{3}$ & $\mathbf{1 9}$ & $\mathbf{2 6}$ \\
\hline
\end{tabular}

Tabla 9. 17. Morfología de las raederas

La sección longitudinal de los soportes son cóncavo-plana en n= 14 (en riolita $n=9$, en cinerita $n=2$, no determinable $n=2$ y volcánica $n d n=1$ ); biconvexo $n=8$ (en riolita $n=7$ y en cinerita $n=1)$; cóncavo-convexo $n=2(n=1$ en riolita y cinerita), por último hay dos no determinables en riolita. En cuanto a los accidentes de talla sólo una raedera de riolita corresponde a una lasca reflejada.

\section{Talones}

Las piezas que presentan talones alcanzan un $n=18$ entre los que podemos mencionar se encuentran talones naturales $n=7$ (en riolita $n=6$, en cinerita $n=1$ ); lisos $n=8$ (en riolita $n=4$, en cinerita $n=2$ y no determinada $n=$ 2); facetado $n=1$ en riolita y lineal $n=1$ en lutita. Dos no pudieron ser determinados, uno en riolita y el otro una materia prima no determinada (Tabla 9.18). La preparación de los talones se presenta en $n=8$ (en riolita $n=5$, cinerita, lutita y no determinada $n=1$ ). En cuanto a la inclinación de los talones, los rectos alcanzan $n=14$ (en riolita $n=10$, cinerita $n=3$, lutita $n=1$ ); oblicuos $n=4$ (en riolita $n=2$, no determinada $n=2$ ), mientras que $n=8$ no pudieron ser determinados.

\begin{tabular}{|l|c|c|c|c|c|c|}
\hline Tipo de talón & Lutita & Volcánica ND & Indet. & Cinerita & Riolita & Total \\
\hline Facetado & & & & & 1 & 1 \\
\hline Lineal & 1 & & & & 1 & 2 \\
\hline Natural & & & & 1 & 6 & 7 \\
\hline Liso & & & 2 & 2 & 4 & 8 \\
\hline Ausente & & 1 & & & 7 & 8 \\
\hline Total & $\mathbf{1}$ & $\mathbf{1}$ & $\mathbf{2}$ & $\mathbf{3}$ & $\mathbf{1 9}$ & $\mathbf{2 6}$ \\
\hline
\end{tabular}

Tabla 9. 18. Tipo de talones y materia prima

El bulbo más característico del conjunto es el difuso $n=20$ representados en todas las materias primas, los difusos con esquirlamiento $n=$ 
1 (en cinerita), los bulbos espesos $n=1$ en riolita, finalmente las raederas que no presentan alcanzan un $n=4$ (todas en riolita) (Tabla 9.19). En relación al labio, $n=15$ raederas son no determinables, difusos $n=8$ (en riolita $n=6$, lutita y no determinada $n=1$ ) y normales $n=3$ (en riolita, cinerita y no determinada $n=$ 1).

\begin{tabular}{|l|c|c|c|c|c|c|}
\hline Bulbo/materia prima & Lutita & Volcánica ND & Indet. & Cinerita & Riolita & Total \\
\hline Difuso con Esquirl. & & & & 1 & & 1 \\
\hline Espeso & & & & & 1 & 1 \\
\hline Ausente & & & & & 4 & 4 \\
\hline Difuso & 1 & 1 & 2 & 2 & 14 & 20 \\
\hline Total & $\mathbf{1}$ & $\mathbf{1}$ & $\mathbf{2}$ & $\mathbf{3}$ & $\mathbf{1 9}$ & $\mathbf{2 6}$ \\
\hline
\end{tabular}

Tabla 9. 19. Tipo de bulbos presentes en las raederas

La corteza está ausente en casi la mitad de las piezas del conjunto $n=$ 12, abarcando todas las materias primas. En cuanto aquellas que presentan algún porcentaje de corteza las más abundantes son las raederas con escasa corteza $n=11$ (en riolita $n=10$ y en cinerita $n=1$ ); con corteza parcial $n=2$ en riolita y con abundante corteza sólo una sobre la materia prima no determinada (Tabla 9.20).

\begin{tabular}{|l|c|l|c|c|c|c|}
\hline Presencia de corteza & Lutita & Volcánica ND & Indet. & Cinerita & Riolita & Total \\
\hline Abundante & & & 1 & & & 1 \\
\hline Parcial & & & & & 2 & 2 \\
\hline Escasa & & & & 1 & 10 & 11 \\
\hline No presenta & 1 & 1 & 1 & 2 & 7 & 12 \\
\hline Total & $\mathbf{1}$ & $\mathbf{1}$ & $\mathbf{2}$ & $\mathbf{3}$ & $\mathbf{1 9}$ & $\mathbf{2 6}$ \\
\hline
\end{tabular}

Tabla 9. 20. Presencia de corteza en raederas y materia prima

Detalle de los filos

El total de filos del conjunto de raederas asciende a 35 , mientras que las piezas son $n=26$, raederas dobles $n=9$ y raederas simples $n=17$. Los filos son mayoritariamente distales $n=14$ (en riolita $n=10$, en cinerita $n=2$, en roca volcánica $n d n=1$ ); derechos $n=8$ (en riolita $n=5$, en cinerita, lutita y no determinada $n=1$ ); izquierdos $n=7$ (en riolita $n=6$ y lutita $n=1$ ); proximales $N=$ 5 (en riolita $n=3$, en no determinada $n=1 y$ en volcánica $n d n=1$ ) no determinables sólo uno en riolita (Tabla 9.21). 


\begin{tabular}{|l|c|c|c|c|c|c|}
\hline Posición de los filos & Lutita & Volcánica ND & Cinerita & Indet. & Riolita & Total \\
\hline Indet. & & & & & 1 & 1 \\
\hline Proximal & & 1 & & 1 & 3 & 5 \\
\hline Izquierdo & 1 & & & & 6 & 7 \\
\hline Derecho & 1 & & 1 & 1 & 5 & 8 \\
\hline Distal & & 1 & 2 & 1 & 10 & 14 \\
\hline Total & $\mathbf{2}$ & $\mathbf{2}$ & $\mathbf{3}$ & $\mathbf{3}$ & $\mathbf{2 5}$ & $\mathbf{3 5}$ \\
\hline
\end{tabular}

Tabla 9. 21. Posición de los filos

En cuanto a la delineación de los filos $n=25$ corresponden a los convexos (en riolita $n=16$, cinerita $n=3 ; n=2$ en no determinada, lutita y roca volcánica $n d$ ); rectos $n=9$ (en riolita $n=8$, en no determinada $n=1$ ) y sinuoso $\mathrm{n}=1$ en riolita. Sin embargo la sección longitudinal es en general recta en $\mathrm{n}=$ 25 , curvada en $n=7$ y sinuosa en $n=3$ (Tabla 9.22).

\begin{tabular}{|l|c|c|c|c|c|c|}
\hline $\begin{array}{l}\text { Delineación } \\
\text { sección longitudinal/ } \\
\text { Materia prima }\end{array}$ & Lutita & Volcánica ND & Cinerita & Indet. & Riolita & Total \\
\hline Sinuosa & & & & & 1 & 1 \\
\hline Recta & & & & 1 & 8 & 9 \\
\hline Convexa & 2 & 2 & 3 & 2 & 16 & 25 \\
\hline Total & $\mathbf{2}$ & $\mathbf{2}$ & $\mathbf{3}$ & $\mathbf{3}$ & $\mathbf{2 5}$ & $\mathbf{3 5}$ \\
\hline Sinuosa & 1 & & & & 2 & 3 \\
\hline Curva & 1 & & & & 6 & 7 \\
\hline Recta & & 2 & 3 & 3 & 17 & 25 \\
\hline Total & $\mathbf{2}$ & $\mathbf{2}$ & $\mathbf{3}$ & $\mathbf{3}$ & $\mathbf{2 5}$ & $\mathbf{3 5}$ \\
\hline
\end{tabular}

Tabla 9. 22. Relación entre delineación-sección longitudinal y materia prima

Detalle del retoque

El retoque es irregular en todos los casos, directo en $n=32$, bifacial $n=2$ $e$ indirecto $n=1$. En relación a los directos, estos están presentes en raederas confeccionadas en riolita $n=22$, cinerita $n=3$, no determinada $n=3$, lutita $y$ volcánica $n d n=2$; tanto bifacial $n=2$, como el indirecto corresponden a piezas en riolita (Tabla 9.23).

\begin{tabular}{|l|c|c|c|c|c|c|}
\hline Retoque/materia prima & Lutita & Volcánica ND & Cinerita & Indet. & Riolita & Total \\
\hline Indirecto & & & & & 1 & 1 \\
\hline Bifacial & & & & & 2 & 2 \\
\hline Directo & 2 & 2 & 3 & 3 & 22 & 32 \\
\hline Total & $\mathbf{2}$ & $\mathbf{2}$ & $\mathbf{3}$ & $\mathbf{3}$ & $\mathbf{2 5}$ & $\mathbf{3 5}$ \\
\hline
\end{tabular}

Tabla 9. 23. Posición del retoque en raederas 
La extensión del retoque más representada es restringido $n=14$ (en riolita $n=10$, en cinerita $n=2$, en lutita y en no determinada $n=1$ ); $\operatorname{largo} n=12$ (en riolita $n=8$, en volcánica $n d n=2$, con $n=1$ cinerita y no determinada), extendido $n=5$ (en riolita $n=4$ y en lutita $n=1$ ); perimetral $n=2$ en riolita y finalmente cortos $n=2$, uno en riolita y el otro en no determinada (Tabla 9.24).

\begin{tabular}{|l|c|l|c|c|c|c|}
\hline Extensión del filo & Lutita & Volcánica ND & Cinerita & Indet. & Riolita & Total \\
\hline Corto & & & & 1 & 1 & 2 \\
\hline Perimetral & & & & & 2 & 2 \\
\hline Extendido & 1 & & & & 4 & 5 \\
\hline Largo & & 2 & 1 & 1 & 8 & 12 \\
\hline Restringido & 1 & & 2 & 1 & 10 & 14 \\
\hline Total & $\mathbf{2}$ & $\mathbf{2}$ & $\mathbf{3}$ & $\mathbf{3}$ & $\mathbf{2 5}$ & $\mathbf{3 5}$ \\
\hline
\end{tabular}

Tabla 9. 24. Extensión de los filos

La profundidad del retoque más representada es las marginal $n=21$ representada en todas las materias primas, luego la profunda $n=9$ en riolita, cinerita y no determinada; muy marginal $n=4$ en riolita y cinerita y finalmente sólo una pieza en riolita presenta retoque muy profundo.

Los ángulos que caracterizan los retoques de este conjunto abarcan un rango amplio desde los $35^{\circ}$ hasta los $80^{\circ}$ y podemos agruparlos de la siguiente forma; de entre 35-45 n= 3; 45 a $55 \mathrm{n}=9$; 55 a $65 \mathrm{n}=17$; 67 a $75 \mathrm{n}=4$ y mayores a $75 n=2$. Podemos ver que entre los valores intermedios se encuentran la mayor cantidad de piezas y lo mismo ocurre en cuanto a las materias primas que se agrupan en relación a estos valores (Tabla 9.25).

\begin{tabular}{|l|c|c|c|c|c|c|}
\hline Ángulo del retoque & Volcánica ND & Lutita & Indet. & Cinerita & Riolita & Total \\
\hline 35 & & & & 1 & & 1 \\
\hline 45 & 1 & & & & 1 & 2 \\
\hline 50 & & & & & 4 & 4 \\
\hline 53 & & & 1 & & & 1 \\
\hline 55 & & & & & 4 & 4 \\
\hline 60 & & 1 & 1 & 1 & 6 & 9 \\
\hline 65 & 1 & & & & 7 & 8 \\
\hline 70 & & 1 & & & 2 & 3 \\
\hline 75 & & & & & 1 & 1 \\
\hline 80 & & & 1 & 1 & & 2 \\
\hline Total general & 2 & 2 & 3 & 3 & 25 & 35 \\
\hline
\end{tabular}

Tabla 9. 25. Ángulos de los filos 
Mayor diversidad se presenta en relación a la longitud de los filos, que van desde los $3,2 \mathrm{~cm}$ hasta los $13,5 \mathrm{~cm}$. Los menores a $4 \mathrm{~cm}$ son sólo $\mathrm{n}=3$; entre 4 y $6 \mathrm{~cm} \mathrm{n}=11$; entre 6 y $8 \mathrm{~cm} \mathrm{n}=10$; y superiores a $8 \mathrm{~cm} \mathrm{n}=11$. La mayor diversidad de materias primas se agrupa entre los rangos 4 a $6 \mathrm{~cm}$ y los superiores a $8 \mathrm{~cm}$.

Fragmentos de instrumento

Los fragmentos de instrumento están conformados por $n=9$ artefactos, de los cuales $n=8$ están confeccionados en riolita y uno en andesita. La conservación es mala, principalmente presentan adherencias, además de pátinas $n=5$ y líquenes $n=3$. Al ser fragmentos de instrumento todos presentan grado de fragmentación tipo 2.

\section{Forma base}

La fragmentación y la mala conservación de las piezas impiden aportar datos sobre la forma base.

Detalle de los filos

Los filos alcanzan un $n=10$, dado que una de las piezas presenta dos filos. Estos se distribuyen según su situación en la pieza de la siguiente manera: no determinable $n=5$, distal $n=4$, izquierdo y derecho $n=1$. En cuanto a la delineación, convexos $n=5$, no determinables $n=4$ y rectos $n=2$ (Tabla 9.26). La sección longitudinal presenta filos principalmente rectos $n=8$, curvados $n=2$ y uno no determinable.

\begin{tabular}{|l|r|r|r|}
\hline Posición de los filos & Andesita & Riolita & Total \\
\hline Izquierda & & 1 & 1 \\
\hline Derecha & & 1 & 1 \\
\hline Distal & & 4 & 4 \\
\hline Indet. & 1 & 4 & 5 \\
\hline Total & $\mathbf{1}$ & $\mathbf{1 0}$ & $\mathbf{1 1}$ \\
\hline
\end{tabular}

Tabla 9. 26. Ubicación de los filos

Detalle del retoque

El retoque es irregular en todos los filos, directo en $n=8$ y no determinable en $n=3$. En cuanto a la extensión del retoque, esta es no 
determinable en $n=7$, restringido $n=3$ y largo $n=1$. La repartición del retoque sobre los filos es continua en $n=8$, y no determinable en $n=3$. En relación con la profundidad del retoque, este es marginal en $n=9$ y profundo en $n=2$.

Los filos presentan longitudes, en general inferiores a los $45 \mathrm{~cm} \mathrm{n}=7$, entre los 45 a $65 \mathrm{~cm} \mathrm{n}=4$. En cuanto a los ángulos, entre $55^{\circ}$ y $65^{\circ} \mathrm{n}=5$, entre los $65^{\circ}$ y $75^{\circ} n=4$ y entre los $75^{\circ}$ y $85^{\circ} n=2$.

\section{Análisis funcional}

En este caso tampoco fue posible identificar rastros de uso debido al estado de conservación de las superficies y redondeamiento de los filos. Dado que los rastros de uso normalmente aparecen pegados al filo en una extensión que rara vez supera medio $\mathrm{mm}$, el redondeamiento y abrasión tafonómicos alteraron totalmente o eliminaron los posibles rastros microscópicos.

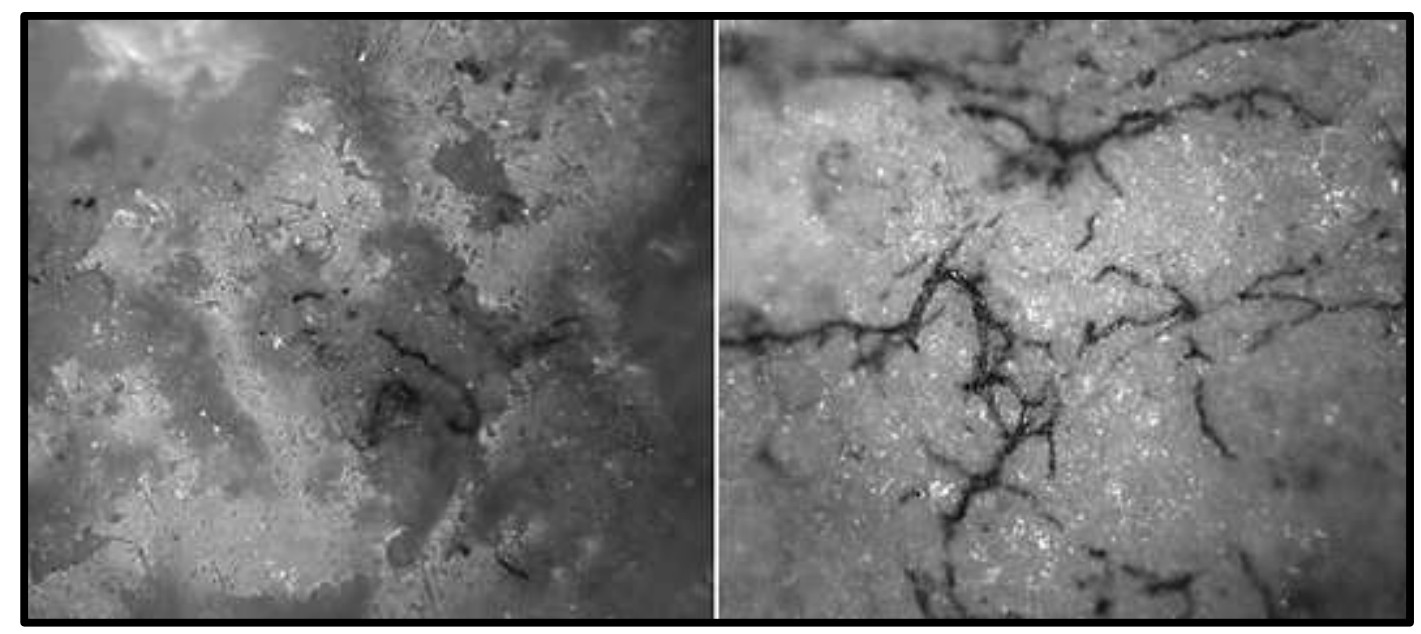

Figura 9. 3. Alteraciones Izq. Alteración por alta temperatura. Der. Alteración superficial

\section{DISCUSIÓN}

El conjunto lítico de Kami 6, proviene del trabajo de recolección superficial sobre un sector en el que el lago Fagnano y la laguna Bombilla se unen por una espiga de sedimento ya ocupada por algo de vegetación.

Una de las características principales del conjunto es su estado de conservación. Este es en general malo, muchas piezas presentan pátinas amarillentas o blanquecinas, líquenes de tipo crustoso y adherencias en su 
superficie, impidiendo a veces hasta poder determinar la presencia o ausencia de corteza.

En relación a los artefactos que componen el conjunto, se nota la ausencia de los pertenecientes al subgrupo de los menores a $2 \mathrm{~cm}$, sólo hay 8 lasquitas. Esto se relaciona principalmente con su carácter superficial, además las características del sedimento permiten que las piezas pequeñas se entierren con facilidad o sean tapadas por el sedimento aportado por el viento, con más facilidad que los de mayor tamaño.

En cuanto al subgrupo mayor a $2 \mathrm{~cm}$, este se caracteriza por tener artefactos de talla por percusión directa y principalmente con explotación de materias primas locales como riolitas y cineritas, seguidas en menor medida por calcedonia, cuarzo, basalto y sílex. En relación con esto podemos ver que disminuyen las cantidades en relación a las posibilidades de acceso y a la calidad para la talla. Es muy probable que el primer factor sea el más influyente, en este sentido, ya que las playas asociadas a los conjuntos presentan gran cantidad de rodados de riolita y cinerita (principalmente riolita) pero también hay una gran cantidad de pizarra y esta no se presentan de forma muy abundante dentro de conjunto arqueológico, aquí lo que influye es la calidad para la talla. En cuanto a esto último también puede relacionarse con las materias primas como sílex, basalto, andesita, que son de muy buen calidad y que al ser mucho más escasas probablemente no se descartaran con tanta facilidad como las riolitas. Esto también se ve reflejado en el grado de explotación de los núcleos en materias primas diferentes a las riolitas, los cuales se encontraban agotados.

Si bien el conjunto no presenta una gran diversidad artefactual, si podemos ver mayor diversidad dentro de cada tipo artefactual, sobre todo en el caso de las raederas, donde podemos distinguir al menos 5 tipos diferentes. Esta diferencia no creo que pueda estar relacionada con condicionantes de talla de las materias primas, ya que la mayor diversidad se ve en las raederas confeccionadas sobre riolita, mientras que las manufacturadas en otras materias primas sólo presentan raederas simples y dobles (también presentes en riolita). Una explicación podría ser la finalidad a las cuales estaban destinadas estas piezas, sin embargo, debido al estado de conservación, como se mencionó, no fue posible recuperar esta información a través del análisis 
funcional. Finalmente, en relación con esto, la diversidad también puede estar relacionada con el carácter superficial del conjunto, dado que no se puede asegurar que se trate de un conjunto contemporáneo, incluso podría representar un palimpsesto. 


\section{Capítulo 10}

ANÁLISIS TECNO-MORFOLÓGICO Y FUNCIONAL DE LOS CONJUNTOS LÍTICOS DEL SITIO KAMI 7 


\section{INTRODUCCION}

El sitio Kami 7 es un sitio extenso con características particulares que lo hacen comparable y a la vez diferente de Kami 1 y Kami 6, pero que al mismo tiempo lo constituyen en un sitio de importancia para abordar el estudio propuesto en esta investigación de doctorado.

Como se mencionó en la presentación del sitio, éste se encuentra ubicado en la parte central de la margen sur del lago Fagnano, a un kilómetro de distancia de Kami 1. El sector de costa donde se emplaza el sitio se caracteriza por presentar una pequeña playa de guijarros que rodea la elevación sobre la cual se sitúa Kami 7. Hasta la orilla, el lugar se encuentra cubierto por bosque. Hacia el este, el sitio está flanqueado por un turbal, atrás de la elevación corre el curso del rio Palacios, que desemboca en el lago.

El sitio fue abordado desde la sectorización total del mismo, con recolección superficial de materiales y excavación en dos sectores. En consecuencia, aquí se presentarán los resultados de los análisis tecnomorfológicos siguiendo estas líneas de trabajo. En primer término abordaremos los resultados de los materiales obtenidos por excavación sistemática de las cuadrículas ubicadas en el sector oriental del sitio; en segundo lugar presentaremos los resultados de los materiales provenientes de la excavación de una cuadrícula en el sector oeste que se llevó a cabo sobre un pequeño sector en riesgo. Finalmente, en tercer término, se tratará el análisis de los materiales obtenidos a partir de la recolección superficial intensiva de todo el sitio.

\section{LOS MATERIALES DE LAS CUADRICULAS E.}

El conjunto lítico de las cuadrículas excavadas en el sector oriental de Kami 7, consta de 2.210 piezas, incluyendo artefactos mayores y menores a 2 $\mathrm{cm}$. Tomando esta división, 617 corresponden al subgrupo de los mayores a 2 cm y 1.593 al subgrupo de los materiales menores a $2 \mathrm{~cm}$ (Tabla 10.1). 
En el primer subgrupo, las materias primas predominantes son las riolitas (73\%), y las cineritas (21\%). Esto nos deja un $6 \%$ de otras materias primas, que se dividen de la siguiente manera: $2 \%$ pizarra, $1 \%$ cuarzo y basalto y $0,5 \%$ calcedonia. Las materias primas que no pudieron ser determinadas alcanzan sólo un $2 \%$.

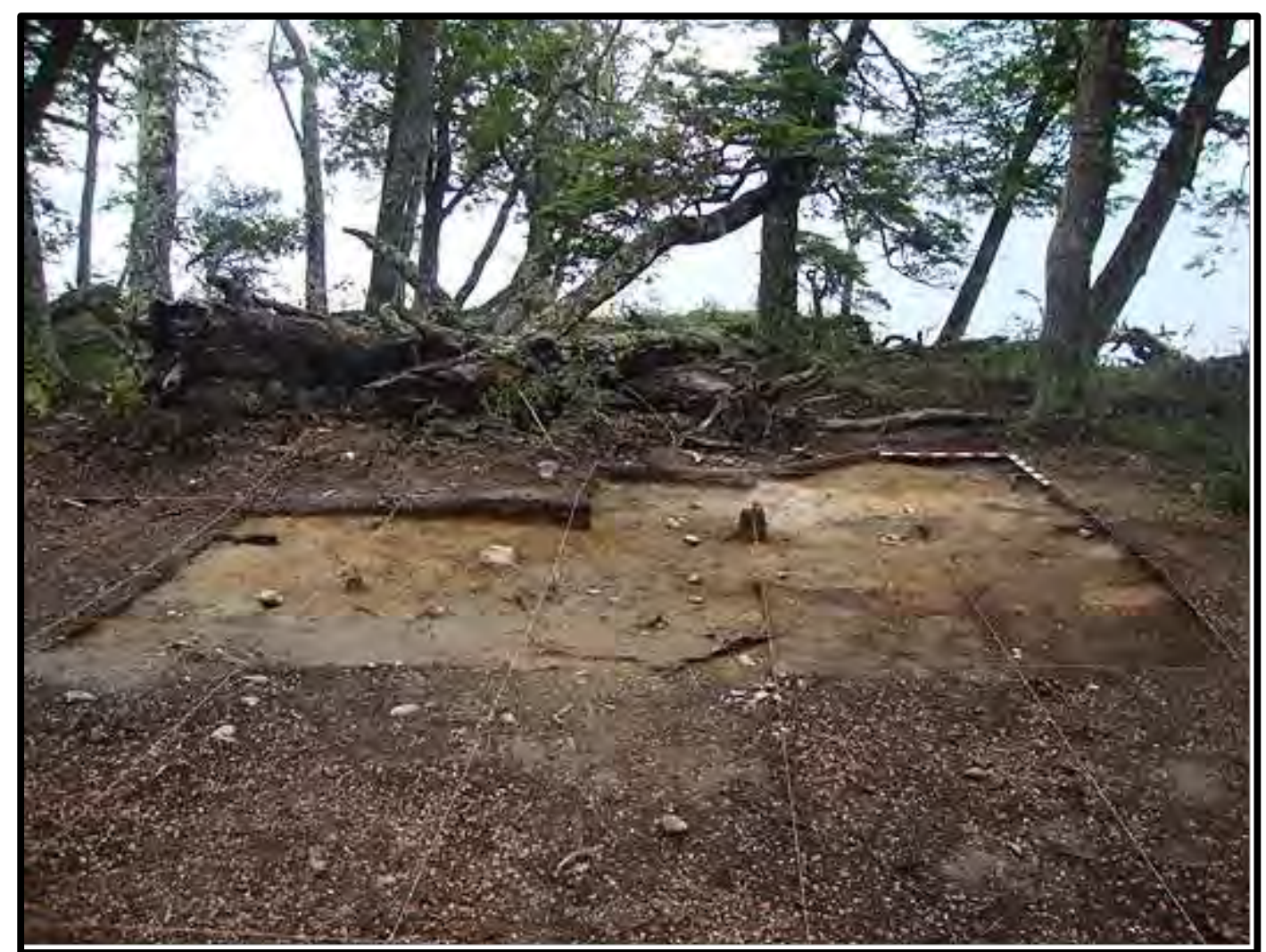

Figura 10. 1. Vista general del sector de cuadrículas E del sitio Kami 7 


\begin{tabular}{|c|c|c|c|c|c|c|c|c|c|c|c|c|c|c|c|}
\hline & Tipo / Materia prima & Basalto & Calcedonia & Chert & Cinerita & Cuarzo & Indet. & Lutita & Pizarra & Riolita & Sílex & Vidrio & Total & $\%$ \\
\hline \multirow{32}{*}{ 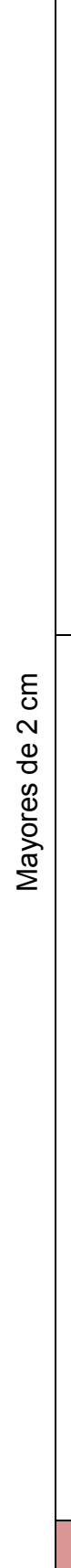 } & & Frag. de instrumento & & 1 & & 2 & & & 1 & & 3 & & & 7 & \\
\hline & & Instrumento bifacial & & & & 1 & & & & & & & & 1 & \\
\hline & & Instrumento compuesto & & & & 1 & & & & & & & & 1 & \\
\hline & & Muesca & & & & & & & & 1 & & & & 1 & \\
\hline & & Objeto bifacial frag. & & & & 2 & & & & & & & & 2 & \\
\hline & $\stackrel{\infty}{\frac{0}{0}}$ & Punta preforma & & & & & & & & & 1 & & & 1 & \\
\hline & ర్용 & Raedera doble & 1 & & & & & & & & 1 & & & 2 & \\
\hline & 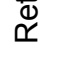 & Raedera simple lateral & & & & 3 & & & & & 2 & & & 5 & \\
\hline & & Raedera transversal & & & & & & & & & 1 & & & 1 & \\
\hline & & Raspador atípico & & & & 1 & & & & & 1 & 1 & & 3 & \\
\hline & & Raspador circular & & & & & & & & & 1 & & & 1 & \\
\hline & & Raspador simple & 1 & 1 & 2 & & & & & & 8 & 1 & & 13 & \\
\hline & & Total retocados & 2 & 2 & 2 & 10 & & & 1 & 1 & 18 & 2 & & 38 & 2,6 \\
\hline & & Lámina & & & & 1 & & & & & 2 & & & 3 & \\
\hline & & Lasca & & 9 & & 130 & 2 & 10 & 3 & & 340 & & 1 & 495 & \\
\hline & & Lasca con retoque & & & & & & & & & 1 & & & 1 & \\
\hline & & Fragmento & & 4 & 4 & 108 & 4 & 21 & 4 & 12 & 337 & & & 494 & \\
\hline & & Guijarro & 1 & & & & & & & 2 & 6 & & & 9 & \\
\hline & & Fragmento bipolar & & & 1 & & & & & & & 2 & & 3 & \\
\hline & & Indet. & & & & & & 4 & & 2 & & & & 6 & \\
\hline & \% & Hemi guijarro bipolar & & & & & & 1 & & & & & & 1 & \\
\hline & ల్ & Lasca bipolar & 2 & & & & 1 & & & & & 2 & & 5 & \\
\hline & $\frac{\pi}{2}$ & Núcleo bipolar & & & & & & & & & & 1 & & 1 & \\
\hline & z & Núcleo & & & & 1 & & & & & 6 & & & 7 & \\
\hline & & Núcleo amorfo & & 1 & & & & & & & 9 & & & 10 & \\
\hline & & Núcleo apical & & & & & & & & & 4 & & & 4 & \\
\hline & & Núcleo Discoidal & & 1 & & & & & & & 2 & & & 3 & \\
\hline & & Núcleo fragmentado & & & & 3 & & & & & 20 & & & 23 & \\
\hline & & Percutor & & & & & & & & & 1 & & & 1 & \\
\hline & & Rodaja & & & & & & & & 1 & & & & 1 & \\
\hline & & Total no retocados & 3 & 15 & 5 & 243 & 7 & 36 & 7 & 17 & 728 & 5 & 1 & 1067 & 37 \\
\hline & & Total mayores a $2 \mathrm{~cm}$ & 5 & 17 & 7 & 253 & 7 & 36 & 8 & 18 & 746 & 7 & 1 & 1105 & 39,6 \\
\hline \multirow{9}{*}{ 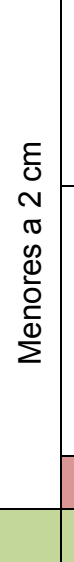 } & $\begin{array}{l}\infty \\
\frac{0}{0}\end{array}$ & Raspador simple & & & & 1 & 1 & 1 & & & 1 & & & 4 & \\
\hline & $\begin{array}{l}\frac{0}{0} \\
\frac{1}{\alpha}\end{array}$ & Total retocados & & & & 1 & 1 & 1 & & & 1 & & & 4 & 0,2 \\
\hline & & Debris & & 12 & 2 & 692 & 5 & 3 & 24 & 18 & 53 & 1 & 16 & 826 & \\
\hline & $\frac{0}{8}$ & Microfragmento & & & & 404 & 1 & & 7 & & 2 & & 8 & 422 & \\
\hline & $\frac{0}{0}$ & Lasquita & & 2 & 2 & 335 & 2 & 2 & 3 & & 36 & & 23 & 405 & \\
\hline & 인 & Microlascas & 1 & & & 61 & & & & & & & 15 & 77 & \\
\hline & & Total no retocados & 1 & 14 & 4 & 1492 & 8 & 5 & 34 & 18 & 91 & 1 & 62 & 1730 & 60,2 \\
\hline & & Total menores a $2 \mathrm{~cm}$ & 1 & 14 & 8 & 1493 & 9 & 6 & 34 & 18 & 92 & 1 & 62 & 1734 & 60,4 \\
\hline & & Total general & 6 & 28 & 12 & 2985 & 17 & 11 & 68 & 36 & 183 & 8 & 63 & 2843 & \\
\hline
\end{tabular}

Tabla 10. 1. Materiales líticos del sitio Kami 7, excavación y recolección superficial 
Desde el punto de vista morfo-técnico tenemos, por un lado, artefactos no retocadosmayores a $2 \mathrm{~cm}$ : lascas $n=301$ y fragmentos $n=285$, núcleos $n=$ 8 , láminas y lascas bipolares $n=3$ en cada caso. En cuanto a los retocados, el conjunto presenta 4 raspadores simples y uno atípico o no estandarizado, 3 raederas laterales simples y un objeto de talla bifacial. Además el conjunto incluye guijarros $n=4$ y un clasto, mientras que los indeterminados presentan un $n=5$ (Tabla 10.2).

Los instrumentos retocados están confeccionados principalmente, sobre riolita, como lo evidencian las tres raederas y tres raspadores (el no estandarizado y dos simples), luego uno sobre cuarzo, otro sobre basalto y finalmente una pieza bifacial confeccionada sobre cinerita (Tabla 10.2).

\begin{tabular}{|l|c|c|c|c|c|c|c|c|}
\hline $\begin{array}{l}\text { Tipos tecnológicos } \\
\text { y materias primas }\end{array}$ & Calcedonia & Basalto & Cuarzo & Pizarra & Indet. & Cinerita & Riolita & Total \\
\hline Fragmento & & & 2 & 8 & 9 & 62 & 204 & 285 \\
\hline Indet. & & & & 2 & 4 & & & 6 \\
\hline Lámina & & & & & & 1 & 2 & 3 \\
\hline Lasca & 2 & & 1 & & 3 & 63 & 231 & 300 \\
\hline Lasca bipolar & & 2 & 1 & & & & & 3 \\
\hline Núcleo & & & & & & 1 & 6 & 7 \\
\hline Objeto bifacial & & & & & & 2 & & 2 \\
\hline Raedera simple & & & & & & 1 & 2 & 3 \\
\hline Raspador atípico & & & & & & & 1 & 1 \\
\hline Raspador simple & & 1 & 1 & & & & 2 & 4 \\
\hline Total & $\mathbf{2}$ & $\mathbf{3}$ & $\mathbf{5}$ & $\mathbf{1 0}$ & $\mathbf{1 6}$ & $\mathbf{1 3 0}$ & $\mathbf{4 4 8}$ & $\mathbf{6 1 4}$ \\
\hline
\end{tabular}

Tabla 10. 2. Tipos tecnológicos del sitio Kami 7, excavación

El subconjunto de artefactos no retocados menores a $2 \mathrm{~cm}$ (1590 elementos) está conformado por debris $n=770$, lasquitas $n=347$, microfragmentos $n=413$ y microlascas $n=60$ (Tabla 10.3. Gráfico 10.1).

\begin{tabular}{|l|c|c|c|c|c|}
\hline Materias primas & microlascas & lasquita & microfragmentos & debris & Total \\
\hline cinerita & 60 & 321 & 403 & 683 & 1467 \\
\hline riolita & & 22 & 2 & 31 & 55 \\
\hline lutita & & 3 & 7 & 24 & 34 \\
\hline pizarra & & & & 18 & 18 \\
\hline calcedonia & & 1 & & 11 & 12 \\
\hline cuarzo & & & 1 & 3 & 4 \\
\hline Total general & $\mathbf{6 0}$ & $\mathbf{3 4 7}$ & $\mathbf{4 1 3}$ & $\mathbf{7 7 0}$ & $\mathbf{1 5 9 0}$ \\
\hline
\end{tabular}

Tabla 10. 3. Elementos menores a $2 \mathrm{~cm}$ y materia prima 


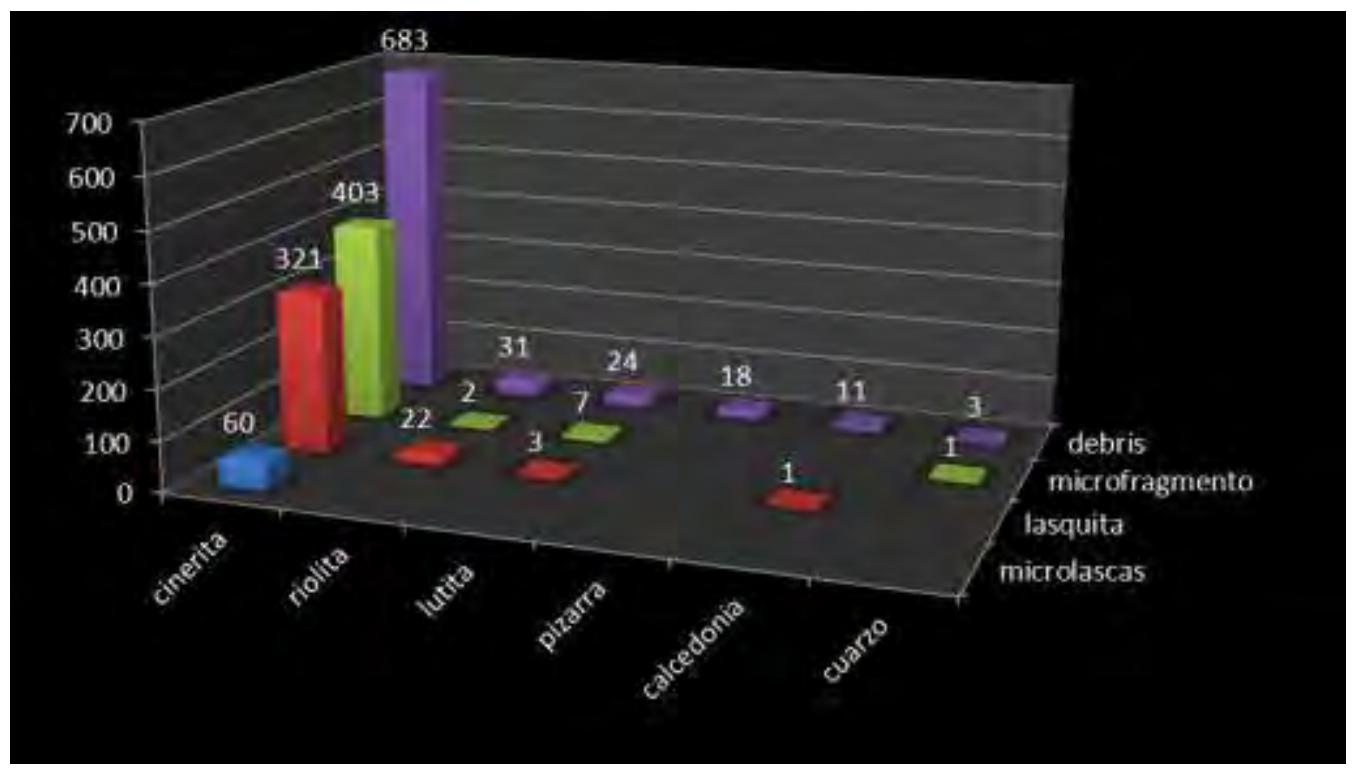

Gráfico 10. 1. Relación entre materia prima y elementos menores a $2 \mathrm{~cm}$

Las materias primas representadas en este subgrupo, presentan una gran diferencia numérica entre unas y otras. Las cineritas están representadas en todos los tipos tecnológicos, mientras que las riolitas y lutitas aparecen en mucho menor número, representadas por debris, microfragmentos y lasquitas pero ya no en microlascas. Luego siguen las pizarras (sólo debris), continúa la calcedonia (debris y una lasquita) y finalmente cuarzo (3 debris y un microfragmento).

Un rasgo particular de este subgrupo es la presencia de elementos de vidrio. Se trata de una serie de restos de talla que en total suman $n=63$ elementos, que podemos diferenciar de la siguiente forma: lasquitas $n=23$, debris $n=16$, microlascas $n=15$, y microfragmentos $n=8$ y un fragmento de pico de botella.

\section{Análisis tecno-morfológico}

\section{Núcleos}

El conjunto está compuesto por $n=7$ núcleos fragmentados; sólo uno se pudo determinar como apical, $n=4$ corresponden a la categoría de núcleos amorfos y dos son no determinables (Tabla 10.4). La materia prima más representada es la riolita $n=6$, y la cinerita está presente sólo en un núcleo fragmentado que presenta rastros de talla bifacial. 
El módulo longitud-anchura caracteriza al conjunto con piezas con una longitud intermedia, mientras que el módulo ancho-espesor divide al conjunto entre gruesos $n=3$ y de grosor medio $n=4$.

Los soportes utilizados no pudieron ser determinados debido al grado de explotación, excepto uno identificado como guijarro. En relación a esto, la corteza se presenta de la siguiente manera: abundante $n=2$, escasa $n=3$, parcial $n=1$ y $\sin$ corteza $n=1$. Como mencionamos más arriba, si bien todos presentan un grado importante de explotación, 6 de ellos aún pueden seguir siendo utilizados para la extracción de lascas y sólo en un caso podríamos decir que está totalmente agotado.

\begin{tabular}{|l|c|c|c|}
\hline $\begin{array}{l}\text { Tipo de núcleos/ } \\
\text { materia prima }\end{array}$ & Cinerita & Riolita & Total \\
\hline Amorfo & & 4 & 4 \\
\hline Apical & & 1 & 1 \\
\hline Indet. & 1 & 1 & 2 \\
\hline Total & $\mathbf{1}$ & $\mathbf{6}$ & $\mathbf{7}$ \\
\hline
\end{tabular}

Tabla 10. 4. Tipo de núcleos y materia prima

\section{$\underline{\text { Lascas }}$}

Consideraremos aquí los productos de talla por percusión directa mayores a $2 \mathrm{~cm}$ reconocibles como lascas, que suman un total de 303 piezas, incluyendo las láminas que para este caso son 3, dos sobre riolita y una sobre cinerita. Las lascas están confeccionadas en un $98 \%$ en riolita y cinerita $(77 \%$ y $21 \%$ respectivamente), el $2 \%$ restante se divide entre calcedonia y cuarzo, y materia prima no determinable. De las piezas un 30\% están enteras, un $69 \%$ fragmentadas y sólo un 1\% corresponden a fragmentos (Gráfico 10.2).

La conservación en general es buena ( $n=291$ lascas). Las lascas con planos de oxidación presentan un $n=9$, patina blanquecina $n=2$ y sólo una contiene concreciones.

Los tipos de soportes reconocidos son principalmente lascas en un 92\%, en segundo lugar se encuentran las lascas de talla bifacial en un $5 \%$, luego las lascas iniciales de descortezamiento en un $2 \%$ y finalmente las lascas con dorso natural en un $1 \%$. 


\section{Representación de materias primas}

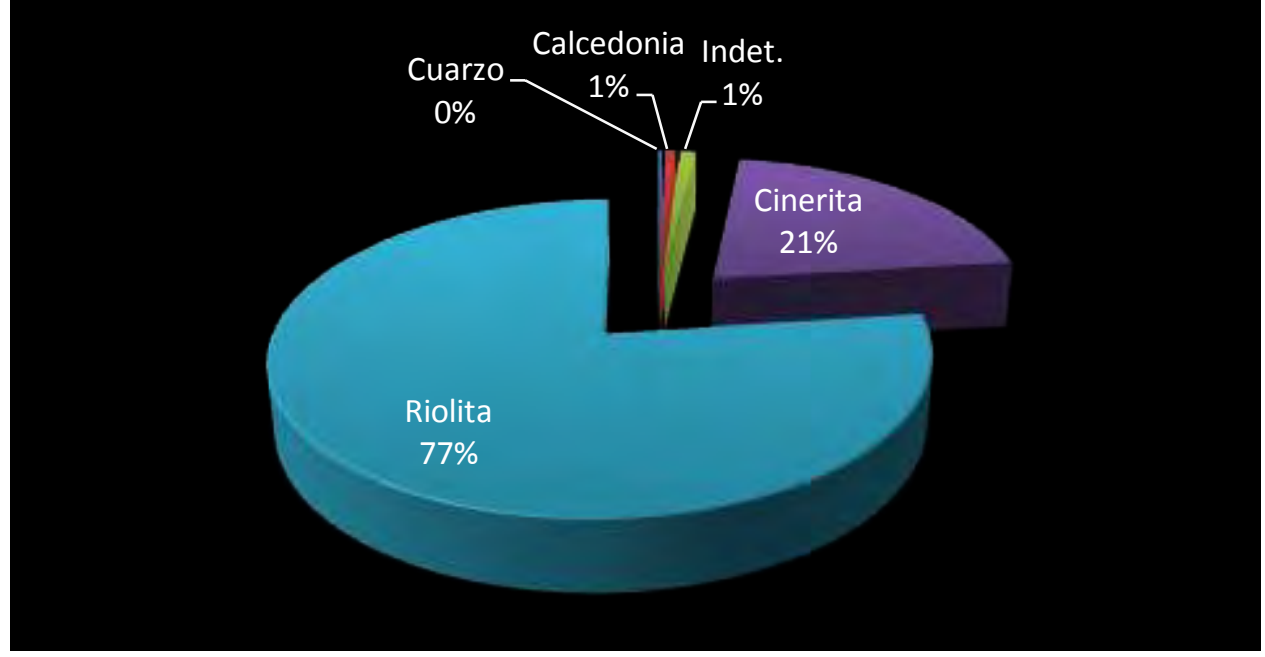

Gráfico 10. 2. Representatividad de materias primas en lascas

En relación a la morfología, en vista dorsal, podemos agruparlas de la siguiente forma $n=114$ son anchas, largas $n=85$ y luego, las oblicuas $n=73$. A partir de aquí en cantidades menores, lascas trapezoidales $n=17$, semicirculares con $n=9$ y finalmente indeterminadas con $n=2$ (Tabla 10.5).

\begin{tabular}{|l|r|l|r|r|r|r|}
\hline Morfología/materia prima & Cuarzo & Calcedonia & Indet. & Cinerita & Riolita & Total \\
\hline Indet. & & & & 1 & 1 & 2 \\
\hline Semicircular & & & & 2 & 7 & 9 \\
\hline Trapezoidal & & & & 2 & 15 & 17 \\
\hline Oblicua & & & 3 & 13 & 57 & 73 \\
\hline Alargada & 1 & & & 25 & 62 & 88 \\
\hline Ancha & & 2 & & 21 & 91 & 114 \\
\hline Total & $\mathbf{1}$ & $\mathbf{2}$ & $\mathbf{3}$ & $\mathbf{6 4}$ & $\mathbf{2 3 3}$ & $\mathbf{3 0 3}$ \\
\hline
\end{tabular}

Tabla 10. 5. Relación entre morfología y materia prima

Si consideramos las materias primas, vemos algunas variaciones. En las riolitas el patrón anterior se mantiene prácticamente igual, sin embargo en las cineritas son más numerosas las alargadas, luego las anchas y en tercer lugar las oblicuas. En cuarzo sólo se ve una lasca alargada, al contrario de lo que ocurre con las calcedonias que sólo presentan dos lascas anchas.

La sección longitudinal muestra que un mayor número de lascas presentan curvatura biconvexa $n=145$, en segundo figuran lugar las planas $n=$ 60; luego las helicoidales $n=54$ (incluidas las láminas), las cóncavo-convexas 
$n=25$; bicóncavas $n=8$, plano-convexas $n=3$, las cóncavas-planas $n=2$, las indeterminadas $n=2$ y finalmente plano-cóncava $n=1$ (Tabla 10.6).

\begin{tabular}{|l|r|r|r|r|r|r|}
\hline Sección longitudinal & Cuarzo & Calcedonia & Indet. & Cinerita & Riolita & Total \\
\hline Plano-cóncavo & & & & & 1 & 1 \\
\hline Cóncavo-plano & & & & & 2 & 2 \\
\hline Indet. & & & & 2 & & 2 \\
\hline Plano-convexo & & & & 2 & 1 & 3 \\
\hline Bicóncavo & & & & & 8 & 8 \\
\hline Cóncavo-convexo & & 1 & & 5 & 19 & 25 \\
\hline Helicoidal & & & & 14 & 43 & 57 \\
\hline Plano & 1 & 1 & 2 & 10 & 46 & 60 \\
\hline Biconvexo & & & 1 & 31 & 113 & 145 \\
\hline Total general & $\mathbf{1}$ & $\mathbf{2}$ & $\mathbf{3}$ & $\mathbf{6 4}$ & $\mathbf{2 3 3}$ & $\mathbf{3 0 3}$ \\
\hline
\end{tabular}

Tabla 10. 6. Relación entre sección longitudinal y materia prima

En las lascas de riolita y cinerita, las más abundantes son las biconvexas, planas y helicoidales, luego siguen las cóncavo-convexas. Las restantes morfologías de la sección longitudinal se presentan en porcentajes muy bajos (ver Tabla 10.6). En cuanto a las otras materias primas, la sección longitudinal en las lascas de calcedonia es una plana y una cóncavo-convexa, en cuarzo sólo una plana.

De las piezas que presentan accidentes de talla, 88 son lascas reflejadas, 29 son lascas reflejadas con lengüeta, mientras que lascas sobrepasadas hay sólo 2. Las láminas no poseen accidentes de talla.

Si tenemos en cuenta la distribución de los accidentes en relación con las materias primas, tanto en riolitas como cineritas el patrón se presenta de la siguiente manera: en primer lugar las que no poseen accidentes, luego las reflejadas, en tercer lugar las reflejadas con lengüeta y por último una lasca sobrepasada en cada una de estas materias primas. En cuanto a las lascas de calcedonia, éstas no presentan accidentes, a diferencia del cuarzo que sí presenta en una lasca reflejada. Las 3 lascas correspondientes a materias primas indeterminadas tampoco poseen accidentes de talla.

La presencia de talones es del 93\%. De los tipos de talones, el más representado es el liso (67\%), luego los talones naturales (12\%), los talones en ala de pájaro ( $4 \%$ ), lineales, diedros y facetados ( $3 \%$ cada uno) y finalmente los puntiformes (1\%). La ausencia de los mismos (7\%) se debe principalmente a fracturas o ausencia por talla (Tabla 10.7). 


\begin{tabular}{|l|r|r|r|r|r|r|}
\hline Tipo de talón & Cuarzo & Calcedonia & Indet. & Cinerita & Riolita & Total \\
\hline Puntiforme & & & & 3 & 1 & 4 \\
\hline Facetado & & & & 3 & 5 & 8 \\
\hline Diedro & & & & & 8 & 8 \\
\hline Lineal & & & 1 & 1 & 8 & 10 \\
\hline Liso en ala de pájaro & & 1 & & 2 & 10 & 13 \\
\hline Ausente & & & & 5 & 16 & 21 \\
\hline Natural & & 1 & 1 & 5 & 29 & 36 \\
\hline Liso & 1 & 1 & 45 & 156 & 203 \\
\hline Total & $\mathbf{1}$ & $\mathbf{2}$ & $\mathbf{3}$ & $\mathbf{6 4}$ & $\mathbf{2 3 3}$ & $\mathbf{3 0 3}$ \\
\hline
\end{tabular}

Tabla 10. 7. Relación entre tipo de talón y materia prima

En relación con las materias primas más abundantes, riolita y cinerita, los talones lisos son los principales, seguidos por los naturales. Luego en lascas de riolita aparecen en tercer lugar los talones en ala de pájaro y luego los lineales junto con los diedros, después los facetados y a continuación una lasca con talón puntiforme. Para las lascas de cinerita en cambio en el tercer lugar aparecen los puntiformes, seguidos por los facetados y los talones en ala de pájaro y finalmente una lasca con talón lineal. Las calcedonias presentan uno en ala de pájaro y uno natural mientras que la lasca de cuarzo presenta un talón liso. En cuanto a las lascas con materia prima indeterminada presentan uno liso, uno lineal y uno natural.

Del total un $29 \%$ de talones presentaron evidencia de preparación. En cuanto a la inclinación de los talones la mayoría son oblicuos $60 \%$, mientras que los rectos aparecen en un $28 \%$ y los muy oblicuos en un $5 \%$. La distribución de las materias primas tanto en la preparación como en la inclinación de los talones es muy similar.

El bulbo se presenta en general de forma difusa en primer término y espeso en segundo para todas las materias primas. Sólo dos lascas de riolita presentan bulbos dobles (Tabla 10.8).

\begin{tabular}{|l|r|r|r|r|r|r|}
\hline Bulbo/materia prima & Cuarzo & Calcedonia & Indet. & Cinerita & Riolita & Total \\
\hline Doble & & & & & 2 & 2 \\
\hline Ausente & & & & 1 & 4 & 5 \\
\hline Espeso & 1 & 1 & 1 & 18 & 40 & 61 \\
\hline Difuso & & 1 & 2 & 45 & 187 & 235 \\
\hline Total & $\mathbf{1}$ & $\mathbf{2}$ & $\mathbf{3}$ & $\mathbf{6 4}$ & $\mathbf{2 3 3}$ & $\mathbf{3 0 3}$ \\
\hline
\end{tabular}

Tabla 10. 8. Tipo de bulbo y su relación con materias primas 
El tipo de labio más abundante es el normal y se encuentra presente en todas las materias primas. Siguen las lascas con ausencia de labio representadas en riolita y cinerita, finalmente lascas con labios difusos en las mismas materias primas.

El porcentaje de corteza se caracteriza principalmente por un $68 \%$ de lascas sin corteza, seguido por un $15 \%$ con escasa corteza, luego aparecen piezas con corteza parcial y abundante, ambos con $7 \%$; por último un $3 \%$ con muy abundante corteza.

En relación a materia prima y corteza vemos que entre riolita y cinerita no existen diferencias en cuanto al patrón de distribución entre unos y otros. Únicamente en el caso de la riolita aparecen lascas con muy abundante corteza (Gráfico 10.3).

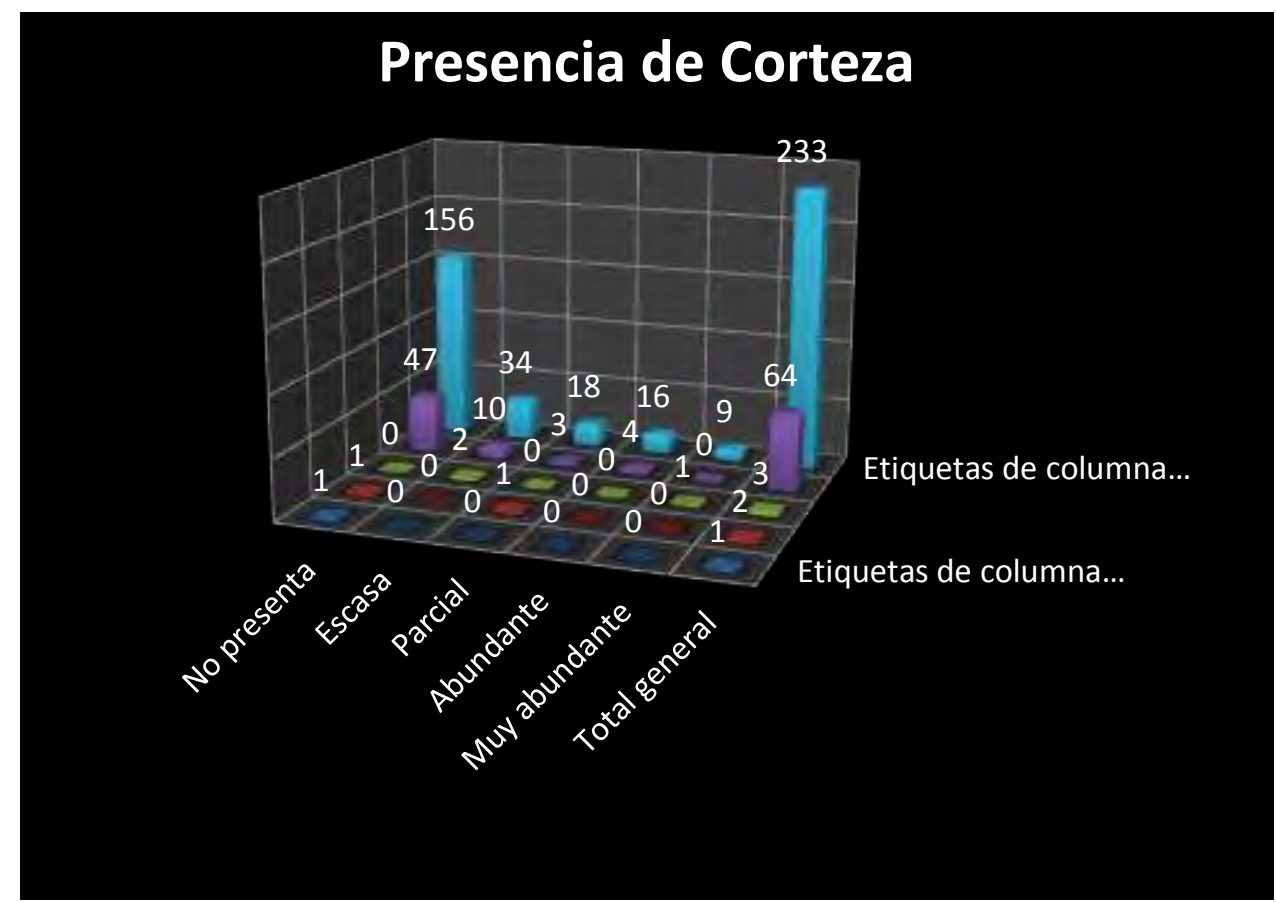

Gráfico 10. 3. Relación entre presencia de corteza y materia prima

Los filos potencialmente utilizables están presentes en $n=15$, de los cuales dos son en láminas de riolita y cinerita; la primera es la única que presenta dos filos laterales. Las lascas presentan un filo y se confeccionaron sobre riolita $n=8$, cinerita $n=4$ y en calcedonia $n=1$ (Tabla 10.9).

La posición de los filos es derecha en $n=7$, luego izquierdos y distales $n=4$ para cada uno. En cuanto a la delineación, en general los filos son rectos $n=12$, mientras que 2 son convexos y sólo uno es cóncavo. La sección 
longitudinal de los filos es principalmente recta $n=8$, curvada $n=4$ y sinuosa $n=$ 3.

Los ángulos de los filos pueden agruparse de la siguiente forma: filos entre $30-35^{\circ} \mathrm{n}=4$; filos entre $40-55^{\circ} \mathrm{n}=10$ y con un ángulo de $70^{\circ} \mathrm{n}=1$. Las longitudes se pueden agrupar entre aquellos que van desde los $2-2,9 \mathrm{~cm} \mathrm{n}=7$, de $3-4,9 \mathrm{~cm} \mathrm{n}=5$, y mayores a $5 \mathrm{~cm} n=3$.

\begin{tabular}{|l|r|r|r|r|}
\hline Filos/materia prima & Calcedonia & Cinerita & Riolita & Total \\
\hline Lámina & & $\mathbf{1}$ & $\mathbf{1}$ & $\mathbf{2}$ \\
\hline Derecha & & & 1 & 1 \\
\hline Izquierda & $\mathbf{1}$ & $\mathbf{4}$ & $\mathbf{8}$ & $\mathbf{1 3}$ \\
\hline Lasca & 1 & 2 & 3 & 6 \\
\hline Derecha & & 1 & 3 & 4 \\
\hline Distal & & 1 & 2 & 3 \\
\hline Izquierda & $\mathbf{1}$ & $\mathbf{5}$ & $\mathbf{9}$ & $\mathbf{1 5}$ \\
\hline Total general & & & & 1 \\
\hline
\end{tabular}

Tabla 10. 9. Ubicación de los filos en lascas y láminas

En cuanto a los módulos de longitud-ancho, y el de ancho-espesor, vemos que las lascas cortas son las más abundantes $n=177$, en segundo lugar aparecen las de longitud media con $n=114$ y luego las lascas largas con $n=12$. En relación al grosor las piezas delgadas son las principales $n=178$, luego las de grosor medio con $n=105$ y finalmente las gruesas con $n=20$.

Si relacionamos los módulos las piezas más abundantes son las cortas y delgadas $(n=127)$, luego las que presentan longitud y grosor medios $(n=55)$, aparecen las lascas cortas y de grosor medio $(n=47)$, al igual que las delgadas de longitud media, seguidas por las gruesas de longitud media $(n=12)$. Finalmente en menores cantidades aparecen lascas largas y gruesas $(n=5)$, largas y delgadas $(n=4)$, largas y de grosor medio $(n=3)$ al igual que las cortas y gruesas (Gráfico 10.4). 


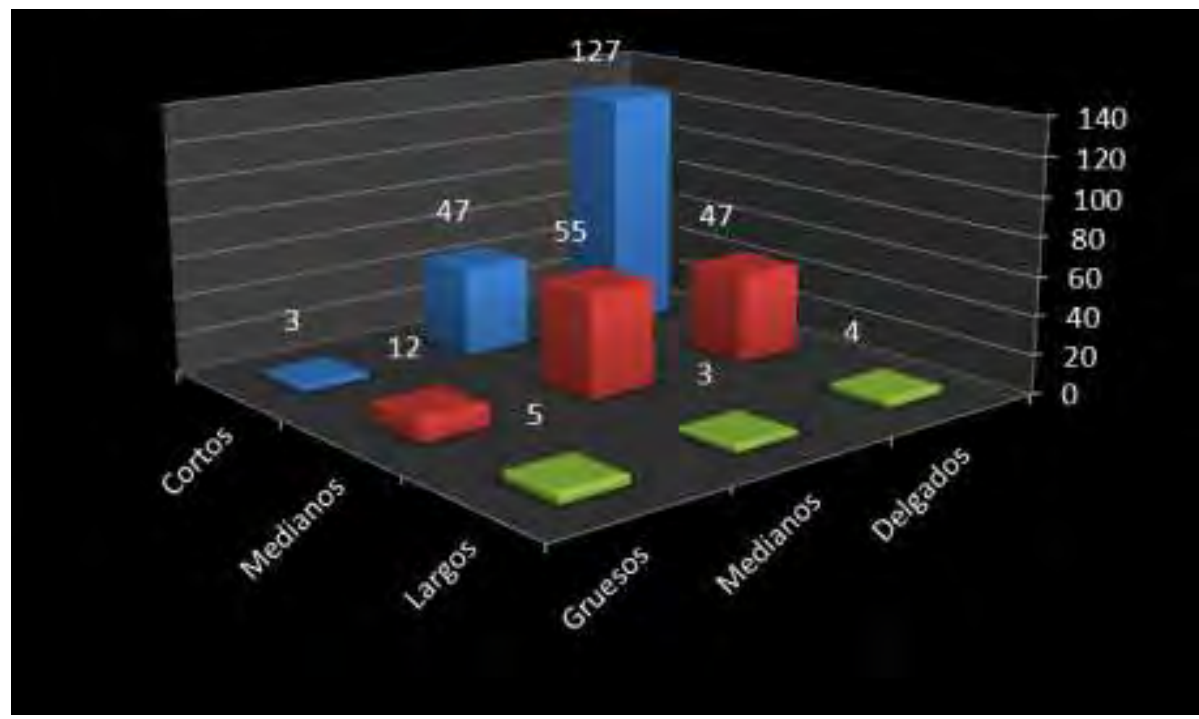

Gráfico 10. 4. Relación entre los módulos Longitud-Ancho/Ancho-Espesor

\section{Instrumentos retocados}

Raspadores

El total de raspadores asciende a $n=5$, sin embargo el número de filos es de 8. Esto se debe a que una pieza presenta dos filos y otra tres. Sin embargo, como veremos más adelante, debido a las características de los filos complementarios las piezas se consideran de todas formas como raspadores simples.

Tres de los raspadores están confeccionados sobre riolita, uno sobre cuarzo hialino y uno sobre basalto. En cuanto a los tipos representados existen dos variantes: cuatro raspadores simples y un raspador atípico.

Si se considera su largo máximo, los raspadores pueden agruparse de la siguiente manera: un micro-raspador (menor a $2 \mathrm{~cm}$ ), dos raspadores chicos (entre 2 y $4 \mathrm{~cm}$ ), y dos raspadores medianos (entre 4 y $8 \mathrm{~cm}$ ).

En relación con los módulos $\mathrm{LA}$ y $\mathrm{AE}$, podemos discriminar al conjunto en tres raspadores de longitud intermedia con grosor medio, uno de longitud intermedia y delgado y uno corto con espesor intermedio.

\section{Forma base y talones}

Los soportes sobre los cuales fueron confeccionados son principalmente lascas en 3 casos, mientras que uno de ellos fue confeccionado sobre un fragmento y otro fue confeccionado sobre la terminación de una lasca 
sobrepasada. En relación a la forma, vista desde la cara dorsal, podemos dividirlos entre los que presentan forma alargada $n=3$ y los que presentan forma semicircular $n=2$.

Los accidentes de talla representados son: lasca reflejada $n=1$, lasca sobrepasada $n=1$, mientras que los tres restantes no presentan accidentes.

De las 3 piezas que presentan talones, dos de ellos son lisos y uno natural. Los primeros muestran evidencia de preparación y orientación oblicua, mientras que el natural presenta orientación recta y no muestra indicios de preparación. Tanto el bulbo difuso como el labio normal se repiten en los tres casos.

La corteza está completamente ausente en tres raspadores, mientras que el raspador de riolita presenta corteza muy abundante y el raspador de basalto presenta escasa corteza.

\section{Detalle de los filos}

Como mencionamos hay dos instrumentos que presentan más de un filo. Ambos tienen un filo principal retocado, que se corresponde con el filo de raspador. Una de las piezas presenta 2 filos, uno formatizado y un filo natural recto y más agudo. La segunda pieza presenta 3 filos, dos de ellos naturales, largos y agudos. El resto de los raspadores presentan un filo retocado. En cuanto a la situación de los filos, hay 4 filos distales, 2 derechos (uno natural) y 2 izquierdos (ambos naturales).

De los 5 filos retocados, 4 son convexos y uno recto; la sección longitudinal es recta en todos ellos. En cuanto a la delineación de los filos naturales, uno es convexo y dos son rectos. La sección longitudinal es curva en $n=2$ y recta en $n=1$. En cuanto a la longitud de los filos, dos superan los $3 \mathrm{~cm}$, dos se encuentran entre los 2 y $3 \mathrm{~cm}$, y el filo del micro-raspador mide $1,1 \mathrm{~cm}$.

Detalle del retoque

El retoque es en todos los casos irregular. Los ángulos del retoque se encuentran entre los $65^{\circ}$ y $75^{\circ}$. La posición es directa en 4 piezas e invertida en una de ellas. La extensión del retoque es corto en 3 de los raspadores, largo en uno y restringido en el ultimo. Todos los filos presentan retoque continuo con profundidad marginal. 
Filos largos retocados (raederas)

Las raederas $n=3$, están confeccionadas sobre riolita y corresponden al tipo raedera lateral simple. En cuanto al estado de las piezas no presentan alteraciones como pátinas o termoalteración por exposición al fuego o altas temperaturas, ni rastros macroscópicos como adherencias o concreciones, sólo una presenta fragmentación de tipo 1.

En cuanto a los tamaños una se ubica dentro de los artefactos largos mientras que las otras dos corresponden a medianos. A partir de los módulos de $L A$ y $A E$, podemos considerar a la raedera de mayor tamaño como un instrumento largo y delgado, mientras que los otros dos pertenecen al grupo de longitud y grosor intermedio.

En relación con lo anterior, el soporte donde se formatizó la raedera de mayor longitud corresponde a una lámina, mientras que las otras se confeccionaron sobre lascas, de las cuales una presenta forma oblicua, desde la perspectiva de la cara dorsal, mientras que las formas alargadas se reservan para las dos restantes.

Las 3 piezas se presentan planas, con ausencia de accidentes de talla y bulbos difusos. Los labios están ausentes en dos raederas, en una por talla y en la otra por su característica plana en la cara ventral. La restante presenta un labio normal.

En cuanto a los talones, sólo están presentes en dos de las piezas, uno facetado y oblicuo (lámina) y uno liso y recto. Ambos casos presentan evidencias de preparación de talones.

Detalle de los filos

Cada instrumento presenta un filo, dos de ellos izquierdos y uno derecho, el primero presenta una delineación recta, una sección longitudinal sinuosa y una longitud de $7,5 \mathrm{~cm}$. En el segundo filo la delineación es convexa y la sección longitudinal recta, la longitud del mismo es de $4,2 \mathrm{~cm}$. El filo derecho presenta la misma delineación y sección longitudinal y la longitud alcanza los $6 \mathrm{~cm}$. 
Detalle del retoque

En todos los casos el retoque es irregular, de posición directa y con retoques continuos y marginales a lo largo del filo. Dos de los filos son largos y uno restringido. Los filos presentan ángulos que van de los $40^{\circ}(n=1)$ a los $60^{\circ}$ $(n=2)$.

\section{Cristales de cuarzo}

Durante la excavación llamó la atención la presencia de varios cristales prismáticos de cuarzo hialino. El conjunto está compuesto por 8 cristales prácticamente enteros y de gran tamaño, piramidales y bipiramidales de entre 2 y $5 \mathrm{~cm}$. Todos ellos presentan evidencias de impactos en ambos extremos, lo que nos permite inferir que fueron sometidos a la técnica de talla bipolar (Figura 10.2).

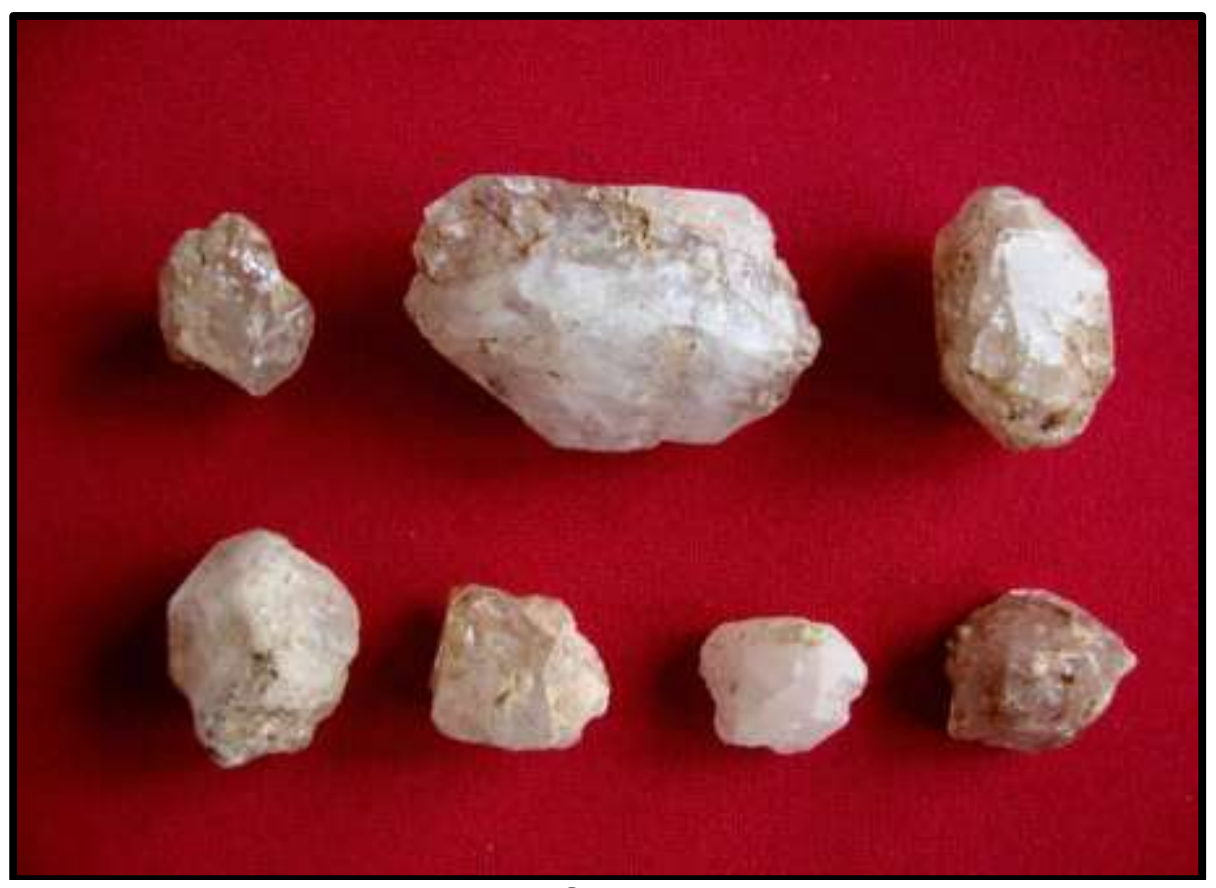

Figura 10. 2 . Cristales de cuarzo

\section{Análisis funcional}

El análisis funcional se llevó a cabo siguiendo la metodología expuesta, de la misma forma que se efectuó el del sitio Kami 1. Se utilizó una lupa binocular y un microscopio metalográfico, ya que la utilización de ambos equipos es indispensable para un análisis funcional completo. 
En general las piezas presentaban, a nivel microscópico, alteraciones con presencia de pátinas blanquecinas o amarillentas, las cuales hicieron dificultoso el análisis funcional.

\section{Raspadores}

Como mencionamos los raspadores ascienden a $n=5$, de los cuales dos presentaban diversos filos llegando a ocho. Los resultados del análisis funcional permitieron determinar uso seguro en 2 de los filos, uso probable en 3 de ellos y los 3 restantes no presentaron evidencias de uso. La falta de evidencia de uso de una pieza puede deberse a que efectivamente no haya sido utilizada, o porque las alteraciones impiden ver cualquier indicio de uso.

Para los casos de uso seguro, la cinemática de trabajo es transversal al filo, con un ángulo de trabajo intermedio a recto. Este modo de uso inferido por las características y disposición de los rastros de uso sobre filo y caras es indicativo de tareas de raspado.

El material trabajado por estos dos raspadores es madera, sin indicios de agregados de abrasivos. Los filos presentan redondeamiento, así como micropulidos que dan la sensación de volumen y que se encuentran ocupando principalmente zonas altas de la microtopografía, pero también parte de zonas bajas (Figura 10.3). Hay presencia de estrías y el micropulido es muy brillante, con colmatación en microporosidades. 


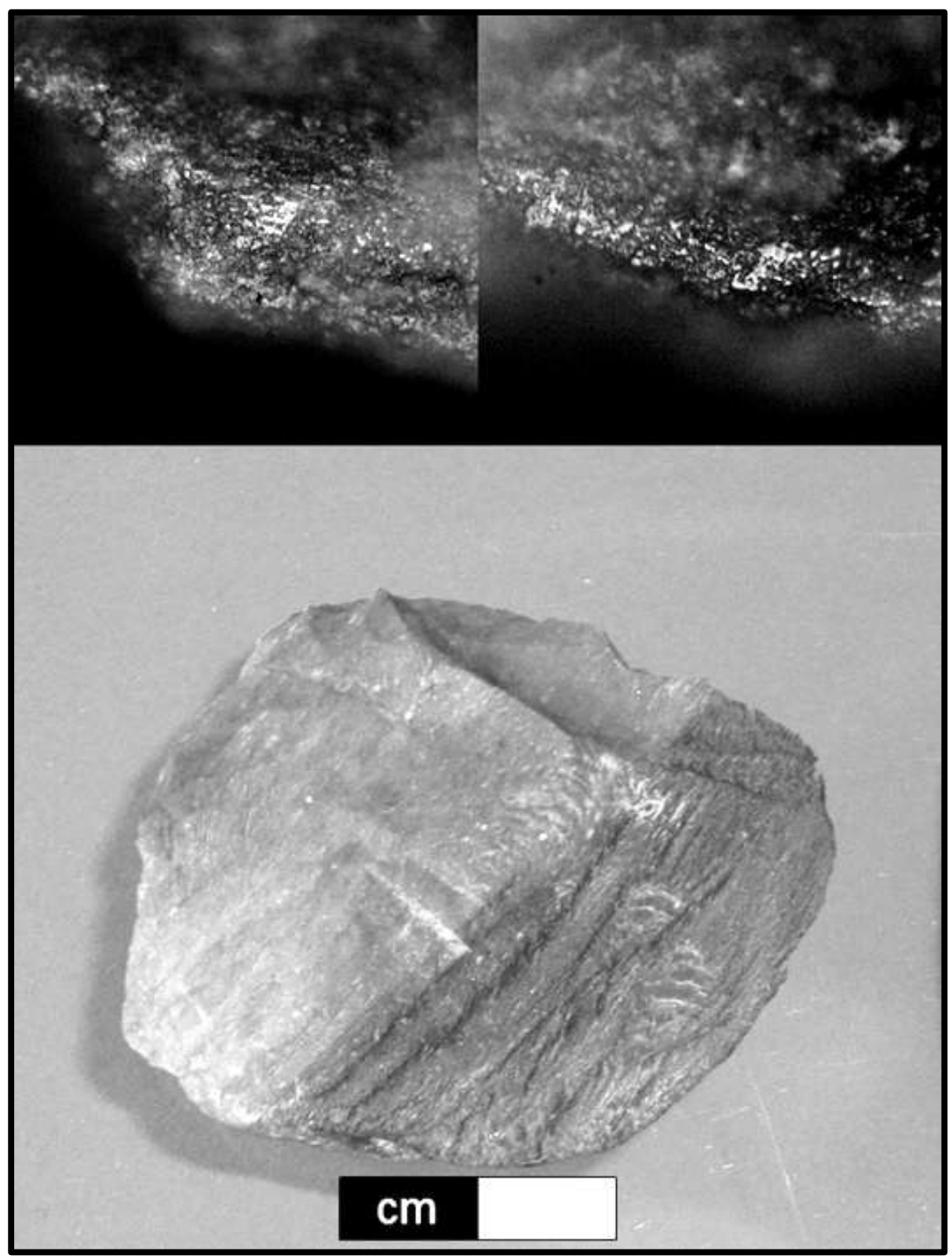

Figura 10. 3. Raspador con micropulido de trabajo transversal en madera. Micrifitigrafía tomada a 200X

En estas dos piezas no se observaron rastros que puedan ser atribuidos al uso de enmangues, como así tampoco de reactivación de los filos.

En cuanto a los raspadores con utilización probable, en uno de los casos el instrumento presenta pequeños sectores redondeados hacia los laterales del filo, pero en la zona central éste se evidencia fresco y con un ángulo casi recto; tiene además mucho microesquirlamiento y microlascas adventicias que no alcanzaron a desprenderse. Estas características podrían estar indicando reactivación del filo, actividad que al eliminar parte del filo, elimina también los 
rastros de uso. En cuanto al filo izquierdo, natural, éste no muestra evidencias de alteración por uso.

Otro de los raspadores presenta poco redondeamiento en el filo frontal y algunas estrías. Esto podría deberse a un instrumento con poco uso y por lo tanto escaso desarrollo de microrrastros, pero además la pieza está un poco alterada por pátina. En cuanto al filo izquierdo, natural, podría presentar algún indicio de corte pero, al igual que en filo frontal, los rastros están muy poco desarrollados por lo que no es posible asegurar su uso. El filo derecho, también natural, no presenta ningún tipo de evidencias de uso.

Finalmente el raspador que se suma al conjunto de los no utilizados, se trata de un instrumento con filo distal, el cual no presenta alteración por uso, el análisis mostró un filo fresco, cuyos cristales no presentaban ningún tipo de modificación causada por la utilización.

\section{Filos largos retocados}

El conjunto de filos largos retocados (raederas) está compuesto por tres artefactos con un filo cada uno. De estos, sólo en un caso pudo determinarse uso probable.

Se trata de un filo donde pueden verse pequeñas estrías con dirección longitudinal, que presenta un leve redondeamiento principalmente en las zonas elevadas. Sin embargo, en el lado opuesto al filo retocado hay un pequeño filo que se continúa con el otro, que es extendido, cuya terminación es sin retoque. Sobre este filo las evidencias de uso son más notorias, especialmente son estrías abundantes y un mayor redondeamiento del filo. El material trabajado podría ser de origen vegetal, sin embargo no puede determinarse con seguridad, aunque sí la cinemática, que es longitudinal al filo.

En los otros dos casos, los filos sólo presentan pequeños microesquirlamientos y ligero redondeamiento, pero estos rastros no son suficientes para atribuirlos a utilización.

\section{Lascas con filos potencialmente utilizables}

El total de lascas con filos potenciales es de $n=15$. Todas ellas fueron analizadas microscópicamente, sin embargo ninguna presentó evidencias de haber sido utilizada. 


\section{LOS MATERIALES DE LA CUADRÍCULA AT 17}

El conjunto recuperado en la cuadrícula AT-17, cuadrante NO (ver capítulo 4) ubicada en el sector oeste del sitio, consta de 109 artefactos líticos, principalmente fragmentos y lascas, que constituyen el $91 \%$ del conjunto, en tanto que el $9 \%$ restante se divide entre núcleos $n=4$ (entre enteros y fragmentados), fragmentos de instrumentos $n=2$, raspador $n=1$ y lasquitas $n=$ 2 (Tabla 10.10).

\section{Análisis tecno-morfológico}

En cuanto a la relación de los tipos de artefactos y materias primas, se debe consignar que la riolita es la materia prima más abundante y con mayor diversidad artefactual, ya que presenta 43 fragmentos, 34 lascas, 2 fragmentos de instrumento, y 4 núcleos (1 apical, 1discoidal, 2 núcleos fragmentados). La cinerita se encuentra representada por 9 lascas, 5 fragmentos y 2 lasquitas. Continúa el chert con 4 fragmentos, mientras que sobre lutita, cuarzo y calcedonia sólo hay una lasca de cada una. Finalmente 2 lascas y un raspador, cuya materia prima no pudo determinarse (Tabla 10.10).

\begin{tabular}{|c|c|c|c|c|c|c|c|c|}
\hline Tipos/materia prima & Calcedonia & Chert & Cinerita & Cuarzo & Indet. & Lutita & Riolita & Total \\
\hline Fragmento & & 4 & 5 & & & & 43 & 52 \\
\hline Lasca & 1 & & 9 & 1 & 2 & 1 & 34 & 48 \\
\hline lasquita & & & 2 & & & & & 2 \\
\hline Núcleo apical & & & & & & & 1 & 1 \\
\hline Núcleo discoidal & & & & & & & 1 & 1 \\
\hline Núcleo fragmentado & & & & & & & 2 & 2 \\
\hline Raspador simple & & & & & 1 & & & 1 \\
\hline Fto. De instrumento & & & & & & & 2 & 2 \\
\hline Total & 1 & 4 & 16 & 1 & 3 & 1 & 83 & 109 \\
\hline
\end{tabular}

Tabla 10. 10. Tipos tecnológicos de Kami 7, AT 17

La conservación en general es buena en $n=59$, sin embargo existen algunas piezas con alteraciones por alta temperatura $n=19$, piezas que presentan pátinas $\mathrm{N}=28$, y 3 que presentan líquenes sobre la superficie.

En cuanto al grado de fragmentación, $n=52$ corresponden a fragmentos, $\mathrm{n}=38$ corresponden a piezas fragmentadas (de los cuales 32 corresponden a lascas fragmentadas, 2 a fragmentos de instrumento, 3 a núcleos 
fragmentados), mientras que las piezas enteras ascienden a $n=18$. El raspador presenta un fractura lateral.

En cuanto a las dimensiones del conjunto éste muestra principalmente piezas de longitud y grosor medio $n=17$, y piezas cortas y delgadas $n=16$; continúan luego las cortas de grosor medio $n=10$, y las de longitud media y gruesas $n=7$. Tanto las piezas cortas y gruesas como las de longitud intermedia y delgadas, así como las largas de grosor medio, presentan $n=2$ cada una; por ultimo sólo hay una pieza larga y delgada.

\section{$\underline{\text { Lascas }}$}

Los tipos de lasca (o soportes) que se pueden diferenciar dentro del conjunto son las lascas $n=47$ (en riolita $n=33$, cinerita $n=10$, no determinada $n=2$, lutita y cuarzo $n=1$ ), luego un artefacto sobre lámina (en riolita), lasca primera de descortezamiento $n=1$ (en riolita) y lasca sobrepasada $n=1$ (en calcedonia) (Tabla 10.11).

\begin{tabular}{|l|r|r|r|r|r|r|r|}
\hline Soportes/materia prima & Calcedonia & Cinerita & Cuarzo & Indet. & Lutita & Riolita & Total \\
\hline Lámina & & & & & & 1 & 1 \\
\hline Lasca & & 10 & 1 & 2 & 1 & 33 & 47 \\
\hline Lasca de descortezamiento & & & & & & 1 & 1 \\
\hline Lasca sobrepasada & 1 & & & & & & 1 \\
\hline Total & $\mathbf{1}$ & $\mathbf{1 0}$ & $\mathbf{1}$ & $\mathbf{2}$ & $\mathbf{1}$ & $\mathbf{3 5}$ & $\mathbf{5 0}$ \\
\hline
\end{tabular}

Tabla 10. 11. Relación entre soportes utilizados y materia prima

La corteza está ausente en el $65 \%$ de las lascas, el $35 \%$ restante se encuentra dividido entre aquellas con presencia corteza parcial con el $17 \%$, lascas con escasa, abundante y muy abundante presencia de corteza con un $6 \%$ cada una.

Hay 5 lascas que presentan filos potencialmente utilizables. Se trata de un grupo de lascas enteras de las cuales 3 son de riolita (dos corresponden a piezas cortas y delgadas, mientras que la restante es larga y gruesa), una de cinerita (corta y delgada) y una de calcedonia (larga y de grosor intermedio).

En cuanto a la conservación de las piezas, dos presenta alteraciones. Una de ellas con evidencia de termoalteración por alta temperatura y otra con presencia de pátina blanca. De las 5 piezas sólo una presenta fractura en el extremo distal. 
Los filos se agrupan en distales $n=3$, izquierdos $n=2$ y derecho $n=1$. Sólo la lasca de calcedonia presenta dos filos ubicados lateralmente. En cuanto a la forma de los filos 2 son convexos, 3 rectos y uno cóncavo. Los ángulos se encuentran dentro del rango de los $30^{\circ}$ a los $40^{\circ}$ y las longitudes pueden agruparse entre las que rondan los $2,5 \mathrm{~cm} \mathrm{n}=4$ y las que superan los $4 \mathrm{~cm} \mathrm{n=}$ 2.

\section{$\underline{\text { Instrumentos }}$}

Raspador

Como mencionamos arriba este conjunto lítico contiene sólo un raspador, que corresponde al tipo raspador simple, y dado que su largo máximo es inferior a los $2 \mathrm{~cm}$ pertenece a la categoría micro-raspador, con un filo lateral. En relación a las dimensiones, según los módulos LA/AE corresponde a una pieza corta y gruesa.

Debido a la fractura que presenta no fue posible determinar el talón, bulbo o labio, como así tampoco el tipo de soporte sobre el que fue confeccionado. En relación a la conservación del material, presenta evidencia de termoalteración por fuego.

El filo es corto y convexo con una longitud de $1,8 \mathrm{~cm}$ y un ángulo de $65^{\circ}$. La sección longitudinal del filo es de tipo sinuosa. El retoque es irregular y continuo a lo largo de todo el filo y de posición directa, la profundidad lo acerca a un retoque marginal.

Fragmentos de instrumento

Los dos fragmentos corresponden a un mismo instrumento, que remontan entre sí. El mismo está confeccionado sobre riolita y presenta signos de termoalteración por fuego. De hecho, las fracturas presentes no parecen estar relacionadas con accidentes de talla sino con la exposición a alta temperatura.

Si bien los dos fragmentos pudieron remontarse, la pieza está incompleta por lo que no podemos hacer inferencias en cuanto a las dimensiones. Sin embargo, podemos decir que el filo corresponde a un filo 
recto y de sección longitudinal también recta. El retoque es irregular y de posición directa, continuo, marginal y presenta un ángulo de $50^{\circ}$.

\section{Análisis funcional}

El análisis funcional de los instrumentos no reveló la presencia de rastros de utilización. Esto puede ser debido a las alteraciones por alta temperatura que se observaban incluso macroscópicamente.

\section{DISCUSIÓN: LOS MATERIALES EXCAVADOS DE KAMI 7}

Como se desprende de este análisis, el conjunto lítico proveniente de las excavaciones en el sitio Kami 7 presenta algunas características interesantes en cuanto a materias primas, artefactos retocados y restos de talla.

En primer lugar, las materias primas representadas en los dos subgrupos (mayores y menores a $2 \mathrm{~cm}$ ), son la riolita y la cinerita. Este orden corresponde al primer subgrupo, mientras que se invierte para los elementos menores a $2 \mathrm{~cm}$. Aquí las cineritas no sólo ocupan el primer lugar, sino que la diferencia es muy grande, en tanto que la riolita se acerca más a la cantidad de restos de talla en lutita. El cuarzo es la materia prima que menos representada, está dentro de este subgrupo.

En cuanto a las materias primas de los artefactos mayores a $2 \mathrm{~cm}$, como se mencionó, las riolitas son las más abundantes con un $73 \%$ y luego las cineritas con un $21 \%$. El resto corresponde a calcedonia, basalto y pizarra.

Sin embargo, un elemento llamativo del conjunto lítico es la presencia de algunos cristales de cuarzo que, aunque están enteros, presentan evidencias de talla bipolar en sus extremos. Llama la atención que tanto instrumentos como restos menores a $2 \mathrm{~cm}$ sobre cuarzo, casi no se encuentran en el conjunto y que estos cristales hayan sido abandonados aun cuando podían ser explotados. El abandono puede explicarse por las múltiples fracturas internas que presentan algunos cristales que impediría extraer algún producto útil para la confección de un instrumento. 
Otro elemento llamativo de este conjunto son los restos de talla de vidrio, todos menores a $2 \mathrm{~cm}$; los más abundantes son las lasquitas, aunque están representados todos los tipos.

Ahora bien, volviendo al tema de las materias primas locales, riolita y cinerita, es importante mencionar esta inversión entre unas y otras según se trate de un subgrupo $u$ otro. Tanto los núcleos como los instrumentos, las lascas y los fragmentos están representados principalmente en riolita, y luego (en restos de talla y un fragmento de instrumento) en cinerita. En cambio en todos los tipos tecnológicos menores a $2 \mathrm{~cm}$ (lasquitas, debris, microlascas y microfragmentos) la materia prima preponderante, y por mucho, es la cinerita. En relación con esta materia prima, puede verse que los restos de talla son superiores a los restos de retalla o retoque.

Una explicación posible, en relación a la calidad de esta materia prima para la talla, que es superior generalmente a la riolita, podría estar asociada con una estrategia de tipo conservada. De esta forma en el sitio se podrían estar confeccionando formas base (restos de talla) o instrumentos (restos de retalla o retoque) que no se abandonaran tan fácilmente como aquellos en riolita, que además es más abundante entre los guijarros costeros del lago. Esto queda evidenciado, además, por el bajo porcentaje de lascas y fragmentos con corteza.

Lo mismo ocurre con la lutita y el vidrio, que presentan un número considerable de elementos menores a $2 \mathrm{~cm}$, principalmente debris y lasquitas, pero no está representada en ningún artefacto mayor a $2 \mathrm{~cm}$.

Por otro lado, en cuanto a la riolita, esta se presenta como la materia prima más abundante del subgrupo mayor a $2 \mathrm{~cm}$, y como la segunda más abundante en los menores, fundamentalmente entre aquellos comprendidos entre 2 a $0,5 \mathrm{~cm}$. incluso en relación con la presencia de corteza tanto en lascas como en fragmento es superior que en el caso de las cineritas.

Desde el punto de vista tecno-morfológico el conjunto no posee una gran diversidad. La baja diversidad puede estar relacionada con las características mencionadas arriba, dado que las materias primas representadas en los artefactos es básicamente la misma, riolita. Además, los resultados del análisis funcional demostraron trabajo sobre material de origen vegetal, para los 
instrumentos representados en este sitio. Ello también puede estar influyendo en la búsqueda de una morfología determinada.

En resumen el conjunto lítico excavado en el sitio Kami 7 presenta diferencias significativas en cuanto a la presencia de materias primas en relación con los tamaños de los artefactos, una baja diversidad artefactual en relación con lo anterior y con la funcionalidad a la que se destinaron los instrumentos.

\section{LOS MATERIALES DE RECOLECCIÓN SUPERFICIAL}

Este conjunto proviene de la recolección superficial llevada a cabo durante el desarrollo del estudio distribucional, que luego se completó con la recolección sistemática de la totalidad del material de superficie según el reticulado de cuadrículas del sitio. El material recuperado a partir de estos trabajos se caracteriza por artefactos mayores a $2 \mathrm{~cm}$, pero también numerosos elementos entre 2 y $5,0 \mathrm{~cm}$.

El conjunto está constituido principalmente por elementos de talla por percusión directa como núcleos, lascas, fragmentos, instrumentos retocados, lasquitas y debris. Los artefactos de talla bipolar son muy escasos (Figura 10.12) 


\begin{tabular}{|c|c|c|c|c|c|c|c|c|c|c|c|c|c|c|c|c|c|c|c|c|c|c|c|c|c|c|c|c|c|c|c|c|c|c|}
\hline \multirow[b]{3}{*}{ 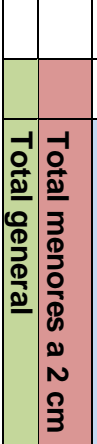 } & \multicolumn{8}{|c|}{ Menores a $2 \mathrm{~cm}$} & & & \multicolumn{24}{|c|}{ Mayores a $2 \mathrm{~cm}$} \\
\hline & \multicolumn{5}{|c|}{ No retocados } & \multicolumn{3}{|c|}{ Retocados } & \multirow{2}{*}{\multicolumn{2}{|c|}{ 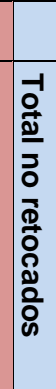 }} & \multicolumn{13}{|c|}{ No retocados } & \multirow[b]{2}{*}{ 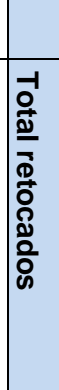 } & \multicolumn{9}{|c|}{ Retocados } & \multirow[b]{2}{*}{ 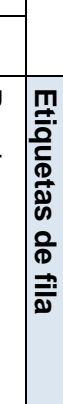 } \\
\hline & 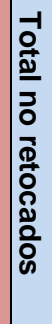 & . & 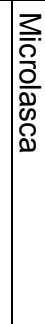 & 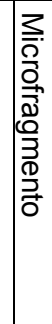 & 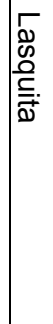 & 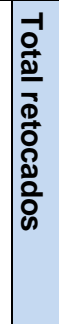 & 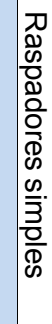 & 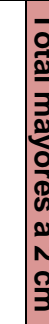 & & & 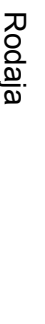 & 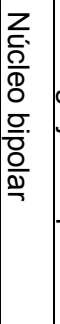 & 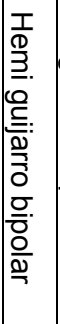 & 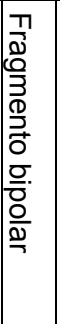 & 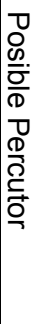 & 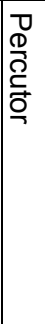 & 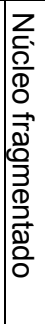 & 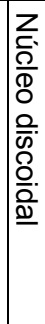 & 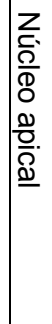 & 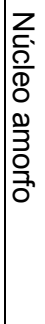 & 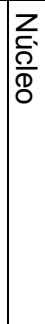 & 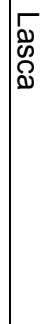 & 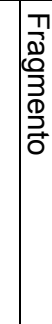 & & 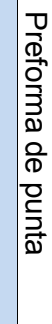 & 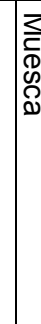 & . & 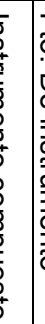 & 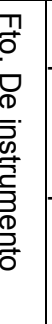 & 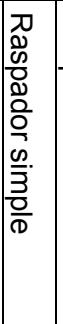 & 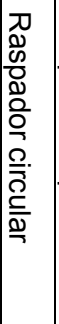 & 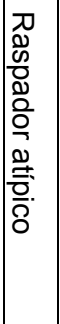 & & \\
\hline ـ & & & & & & & & - & + & & & & & & & & & & & & & & & - & & & & & & & & & - & 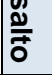 \\
\hline$\vec{a}$ & n & $\rightarrow$ & & & $\rightarrow$ & & & f & i & $\vec{N}$ & & & & & & & & $\rightarrow$ & & & $\rightarrow$ & os & A & N & & & & & $\rightarrow$ & $\rightarrow$ & & & & స్. \\
\hline $0 \rightarrow$ & $\rightarrow$ & n & & & n & & & n & 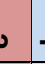 & - & & & & $\rightarrow$ & & & & & & & & & & - & & & & & & $\rightarrow$ & & & & $\frac{\overline{\underline{0}}}{\underline{7}}$ \\
\hline مீ & $\mathscr{v}$ & $y$ & 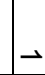 & $\rightarrow$ & $\mathscr{\infty}_{\infty}^{\omega}$ & & & ¿ & $i$ & స & & & & & & & $\omega$ & & & & & $\mathscr{\infty}_{\infty}$ & $\stackrel{\Delta}{ }$ & $v$ & & & & $\Delta$ & N & $\rightarrow$ & & - & n & $\frac{\Phi}{\bar{\Phi}}$ \\
\hline $0 \rightarrow$ & $\rightarrow$ & N & & & n & & & n & 1 & N & & & & & & & & & & & & & n & & & & & & & & & & & స్ \\
\hline $\mathrm{N}$ or & or & $\omega$ & & & n & & & $\hat{n}$ & 0 & N & & & $\rightarrow$ & & N & $\rightarrow$ & & & & & & or & $\vec{\omega}$ & & & & & & & & & & & $\frac{0}{0}$ \\
\hline$v$ & & & & & & & & - & $\mathrm{s}$ & $\sigma$ & & & & & & & & & & & & N & $A$ & 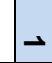 & & & & & $\rightarrow$ & & & & & $\bar{\Xi}$ \\
\hline ه & & & & & & & & - & c & or & $\rightarrow$ & & & & & & & & & & & & 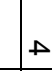 & - & & - & & & & & & & & $\frac{\$}{2}$ \\
\hline$\hat{a} \omega$ & $\omega$ & $N$ & & & $\vec{A}$ & - & 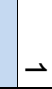 & ¿े & $\dot{q}$ & $\vec{\bullet}$ & & & & & & $\rightarrow$ & $\vec{v}$ & $\rightarrow$ & $\omega$ & $\Delta$ & or & $\stackrel{A}{A}$ & 8 & $\vec{\omega}$ & $\rightarrow$ & & & & $\omega$ & $\infty$ & $\Delta$ & & N & 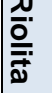 \\
\hline$v-$ & & & & & & - & $\rightarrow$ & o & c & or & & - & & $\rightarrow$ & & & & & & & & n & $\rightarrow$ & - & & & & & & & & $\rightarrow$ & & $\overline{\overline{\bar{D}}}$ \\
\hline- & & & & & & & & - & t & - & & & & & & & & & & & & $\rightarrow$ & & & & & & & & & & & & 흠. \\
\hline 컹ํㅇ & $\vec{\infty}$ & $\stackrel{\infty}{v}$ & 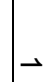 & $\rightarrow$ & சु & N & N & $\vdots$ & $\vec{J}$ & 島 & $\rightarrow$ & $\rightarrow$ & - & N & N & $n$ & N & N & $\omega$ & $A$ & o & $\stackrel{+}{\infty}$ & $\overrightarrow{~ ज ु ~}$ & v & $\rightarrow$ & - & & د & $v$ & 0 & $\rightarrow$ & $n$ & or & 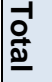 \\
\hline 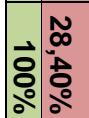 & œ & & & & & 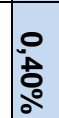 & & D & 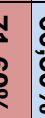 & 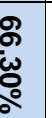 & & & & & & & & & & & & & & $\begin{array}{l}\widetilde{\omega} \\
\stackrel{\omega}{\circ} \\
0\end{array}$ & & & & & & & & & & $0^{\circ}$ \\
\hline
\end{tabular}


El subgrupo mayor a $2 \mathrm{~cm}$, sin contar los restos de talla bipolar, es el más numeroso con un $n=$ de 357 artefactos que podemos agrupar de la siguiente manera: lascas $n=148$, fragmentos $n=159$, núcleos y núcleos fragmentados $n=35$, instrumentos retocados $n=23$ y fragmentos de instrumentos $n=7$.

Las materias primas representadas en este subgrupo son las riolitas con un $55 \%$, luego las cineritas con el 31\%, en tercer lugar aparecen las calcedonias con un $4 \%$, seguida por pizarra y lutita con un $2 \%$ cada una. El cuarzo, vidrio y basalto sumados apenas llegan al 1\%. Un 5\% corresponde a materias primas que no pudieron ser determinadas (Gráfico 10.5).

\section{Porcentaje de materias primas}

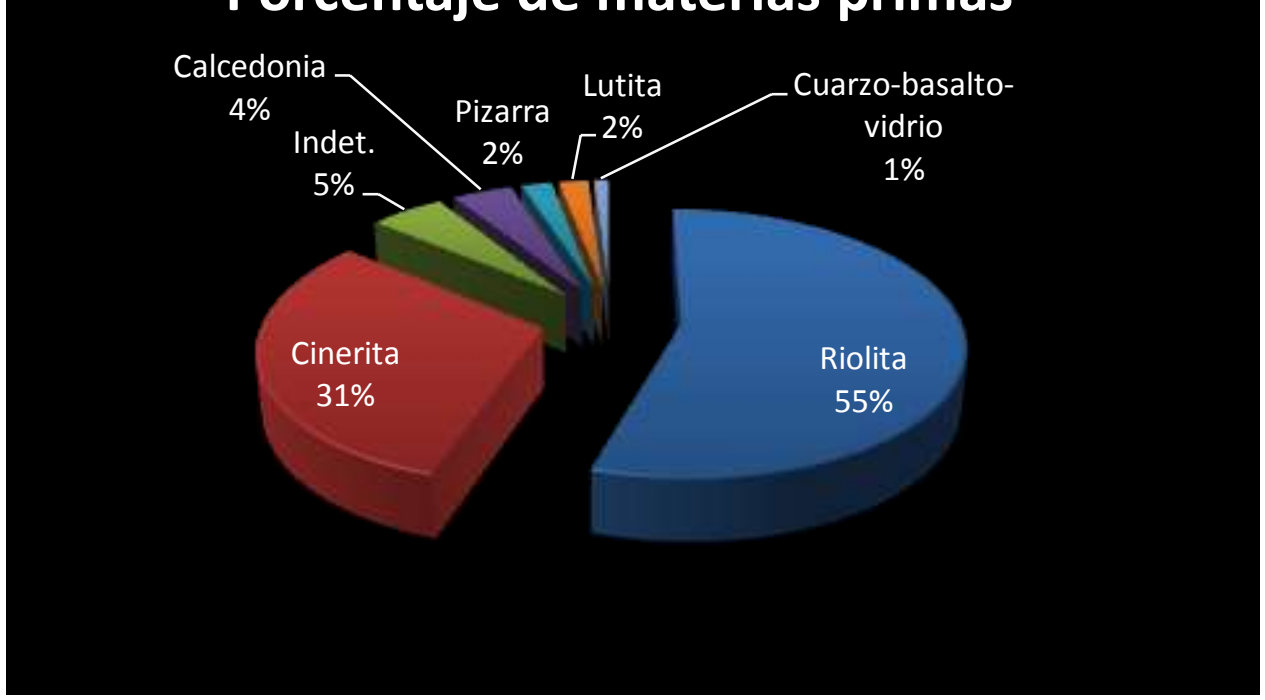

Gráfico 10. 5. Porcentajes de materias primas en artefactos mayores a $2 \mathrm{~cm}$

El subgrupo menor a $2 \mathrm{~cm}$ comprende los debris con $\mathrm{n}=87$, lasquitas con $n=59$, un microfragmento y una microlasca. Aquí, tal como en el caso de los materiales de excavación, las materias primas se ordenan casi de forma inversa que en el subgrupo anterior. Las cineritas ocupan el primer lugar con un $66 \%$, las riolitas comprenden el $24 \%$ de la muestra, mientras que los cuarzos y el chert ocupan un $3 \%$ cada uno, la calcedonia aparece en último lugar con $1 \%$ (Gráfico 10.6). 


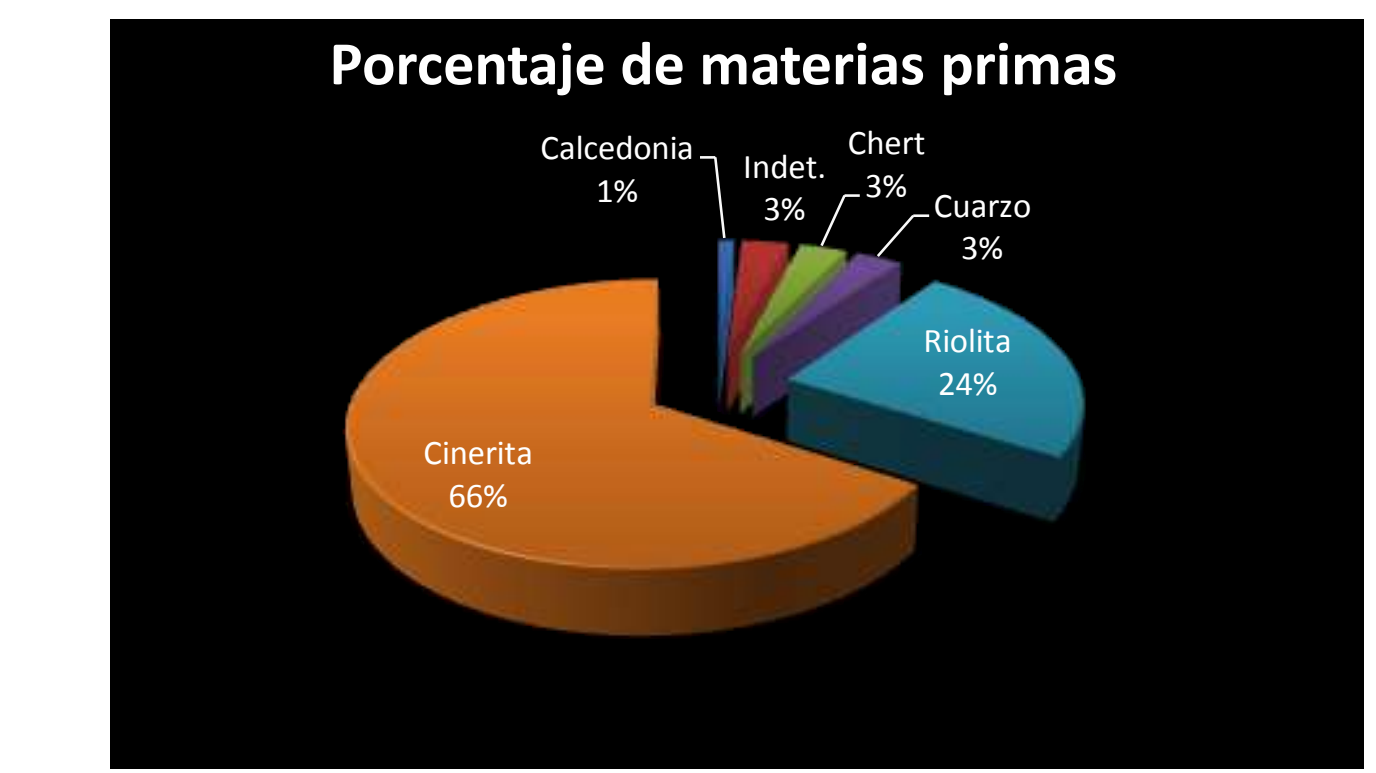

Gráfico 10. 6. Porcentajes de materias primas en artefactos menores a $2 \mathrm{~cm}$

Los materiales bipolares están representados por 3 fragmentos, 2 lascas, un hemiguijarro, un núcleo y un raspador simple. En cuanto a las materias primas, 5 corresponden a sílex, 2 a chert y una no pudo ser determinada.

\section{Análisis tecno-morfológico}

Núcleos

El total de núcleos es de $n=35$, estos se dividen entre enteros $y$ fragmentados, siendo estos últimos los más abundantes con $n=20$, luego entre los enteros tenemos amorfos $n=10$, apicales $n=3$ y discoidales $n=2$.

En cuanto a las materias primas en relación con los tipos de núcleos, vemos que la riolita representa a todos, principalmente los núcleos fragmentados $n=17$, luego los amorfos $n=9$, los apicales y uno de los discoidales. La cinerita aparece en segundo término con núcleos fragmentados $\mathrm{n}=3$ y finalmente la calcedonia con un núcleo discoidal y uno amorfo.

Prácticamente la mitad presentan algún grado de alteración, como por ejemplo pátinas o presencia de líquenes en la superficie. Los núcleos con patina blanquecina o amarillenta son $n=11$, mientras que los que presentan no sólo pátinas sino también la adherencia de líquenes de tipo crustoso son $n=5$ (Dra. Irene Garibotti com. pers.) (Figura 10.4). 


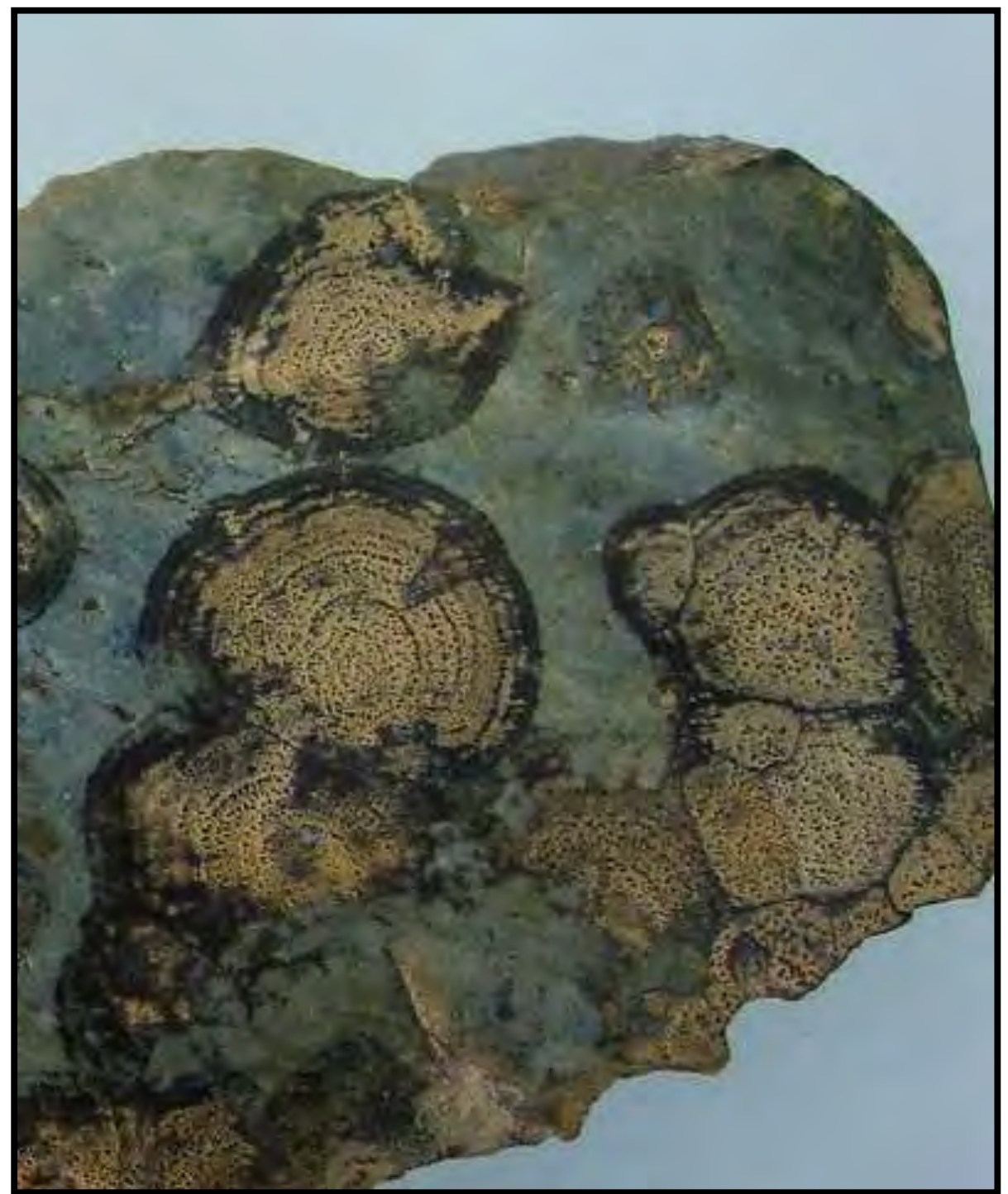

Figura 10. 4. Líquenes crustosos presentes en las piezas superficiales

Las riolitas presentan un $45 \%$ de piezas alteradas principalmente por pátinas; la cinerita presenta dos piezas en buen estado de conservación y una con pátina. Entre los núcleos de calcedonia uno muestra patina blanquecina, mientras que el otro tiene líquenes en la superficie.

Los soportes en general no pudieron ser determinados por el grado de fragmentación de las piezas. Sin embargo, de los núcleos de riolita, al menos 8 corresponden a guijarros costeros en función de su morfología y de los restos de corteza presente en estos artefactos.

En cuanto a la presencia de corteza, 4 carecen por completo de ella. El resto, salvo dos que no pudieron determinarse, presentan algún porcentaje de corteza. De mayor a menor presencia, y en relación a la materia prima, podemos mencionar el siguiente orden: abundante corteza $n=11$, de los cuales 
9 son de riolita y 2 de calcedonia; corteza parcial $n=8,6$ de riolita y 2 de cinerita; escasa corteza $n=7$ todos de riolita, y corteza muy abundante $n=3,2$ de riolita y uno de cinerita.

Tomando los módulos LA y AE, podemos caracterizar a los núcleos como piezas de longitud intermedia, con espesores gruesos $n=16 \mathrm{e}$ intermedios $n=10$, luego aparecen algunos cortos y gruesos $n=4$ y cortos con espesor intermedio $n=2$, al igual que los núcleos largos con espesor grueso. Según el largo máximo de la pieza podemos agruparlos en medianos $n=9$, grandes $n=18$ y muy grandes $n=7$. En relación a esto, se pueden contabilizar más núcleos con posibilidades de seguir siendo utilizados que núcleos agotados.

\section{$\underline{\text { Lascas }}$}

Es un conjunto formado por 146 lascas, de las cuales el $51 \%$ de riolita, el $40 \%$ de cinerita, un $4 \%$ de calcedonia; lutita y vidrio un $1 \%$ para cada uno. Un $3 \%$ corresponde a materias primas no determinables.

Del total de lascas, casi la mitad presentan buen estado de conservación, el resto presentan algún tipo de pátina blanca o amarillenta como se ve a continuación: líquenes en la superficie $n=20$ y rastros de oxidación $n=$ 1. En cuanto a la fragmentación de las lascas el $38 \%$ se encuentran enteras, el resto presentan grados tipo 1 de fragmentación.

\section{Corteza}

La corteza se encuentra totalmente ausente en el $56 \%$ de lascas, mientras que la presencia parcial y muy abundante de corteza es del $13 \%$ cada una, con el $8 \%$ se encuentran aquellas lascas con escasa presencia de corteza y con abundante corteza el $7 \%$. Sólo en el 3\% no pudo determinarse la presencia de corteza.

La relación entre materias primas y corteza, se presenta de la siguiente forma: en riolita las más abundantes son las lascas sin corteza. En segundo lugar, lascas con corteza muy abundante, en tanto que las lascas con corteza abundante y parcial ocupan el tercer lugar. Al final se encuentran aquellas con corteza escasa. Para cinerita, las más abundantes también son las lascas sin corteza, en segunda instancia se encuentran aquellas con corteza parcial, 
luego figuran las lascas con corteza escasa seguidas por las que presentan muy abundante porcentaje de corteza y finalmente las piezas con corteza abundante.

En cuanto a las materias primas, la calcedonia está representada por 3 lascas con corteza parcial, 2 sin corteza y una con corteza escasa. Las lutitas son sólo dos lascas, una sin corteza y otra con abundante corteza. En cuanto a la lasca de vidrio, ésta no presenta corteza (Tabla 10.13).

\begin{tabular}{|l|r|r|r|r|r|r|r|}
\hline $\begin{array}{l}\text { Materia prima/ } \\
\text { corteza }\end{array}$ & Indet. & Abundante & Escasa & Muy abundante & Parcial & No presenta & Total \\
\hline Vidrio & & & & & & 1 & 1 \\
\hline Lutita & & 1 & & & & 1 & 2 \\
\hline Indet. & 2 & & & & 1 & 2 & 5 \\
\hline Calcedonia & & & 1 & & 3 & 2 & 6 \\
\hline Cinerita & & 2 & 6 & 5 & 8 & 37 & 58 \\
\hline Riolita & 3 & 7 & 5 & 14 & 7 & 38 & 74 \\
\hline Total & 5 & 10 & 12 & 19 & 19 & $\mathbf{8 1}$ & 146 \\
\hline
\end{tabular}

Tabla 10. 13. Relación entre presencia de corteza y materia prima

Filos potencialmente utilizables

Las lascas que presentan filos potencialmente utilizables son $n=9$. Las materias primas representadas en estas lascas son riolita $n=4$ entre las cuales hay dos izquierdos, uno derecho y uno distal; cinerita también con $n=4$, pero con dos filos distales, uno derecho y otro izquierdo; calcedonia sólo una lasca con filo derecho (Tabla 10.14).

\begin{tabular}{|l|r|r|r|r|}
\hline Filos & Derecho & Distal & Izquierdo & \multicolumn{1}{l|}{ Total } \\
\hline Calcedonia & 1 & & & 1 \\
\hline Cinerita & 1 & 2 & 1 & 4 \\
\hline Riolita & 1 & 2 & 1 & 4 \\
\hline Total & $\mathbf{3}$ & $\mathbf{4}$ & $\mathbf{2}$ & $\mathbf{9}$ \\
\hline
\end{tabular}

Tabla 10. 14. Ubicación de filos potencialmente utilizables

\section{Dimensiones}

Las dimensiones del conjunto, tomando los módulos LA y AE, agrupan principalmente lascas cortas y delgadas con $\mathrm{n}=60$, cortas y de grosor intermedio $n=40$, en menor medida cortas y gruesas $n=7$. Las piezas de longitud intermedia se encuentran en el segundo lugar repartidas entre 
delgadas $n=9$, de grosor intermedio $n=19$ y gruesas $n=8$. En cuanto a las lascas largas sólo hay 3 que presentan grosor intermedio.

En relación con las materias primas vemos que las riolitas, si bien muestran una mayor dispersión entre las dimensiones, se concentran más hacia piezas cortas y poco anchas y luego entre las de longitud y grosor intermedio. Las cineritas son principalmente cortas y poco anchas.

Las lascas representadas por las demás materias primas son generalmente cortas y poco anchas, salvo en calcedonia donde se incluyen lascas de dimensiones intermedias.

\section{Fragmentos}

Los fragmentos alcanzan un $n=156$. Estos corresponden principalmente a riolita $n=89$, en segundo lugar a cinerita $n=41$, a lutita y calcedonia con $n=4$ en cada caso, luego a pizarra con $n=3$ y finalmente en cuarzo $n=2$. Los fragmentos de materias primas indeterminadas llegan a $n=13$.

La mitad de los fragmentos muestran algún grado de alteración, principalmente pátinas blancas o amarillentas, otros presentan signos de termoalteración, además de líquenes sobre la superficie de alguno de ellos (Tabla 10.15).

En cuanto a la presencia de corteza, un gran número de fragmentos no presenta corteza $n=104$, mientras que aquellas piezas con parcial, escasa y muy abundante corteza presentan cifras similares, $n=13,12$ y 10 , respectivamente y con abundante presencia de corteza $n=4$, los restantes no pudieron ser determinados.

\begin{tabular}{|l|l|r|r|r|r|r|r|r|}
\hline Conservación & QZ & PIZ & LUT & CAL & IND & CI & RIO & Total \\
\hline Liquen & & & & & 1 & 1 & 2 & 4 \\
\hline Lique/pátina & & & 1 & & & 6 & 7 & 14 \\
\hline Pátina & & 2 & & & 9 & 6 & 40 & 57 \\
\hline Buena & 2 & 1 & 3 & 4 & 3 & 28 & 40 & 81 \\
\hline Total & $\mathbf{2}$ & $\mathbf{3}$ & $\mathbf{4}$ & $\mathbf{4}$ & $\mathbf{1 3}$ & $\mathbf{4 1}$ & $\mathbf{8 9}$ & $\mathbf{1 5 6}$ \\
\hline
\end{tabular}

Tabla 10. 15. Conservación de los fragmentos 


\section{Instrumentos}

Los instrumentos son principalmente raspadores $n=14$ y raederas $n=5$, luego aparecen fragmentos de instrumentos $n=7$, un instrumento compuesto, una preforma de punta y una posible muesca de pizarra (Tabla 10.16).

\begin{tabular}{|l|r|r|r|r|r|r|r|r|r|}
\hline $\begin{array}{l}\text { Instrumento/ } \\
\text { materia prima }\end{array}$ & Basalto & Calcedonia & Chert & Cinerita & Lutita & Pizarra & Riolita & Sílex & Total \\
\hline Raedera & 1 & & & 2 & & & 2 & & 5 \\
\hline Raspador atípico & & & & 1 & & & & 1 & 2 \\
\hline Raspador circular & & & & & & & 1 & 1 \\
\hline Raspador simple & & 1 & 1 & 1 & & & 7 & 1 & 11 \\
\hline Fto. De instrumento & & 1 & & 2 & 1 & & 3 & & 7 \\
\hline Instrumento compuesto & & & & 1 & & & & & 1 \\
\hline Muesca & & & & & & & & & 1 \\
\hline Preforma de punta & & & & & & & & & 1 \\
\hline Total & 1 & 2 & 1 & 7 & 1 & 1 & 15 & 2 & 29 \\
\hline
\end{tabular}

Tabla 10. 16. Relación entre instrumentos representados y materia prima

El estado de conservación de las piezas presenta en general algún tipo de alteración, principalmente pátina $(n=19)$ blanquecinas, amarillentas y negras. Sólo en uno pudo verse la presencia de líquenes como así también una pieza con evidencias de termoalteración por alta temperatura. El resto presenta un estado de conservación bueno. En cuanto a la presencia de fracturas tenemos 13 piezas enteras, luego hay 14 piezas fragmentadas y sólo tres artefactos que corresponden a fragmentos.

\section{Raspadores}

Los raspadores llegan a un total de $n=14$, de los cuales en riolita son $n=$ 8 , en sílex $n=2$, en cinerita $n=2$, en calcedonia y chert sólo uno.

Los tipos en los que podemos agrupar estos instrumentos son: raspadores simples $n=11$, raspadores atípicos $n=2$ y raspador circular $n=1$. Éste último confeccionado sobre riolita al igual que 7 de los raspadores simples, dentro de este grupo además hay uno de calcedonia, uno en chert, en cinerita y otro en sílex. Entre los atípicos hay uno sobre sílex y otro sobre cinerita. 


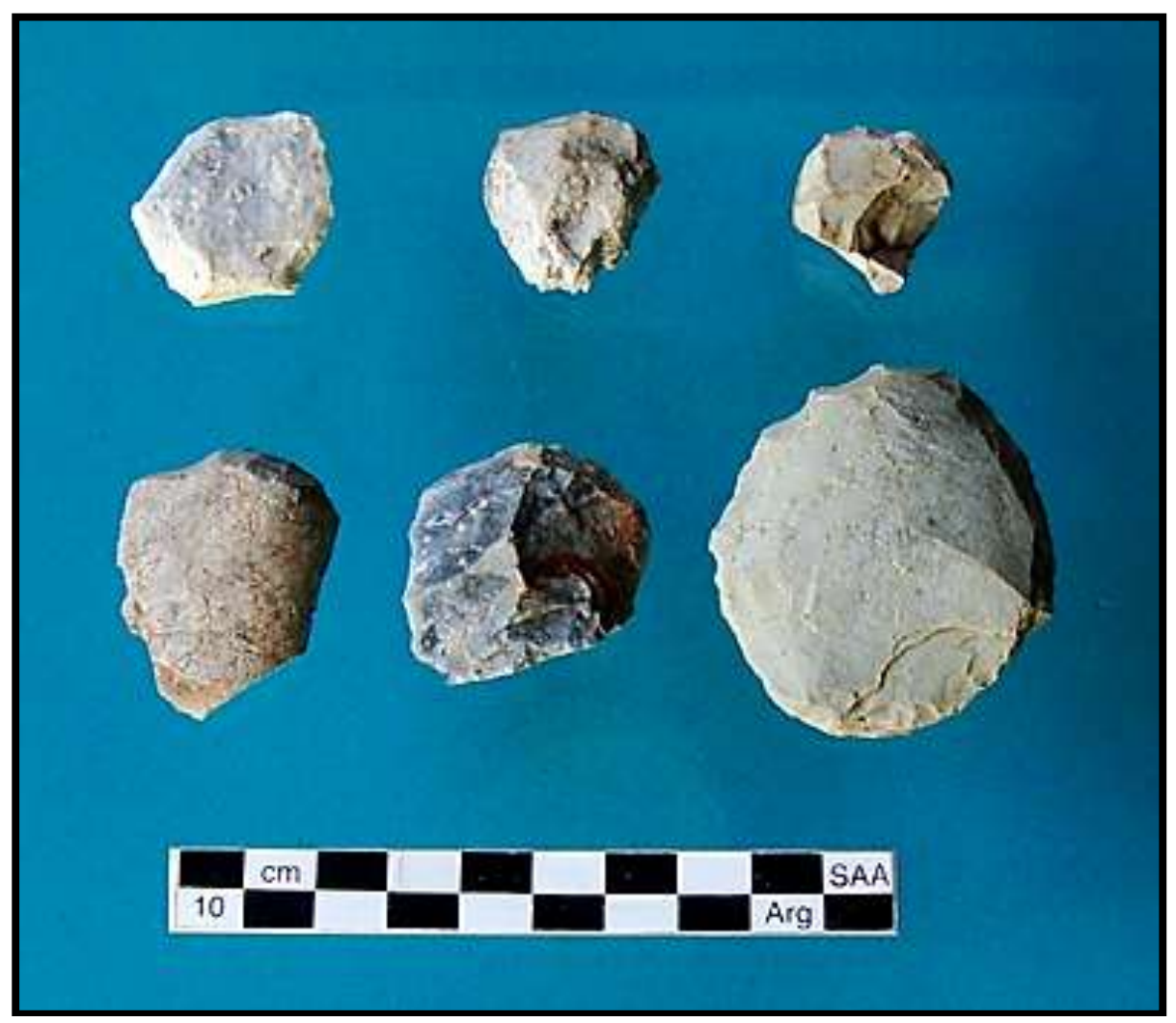

Figura 10. 5. Raspadores.

La conservación de los raspadores es buena sólo en 3 de ellos, mientras que en 11 casos muestran pátinas blancas y amarillas. La presencia de fracturas en los instrumentos se da en la mitad del conjunto.

En relación a la morfología de los raspadores, la forma base presenta las siguientes características: en cuanto a los soportes se utilizaron principalmente lascas $n=8$, sobre fragmentos $n=2$ y sobre lasca bipolar $n=1$, mientras que en $\mathrm{n}=3$ no pudo determinarse el tipo de soporte utilizado. Los talones están ausentes en $n=7$, luego se dividen entre lisos $n=3$, naturales $n=2$, lineal $n=1$ y facetado, también $n=1$. La inclinación de los talones se divide entre 4 oblicuos y 3 rectos. Lo mismo sucede entre los no preparados y los preparados, con $n=$ 4 y $n=3$ respectivamente (Tabla 10.17).

Los bulbos difusos están presentes en 6 raspadores, los espesos están representados en 3 raspadores, mientas que en 5 casos los bulbos están ausentes ya sea por fractura o por talla. Algo similar ocurre con la presencia de labio ya que en 4 casos estos se presentan de forma difusa, 3 de forma normal y 7 de las piezas no presentan labio. 
En cuanto a la presencia de corteza podemos ver que la mayoría de los instrumentos carecen por completo de ella, mientras que hay un raspador con muy abundante corteza, uno con corteza parcial y uno con escasa presencia de corteza. Sólo en dos casos no pudo determinarse si presentan o no corteza debido al grado de alteración de la superficie.

\begin{tabular}{|l|r|r|r|r|r|}
\hline & Lasca bipolar & Fragmento & Indet. & Lasca & Total \\
\hline Raspador atípico & & & & $\mathbf{2}$ & $\mathbf{2}$ \\
\hline Cinerita & & & & 1 & 1 \\
\hline Sílex & & & & 1 & 1 \\
\hline Raspador circular & & & $\mathbf{1}$ & $\mathbf{1}$ \\
\hline Riolita & $\mathbf{1}$ & & & 1 & 1 \\
\hline Raspador simple & & & $\mathbf{3}$ & $\mathbf{5}$ & $\mathbf{1 1}$ \\
\hline Calcedonia & 1 & & & 1 & 1 \\
\hline Chert & & & & 1 & 1 \\
\hline Cinerita & & & 2 & 3 & 7 \\
\hline Riolita & & & 1 & & 1 \\
\hline Sílex & & & & & 14 \\
\hline Total & & & & & \\
\hline
\end{tabular}

Tabla 10. 17. Relación entre soporte, tipo de raspador y materia prima

En relación a las dimensiones, dos de los raspadores pueden clasificarse como microrraspadores ya que no superan los $2 \mathrm{~cm}$ en su largo máximo. De los restantes $n=7$ corresponden a raspadores chicos, $n=4$ a los medianos y uno sólo supera los $8 \mathrm{~cm}$ por lo que se encuentran dentro de los grandes.

En cuanto a la relación entre los módulos LA y AE podemos ver que el conjunto presenta instrumentos de grosor medio $n=11$, de los cuales 6 son cortos y 5 de longitud intermedia, luego dos de los raspadores son delgados y de longitud intermedia y sólo uno es corto y delgado.

Detalle de los filos

El total de filos llega a 15, debido a que uno de los raspadores presenta dos filos retocados. Los filos que más se destacan son los distales $n=8$, luego derechos $\operatorname{con} n=2$, izquierdo y circular $\operatorname{con} n=1$. En 3 casos no pudo determinarse la ubicación de los filos. En cuanto a la delineación, los filos están representados principalmente por los convexos $n=11$, rectos $n=3$ y finalmente uno semicircular. En la sección longitudinal los filos son mayoritariamente 
rectos y sólo dos presentan secciones sinuosas. En cuanto a la longitud de los filos estos pueden agruparse en las siguientes categorías: hasta los $3 \mathrm{~cm} \mathrm{n}=8$, de 3 a $5 \mathrm{~cm} \mathrm{n}=5$ y los mayores a $5 \mathrm{~cm} \mathrm{n}=2$.

Detalle del retoque

Los raspadores en general presentan ángulos superiores a los $60^{\circ}(\mathrm{n}=$ 11). Sin embargo, hay $n=4$ con ángulos que van desde los 40,55 y $60^{\circ}$, dos para este último caso.

En todos los casos la morfología del retoque es irregular y su posición en cuanto a la cara desde donde se produjo es directa para 14 de los filos, mientras que uno de ellos, por el grado de fragmentación de la pieza no pudo determinarse. En cuanto a la extensión del retoque sobre el filo, vemos que hay un $n=7$ para los filos restringidos y un $n=6$ para los filos largos, un sólo filo corto y uno extendido.

Los retoques son continuos en casi todos los filos, excepto en uno, el cual se encuentra interrumpido por un negativo de lascado muy profundo en el medio del filo. La profundidad del retoque es principalmente marginal aunque hay 3 casos donde llegan a muy marginales.

Filos largos retocados

El conjunto formado por filos largos retocados está compuesto por $n=5$ piezas, de las cuales 2 fueron confeccionados sobre riolita, dos sobre cinerita y una sobre basalto (Figura 10.5). En cuanto a la conservación de las piezas vemos que 3 de ellas presentan algún tipo de pátina y otra muestra líquenes en la superficie. Dos de ellos son raederas que presentan un grado de fragmentación de tipo 1.

Los tipos representados pueden dividirse de la siguiente manera: 2 raederas dobles (bilaterales) una de ellas sobre basalto y otra sobre riolita; 1 raedera transversal de riolita y 2 raederas laterales ambas en cinerita. 


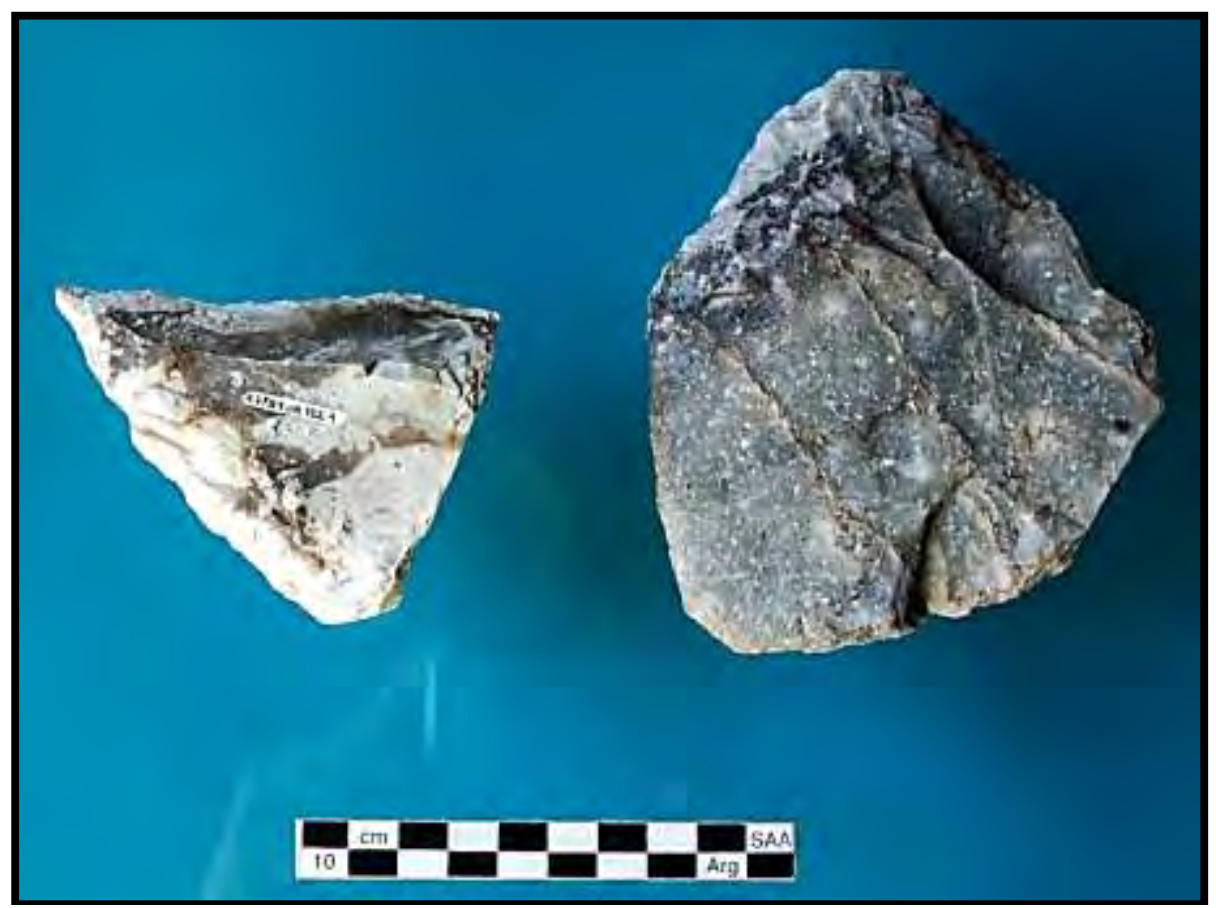

Figura 10. 6. Filos largos retocados

\section{Forma base}

El soporte más utilizado para la confección de estas raederas son lascas (una en riolita y dos en cinerita), una de ellas está confeccionada sobre una lámina (basalto) y finalmente una sobre un fragmento (riolita).

Morfológicamente las piezas se presentan alargadas en $n=4$ y sólo una pieza ancha. Desde la sección longitudinal la forma es biconvexa en todos los casos.

En cuanto a las características tecnológicas, 2 piezas presentan accidentes de talla, una lasca reflejada y una lasca sobrepasada. Los talones son principalmente lisos, uno lineal y en una de las piezas está ausente. Sólo pudo determinarse preparación de los talones para dos de los instrumentos. Los talones presentan dos tipos de inclinación rectos $n=2$ y oblicuos $n=2$.

Dentro de los rasgos tecnológicos el bulbo se presenta en todos los casos difuso, mientras que el labio está ausente en una de las piezas, pero el tipo normal está presente para dos de ellas y difuso para las otras dos.

La corteza está ausente en 3 piezas, (de cada materia prima: basalto, riolita y cinerita), de las restantes, la raedera de riolita presenta escasa corteza y la de cinerita presenta cobertura parcial. 
Detalle de los filos

A pesar de contar con 5 instrumentos, los filos ascienden a 7, dado que dos raederas presentan dos filos. En el caso de la raedera de basalto los filos son laterales, mientras que la de riolita presenta un filo lateral (derecho) y uno distal. Las 3 raederas restantes los presentan como sigue: la de riolita de forma distal, las dos de cinerita uno izquierdo y la otra derecho. De los 7 filos, 4 son convexos mientras que los otros 3 son rectos. Incluso la pieza con doble filo presentan uno de cada uno. En cuanto a la sección longitudinal de los filos, 4 son curvos mientras que los otros 3 son rectos.

La longitud de los filos es variada, incluso en las piezas dobles, los mismos van desde los $4 \mathrm{~cm}$ hasta los $11 \mathrm{~cm}$. En cuanto a los ángulos de los filos, estos van desde los $45^{\circ}$ hasta los $65^{\circ}$.

\section{Detalle del retoque}

En los filos retocados, el retoque es irregular. En cuanto a la dirección del retoque, 4 de ellos son directos, uno es bifacial y el filo restante presenta un sector bifacial y otro unifacial directo.

En relación a la extensión del retoque sobre el filo, en 5 casos se trata de filos largos, mientras que el filo restante corresponde a un filo corto. Todos presentan retoque continuo, incluso el que tiene dos tipos de retoque (bifacial y unifacial). La profundidad del retoque es en general marginal, sólo se presenta un caso donde la profundidad es muy marginal.

Fragmentos de instrumento

Los fragmentos de instrumento son 5 piezas, de las cuales 2 son en cinerita, una en riolita, otra en lutita y una en calcedonia. La conservación es buena en dos casos, otros dos presentan pátina y el restante muestra evidencia de alteración por alta temperatura.

Muchos aspectos de la forma base no pueden ser definidos debido al alto grado de fragmentación de las piezas.

En cuanto a los filos, en todos los casos presentan un filo, de los cuales 3 son rectos y 2 convexos. En general las longitudes son pequeñas, rondando los $3 \mathrm{~cm}$, salvo uno cuya longitud es de $7,5 \mathrm{~cm}$. 
En cuanto al retoque, es irregular en todas las piezas, directo en 4 de ellas y una pieza presenta retoque bifacial. Todos los filos tienen retoque continuo y la profundidad se divide entre los marginales $n=3$ y los profundos $n=$ 2.

\section{Punta de proyectil}

Se trata de una pieza de 3,5 x 3,3 x 0,8 cm, con reducción bifacial que concuerda con la forma de una punta de aletas y pedúnculo alargado. Sin embargo el grosor es muy elevado y la forma no está bien definida. Podría tratarse de una preforma abandonada en curso de manufactura dadas sus características de filos y módulos que impiden su terminación (Figura 10.6).
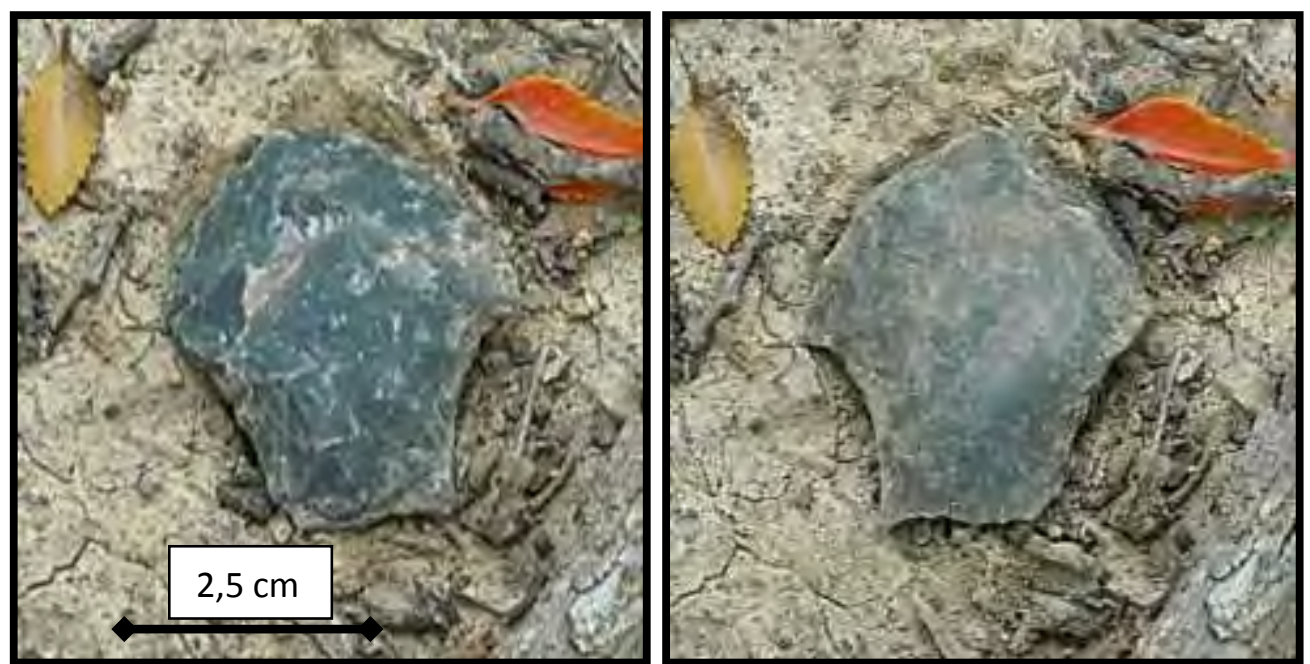

Figura 10. 7. Preforma de punta de proyectil

\section{Análisis funcional}

En estos materiales de superficie, tampoco fue posible identificar rastros de uso debido al estado de conservación de las superficies y redondeamiento de los filos. Dado que los rastros de uso normalmente aparecen pegados al filo en una extensión que rara vez supera medio $\mathrm{mm}$, el redondeamiento y abrasión tafonómicos alteraron totalmente o eliminaron los posibles rastros microscópicos que evidencien uso. 


\section{DISCUSIÓN}

El conjunto lítico descripto proviene de la recolección superficial intensiva en la totalidad del sitio Kami 7. Los elementos menores de $2 \mathrm{~cm}$ son muy escasos; esto puede deberse a su procedencia de superficie, ya que es posible que los mismos sean enterrados o cubiertos por el sedimento que cae de la misma barranca y que el viento vuelve a depositar.

En líneas generales este conjunto presenta una gran diversidad tanto en materias primas, como artefactual. Así vemos que hay al menos 10 materias primas diferentes representadas, siendo las más abundantes las riolitas y las cineritas, y en mucha menor cantidad calcedonia, basalto, lutita, entre otras.

En cuanto a la diversidad artefactual vemos que presenta diversos tipos de instrumentos (diversos clases de raspadores, raederas, un instrumento combinado, una preforma de punta de proyectil, una muesca y varios fragmentos de instrumento), núcleos apicales, discoidales y amorfos, entre otros restos de talla.

Vemos que en relación a las materias primas, el orden, en cuanto a abundancia, se invierte entre los subgrupos dimensionales. Entre los elementos mayores a $2 \mathrm{~cm}$, la riolita es la más numerosa y luego la cinerita, esto se invierte en el subgrupo menor a $2 \mathrm{~cm}$. Como se mencionó, este subgrupo se encuentra sub-representado, dado que por su tamaño son propensos a enterrarse o a perderse con mucha más facilidad que otros restos de mayor tamaño.

En cuanto a las materias primas restantes, su presencia es muy escasa y se distribuye principalmente entre restos de talla, más que en instrumentos terminados. Esto lleva a plantearse la posibilidad de que al ser muy escasas, ya sea por provenir de zonas lejanas o por no presentarse de forma natural en los alrededores, estas materias primas se conserven o cuiden en relación con las locales y de fácil acceso. La corteza está ausente en el $60 \%$ de todas las materias primas, incluidas las riolitas y cineritas.

Finalmente, en relación al total estudiado en el sitio Kami 7, resulta importante recordar la existencia de áreas de combustión con fechados diferentes (ver capítulo 4), materias primas que indican diferencias cronológicas como las líticas y el vidrio. Estas estarían indicando un palimpsesto, con una 
serie de ocupaciones no fácilmente aislables entre sí, comprendidas en un lapso de al menos 1000 años de antigüedad según lo que indican los fechados que tenemos hasta hoy. 
Capítulo $1 \mathfrak{l}$

DISCUSIÓN y CONCLUSIONES 


\section{INTRODUCCIÓN}

Tal como se planteó al comienzo de este trabajo de Tesis, el objetivo general de la investigación es el estudio de la organización tecnológica de las sociedades cazadoras-recolectoras que habitaron la faja central de la Isla Grande de Tierra del Fuego y la evaluación de la ocupación del espacio en el bosque subantártico, considerando los distintos ambientes representados y la oferta diferencial de recursos. La principal hipótesis de partida fue considerar que la organización tecnológica, en tanto que estrategia organizativa, depende del marco social en el que está inserta pero además refleja conocimientos y decisiones técnicas que tienen que ver con los modos de gestión de los recursos. Por ello, en un ámbito geográfico como el de la Cordillera fueguina, la evaluación de las características y diversidad de recursos disponibles podía constituir una clave para explicar la variabilidad arqueológica. Propusimos como elementos clave para este estudio el de las materias primas líticas y el uso de los instrumentos.

Para poder cumplir con los objetivos propuestos, el trabajo se estructuró siguiendo dos grandes ejes teórico-metodológicos: el de la organización tecnológica con especial énfasis en la tecnología lítica y el de la ocupación del paisaje y la diversidad ambiental.

En cuanto al primero, la organización tecnológica comprende los procesos de producción y uso de los instrumentos que participan en las diferentes cadenas operativas. Las de producción lítica se componen de un número variable de actividades que van desde la búsqueda de una fuente de aprovisionamiento lítico hasta el reciclado y abandono del instrumento.

Para abordarlos, se llevaron a cabo análisis integrales en los conjuntos líticos provenientes de las localidades arqueológicas Ewan y Kami, estudiando diversos aspectos. Uno de ellos fue el de las materias primas, considerando sus orígenes, calidades para la talla, representatividad en relación a su localización en el paisaje, su comportamiento durante los procesos de manufactura y uso, etc. Además, se hicieron estudios experimentales donde se replicaron tanto los instrumentos como el proceso de uso sobre diversos 
materiales, como madera, piel y hueso. Se efectuaron estudios tecnomorfológicos y funcionales que aportaron información sobre los procesos de manufactura y uso en los conjuntos arqueológicos; ellos permitieron inferir el procesamiento de otros recursos que por su naturaleza perecedera están ausentes en los conjuntos arqueológicos, como los vegetales, las pieles, etc. Finalmente, se reconstruyeron las etapas de las cadenas operativas para explicar las diferencias entre los artefactos tallados sobre rocas locales y no locales, así como las posibilidades de introducción de estas últimas a los campamentos en formas reducidas, por ejemplo como formas-base 0 instrumentos terminados.

Con respecto al segundo eje, el trabajo se centró en la ocupación de los diversos ambientes por parte de las sociedades cazadoras-recolectoras. Para ello se desarrollaron estudios distribucionales siguiendo un programa sistemático de transectas; su objetivo fue abarcar la mayor diversidad ambiental posible para comprender las posibilidades de acceso a recursos bióticos y abióticos fundamentales para la subsistencia de los grupos cazadores-recolectores. A partir de este planteo se llevaron a cabo transectas en ambientes de ecotono, de cordillera y de valles fluviales. En todos los casos se pudieron identificar prácticamente los mismos recursos. La diferencia entre ellos reside principalmente en la posibilidad de acceso a los mismos, tal como se observó para el caso de las fuentes secundarias de aprovisionamiento lítico, que se presentan extensas y de fácil acceso en los lagos y lagunas, pero más reducidas y en localizaciones puntuales de los cauces de los ríos.

\section{ÁREA DE ESTUDIO}

Como se mencionó en el capítulo 1, el área de estudio abarca la depresión que forma la falla generada por el contacto entre la placa de Nueva Scotia y la de Sudamérica, sector donde se encuentra el lago Fagnano. Hacia el sur se desarrolla la zona cordillerana, con pie de monte ocupado por bosque mixto cerrado de Nothofagus sp.. Hacia el norte del lago se extiende una zona caracterizada por un ambiente de ecotono, donde se desarrollan diversos cuerpos de agua como lagunas y lagos, rodeados por bosque con espacios de pastizales. Finalmente, la zona que se extiende entre la cabecera del lago 
Fagnano y la costa atlántica, recortada por valles de ríos que desembocan en el océano.

Las clases de recursos que presentan estos tres ambientes no difieren sustancialmente de entre sí; de hecho, con excepción de algunos recursos vegetales, todos fueron reconocidos a lo largo de los trabajos de campo. En todos los ambientes se pudieron observar cuerpos de agua dulce, sectores con acumulación de guijarros provenientes de las formaciones de Le Maire y Yaghan, redepositados por la acción glacifluvial; también recursos vegetales como madera, algún tipo de baya, herbáceas, juncos, etc., diversas especies de hongos comestibles y fauna como el guanaco y aves.

\section{PRIMER EJE: ORGANIZACIÓN TECNOLÓGICA}

\section{LOCALIDAD EWAN}

Como se mencionó en los capítulos 4 y 7, la localidad arqueológica Ewan se encuentra ubicada en la zona de ecotono, caracterizada por estribaciones bajas, sectores de bosque abierto y pastizales cortados por diversos cursos de agua como el río Ewan. La localidad está conformada por dos sectores que cumplieron funciones diferentes pero a su vez interdependientes, ya que ambos participaron de una ceremonia de Hain que fue realizada, según el fechado por dendrocronología, en la primavera de 1905. Mientras que Ewan I funcionó como la choza ceremonial, en Ewan II se desarrollaban las actividades domésticas de las distintas unidades familiares reunidas allí.

En relación a las materias primas líticas utilizadas para la confección de instrumentos, una característica particular de los conjuntos de ambos sitios es que están compuestos en su totalidad por artefactos de vidrio, material que fue introducido por los europeos. Este es un dato de importancia, ya que hasta el momento estos sitios son los únicos en toda Tierra del Fuego en los que la única materia prima presente es el vidrio. En Ewan I sólo se encuentran representados los restos de talla; todos son menores a $2 \mathrm{~cm}$ y presentan una gran diversidad de colores (verde, azul, rojo, transparente, celeste, turquesa). Estos estaban concentrados principalmente en el área de combustión. En cambio el conjunto de Ewan II, aún cuando estaba conformado casi 
íntegramente por restos de talla menores a $2 \mathrm{~cm}$, incluía también algunos instrumentos retocados, como raspadores, puntas de proyectil y un filo largo retocado. En este caso los artefactos son de color verde y transparente.

Es importante mencionar que el aumento de la frecuencia de vidrio en los conjuntos arqueológicos a partir de la instalación de las estancias, que podemos considerar como fuentes de aprovisionamiento terciarias, jugó un papel central en el reemplazo progresivo de las materias primas locales por este material. Esto queda evidenciado, además, por las fuentes escritas que se refieren a la explotación del vidrio para la confección de instrumentos por parte de las sociedades cazadoras-recolectoras fueguinas (Outes 1906; Gallardo 1910; Gusinde 1982; cf. Parmigiani et al. 2010). Algo comparable ocurrió con la introducción de animales alóctonos como es el caso de las ovejas, ingresadas a la Isla principalmente para la explotación lanar, que se introdujeron en la dieta de los habitantes a partir del contacto con las misiones (Parmigiani et al. 2010).

Como mencionamos en el capítulo 6, fue necesario desarrollar un programa experimental que nos permitiera conocer el comportamiento de esta materia prima en relación a los procesos de manufactura y de uso. Los resultados obtenidos en relación al proceso de manufactura permitieron identificar un tipo particular de microlasca que se produce al formatizar los filos de raspadores. Estas presentan en las dos caras (proximal y distal) la superficie original del vidrio y su curvatura es biconvexa. En consecuencia, a partir de la presencia de este tipo de lasca en un conjunto arqueológico, es posible llegar a reconocer qué tipo de instrumentos de vidrio se pudo haber confeccionado en el lugar, aunque no se hayan conservado artefactos retocados.

Los resultados del análisis tecno-morfológico confirman que en Ewan I se estuvieron confeccionando tanto puntas de proyectil, debido a la presencia de lascas típicas de adelgazamiento bifacial, como raspadores, por la presencia de estas lascas de formatización de filo de raspador. En cuanto al conjunto de Ewan II, si bien este sí incluía artefactos formatizados, los resultados del análisis tecno-morfológico de los restos menores a $2 \mathrm{~cm}$, también revelaron la presencia de estos dos tipos de lascas.

En cuanto al proceso de uso de los instrumentos, como se mencionó en el capítulo 7, tanto las puntas como el filo largo retocado estaban 
termoalteradas por fuego; sólo se pudo llevar a cabo el análisis funcional en los raspadores, que fueron los únicos instrumentos que no presentaron termoalteración. Los resultados mostraron que los tres raspadores realizaron trabajo transversal sobre piel y además se pudo comprobar la reactivación de los filos, al menos en dos de los raspadores, ya que estos presentaban importante desarrollo de rastros de uso en algún sector del filo, como en los extremos, y muy poco desarrollo en las partes centrales de los filos frontales, no relacionado con sectores sobresalientes. Por otro lado, en ninguno de los casos se encontraron evidencias de enmangue de los raspadores para su utilización.

Las puntas de proyectil presentan fracturas en diversos lugares y grados. En todos los casos se trata de fracturas tecnológicas producidas durante el proceso de manufactura.

En resumen, podemos decir que hay al menos 2 cadenas operativas diferentes, pero que se imbrican con cadenas de procesamiento de otros materiales: la primera de ellas corresponde al retoque directo sobre fragmentos de vidrio, para formatizar raspadores, que fueron utilizados en el procesamiento de pieles; la segunda cadena operativa implicó el adelgazamiento y retoque bifacial sobre fragmentos también, para formatizar puntas de proyectil. Las que se encontraron en el sitio presentaban fracturas producidas durante la manufactura; sin embargo su confección implica también la preparación de astiles y enmangamiento. Si bien no contamos con instrumentos de vidrio con rastros de uso sobre maderas, sí se hallaron en el sitio restos de metal, por lo cual es posible que el trabajo de la madera (por ejemplo la preparación de los astiles) haya sido efectuado con instrumental en metal de tipo "conservado" que no se dejó en el lugar.

De todas formas es importante recalcar que para todos los instrumentos, la materia prima utilizada no es un recurso de origen local, sino alóctona, de una fuente que podemos considerar terciaria.

\section{LOCALIDAD KAMI}

Como se presentó en el capítulo 8 , se estudiaron tres sitios de la localidad arqueológica Kami (Kami 1, 6 y 7), ubicados sobre la costa sur del 
lago Fagnano. Estos sitios se caracterizan por la presencia de abundante material lítico, a diferencia de otros sitios de la zona central de Tierra del Fuego, como Marina 1 o los otros mencionados en el capítulo 2, en los cuales el material lítico es escaso. Al contrario del material litico, en todos los sitios los restos faunísticos son muy escasos, debido a la acidez característica del suelo de bosque que no permite la supervivencia de los materiales de origen orgánico.

Se trata de sitios extensos. A partir de los resultados presentados en los capítulos $4,8,9$ y 10 , se puede confirmar que tuvieron sucesivas reocupaciones, al menos a lo largo de los últimos 1000 años aproximadamente, como lo demuestran los fechados y la presencia de elementos de origen europeo asociados a los contextos arqueológicos.

A partir de los análisis tecno-morfológicos se puede considerar a los conjuntos líticos como poco diversificados, con tipos tecnológicos representados principalmente por núcleos, lascas, fragmentos, filos largos retocados (raederas), raspadores y puntas de proyectil. De todas formas, dentro de cada uno de estos grupos podemos ver cierta diversidad; entre los artefactos retocados, por ejemplo, los filos largos presentan tipos como raedera oblicua, lateral simple, transversal, dobles, doble-convergentes, algunas lascas con retoque, con diversidad de ángulos de filo que van desde los $30^{\circ}$ hasta los $75^{\circ}$. De la misma forma, los raspadores también muestran más diversidad intra-tipo ya que hay raspadores simples, dobles, circulares, triples, atípicos o no estandarizados, etc. En cuanto a las puntas de proyectil, estas son muy escasas en comparación con los otros instrumentos: sólo dos puntas triangulares apedunculadas, otra fragmentada, una punta de flecha con aleta también fragmentada y finalmente una preforma abandonada.

En cuanto a los tamaños de los instrumentos, vemos que para las raederas éstos incluyen desde muy grandes a chicas, aunque se buscaron principalmente tamaños intermedios, con soportes anchos más que alargados. En cambio para los raspadores los tamaños se concentran principalmente en los microrraspadores y raspadores chicos, siendo muy escasos los raspadores que superan los $4 \mathrm{~cm}$. En cuanto a las puntas de proyectil, podemos decir que en general muestran tamaños intermedios, salvo una de tamaño chico. 
Con respecto a los artefactos no retocados mayores a $2 \mathrm{~cm}$, los núcleos en general no están agotados, sobre todo los de rocas locales. La técnica de talla generó dos tipos principales, los núcleos tallados por percusión directa y los bipolares. Entre los primeros, los más representados, en relación a la forma en que fueron tallados, son los amorfos, los discoidales y luego los apicales.

Las lascas son en general de tamaños intermedios, no habiendo prácticamente lascas grandes o muy grandes. La gran mayoría son lascas de talla por percusión directa, siendo las bipolares muy escasas. Entre las primeras hay algunas lascas de reducción bifacial, si bien estas no son las más abundantes. Sin embargo están menos representadas aún las lascas primarias de descortezamiento o las lascas con dorsos naturales. Lo mismo ocurre con respecto a las lascas con talones preparados, que si bien están presentes, no son las más representadas.

En general entre los artefactos mayores a $2 \mathrm{~cm}$, la presencia de corteza es más bien escasa, tanto en núcleos como en lascas y fragmentos. Esto puede deberse, como se mencionó en el capítulo 8, a que las primeras etapas del proceso de manufactura se estén llevando a cabo fuera del sitio. Esta característica de ausencia o escasez de corteza se da tanto en materias primas locales como en no locales, aunque en estas últimas es más acentuada. En el caso de las locales, las etapas iniciales podrían haberse realizado en la playa de guijarros junto al sitio; en el de las alóctonas, porque provienen de afloramientos lejanos como el caso de la toba silicificada de Miraflores.

Los elementos menores a $2 \mathrm{~cm}$ son muy abundantes en los conjuntos provenientes de las excavaciones, principalmente las lasquitas y los debris. A diferencia de lo que sucede con el subgrupo de artefactos mayores a $2 \mathrm{~cm}$, donde la riolita aparece más representada que la cinerita, en este subgrupo la preponderancia de elementos de cinerita es mayor con respecto a los de riolita. Esta inversión según el subgrupo, puede estar relacionada a las diferencias que presentan estas rocas en cuanto a la calidad para la talla.

Las cinerita es una roca de grano más fino y de mejor calidad para la talla que la riolita, pero menos abundante y de más difícil localización. Esto podría implicar un uso más intensivo de la materia prima, con una mayor reactivación y recuperación de instrumentos, etc. lo que se vería reflejado en 
artefactos de menor tamaño y/o con filos más abruptos, como es el caso de algunos filos largos en cinerita o en lutita.

Este tipo de elección en cuanto a la gestión de las materias primas puede corroborarse también con otras rocas de muy buena calidad para la talla y que aparecen muy esporádicamente en los conjuntos, tal es el caso de la toba silicificada para los raspadores; en este caso fueron reactivados hasta llegar al extremo considerando sus tamaños, y por ello fueron abandonados.

Sin embargo, la presencia preponderante de cinerita entre los elementos menores a $2 \mathrm{~cm}$, también puede tener otra explicación. Dado que la cinerita no es tan abundante como la riolita, los instrumentos confeccionados en esa materia prima pueden ser transportados o conservados por más tiempo; en tal caso sólo aparecerían en los sitios las lascas de reactivación de filos o aquellas propias de formatización.

En cuanto al contexto de uso de los instrumentos, estos se pueden agrupar en dos series bien definidas. Una es la de los filos largos retocados, en los cuales el análisis microscópico reveló que fueron utilizados para trabajar principalmente madera. En cuanto a su cinemática, la extensión y orientación de los rastros de utilización, tanto longitudinal como transversal sobre un mismo filo, indican acciones de adelgazamiento por corte longitudinal y /o descortezamiento madera.

La otra serie es la de los filos cortos, representados exclusivamente por raspadores, que en general se caracterizan por presentar rastros de uso producidos por el trabajo sobre piel y en menor medida sobre madera. En Kami 1, el trabajo es principalmente raspado de pieles, ya que todos los filos mostraron evidencias claras de uso transversal sobre este material. La única excepción es un raspador con probable trabajo sobre material vegetal. En cuanto a Kami 7, dos de los raspadores presentan evidencia de uso transversal sobre madera.

Cabe mencionar que los materiales superficiales, presentaban un alto grado de alteración y redondeamiento de la superficie por lo que no fue posible determinar su uso. También es interesante mencionar que de los filos con rastros de uso, ninguno mostró evidencias de trabajo sobre hueso. En cuanto a las lascas con filos potencialmente utilizables, sólo unas pocas $(n=10)$ presentaron un escaso redondeamiento y brillo en el filo. No se trata de rastros 
bien desarrollados; por lo tanto, si fueron utilizados en alguna tarea, tuvieron tan poco uso que no generó rastros que puedan diferenciarse del lustre de suelos. En todo caso, por sus características, no fueron utilizados en los trabajos mencionados más arriba, que se centraban en la regularización de la superficie de madera, donde los filos naturales pueden no ser efectivos dado que son más frágiles que los filos retocados, o bien el trabajo de raspado de pieles, donde los filos naturales pueden cortar el cuero dado que son filos muy agudos. Además en esos casos habrían tenido rastros de uso identificables.

\section{SÍNTESIS TECNO-MORFO-FUNCIONAL Y CADENA OPERATIVA}

Discusión sobre la manufactura, contexto de confección y de uso, gestión de los instrumentos y gestión de las materias primas

A partir de lo expuesto en los capítulos referentes a los diversos análisis tecnológicos y funcionales, podemos decir que los conjuntos líticos están definidos por la explotación de una diversidad de materias primas locales y no locales. Dichas materias primas fueron elegidas específicamente para ser utilizadas en actividades bien definidas, con instrumentos cuya morfología fue buscada para cumplir tal fin. Esto se corrobora cuando vemos la diferencia en el uso de las materias primas seleccionadas para la confección de instrumentos con filos largos retocados, en los cuales se utilizaron rocas duras, principalmente de origen local como las riolitas o cineritas, y para la confección de raspadores, en la cual se eligió otro tipo de materias primas, como el cuarzo o la toba silicificada. Lo mismo podemos decir para la confección de las puntas de proyectil, para las cuales aunque no son numerosas se seleccionaron rocas de grano muy fino como lutita y cinerita.

Una mención aparte merecen los materiales de Ewan, ya que el vidrio ofrece excelentes características para la confección de instrumentos, tanto raspadores, como puntas de proyectil o filos largos retocados (aunque de estos últimos sólo se cuenta con un ejemplar y lamentablemente la alteración no permitió definir si fue utilizado o no). En cuanto a los raspadores, es interesante mencionar la selección de vidrios curvos (estilo cuerpo de botella) para su confección. Esto puede deberse a que la curvatura propia del fragmento de vidrio, al ser transversal al filo, otorga más resistencia a las fracturas; ya que al 
estar posiblemente enmangados, si fueran vidrios rectos, la presión podría fracturarlos más fácilmente. En otros casos de raspadores de vidrio que conocemos, la curvatura se aprovecha para darle la forma al raspador y retocar uno de extremos paralelo a la curvatura.

En cuanto a la gestión de la materia prima, vemos una elección de actividades técnicas particulares en relación con las rocas locales. Como se mencionó más arriba, los sitios están ubicados junto a los depósitos de guijarros que funcionan como fuentes de materia prima, por lo que uno esperaría encontrar gran cantidad de lascas de descortezamiento o lascas con abundante corteza en los sitios, dada la poca energía que implica transportar los guijarros unos pocos metros. Sin embargo, el bajo porcentaje de lascas de preparación (lascas con mucha corteza, lascas de dorso natural, o primarias de descortezamiento), y la existencia de núcleos con, también, muy bajo porcentaje de corteza, implica que estos fueron descortezados en parte probablemente en la misma costa de guijarros, y no en el sitio. Este tratamiento sería más esperable en rocas no locales, que deben transportarse muchos kilómetros, lo que también ocurre aquí, como por ejemplo con las tobas silicificadas. Este comportamiento con las rocas locales podría explicarse por el hecho que los guijarros no expresan externamente sus características internas, y es necesario testearlos para saber qué calidad para la talla puedan tener, ya que las cortezas están muy alteradas por todos los procesos sufridos, y son muy frágiles, por lo que tampoco serían muy útiles lascas con filos que conserven corteza.

Otra característica que se destaca es el tamaño de las lascas. En general, son lascas chicas o medianas, no hay prácticamente lascas de gran tamaño, pero sí hay instrumentos que superan los $15 \mathrm{~cm}$. Esto corrobora que las etapas iniciales de reducción de la materia prima no se llevaron a cabo en los sitios, tal como sugería la presencia de corteza sobre los productos de talla. Podemos plantear que los guijarros se descortezarían en la costa y se los terminaría de confeccionar en el sitio donde son utilizados, reactivados y abandonados. Esta hipótesis se corrobora con la abundante presencia de elementos menores a $2 \mathrm{~cm}$ principalmente lasquitas y debris, en menor medida microfragmentos y microlascas. 
Esto nos está indicando una recurrencia en cuanto a las primeras etapas de la cadena operativa realizadas fuera del sitio, introduciendo en éste las materias primas ya en forma de lascas, preformas o instrumentos terminados; de esta manera en los sitios se llevarían a cabo las etapas finales de la cadena como la formatización de los instrumentos, la estabilización y reactivación de los filos, el uso de los instrumentos terminados y el posterior abandono.

También es llamativo que una parte importante de los instrumentos terminados, con posibilidades de seguir siendo utilizados, sean abandonados, pero además algunos son abandonados dentro de las áreas de combustión. Como se mencionó en los capítulos 7 al 10, muchos instrumentos presentan alteraciones en su superficie por fuego o altas temperaturas. En estos casos es muy común que estos artefactos presenten fracturas producidas por tal motivo.

En el caso de Ewan esto se explica por un comportamiento de ocultamiento de las actividades llevadas a cabo en la choza ceremonial, pero también hay algo de descarte de residuos en el fogón en la choza doméstica (Mansur y Piqué 2012). Para los sitios de la localidad Kami no puede asegurarse que este sea el objetivo, tembién puede ser el resultado de las sucesivas reocupaciones donde los fogones puede afectar los artefactos más antiguos.

\section{SEGUNDO EJE: OCUPACIÓN DE LOS DIVERSOS AMBIENTES}

\section{ESTUDIO DEL PAISAJE Y LAS POSIBILIDADES DE MOVILIDAD Y EXPLOTACIÓN DE LAS FUENTES POTENCIALES DE APROVICIONAMIENTO}

Los resultados obtenidos del estudio distribucional y de los muestreos de materias primas realizados en los diversos ambientes indican que los recursos abióticos y bióticos se encuentran representados en todos ellos. Sin embargo el acceso, la disponibilidad y la visibilidad no son iguales. Esto puede verse a partir de lo expuesto en el capítulo 5, en cuanto a las dificultades que presenta el hallazgo de las diversas fuentes de aprovisionamiento en relación a los ríos y las lagunas.

Con respecto a esto, la densidad del material arqueológico se presenta de forma desigual, en relación directa con la densidad de los recursos líticos. 
Mas allá del ambiente del que se trate, lo que parece influir de manera positiva en las diferencias en las densidades del material arqueológico es la presencia o la cercanía de estos depósitos de guijarros de tamaños variables, visibles, de fácil acceso y de buena calidad para la talla. Un ejemplo de esto puede ser la concentración de material lítico reconocida en la cabecera del río Irigoyen, cerca de la cual, sobre un recodo del río se encuentra una fuente potencial de aprovisionamiento rocoso; otro ejemplo es el que puede verse en la costa sur de lago Fagnano donde la presencia de altas densidades de artefactos líticos esta relacionada a la proximidad de una playa con guijarros de diversos tamaños, incluso grandes, que permiten una fácil explotación.

Otra característica con respecto al emplazamiento de las concentraciones de material arqueológico es que en la mayoría de los casos se encuentran en lugares relativamente altos y con buena visibilidad panorámica. Prácticamente todos los sitios de la costa sur del lago Fagnano y también las concentraciones en los márgenes de los ríos que se extienden hacia el este están sobre barrancas. Pero además de ello, estos lugares tienen dos características en común: por un lado el acceso a depósitos de guijarros y por otro la capacidad de estos lugares como puntos panorámicos, en particular sobre los valles para los sitios de las laderas de los ríos. En efecto, una característica de estos espacios es la visual, que permite tener un control del paisaje, por ende un control de los movimientos tanto de la fauna como de otros grupos humanos.

Finalmente otra característica que puede explicar concentraciones heterogéneas de material arqueológico en el paisaje es la presencia de una estacionalidad marcada. Tierra del Fuego se caracteriza por poseer períodos invernales largos y con presencia nívea durante varios meses. En este tiempo gran parte de la faja central permanece cubierta de nieve y los suelos permanecen congelados aún más tiempo. Esto produce cambios principalmente en el acceso a los recursos bióticos, la mayoría de los recursos vegetales comestibles no están y los animales, como el guanaco, se mueven en busca de alimento (Raedeke 1978).

En relación con esto último, es posible que el bosque haya funcionado como un lugar favorable dado que ofrece reparo, combustible, y árboles con hojas donde los guanacos van a ramonear, por ende ofrece alimento. Esto se 
condice con los estudios arqueobotánicos efectuados para el sitio Kami 1, ubicado en la zona de bosque cordillerano, donde los resultados arrojaron muy baja presencia de semillas de frutos, que son muy abundantes en épocas de primavera y verano. Esto no significa forzosamente que la falta de semillas o frutos indiquen ocupación invernal, ya que existen problemas de conservación. Sin embargo, para este caso en particular, se han hecho pruebas de sedimentos quemados y los resultados dieron presencia de semilla, o sea que la ausencia de este registro aquí no se debe a problemas de conservación. Entonces esto podría estar indicando al menos alguna ocupación del sitio no estival. En contraposición, los mismos estudios llevados a cabo para la localidad Ewan, ubicada hacia la zona de ecotono, indican que este fue ocupado durante el periodo de primavera- verano.

Como se pudo ver a lo largo de los capítulos 7 y 8 , las materias primas explotadas por las sociedades cazadoras-recolectoras de la faja central de Tierra del Fuego son muy variadas. Esto se relaciona con los tipos de fuentes de aprovisionamiento explotadas, que son principalmente secundarias, lo que puede deberse a las características mencionadas (acceso, visibilidad, y diversidad de rocas). Sin embargo, a partir de los resultados obtenidos en este estudio, se pudo comprobar la explotación de los tres tipos de afloramientos: primario, secundario y terciario. Con afloramiento primario nos referimos aquí al afloramiento Miraflores, ubicado al norte de la Isla a unos 200 km del lago Fagnano, mientras que las fuentes de aprovisionamiento terciarias están representadas aquí por emplazamientos de origen europeo, estilo puesto de estancia, tal el caso de los vidrios o los metales (Parmigiani et al. 2012).

En relación a las materias primas utilizadas vemos que fueron cambiando en la escala temporal. Para los sitios de contextos más antiguos obviamente la explotación era sobre materias primas naturales, ya sean locales o no locales, y para ello los circuitos de movilidad deberían ser amplios, ya que como vimos este recurso, si bien abundante, se ubica puntualmente en el paisaje. Tal es el caso de los sitios con antigüedades que rondan los 1000 años AP. como Kami 1 y un sector de Kami 7.

Luego vemos que entre los recursos comienzan a aparecer materiales naturales pero también otros manufacturados, como el vidrio o el metal, que comenzaron a llegar a la Isla primero como resultados de los naufragios y 
luego probablemente por intercambio con los viajeros. En Tierra del Fuego son numerosos los sitios que presentan esta dicotomía en cuanto al uso de materias primas naturales y no naturales, de los presentados aquí podemos mencionar a Kami 7, área de combustión 1.

Finalmente con la implantación efectiva de las estancias, las sociedades cazadoras-recolectoras Selknam tuvieron acceso directo a las materias primas manufacturadas. Esto junto con las características que presentan estos materiales para la talla, pero principalmente la reducción espacial en los circuitos de movilidad debido al arrinconamiento europeo, llevó a estas sociedades al uso casi exclusivo de estos materiales para principio del siglo XX (Parmigiani et al. 2010). Esto queda evidenciado tanto arqueológicamente, a través de los sitios de la localidad arqueológica Ewan, donde sólo se utilizó el vidrio, como por los datos etnográficos que detallan el uso del vidrio para la confección de raspadores y puntas de proyectil (Outes 1906, Gallardo 1998 [1910], Gusinde 1982 [1937], entre otros) y los abundantes materiales de colecciones etnográficas depositados en diferentes museos.

\section{CONCLUSIONES}

El aporte principal de esta tesis es estudiar la relación de las sociedades cazadoras-recolectoras Selknam y Pre-Selknam con los recursos bióticos y abióticos y ampliar el conocimiento que se tiene de la ocupación del bosque subantártico de la faja central de la Isla Grande de Tierra del Fuego.

En relación con este objetivo se llevaron a cabo estudios desde diversos enfoques, para poder abarcar la variabilidad intrínseca en el comportamiento humano. Por ello los estudios tomaron como ejes principales el estudio de la tecnología lítica, actividad que ofrece información fundamental a través de los materiales utilizados en los procesos de producción, y el estudio del paisaje en el que los grupos humanos se mueven y del que obtienen y transforman los recursos.

Como hemos visto, a partir del enfoque distribucional pudimos ampliar el conocimiento que se tiene sobre el uso del paisaje, la movilidad y la gestión del medio ambiente social y natural por parte de las sociedades cazadorasrecolectoras que habitaron la zona central de Tierra del Fuego. 
Este acercamiento, al no restringirse a las características particulares de los sitios arqueológicos, sino al ampliar la escala espacial, contempla como elemento fundamental la ocupación del espacio y los desplazamientos de poblaciones, permitiendo avanzar sobre el estado actual de esta ocupación y explotación de recursos a través de la constatación en el campo de la diferencia en la densidad de hallazgos arqueológicos. Esta diferencia la podemos explicar, por un lado, a partir de la ubicación de uno de los recursos fundamentales en esta zona, como es el recurso lítico, y por el otro en relación con la estacionalidad marcada existente para esta zona. Vimos que la posibilidad de acceso a este recurso no es igual en todos los ambientes; por ejemplo sobre la costa del lago Fagnano existen playas extensas con guijarros de buena calidad para la talla y en estos lugares la correlación con una alta densidad de artefactos líticos es positiva en comparación con los afloramientos secundarios relevados en las veras de los ríos.

Como se vio a partir de los análisis tecno-morfológicos y funcionales, los conjuntos presentan baja variabilidad artefactual, y una explotación de materias primas principalmente locales, para determinados instrumentos, como los filos largos retocados. Sin embargo se explotaron recursos no locales en la confección de raspadores. Esta elección de materias primas también se relaciona con la morfología y los tamaños de los instrumentos y en definitiva con el uso específico de cada uno.

En cuanto a la función que pudieron cumplir los sitios presentados, es indiscutible la función ceremonial de Ewan (Mansur y Pique 2012). Las diferencias entre los materiales de ambos sitios y el manejo que se hizo de estos materiales en cuanto a su intención de ocultar las actividades desarrolladas en la choza ceremonial, todo ello junto con los datos etnográficos disponibles que describen esta ceremonia, permitieron llegar a esta conclusión. Podemos hablar aquí de un sitio de agregación, donde la cantidad de material generado se debe a la presencia de un grupo numeroso de personas ocupando un mismo lugar por un largo tiempo.

En relación a los sitios correspondientes a la localidad Kami, podemos decir que por la diversidad de las actividades inferidas a partir de los estudios efectuados allí, se corresponden con sitios de actividades múltiples coincidentes con las llevadas a cabo en un campamento. 
Para esta localidad la presencia en playa de fuentes secundarias de guijarros de buena calidad para la talla, pudo haber funcionado como un atractor en el paisaje para las sociedades cazadoras-recolectoras de la faja central de la Isla. Esto es importante, en cuanto a densidad de ocupación, cuando lo comparamos con la presencia de estas fuentes en zonas como los valles de los ríos donde, aunque existen, son menos visibles y de menor tamaño.

Como mencionamos anteriormente para la localidad arqueológica Kami, el análisis de los materiales asociados al contexto arqueológico de origen local, pero también de origen europeo, junto con las antigüedades expresadas por los fechados, demuestra que en este caso la extensión de los sitios y su densidad no tiene que ver con un eventual sitio de agregación, sino con redundancia ocupacional, en el sentido de ocupaciones reiteradas a lo largo del tiempo, para este caso puntual de los últimos 1000 años, aproximadamente. Esta reocupación está relacionada, principalmente, con la búsqueda de materias primas, ya que los demás recursos se encuentran distribuidos más homogéneamente en los demás ambientes.

Esta reocupación del espacio, coincide con el supuesto que dice que cuantos más recursos ofrezca un ambiente, mayor pudo haber sido su explotación (Bettinger 2001). Entonces es esperable la reocupación de aquellos ambientes que brinden seguridad en cuanto a la explotación de algún recurso. Como vimos, el bosque puede presentarse como un ambiente favorable en este sentido. Esta redundancia ocupacional sería uno de los posibles factores que intervengan en la variabilidad de la densidad de artefactos arqueológicos (Massone 1997; Morello et al. 1999).

Finalmente, si el trabajo aquí presentado aportó al conocimiento que se tenía hasta ahora de la ocupación humana en la zona central de Tierra del Fuego, también abre la puerta al desarrollo de nuevas líneas de investigación que permitan profundizar los temas aquí tratados. Entre ellas podemos mencionar dos órdenes: Uno es estudios que permitan confrontar este modelo en otras regiones de la Isla Grande, en particular sería importante con la zona de estepa. Otro es el de estudio de recursos y, en este orden, los de recursos líticos, que aporten a generar una base regional de recursos líticos y la creación de una litoteca específica. También los estudios que aporten al 
conocimiento del uso de la fauna, en particular la estacionalidad de las especies explotadas y su uso en tecnología además de alimentación, así como estudios experimentales dirigidos a ampliar el conocimiento en cuanto a usos específicos de los instrumentos, con replicación de bienes equivalentes a los conocidos por las colecciones etnográficas. 


\section{虍iblíourafía}


AGI.

1976. American Geological Institute, Dictionary of Geological Terms. Anchor Press, New York.

ALONSO, LIMA M. y M. E. MANSUR.

1986-1990. Estudo Traceológico de Instrumentos em Quartzo e Quartzito de Santana do Riacho (MG). Arquivos do Museu de História Natural 11: 173- 190.

\section{ÁLVAREZ, M. R.}

1998. La explotación de recursos líticos en las ocupaciones tempranas del Canal Beagle: el caso de Túnel I. En: J. Belardi, F. Carballo Marina, S. Espinosa (eds.), Desde el País de los Gigantes. Perspectivas arqueológicas en Patagonia. Tomo I, pp. 73-85. Río Gallegos. Universidad Nacional de la Patagonia Austral.

\section{ÁLVAREZ, M. R.}

2003. Organización tecnológica en el canal de Beagle. El caso de Túnel 1 (Tierra del Fuego, Argentina). Tesis de doctorado. Facultad de Filosofía y Letras, Universidad del Buenos Aires. MS.

\section{ÁLVAREZ, M. R.}

2004a. Estrategias tecnológicas en los grupos canoeros tempranos del área Fuego-Patagónica. Magallania, 32:191-208.

\section{ÁLVAREZ, M. R.}

2004b. A qué responde la diversidad instrumental? Algunas reflexiones a partir del análisis funcional de materiales líticos de la costa norte del canal Beagle En: T. Civalero, P. Fernández y A. G. Guráieb (eds.), Contra viento y marea. Arqueología de Patagonia, Tomo 1, pp. 29-43. Neuquén- Buenos Aires. Instituto Nacional de Antropología y Pensamiento Latinoamericano y Universidad Nacional del Comahue. 


\section{ÁLVAREZ, M. R.}

2004c El uso de materias primas vegetales en la costa norte del canal Beagle a través del análisis funcional de base microscópica. En: T. Civalero, P. Fernández y A. G. Guráieb (eds.), Contra viento y marea. Arqueología de Patagonia, Tomo 2, pp. 279-294. Neuquén-Buenos Aires. Instituto Nacional de Antropología y Pensamiento Latinoamericano y Universidad Nacional del Comahue.

\section{ÁLVAREZ, M. R., A. LASA y M. E. MANSUR.}

2000. La explotación de recursos naturales perecederos: análisis funcional de los raspadores de la costa norte del canal Beagle. Relaciones de la Sociedad Argentina de Antropología XXV: 275-295.

\section{ÁLVAREZ M. R. y M. E. MANSUR.}

2004. El problema de ciertas variables morfológicas como criterio clasificatorio en la definición de instrumentos: perspectiva desde el análisis funcional de base microscópica. Taller Morfología macroscópica en la clasificación de artefactos líticos: innovaciones y perspectivas, Instituto de Arqueología y Museo, Univ. Nacional de Tucumán (Horco Molle, Tucumán). Resumen publicado en:

http://www.naya.org.ar/eventos/liticos resumenes.htm

\section{ANDERSON-GERFAUD, $P$.}

1981. Contribution méthodologique à l"analyse des micro-traces d"utilisation sur les outils préhistoriques. Tesis de Doctorado. Université de Bordeaux I. MS.

\section{ANDREFSKY, W.}

1994. Raw material availability and the organization of technology. American Antiquity 59 (1): 21-35.

\section{ANDREFSKY, W.}

1998. Lithics. Macroscopic approaches to analysis. Cambridge University Press. 
ANSCHUETZ, K. F., R. H. WILSHUSEN \& C. L. SCHIECK.

2001. An archaeology of landscapes: perspectives and directions. Journal of Archaeological Research 9:157-211.

ARAGÓN, E. y N. FRANCO.

1997. Características de rocas para la talla por percusión y propiedades petrográficas. Anales del Instituto de la Patagonia 25: 187199.

\section{ARCHIBOLD, O. W.}

1995. Ecology of World Vegetation. Londres. Chapman \& Hall. (eds.).

\section{ASCHERO, C.}

1975-1983 Ensayo para una clasificación morfológica de artefactos líticos aplicada a estudios tipológicos comparativos. Informe CONICET y Revisión Cátedra de Ergología y Tecnología (FFyL-UBA). Buenos Aires.

\section{ATALAH, A., W. SIEFELD y C. VENEGAS.}

1980. Antecedentes sobre nicho trófico de Canis g. griseus Gray 1863 en Tierra del Fuego. Anales del Instituto de la Patagonia, 11:259-271.

\section{BAHAMONDES, $M$.}

2004. Las aves en la cultura selk'nam: estudio del registro arqueofaunístico de cuatro sitios de bahía Inútil (Tierra del Fuego). Magallania 32:163-189.

\section{BALFET, H. (Editor)}

1991. Des chaînes opératoires pourquoi faire?". En: Observer l'action technique. Des chaînes opératoires, pour quoi faire?, pp. 11-19. Paris. Éditions du CNRS. 


\section{BAMFORTH, D.}

1986. Technological effiency and tool curation. American Antiquity 51(1): 38-50.

BARBERENA, R.

2008 Arqueología y biogeografía humana en Patagonia meridional. Buenos Aires. Sociedad Argentina de Antropología.

\section{BARQUEZ, R., M. DIAZ y R. OJEDA. (Editores)}

2006. Mamíferos de Argentina: sistemática y distribución. Tucumán. Sociedad Argentina para el estudio de los Mamíferos -SAREMArgentina.

BAVA J.

1998. Los Bosques de lenga en el sector Argentino de Tierra del Fuego. Revista Patagonia Forestal CIEFAP, 6: 5-8.

BEAUVOIR, J. M.

1998 [1915]. Diccionario Shelknam. Indígenas de Tierra del Fuego: sus tradiciones, costumbres y lengua. Ushuaia. Zagier \& Urruty.

\section{BELARDI, J. B.}

2005. Paisajes arqueológicos: un estudio comparativo de diferentes ambientes patagónicos. Oxford. British Archaeological Reports 1390Archaeopress.

BELARDI, J. B. y M. F. GARCÍA.

1994. Distribuciones comparadas en Fuego-Patagonia. Actas $y$ memorias del XI CNAA. Revista del museo de historia natural de San Rafael XIII (1/4): 244-247. 
BELLELLI, C., A. G. GURAIEB y J. A. GARCíA.

1985-1987. Propuesta para el análisis y procesamiento por computadora de desechos de talla lítica (DELCO - Desechos líticos computarizados). Arqueología Contemporánea 1(2): 36-53.

\section{BERIHUETE, M.}

2006. Aportaciones de la carpología al análisis de la gestión de los recursos vegetales en las sociedades cazadoras recolectoras: el grupo selknam de Tierra del Fuego (Argentina), Tesis de Tercer ciclo, Departamento de Prehistoria, Universidad Autonoma de Barcelona. MS.

\section{BERIHUETE, M.}

2010. El papel de los recursos vegetales no leñosos en las economías cazadoras-recolectoras. Propuesta para el estudio de su gestión: el caso de Tierra del Fuego (Argentina). Tesis de doctorado. Departamento de Prehistoria, Universidad Autonoma de Barcelona. MS.

BeriHuete, M., L. CARUSO, G. MASSACCESI, M. E. MANSUR, C. MENSUA, V. PARMIGIANI Y R. PIQUÉ. 2007. Estudios arqueobotánicos en Tierra del Fuego: El caso de la localidad Ewan. Pacarina (Número especial de las Actas del XVI CNAA, Jujuy.) I: 91- 97.

\section{BETTINGER, R. L.}

2001 Holocene Hunter-Gatherers. En: G. Feinman y T. D. Price (eds.), Archaeology at the Millennium, pp. 137-195. New York. Kluwer-Plenum press.

\section{BETTINGER, R. L. \& M. BAUMHOFF.}

1982. The Numic Spread: Great Basin Cultures in Competition. American Antiquity 47:485-503. 
BEYRIES, S. (Editor)

1988. Industries lithiques: Tracélogie et Technologie. Oxford. British Archaeological Reports. International Series 411.

BINFORD, L. R. (Editor)

1977. General Introduction. En: For theory building in Archaeology, pp.

1-10. New York, Academic Press.

\section{BINFORD, L. R.}

1978a. Dimensional analysis of behavior and site structure: learning from an Eskimo hunting stand. American Antiquity 43(3):330-361.

BINFORD, L. R.

1978b. Nunamiut Ethnoarchaeology. New York. Academic Press.

\section{BINFORD, L. R.}

1979. Organization and formation processes: looking and curated technologies. Journal of Anthropological Research 35 (3):255-273.

\section{BINFORD, L. R.}

1980. Willow smoke and Dogs Tails: Hunter-Gatherer settlement systems and archaeological site formation. American Antiquity 45 (1): 420.

BINFORD, L. R.

1982. The archaeology of place. Journal of Anthropological Archaeology 1(1):5-31.

\section{BINFORD, L. R.}

1983. Long-term land use pattern: some implications for Archaeology En: R.C. Dunnel y D.K. Grayson (eds.), Lulu linear punctuated: essays in honour to George Irving Quimby, pp. 27-53. Michigan. University of Michigan. 
BINFORD, L. R.

1992. Seeing the present and interpreting the past-and keeping things straight. En: J. Rossignol y I. Wandsnider (eds.), Space, time, and archaeological landscapes, pp. 43- 59. New York Plenum press.

\section{BINTLIFF, L. \& A. SNODGRASS.}

1988. Off-site pottery distributions, a regional and interregional perspective. Current anthropology 29: 506-413.

\section{BLEED, $P$.}

1986. The optimal design of hunting weapons: maintainability or reliability? American Antiquity 56: 19-35.

BOGDANOVIC, I., E. CAMAROS, H. DE ANGELIS, A. LASA, M. E. MANSUR, A. MAXIMIANO, V. PARMIGIANI, R. PIQUE HUERTA y O. VICENTE.

2009. El paraje de Ewan, un lugar de reunión Selk'nam en el centro de la isla. En: M. Salemme, F. Santiago, M. Álvarez, E. Piana, M. Vázquez y M.E. Mansur (eds.) Arqueología de Patagonia: Una mirada desde el último confín, Tomo 2, pp. 941-956. Ushuaia, Editorial Utopías.

\section{BORDES, F.}

1961. Tipología del Paleolítico Antiguo y Medio. Traducción: L. A. Orquera. 1969. Facultad de Filosofía y Letras. UBA. Buenos Aires.

BORELLA, F.

2004. Tafonomía Regional y Estudios Arqueofaunísticos de cetáceos en Tierra del Fuego y Patagonia Meridional. Oxford. British Archaeological Reports. 1257. Archeopress.

\section{BORELLA, F., L.A. BORRERO y M. A. COZZUOL.}

1996. Los restos de cetáceos en el sitio Punta María 2. Costa atlántica de Tierra del Fuego. Arqueología 6:143-158. 
BORRAZZO, K.

2009. El uso prehistórico de los afloramientos terciarios en la bahía San Sebastián (Tierra del Fuego, Argentina). En: M. Salemme, F. Santiago, M. Álvarez, E. Piana, M. Vázquez y M.E. Mansur (eds.), Arqueología de Patagonia: Una mirada desde el último confín, pp. 291-305. Ushuaia. Editorial Utopías.

BORRAZZO, $\mathrm{K}$.

2010. Arqueología de los esteparios fueguinos. Tesis de doctorado. Facultad de Filosofía y Letras, Universidad de Buenos Aires, Buenos Aires. MS.

BORRAZZO, K.

2012. Raw material availability, flaking quality and hunter-gatherer decisión making in Northern Tierra del Fuego Island (Argentina). Journal of Archaeological Science. En prensa.

\section{BORRAZZO, K., M. D'ORAZIO y M. C. ETCHICHURY.}

2010. Distribución espacial y uso prehistórico de las materias primas líticas del chorrillo miraflores en el norte de la Isla Grande de Tierra del Fuego (Argentina). Revista chilena de antropología 22:77-97.

\section{BORRAZZO, K., F. MARTIN, R. BARBERENA y L. A. BORRERO.}

2007. Prospección arqueológica del norte de la isla Grande de Tierra del Fuego. Pacarina (Número especial de las Actas del XVI CNAA, Jujuy.) III:315-321.

BORRAZZO, K., F. MARTIN, R. BARBERENA y L. A. BORRERO.

2008. Geografía cultural y circulación humana en el norte de Tierra del Fuego. En: L.A. Borrero y N.V. Franco (comp.), Arqueología del extremo sur del continente americano, pp. 227-249. Buenos Aires. CONICET-IMHICIHU. 
BORRERO, L. A.

1979. Excavaciones en el alero "Cabeza de León". Isla Grande de Tierra del Fuego. Relaciones XIII:255-271.

BORRERO, L. A.

1985. La economía prehistórica de los habitantes del norte de la isla grande de Tierra del Fuego. Tesis de doctorado. Facultad de Filosofía y Letras, Universidad del Buenos Aires. MS.

BORRERO, L. A.

1991. Los selk'nam (onas). Su evolución cultural. Ed. Búsquedayuchán, Buenos Aires.

BORRERO, L. A.

1998. El proyecto Magallania y el norte de Tierra del Fuego. La evidencia costera. En: Arqueología de la Patagonia meridional ("Proyecto Magallania"). Col. Temas de Arqueología, pp. 13-28. Buenos. Aires. Ed. Dunken.

BORRERO L. A.

2007. Longitudinal Taphonomic Studies in Tierra del Fuego, Argentina. En: M. Gutierrez, L. Miotti, G. Barrientos, G. Mengoni Goñalons y M. Salemme, (eds.) Taphonomy and Zooarchaeology in Argentina, pp. 219-233. Oxford. British Archaeological Reports. Internacional Series 1601.

BORRERO, L.A. y M. CASIRAGHI.

1980. Excavaciones en el sitio Bloque Errático 1 (San Sebastián, Tierra del Fuego). Relaciones XIV (1): 129-142.

\section{BORRERO, L. A., M. CASIRAGHI y M. I. HERNÁNDEZ LLOSAS.}

1981. Arqueología del Norte de Tierra del Fuego. En: Publicaciones del Museo Territorial 1: 1-23. Ushuaia. 
BORRERO, L.A., M. CASIRAGHI \& H.D. YACOBACCIO.

1985. First Guanaco-Processing Site in Southern South America. Current Anthropology 26(2):273-276.

BORRERO, L. A. y J. L. LANATA.

1988. Estrategias adaptativas representadas en los sitios de estancia María Luisa y cabo San Pablo. En: Precirculados IX Congreso Nacional De Arqueología Argentina, pp. 166-174. Facultad de Filosofía y Letras, Universidad del Buenos Aires.

BORRERO, L. A., J. L. LANATA y B. N. VENTURA.

1992. Distribuciones de hallazgos aislados en Piedra del Águila. En: Borrero, L. A. y J. L. Lanata (comp); Análisis espacial en la arqueología patagónica, pp. 9-20. Buenos Aires, ediciones ayllu.

BORRERO, L. A., F. M. MARTIN, V. D. HORWITZ, N. V. FRANCO, C. FAVIER DUBOIS, F. BORELLA, F. CARBALLO MARINA, P. CAMPAN, R. GUICHÓN, A. S. MUÑOZ, R. BARBERENA, F. SAVANTI y K. BORRAZZO.

2008. Arqueología de la costa norte de Tierra del Fuego. En: I. Cruz, S. Caracotche, X. Senatore y B. Ladrón de Guevara (eds.), Arqueología de la costa patagónica, pp. 250-264. Río Gallegos. Universidad Nacional de la Patagonia Austral.

BORRERO, L., K. BORRAZZO, I. GARIBOTTI y C. PALLO.

2011. Concentraciones de pilas de rocas en la cuenca superior del río Santa Cruz (Argentina). Magallania. 39:193 - 206.

\section{BOY C.C., E. MORRICONI y J. CALVO.}

2005. Reproducción del puyen, Galaxias maculatus, en el límite sur de su distribución (Río Ovando, Tierra del Fuego). Resúmenes del XI Congreso Latinoamericano de Ciencias del Mar, XXV Congreso de Ciencias del Mar de Chile, Viña del Mar, Chile. 


\section{BRIDGES, L.}

1978. [1951]. The uttermost part of the Earth. Traducción: El último confín de la Tierra. Buenos Aires. Ed. Marymar.

\section{BRIZ GODINO, I.}

2004. Dinàmiques econòmiques de producció-consum en el registre lític caçador-recol-lector de l"extrem sud americà. La societat yàmana, Tesi doctoral, Universitat Autònoma de Barcelona, MS.

\section{CAVIGLIA, S. E.}

1985-86. Nuevos restos de cánidos tempranos en sitios arqueológicos de Fuego-Patagonia. Anales del Instituto de la Patagonia, Serie Ciencias Sociales, 16: 85-93.

\section{CAMARÓS, E. y V. PARMIGIANI.}

2007. Análisis del Material Faunístico de sitios de la Localidad Ewan (Tierra del Fuego). Pacarina (Número especial de las Actas del XVI CNAA, Jujuy.), I: 619-623.

\section{CAMARÓS, E., V. PARMIGIANI \& E. VERDÚN.}

2010. Differential faunal resources management in ritual spaces and domestic spaces in the selk'nam society (Argentina, Tierra del Fuego). En: K. Hardy (ed.) Archeological Invisibility and Forgotten Knowledge, pp. 192-201. British Archaeological Reports, International Series 2183.

\section{CAMINOS, $\mathbf{R}$.}

1980. Cordillera fueguina. En: Geología regional Argentina 2:14631501. Córdoba. Academia Nacional de Ciencias.

\section{CAMINOS, R., J. M. HALLER, O.LAPIDO, A. LIZUAIN, R. PAGE y V.RAMOS.} 1981. Reconocimiento geológico de los andes fueguinos. Territorio nacional de Tierra del Fuego. En: actas del VIII Congreso Geológico Argentino, pp. 759-786. San Luis. 


\section{CAMPAN, P. y L. MANZI.}

2000. Rayas y centollas. Uso de la costa en la Isla Grande de Tierra del Fuego a través del registro arqueológico de la fauna ictícola y de las fuentes etnohistóricas. En: J. Belardi, F. Carballo Marina, S. Espinosa (eds.), Desde el País de los Gigantes. Perspectivas arqueológicas en Patagonia. Tomo II, pp. 533-540. Río Gallegos. Universidad Nacional de la Patagonia Austral.

\section{CAMPAN, P. y G. PIACENTINO.}

2004. Análisis arqueofaunístico de peces del norte de la isla Grande de Tierra del Fuego, Argentina. En: L.A. Borrero y R. Barberena (comp.), Arqueología del Norte de la Isla Grande de Tierra del Fuego, pp. 87105. Buenos Aires. Editorial Dunken.

\section{CASTRO, A.}

1994. El análisis funcional de materiales líticos por medio de la observación microscópica de huellas de uso: un modelo alternativo de clasificación tipológica. Tesis de Doctorado. Facultad de Ciencias Naturales y Museo, Universidad Nacional de La Plata. MS.

\section{CASTRO, A.}

1996. El análisis funcional de material lítico: un punto de vista. Revista del Museo de La Plata (Nueva Serie). Tomo IX. Pág. 318-326.

\section{CAVIGLIA, S. E.}

1985-86. Nuevos restos de cánidos tempranos en sitios arqueológicos de Fuego-Patagonia. Anales del Instituto de la Patagonia, Serie Ciencias Sociales, 16: 85-93.

\section{CHAPMAN, A.}

1986. Los selk'nam. La vida de los onas. Buenos aires. Emecé. 


\section{CHAPMAN, A.}

2008. El Fin de Un Mundo: Los Selk'nam de Tierra del Fuego. Ushuaia: Zagier \& Urruty.

\section{CHARLIN, J.}

2002. Aprovisionamiento de materias primas líticas en el $\mathrm{NO}$ de la provincia de La Pampa a fines del siglo XIX. En: D. Mazzanti, M. Berón y F. Oliva. (eds.) Del Mar a Los Salitrales. 10000 años de historia pampeana en el umbral del tercer milenio, pp.205 - 218. Mar del Plata. Universidad Nacional de Mar del Plata y Sociedad Argentina de Antropología.

\section{CHURCH, T.}

1994. The "S" word: sampling in lithic resource studies. En: Lithic Resource Studies: a Sourcebook for Archaeologists, Lithic Technology, Special Publication $\mathrm{N}^{\circ}$ 3, pp. 33-44. Oklahoma. Department of Anthropology. University of Tulsa.

\section{CLEMENTE CONTE, I.}

1995. Instrumentos de trabajo líticos de los Yámanas (Canoeros nómades de la Tierra del Fuego): una perspectiva desde el análisis funcional. Tesis de doctorado. Departamento de Prehistoria, Universitat Autònoma de Barcelona. MS.

\section{CLEMENTE CONTE, I.}

1997. Los instrumentos líticos de Túnel VII: una aproximación etnoarqueológica. Treballs d'etnoarqueologia, 2. Universidad Autónoma de Barcelona.

\section{CLEMENTE CONTE I. y F. GÓMEZ ROMERO.}

2008. Microwear análisis of retouched glass fragments from fortlet Miñana, Azul, Argentina 1860-1863. International Journal of Historical Archaeology 12(3) 248-263. 


\section{CLEMENTE CONTE I. y F. GÓMEZ ROMERO.}

2006. Análisis de vidrios 'retocados' del fortín Miñana (Azul, Provincia de Buenos Aires)". En: A Tapia, M. Ramos, y C. Baldasarre (eds), Estudios de arqueología histórica, pp. 109- 124. Tierra del Fuego, Museo de Río Grande.

\section{CLEMENTE CONTE, I. y X. TERRADAS.}

1993. Matières premières et fonctions: I' exemple de l'outillage lithique des Yamanas (Terre du Feu). En : Anderson P., S. Beyries, M. Otte y H. Plisson (eds), Traces et fonction: les gestes retrouvés. 50: 513-521. ERAUL.

\section{CLEMENTE I.; M. MANSUR; X. TERRADAS y A. VILA MITJA.}

1996. Al César lo que es del César: los "instrumentos" líticos como instrumentos de trabajo. En: J.Gómez Otero (coord.), Arqueología. Sólo Patagonia. Actas de las II Jornadas de Arqueología de la Patagonia, pp. 319-332. Puerto Madryn. CENPAT.

COLLADO, L.

2001. Los bosques de Tierra del Fuego: Análisis de su estratificación mediante imágenes satelitales para el inventario forestal de la provincia. Multequina 10:1-15.

\section{COLLADO, L.}

2007. La vegetación de Tierra del Fuego: de la estepa a la selva. En: C. Godoy Martinez (ed.), Patagonia Total, Antartida e islas Malvinas. pp. 755-772. Buenos Aires. Barcel Baires ediciones.

\section{COLLANTES, M. B., J. ONTIVERO y O. BIANCIOTTO.}

1990. Análisis de las comunidades de Nothofagus sp. de Tierra del Fuego. Parodiana 6 (1): 441-451. 
CORONATO, A., A. M. BORROMEY y J. RABASSA.

2007. Paleoclimas y paleoescenarios en la Patagonia Austral y en Tierra del Fuego durante el Cuaternario. Boletín Geográfico de la Universidad Nacional del Comahue. Número Especial de las Jornadas sobre el Calentamiento Global: 18-28.

CORONATO, A.J. RABASSA, A. BORROMEI, M. QUATROCCIO \& G. BUJALESKY.

1999. Nuevos datos sobre el nivel relativo del mar durante el Holoceno en el Canal Beagle, Tierra del Fuego, Argentina. En: Las actas del Congreso Argentino de Geomorfología y Cuaternario 1: 27-28. Santa Rosa.

CORONATO, A., C. ROIG, L. COLLADO \& F. ROIG.

2006. Geomorphologic emplacement and vegetation characteristics of Fuegian peatlands, southernmost Argentina, South America. En: I. P., Martini, A. M. Cortizas \& W. Chesworth (eds.) Peatlands :evolution and records of environmental and climate changes, pp. 111-128. Elsevier, Netherlands.

CORONATO, A., F. CORONATO, E. MAZZONI \& M. VAZQUEZ.

2008. The physical geography of Patagonia and Tierra del Fuego. En: J. Rabassa. (edit), Late Cenozoic of Patagonia and Tierra del Fuego. Development in Quaternary Sciences, 11(3):13-56. Amsterdam. Elsevier.

CORONATO, A., M. SEPPÄLÄ, F. PONCE \& J. RABASSA.

2009. Glacial geomorphology of the Pleistocene Lake Fagnano ice lobe, Tierra del Fuego, southern South America. Geomorphology 112: 67-81.

CRESSWELL, R.

1983. Transferts de techniques et chaînes opératoires. Techniques et Culture 2, pp. 143-169. 
DAVID, N. \& C. KRAMER.

2001. Ethnoarchaeology in Action. Cambridge University Press.

DE AGOSTINI, A. M.

1956. Treinta años en la Tierra del Fuego. Buenos Aires. Editorial Peuser.

DE ANGELIS, $\mathrm{H}$.

2007. La utilización de materias primas introducidas en el período de contacto europeo en Tierra del Fuego. Pacarina (Número especial de las Actas del XVI CNAA, Jujuy.) II: 631-635.

DE ANGELIS, $\mathrm{H}$.

2009. El vidrio como materia prima introducida en el período de contacto europeo en Tierra del Fuego. En: M. Salemme, F. Santiago, M. Álvarez, E. Piana, M. Vázquez y M.E. Mansur (eds.) Arqueología de Patagonia: Una mirada desde el último confín, Tomo 1, 335- 348. Ushuaia, Editorial Utopías.

DE ANGELIS, $\mathrm{H}$.

2012. Recursos minerales y de origen industrial. En: Arqueología del Hain. Investigaciones etnoarqueológicas en un sitio ceremonial de la sociedad Selknam de tierra del fuego. Implicancias teóricas y metodológicas para los estudios arqueológicos. Treballs d"etnoarqueologia 9, Madrid. CSIC. pp 185-198.

DE ANGELIS, H., A LASA, M. E. MANSUR, L. SOSA y G. VALDEZ.

2009. Análisis tecnomorfológico y funcional de Artefactos de Vidrio: Resultados de un Programa de Experimentación. En: T. Palacios et al. (eds), Arqueometría latinoamericana. Segundo Congreso Argentino y Primero Latinoamericano. pp. 134 -141. Buenos Aires. Comisión Nacional de Energía Atómica. 
DE ANGELIS H. y M. E. MANSUR.

2010. Artefactos de vidrio en contextos cazadores-recolectores. Consideraciones a partir del análisis tecnológico y funcional. Revista Atlántica-Mediterránea de Prehistoria y Arqueología Social. 12(4):5973.

DE ANGELIS, H., M. E. MANSUR y R. PIQUE.

2012a. Ethnoarchaeology and experimentation. Studies on the use of glass as raw material in the Selknam society. En: Ethnoarchaeology: current research and field methods. British Archaeological Reports. En prensa.

DE ANGELIS, H., V. PARMIGIANI, M. y C. ALVAREZ SONCINI.

2012b. Prospecciones en el corazón de la isla Grande de Tierra del Fuego. En: Tendencias teórico-metodológicas y casos de estudio en la arqueología de Patagonia. En prensa.

\section{DEMARS, P. Y.}

1994. L' économie du silex au Paléolithique supérieur dans le Nord de l'Aquitaine. Tesis de Doctorado presentada en la Universidad de Bordeaux I. Francia. Ms.

\section{DUNNELL, R. y W. DANCEY.}

1983. The siteless survey: a regional scale data collection strategy. En: M. Schiffer (ed.), Advances in archaeological method and theory. 6:267287. New York. Academic press.

\section{DYSON-HUDSON, R. \& E. SMITH.}

1978. Human territoriality: an ecological reassessment. American Anthropologist 80: 21-41.

\section{EBERT, J.}

1992. Distributional archaeology. New Mexico. University of New Mexico press. 


\section{ESTÉVEZ, J., E. L. PIANA, A. SCHIAVINI \& N. JUAN-MUNS.}

2001. Archaeological Analisis of the Shell Middens in the Bealge Cannel, Tierra del Fuego Island. International Journal of Osteoarchaeology 11:24-33.

\section{ESTÉVEZ, J. Y A. VILA (coords.)}

1995 Encuentros en los conchales fueguinos. Treballs d'Etnoarqueologia, 1. Bellaterra: CSIC-UAB.

\section{FAVIER DUBOIS, C.}

1998. Dinámica sedimentaria y cambios ambientales en relación al registro arqueológico y tafonómico del Cerro Cabeza de León. Anales del Instituto de la Patagonia, Serie Ciencias Humanas, 26:137-152.

\section{FAVIER DUBOIS, C.}

1999. Pedogénesis y formación del registro en bahía San Sebastián (Tierra del Fuego) y lago Roca (Santa Cruz). En: Soplando en el viento. Actas de las III Jornadas de Arqueología de la Patagonia, pp. 319-332. Neuquén- Buenos Aires. Instituto Nacional de Antropología y Pensamiento Latinoamericano y Universidad Nacional del Comahue.

\section{FAVIER DUBOIS, C.}

2001. Análisis geoarqueológico de los procesos de formación del registro, cronología y paleoambientes, en sitios arqueológicos de fuego-patagonia. Tesis de doctorado. Facultad de Ciencias Exactas y Naturales, Universidad de Buenos Aires. Ms.

\section{FIORE, D.}

1999. Diseños y técnicas en la decoración de artefactos: el caso de los sitios del canal Beagle, Tierra del Fuego. XII Congreso de Arqueología Argentina. Córdoba. 


\section{FIORE, D.}

2002. Body painting in Tierra del Fuego. The power of images in the uttermost part of the world. PhD Thesis. University College London. Institute of Aechaeology. Londres.

\section{FLEGENHEIMER N., Y C. BAYÓN.}

2002. ¿Cómo, cuándo y dónde? Estrategias de abastecimiento lítico en la pampa bonaerense. En: D. Mazzanti, , M. Berón y F. Oliva (eds.) Del Mar a Los Salitrales. 10000 años de historia pampeana en el umbral del tercer milenio pp. 231-241. Mar del Plata. Universidad Nacional de Mar del Plata y Sociedad Argentina de Antropología.

FOLEY, R.

1981a. Off-site archaeology and human adaptation in eastern Africa. An analysis of regional artefact density in the Amboseli, southern Kenia. Cambridge monographs in African archaeology 3. Oxford. BAR international series 97.

\section{FOLEY, R.}

1981b. Off-site archaeology: an alternative approach for the short sited. En: I. Hodder; N. Hammond y G. Isaac (eds.), Pattern in the past: essays in honour of David Clarke, pp. 157-183. Cambridge. Cambridge university press.

\section{FRANCO N.V. Y E. ARAGÓN.}

2002. Muestreo de fuentes potenciales de aprovisionamiento lítico: un caso de estudio. En: D. Mazzanti, M. Berón y F. Oliva. (eds.) Del Mar a Los Salitrales. 10000 años de historia pampeana en el umbral del tercer milenio, pp. 243-250. Mar del Plata. Universidad Nacional de Mar del Plata y Sociedad Argentina de Antropología.

\section{FRANCO, N.V. Y E. ARAGÓN.}

2004. Variabilidad en fuentes secundarias de aprovisionamiento lítico: El caso del sur del lago Argentino (Santa Cruz, Argentina). Estudios Atacameños 28:71-85. 


\section{FRANCO N. Y N. CIRIGLIANO.}

2009. Materias primas y movilidad humana entre las cuencas de los ríos Santa Cruz y Chico (provincia de Santa Cruz, Argentina): primeros resultados. En M. Salemme, F. Santiago, M. Álvarez, E. Piana, M. Vázquez y M.E. Mansur (eds.) Arqueología de Patagonia: Una mirada desde el último confín, pp. 361-368. Ushuaia. Editorial Utopías.

FRANGI, J. L., M. D. BARRERA, J. PUIGDEFÁBREGAS, P. F. YAPURA , A. M. ARAMBARRI y L. L. RICHTER.

2004. Ecología de los bosques de Tierra del Fuego. En: M. Arturi, J. Frangi y J. F. Goya (eds), Ecología y manejo de los bosques de argentina. La Plata. Editorial de la Universidad Nacional de La Plata.

GALLARDO, C.

1998 [1910]. Los onas de Tierra del Fuego. Buenos Aires. Zagier \& Urruty Publications.

\section{GAMBLE, C.}

1986. The paleolithic settlement of Europe. Cambridge, Cambridge University Press.

\section{GARCÍA, M. F.}

1993-94. Las perspectivas de la arqueología distribucional en el noreste de Tierra del Fuego. Shincal 4:103-121.

\section{GENESTE J. M.}

1983. Approvisionnement en silex au Paléolithique supérieur en Périgord : le site de plein air du Caillou dans la vallée de la Dordogne. En: Exemples périgourdins d'économie des matières premières lithiques, pp. 228-235. Paris. 


\section{GENESTE, J. M.}

1985 Analyse lithique d'industries moustériennes du Périgord: une approche technologique du comportament des groupes humains au Paléolithique moyen. Thèse de $3^{\circ}$ cycle, Université de Bordeaux I.

\section{GENESTE, J. M.}

1991. Systèmes techniques de production lithique: variations technoéconomiques dans les processus de réalisation des outillages paléolithiques. Techniques et culture. 17-18: 1-35.

\section{GENESTE, J. M.}

1992. L`approvisionnement en matières premières dans les systèmes de production: la dimension spatiale de la technologie. Tecnología y Cadenas Operativas Líticas. Treballs d’ Arqueologia I: 2-35.

\section{GENESTE, J. y J. RIGAUD.}

1989. Matières premières lithiques et occupation de l'espace. Cahiers du Quaternaire 13:205-218.

GODAGNONE R. E y J. C. DE LA FUENTE.

2011. Los suelos de Bahía Esperanza, península de Tabarin, Antártida Argentina. Contribuciones Científicas GAEA, 23:131-149.

\section{GONZÁLEZ-GUILLOT M., R. ACEVEDO y M. ESCAYOLA.}

2010. El Gabro Rancho Lata: Magmatismo mesozoico off-axis de la cuenca marginal Rocas Verdes en los Andes Fueguinos de Argentina. Revista Mexicana de Ciencias Geológicas, 27, 3:431-448.

\section{GONZÁLEZ RUIBAL, A.}

2003. La experiencia del otro. Una introducción a la etnoarqueología. Madrid. Editorial Akal. 


\section{GONZÁLEZ RUIBAL, A.}

2009. De la Etnoarqueología a la Arqueología del Presente. Mundos Tribales. Una visión etnoarqueológica. 16-27.

GOULD, $\mathbf{R}$.

1978. The Anthropology of Human Residues. American Anthropologist, 80: 815-835.

\section{GUICHÓN, R. A.}

2000. Agenda para una evaluación en la antropología biológica de Patagonia Austral. En: J. Belardi, F. Carballo Marina, S. Espinosa (eds.), Desde el País de los Gigantes. Perspectivas arqueológicas en Patagonia. Tomo I, pp. 99-108.Río Gallegos. Universidad Nacional de la Patagonia Austral.

\section{GUICHÓN, R. A., A.S. MUÑOZ y L.A. BORRERO.}

2000. Datos para una tafonomía de restos óseos humanos en Bahía San Sebastián, Tierra del Fuego. Relaciones XXV:297-311.

\section{GUSINDE, M.}

1982 [1937] Los selk'nam. Los Indios de Tierra del Fuego, tomo I (I y 2). Centro Argentino de Etnología Americana, Buenos Aires.

\section{HAYDEN, B.}

1979. Palaeolithic reflections: lithic technology and ethnographic excavations among Australian Aborigines. New Jersey. Australian Institute of Aboriginal Studies.

\section{HAYDEN, B., N. FRANCO \& J. SPAFFORD.}

1996. Evaluating lithics strategies and desing criteria. En: G. Odell (ed.), Stone Tools: Theoretical Insigths into Human Prehistory. New York. Plenum Press. 


\section{HERNANDO, A.}

2006. Arqueología y Globalización. El problema de la construcción del "otro" en la postmodernidad. Complutum, 17:221-234.

HODDER, I.

1982a. Symbols in action. Ethnoarchaeological studies of material culture.

\section{HODDER, I.}

1982b. The Present Past. An introduction to anthropology for archaeologists.

HORWITZ, V.

1995. Ocupaciones prehistóricas en el sur de Bahía San Sebastián (Tierra del Fuego, Argentina). Arqueología 5:105-136.

\section{HORWITZ, V.}

1996-98. Espíritu Santo 1: primeros trabajos de campo en el extremo norte de la costa atlántica fueguina. Palimpsesto 5:151-159.

\section{HORWITZ, V.}

2004. Arqueología de la costa atlántica septentrional de Tierra del Fuego, Argentina. En: L.A. Borrero y R. Barberena (comp.) Arqueología del Norte de la Isla Grande de Tierra del Fuego, pp. 29-54. Buenos Aires. Editorial Dunken.

HORWITZ, V., L.A. BORRERO Y M. CASIRAGHI.

1993-94. San Julio 2 (Tierra del Fuego). Estudios del registro arqueológico. Relaciones XIX:391-415.

\section{INGOLD, T.}

1997. Eight themes in the Anthropology of technology. En: P. Harvey (ed.) Techology as skilled practice. Social Analysis 41 (1): 106-138. 


\section{ITURRASPE, R. y A. URCIUOLO.}

2007. Los Recursos Hídricos de Tierra del Fuego. En: Patagonia Total. Antártida e Islas Malvinas, pp 733-754. Buenos Aires. Barcel-Baires,

JACKSON, D.

1987. Componente lítico del sitio arqueológico Tres Arroyos. Anales del Instituto de la Patagonia. Serie Ciencias Sociales 17:67-72.

\section{JACKSON, D.}

2002. Los instrumentos líticos de los primeros cazadores de Tierra del Fuego. Santiago. Centro de investigación Diego Barros Arana.

\section{JUAN-MUNS I PLANS, $\mathbf{N}$.}

1992. La pesca com alternative económica per als Yámana, nómades canoers del Canal Beagle. (Tierra del Fuego, Argentina) Tesis de doctorado. Departamento de Prehistoria, Autonoma de Barcelona. MS.

\section{KARLIN, C,}

1984. Le débitage du silex à Pincevent, précedé de quelques notes de vocabulaire. En: Tixier, J. (ed.), Prehistoire de la Pierre taillée 2. Économie du débitage laminaire, pp. 39-44. París. CNRS.

\section{KARLIN, C,}

1991a. Connaissances et savoir-faire: comment analyser un processus technique en Préhistoire: Introduction. En: R. Mora, X. Terradas, A. Parpal y C. Plana (eds.), Tecnología y cadenas operativas líticas, pp. 99-124. Universidad Autónoma de Barcelona.

\section{KARLIN, C.}

1991b. Analyse d'un processus technique: le débitage laminaire des magdaléniens de Pincevent (Seine et Marne). En: R. Mora, X. Terradas, A. Parpal y C. Plana (eds.), Tecnología y cadenas operativas líticas, pp.125-162. Universidad Autónoma de Barcelona. 


\section{KARLIN, C., P. BODU y J. PELLEGRIN.}

1991. Processus techniques et chaines opératoires. Comment les préhistoriens s'approprient un concept élaboré par les ethnologues. En: H. Balfet (ed.), Observer l'action technique. Des chaines opératoires, pour quoi faire?, pp. 101-117. Paris. Éditions du CNRS.

\section{KEELEY, L. H.}

1974: Technique and methodology in microwear studies: A critical review. World Archaeology, 5:323-336.

\section{KEELEY L. H.}

1980. Experimental determination of stone tool uses: a microwear analysis. Univ. Chicago Press.

\section{KELLY, R. L.}

1988. The three sides of a biface. American Antiquity 53 (4):717-734.

\section{KELLY, R. L.}

1995. The foraging spectrum. Diversity in hunter-gatherer lifeways. Washington and London. Smithsonian Institution press.

\section{L'HEUREUX, G. L.}

2007. Patrones morfológicos de Lama guanicoe en el extremo sur de la Patagonia continental e insular. En: F. Morello, M. Martinic, A. Prieto y G. Bahamonde (eds.), Arqueología de Fuego-Patagonia: levantando piedras, desenterrando huesos... y develando arcanos, pp. 95-107. Punta Arenas. Ediciones CeQua.

\section{L'HEUREUX, G. L.}

2008. El estudio arqueológico del proceso coevolutivo entre las poblaciones humanas y las poblaciones de guanacos en Patagonia Meridional y Norte de Tierra del Fuego. Oxford. British Archaeological Reports International Series 1751. Archaeopress. 


\section{LAMING-EMPERAIRE, A.}

1965. Mission archeólogique française au Chili austral. Journal de la Société des Américanistes LIV(I):125-135.

\section{LAMING-EMPERAIRE, A.}

1968a. Missions archéologiques françaises au Chili Austral et au Brésil Méridional. Journal de la Société des Américanistes. 57, (1):77-99.

\section{LAMING-EMPERAIRE, A.}

1968b Le site Marazzi en Terre de Feu. Rehue № 1: 133-143.

\section{LAMING-EMPAREAIRE, A.}

1972a. Sites préhistoriques de Patagonie chiliene. Objets et Mondes XII (2): 201-224.

\section{LAMING-EMPAREAIRE, A.}

1972b. Présentation historique de la province de Magellan (Patagonie chilienne). Objets et Mondes XII (2): 159-184.

\section{LAMING-EMPERAIRE, A., D. LAVALLEE y R. HUMBERT.}

1972. Le site de Marazzi en Terre de Feu. Objets et Mondes. XII (2), 225-244.

\section{LANATA, J. L.}

1985 Sitios arqueológicos en el área de Estancia María Luisa, Tierra del Fuego. En: Actas del VIII Congreso Nacional de Arqueología Argentina, Concordia.

\section{LANATA, J.L. (comp.)}

1993 Estados alterados: Procesos de formación y conjuntos arqueológicos de Rancho Donata, Tierra del Fuego. En: Explotación de recursos faunísticos en sistemas adaptativos americanos, Arqueología Contemporánea (Edición Especial) 4:163-176. 


\section{LANATA, J. L.}

1995. Paisajes arqueológicos y propiedades del registro en el sudeste fueguino. Tesis de doctorado. Facultad de Filosofía y Letras, Universidad del Buenos Aires. MS.

LANATA, J. L.

1996 La diversidad instrumental en el norte de Península Mitre, Tierra del Fuego. Arqueología 6: 159-197.

\section{LATORRE, C.}

1998. Paleontología de mamíferos del alero Tres Arroyos 1. Tierra del Fuego, XII Región, Chile, Anales del instituto de la Patagonia, Serie Ciencias Naturales, 26: 77-90.

\section{LEIPUS, $M$.}

2001 Análisis de Rastros de Uso Experimentales en Materias Primas Líticas de la Región Pampeana. En: Actas del IX Congreso Nacional de Arqueología Uruguaya: Arqueología Uruguaya Hacia el Fin del Milenio (Montevideo), I: 491-503.

\section{LEIPUS, $M$.}

2004 Evidencias del uso sobre madera de artefactos líticos manufacturados por talla en el área Interserrana: el aporte del análisis funcional. En: G. Martínez, M. A. Gutierrez, R. Curtoni, M. Berón y P. Madrid (eds), Aproximaciones contemporáneas a la arqueología Pampeana. Perspectivas teóricas, metodológicas, analíticas y casos de estudio, pp.147-168. Olavarría. Facultad de Ciencias Sociales, Universidad Nacional del Centro de la Provincia de Buenos Aires.

\section{LEIPUS, $M$.}

2006. Análisis de los modos de uso prehispánicos de las materias primas líticas del Sudeste de la Región Pampeana: una aproximación funcional. Tesis de Doctorado. Facultad de Ciencias Naturales y Museo, Universidad Nacional de La Plata. MS. 


\section{LEIPUS, M. y M. E. MANSUR.}

2007. El análisis funcional de base microscópica aplicado a materiales heterogéneos. Perspectivas metodológicas para el estudio de las cuarcitas de la Región Pampeana. En: Arqueología de las Pampas. Tomo I, pp 179-200. Buenos Aires. Sociedad Argentina de Antropología.

\section{LENCINAS M. V., G. MARTINEZ PASTUR, E. GALLO y C. BUSSO.}

2001 Riqueza y cobertura del sotobosque en un rango de calidades de sitio en bosques de Nothofagus pumilio. Boletín de la sociedad Argentina de botánica 36:95.

\section{LEROI-GOURHAN, A.}

1964. Le Geste et la Parole I. Technique et langage. Paris. Albin Michel.

\section{LIZARRALDE, M., BIANCHI, N. y J.GOLDENBERG.}

1986a. Ecología de dos poblaciones de roedores silvestres de Tierra Del Fuego I: Dinámica Poblacional. Physys. 44 (106): 67-72.

LIZARRALDE, M., BIANCHI, N. y J. GOLDENBERG.

1986b. Ecología de dos poblaciones de roedores silvestres de Tierra Del Fuego II: Área habitacional, movilidad y heredabilidad. Physys 44 (106): 73-81.

LIZARRALDE, M., ESCOBAR, J., S.ALVAREZ y G. DEFERRARI. 1994. Un nuevo registro de Euneomys en Tierra del Fuego.Trabajo presentado en IX Jornadas Argentinas de Mastozoología. Córdoba.

\section{LLORIS, D. y J. RUCABADO.}

1991. Ictiofauna del Canal Beagle (Tierra del Fuego), Aspectos ecológicos y análisis biogeográfico. $\mathrm{N}^{\circ}$ 8. Madrid. Publicaciones Especiales Instituto Español de Oceanografía. Ministerio de Agricultura, Pesca y Alimentación. 


\section{LOTHROP, S.}

2002 [1928]. The indians of Tierra del Fuego. Buenos Aires. Zagier \& Urruty.

LOW, B. S.

1990. Human Responses to Environmental Extremeness and Uncertainty: A CrossCultural Perspective. En: E.Cashdan (ed.), Risk and Uncertainty in Tribal and Peasant Economics, pp. 229-55. Westview Press, Boulder.

\section{LUEDTKE, B.}

1979. The identification of sources of chert artifacts. American Antiquity 44:744-756.

\section{MAGNE, $M$.}

1989. Lithic reduction stage and assemblage formation processes. En: S. Amick y R Mauldin (eds), Experiments in Lithic Tecnology, British Archaeological Reports. International Series, 528: 15-31.

\section{MANDRYK, C. A. S.}

1993. Hunter-Gatherer Social Costs and the Nonviability of Submarginal Environments. Journal of Anthropological Research 49:3971.

MANSUR-FRANCHOMME, M. E.

1983a. Traces d'utilisation et technologie lithique: exemples de la Patagonie. Tesis de Doctorado. Institut du Quaternarie, Université de Bordeaux I.infor. Bât géologie, Bordeaux.

\section{MANSUR-FRANCHOMME, M. E.}

1983b. Scanning electron microscopy of dry hide working tools: the role of abrasives and humidity in microwear polish formation. Journal of Archaeological Science. 10: 223-230. 


\section{MANSUR-FRANCHOMME, M. E.}

1984. Archéologie de la Patagonie: l'industrie "Nivel 11" de la province de Santa Cruz (Argentine). Technologie lithique et traces d'utilisation. British Archaeological Reports, International Series, 216. Oxford.

MANSUR-FRANCHOMME, M. E.

1986. Microscopie du matériel lithique préhistorique: Traces d'utilisation, altérations naturelles, accidentelles et technologiques. Cahiers du Quaternaire, № 9, Bordeaux, Éditions du C.N.R.S.

\section{MANSUR-FRANCHOMME, M. E.}

1986-1990. Instrumentos líticos: aspectos da análise funcional. Arquivos do Museu de Historia Natural. 11: 115-169.

\section{MANSUR-FRANCHOMME, M. E.}

1987a. El análisis funcional de artefactos líticos. Cuadernos. Serie Técnica 1. Instituto Nacional de Antropología. Buenos Aires.

\section{MANSUR-FRANCHOMME, M. E.}

1987b. Outils etnographiques de Patagonie enmanchement et traces d"utilisation. La main et l"outil: manches et enmanchements préhistoriques. Travaux de la maison de l'Orient 15:297-306.

\section{MANSUR, M. E.}

1991. Microwear on quartzs crystals and obsidian: its contribution to use-wear analysis on heterogeneous materials. Comunicación presentada en el VI International Flint Symposium. Madrid.

\section{MANSUR, M. E.}

1997. Functional analysis of polished stone-tools: some considerations about the nature of polishing. En: M.A. Bustillo y A. Ramos Millán (eds.), Siliceous rocks and Culture, pp. 465-486. Universidad de Granada. 


\section{MANSUR, M. E.}

1999. Análisis funcional de instrumental lítico: problemas de formación y deformación de rastros de uso. En: Actas y Trabajos, XII Congreso Nacional de Arqueología Argentina, pp. 355-366, La Plata.

MANSUR, M. E.

2002. El Corazón de la Isla. Arqueología de la zona central de Tierra del Fuego. En: C. Odone y P. Mason (eds.), Mundos Fueguinos. Doce Miradas. Sobre Selk'nam, Yaganes y Kawesqar. Taller Experimental Cuerpos Pintados, pp. 148-166. Santiago de Chile.

MANSUR, M. E.

2006. Los unos y los otros. El uso de fuentes etnográficas y etnohistóricas en la interpretación arqueológica. En: Etnoarqueologia de la prehistoria: més enllà de l'analogia. Treballs d"etnoarqueologia 6: 316-336. Madrid. CSIC.

\section{MANSUR, M. E., A. CASTRO y M. ÁLVAREZ.}

2009. Perspectivas en el análisis de conjuntos líticos. Teoría, metodología, nuevas tendencias. En: A. Austral y M. Tamagnini (comp.), Problemáticas de la arqueología contemporánea, Tomo II, pp. 277-279. Río Cuarto. Universidad Nacional del Río Cuarto.

\section{MANSUR, M. y H. DE ANGELIS.}

2012. Ambiente, recursos y dinámica poblacional en la faja central en la faja central de Tierra del Fuego: el bosque subantártico. En: Tendencias teórico-metodológicas y casos de estudio en la arqueología de Patagonia. En prensa.

\section{MANSUR, M. E., H. DE ANGELIS y V. PARMIGIANI.}

2010. Explotación de materias primas y circuitos de movilidad en la zona central de Tierra del Fuego. En: Arqueología Argentina en el Bicentenario de la Revolución de Mayo. Actas del XVII Congreso Nacional de Arqueología Argentina, tomo V: 1935-1940. Mendoza. 


\section{MANSUR, M. E. y A. LASA.}

2005. Diversidad artefactual vs. Especialización funcional. Análisis del iv componente de túnel I (Tierra del Fuego, Argentina). Magallania 33 (2) : 69-91.

MANSUR, M. E., A. LASA y M.VAZQUEZ.

2004. Investigaciones arqueológicas en Punta Bustamante, Prov de Santa Cruz: El sitio RUD01BK. En: Contra viento y marea, Arqueología de Patagonia, Tomo 2, pp. 755-774. Neuquén- Buenos Aires. Instituto Nacional de Antropología y Pensamiento Latinoamericano y Universidad Nacional del Comahue.

\section{MANSUR M.E. y M. LEIPUS}

1999. Materias primas, tecnología y función en el sudeste de la región pampeana. En: libro de resúmenes del XIII Congreso Nacional de Arqueología Argentina, pp. 21, Córdoba.

MANSUR, M. E., D. MARTINIONI y A. E. LASA.

2000. La gestión de los recursos líticos en el sitio Marina 1 (zona central de Tierra del Fuego, Argentina). En: J. Belardi, F. Carballo Marina, S. Espinosa (eds.), Desde el País de los Gigantes. Perspectivas arqueológicas en Patagonia. Tomo I, pp. 57-72. Río Gallegos. Universidad Nacional de la Patagonia Austral.

\section{MANSUR, M. E.; A. MAXIMIANO; R. PIQUÉ y O. VICENTE.}

2007b. Arqueología de rituales en sociedades cazadoras-recolectoras. Una aproximación desde el análisis del espacio socialmente producido. En: F. Morello, M. Martinic, A. Prieto y G. Bahamonde (eds.), Arqueología de Fuego-Patagonia. Levantando piedras, Desenterrando huesos...y develando arcanos, pp. 741-754. Punta Arenas. Ediciones CeQua. 


\section{MANSUR-FRANCHOMME, M. E., L. ORQUERA y E. PIANA.}

1987-1988. El alisamiento de la piedra entre cazadores-recolectores: el caso de Tierra del Fuego. Runa, XVII-XVIII:111-205.

\section{MANSUR M. E. y R. PIQUÉ.}

2009. Between the forest and the sea: hunther-gatherer occupations in the subantarctic forests in Tierra del Fuego, Argentina. Arctic Anthropologist 46 (1-2): 144-157.

\section{MANSUR M. E. y R. PIQUÉ. (eds.)}

2012. Arqueología del Hain. Investigaciones etnoarqueológicas en un sitio ceremonial de la sociedad Selknam de tierra del fuego. Implicancias teóricas y metodológicas para los estudios arqueológicos. Treballs d"etnoarqueologia 9, Madrid. CSIC. 220 p. 176 figs.

\section{MANSUR M. E., R.PIQUÉ Y A. VILA MITJA.}

2009. Sociedad y Ritual en Tierra del Fuego. Excavaciones Arqueológicas en un Sitio Ceremonial del Corazón de la Isla. En: A. Austral y M. Tamagnini (comp.), Problemáticas de la arqueología contemporánea. Tomo III, pp. 1313-1317. Río Cuarto. Universidad Nacional del Río Cuarto.

\section{MANSUR M. E.; PIQUE R \& A. VILA MITJA}

2007a. Etude du rituel chez les chasseurs-cueilleurs. Apport de I"ethnoarcheologie des sociétés de la Terre de Feu. En : S. de Beaune (ed.), Chasseurs-cueilleurs. Comment vivaient nos ancetres du paleolithique superieur, .pp. 143-150. Paris. Editions du CNRS.

\section{MANSUR M.E. y R. SREHNISKY.}

1996. El alisador basáltico de Shamakush I: microrrastros de uso mediante el análisis de imágenes digitalizadas. Relaciones. XXI: 267288. 


\section{MARTIN, F. M.}

2004. Tendencias tafonómicas en el registro óseo humano del Norte de Tierra del Fuego. En: L.A. Borrero y R. Barberena (comp.), Arqueología del Norte de la Isla Grande de Tierra del Fuego, pp. 108-133. Buenos Aires. Editorial Dunken.

\section{MARTIN, F. M.}

2006. Carnívoros y huesos humanos de Fuego-Patagonia. Aportes desde la tafonomía forense. Buenos Aires. Sociedad Argentina de Antropología.

\section{MARTIN, F. M. y F. BORELLA.}

1999. Tafonomía de Tierra del Fuego: reevaluación de la arqueología de Cabeza de León. En: Soplando en el Viento. Actas de las III Jornadas de Arqueología de la Patagonia, Tomo 1, pp. 439-450. Neuquén- Buenos Aires. Instituto Nacional de Antropología y Pensamiento Latinoamericano y Universidad Nacional del Comahue.

\section{MARTÍNEZ FERNÁNDEZ, G. y J. A. AFONSO MARRERO.}

1998. La producción lítica: un modelo para el análisis histórico de los conjuntos arqueológicos de piedra tallada. En: J. Bernabeu, T. Orozco y X. Terradas (eds.), Los recursos abióticos en la prehistoria, pp. 1328.Universitat De Valècia. Col-lecció Oberta, Sèrie Història 2.

\section{MARTÍNEZ, J. y C. ASCHERO.}

2003. Proyectiles experimentales: Inca Cueva 7 como caso de estudio. Cuadernos FHyCS-UNJu 20:351-364. 


\section{MARTINIONI, D. R.}

1998. Proyecto Informatización y georreferenciamiento de sitios arqueológicos (Primera Etapa), Informe Final: Parte A, Parte B, Parte C, Parte D y Anexos, 250 pág. Centro Austral de Investigaciones Científicas (CONICET) - Secretaría de Desarrollo y Planeamiento del Gobierno de la Provincia de Tierra del Fuego. Ushuaia.

\section{MARTINIONI, D.R.}

2010. Estratigrafía y sedimentología del Mesozoico Superior-Paleógeno de la Sierra de Beauvoir y adyacencias, Isla Grande de Tierra del Fuego, Argentina. Tesis Doctoral, Facultad de Ciencias Exactas y Naturales, Universidad de Buenos Aires.

(http://digital.bl.fcen.uba.ar/Download/Tesis/Tesis_4608_Martinioni.pdf). Buenos Aires.

\section{MASSOIA, E. y J. CHEBEZ.}

1993. Mamíferos Silvestres del Archipiélago Fueguino. L.O.L.A.. Buenos Aires.

\section{MASSONE, $M$.}

1982. La cultura selk'nam (ona). Departamento de Extensión Cultural del Ministerio de Educación de Chile, Santiago.

\section{MASSONE, $M$.}

1987. Los cazadores paleoindios de Tres Arroyos (Tierra del Fuego). Anales del Instituto de la Patagonia, Serie Ciencias Sociales 17:47-60.

\section{MASSONE, $M$.}

1988. Artefactos óseos del yacimiento arqueológico Tres Arroyos (Tierra del Fuego). Anales del Instituto de la Patagonia, Serie Ciencias Sociales 18:107-112. 


\section{MASSONE, $M$.}

1991. Estudios de las cenizas volcánicas y sus implicaciones en la interpretación de algunos registros arqueológicos de Chile austral. Anales del Instituto de la Patagonia, 20: 111-115.

\section{MASSONE, $M$.}

1997. Prospección arqueológica del sector comprendido entre los ríos Marazzi y Torcido, zona norte de Tierra del Fuego. Anales del Instituto de la Patagonia, Serie Ciencias Humanas 25:123-136.

\section{MASSONE, $M$.}

1999. Aproximación metodológica al estudio de las ocupaciones tempranas de cazadores terrestres en la región de Magallanes. En: Soplando en el viento. Actas de las III Jornadas de Arqueología de la Patagonia, Tomo 1, pp. 99-112. Instituto Nacional de Antropología y Pensamiento Latinoamericano y Universidad Nacional del Comahue, Neuquén- Buenos Aires.

\section{MASSONE, $M$.}

2004 Los cazadores después del hielo. Ediciones de la Dirección de Archivos y Museos. Colección de Antropología 7.

\section{MASSONE, $M$.}

2009. Territorios, movilidad y construcción de paisajes en el mundo selk'nam. En: Arqueología de Patagonia: M. Salemme, F. Santiago, M. Álvarez, E. Piana, M. Vázquez y M. Mansur (eds.), Una mirada desde el último confín, Tomo 1 pp. 249-264. Ushuaia. Editorial Utopías.

\section{MASSONE, M. y F. MORELLO.}

2007. Los cetáceos en el mundo Selk'nam: una evaluación arqueológica. En: F. Morello, M. Martinic, A. Prieto y G. Bahamonde (eds.), Arqueología de Fuego-Patagonia: levantando piedras, 
desenterrando huesos... y develando arcanos, pp. 709-721. Punta Arenas. Ediciones CeQua.

\section{MASSONE, M., A. PRIETO y P. CÁRDENAS.}

1998. Prospección arqueológica en el sector de Boquerón, zona norte de Tierra del Fuego. Anales del Instituto de la Patagonia, Serie Ciencias Humanas 26:127-136.

\section{MASSONE, M. y J. TORRES.}

2004. Pesas, peces y restos de cetáceos en el campamento de Punta Catalina 3 (2.300 años AP). Magallania 32:143-161.

\section{Mc CULLOCH, R. y F. MORELLO.}

2009. Fijando la escena: evidencia glacial y peleoecológica de los ambientes tardi-glaciales y del Holoceno temprano en Fuegopatagonia. En: M. Salemme, F. Santiago, M. Álvarez, E. Piana, M. Vázquez y M. Mansur (eds.) Arqueología de Patagonia: Una mirada desde el último confín, Tomo 1 pp. 119-136. Ushuaia. Editorial Utopías.

\section{MELTZER, D.}

1989. Was Stone Exchange Among Eastern North American Paleoindians? En: C. Ellis y J. Lothrop (ed.) Eastern Paleoindian lithic resource use, pp. 11-39. Boulder. Westview Press.

\section{MENGONI GOÑALONS, G.}

1987. Modificaciones culturales y animales en los huesos de los niveles inferiores del sitio Tres Arroyos 1, (Tierra del Fuego) Chile. Anales del Instituto de la Patagonia, Serie Ciencias Humanas.17: 61-66.

\section{MIOTTI, L. y M. SALEMME.}

2004. Poblamiento, movilidad y territorios entre las sociedades cazadoras-recolectoras de Patagonia. Complutum 15: 177-206. 
MOORE, D. M.

1983 Flora of Tierra del Fuego. Anthony Nelson. Shropshire (Inglaterra).

MORELLO, F.

1999. Cazadores terrestres del Holoceno Medio y Temprano en Tierra del Fuego: Marazzi 1, una discusión abierta. Memoria de título Universidad de Chile, Facultad de Ciencias Sociales Departamento de Antropología, Santiago.

MORELLO, $\mathbf{F}$.

2000. 30 años después, una primera aproximación a la colección Marazzi (Museo Regional, Punta Arenas). En: J. Belardi, F. Carballo Marina, S. Espinosa (eds.), Desde el país de los gigantes. Perspectivas arqueológicas en Patagonia, tomo II, pp. 481-497. Río Gallegos. Universidad Nacional de la Patagonia Austral.

MORELLO, F., L. CONTRERAS y M. SAN ROMAN.

1999. La localidad Marazzi y el sitio arqueológico Marazzi 1, una reevaluación. Anales del Instituto de la Patagonia, Serie Ciencias Humanas 183-197.

MORELLO F, L. BORRERO, M. MASSONE, C. STERN, A. GARCÍA HERBST, R. MCCULLOCH, M. ARROYO-KALIN, E. CALAS, J. TORRES, A. PRIETO, I. MARTINEZ, G. BAHAMONDE \& P. CÁRDENAS.

2012. Hunter-gatherers, biogeographic barriers and the development of human settlement in Tierra del Fuego. Antiquity. 86 (331): 71-87.

MORELLO, F., L. A. BORRERO, J. TORRES, M. MASSONE, M. ARROYO, R. MC CULLOCH, E. CALÁS, M. LUCERO, I. MARTÍNEZ y G. BAHAMONDE. 2009 Evaluando el registro arqueológico de Tierra del Fuego durante el Holoceno temprano y medio: lo positivo de los balances negativos. En: M. Salemme, F. Santiago, M. Álvarez, E. Piana, M. Vázquez y M. 
Mansur (eds.) Arqueología de Patagonia: Una mirada desde el último confín. Tomo 2. pp. 1075-1092. Ushuaia. Editorial Utopías.

\section{MORELLO, F., M. SAN ROMÁN y A. PRIETO.}

2004a. Informe de actividades de sondeo en el sitio Marazzi 2 sector 1 (Río Torcido, Tierra del Fuego). Magallania 32:233-238.

\section{MORELLO, F., M. SAN ROMÁN y A. PRIETO.}

2004b. Obsidiana verde en Fuego-Patagonia: distribución y estrategias tecnológicas. En: M. T. Civalero, P. M. Fernández y A. G. Guraieb (eds.) Contra viento y marea. Arqueología de Patagonia, Tomo 1, pp. 149-166. Buenos Aires. Instituto Nacional de Antropología y Pensamiento Latinoamericano y Sociedad Argentina de Antropología.

\section{MORELLO, F., M. SAN ROMÁN, R. SEGUEL y F. MARTIN.}

1998. Excavación en el sitio Marazzi 2. Sector 2 - terraza superior (Río Torcido, Bahía Inútil). Primer avance. Anales del Instituto de la Patagonia, Serie Ciencias Humanas. 26: 119-126.

\section{MORETTO, A., A. LÁZZARI y O. FERNÁNDEZ.}

2005. Cantidad y calidad de nutrientes de la hojarasca y posterior mineralización en bosques primarios y bajo manejo con distintos sistemas de regeneración. Informe Técnico. pp. 253 - 275. MS.

\section{MUÑOZ, A. S.}

1996. Explotación de pinnípedos en la costa atlántica de Tierra del Fuego. Arqueología 6:199-222.

\section{NAMI, $\mathrm{H}$.}

1992 El subsistema tecnológico de la confección de instrumentos líticos y la explotación de los recursos del ambiente: una nueva vía de aproximación. Shincal 2:33-53. 


\section{NELSON, M.}

1991. The Study of Technological Organization. Archaeological Method and Theory 3: 57-100.

OLAUSSON, D. S.

1982-1983. Flint and groundstone axes in Scanian Neolithic. An evaluation of raw materials based on experiment. Scripta Minora 2: 766.

\section{OLIVE, M.}

1988 Une habitation magdalénienne d’Étiolles: I'unité P15. Mémoires de la Société Préhistoriqué Française, 20 (2).

\section{OLIVERO, E. B. \& N. MALUMIÁN.}

2008. Mesozoic-Cenozoic stratigraphy of the Fuegian Andes, Argentina. Geological Acta, 6 (1): 5-18.

\section{OLIVERO, E.B., N. MALUMIÁN y D. R. MARTINIONI}

2007. Mapa geológico de la Isla Grande de Tierra del Fuego e Islas de Los Estados, República Argentina, escala 1: 400.000. Servicio Geológico Minero Argentino.

\section{ORIA, J.}

2009. Prospecciones en el interior de la estepa fueguina. En: M. Salemme, F. Santiago, M. Álvarez, E. Piana, M. Vázquez y M. Mansur (eds.), Arqueología de Patagonia: Una mirada desde el último confín. Tomo 2, pp. 1109-1126. Ushuaia. Editorial Utopías.

\section{ORQUERA, L. A.}

1995. Túnel VII: la estratigrafía. En: J. Estévez Escalera y A. Vila Mitja (eds.) Encuentros en los conchales fueguinos, pp. 83-103. Treballs d'Etnoarqueología No 1. Barcelona. CSIC y Universidad Autónoma de Barcelona. 
ORQUERA, L. A.

1999. El consumo de moluscos por los canoeros del extremo sur. Relaciones 24:307-327.

ORQUERA, L. A.

2002. The Late Nineteenth-Century Crisis in the Survival of the Magellan- Fueguian Litoral Natives. En: C. Briones y J. L. Lanata (eds.), Archaeological and Anthropological Perspectives on the NativePeoples of Pampa, Patagonia, and Tierra del Fuego to the Nineteenth Century, pp. 145-158. Londres, Bergin \& Garvey.

ORQUERA, L. A.

2005 Mid-Holocene littoral adaptation at the southern end of South America. Quaternary International. 132, 107-115.

\section{ORQUERA, L. A. y E. L. PIANA.}

1986. Normas para la descripción de objetos arqueológicos de piedra tallada. CADIC. Contribución Científica (Publicación Especial) № 1 , Ushuaia.

ORQUERA, L. A. Y E. PIANA.

1986-1987. Composición tipológica y datos tecnomorfológicos y tecnofuncionales de los distintos conjuntos arqueológicos del sitio Túnel I (Tierra del Fuego). Relaciones. 17 (1): 201-239.

\section{ORQUERA, L. A. Y E. PIANA.}

1987 Human littoral adaptation in the Beagle Channel region: the maximum possible age. Quaternary of South America and Antarctic Peninsula 5: 133-165. 


\section{ORQUERA, L. A. y E. PIANA.}

1992. Un paso hacia la resolución del palimpsesto. En: L. A. Borrero y J. Lanata (comp.), Análisis espacial en la arqueología patagónica, pp. 21-52. Buenos Aires Ayllu.

\section{ORQUERA, L. A. y E. PIANA.}

1993-94 Lancha Packewaia: actualización y rectificaciones. Relaciones XIX: 325-362.

\section{ORQUERA, L. A. y E. PIANA.}

1996. La imagen de los canoeros magallánico-fueguinos: conceptos y tendencias. Runa XXII: 187-245.

\section{ORQUERA, L. A. y E. PIANA.}

1999a. La vida material y social de los Yámana. Eudeba.

\section{ORQUERA, L. A. y E. PIANA.}

1999b. Arqueología de la región del canal de Beagle (Tierra del Fuego, República Argentina). Publicaciones de la sociedad argentina de antropología.

\section{ORQUERA, L. A. Y E. PIANA.}

2000. Imiwaia I: un sitio de canoeros del sexto milenio AP en la costa norte de canal Beagle. En: J. Belardi, F. Carballo Marina, S. Espinosa (eds.), Desde el país de los gigantes. Perspectivas arqueológicas en Patagonia, tomo II, pp. 441-453. Río Gallegos. Universidad Nacional de la Patagonia Austral.

\section{ORQUERA, L. A. Y E. PIANA.}

2001 Composición de los Conchales de la costa del canal Beagle (Tierra del Fuego, República Argentina) (Segunda parte) Relaciones XXVI:345-368. 
ORQUERA, L. A. Y E. PIANA.

2005a. La adaptación al litoral sudamericano sudoccidental: qué es y quiénes, cuándo y dónde se adaptaron. Relaciones XXX: 11-32.

\section{ORQUERA, L. A. Y E. PIANA.}

2005b. Vigésima campaña arqueológica en Tierra del Fuego: el sitio Imiwaia I. Actas del XIII Congreso Nacional de Arqueología Argentina, Tomo 4:19-28. Córdoba.

\section{ORQUERA, L. A. y E. PIANA.}

2006 El poblamiento inicial del área litoral sudamericana sudoccidental. Magallania 34 (2): 21-36.

\section{ORQUERA, L. A. y E. PIANA.}

2009. Sea nomads of the Beagle Channel in Southernmost South America: Over six thousand years of coastal adaptation and stability. Journal of Island and Coastal Archaeology 4: 61-81.

\section{OUTES F.}

1906. Instrumentos modernos de los Onas (Tierra del Fuego). Anales del Museo Nacional de Buenos Aires, 3 (VI): pp. 287-296.

\section{PARMIGIANI, V.}

2012. Determination of age and sex on dental pieces of Lama guanicoe: a methodological approach. En: D. M. Kligmann \& M. R. Morales (Eds.), Physical, chemical and biological proxies in argentine archaeology: theory, methods and applications. British Archaeological Reports. International Series. Oxford. Archaeopress. En prensa.

\section{PARMIGIANI V., H. DE ANGELIS y M. E. MANSUR.}

2010. ¿Reemplazo o ampliación?: Cambios en la economía de los grupos cazadores recolectores Selknam del centro de la Isla Grande de Tierra del Fuego. En Circumpolaridad como Fenómeno Sociocultural. Pasado, Presente, Futuro, pp. 199-216. Buenos Aires. UBA. 


\section{PARMIGIANI, V., M. C. ÁLVAREZ SONCINI y A. IPARRAGUIRRE.}

2012. Localidad arqueológica Kami: sitio Kami 7, presentación general. En: Tendencias teórico-metodológicas y casos de estudio en la arqueología de Patagonia. En prensa.

\section{PARMIGIANI, V. y E. CAMARÓS}

2012. Los recursos animales: vertebrados. En: Arqueología del Hain. Investigaciones etnoarqueológicas en un sitio ceremonial de la sociedad Selknam de tierra del fuego. Implicancias teóricas y metodológicas para los estudios arqueológicos. Treballs d"etnoarqueologia 9, Madrid. CSIC. pp 161-182.

\section{PELEGRIN, J.}

1984. Approche technologique expérimentale de la mise en forme de nucléus pour le débitage systématique par presión. En: Tixier, J. (ed.), Prehistoire de la Pierre taillée 2. Économie du débitage laminaire, pp. 93-103. París. CNRS.

\section{PELEGRÍN, J.}

1990. Prehistoric Lithic Technology: Some Aspects of Research. Archaeological Review from Cambridge 9 (1): 116-125.

\section{PERLÈS, C.}

1987. Les industries lithiques taillées de Franchthi (Argolide, Gréce). Présentation genérale et industries paléolihiques. Excavations at Franchthi Cave Greece. Editado por T. W. Jacobsen. Indianapolis. Indianana University Press. Bloomington.

\section{PETERSEN, C.S.}

1949. Informe sobre los trabajos de relevamiento geológicos efectuados en Tierra del Fuego entre 1945 y 1948: Buenos Aires, Dirección General de Industria y Minería, reporte técnico, 50 pp. 
PIANA, E. L.

1984 Arrinconamiento o adaptación en Tierra del Fuego. En: Antropología Argentina 1984, pp. 7-114. Buenos Aires, Editorial de Belgrano.

PIANA, E.L.

2005. Cetaceans and humans beings at the uttermost part of America: a lasting relationship in Tierra del Fuego. En: G. Monks (ed.) The Exploitation and Cultural Importance of Sea Mammals, pp. 121-137. Canada. Oxbow Books.

\section{PIANA, E.L., J. ESTÉVEZ ESCALERA, y A. VILA MITJA.}

2000. Lanashuaia: un sitio de canoeros del siglo pasado en la costa norte del Canal Beagle. En: J. Belardi, F. Carballo Marina, S. Espinosa (eds.), Desde el país de los gigantes. Perspectivas arqueológicas en Patagonia, tomo II, pp. 455 - 469. Río Gallegos. Universidad Nacional de la Patagonia Austral.

PIANA, E. L. y L. A. ORQUERA.

1995. Túnel VII: la cronología. En J. Estevez y A. Vila. (comp.) Encuentros en los conchales fueguinos, pp. 105-111. Treballs d'Etnoarqueología N 1, CSIC y Universidad Autónoma de Barcelona.

\section{PIANA, E. L. y L. A. ORQUERA.}

2007 Diferencias regionales y temporales en el litoral sudoccidental de Sudamérica. En: F. Morelo, M. Martinic, A. Prieto y G. Bahamonde (eds.), Arqueología de Fuego-Patagonia. Levantado piedras, desenterrando huesos... y develando arcanos, pp. 311-323. Punta Arenas. Ediciones CEQUA.

\section{PIANA, E. L. y L. A. ORQUERA.}

2009 The southern top of the World: the first peopling of Patagonia and Tierra del Fuego and the cultural endurance of the fuegian seanomads. Arctic Anthropology 46 (1-2): 103-117. 
PIANA E. L., A. VILA MITJA, L. A. ORQUERA y J. ESTÉVEZ ESCALERA.

1992. Chronicles of Onaashaga: archaeology in the Beagle Channel (Tierra del Fuego, Argentina)". En: C.Gamble y C. Chippendale (comp.), Uttermost ends of the Earth. Antiquity, 66, 252: 771-783. Londres.

PIANA, E.L., A.TESSONE y A.F. ZANGRANDO.

2006 Contextos mortuorios en la región del canal Beagle... del hallazgo fortuito a la búsqueda sistemática. Magallania 34 (1): 87-101.

PIANA E. M. VÁZQUEZ, M. ÁLVAREZ y N. RUA.

2007. El sitio Ajej I: excavación de rescate en la costa del canal Beagle. En: F. Oliva, N. de Grandis y J. Rodriguez (eds.), Arqueología Argentina en los inicios de un nuevo siglo, Tomo I: 345-356. Rosario. Universidad Nacional de Rosario.

PIANA, E., M. VÁZQUEZ, M. ÁLVAREZ.

2008. El sitio Ajej I: un aporte a la variabilidad de estrategias de los canoeros fueguinos. Runa, 29: 87 - 100.

\section{PIANA E. y M. VÁZQUEZ.}

2005. El Sitio Shamakush VIII.: puntualizaciones sobre el uso de recursos y la gestión del asentamiento en el canal Beagle En: Libro de Actas XV Congreso Nacional de Arqueología Argentina, Rio Cuarto. pp. 1057 - 1068.

PIE, J y A. VILA

1992. Relaciones entre objetivos y métodos en el estudio de la industria lítica. En: R. Mora et al (eds), Tecnologías y cadenas operativas líticas, pp. 271-278. Universidad autónoma de Barcelona. 
PIGEOT, N.

1987. Magdaléniens d'Etiolles : économie du débitage et organisation sociale (I'unité d'habitation U 5), Paris, CNRS.

PIQUÉ, R.

1999. Producción y uso del combustible vegetal: una evaluación arqueológica, Treballs d"etnoarqueologia 3 . Madrid. UAB, CSIC.

\section{PLISSON, $\mathrm{H}$.}

1985. Etude fonctionelle d"outillages lithiques préhistoriques par l"analyse des micro-usures: recherche méthodologique et archéologique. Tesis de Doctorado. Université de Paris I. Pantheon Sorbonne. MS.

\section{POLITIS, G.}

1998. Arqueología de la Infancia: una perspectiva etnoarqueológica. Trabajos de Prehistory 55 (2):5-19.

\section{POLITIS, G.}

2004. La Etnoarqueología en América Latina. Tendencias, En: G. Politis y R. Peretti (eds.), Teoría arqueológica en América del Sur, pp. 85-117. Serie Teórica 3. Olavarría. INCUAPA.

\section{POLITIS, G. y A. JAIMES.}

2005. Patrones de descarte entre los hotï del Amazonas venezolano. En: E. Williams (ed.), Etnoarqueología: el contexto dinámico de la cultura material a través del tiempo, pp.237-266. México. El Colegio de Michoacán.

\section{PONCE, J. F., A. CORONATO, A. M BORROMEI \& J. RABASSA.}

2007. Condiciones paleoambientales y paleoclimáticas durante un evento glacial anterior al último máximo glacial (Lago Fagnano, Tierra 
del Fuego, Argentina). En: Libro de Resúmenes de Geosur, pp. 125. Santiago, Chile.

\section{PRIETO, A. y J. CANTO.}

1997 Presencia de un lamoide atípico en cueva Lago Sofía 4 (Última Esperanza) y Tres Arroyos (Tierra del Fuego) región de Magallanes, Chile. Anales del Instituto de la Patagonia, Serie Ciencias Humanas 25:147-150.

\section{PRIETO, A., P. CÁRDENAS, G. BAHAMONDE y M. MASSONE.}

2004. Hallazgo de una fuente de materia prima en el chorrillo Miraflores, Tierra del Fuego, Chile. Magallania 32:229-232.

\section{RABASSA, J., C. HEUSSER \& N. RUTTER.}

1990 Late-Glacial and Holocene of Argentine Tierra del Fuego. Quaternary of South America \& Antarctic Peninsula 7: 327-351.

RAEDEKE, K. J.

1978. El guanaco de Magallanes, Chile. Su distribución y biología. Ministerio de Agricultura de Chile, CONAF. Publicación Técnica 4. MS.

\section{RAMOS, M. y J. MERENZON.}

2002-2004. Misión franco-argentina en el centro de la isla de Tierra del Fuego. Análisis general de los conjuntos líticos hallados. Arqueología. 12: 213-238.

\section{RATTO, N y M. F. GARCÍA.}

1996. Disponibilidad y Aprovisionamiento de materias primas líticas: muestreo piloto en sectores de la costa norte de Tierra del Fuego (Argentina). Arqueología 6:223-263. 


\section{RATTO, N. y O. NESTIERO.}

1998. Ensayos cuantitativos para la determinación de las propiedades físico mecánicas de las rocas: sus implicancias arqueológicas. Actas y Memorias del XI Congreso Nacional de Arqueología Argentina, $8^{a}$ parte. Revista del Museo de Historia Natural de San Rafael 20(3-4): 143-158.

\section{RENFREW, C.}

1977. Alternative models for exchange and spatial distribution. En: T. Earle y J. Ericson (eds.) Exchange Systems in Prehistorypp. 71-90. New York. Academic Press.

\section{SALEMME, M. y G. BUJALESKY.}

2000 Condiciones para el asentamiento humano litoral entre cabo San Sebastián y Cabo Peñas (Tierra del Fuego) durante el holoceno medio. En: J. Belardi, F. Carballo Marina, S. Espinosa (eds.), Desde el País de los Gigantes. Perspectivas arqueológicas en Patagonia. Tomo II, pp. 519-531. Río Gallegos. Universidad Nacional de la Patagonia Austral.

\section{SALEMME, M., G. BUJALESKY y F. SANTIAGO.}

2007a La Arcillosa 2: la ocupación humana durante el Holoceno medio en el Río Chico, Tierra del Fuego, Argentina. En: F. Morello, M. Martinic, A. Prieto y G. Bahamonde (eds.), Arqueología de FuegoPatagonia: levantando piedras, desenterrando huesos... y develando arcanos, pp. 723-736. Punta Arenas. Ediciones CeQua.

\section{SALEMME, M., F. SANTIAGO, J. A. SUBY y R. GUICHÓN.}

2007b. Arqueología funeraria en el norte de tierra del fuego. Pacarina (Número especial de las Actas del XVI CNAA, Jujuy.) I: 71-77.

\section{SANTIAGO, $F$.}

2009. La ocupación humana del norte de tierra del fuego durante el holoceno medio y tardío. Su vinculación con el paisaje. Tesis de doctorado. Universidad Nacional del Centro, Olavarría, Argentina. MS. 
SANTIAGO, F., G. BUJALESKY y M. SALEMME.

2007a. Prospección arqueológica en la cuenca del río Chico. Tierra del Fuego, Argentina. En: F. Morello, M. Martinic, A. Prieto y G. Bahamonde (eds.), Arqueología de Fuego-Patagonia: levantando piedras, desenterrando huesos... y develando arcanos, pp. 357-363. Punta Arenas. Ediciones CeQua.

\section{SANTIAGO F. y J. ORIA.}

2007. Lo que el viento no se llevó. Análisis de superficie en la estepa fueguina. Magallania 35(2):121-132.

\section{SANTIAGO, F., J. ORIA y M. SALEMME.}

2007b. Nuevo contexto arqueológico del Holoceno Medio. Río Chico 1. Tierra del Fuego, Pacarina (Número especial de las Actas del XVI CNAA, Jujuy.) III: 439-445.

\section{SAXON E. C.}

1979. Natural prehistory. The Archaeology of Fuego-Patagonia Ecology. Quaternaria 21: 329-356.

\section{SCHIAVINI, A.}

1990. Estudio de la relación entre el hombre y los pinnípedos en el proceso adapatativo humano al canal Beagle (Tierra del Fuego, Argentina). Tesis de doctorado, Universidad de Buenos Aires. MS.

\section{SCHIAVINI, A.}

2007. Aves y Mamíferos de Tierra del Fuego. En: Patagonia Total, Antártida e Islas Malvinas, pp. 797-820. Buenos Aires. Barcel Baires.

\section{SEMENOV, $\mathbf{S}$.}

1964. Prehistoric Technology. Adams \& Dart. Londres. 


\section{SHOTT, $M$.}

1986. Technological organization and settlement mobility: an ethnographic examination. Journal of Anthropological Research 42: 1551.

STERN, C.

1990. Thephrochronology of southernmost Patagonia. National Geographic research. 6:110-126.

\section{STERN, C.}

1992. Tefrocronología de magallanes: nuevos datos e implicaciones. Anales del Instituto de la Patagonia. Serie Ciencias Humanas, 21:105116.

\section{TERRADAS, $\mathbf{X}$.}

1995. Las estrategias de gestión de los recursos líticos del prepirineo catalán en el IX milenio BP: el asentamiento prehistórico de la Font del Ros (Berga, Barcelona). Barcelona, UAB.

\section{TERRADAS, $\mathbf{X}$.}

1996. La gestió dels recursos minerals entre les comunitatas caçadores-recol/lectores. Vers una representació de les estratègies de proveïment de matèries primeres. Tesis de doctorado. Departement d'historia de les societats precapitalistes i d' antropologia social. Universitat Autonoma de Barcelona. MS.

\section{TERRADAS, $\mathbf{X}$.}

2001. La gestión de los recursos minerales en las sociedades cazadoras recolectoras. Treballs d’etnoarquelogía, $N^{\circ} 4$. Madrid. CSIC. 
TESSONE, A., M. VÁZQUEZ, A. ZANGRANDO, A. CERASO, F. PONCE y L. SOSA.

2007. Recientes excavaciones en bahía Valentín (Tierra del Fuego). , Pacarina (Número especial de las Actas del XVI CNAA, Jujuy.) III: 453459.

THOMAS, D. H.

1975. Nonsite sampling in archeaeology: up the creek withiut a site? En: j. Muller (ed.), Sampling in archaeology, pp. 61-81. Arizona. University of Arizona press.

TIVOLI, A. M.

2010. Las aves en la organización socioeconómica de cazadoresrecolectores- pescadores del extremo sur sudamericano. Tesis de doctorado. Facultad de Filosofía y Letras. Universidad de Buenos Aires. MS.

TIVOLI A. M. \& A. F. ZANGRANDO.

2011. Subsistence variations and landscape use among maritime hunter-gatherers. A zooarchaeological analysis from the Beagle Channel (Tierra del Fuego, Argentina). Journal of Archaeological Science 38 1148-1156.

\section{TIXIER, J.; M. INIZIAN y H. ROCHE.}

1980. Préhistoire de la pierre taillée. I. Terminologie et technologie. Cercle de Recherches et d'etudes préhistoriques, 1-84.

\section{TORRENCE, $\mathbf{R}$.}

1983. Time Budgeting and Hunter-Gatherer Technology. En: G. Bailey (ed.) Hunter-Gatherer economy in Prehistory: a European perspective, pp. 11-22. Cambridge University Press.

TORRENCE, $\mathbf{R}$. 
2001. Hunter-gatherer technology: macro and microscales approaches.

In: C. Panther-Brick, R. Layton y P. Rowley-Conwy (eds.), Huntergatherers am interdisciplinary perspective, pp. 73-98. Cambridge University Press.

TRINGHAM, R., G. COOPER, G. ODELL, B. VOYTEK y A. WHITMAN.

1974. Experimentation in the formation of edge damage: a new approach to lithic analysis. Journal of Field Archaeology 1:171-196.

\section{TUHKANEN, $\mathbf{S}$.}

1992. The Climate of Tierra del Fuego from a vegetation geographical point of view and ecoclimatic counterparts elsewhere. Acta Botnica fennica145, editor in chief: Saara Bäck pp. 1- 64. Finland. Departament of Botany, University of Helsinki.

\section{VAUGHAN, $P$.}

1981. Lithic Microwear Experimentation and the functional analysis of a Lower Magdalenian stone tool assemblage. Tesis de Doctorado. Universidad de Pensylvania. Philadelphia. MS.

\section{VÁZQUEZ, M., A. F. ZANGRANDO, A. TESSONE, A. CERASO y L. SOSA.} 2007 Arqueología de Bahía Valentín (Península Mitre, Tierra del Fuego): nuevos resultados y perspectivas. En: F. Morello, M. Martinic, A. Prieto y G. Bahamonde (eds.), Arqueología de Fuego-Patagonia: levantando piedras, desenterrando huesos... y develando arcanos, pp. 755-766. Punta Arenas. Ediciones CeQua.

VÁZqueZ, M., M. Álvarez, R. BARberenA, K. Borrrazo, L. A. BORRERO, D. ELKIN, M. GROSO, C. MURRAY, J. ORÍA, M. SALEMME y F. SANTIAGO.

2010. Programa arqueológico costa atlántica: hacia la preservación del patrimonio arqueológico costero en Tierra del Fuego. En: R. Barcena y H. Chiavazza. (eds.), Arqueología en el Bicentenario de la Revolución de Mayo, II: 557-562.XVII Congreso Nacional de Arqueología 
Argentina. Mendoza, Facultad de Filosofía y Letras. Universidad Nacional de Cuyo.

\section{VERDÚN I CASTELLÓ, E.}

2011. El consum de mol/luscs en societats caçadores-recol/lectores de Tierra del Fuego (Argentina).Tesis de Doctorado. Departament de Prehistòria Facultat de Filosofia i Lletres.Universitat Autònoma de Barcelona. MS.

\section{VIDAL, H. J.}

1985 Los conchales de bahía Valentín. Tesis de licenciatura. Universidad de Buenos Aires. Buenos Aires. MS.

\section{VIDAL, H. J.}

1987. Primeros lineamientos para una arqueología etnográfica de Península Mitre. En: Actas de las primeras Jornadas de Arqueología de la Patagonia: 303-309. Rawson.

VIDAL H. J.

1988. Bahía Valentín: 6.000 años de ocupaciones humanas en el oriente fueguino. En: Resúmenes de las ponencias científicas presentadas en las IX Congreso Nacional de Arqueología Argentina, pp. 77. Buenos Aires.

VILA, A.

2006. Propuesta de evaluación de la metodología arqueológica. En: Etnoarqueologia de la Prehistoria: més enllà de l'Analogia, Treballs d'Etnoarqueologia 6: 61-76. Madrid: CSIC.

\section{WANDSNIDER, L.}

1998. Landscape Element Configuration, Lifespace, and Occupation History. En: A. P. Sullivan (ed.), Ethnoarchaeological observations and archaeological applications. Surface Archaeology, pp. 21-39. Albuquerque. University of New Mexico Press. 
YACOBACCIO, H.D.

1980. Consideraciones sobre el uso de artefactos del sitio Bloque Errático 1 (norte de Tierra del Fuego). Relaciones. XIV(1):143-146.

ZANGRANDO, A. F. 2002. Ictioarqueología del canal Beagle: la explotación de peces y su implicación en los patrones de subsistencia humana. Tesis de Licenciatura. Facultad de Filosofía y Letras. Universidad de Buenos Aires. MS.

ZANGRANDO, A. F.

2009. Historia evolutiva y subsistencia de cazadores-recolectores marítimos de Tierra del Fuego. Sociedad Argentina de Antropología. Buenos Aires.

\section{ZANGRANDO A. F., L. A. ORQUERA y E. L PIANA.}

2010. Diversificación e intensificación de recursos animales en la secuencia arqueológica del Canal Beagle (Tierra del Fuego, Argentina). Zooarqueología a principios del siglo XXI: aportes teóricos, metodológicos y casos de estudio, pp. 359-370. Buenos Aires.

ZANGRANDO, A., A. TESSONE, S. VALENCIO, H. PANARELlO, M. MANSUR y M. SALEMME.

2004. Isótopos estables y dietas humanas en ambientes costeros. En: M. Ortega, J. Calleja, M. Sánchez, M. Lorenzo, M. Brell, A. Montero y R. Puerto (eds.), Avances en Arqueometría, pp, 91-97. Cádiz. Universidad de Cádiz.

\section{ZANGRANDO, A. F., A. TESSONE Y M. VÁZQUEZ}

2009 El uso de espacios marginales en el archipiélago fueguino: implicaciones de la evidencia arqueológica de Bahía Valentín. En: M. Salemme, F. Santiago, M. Álvarez, E. Piana, M. Vázquez y M.E. Mansur (eds.) Arqueología de Patagonia: Una mirada desde el último confín, Tomo 2, pp. 47-62. Ushuaia, Editorial Utopías. 


\section{ÍNDICE DE FIGURAS}

\section{CAPÍTULO 1}

FIGURA 1. 1. UBICACIÓN DEL ÁREA DE ESTUDIO CON LOS SITIOS Y LUGARES INCLUIDOS

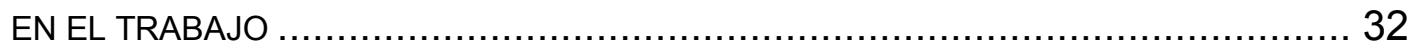

FIGURA 1. 2. IMAGEN DEL ARCHIPIÉLAGO FUEGUINO ................................... 33

FIGURA 1. 3. MAPA DEL EXTREMO AUSTRAL DE AMÉRICA QUE ILUSTRA SIMPLIFICADAMENTE LA DISTRIBUCIÓN DE LAS UNIDADES GEOLÓGICAS

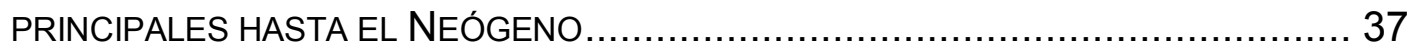

FIGURA 1. 4. VISTA DE LAGO DE ORIGEN GLACIARIO, LAGO ESCONDIDO ................ 38 FIGURA 1. 5. DISTRIBUCIÓN DE LA VEGETACIÓN MAGALLÁNICA-FUEGUINA (TUHKANEN

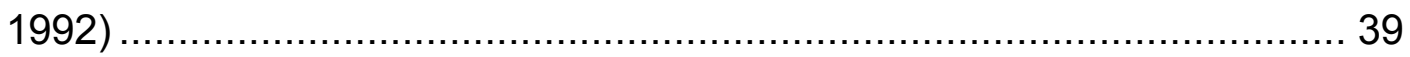

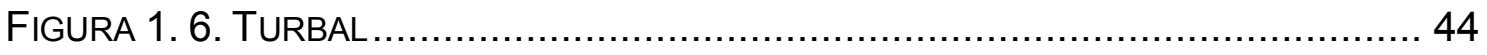

FIGURA 1. 7. ZONA DE BOSQUE CON PASTIZAL ............................................ 44

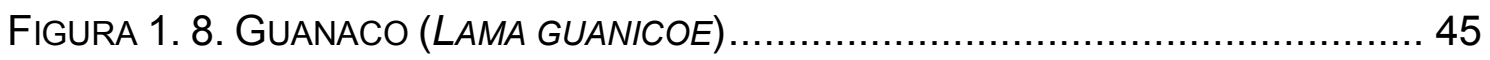

FIGURA 1. 9. CAUQUENES (CHLOEPHAGA PICTA) .......................................... 46

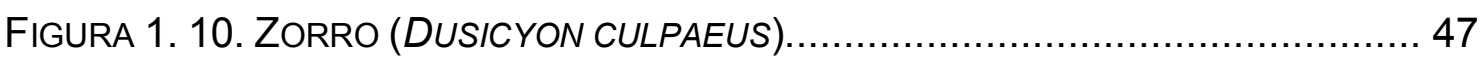

\section{CAPÍTULO 3}

FiguRA 3. 1. NiVELES DE ANÁLISIS DE LA INVESTIGACIÓN (TOMADA DE NELSON, 1991) 80

\section{CAPÍTULO 4}

FIGURA 4. 1. EWAN 1, CHOZA CEREMONIAL DEL HAIN..................................109

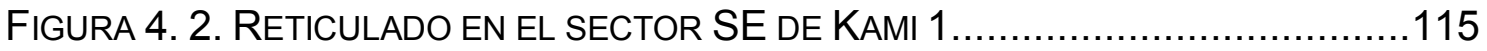

FIGURA 4. 3. DETALLE DE CUADRÍCULAS CAMPAÑA 2009...............................116

Figura 4. 4. A. Fogón; B. MATERIAL ARQUEOlógico asociado; C. ÁreA dE

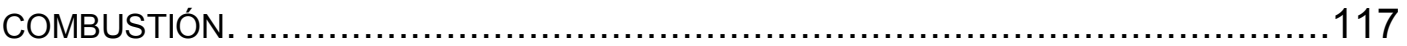

FIGURA 4. 5. DETALLE DE LOS FILOS LARGOS RETOCADOS FRACTURADOS IN SITU...118

FIGURA 4. 6. A. DISTRIBUCIÓN DEL MATERIAL SUPERFICIAL Y EMPLAZAMIENTO DE LOS SONDEOS Y LAS CUADRÍCULAS EXCAVADAS; B. TIPOS REPRESENTADOS EN LA RECOLECCIÓN SUPERFICIAL.

FIgURA 4. 7. A. ESTRATIGRAFÍA ASOCIADA AL SITIO KaMI 7; B. CUADRÍCULAS EXCAVADAS Y DELIMITACIÓN DE LAS ÁREAS DE COMBUSTIÓN; C. MATERIAL LÍTICO ASOCIADO AL ÁREA DE COMBUSTIÓN N 1; D. MATERIAL LÍTICO ASOCIADO AL ÁREA DE COMBUSTIÓN $\mathrm{N}^{\circ} 2$.

FIGURA 4. 8. A. UBICACIÓN DEL CUADRANTE AT-17; B. MATERIAL LÍTICO RECUPERADO EN LA EXCAVACIÓN. 
Figura 5. 1. PAISAJES dE LA FAJA CENTRAL DE TIERRA DEL FuEgo 132

FiguRA 5. 2. AMBIENTES DE LA ZONA CENTRAL DE TIERRA DEL FUEGO. A- TURBAL; BMONTAÑA; C- LAGUNA MARGARITA; D- DESEMBOCADURA DEL RÍO AZARA HACIA LA COSTA ATLÁNTICA; E- BOSQUE DE NOTHOFAgUS; F- VALLE DEL RÍO LÁINEZ. (A Y E ZONA DE ECOTONO), (B Y C ZONA CORDILLERANA), (D Y F ZONA DE VALLES) .....133

FiguRA 5. 3. CoBERTURA VEGETAL DEL CENTRO DE LA ISLA. ARRIBA PASTIZALES DE AMBIENTE FLUVIAL (VISIBILIDAD BAJA). CENTRO VEGETACIÓN DE ZONAS ANEGADAS (VISIBILIDAD MUY BAJA). ABAJO BOSQUE EN ZONA ALEDAÑA AL VALLE (VISIBILIDAD INTERMEDIA).

FIGURA 5. 4. VISUAL DEL VALLE DEL RIO IRIGOYEN CON SECTOR DE ACUMULACIÓN DE GUIJARROS 138

FiguRA 5. 5. DetALLE DE TESTEO DE MATERIAS PRIMAS; ARRIBA: SECTOR DE $1 \mathrm{X} 1 \mathrm{M}$; .138

FIGURA 5. 6. LAGUNA NEGRA, COSTA NORTE CON ACUMULACIÓN DE GUIJARROS ....139

FIGURA 5. 7. ARRIBA, DISTRIBUCIÓN DEL MATERIAL ARQUEOLÓGICO. ABAJO IZQ. TRANSECTAS EN LAGUNAS; DER. TRANSECTAS EN CURSO INFERIOR DE RÍOS QUE DESEMBOCAN EN EL ATLÁNTICO. 142

FIGURA 5. 8. VISTA GENERAL DE LA LAGUNA AGUAS BLANCAS ............................144

FIGURA 5. 9. VISTA GENERAL DE LA LAGUNA MARGARITA ................................. 145

FIGURA 5. 10. VISTA GENERAL DE LA LAGUNA NEGRA .................................146

FIGURA 5. 11. VISTA DE LA LAGUNA DEL INDIO CERCANA A LA DESEMBOCADURA DEL RÍO VALDÉS..................................................................... 147

FIGURA 5. 12. VISTA GENERAL DE LA LAGUNA BOMBILLA ...............................148

FIGURA 5. 13. POSIBLES RETOCADORES DE HUESO, CONFECCIONADOS SOBRE EPÍFISIS DISTAL DE METAPODIO DE LAMA GUANICOE......................................149

FIGURA 5. 14. VISTA GENERAL DE LA LAGUNA PALACIOS ................................ 150

FIGURA 5. 15. VISTA DE LA COSTA SUR DEL LAGO FAGNANO EN LA ZONA DE BAHÍA

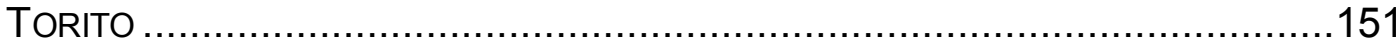

FIGURA 5. 16. CURSO INFERIOR DEL RÍO EL VASCO ..................................... 152

FIGURA 5. 17. BARRANCA DE LA MARGEN DERECHA DEL RÍO IRIGOYEN ..................153

FIGURA 5. 18. SECTOR CON MATERIAL LÍTICO.......................................... 153

FIGURA 5. 19. RETICULADO Y UNIDADES DE RECOLECCIÓN (CUAD. 1 × 1 M) .............154

FIGURA 5. 20. IZQUIERDA: RASPADOR; DERECHA: RAEDERA (FLECHA=10 CM).........154

FIGURA 5. 21. CAMINO DENTRO DEL BOSQUE. ........................................ 155

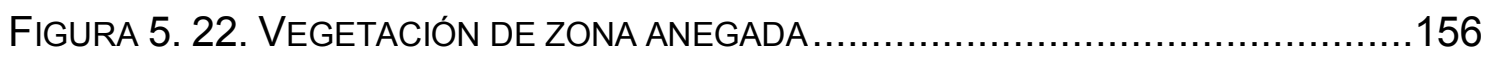

FIGURA 5. 23. SECTOR DE CAÍDA DE ÁRBOLES......................................... 157

FIGURA 5. 24. VISTA DEL CURSO SUPERIOR DEL RÍO LÁINEZ ............................158

FIGURA 5. 25. VISTA DEL CURSO SUPERIOR DEL RÍO SAN PABLO ..........................160

\section{CAPÍTULO 6}

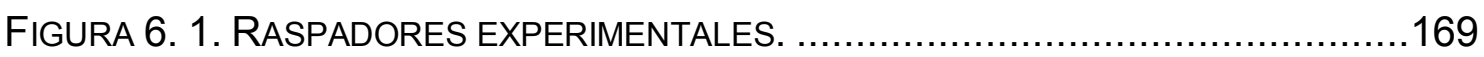

FIGURA 6. 2. PUNTA DE FLECHA EXPERIMENTAL....................................... 170 
FIGURA 6. 3. RESTOS DE TALLA EN EL PROCESO DE CONFECCIÓN DE INSTRUMENTOS DE VIDRIO. ARRIBA: PUNTAS DE FLECHA. ABAJO: RASPADOR ........................ 171

FIGURA 6. 4. MICROLASCAS DE FORMATIZACIÓN DE FRENTE DE RASPADOR. ............175

FIGURA 6. 5. RASTROS DE USO SOBRE ARTEFACTOS EXPERIMENTALES. A: FOTOMICROGRAFÍA DE FILO DE UN RASPADOR EXPERIMENTAL DE VIDRIO DESPUÉS DE 30 MINUTOS DE USO SOBRE HUESO FRESCO, TOMADA A 100X. B: DETALLE DEL SECTOR SEÑALADO EN A, 200X. C: DETALLE DEL SECTOR SEÑALADO EN B, 500X

FIGURA 6. 6. RASTROS DE USO SOBRE DIFERENTES MATERIALES. A: TRABAJO SOBRE HUESO, 30 MIN, 200X. B: TRABAJO SOBRE CUERO, 30 MIN, 200X. C: TRABAJO SOBRE MADERA, $30 \mathrm{MIN}, 200 \mathrm{X}$.

FIGURA 6. 7. MODIFICACIÓN DE LA MICROTOPOGRAFÍA DURANTE EL PROCESO DE USO. FOTOMICROGRAFÍAS DE FILOS DE TRES RASPADORES DE VIDRIO TOMADAS A DIFERENTES INTERVALOS, $200 \mathrm{X}$.

FIGURA 6. 8. IMAGEN DE LOS FILOS FRESCOS Y DE LOS SECTORES QUE PRESENTAN MICROPOROSIDAD. FOTOMICROGRAFÍAS TOMADAS A 100X, 200X Y 500X.......181

FIGURA 6. 9. DESARROLLO DE LOS MICROPULIDOS EN LAS DISTINTAS ETAPAS DE TRABAJO. FOTOMICROGRAFÍA TOMADA A 200X

\section{CAPÍTULO 7}

FIGURA 7. 1. COLORES REPRESENTADOS EN EWAN I .192

FIGURA 7. 2. ARRIBA: DE IZQUIERDA A DERECHA: RASPADORES Y FILO LARGO RETOCADO. ABAJO: PUNTAS Y FRAGMENTOS DE PUNTAS DE PROYECTIL DEL SITIO EWAN II-UNIDAD 1 196

FIGURA 7. 3. RASPADOR 156. IZQUIERDA: MICROFOTOGRAFÍA DE FILO LATERAL, FRESCO. DERECHA: FRENTE CON RASTROS DE USO SOBRE PIEL. 200X. 199

FIGURA 7. 4. RASPADOR 110. IZQUIERDA: MICROFOTOGRAFÍA DE ALTERACIONES TECNOLÓGICAS Y POSTDEPOSITACIONALES. DERECHA: FILO FRONTAL CON ESTRÍAS Y RASTROS DE USO SOBRE PIEL. 200X.

FIGURA 7. 5. RASPADOR 024. IZQUIERDA: MICROFOTOGRAFÍA DE MICROESQUIRLAMIENTOS TECNOLÓGICOS. DERECHA FILO FRONTAL CON ESTRÍAS Y RASTROS DE USO SOBRE PIEL. 200X 200

\section{CAPÍTULO 8}

FIGURA 8. 1. VISTA GENERAL DEL SITIO KAMI 1 .208

FIGURA 8. 2. EJEMPLO DE ALGUNOS NÚCLEOS DE DIVERSAS MATERIAS PRIMAS.

ARRIBA: RIOLITA. DEBAJO DE IZQUIERDA A DERECHA: TOBA SILICIFICADA, RIOLITA, CHERT 213

FIGURA 8. 3. RASPADORES. ARRIBA: RASPADORES EN TOBA SILICIFICADA

MIRAFLORES. ABAJO IZQUIERDA: RASPADORES EN CUARZO, DERECHA:

RASPADORES EN OTRAS MATERIAS PRIMAS

FIGURA 8. 4. FILOS LARGOS RETOCADOS DE TAMAÑO MEDIANO ............................2229 
FIGURA 8. 5. FILOS LARGOS RETOCADOS DE TAMAÑO GRANDE ..........................230

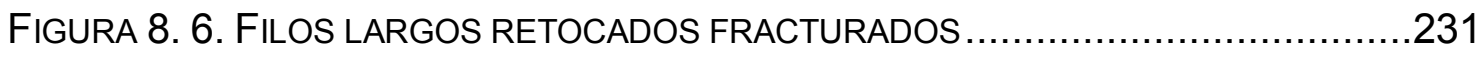

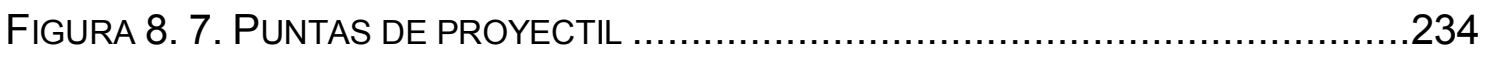

FIGURA 8. 8. PIEZA BIPOLAR, PIĖCES ESQUILLÉES EN SÍLEX ...............................236

FIGURA 8. 9. IZQ. MICRO-RASPADOR DE TOBA SILICIFICADA CON MICROPULIDO DE PIEL; DER. MICRO-RASPADOR DE RIOLITA CON MICROPULIDO DE PIEL.

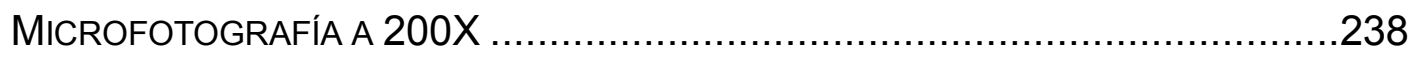

FIGURA 8. 10. IZQ. MICROPULIDO DE MADERA; DER. MICROPULIDO DE PIEL.

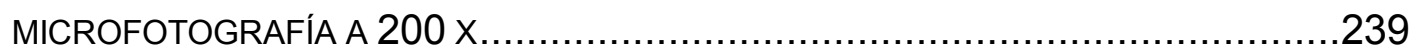

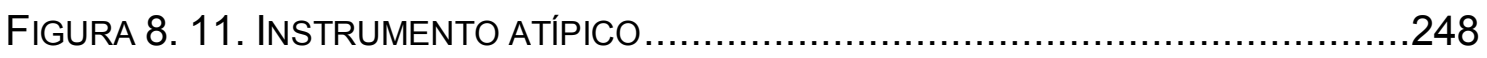

CAPÍTULO 9

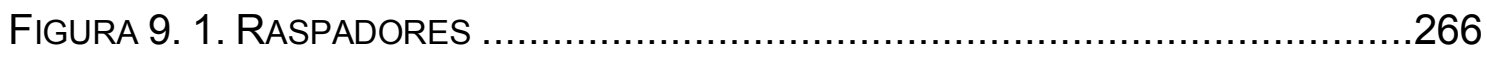

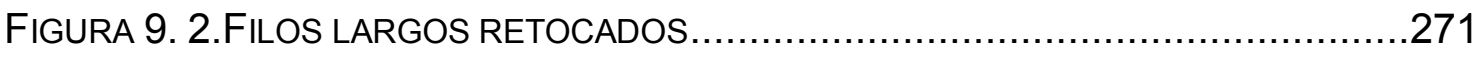

Figura 9. 3. Alteraciones IZQ. Alteración POR alta temperatura. Der.

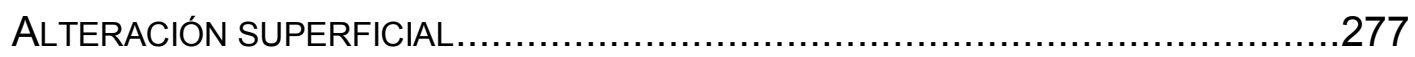

CAPÍTULO 10

FIGURA 10. 1. VISTA GENERAL DEL SECTOR DE CUADRÍCULAS E DEL SITIO KAMI 7.284

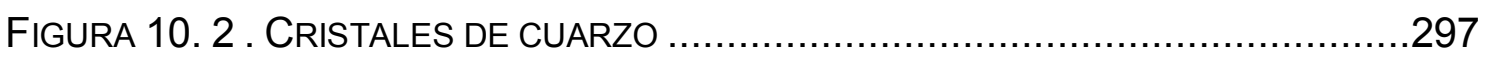

FIGURA 10. 3. RASPADOR CON MICROPULIDO DE TRABAJO TRANSVERSAL EN MADERA.

FIGURA 10. 4. LÍQUENES CRUSTOSOS PRESENTES EN LAS PIEZAS SUPERFICIALES ..310

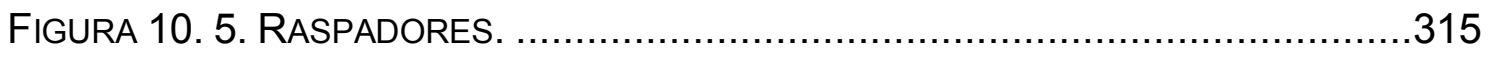

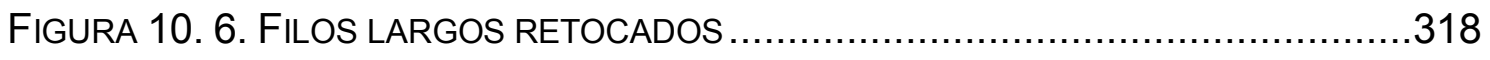

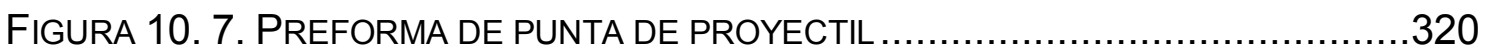




\section{ÍNDICE DE TABLAS}

CAPÍTULO 3

TABLA 3. 1. PlanILLA MODELO dE JERARQUIZACIÓN HIPOTÉTICA DE AMBIENTES .......91

CAPÍTULO 4

TABLA 4. 1. DATACIONES DE LOS SITIOS EWAN I Y II; KAMI 1 Y KAMI 7. 128

\section{CAPÍTULO 5}

TABLA 5. 1. MUESTREO DE MATERIAS PRIMAS SEGÚN LOS AMBIENTES 137

TABLA 5. 2. SECTORES DONDE SE LLEVARON A CABO LAS TRANSECTAS ENTRE 2009 Y 2012. 159

TABLA 5. 3. CANTIDADES Y RELACIÓN ENTRE DE TIPOS Y MATERIAS PRIMAS. 159

\section{CAPÍTULO 6}

TABLA 6. 1. RESTOS DE TALLA EN LA PRODUCCIÓN DE UNA PUNTA DE PROYECTIL ...175

TABLA 6. 2. RESTOS DE TALLA EN LA PRODUCCIÓN DE RASPADORES 176

\section{CAPÍTULO 8}

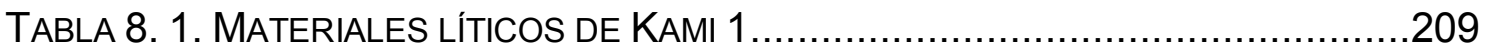

TABLA 8. 2. RELACIÓN ENTRE TIPOS DE NÚCLEO Y MATERIA PRIMA ......................213

TABLA 8. 3. PRESENCIA DE CORTEZA EN NÚCLEOS Y MATERIAS PRIMAS .................214

TABLA 8. 4. GRADO DE EXPLOTACIÓN DE LOS NÚCLEOS..................................215

TABLA 8. 5. LASCAS CON FILOS POTENCIALMENTE UTILIZABLES .........................218

TABLA 8. 6. MORFOLOGÍAS Y SU RELACIÓN CON LAS MATERIAS PRIMAS...................219

TABLA 8. 7. RELACIÓN ENTRE TIPO DE TALONES Y MATERIA PRIMA ........................222

TABLA 8. 8. RELACIÓN ENTRE PRESENCIA DE CORTEZA Y MATERIA PRIMA ...............223

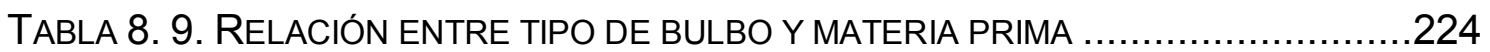

TABLA 8. 10. RELACIÓN ENTRE TIPO DE LABIO Y MATERIA PRIMA ...........................224

TABLA 8. 11. RELACIÓN ENTRE SOPORTES UTILIZADOS PARA LA CONFECCIÓN DE

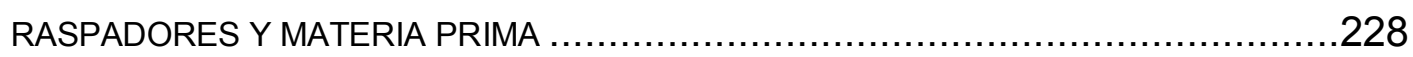

TABLA 8. 12. RELACIÓN ENTRE TIPO DE RAEDERA Y MATERIA PRIMA .....................231

TABLA 8. 13. MATERIALES DE KAMI 1, RECOLECCIÓN SUPERFICIAL .......................240

TABLA 8. 14. RELACIÓN ENTRE TIPO DE LASCAS Y MATERIA PRIMA ........................241

TABLA 8. 15. MORFOLOGÍA Y SECCIÓN LONGITUDINAL EN RELACIÓN CON MATERIAS

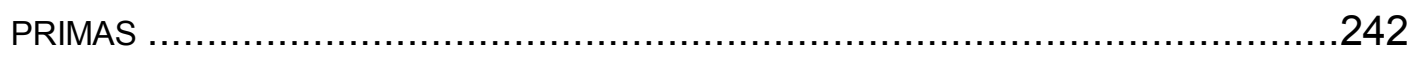

TABLA 8. 16. PRESENCIA DE TIPO DE TALONES CON PRESENCIA/AUSENCIA DE

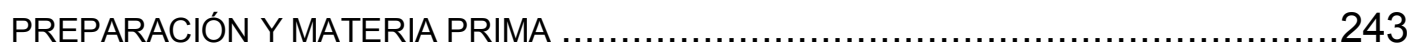

TABLA 8. 17. RELACIÓN ENTRE PRESENCIA DE CORTEZA Y MATERIA PRIMA ..............243

TABLA 8. 18. CONSERVACIÓN DE LOS FRAGMENTOS POR MATERIA PRIMA...............244 
TABLA 8. 19. RELACIÓN ENTRE PRESENCIA DE CORTEZA EN FRAGMENTOS Y MATERIA PRIMA

\section{CAPÍTULO 9}

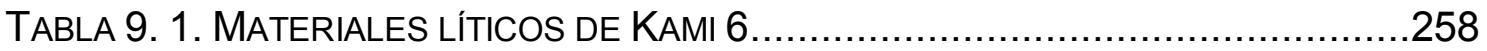

TABLA 9. 2. RELACIÓN ENTRE TIPO DE NÚCLEOS, ESTADO DE FRAGMENTACIÓN Y

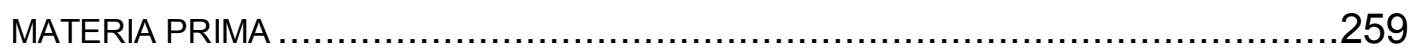

TABLA 9. 3. PRESENCIA DE CORTEZA EN SOPORTES UTILIZADOS …......................260

TABLA 9. 4. CONSERVACIÓN EN LASCAS POR MATERIA PRIMA ...............................261

TABLA 9. 5. RELACIÓN ENTRE MORFOLOGÍA DE LASCAS Y MATERIA PRIMA ..............261

TABLA 9. 6. RELACIÓN ENTRE TIPO DE TALÓN Y MATERIA PRIMA ............................262

TABLA 9. 7. RELACIÓN DE CORTEZA EN LASCAS Y MATERIA PRIMA..........................263

TABLA 9. 8. RELACIÓN ENTRE CORTEZA EN FRAGMENTOS Y MATERIA PRIMA ...........265

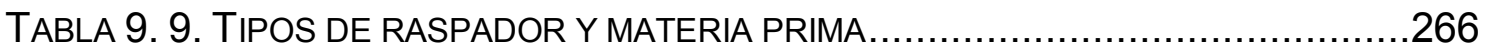

TABLA 9. 10. RELACIÓN ENTRE SOPORTE Y MATERIA PRIMA EN RASPADORES .........267

TABLA 9. 11. MORFOLOGÍA DE LOS RASPADORES Y MATERIA PRIMA ......................267

TABLA 9. 12. TIPOS DE TALONES REPRESENTADOS EN RASPADORES Y MATERIA PRIMA

.268

TABLA 9. 13. TIPO DE BULBO EN RASPADORES Y MATERIA PRIMA ............................268

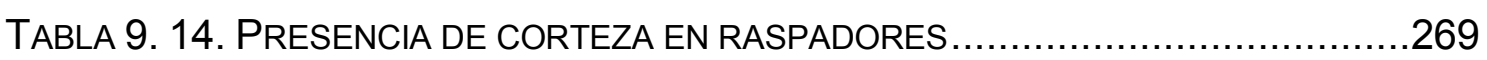

TABLA 9. 15. POSICIÓN Y CANTIDAD DE FILOS EN RASPADORES .............................269

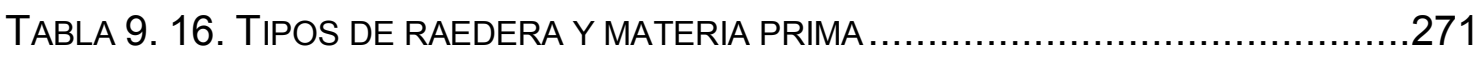

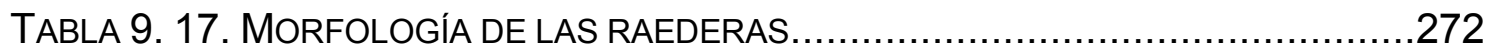

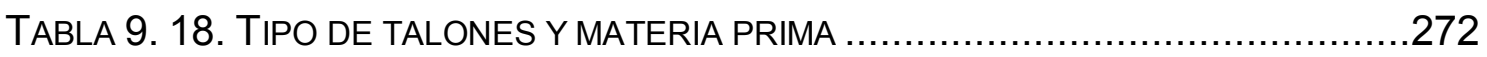

TABLA 9. 19. TIPO DE BULBOS PRESENTES EN LAS RAEDERAS ............................273

TABLA 9. 20. PRESENCIA DE CORTEZA EN RAEDERAS Y MATERIA PRIMA .................273

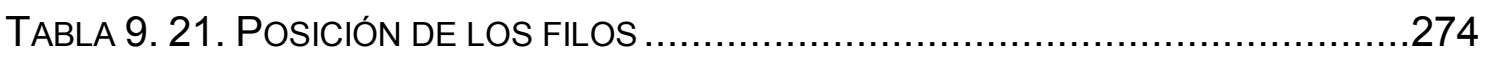

TABLA 9. 22. RELACIÓN ENTRE DELINEACIÓN-SECCIÓN LONGITUDINAL Y MATERIA PRIMA

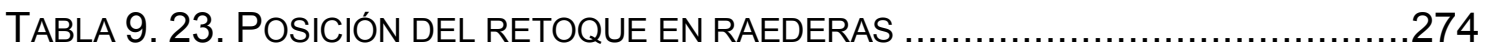

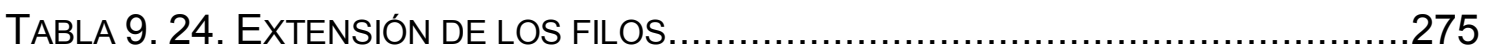

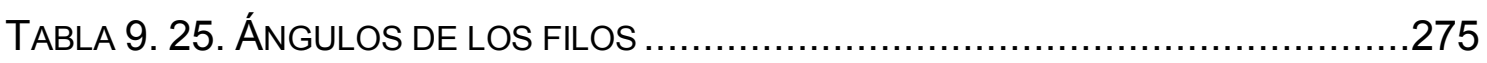

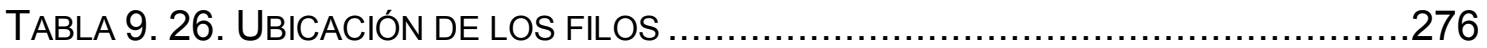

\section{CAPÍTULO 10}

TABLA 10. 1. MATERIALES LítICOS DEL SITIO KAMI 7, EXCAVACIÓN Y RECOLECCIÓN

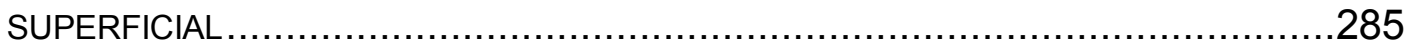

TABLA 10. 2. TIPOS TECNOLÓGICOS DEL SITIO KAMI 7, EXCAVACIÓN......................286

TABLA 10. 3. ELEMENTOS MENORES A 2 CM Y MATERIA PRIMA …........................286

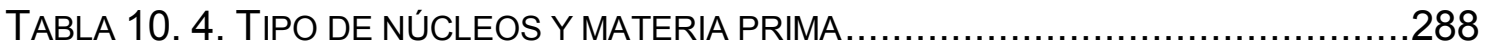

TABLA 10. 5. RELACIÓN ENTRE MORFOLOGÍA Y MATERIA PRIMA .............................289 
TABLA 10. 6. RELACIÓN ENTRE SECCIÓN LONGITUDINAL Y MATERIA PRIMA...............290

TABLA 10. 7. RELACIÓN ENTRE TIPO DE TALÓN Y MATERIA PRIMA …....................291

TABLA 10. 8. TIPO DE BULBO Y SU RELACIÓN CON MATERIAS PRIMAS .....................291

TABLA 10. 9. UBICACIÓN DE LOS FILOS EN LASCAS Y LÁMINAS .............................293

TABLA 10. 10. TIPOS TECNOLÓGICOS DE KAMI 7, AT 17 ....................................301

TABLA 10. 11. RELACIÓN ENTRE SOPORTES UTILIZADOS Y MATERIA PRIMA ..............302

TABLA 10. 12. MATERIAL LÍTICO DE KAMI 7, SUPERFICIAL .................................307

TABLA 10. 13. RELACIÓN ENTRE PRESENCIA DE CORTEZA Y MATERIA PRIMA ............312

TABLA 10. 14. UBICACIÓN DE FILOS POTENCIALMENTE UTILIZABLES......................312

TABLA 10. 15. CONSERVACIÓN DE LOS FRAGMENTOS ……..............................313

TABLA 10. 16. RELACIÓN ENTRE INSTRUMENTOS REPRESENTADOS Y MATERIA PRIMA

TABLA 10. 17. RELACIÓN ENTRE SOPORTE, TIPO DE RASPADOR Y MATERIA PRIMA...316 


\section{ÍNDICE DE GRÁFICOS}

\section{CAPÍTULO 7}

GRÁFICO 7. 1. GRÁFICO QUE MUESTRA LA CANTIDAD DE MICROLASCAS DE EWAN I Y IIUNIDAD 1 DISCRIMINADAS POR COLORES. 192

GRÁFICO 7. 2. PORCENTAJES DE TIPOS TECNO-MORFOLÓGICOS DE RESTOS DE TALLA REPRESENTADOS, PARA EWAN I Y II 194

CAPÍTULO 8

GRÁFICO 8. 1. PORCENTAJE DE ARTEFACTOS MENORES A 2 CM 211

GRÁFICO 8. 2. CANTIDAD DE MATERIAS PRIMAS EN ARTEFACTOS MENORES A 2 CM. 212

GRÁFICO 8. 3. RELACIÓN ENTRE TIPO DE NÚCLEOS Y MATERIA PRIMA ....................214

GRÁFICO 8. 4. RELACIÓN ENTRE LASCAS Y MATERIA PRIMA ...............................216

GRÁFICO 8. 5. PORCENTAJES DE CORTEZA EN LASCAS ..................................217

GRÁFICO 8. 6. RELACIÓN ENTRE LOS MÓDULOS LARGO-ANCHO/ANCHO-ESPESOR .218

GRÁFICO 8. 7. REPRESENTATIVIDAD DE SOPORTES....................................220

GRÁFICO 8. 8. RELACIÓN ENTRE SOPORTE Y MATERIA PRIMA .............................22

GRÁFICO 8. 9. RELACIÓN ENTRE FRAGMENTO Y MATERIA PRIMA .........................225

GRÁFICO 8. 10. PRESENCIA DE CORTEZA EN LOS FILOS LARGOS RETOCADOS Y SU RELACIÓN CON LAS MATERIAS PRIMAS ...........................................22

GRÁFICO 8. 11. RELACIÓN ENTRE PRESENCIA DE CORTEZA EN ARTEFACTOS BIPOLARES

\section{CAPÍTULO 10}

GRÁFICO 10. 1. RELACIÓN ENTRE MATERIA PRIMA Y ELEMENTOS MENORES A 2 CM .287

GRÁFICO 10. 2. REPRESENTATIVIDAD DE MATERIAS PRIMAS EN LASCAS .................289

GRÁFICO 10. 3. RELACIÓN ENTRE PRESENCIA DE CORTEZA Y MATERIA PRIMA ..........292

GRÁFICO 10. 4. RELACIÓN ENTRE LOS MÓDULOS LONGITUD-ANCHO/ANCHO-ESPESOR

GRÁFICO 10. 5. PORCENTAJES DE MATERIAS PRIMAS EN ARTEFACTOS MAYORES A 2

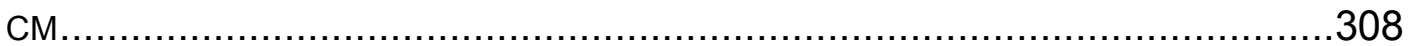

GRÁFICO 10. 6. PORCENTAJES DE MATERIAS PRIMAS EN ARTEFACTOS MENORES A 2

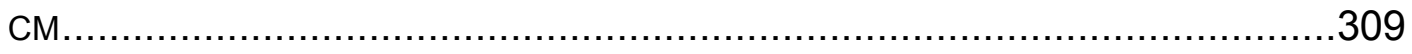

